Internationale Psychoanalytische Bibliothek Band 10

\title{
Klinische Beiträge zur Psychoanalyse
}

\author{
von \\ Dr. Karl Abraham
}

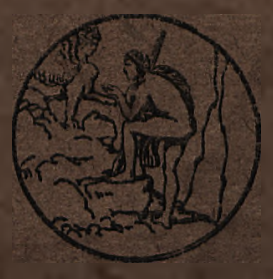

$$
\therefore 9.21
$$

Internationaler Psychoanalytischer Verlag Leipzig - Wien F Zürich 


\section{In unserem Verlage erschienen:}

Werke von Prof. Dr. Sigm. Freud

Vorlesungen zur

Einführung in die Psychoanalyse

Drei Teile (in einem Bande):

Fehlleistungen $\rightarrow$ Traum

Algemeine Neurosenlehre

Dritte, durchgesehene Auflage

- Mit einem Sachregister

35 Bogen Groß-Oktav (553 Seiten)

Preis 55 Marls

Halbleinen 65 Mark

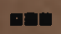 \\ Zur}

Psychopathologie desAlltagslebens Uber Vergessen, Versprechen, Vergreifen, Aberglaube und Irrtum

Siebente, erweiterte Anflage

Prela 42 Mark

Halbleinen 50 Mark

\section{Ene \\ Totem und Tabu}

Uber einige Übereinstimmungen im Seelenleben der Wilden und der Neurotiker

Zweite, durchgersehene Auflage

Preis 35 Mark

Halbleinen 42 Mark

Sämtliche Werke auf tadellosem holufreien Friedenspapier 
Internationale Psychoanalytische Bibliothek Band Io

\title{
Klinische Beiträge zur Psychoanalyse
}

\author{
aus den Jahren \\ 1907 - 1920
}

von

Dr. Karl Abraham

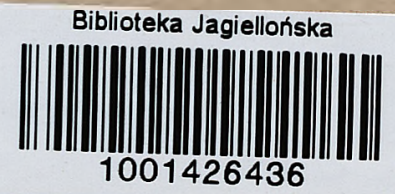

I 922 I

Internationaler Psychoanalytischer Verlag Leipzig - Wien - Zürich 

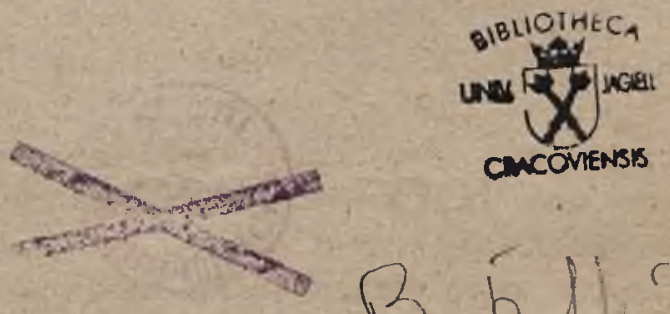

2568

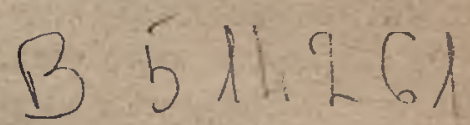

Alle Rechte, insbesondere das der Ubersetzung in alle Sprachen vorbehalten.

Copyright by „Internationaler Psychoanalytiseher Verlag, Ges. m. b. H. “ Wien, I. 
"Ja, das ist das rechte Gleis,

DaB man nicht weiB, was man denkt, Wenn man denkt:

Alles ist wie geschenkt."

Goethe.

\section{Vorwort.}

Wenn ich, einer Aufforderung des "Internationalen Psychoanalytischen Verlages" nachkommend, meine klinischen Beiträge zur Psychoanalyse gesammelt herausgebe, so erscheint mir ein Hinweis auf ihre Entstehung angebracht, auBerdem aber eine Bemerkung tiber die gegenwärtige Giltigkeit der in ihnen niedergelegten Ergebnisse. Denn in dem Zeitraum von vierzehn Jahren, während dessen diese Arbeiten verfaßt wurden, hat die psychoanalytische Wissenschaft ungeahnte Fortschritte gemacht.

Bevor ich im Jahre 1904 in Zürich als Assistent Bleulers mit den Anschauungen $\mathrm{Fr}$ e ud $\mathrm{s}$ bekannt wurde, hatte ich eine Reihe wissenschaftlicher Beiträge zur klinischen Deskription der Geistesund Gehirnkrankheiten geliefert. Nunmehr nahmen die psychoanalytischen Forschungen alsbald mein ganzes Interesse in Anspruch. Meiner damaligen Tätigkeit entsprechend zog mich die noch wenig erforschte Psychologie der Geistesstörungen am stärksten an; ihr galten daher auch meine ersten psychoanalytischen Arbeiten. Später, nachdem ich die Anstaltstätigkeit mit der freien psychotherapeutischen Praxis vertauscht hatte, bot sich eine reiche Fülle ungelöster Aufgaben psychologischer und praktisch-medizinischer Art. So erklărt es sich, daß der größte Teil meiner Schriften klinischen Gegenständen gewidmet ist. Diese Arbeiten sind in der vorliegenden Sammlung vereinigt. Ausgeschlossen von ihr blieben diejenigen meiner Publikationen, welche den außermedizinischen Anwendungsgebieten der Psychoanalyse (Mythologie, Kulturgeschichte, Kunstpsychologie etc.) angehören. 
Zur Zeit meiner ersten Bekanntschaft mit der Psychoanalyse war die Fachliteratur kaum über ihre ersten Anfänge hinausgekommen. Außer den "Studien über Hysterie“ waren von Freuds grundlegenden Werken nur die "Psychopathologie des Alltagslebens" und die "Traumdeutung" erschienen. Meine eigenen Beiträge zur Psychoanalyse entstanden in enger Fühlung mit der sich allmählich entwickeInden Spezialliteratur. Außerdem aber wurden sie durch mündlichen und schriftlichen Gedankenaustausch mit Freud und den anderen an Zahl allmählich zunehmenden Mitarbeitern der neuen Wissenschaft gefördert. So ist denn jede Arbeit aus der Zeit ihrer Niederschrift zu verstehen. Meine Aufstellungen über Hysterie und Dementia praecox (1908) wären nach dem heutigen Stand der Wissenschaft in mancher Hinsicht zu ergänzen. Das Gleiche gilt unter anderen auch für den Aufsatz vom Jahre 1908 zur Psychologie des Alkoholismus. Ich habe aber von jeder Änderung der ursprünglichen Form abgesehen, teils um die historische Treue nicht zu beeinträchtigen, teils weil ich keines der Ergebnisse meiner Abhandlungen als prinzipiell irrig zu widerrufen habe; auch enthalten die späteren Aufsätze manche Ergänzung der früheren.

Gleichzeitig mit der vorliegenden deutschen Ausgabe befindet sich eine englische in Vorbereitung.

Berlin-Grunewald, im Juni 1920.

Dr. Karl Abraham. 


\section{Über die Bedeutung sexueller Jugendtraumen für die Symptomatologie der Dementia praecox. ${ }^{1}$}

Den Symptomen der Hysterie liegen nach F re uds Theorie gefiiblsbetonte Reminiszenzen zugrunde, welche in erster Linie dem Gebiet der Sexualität angehören und sich bis in die frühe Kindheit des Individuums zurtïckverfolgen lassen. Unerfüllte Wünsche und unlustbetonte Erlebnisse, welche dem Selbstbewußtein unerträglich sind, werden aus dem Bewustsein verdrängt. Sie wirken aber im Unbewußten fort und können unter besonderen Umständen später als hysterische Symptome aus dem UnbewuBten wieder auftauchen. Die Mechanismen dieser psychischen Vorgänge - der Verdrängung und der Konversion in hysterische Symptome - sind uns ebenfalls durch $\mathrm{F}$ r e u d s Forschungen bekannt geworden. Neuere Untersuchungen - ich verweise u. a. auf die Veröffentlichungen von $\mathrm{Bleul} \mathrm{er}^{2}$ und $\mathrm{Jung}^{3}-$ haben gezeigt, daB die Freud'schen Theorien auch für die Auffassung der Dementia praecox auBerordentlich fruchtbar sind, daB wir in den Symptomen der Dementia praecox das gleiche Material verarbeitet finden wie bei der Hysterie, daß hier wie dort die Sexualităt eine dominierende Rolle spielt, und daB hier wie dort die gleichen psychischen Mechanismen wirksam sind. Es bestehen also weitgehende Analogien zwischen Hysterie und Dementia praecox. Es schien mir nun von großem Interesse, festzustellen, ob die inf a ntile Sexualität des Individuums in den Symptomen einer späteren Dementia praecox in der gleichen Art zum Ausdruck komme, wie Freud es für die Hysterie erwiesen hat, ob die Analogie zwischen den beiden Krankheiten sich auch 'auf dieses Gebiet erstrecke. Die Vermutung, daB dem so sei, hat sich mir in einer

1 Aus der psychiatrischen Universitätsklinik in Zürich. Nach einem Vortrag, gehaiten aui der Jahresversammlung des deutschen Vereins für Psychiatrie in Frankfurt am 27. April 1907. Zuerst verötfentlicht im „Zentralblatt für Nervenheilkunde und Psychiatrie $^{*}$, XXIV. Jahrgang, Nr. 238, 1907.

2 Bleuler: Freudsche Mechanismen in der Symptomatologie von Psychosen. Psychiatr.-neurolog. Wochenschrift 1906.

${ }^{3}$ J u n g : Die Psychologie der Dementia praecox. Halle 1907. 
Reihe von Fällen bestätigt. Ich teile zunächst aus einer meiner Krankengeschichten mit, was zum Thema von Interesse ist.

Im väterlichen Hause der Patientin, welche jetzt 57 Jahre alt ist, wurde mit den Kindern ein noch unerwachsener Bruder der Mutter, also ein Onkel der Patientin, erzogen. Er wurde vom Vater der Patientin öfter bestraft und lief deshalb eines Tages davon. Nach Jahren kehrte er zurück, drohte mit Rache für die frühere schlechte Behandlung und trieb sich in den Wirtshäusern der Umgegend herum. Einmal nahm er die damals zehnjährige Patientin mit sich in die Scheuer und vergewaltigte sie. Er drohte ihr, wenn sie den Eltern davon erzähle, werde er das Haus anzünden. $\mathrm{Da}$ der Onkel oft betrunken und auch gegen den Bruder der Patientin sehr roh war, fürchtete sie, er könne die Drohung ausführen. Sie verriet daher von dem Vorgefallenen nichts und war dem Onkel noch mehrmals zu Willen. Der Onkel verschwand nach einiger Zeit wieder, das Mädchen verschloB aber das Erlebte auch weiter in sich. Einige Zeit nach dem Attentat hatte sie oft Sensationen an den Genitalien, welche denen beim Attentat des Onkels ähnlich waren und die Patientien zur Masturbation veranlaßten. Weiterhin bekam sie ein Gefühl der Unsicherheit: es war ihr, als wüßten alle Leute von dem, was vorgegangen war und verachteten sie deshalb. Auf der Straße kam es ihr immer vor, als lachten die Leute über sie: wenn sie daherkam, erwiderten die Leute ihren GruB nicht und sprachen über sie. Sie selbst sagt, sie sei nach dem Attentat des Onkels "finster und verrückt" geworden. Lange Zeit war sie sehr deprimiert und beschäftigte sich mit Selbstmordplänen. Sie blieb ihr Leben lang scheu und eingezogen. Sie litt ferner uber viele Jahre an nächtlichen Visionen, besonders sah sie dieScheuer brennen. Diese Vision ist offenbar zwiefach determiniert: der Onkel hatte mit Feueranlegen gedroht und hatte sie in der Scheuer mißbraucht. Daneben hatte sie schrcckliche Träume. Einmal kam ein Schwarm von Nachteulen; die Tiere sahen sie scharf an, flogen $z \mathfrak{u}$ ihr, rissen ihr Decke und Hemd fort und schrien: schäm' dich, du bist ja nackt! Offenbar ist dies eine Reminiszenz an das Attentat. In späterer Zeit sah sie im wachen Zustande die Hölle. Die Szenen, die sie hier sah, waren stark sexuell gefärbt. Sie sah ,verwandelte Geschöpfe", halb Tiere, halb Menschen, wie Schlangen, Tiger, Eulen. Es kamen auch Trunkenbolde, die verwandelten sich in Tiger und gingen auf die weiblichen Tiere los. Auch hier wieder eine Erinnerung an den trinkenden Onkel. Hinter dem Angstaffekt verbirgt sich wahrscheinlich der Wunsch nach sexueller Befriedigung. Die Patientin hat im Laufe ihres Lebens sehr wenig Erfreuliches erlebt, dagegen viel mit ihrer Familie durchmachen müssen und hat oft Not 
gelitten. Mit 37 Jahren hatte sie eine besonders böse Zeit. Da hörte sie die Stimme eines anderen Onkels. Der war ihr von Jugend an sympathisch gewesen; er lebte in unglucklicher Ehe. Zuneigung und Mitleid fesselten sie besonders an diesen Onkel, der ihr zugleich in allem der Gegensatz des bösen Onkels war. Zu der Zeit, als sie die Stimme hörte, war dieser gute Onkel bereits gestorben. Seine Stimme kam vom Himmel, sie war eine Engelsstimme. Die Stimme verbot der Patientin den Selbstmord und weissagte ihr, sie werde alle ihre Geschwister überleben, das Heimwesen erben, einen Nachbarsohn heiraten und zwei Kinder bekommen. Diese Halluzination begreift eine klare Wunscherfüllung in sich, wie sie nach $\mathrm{F}$ r e u d s Forschungen im Traume vor sich geht, hier allerdings meistens in mehr verschleierter Form. Diese Halluzination im 37. Jahre ist einfach eine Lebensbejahung, sie will sagen: du brauchst noch nicht alle Hoffnung aufzugeben. Die Hoffnung hat sich aber nicht erfüllt. Vor einigen Jahren hat ein Schwindler die Patientin um ihr kleines Vermögen gebracht. Sie war nur noch beschränkt erwerbsfähig, mußte aus öffentlichen Mitteln unterstützt werden und führte ein kümmerliches Dasein. So trat wieder eine starke Depression ein. Die nun 57 jährige Kranke hat vom Leben nicht mehr viel zu erwarten. Wieder traten Selbstmordpläne auf. Und wieder kamen Halluzinationen. Dieses $\mathrm{Mal}$ aber ertönte die Stimme aus der Hölle und war die Stimme des bösen Onkels. Sie machte der Kranken Angst vor der Zukunft und riet ihr den Selbstmord an. Wegen dieses Depressionszustandes ist sie in die Anstalt gekommen.

Soweit die uns hier interessierenden Züge aus der Krankengeschichte. In diesem Falle ist es außerordentlich klar, daß ein mit starkem Affekt verbundenes Erlebnis aus der Kindheit, also ein Trauma der Vorpubertätszeit im Sinne Freuds, den Halluzinationen und Wahnideen der Patientin einen ganz bestimmten Inhalt gegeben hat. Der Eindruck dieses Erlebnisses auf die kindliche Psyche wirkt noch jetzt, im 57. Lebensjahre der Patientin, bestimmend auf die Symptome der Psychose. Damit soll nun keineswegs behauptet sein, daß die Person ohne dies sexuelle Trauma geistig gesund geblieben wäre, schon mit Rücksicht darauf, daß zwei Geschwister der Kranken ebenfalls an Dementia praecox gelitten haben. Auch erleidet ja noch manches Kind in seiner Jugend ein ähnliches Trauma und wird dennoch nicht geisteskrank. Wir halten vorläufig fest, daB in diesem Falle die manifesten Zeichen der Psychose sehr rasch nach einem sexuellen Trauma aufgetreten sind. Ich teile zunächst weitere Beobachtungen mit und werde später auf die Bedeutung des sexuellen Traumas zurückkommen.

Eine andere Patientin wurde mit neun Jahren von einem Nachbar 
in den Wald gelockt. Er versuchte, sie zu vergewaltigen, es gelang ihr aber noch, sich zu befreien. Sie erzählte daheim nichts von dem Vorfall. Damals tiberstand sie den Schrecken ohne bemerkbare Folgen. Erst als mit dem Auftreten der ersten Menstruation ihre Phantasie sich mehr mit sexuellen Dingen beschäftigte, mußte sie viel an das Erlebnis denken. Sie selbst sagt: ich durchlebte es immer wieder. Doch wurde sie allmählich wieder heiter und lebenslustig. Mit 23 Jahren wollte sie heiraten; der Vater hintertrieb aber die Heirat aus egoistischen Gründen. Die Patientin befand sich in starker sexueller Erregung. Als sie nun den Geliebten nicht heiraten durfte, bekam sie, zum ersten Male in ihrem Leben, einen Anfall. Sie schrie auf und schnaufte heftig, ohne das BewuBtsein zu verlieren. Die Analyse ergab, daß die Patientin damals in den Reben arbeitete. Sie ging gegen das Haus ihres Geliebten zu und war voller Erwartung, ob sie ihn etwa sehen whirde. Dabei mußte sie plötzlich tief atmen, und nun gab es den ersten Anfall. Als ich mit vorsichtigen Fragen etwas auf die Anfälle einging, gab die Patientin an, sie spüre, daß die Anfälle mit dem Attentat des Nachbarn zusammenhingen. Es ergab sich, daB dieser so furchtbar geschnauft hatte, während die Patientin unter Angstschreien von ihm loszukommen versucht hatte. Daher das Schreien und Schnaufen. Die starke sexuelle Erregung im 23. Lebensjahre rief die Erinnerung an das erste sexuelle Erlebnis der Patientin wieder wach. Die Anfälle sind nur als ein Ausdruck des Wunsches nach sexueller Befriedigung zu betrachten. Die Kranke träumt sich gewissermaßen in diejenige sexuelle Situation zurück, die ihr in der Kindheit einen starken Eindruck hinterlassen hatte. Der Anfall will sagen: das Unbewußte der Patienlin wäre froh, wenn jetzt nur ein Mann käme und sie in eine solche Situation versetzte. Nachdem die Anfälle eine Zeit lang sich oft wiederholt hatten, setzten sie Jahre lang aus. Mit 33 Jahren wurde der Patientin abermals ein Heiratsplan zunichte, während kurz darauf ihr jüngerer Bruder heiraten konnte. Als Reaktion darauf gab es nun wieder Anfälle nach Art der früheren. Zugleich bildete sich ein Verfolgungswahn gegen die Frau des Bruders aus, in den nach und nach immer mehr Leute einbezogen wurden. Die Bemerkungen, die sie von den Leuten zu hören glaubt, beziehen sich alle darauf, daB sie nicht geheiratet hat. Sie war von Anfällen wieder Jahre lang frei. In ihrer Phantasie beschäftigte sie sich bestăndig mit Heiratsplänen, auch noch in vorgeschrittenem Alter. Wegen ihrer sexuellen Erregung suchte sie sogar ärztliche Hilfe. Vor kurzem haben ihr nun äußere Verhältnisse die letzten Zukunftsaussichten geraubt, und daraufhin gab es wieder Anfälle. Wegen ihrer gleichzeitigen heftigen Erregungsausbrüche gegen ihre 
vermeintlichen Verfolger mußte die jetzt 43 jährige Person in die Anstalt gebracht werden.

Die Anfälle waren hysterischen durchaus ähnlich; die Diagnose der Dementia praecox war aber aus vielerlei Gründen, auf die ich hier leider nicht eingehen kann, durchaus sicher. Auch in diesem Falle, wie in dem zuerst mitgeteilten, besteht ein Zusammenhang zwischen sexuellem Trauma und Symptomen der Psychose. Nur sind in dem zweiten Falle die Symptome erst längere Jahre nach dem Erlebnis aufgetreten. Auslösend wirkte ein Erlebnis, das mit dem Attentat das sexuell Erregende gemeinsam hatte. Während im ersten Falle der AnschluB ein unmittelbarer war, bildet hier ein Analogiefall das auslösende Moment. Ich habe Gelegenheit gehabt, noch andere Fälle mit der einen oder der anderen Verlaufsart zu beobachten. Ich erwähne nur kurz den Fall einer Frau, die seit der frühen Jugend bestăndig unter den sexuellem Nachstellungen ihres Vaters und ihres alteren Bruders zu leiden hatte. Als sie erwachsen war, lieb sie sich von einem Manne verführen und heiratete ihn später. Er stieb sie durch rohe Behandlung $a b$, soda $B$ die Frau von einer tiefen Abneigung ergriffen wurde. Während der ersten Gravidität kam die Psychose zum Ausbruch. Während derselben wurde sie von Visionen geängstigt. Ein Stier, der dem Vater ahnlich war, kam drohend auf sie $\mathbf{z u}$, andere Mal sah sie den Teufel mit den Zügen ihres Mannes; er trug einen Speer, mit dem er nach ihr stach. Wer die Symbolik der Träume kennt, wird luber die Bedeutung dieser Vision nicht im Zweifel sein. Die Ideengänge dieser Patientin bewegten sich ganz und gar in dieser durchsichtigen Sexualsymbolik. Die Roheit und die Rlucksichtslosigkeit des Mannes rief in ihr die Erinnerung an die analogen Eigenschaften ihres Vaters wach, und in der Psychose kam beides wie erwähnt zum Ausdruck.

Freud hat ursprunglich gelehrt, daß jede Hysterie ihren Ausgang von einem psychosexuellen Trauma der Vorpubertătszeit nehme. Er hat diese Lehre neuerdings modifiziert. ${ }^{1} \mathrm{Er}$ legt jetzt das Hauptgewicht auf die Art, wie ein Individuum vermöge seiner angeborenen Veranlagung auf sexuelle Eindrücke reagiert. Bei Personen, welche spater an Hysterie erkranken, finden sich in der Jugend Zeichen einer abnormen Sexualităt. Die letzte Wurzel der Hysterie liegt also auch jetzt in der infantilen Sexualität; nur ist das Trauma keine Conditio sine qua non und hat eine mehr sekundäre Bedeutung. Meine Erfahrungen bei der Dementia praecox sprechen nun in dem nämlichen 
Sinne, wenngleich ich erst eine verhältnismäßig kleine Anzahl von Fällen in dieser Hinsicht analysieren konnte. Ein Teil dieser Fälle weist ein sexuelles Trauma auf, wie die mitgeteilten. Andere dagegen lassen Abnormitäten der Sexualität in der Kindheit erkennen, ohne daB ein schwerer Eingriff von außen stattgefunden hat. Die abnorme Sexualität dieser Patienten kommt, wie es mir nach den bisherigen Erfahrungen scheint, außer in vorzeitigem Auftreten der Libido in einer krankhaften Phantasie zum Ausdruck, welche sich vorzeitig und in solchem Grade mit sexuellen Dingen beschäftigt, daß diese die übrigen Bewußtseinsinhalte beiseite schieben. Bricht im späteren Leben eine Dementia praecox aus, so gewinnt diese Phantasie vollends die Oberhand. Ich möchte diese Anschauung mit einem prägnanten Beispiel belegen.

Ein Knabe wird schon in früher Jugend durch den Anblick weiblicher Personen erregt und bietet auch sonst Zeichen sexueller Frühreife. Eine erwachsene Schwester, die ihn sehr zärtlich liebt, betet er förmlich an. Diese Schwester bildet den Mittelpunkt der späteren Psychose. Der Patient, der jetzt 24 Jahre alt ist, erzählt nach anfänglichen starken Sperrungen schließlich mit großer Lebhaftigkeit eine Szene aus seiner Kindheit. Eines Morgens kam die Schwester, die ihn durch ihre üppige Gestalt sehr anzog, zu ihm ins Schlafzimmer und umarmte ihn zärtlich. Sie starb kurze Zeit darauf, Patient bewahrte ihr aber auch nach ihrem Tode seine schwärmerische Liebe. Er war damals zehn Jahre alt. Von der Pubertätszeit an kam er in der Schule nicht mehr vorwärts, konnte auch keinen Beruf erlernen und bietet seither die ausgesprochenen Erscheinungen der Katatonie dar. Aus dem sehr komplizierten Krankheitsbilde seien nur einige Züge erwähnt. In den Gesichtshalluzinationen des Patienten spielt die Schwester die Hauptrolle. Sie erscheint ihm z. B. als Christus, weshalb er sie auch als das Christusmädchen bezeichnet - nebenbei ein schöner Beleg dafür, wie religiöse und sexuelle Ekstase in psychopathischen Zuständen nahe bei einander wohnen. Oder der Patient sieht, wie ein sehr schöner Jüngling in den Besitz einer schönen Jungfrau zu gelangen sucht. Es sind Apollo und Diana; diese sind ja im griechischen Mythus Geschwister. Die Diana hat die Züge der verstorbenen Schwester, während Apollo dem Patienten selbst gleicht.

So wird in diesen und vielen anderen Halluzinationen des Patienten die sexuelle Attraktion, welche die Schwester auf den Patienten in seiner Kindheit ausgeubt hat, abgebildet, und die sexuelle Vereinigung als vollzogen dargestellt. Wir wissen aus Freuds Traumforschungen, wie in den Träumen der Erwachsenen infantile Wünsche wiederkehren. Das Gleiche gilt für die Halluzinationen der Dementia praecox. 
Bei einer hebephrenen Patientin mit Wahnideen, deren sexuelle Natur auf der Hand liegt, konnte ich deren Wurzel in einem Erlebnis aus dem sechsten Lebensjahre finden. Damals hatte sie beobachten können, wie bei ihrer Mutter die Periode eintrat. Dieser Eindruck hatte von da $\mathrm{ab}$ ihre Phantasie beständig beschäftigt.

Leider kann ich in Rücksicht auf die begrenzte Zeit nur diese Fragmente aus Krankengeschichten geben.

Es bleibt fraglich, ob die vorhin angenommene abnorme Phantasie schon eine Früherscheinung der Dementia praecox ist, oder ob eine im späteren Alter ausbrechende Dementia praecox die infantilen Sexualphantasien und -erlebnisse nur ausnutzt. Ich halte aber jedenfalls die individuelle Veranlagung durchaus für das Primäre. Erlebnisse sexueller Art, seien es solche vom wirklichen Werte eines Traumas, seien es weniger heftige Eindrücke auf die kindliche Sexualität, bilden nicht die Ursache der Krankheit, sondern sie determinieren die Symptome der Krankheit. Sie sind nicht die Ursache, daß Wahnideen und Halluzinationen auftreten, sondern sie geben diesen einen individuellen Inhalt. Sie sind nicht schuld am Auftreten von Wort- und Haltungsstereotypien, sondern bedingen nur deren Erscheinungsform im einzelnen Krankheitsfall. Ob jede Dementia praecox infantil-sexuelles Material enthält, oder ob dies nur für einen beschränkten Teil der Fälle zutrifft, wird schwer $\mathrm{zu}$ entscheiden sein. Die Nachforschungen in dieser Hinsicht sind schwierig und scheitern nicht selten gänzlich.

In den verschiedenen Fällen, welche ich als Beispiele angefahrt habe, und in einer Reihe von anderen Fallen konnte ich feststellen, daß die Kranken das sexuelle Erlebnis in der Kindheit und auch spater in sich verschlossen hatten. Breuer und Freud haben in den Studien uber Hysterie der gleichen Tatsache bei Hysterischen eine große Bedeutung beigelegt. Das spätere "Abreagieren" der ins Unbewußte verdrängten Erinnerungen haben sie zur Grundlage der psychoanalytischen Behandlung der Hysterie gemacht. Ich möchte hier nur beilăufig bemerken, daß eine ganze Anzahl von Patienten einen Wahn der Versundigung daran kntipften, daß sie in der Jugend nicht aufrichtig gewesen seien und ihren Angehörigen von dem Erlebnis nichts mitgeteilt hätten. Auf die psychische Wirkung des Abreagierens bei der Dementia praecox kann ich leider an dieser Stelle nicht eingehen.

Die Form, unter der die sexuellen Vorstellungskomplexe in der Dementia praecox auftreten, ist vorwiegend symbolisch. Der Bildung einer Symbolik sind alle die Zustände besonders günstig, welche mit einer Störung der Aufmerksamkeit einhergehen. $\mathrm{DaB}$ bei der Dementia praecox die Aufmerksamkeitsstörung von grundlegender Bedeutung 
ist, haben die neueren Forschungen erwiesen. Ganz das Gleiche trifft für die Neurosen und für unsere Träume $\mathrm{zu}$, und auch hier finden wir die gleiche Neigung zum Symbolisieren. Die Bedeutung des Infantilen im Traum und in der Hysterie ist durch Fre uds Arbeiten nachgewiesen worden. Wir haben uns davon uberzeugt, daß ganz Ähnliches für die Dementia praecox gilt. Damit haben wir eine neue Analogie zwischen Traum, Hysterie und Dementia praecox kennen gelernt.

Am Schlusse möchte ich dem Einwand begegnen, den Patienten seien die Erzählungen von sexuellen Erlebnissen suggeriert worden. Bei der Untersuchung wurde alles Suggestive streng vermieden. In verschiedenen Fallen trugen die Patienten mir ihre Berichte darüber förmlich entgegen. Die Möglichkeit, daß Geisteskranke ihre jetzigen sexuellen Phantasien in die Kindheit zurückverlegen, ist freilich zuzugeben. In keinem der Fälle, die ich meinen Mitteilungen zugrunde gelegt habe, besteht aber ein begrtindeter Verdacht in dieser Richtung. Übrigens haben wir ja bei einer Dementia praecox Mittel genug, um wahnhafte und tatsächliche Berichte voneinander unterscheiden zu können.

Aus der Analyse der Symptome der Dementia praecox ersehen wir, daB in der Psychologie dieser Krankheit dem infantilen Vorstellungsmaterial und der Sexualităt die gleiche Bedeutung zukommt wie in der Hysterie und im Traum. Die psychologische Erforschung der Dementia praecox wird daher auf die Fre udschen Lehren zurlick. gehen müssen. Aus ihnen kann sie eine mächtige Förderung erfahren. 


\section{Das Erleiden sexueller Traumen als Form infantiler Sexualbetätigung. ${ }^{1}$}

Freuds Lehre von der Ätiologie der Hysterie hat im Laufe der Zeit bedeutende Wandlungen durchgemacht. Freud hat aber, wie er selbst betont, ${ }^{2} z$ wei Gesichtspunkte festgehalten und ist in die Erkenntnis ihrer Bedeutung immer tiefer eingedrungen: das sind die Gesichtspunkte der Sexualität und des Infantilismus. An den Wandlungen der gesamten Sexualtheorie und Neurosenlehre hat auch das Problem des sexuellen Jugendtraumas Anteil genommen. Fre ud sah in diesem eine Zeit lang die letzte Wurzel der hysterischen Erscheinungen und nahm an, eine solche Wurzel sei in allen Fallen von Hysterie auffindbar. Diese Anschauung hat sich nicht in ihrer ursprünglichen Form halten lassen. In seinem Aufsatz: "Meine Ansichten über die Rolle der Sexualität in der Ätiologie der Neurosen ${ }^{3}{ }^{3}$ hat Freud dem sexuellen Jugendtrauma eine sekundäre Rolle angewiesen und eine abnorme psychosexuelle Konstitution als primäre Grundlage der Neurosen angenommen. Diese Auffassung wird der Tatsache gerecht, daß keineswegs alle Kinder, die ein sexuelles Trauma erleiden, später an Hysterie erkranken. Die zur Hysterie veranlagten Kinder reagieren nach $\mathrm{F}$ re u d infolge jener abnormen Veranlagung in einer abnormen Weise auf sexuelle Eindrücke aller Art. Ich selbst habe vor kurzem auch bei Geisteskranken das Vorkommen infantiler Sexualtraumen, erwiesen. ${ }^{4}$ Ich habe die Ansicht vertreten, daB ein solches Trauma nicht als Ursache der Krankheit in Betracht komme, wohl aber einen formgebenden Einfluß auf die Krankheit ausübe. In der Annahme einer abnormen psychosexuellen Konstitution schloB ich mich F re u d an.

Diese Annahme bringt uns jedoch nur um e in en Schritt vor-

1 Aus der psychiatrischen Klinik der Universităt Zürich. Zuerst veröffentlicht Im .Zentralblatt für Nervenheilkunde und Psychiatrie*, XXX. Jahrgang, Nr. 249, 1907.

2 Kleine Schriften zur Neurosenlehre, 1907, S. 232.

3 ibid. S. $225 \mathrm{f}$.

4 Über die Bedeutung sexueller Jugendtraumen fuir die Symptomatologie der Dementia praecox. (Zentralblatt für Nervenheilkunde und Psychiatrie, 1907.) 
wärts, während sie vor dem zweiten, wichtigeren, Halt macht. Sie erklärt uns zwar, warum ein in der Kindheit erlittenes Sexualtrauma in der Geschichte vieler Individuen von so großer Bedeutung ist. Dagegen bleibt das Problem, warum so viele neurotische und psychotische Personen in ihrer Kindheits-Anamnese ein sexuelles Tra uma a uf we is e n, unaufgeklärt. Lösen wir dieses, so werden wir auch über das Wesen der angenommenen abnormen Konstitution, wenigstens zum Teil, Aufschluß erhalten.

Mit der vorliegenden Arbeit beabsichtige ich diesen Fragen näher $\mathrm{zu}$ treten. Ich werde dabei insbesondere den Nachweis führen, daB in einer großen Anzahl von Fällen das Erleiden des Traumas vom Unbewußten des Kindes gewollt wird, daß wir darin eine Form infantiler Sexualbetätigung zu erblicken haben.

Jeder, der Kinder in ihrer psychologischen Eigenart beobachtet, wird die Wahrnehmung machen, daß das eine Kind Verlockungen oder Verführungen schwer, das andere dagegen leicht zugänglich ist. Es gibt Kinder, welche der Aufforderung eines Unbekannten, ihm zu folgen, fast ohne Widerstand nachkommen, und andere, welche in dem gleichen Falle entgegengesetzt reagieren. Geschenke, Süßigkeiten, oder auch die Aussicht auf dergleichen Dinge wirken auf Kinder sehr verschieden ein. Ferner gibt es Kinder, welche Erwachsene in sexueller Hinsicht geradezu provozieren. Sehr lehrreich sind in dieser Hinsicht die Akten der Prozesse wegen Vornahme unsittlicher Handlungen mit Kindern. Aus zwei Fällen, in denen ein Senil-Dementer sich an Kindern vergangen hatte, ist mir ein solches Verhalten der Kinder bekannt; in einer ganzen Anzahl anderer Fälle bestand in der gleichen Richtung ein dringender Verdacht. Selbst unter Geschwistern erlebt man in dieser Hinsicht auffällige Differenzen. Mir sind mehrere derartige Fălle bekannt. Von mehreren Schwestern läßt sich, z. B. die eine von einer fremden Person verlocken, mit ihr zu gehen, ein anderes Mal folgt sie beim Spielen einem älteren Knaben in einen abgelegenen Raum und läßt sich von ihm kusssen. Die beiden anderen Schwestern zeigen das entgegengesetzte Verhalten. Die erste Schwester, von der sich noch mehr ähnliche Züge erzählen ließen, bietet schon in der Kindheit neurotische Züge und erkrankt später an einer ausgesprochenen Hysterie. Dieses Beispiel ist nicht singulär, sondern typisch. Wir stellen vorläufig ganz allgemein fest, daß gewisse Kinder gegenüber Verlockungen sexuellen und anderen - ein stärkeres Entgegenkommen zeigen als andere. Diese Erfahrung kann uns dazu dienen, die sexuellen Traumen trotz ihrer großen Mannigfaltigkeit in Gruppen zu teilen. Wir können diejenigen sexuellen Traumen, welche unvorhergesehen uber ein Kind 
hereinbrechen, unterscheiden von denjenigen, welche durch Verfuhrung oder Verlockung eingeleitet werden, oder irgendwie vorauszusehen waren, oder aber geradezu provoziert wurden. In den Fällen der ersten Gruppe fehlt jeder Grund, auf seiten des Kindes ein Entgegenkommen anzunehmen. In den Fällen der zweiten Gruppe kann man sich dagegen der Annahme eines solchen Entgegenkommens nicht verschließen. In diesen beiden Gruppen gehen noch nicht alle Fälle auf : bricht ein sexuelles Attentat unvorhergesehen herein, so kann die davon betroffene Person sich aktiv und ernstlich abwehrend verhalten, oder sie kann sich der Gewalt fügen. In letzterem Falle finden wir wieder ein Entgegenkommen, eine Hingabe auf Seiten der angegriffenen Person. Mit einem in den Quellen des römischen Rechtes gebräuchlichen Ausdruck möchte ich sagen: eine solche Person unterliegt einer vis haud ing r a t a.

Die "vis haud ingrata" hat zu allen Zeiten das Interesse der Gesetzgeber auf sich gezogen, wo es sich um Bestimmungen uber die Ahndung sexueller Vergehen handelte. Ich verweise z. B. auf die mosaische Gesetzgebung, welche ihr voll Rechnung getragen hat, und zitiere aus dem fünften Buche Mosis Kap. 22, 22-27:

"Wenn eine Dirne jemand verlobet ist, und ein Mann krieget sie in der Stadt und schläft bei ihr, so sollt ihr sie alle beide zu der Stadt Thor ausführen, und sollt sie beide steinigen, daß sie sterben; die Dirne darum, daß sie nicht geschrien hat, weil sie in der Stadt war; den Mann darum, daß er seines Nächsten Weib geschändet hat; und sollst das Böse von dir tun. Wenn aber jemand eine verlobete Dirne auf dem Felde krieget und ergreift sie und schläft bei ihr, so soll der Mann allein sterben, der bei ihr geschlafen hat, und der Dirne sollst du nichts tun; denn sie hat keine Sünde des Todes wert getan, sondern gleich wie jemand sich wider seinen Nächsten erhübe, und schlüge seine Seele tot, so ist dies auch. Denn er fand sie auf dem Felde, und die verlobete Dirne schrie, und war niemand, der ihr half."

Ich verweise ferner auf die vortreffliche kleine Geschichte aus Don Quijote, welche Freud (Psychopathologie des Alltagslebens, II. Aufl. S. 87) mitteilt:

"Eine Frau zerrt einen Mann vor den Richter, der sie angeblich gewaltsam ihrer Ehre beraubt hat. Sancho entschädigt sie durch die volle Geldbörse, die er dem Angeklagten abnimnit, und gibt diesem nach dem Abgange der Frau die Erlaubnis, ihr nachzueilen und ihr die Börse wieder zu entreißen. Sie kommen beide ringend wieder, und die Frau berühmt sich, daß der Bösewicht nicht imstande gewesen sei, sich der Börse zu bemächtigen. Darauf Sancho: Hättest du deine Ehre 
halb so ernsthaft verteidigt wie diese Börse, so hätte sie dir der Mann nicht rauben können."

Die angeführten Beispiele beziehen sich nun freilich auf Erwachsene; wir werden uns aber nochdavon uberzeugen, daß in dieser Hinsicht kein Unterschied zwischen Kindern und Erwachsenen besteht.

Das mosaische Gesetz macht die Bestrafung des Mädchens davon abhängig, ob es um Hilfe gerufen hat. Das will sagen: ob es von der Möglichkeit, das Vorkommnis zu verhüten, Gebrauch gemacht hat. Ich habe in dieser Hinsicht u. a. die Fälle geprüft, die ich früher (l. c.) veröffentlicht habe. In jedem dieser Fälle hätte das Trauma verhindert werden können. Statt den Verlockungen $z u$ folgen, hätten die Kinder um Hilfe rufen, flüchten, oder sich widersetzen können. In einer Reihe von anderen Fällen habe ich das Gleiche feststellen können.

Beweisend für die Annahme eines Entgegenkommens auf seiten des Kindes ist nicht nur sein Verhalten während der Vorbereitungen zum Attentat und während des Attentates selbst, sondern auch sein Verhalten nach erlittenem Trauma. Schon Bre u e r und F r e ud haben, als sie erwiesen, daß Hysterische an Reminiszenzen leiden, die Aufmerksamkeit auf die Tatsache gelenkt, daß das infantile Sexualtrauma von den Kindern nicht den Angehörigen mitgeteilt, sondern verschwiegen wurde. Dies geschieht nicht nur unter dem frischen Eindruck des Erlebnisses, sondern, wie die Autoren erwiesen, wird das Erlebnis in das Unterbewußte verdrängt, so daß es der willkürlichen Erinnerung gar nicht zugänglich ist. Ich habe (1. c. S. 415) ein ähnliches Verhalten bei Kindern mit spaterer Dementia praecox konstatiert. Auf eine Erklärung dieses Verhaltens bin ich damals nicht eingegangen.

$\mathrm{DaB}$ ein Kind ein sexuelles Erlebnis hat und es trotz der damit verbundenen Emotion seinen Eltern verschweigt, ist eine auffallige Erscheinung. Ein Kind, das etwa von einem anderen verfolgt und geprtigelt worden ist, wendet sich klagend an seine Mutter. Ich erwarte hier den Einwand, die konventionelle Prüderie hindere das Kind am Sprechen, da es ja dazu erzogen werde, im Gespräch alles auf das Sexuelle Bezügliche zu vermeiden. Dieser Einwand ist aber keineswegs stichhaltig. Erstens kummert sich ein Kind unter dem Eindruck einer heftigen Emotion durchaus nicht um das Konventionelle. Namentlich aber zeigen durchaus nicht alle Kinder, denen ein Erlebnis sexueller Art begegnet ist, dieses Verhalten. Ich will das durch ein Beispiel und ein Gegenbeispiel erläutern.

Im Keller eines Hauses muß ein Wasserrohr revidiert werden. Ein Arbeiter betritt das Haus und verlangt den Kellerschlüssel. Eine im Hause wohnende Frau ruft ihm $z \mathfrak{u}$, er solle nur die Treppe hinunter- 
gehen, sie werde ihm den Schlüssel schicken. Er geht hinunter; gleich darauf bringt ihm die kleine Tochter jener Frau den Schlüssel. Der Mann geht in den Keller und kommt nach kurzer Zeit zurück. Auf der halbdunklen Treppe erwartet ihn das Kind, um den Schlussel zurlickzubringen. Ehe die Kleine es sich versieht, nimmt der Mann eine unsittliche Handlung vor. Erschreckt läuft sie die Treppe hinauf und meldet sofort der Mutter, was vorgefallen sei. Der Mann wird darauf verfolgt und festgenommen.

Als Gegenbeispiel diene einer meiner früher veröffentlichten Fälle. Das neunjährige Mädchen wird von einem Nachbarn in den Wald gelockt. Es folgt ohne Widerstand. Er versucht dann, das Kind zu vergewaltigen. Erst als er seinen Zweck nahezu oder ganz erreicht hat, gelingt es dem Kinde, sich $z u$ befreien. Es eilt nach Hause, erzählt aber nichts von dem Geschehenen. Auch später bewahrt es das Geheimnis vor seinen Angehörigen.

Das Verhalten dieser zwei Kinder nach erlittenem Trauma ist völlig entgegengesetzt; warum dies? Zunächst sei auf das Verhalten von Kindern bei andern Gelegenheiten verwiesen. Ein Kind zum Beispiel, das sich bei einem ihm verbotenen Spiel verletzt hat, wird den Schmerz verbeißen und in diesem Falle nicht wie sonst den Trost der Mutter suchen. Der Grund ist klar: das Kind ist dem Reiz des Verbotenen unterlegen und hat das Gefühl, daB es schuld an seinem Unfall ist.

Dieses Schuldgefühl ist bei Kindern außerordentlich fein. Aus der Jugend einer Dame ist mir folgende Geschichte bekannt, die zu dem uns beschäftigenden Problem eine interessante Illustration gibt. Sie suchte als kleines Mädchen mit einer Freundin Blumen. Da kam ein fremder Mann hinzu und redete den beiden Mädchen $z u$, mit ihm zu kommen, er werde ihnen zeigen, wo es viel schönere Blumen gebe. Sie gingen ein Stück weit mit ihm. Dann kamen ihr Bedenken, mit dem Fremden weiterzugehen; sie wandte sich plötzlich um und lief davon. Ihre Freundin tat es ihr dann nach. Obgleich nun zwischen dem Manne und den beiden Kindern nichts weiter geschehen war, als daB sie eine Strecke miteinander gegangen waren, erinnert die Dame sich bestimmt, dab sie damals eine Scheu empfunden hat, daheim von dem Erlebten zu sprechen. Sie hütete das Geheimnis streng vor ihren Angehörigen und sprach sogar mit der Freundin nie mehr davon. Dieses Schweigen ist nur aus einem Gefühl der Schuld zu erklären. Das Kind hat offenbar die mehr oder weniger bestimmte Empfindung, daß die Schuld nicht allein auf seiten des Verlockenden liegt, sondern auch auf Seite dessen, der sich verlocken läßt. 
Die gleiche Erklärung trifft ganz offenbar auf die zwei vorhin angeführten Beispiele zu. Das eine Kind wurde ahnungslos überfallen und befand sich dabei in einer Situation, die es nicht selber herbeigeführt hatte; es war ja von der Mutter in den Keller geschickt worden. Ihm kann niemand einen Vorwurf machen, und darum findet es sofort Worte, der Mutter zu erzählen, was ihm zugestoßen ist. Das andere Kind hingegen ließ sich verlocken. Es folgte dem Nachbarn in den Wald und ließ ihn in der Ausführung seines Vorhabens ziemlich weit kommen, ehe es sich aus seinen Händen befreite und davonlief. Es ist nicht $z u$ verwundern, daß dieses Kind das Vorkommnis verschwieg.

Das Verlockende jeder sexuellen Betätigung ist der mit ihr verbundene Lustgewin n. Freud $\mathrm{d}^{1}$ unterscheidet bei jedem sexuellen Akt zwischen der Vorlust und der Befriedigungslust. Die Vorlust kann auf körperlichem Wege durch direkte taktile Reizung erogener Körperzonen erzeugt werden, sie kann aber auch durch andere sinnliche Reize, z. B. durch optische Eindrücke, hervorgerufen werden, und endlich rein psychisch durch Vorstellungen, - etwa durch das Spannende und Erregende der Situation. Es ist schwer zu entscheiden, welche dieser beiden Arten von Lust bei einem Kinde die größere Rolle spielt. Gewiß gibt es hier starke individuelle Differenzen. In einigen von mir beobachteten Fällen schien es mir, als wenn das Außergewöhnliche und Geheimnisvolle der Situation, also das Abenteuer als solches, den Hauptreiz auf das Kind ausgetibt hätte. Andrerseits muß ich wieder auf die Fälle verweisen, in welchen Kinder Erwachsene direkt zu sexuellen Handlungen provozieren; hier mussen wir selbstverständlich auch ein Verlangen nach Befriedigungslust annehmen.

Der Gewinn an sexueller Vorlust oder Befriedigungslust ist és, nach dem die kindliche Libido tendiert, wenn das Kind sich dem Trauma hingibt. Dieser Lustgewinn ist das Geheimnis, welches das Kind ängstlich hütet. Er allein erklärt das Schuldgefühl des Kindes und die weiteren psychologischen Vorgänge, welche sich an das Erleiden eines sexuellen Traumas anschließen. Ich muB hier auf $F r$ e $\mathrm{d} \mathrm{s}$ Anschauungen uber die frühen Phasen der Sexualität verweisen. Fre ud hat die alte Fabel von der bis zur Pubertät reichenden sexuellen Latenzzeit gründlich zerstört. Wir erfahren aus. seinen Untersuchungen, daB die ersten Spuren sexueller Betätigungen schon sehr fruh auftreten, und daß sie eine Zeitlang autoerotischen Charakter 
tragen. Es folgt ein Stadium, in welchem sich das Kind zur "Objektliebe" wendet; das Sexualobjekt braucht jedoch nicht anderen Geschlechtes zu sein. Neben heterosexuellen und homosexuellen Regungen kommen sodann noch andere zum Ausdruck, welche sadistischen oder masochistischen Charakter tragen. Freud spricht daher von einem polymorph-perversen Stadium. Alle diese frühen Regungen kommen dem Kinde natürlich nicht in ihrer wahren Natur zum Bewußtsein. Sie entspringen dem Unbewußten. Sie tendieren nach einem bestimmten Sexualziel, ohne daß dem Kinde diese Tendenz klar wird. Ganz in diesem Sinne ist für das zur Hysterie oder zur Dementia praecox veranlagte Kind das sexuelle Erlebnis ein Sexualziel. Das Kind erleidet das Trauma aus einer Absicht seines Unbewußten. Das Erleiden sexueller Traumen in der Kindheit gehört, wenn ihm ein unbewußtes Wollen zugrunde liegt, zu den masochistischen Äußerungen des Sexualtriebes. Es stellt also eine Form infantiler Sexualbetätigung dar.

Die Ubergänge vom Normalen zum Abnormen sind auf dem Gebiete der Sexualität fließend wie uberall. Dennoch halte ich es für berechtigt, in dem sexuellen Reizhunger, der zur Hingabe an sexuelle Traumen führt, im allgemeinen eine abnorme Art der Sexualbetätigung $\mathrm{zu}$ erblicken. Es ist auffallend, daß wir ihr gerade in der Vorgeschichte neurotischer oder geisteskranker Individuen begegnen, in deren späterem Leben sich sexuelle Abnormitäten in Hülle und Fülle finden. Als ich (1. c.) Freud's Lehre von einer psychosexuellen Basis der Hysterie auf die Dementia praecox zu ubertragen versuchte, habe ich bereits in einigen groben Umrissen ausgeführt, inwiefern die Sexualität der Kinder, welche später diesen Krankheiten unterliegen, abnorm sei. Ich gelangte zu der Annahme, daB die Sexualentwicklung zeitlich verfrüht und die Libido selbst quantitativ abnorm sei, daß außerdem aber die Phantasie dieser Kinder sich vorzeitig und in abnormem Grade mit sexuellen Dingen beschäftige. Diese Anschauung läßt sich nunmehr bestimmter fassen, indem wir. sagen: die Kinder jener Kategorien zeigen ein abnormes Begehren nach sexuellem Lustgewinn und infolgedessen erleiden sie sẹxuelle Traumen.

Verfolgen wir das weitere Schicksal der mit dem erlittenen Trauma zusammenhängenden Vorstellungen, so finden wir neue Anhaltspunkte für die vertretene Anschauung.

Das Schuldgefühl ist dem Bewußtsein des Kindes, ebenso wie dem des Erwachsenen, nicht erträglich. Das Kind sucht daher die unlustbetonten Reminiszenzen in irgend einer Weise zu verarbeiten, durch welche ihr störender Einfluß ausgeschaltet wird. Sie werden 
daher von den ubrigen Bewußtseinsinhalten abgespalten. Sie führen alsdann eine Sonderexistenz als "Komplex".

Anders bei solchen Kindern, welche ein sexuelles Trauma erlitten haben, ohne ihm in irgendeiner Weise entgegengekommen $z u$ sein. Solche Kinder können sich frei aussprechen; sie brauchen daher die Reminiszenzen an den Vorfall nicht gewaltsam aus dem Felde des BewuBtseins zu verdammen.

Der ProzeB der Ausschaltung unlustbetonter Vorstellungen aus dem Bewußtsein ist bei der Hysterie und bei der Dementia praecox (resp. bei Personen, welche später an einer der beiden Krankheiten leiden) der gleiche. Ubrigens können wir ihn ja auch bei Gesunden täglich beobachten. Früher oder später zeigt es sich aber, daß die Verdrängung nur ein Notbehelf ist. Der Komplex kann zwar lange im Unterbewußten verbleiben. Aber dann kommt eines Tages ein dem primären Sexualtrauma analoges Erlebnis und bringt das verdrängte Vorstellungsmaterial in Aufruhr. Dann geschieht die Konversion in Symptome einer Hysterie oder einer Dementia praecox. Bei der Dementia praecox besteht freilich noch die andere Möglichkeit, da $B$ aus endogenen Gründen ein "Schub“ der Krankheit auftritt, und daB nun dieses Material in den Symptomen verarbeitet wird.

Freud hat uns noch andere Mechanismen kennen gelehrt, welche im Grunde dem gleichen Zwecke dienen wie die Verdrängung. Hier ist z. B. die Transposition des Affektes auf indifferente Vorstellungen zu erwähnen; wird dieser Weg eingeschlagen, so entstehen Zwangssymptome. Ebenso wie der Prozeb der Verdrängung, so kommt auch der ProzeB der Transposition auf indifferente Vorstellungen bei der Dementia praecox ganz in der gleichen Weise vor wie bei den "Neurosen". Ich erinnere in ersterer Hinsicht nur, beispielsweise an die eingebildeten Schwangerschaften bei der Dementia praecox, die ihrer psychologischen Genese nach den hysterischen Schwangerschaften durchaus gleichen, und in letzterer Hinsicht an die Tatsache, dab in manchen diagnostisch durchaus klaren Fällen von Dementia praecox Zwangsvorstellungen den hervorstechendsten Zug des Krankheitsbildes ausmachen. Zwei Arten des Ausdruckes eines sexuellen Schuldgefühis sind also der Hysterie und der Dementia praecox gemeinsam. Die Dementia praecox verfügt noch ubber eine dritte: die Ausbildung eines Versündigungswahnes, welcher auf indifferente Vorstellungen verschoben wird. Ich kann an dieser Stelle nicht an der Hand von Krankengeschichten den Nachweis fuhren, daB Selbstvorwürfe sexuellen Inhaltes eine wesentliche Quelle des Verstindigungswahnes sind. Ich habe in meiner letzten Arbeit darauf verwiesen, daB eine Anzahl 
von Patienten früher oder später einen Wahn der Versündigung daran knüpfen, daB sie in der Jugend nicht aufrichtig gewesen seien, indem sie von einem sexuellen Erlebnis ihren Angehörigen nichts mitteilten. Das Schuldgefühl, welches sich in Wirklichkeit an das widerstandslose Hinnehmen eines sexuellen Traumas knlipft, wird auf die weit geringere "Sünde" der mangelnden Aufrichtigkeit verschoben. Mir scheint, daB dieser psychische Mechanismus der Verschiebung auf eine weniger affektvolle Vorstellung mit der Transposition, wie sie der Bildung von $Z$ wangsvorstellungen zugrunde liegt, nahe verwandt ist. Verschieden ist das Resultat : hier Zwangsvorstellung, dort Wahnvorstellung. Andere ähnliche Mechanismen, welche uns ebenfalls durch Freud bekannt geworden sind und verwandten Zwecken dienen, kann ich hier nur streifen, wie z. B. die bei der Hysterie und Dementia praecox (übrigens auch im Traum) so überaus häufigen "Verlegungen", z. B. die Verlegung einer Genitalsensation nach dem Munde.

Also auch die weiteren Schicksale des. Komplexes und seine späteren Äußerungen sprechen durchweg für die oben vertretene Auffassung vom Wesen des sexuellen Jugendtraumas. Einen besonders merkwlirdigen, aus unserer Anschauung aber durchaus erklärlichen Beweis dafür, daß ihr Unbewußtes dem sexuellen Trauma entgegenkommt, liefern Kinder, welche später der Hysterie oder der Dementia praecox verfallen, dadurch, daß es bei ihnen häufig nicht mit e in em Traum sein Bewenden hat. Man sollte erwarten, gebrannte Kinder whirden das Feuer scheuen, d. h. jeder Wiederholung eines sexuellen Traumas, ja der bloßen Möglichkeit einer Wiederholung ausweichen, zumal das Vorkommnis außer der Lust für sie Schmerz oder andere Unlustgefühle direkt mit sich brachte oder indirekt nach sich zog. Die Erfahrung lehrt aber das Gegenteil. Individuen, welche einmal ein sexuelles Trauma erlitten haben, an welchem sie selbst durch ihr Entgegenkommen einen Teil der Schuld trugen, aus dem sie aber auch einen Lustgewinn gezogen haben, neigen auch ferner dazu, sich solchen Erlebnissen auszusetzen. Erleiden sie ein zweites Trauma, so wird dieses vom Unbewußten dem verdrängten ersten assimiliert. Das zweite oder ein späteres Trauma wirkt ${ }_{n}$ auxiliär ${ }^{\text {u }}$ um das psychische Gleichgewicht zu stören, und die Krankheit bricht aus. Je nach der angeborenen Veranlagung ist es eine Hysterie oder eine Dementia praecox.

Die Neigung zum fortgesetzten Erleiden sexueller Traumen ist eine Eigentumlichkeit, die wir oft genug bei erwachsenen Hysterischen beobachten können. Man könnte bei ihnen von einer traumatophilen Diathese sprechen, die sich tubrigens nicht auf sexuelle Traumen beschränkt. Die Hysterischen sind in der Gesellschaft die interessanten 
Menschen, denen immer etwas passiert. Weiblichen Hysterischen besonders begegnen beständig Abenteuer. Sie werden auf offener Straße belästigt, auf sie werden dreiste sexuelle Attentate verubbt, etc. In ihrem Wesen liegt es, daß sie sich einer traumatischen Einwirkung von außen exponieren müssen. Es ist ihnen Bedurfnis, als die einer außeren Gewalt unterliegenden $z u$ erscheinen; wir finden hierin eine allgemeine psychologische Eigenschaft des Weibes in libertriebener Form wieder. ${ }^{1} \mathrm{Da}$ wir also auch bei ausgesprochener Hysterie im erwachsenen Alter eine Neigung zum Erleiden von Traumen finden, so erhalt die Annahme einer solchen Neigung in der Kindheit dieser Personen eine wichtige Stütze.

Freud hat in seiner Psychopathologie des Alltagslebens die Aufmerksamkeit darauf gelenki, daß kleine Ungeschicklichkeiten, Fehlgriffe, Selbstbeschädigungen, Unfälle und ähnliche Vorkommnisse des alltäglichen Lebens vielfach auf einer unbewußten Absicht dessen beruhen, dem sie begegnen. Ich habe oben eine von Freud mitgeteilte Anekdote zitiert; diese zeigt, daß auch sexuelle "Unfälle" auf einem Wollen des UnbewuBten beruhen können. Diese Lehre Fre ud s gibt der von mir vertretenen Anschauung, daB dem infantilen Sexualtrauma in den genauer bezeichneten Fällen ein Wollen des Unbewußten zugrunde liegt, eine weitere und sehr wichtige Stätze. Um die Berechtigung $z u$ erweisen, mich hier auf $F_{r}$ e $u d s$ Forschungsergebnisse zu berufen, will ich aus meiner eigenen Erfahrung einige einschlägige Beispiele mitteilen.

Ein 19jähriges Mädchen wird in einer breiten, gut übersehbaren Straße am hellen Tage von einem Soldaten, der im Trab reitet, überritten. Sie ist kurze Zeit bewußtlos, hat aber keine schweren körperlichen Verletzungen erlitten. Kurze Zeit darauf treten die Symptome einer sogenannten traumatischen Neurose auf.

Die Vorgeschichte des Mädchens ergibt folgendes. Seit ihrer Kindheit haben die verschiedenstens Eindrücke und Erfahrungen deprimierend auf sie gewirkt. Sie war zuerst Zeugin des Zerwürnisses ihrer Eltern. Als diese sich scheiden ließen, wurde die Tochter der Mutter zugesprochen. Sie hatte aber keine Sympathien für diese, eine ungebildete Frau ohne Feingefühl. Der Vater hingegen, der trotz seines einfachen Handwerkerberufes literarisch tätig war, besab ihre Sympathien.

1 Nebenbei sei hier auf die Trăume gesunder Mädchen und Frauen hingewiesen, in denen sie von einem Manne erstochen oder sonstwie ermordet werden. Freud hat uns gelehrt, daB hierin eine symbolische Darstellung sexueller Wünsche zu erblicken ist. Im Traume wird dem Manne die Rolle des Angreifers, der Trăumenden eine passive Rolle zuerteilt. Sie ist dann nicht einmal Schuld an dem symbolischen sexuellen Akte. 
Mit 12 Jahren entlief sie der Mutter und ging zum Vater. Sie war eine der besten Schülerinnen und machte schon fruh dichterische Versuche. Ihr Wunsch war, Lehrerin zu werden, wozu sie außer ihrer Veranlagung die Schwärmerei für einen Lehrer bestimmt zu haben scheint. $\mathrm{Da}$ aber dem Vater die Mittel fehlten, seine Tochter das Seminar besucten zu lassen, so mußte sie früh die Schule verlassen und nacheinander verschiedene Aushilfsstellen als Dienstmagd versehen. Sie fühlte sich sehr unglücklich, da sie weder ihren Lerneifer befriedigen, noch in ein höheres soziales Milieu gelangen konnte. An einer Stelle blieb sie $1 \frac{1}{2}$ Jahre. Dann versuchte sie, sich weiter $z u$ bringen, indem sie Stenographie und Maschinenschreiben erlernte. Ehe sie ihr Ziel erreichte, versagten aber die Geldmittel; sie nahm daher Arbeit in einer Fabrik, wo ihr aber der Verkehr mit den ungebildeten Arbeiterinnen nicht zusagte. Das Verhältnis zur Mutter war ganz schlecht geworden, seitdem die Patientin sich zu dem Verdacht berechtigt glaubte, daß ihre jüngere Schwester aus einem unerlaubten Verhältnis ibrer Mutter vor der Ehescheidung hervorgegangen sei. Sie stand gănzlich isoliert da, zumal auch der Vater sich wenig um sie kümmerte; sie muBte in einem ihr verhaßten Beruf und in einem ihr verhaBten sozialen Milieu leben. Die jüngere Schwester, welche Patientin aus ihrem Verdienst unterstützte, um sie einen Beruf erlernen zu lassen, lohnte ihr dies mit Undank. All diese Umstände, wahrscheinlich außerdem noch ein unglückliches Liebesverhältnis, wirkten so deprimierend auf sie ein, daB sie alle Lust am Leben verlor. Sie schrieb in der Zeit, welche dem Unfall vorausging, Gedichte, in welchen sie ihre Lebensmuligkeit zum Ausdruck brachte. Da ereignete sich der oben erwähnte Unfall.

Wenn - wie in diesem Falle - einer Person die Freude am Leben verloren gegangen ist, wenn der Gedanke: lieber sterben als unter solchen Verhältnissen leben, offenbar vorhanden ist und wenn dann dieser Person ein Unfall unter Verhältnissen zustöBt, die ein Entrinnen keineswegs ausgeschlossen hătten, so halte ich die Annahme einer unbewußten Absicht zum Selbstmord für berechtigt. Das Mådchen hat sich nicht etwa absichtlich vor das Pferd geworfen, das wäre ein bewußter Selbstmord, sondern es hat die Möglichkeit des Ausweichens nicht genügend wahrgenommen. $\mathrm{Freud}$ hat bereits ăhnlichen Fällen von Selbstmord oder Selbstmordversuch, die äußerlich als Unfall imponierten, diese Erklärung gegeben. Bemerkenswert ist, daB sich der Zustand besserte, als man ihr Beschätigung gab, welche in der Richtung ihres Komplexes lag, und sich um eine bessere Stellung für sie bemlihte.

Welch sonderbare und doch zweckmäBige Wege das UnbewuBte 
einschlägt, um einen Zweck zu erreichen, zeigt folgende Unfallsgeschichte einer an Dementia praecox leidenden Dame. Die Patientin äußerte vor allem einen Versündigungswahn, als dessen Grundlage sich lange fortgesetzte Masturbation erweisen ließ. Sie gab an, die Masturbation gehe auf einen Unfall zurück, der ihr vor einer Reihe von Jahren zugestoßen sei. Damals war sie ausgeglitten und gerade mit der Genitalgegend gegen eine Tischecke gefallen. Nach der Art, wie die Patientin den Hergang beschreibt, kann man sich den Mechanismus dieses Unfalls gar nicht anders vorstellen, als indem man eine unbewußte Absicht bei der Patientin annimmt. Die Patientin spürte damals offenbar einen geschlechtlichen Reiz und konnte ihn nicht auf dem normalen Wege befriedigen. Sie kämpfte gegen den Drang zur Masturbation an. Was das Bewußte ihr sich zu verschaffen verbot, verschaffte ihr auf dem geschilderten Wege das Unbewußte.

Eine andere Patientin hatte von klein auf eine überaus starke Zuneigung zu ihrem Bruder. Als sie erwachsen war, maB sie jeden Mann an den Eigenschaften ihres Bruders. Sie verliebte sich später in einen anderen, diese Liebe nahm aber einen unglücklichen Ausgang. Kurz darauf, als die Patientin noch sehr deprimiert war, brachte sie sich auf einer Bergtour durch Ungeschicklichkeit zweimal in die gröBte Gefahr. Da sie eine geubte Touristin war, so blieb der zweimalige Absturz an ganz leichten und ungefährlichen Stellen ihrer Umgebung rätselhaft. Später ergab sich, daß sie damals schon mit Selbstmordplänen spielte. Seit jener unglücklichen Liebe wandte sie ihre ganze Zuneigung wieder dem Bruder zu, der sich einige Zeit danach verlobte. Bald danach erkrankte sie an Dementia praecox. (Vermutlich hatte die Krankheit sich ganz schleichend entwickelt.) In dem initialen Depressionszustand suchte sie sich aus dem Fenster zu stürzen - offenbar eine Analogie zu dem Absturz im Gebirge. In der Anstalt besserte sich der Zustand sehr langsam. Schlieblich konnte Patientin mit einer Wärterin im Park spazieren gehen. Damals wurde dort ein Kanal angelegt. Sie tuberschritt den Graben täglich auf einer Brücke von Brettern, obgleich sie ihn ganz leicht auch hätte überspringen können. In jener Zeit erfuhr sie den Tag, an welchem ihr Bruder heiraten sollte. Sie sprach beständig von dieser Hochzeit. An dem der Hochzeit des Bruders vorausgehenden Tage benutzte sie auf ihrem Spaziergang nicht die Brücke, sondern sprang über den Graben, und zwar so ungeschickt, daß sie sich den $\mathrm{FuB}$ verstauchte. Auch spăter kamen solche Selbstbeschädigungen bei ihr öfter vor, so daß sogar die Wärterin Verdacht schöpfte, daß irgend etwas Gewolltes im Spiele sein müsse. Offenbar brachte das Unbewußte durch diese kleinen Unfälle eine Absicht zum Selbstmord zum Ausdruck. 
Alle solchen Vorkommnisse erscheinen in einem ganz anderen Licht, sobald man die vorausgehenden Ereignisse und die begleitenden Umstände kennt. Je mehr man dergleichen Vorkommnisse der psychologischen Analyse unterwirft, desto umfassender lernt man die Bedeutung des "Wollens des Unbewußten " einschätzen. Selbstverständlich ist eine strikte Grenze $z$ wischen unbewuBter und bewuBter Absicht hier nicht zu ziehen.

Für das fortgesetzte Erleiden von Traumen (nicht nur sexueller Art) bieten uns erwachsene Neurotiker und Geisteskranke auch sonst höchst interessante Beispiele. Wir müssen einen kleinen Exkurs auf ein nahe benachbartes Gebiet machen. $\mathrm{DaB}$ die traumatische Hysterie in einer luberaus großen Zahl von Fällen gleichbedeutend ist mit einer Rentenhysterie, steht außer Diskussion. Der Kampf um die Erlangung einer Entschädigung läßt die Krankheitserscheinungen nicht zum Verschwinden kommen. Droht im Falle der Besserung Reduktion oder gar gänzliche Entziehung der Rente, so treten die schon geschwundenen oder milder gewordenen Symptome von neuem oder in verstärktem Grade auf. Hier öffnet sich uns ein Einblick in die Mannigfaltigkeit der Arten, wie das Unbewußte solche Wünsche, die dem Bewußten gar nicht klar $z \mathfrak{u}$ werden brauchen, zu realisieren weib. In nicht seltenen Fällen erleiden Personen, welche einmal einen Unfall erlitten haben, bald noch einen weiteren, oft ganz unbedeutenden Unfall, der zur Unterstutzung des Rentenanspruchs wie gerufen kommt. Namentlich habe ich diese Erfahrung bei einer zur Hysterie besonders disponierten Menschenklasse gemacht, nämlich bei polnischen Arbeitern unter dem deutschen Unfallversicherungsgesetz. Nach allgemeiner Erfahrung verteidigen diese Leute ihre Rentenansprüche mit einer ganz besonderen Zähigkeit, und die traumatisch-hysterischen Symptome haften bei ihnen mit einer ganz ausnehmenden Hartnäckigkeit. Die Zahl der polnischen Arbeiter, welche wegen mehrerer Unfalle auf Rentenzahlung dringen, ist uberraschend groß.

Die Tendenz, den ersten Unfall durch einen zweiten zu verstärken, äußert sich sogar, wenn die Person, welche den Unfall erlitten hat, an ihren hysterischen Symptomen krank liegt und daher keine Gelegenheit hat, einen zweiten Betriebsunfall zu erleiden. Ein italienischer Arbeiter, den ich kürzlich za begutachten hatte, war durch eine von einem Gerüst herabfallende eiserne Klammer am Kopf verletzt worden. Ich ließ ihn seine Träume erzählen. Wiederholt berichtete er mir, im Traume habe ihn jemand mit einem Stock über den Kopf geschlagen, oder ein anderer Unfall sei ihm zugestoBen. Sein Unbewußtes wünschte offenbar den traumatischen Symptomenkomplex 
wachzuhalten und brachte diesen Wunsch im Traume zum Ausdruck. $\mathrm{DaB}$ die begleitende Angst nicht gegen diese Auffassung spricht, geht aus Freuds Traumtheorie hervor. Ich glaube auf diese Art die so häufigen Angstträume Unfallverletzter mit $\mathrm{Freuds}$ Wunschtheorie in Einklang bringen zu können. Das UnbewuBte ruht nicht, wenn es gilt, den Komplex zur Geltung zu bringen. Es sorgt dafür, daB der affektive Wert des erlittenen Traumas nicht verloren geht und bringt das Erlebnis von Zeit zu Zeit durch einen Angsttraum wieder zur Erinnerung.

Alle diese Beobachtungen bei Erwachsenen wie bei Kindern, die Analyse von Träumen der Gesunden wie der Neurotiker und Geisteskranken, von Symptomen der Hysterie wie der Demetia praecox, führen uns $z u$ dem Schlusse, daB den sexuellen Traumen und speziell den infantilen, ebenso wie anderen Traumen in vielen Fällen eine unbewußte Absicht auf Seiten des scheinbar passiven Teiles zugrunde liegt. Daß Personen, welche später an Hysterie oder Dementia praecox erkranken, in der Jugend ein abnormes Entgegenkommen gegen sexuelle Traumen zeigen, haben wir auf ihre schon im Kindesalter abnorme Sexualitat zurückgefuhrt. Wir kamen zu der Auffassung dieses Verhaltens als einer Form abnormer infantiler Sexualbetätigung. Die ursprüngliche Fre ud sche Lehre erleidet dadurch eine wesentliche Ảnderung. Das infantile Sexualtrauma spielt für die Hysterie und die Dementia praecox keine atiologische Rolle. In dem Erleiden sexueller Traumen spricht sich vielmehr schon in der Kindheit die Veranlagung $z u$ der späteren Neurose oder Psychose aus. An Stelle der ätiologischen Bedeutung des sexuellen Traumas tritt seine formgebende Bedeutung. Wir verstehen so, wie das Sexualtrauma der KTankneit eine bestimmte Verlaufsrichtung und vielen Symptomen das individuelle Gepräge zu geben vermag.

Unsere Untersuchungen haben uns die weitgehende Ähnlichkeit in der Symptomatologie der Hysterie und der Dementia praecox aufs neue vor Augen geführt. Ungelöst bleibt die Frage der zweifellos vorhandenen Differenzen zwischen den beiden Krankheiten. Diese liegen $z u$ einem großen Teil auf psychosexuellem Gebiet; sie sollen den Gegenstand einer weiteren Untersuchung bilden.

\section{Nachwort (1920).}

Der vorstehende Aufsatz, der im Jahre 1907 geschrieben wurde, enthält mancherlei Irrtümliches in der Wiedergabe der F r e u d'schen Anschauungen. Der Verfasser begann damals, sich in die Gedankenwelt der Psychoanalyse einzuarbeiten. Ein allgemeiner Hinweis hierauf erscheint inm jetzt richtiger als eine nachtrăgliche Korrektur im Einzelnen, zumal die Ergebnisse der Untersuchung durch jene Irrtümer nicht beeinflußt werden! 


\section{Die psychosexuellen Differenzen der Hysterie und der. Dementia praecox ${ }^{1}$.}

Die psychoanalytische Methode hat uns mit wichtigen Analogien im Aufbau der Hysterie und der Dementia praecox bekannt gemacht ${ }^{2}$. In diesem Kreise wird ein Hinweis auf die wichtigsten Punkte genügen. Die Quellen für die Symptome beider Krankheiten liegen in verdrängten sexuellen Komplexen. In beiden Fällen können sowont normale wie perverse Regungen determinierend auf die Symptombildung wirken. Die Ausdrucksmittel beider Krankheiten sind zu einem erheblichen Teil die gleichen; ich brauche nur auf die sexuelle Symbolik zu verweisen. $\mathrm{DaB}$ trotz dieser gemeinsamen Züge ein prinzipieller Gegensatz besteht, darin sind sich alle Beobachter einig. Aber sie haben diesen Gegensatz bisher nicht in einer befriedigenden Form präzisiert. Was sie uns gaben, waren nur graduelle Verschiedenbeiten, die uns eigentlich nur wiederum die Ähnlichkeit beider Krankheitsbilder vor Augen führten.

Da nun wichtige gemeinsame Züge der Hysterie und der Dementia praecox psychosexueller Natur sind, so liegt die Frage nahe, wo dieses analoge Verhalten seine Grenzen finde. Mit andern Worten: Auf der Suche nach prinzipiellen Differenzen der beiden Krankheiten werden wir wiederum auf das psychosexuelle Gebiet gelenkt.

Die Grundlage für eine solche Untersuchung bieten Freuds "Drei Abhandlungen zur Sexualtheorie" (1905) und speziell die in diesen niedergelegten Anschauungen über die Sexualität des Kindes, die sexuellen Perversionen und den Sexualtrieb der Neurotiker. Alles Theoretische, was ich Ihnen tuber die Sexualität der chronisch Geisteskranken vortragen möchte, steht und fällt mit Freuds Sexualtheorie ${ }^{3}$.

' Nach einem Vortrag. Zuerst veröfentlicht im „Zentralblatt für Nervenhellkunde und Psychlatrie." 31. Jahrgang. Zweites Juliheft 1908. Neue Folge 19. Bd.

${ }^{2}$ Vgl. besonders Jung, Über die Psychol. der Dementia praecox. Halle 1907.

${ }^{3}$ Die wichtigste Anregung zu den folgenden Ausführungen, welche über die veröffentlichten Anschauungen Fre uds erheblich hinausgehen, verdanke ich schriftlichen und mündlichen Mitteilungen von Herrn Prof. Freud; manches hat durch Besprechung mit den Herren Prof. Bleuler und Dr. Jung wăhrend meiner Tatigkeit in der Zaricher Psychiatrischen Klinik festere Form angenommen. 
Die frahesten sexuellen Regungen des Kindes stehen nach Freud in Zusammenhang mit einer einzigen erzogenen Zone - dem Munde. Während der ersten Lebensjahre übernehmen außer der oralen Zone noch weitere Körpergegenden die Funktionen erogener Zonen. Die ersten Äußerungen der Libido beim Kinde tragen autoerotischen Charakter. Das Kind kennt in diesem Stadium noch kein Sexualobjekt außer sich selbst. In der folgenden Entwicklungsperiode geht es zur Objektliebe uber. Diese hat aber nicht sogleich eine bestimmte und definitive Richtung auf Personen des anderęn Geschlechtes. Das Kind trägt eine Reihe von Partialtrieben in sich, unter welchen normalerweise ein einziger, der heterosexuelle, die Oberhand gewinnt und behält. Die den anderen Partialtrieben entstammenden Energien werden der sexuellen Verwendung entzogen und auf wichtige soziale Ziele gelenkt; dies ist der Prozeß der Sublimierung. In der Hauptsache entstehen aus der Sublimierung der homosexuellen Komponente die Ekelgefuhle, aus der Sublimierung der infantilen Schau- und Exhibitionslust die Scham, aus der Sublimierung der sadistischen und masochistischen Komponenten Grauen, Mitleid und ahnliche Gefühle.

Die psychosexuelle Entwicklung ist nicht damit erschöpft, daß das Kind seine Libido auf Personen des anderen Geschlechtes übertragen lernt und seine übrigen Partialtriebe zu jenen sozialen Gefühlen umformt. Sowohl die Sexualübertragung als die Sublimierung sexueller Energien gehen weit itber diese Grenzen hinaus; beide Prozesse wirken normalerweise harmonisch zusammen. Künstlerische ${ }^{1}$ und wissenschaftliche Tätigkeit, und bis zu einem gewissen Grade auch viele andere Berufstätigkeiten beruhen auf Sublimierungsvorgăngen. Personen mit unbefriedigter Libido setzen die nicht gebundene sexuelle Energie in eine oft fieberhafte Berufstätigkeit um. Andere wenden ihre überschüssige Libido sozialen Bestrebungen $\mathrm{zu}$ und finden darin, wie die deutsche Sprache uberaus treffend sagt, ihre "Befriedigung". Der Kranken- und Säuglingspflege, der öffentlichen Wohltätigkeit, den Tierschutzbestrebungen uSw. strömen aus diesen Quellen die besten Kräfte zu.

Das soziale Verhalten des Menschen beruht auf der Fähigkeit der Anpassung; diese aber ist sublimierte Sexualübertragung. Zwischen Menschen entsteht nach einer gewissen Dauer des Beisammenseins ein positiver oder negativer psychischer Rapport, der sich in Gefihlen der Sympathie oder Antipathie äußert. Die Gefühle der Freundschaft, der seelischen Harmonie erwachsen auf diesem Boden. Das Verhalten eines Wien 1907. 
Menschen im sozialen Verkehr entspricht durchaus seiner Art, auf sexuelle Reize zu reagieren. Hier wie dort zeigen die gleichen Menschen sich leichter oder schwerer zugänglich, derb oder feinfühlig, wählerisch oder anspruchslos. Was wir im Auftreten des einen als steif, linkisch, eckig, im Auftreten des andern als graziös, gewandt usw. bezeichnen, ist Anzeichen seiner geringeren oder größeren Anpassungsfähigkeit, d. h. Ubertragungsfähigkeit.

Von der Ubertragung machen wir therapeutisch wie bei jeder Form psychischer Behandlung so auch bei der Psychoanalyse Gebrauch ${ }^{1}$. Eine eklatante.Form der Sexualubertragung ist die Suggestion, die wiederum ihren höchsten Grad in der Hypnose erreicht.

Der Mensch überträgt seine Libido nun aber nicht allein auf lebende, sondern auch auf leblose Objekte. Er steht zu einem großen Teil der ihn umgebenden Gegenstände in einem subjektiven Verhältnis, welches aus seiner Sexualität entspringt. In einer Abhandlung über "Traum und Mythus “2 ${ }^{2}$, welche demnächst erscheint, werde ich diese Frage ausführlich erörtern. Hier erwähne ich nur einige wesentliche Gesichtspunkte. Unsere Sprache legt den leblosen Gegenständen ein Geschlecht bei, weil sie sie auf Grund bestimmter Eigenschaften mit dem Manne oder Weibe vergleicht. "Der Mensch sexualisiert das All", wie Kle inpa $1^{3}$ sagt. Aus der gleichen Quelle entspringt die Sexualsymbolik der Sprache, der wir im Traume und in den psychischen Störungen wieder begegnen. Zu Gegenständen, die uns durch Gebrauch oder durch ästhetische Werte der verschiedensten Art lieb geworden sind, stehen wir in einem offensichtlich persönlichen Verhältnis, welches ganz der sexuellen Attraktion entspricht. Die Geschmacksrichtung in der Wahl von Gegenständen entspricht durchaus der sexuellen Objektwahl. Der Grad dieser Art der Objektliebe differiert sehr; manche Personen sind fast bedürfnislos in dieser Hinsicht, andere werden von ihrer Neigung für bestimmte Gegenstände als von einer Leidenschaft völlig beherrscht. Mit feinem Gefühl für diese psychologischen Zusammenhänge nennt die deutsche Sprache den, weicher zur Erlangung eines begehrten Objektes kein Opfer scheut, einen "Liebhaber", stellt ihn also neben den Verehrer einer weiblichen Person. Die ausgeprägteste Spezies des Liebhabers ist der Sammler. Seine übertriebene Wertschätzung des Sammelobjektes entspricht durchaus der Sexaal-

1 Vgl. F r e u d, Bruchstück einer Hysterie-Anlayse, Monatsschr. f., Psychiatrie und Neurol. 1906, und Sadger, Die Bedeutung der psychoanalyt. Methode nach Fre ud, Zentralblatt für Nervenheilkunde und Psychiatrie, 1907.

2 Schriften zur angewandten Seelenkunde, Heft 4.

${ }^{3}$ K le in p a u l, Stromgebiet der Sprache, S. 468. 
überschätzung des Verliebten. Eine Sammelleidenschaft ist manchmal geradezu das Surrogat einer sexuellen Neigung; in der Wahl des Sammelobjektes liegt dann bisweilen eine feine Symbolik verborgen. Die Sammelneigung des Junggesellen eilahmt oft, wenn er heiratet. Bekannt ist, daB Sammelinteressen mit dem Lebensalter wechseln.

Dem normalen Sexualtrieb gegenüber ist der des Neurotikers zunächst durch libermäBige Stärke des Verlangens ausgezeichnet. Sodann fehlt es ihm an innerer Harmonie: die Partialtriebe werden dem heterosexuellen Triebe nur unvollkommen untergeordnet, während andererseits eine Neigung zur Verdrängung des heterosexuellen Triebes besteht. Die mit der normalen Sexualbetätigung zusammenhängenden Vorstellungen rufen Widerwillen und Ekel hervor. Im Neurotiker kämpft zeitlebens ein Partialtrieb mit dem anderen, kämpft übermäßiges Verlangen mit übermäßiger Ablehnung. Aus diesem Konflikt flieht der Mensch in die Krankheit. Mit dem Ausbruch der Neurose kommt verdrängtes Material ins Bewabtsein herauf, wobei es in hysterische Symptome konvertiert wird. Die Konversion dient der Abfuhr verdrängter Strebungen normaler; besonders aber perverser Art; die Krankheitssymptome sind abnorme Sexualbetätigung.

Die neurotische Libido manifestiert sich außerhalb der Krankheitszeiten im engeren Sinne durch eine gesteigerte Ubertragung; die Objekte werden in abnormem Grade mit Libido besetzt. Auch zur Sublimierung besteht eine tuber das gewöhnliche $M a ß$ hinausgehende Neigung.

Auf Grund dieser Anschauungen können wir nun das psychosexuelle Verhalten der an Dementia praecox Leidenden mit dem der Gesunden und der Neurotischen vergleichen. Wir vergegenwärtigen uns zu diesem $Z$ wecke ein paar Typen aus der großen Gruppe der chronisch Geisteskranken, welche wir mit $\mathrm{Kraepelin}$ als Dementia praecox zusammenfassen.

Einen Patienten mit schwerer Krankheitsform in vorgeschrittenem Stadium sehen wir in der Anstalt in irgendeinem Winkel stehen oder auch unstet umherlaufen. Er starrt wie abwesend vor sich hin, halluziniert, flusstert ein paar Worte, gestikuliert sonderbar. Er spricht mit niemandem und weicht jeder persönlichen Begegnung aus. Er hat keinen Trieb zu einer Tätigkeit. Er vernachlässigt sein Äußeres, ißt unappetitlich, verunreinigt sich auch oder schmiert mit seinen Exkrementen und onaniert öffentlich ohne Scham. Es ist, als existierte die Umgebung für. ihn überhaupt nicht.

Ein weniger schwer Erkrankter zeigt im Grunde das gleiche Verhalten; es ist nur nicht so ins Extrem getrieben. Auch er ist unsozial 
und ablehnend; er produziert Verfolgungs- und Größenideen. Sein Benehmen und seine Redeweise sind sonderbar, maniriert, geschraubt. Er klagt lebhaft uber seine Internierung, trägt diese Klagen aber wie alles andere - ohne adäquaten Affekt vor. Er faßt die Vorgänge in der Außenwelt auf, zeigt aber kein wirkliches Interesse für sie. Er läßt sich zu mechanischer Arbeit herbei; aber er findet keine Befriedigung in ihr.

Ein Patient, dessen Erkrankung keine ganz groben Erscheinungen macht und die Internierung des Kranken vielleicht umgehen läßt, fühlt sich leicht von anderen beeinträchtigt, verträgt sich nicht mit seinen Angehörigen, findet keine Freunde, entbehrt sie aber auch nicht. Er ist ohne gematliche Bedürfnisse, ohne Takt und Feingefühl. Wir erlangen keinen gemütlichen Rapport mit ihm. Er besitzt vielleicht eine mehr als normale Intelligenz; dennoch sind seine Leistungen in der Regel nicht vollwertig. Was er in intellektueller Hinsicht produziert, ist zumeist sonderbar und geschraubt, verletzt die Ästhetik und entbehrt einer normalen Gefühlsbetonung.

Allen diesen Formen ${ }^{1}$ gemeinsam sind die gleichen Anomalien des Gefühlslebens; die Unterschiede in dieser Richtung sind nur graduell. Aus einer leichten Form kann eine schwere werden; eine schwere kann erhebliche Remissionen bieten. Während die Vorstellungen des gesunden Menschen von adäquaten Gefülen begleitet sind, fehlt den Vorstellungen dieser Kranken die adăquate Gefühlsbetonung. Wir haben aber alle Gefühlsübertragung auf die Sexualität zurūckgeführt. Wir kommen zu dem Schluß, daB die Dementia praecox die Fähigkeit zur Sexualübertragung, zur Objektliebe vernichte.

Die erste, unbewußt sexuelle Zuneigung des Kindes gilt den Eltern, speziell dem andersgeschlechtlichen Teil des Elternpaares. Auch unter Geschwistern findet eine lebhafte Ubertragung statt. Doch kommt es, besonders den Angehörigen des gleichen Geschlechtes gegenüber, auch zu Gefühlen der Auflehnung, des Hasses. Diese verfallen unter der Einwirkung der Erziehung und anderer exogener Faktoren der Verdrängung. Unter normalen Verbăltnissen besteht zwischen Eltern und Kindern ein Verhältnis der Zuneigung, ein Gefühl der Zusammengehörigkeit. Bei Hysterischen finden wir diese Zuneigung der einen Person gegenüber oft krankhaft gesteigert, der anderen gegenuber in heftige Ablehnung verwandelt. Bei Kranken mit Dementia

${ }^{1}$ Mit ,schwerer" und .Jeichter" Erkrankung soll hier nichts uber den KrankheitsprozeB ausgesagt werden, sondern nur über die praktischen (sozialen) Folgen der Erkrankung. 
praecox vermissen wir in der Regel die Zuneigung zu den Angehörigen; wir finden Gleichgültigkeit oder ausgesprochene, in Verfolgungswahn übergehende Feindschaft.

Ein gebildeter Patient erhielt die Nachricht vom Tode seiner Mutter, die ihm in seiner langen Krankheit trotz seines abweisenden Verhaltens eine zärtliche Liebe bewahrt hatte. Seine Reaktion auf die Nachricht bestand darin, daß er unwillig äußerte: „Ist das das Neueste?" - Es ist eine alltägliche Erfahrung, daß die Dementia praecox in ganz derselben Weise die Gefuhle der Eltern für ihre Kinder erkalten läßt.

Bei einem jungen Manne, den ich beobachtete, war die Krankheit sehr früh zum Ausbruch gekommen. Er hatte in früher Kindheit in solchem Grade auf die Mutter übertragen, daB er mit drei Jahren einmal erklärte: „Mutter, wenn du stirbst, werfe ich mir einen Stein auf den Kopf, und dann bin ich auch tot." Er gönnte die Mutter dem Vater keinen Augenblick, nahm sie bei Spaziergängen für sich allein in Anspruch, überwachte sie eifersüchtig und war gehässig gegen se nen Bruder. Von klein auf zeigte er eine abnorme Neigung zum Widerspruch; die Mutter sagt von ihm : er war schon damals der Geist, der stets verneint. Anderen Knaben schloB er sich nicht an, sondern hing nur an der Mutter. Mit 13 Jahren wurde er zu Hause undisziplinierbar, so daB die Eltern ihn in fremde Hände geben mußten. Die Mutter brachte ihn nach seinem neuen Aufenthaltsorte. Vom Augenblick des Abschieds an war er völlig verändert. Die, bisherige übergroße Liebe und Zärtlichkeit für die Mutter verwandelte sich in absolute Gefühlskälte. Er schrieb steife, förmliche Briefe, in denen er die Mutter nie erwähnte. Allmählich hat sich bei dem Patienten eine schwere, halluzinatorische Psychose entwickelt, in deren Verlauf die Verodung des Gefühlslebens immer deutlicher geworden ist.

Wie die psychoanalytische Untersuchung ergibt, ist eine heftige Feindschaft bei Geisteskranken sehr oft an Stelle einer vorherigen überschwänglichen Zuneigung getreten. Diese Abkehr der Libido von einem Objekt, auf welches einstmals mit besonderer Intensität übertragen wurde, ist bei der Dementia praecox unwiderruflich.

In der Anamnese unserer Patienten heißt es überaus häufig: er (oder sie) war von jeher still, neigte zum Grubeln, schloB sich niemandem an, mied Geselligkeit und Vergnügungen, war nie recht fröhlich wie andere. Solche Personen hatten also von jeher nicht die rechte Fähigkeit, ihre Libido auf die Außenwelt zu ubertragen. Diese Personen bilden später die unsozialen Elemente in den Anstalten. Ihren Worten fehlt der Gefuhisinhalt. Sie sprechen vom Allerheiligsten und vom Nichtigsten mit dem gleichen Tonfall, mit der gleichen Mimik. 
Nur wenn wir im Gespräch den Komplex berühren, gibt es mitunter eine Reaktion des Affektes, welche sehr heftig sein kann.

Die Kranken mit Dementia praecox sind in gewissem Sinne sehr suggestibel, und dies könnte als ein Widerspruch gegen die angenommene mangelhafte Sexualübertragung erscheinen. Die Suggestibilităt ist aber durchaus anderer Art als bei der Hysterie. Sie scheint mir lediglich darin zu bestehen, daß der Patient sich gegen diese oder jene Beeinflussung $\mathrm{nicht} \mathrm{strä} u b t$, weil er momentan $z u$ indifferent ist, um sich zu sträuben (Kraepelins „Befehlsautomatie“). Die Störung der Aufmerksamkeit ist hier sicher von großer Bedeutung. Es scheint mir also, als wåre diese Suggestibilität einfach Widerstandslosigkeit. Sie schlägt sehr leicht in Widerstand um. Der Negativismus bei der Dementia praecox ist das vollste Gegenteil der Übertragung. Die Kranken sind - im Gegensatz zu den Hysterischen - der Hypnose nur in beschränktem Maße zugänglich. Auch beim Versuch der Psychoanalyse bemerken wir das Fehlen der Ubertragung; als therapeutisches Verfahren kommt diese bei der Dementia praecox daher kaum in Betracht. Im Verkehr mit den Patienten bemerken wir die mangelnde Übertragung auch, sonst. Wir sehen sie nie wirklich heiter. Sie haben keinen Sinn für Humor. Ihr Lachen ist oberflächlich, oder krampfhaft, oder grob erotisch, aber niemals herzlich. Oft bedeutet es auch nicht etwa Heiterkeit, sondern zeigt nur an, daß der Komplex getroffen ist; dies gilt z. B. für das stereotype Lachen der Halluzinierenden, denn die Halluzinationen betreffen stets den Komplex. Das Auftreten der Kranken wird ungewandt und steif; es zeigt das Fehlen der Applikation an die Umgebung besonders deutlich. Kraepelin spricht sehr bezeichnend von einem "Verlust der Grazie". Das Bedürfnis, ihre Umgebung behaglich und freundlich $z u$ gestalten, geht den Kranken verloren. Wie die Anhänglichkeit an Menschen, so schwindet auch die Anhänglichkeit an Tätigkeit und Beruf. Die Kranken versinken gern in sich und - was mir besonders charakteristisch scheint - sie kennen keine Langeweile. Man kann die Kranken in den Anstalten allerdings grobenteils zu ganz brauchbaren Arbeitern erziehen. Es gehört dazu eine Arbeitssuggestion, der sich die Patienten gleichgültig unterordnen, ohne Freude an ihrem Tun. Hört die Suggestion auf, so stellen sie die Arbeit ein. Eine scheinbare Ausnahme bilden jene Patienten, die unermüdlich, ohne Erholungsbedürfnis, von früh bis spăt arbeiten. Dieses Arbeiten geschieht dann ausnahmslos einem Komplex zuliebe. Ein Kranker ist z. B. in der Landwirtschaft der Anstalt uberaus tătig, weil er das ganze Anstaltsterrain für sein Eigentum hält. Ein hochbetagter Patient ist unermuldich in der 
Abwaschküche seiner Abteilung tätig und duldet nicht die Hilfe eines andern. Er hört nämlich aus dem Wasser des Abwaschtroges die Elfen sprechen. Einmal haben sie ihm geweissagt, er werde $z u$ ihnen kommen, wenn er vor seinem Tode noch 100.000 Stück Geschirr abwasche. Der 80 jährige Mann zeigte für nichts Interesse als für diese Tätigkeit, der er unter geheimnisvollen Zeremonien nachging.

Zư den Gegenständen, zu ihrem Eigentum, haben die Kranken kein intimeres Verhältnis mehr. Alles, was sie umgibt, ist ohne Reiz für sie. Oft freilich äuBern sie das intensive Verlangen nach einem Gegenstande; aber die Erfüllung des Wunsches bleibt ganz ohne Eindruck. Auch behüten sie gewisse Gegenstände mit Sorgfalt, aber es zeigt sich dann doch bei Gelegenheit, daB ihr Herz nicht an den Dingen hängt. Ein Patient z. B. sammelt eine große Menge von gewöhnlichen Steinen, erklärt sie für Edelsteine und mißt ihnen einen ungeheuren Wert bei. Die Schublade, in der er sie aufbewahrte, brach schließlich von der Last. Als man die Steine nun beseitigte, protestierte der Patient gegen den Eingriff in sein Recht. Den verlorenen Kostbarkeiten trauerte er nicht nach, sondern suchte sich neue Kieselsteine zusammen. Diese eigneten sich zu Symbolen seines vermeintlichen Reichtums ebensogut wie die früheren. - In dem Fehlen der Freude an Gegenständen wurzelt sicher auch teilweise die so häufige Zerstörungssucht der Kranken.

In sehr vielen Fällen betrifft die Störung nicht nur jene feineren sozialen Sublimierungen, die sich im Laufe des Lebens allmählich herausgebildet haben, sondern auch diejenigen, welche in fruher Kindheit entstanden sind: Scham, Ekel, moralische Gefühle, Mitleid usw. Eine genaue Untersuchung durfte wohl in jedem Falle von Dementia praecox ein wenigstens teilweises Erlöschen dieser Gefühle ergeben. In allen schweren Fallen ist die Störung ohne weiteres wahrnehmbar. Die gröbsten Vorkommnisse dieser Art sind das Schmieren mit den Dejektionen, das Urintrinken, die Unsauberkeit, die alle auf einen Verlust des Ekelgefühls hinweisen, ebenso wie das aufdringlich erotische Benehmen, das Exhibieren auf den Verlust des Schamgefühls schließen lassen. Wir werden hier an das Verhalten des Kindes erinnert, das den Ekel vor den Exkrementen und das Schamgefühl bei Entblößung noch nicht kennt. In dasselbe Gebiet gehört auch die Hemmungslosigkeit, mit welcher viele Kranke liber Intimitäten ihres Vorlebens sprechen. Sie stoBen auf diese Weise nur Reminiszenzen von sich ab, die Wert und Interesse für sie verloren haben. DaB auch das Mitgefühl schwindet, zeigt uns besonders das Verhalten der Kranken angesichts grausamer Handlungen, die sie selbst begangen haben. Ich sah 
einmal einen solchen Kranken, wenige Stunden nachdem er einen harmlosen Nachbarn erschossen und seine Frau schwer verletzt hatte, mit aller Seelenruhe von den Motiven der Tat und von dieser selbst erzählen und dabei das ihm gereichte Essen behaglich verzehren.

Wir lernen aus dem Bisherigen zwei Reihen von Erscheinungen kennen : die einen zeigen, daß die Libido von belebten und unbelebten Objekten abgekehrt wird, die andern zeigen den Verlust der durch Sublimierung entstandenen Gefuhle. Die Dementia praecox führt also zur Aufhebung der Objektliebel und der $\mathrm{Sublimierung.} \mathrm{Einen} \mathrm{solchen} \mathrm{Zustand} \mathrm{der} \mathrm{Sexualităt} \mathrm{kennen} \mathrm{wir}$ sonst nur in der frühen Kindheit. Wir benannten ihn hier mit Fre u d ${ }_{n}$ Autoerotismus" Auch in dieser Zeit fehlen Objektbesetzung und Sublimierung. Die psychosexuelle Eigenart der Dementia praecox besteht somit in der Ruckkehr des kranken Individuums zum Auto. erotismus. Die Symptome der Krankheit sind eine Form autoerotischer Sexualbetätigung.

Selbstverstăndlich soll nicht gesagt sein, daß jede sexuelle Regung der Kranken rein autoerotisch sein müsse. Wohl aber ist jede Neigung der Kranken zu einer anderen Person sozusagen von der Blässe des Autoerotismus angekränkelt. Wenn wir bei einer weiblichen Kranken eine anscheinend sehr starke, ja stürmisch sich äußernde Liebe bemerken, so wird uns zugleich jedesmal der Mangel an Schamgefühl in der ÄuBerung auffallen. Der Verlust des Schamgefühls als eines Sublimierungsproduktes bedeutet für uns aber einen Schritt in der Richtung zum Autoerotismus. Ferner sehen wir diese Kranken sich rasch und wahllos in eine Person verlieben, diese aber ebenso rasch gegen eine andere vertauschen. In der Anstalt sind immer gewisse Frauen in den jeweiligen Arzt verliebt; bald hat jede von ihnen den Wahn, mit dem Arzt verlobt oder verheiratet zu sein, glaubt sich von ihm geschwängert, sieht in jedem Wort von ihm ein Zeichen der Liebe. Geht der Arzt fort, so tritt im Gefuhlsleben jener Patientinnen sehr rasch der Nachfolger an seine Stelle. Die Kranken sind also wohl noch imstande, ihr sexuelles Bedürnis auf eine Person zu projizieren, aber nicht mehr zur wirklichen Applikation an die geliebte Person fähig. Andere Patienten pflegen jahrelang eine imaginăre Liebe; diese existiert nur in ihrer Phantasie - das Sexualobjekt haben sie vielleicht nie gesehen; in Wirklichkeit sperren sie sich gegen jede Berührung mit einem Menschen ab. Kurz, irgendeine Äußerung des Autoerotismus ist stets nachweisbar. - In solchen Fällen, welche durch

1 Ein von mir beobachteter Patient redete sich in seinen zahllosen Schriftstucken selbst $d u$ an; er selbst war eben das einzige Objekt, das ihn interessierte. 
weitgehende Remission eine Heilung vortäuschen, ist die mangelnde Fähigkeit der Applikation an die Außenwelt in der Regel derjenige krankhafte Zug, der sich am leichtesten erkennen läßt.

Der Kranke, der seine Libido von den Objekten abkehrt, setzt sich damit in einen Gegensatz zur Welt. Er allein steht nun einer Welt, die ihm feindselig ist, gegenüber. Es scheint, als ob die Verfolgungsidee ${ }^{1}$ sich besonders gegen diejenige Person richten, auf welche der Patient einstmals seine Libido in besonderem Grade übertragen hatte. In vielen Fällen wäre also der Verfolger ursprünglich Sexualobjekt gewesen und der Verfolgungswahn hätte einen erogenen Ursprung.

Im Autoerotismus der Dementia praecox liegt nun nicht bloß die Quelle des Verfolgungswahns, sondern auch die des Größenwahns. Unter normalen Verhältnissen besteht zwischen zwei Personen, die ihre Libido aufeinander ubertragen haben, ein Verhälnis gegenseitiger verliebter Uberschätzung (von Freud als "Sexualubberschätzung " bezeichnet). Der Geisteskranke uberträgt die gesamte Libido, die der Gesunde all den lebenden und unbelebten Objekten der Umgebung zuwendet, allein auf sich selbst, als auf sein einziges Sexualobjekt. Die Sexualibberschätzung gilt ebenfalls nur ihm selbst. Sie nimmt gewaltige Dimensionen an, bedeutet er selbst sich doch die Welt! D ie a uf das Ich zuritckgewandte reflexive oder a utoerotische Sexualuberschätzung istdie $Q u$ elledes GröBenwahns bei der Dementia praecox ${ }^{2}$. Verfolgungswahn und Größenwahn sind also eng miteinander verknüpft. Jeder Verfolgungswahn bei Dementia praecox enthält implizite einen Größenwahn.

Die autoerotische Absperrung gegen die Außenwelt wirkt nicht nur auf das reaktive Verhalten des Kranken, sondern auch auf das rezeptive ein. Der Kranke verschließt sich gegen die ihm zuströmenden realen Sinneswahrnehmungen. Sein Unbewußtes formt sich auf halluzinatorischem Wege Sinneswahrnehmungen, wie sie den verdrängten Wünschen entsprechen. Der Kranke geht also in der Selbstabsperrung so weit, daß er die Außenwelt gewissermaßen boykottiert; er produziert nicht mehr für sie und bezieht nicht mehr von ihr, für die Lieferung der Sinneseindrücke erteilt er sich selbst das Monopol.

1 Die Abkehr der Libido von der Außenwelt ist die Grundlage für die Bildung des Verfolgungswahns im allgemeinen. Auf die weiteren in Betracht kommenden Faktoren kann hier nicht eingegangen werden.

2 Ich sehe die autoerotische Sexualüberschătzung als Quelle des GroBenwahns bei der Dementia praecox i m a $11 \mathrm{gem}$ e ine $n$ an. Die spezielle Form des Wahns die Groben ide e - wird durch einen bestimmten verdrängten Wunsch determiniert. 
Der Patient, der sich für die Außenwelt nicht interessiert, der völlig in sich gekehrt dahinvegetiert, der durch seinen unbelebten Gesichtsausdruck den Anschein völliger Abgestumpftheit erweckt, erscheint der gewöhnlichen Betrachtung als intellektuell und gemütlich verblödet. Für diesen Zustand ist der Ausdruck "Demenz" gang und gäbe. Derselbe Ausdruck wird aber auch für die Folgezustände anderer Psychosen angewandt, die tatsächlich von der uns hier interessierenden Form absolut verschieden sind. Ich meine die epileptische, paralytische und senile Demenz. Gemeinsam ist diesen Zuständen nur die Wirkung - eine Herabsetzung der intellektuellen Le is t ung en und auch diese nur bis zu einem gewissen Grade. Nur wenn man dies im Auge behält, darf man den gemeinsamen Namen anwenden. Vor allen Dingen sollte man sich hüten, etwa - wie es oft geschieht - eine Wahnidee "schwachsinnig " zu nennen, weil sie absurd ist. Man müBte dann auch die sinnvollen Absurditäten des Traumes als schwachsinnig bezeichnen. Die paralytische Demenz, desgleichen die senile zerstört die intellektuellen Fähigkeiten von Grund aus; sie führt zu groben Ausfallserscheinungen. Die epileptische Demenz führt $\mathrm{zu}$ einer außerordentlichen Verarmung und Monotonie des Vorstellungslebens, zu einer Erschwerung der Auffassung. Die Veränderungen bei diesen Krankheiten sind höchstens eines zeitweisen Stillstandes fähig, im allgemeinen aber progressiv. Die "Demenz" bei der Dementia praecox hingegen beruht auf Gefühlsabsperrung. Die intellektuellen Fähigkeiten bleiben erhalten; das oft behauptete Gegenteil ist wenigstens noch nie erwiesen worden. Infolge autoerotischer Absperrung nimmt der Kranke nur keine neuen Eindrücke auf und reagiert auf die Außenwelt gar nicht oder in abnormer Weise. Der Zustand kann sich jederzeit lösen; die Remission kann einen solchen Grad erreichen, daß kaum mehr der Verdacht eines intellektuellen Defektes entsteht.

Während die "Demenz" bei der Dementia praecox ein autoerotisches Phänomen ist, während wir in diesem Zustande jede normale Gefühlsreaktion auf die Außenwelt vermissen, reagieren 'die epileptisch oder organisch Dementen uberaus lebhaft mit dem Gefühl, sofern sie noch fähig sind, einen Vorgang aufzufassen. Der Epileptiker verhält sich nie indifferent; er steht mit einem Gefuhlsüberschwang auf seiten der Liebe oder des Hasses. Er überträgt seine Libido in außerordentlichem Maße auf Menschen und Gegenstände, er bezeugt seinen Angehörigen Liebe und Dankbarkeit. Er hat Wohlgefallen an seiner Arbeit und hängt mit großer Zähigkeit an seinem Eigentum, bewahrt jeden Papierfetzen sorgsam auf und betrachtet seine Schätze immer wieder mit Freude. 
Im Autoerotismus liegt der Gegensatz der Dementia praecoxauch gegentiberderHysterie. Hier Abkehrder Libido, dort übermäBige Objektbesetzung, hier Verlust der Sublimierungsfähigkeit, dort gesteigerte Sublimierung.

Die psychosexuellen Eigentumlichkeiten der Hysterie können wir häufig schon in der Kindheit beobachten, während der Ausbruch der schweren Krankheitserscheinungen erst viel später erfolgt. Ein Teil der Falle bietet aber auch schon in der Kindheit manifeste Krankheitszeichen. Wir schließen daraus, daß die psychosexuelle Konstitution der Hysterischen angeboren sei. Der gleiche Schluß ist für die Dementia praecox berechtigt. In den Anamnesen finden wir überaus häufig, daB die Kranken von jeher sonderbar und träumerisch waren und sich niemanden anschlossen. Sie vermochten schon lange vor dem "Ausbruch" der Krankheit ihre Libido nicht zu ubertragen und machten daher die Phantasie zum Felde ihrer Liebesabenteuer. Von diesen Eigentümlichkeiten dürfte kaum ein Fall frei sein. Auch auf die besonders große Neigung dieser Personen zur Onanie soll verwiesen werden. Solche Individuen haben also den infantilen Autoerotismus nie völlig überwunden. Die Objektliebe hat sich bei ihnen nicht voll entwickelt, und daher wenden sie sich, wenn die Krankheit manifest wird, dem Autoerotismus vollends wieder zu. Die psychosexuelle Konstitution der Dementia praecox beruht demnach a uf einer Entwicklungsh'emmung. Die Minderzahl von Krankheitsfällen, die schon in der Kindheit psychotische Erscheinungen im groben Sinne darbietet, bestätigen diese Anschauung in eklatanter Weise, indem sie ein pathologisches Verharren beim Autoerotismus klar erkennen lassen. Ein von mir beobachteter Patient hatte schon im dritten Lebensjahre ausgesprochenen Negativismus gezeigt. Wenn er gewaschen war, krampfte er die Finger ein und ließ sie nicht trocknen. Dies Verhalten zeigte er später noch als Sekundaner des Gymnasiums. Derselbe Patient war im dritten Lebensjahr monatelang nicht $z u$ bewegen, seinen Stuhl zu entleeren; die Mutter muBte ihn alle Tage bitten, von dieser Gewohnheit abzulassen. Dieses Beispiel zeigt ein abnormes Festhalten an einer erogenen Zone - eine typisch autoerotische Erscheinung. - Der jugendliche Patient, von dem ich berichtete, daß mit 13 Jahren plötzlich seine Libido von der Mutter abkehrte, verhielt sich ebenfalls schon in frühester Kindheit negativistisch.

Die Hemmung der psychosexuellen Entwicklung äußert sich nicht nur darin, daB das Individuum den Autoerotismus nicht vollkommen ubberwindet, sondern auch in einem abnormen Persistieren der Partialtriebe. Diese Eigentümlichkeit, welche eine gesonderte und eingehende 
Betrachtung verdient, soll hier nur durch einen einzelnen Zug aus der Krankengeschichte des gleichen Patienten illustriert werden, dessen autoerotisch-negativistisches Verhalten ich soeben geschildert habe. Als er (im Alter von 27 Jahren) wegen Nahrungsverweigerung einmal vom Arzt mit Hilfe der Schlundsonde gefüttert worden war, sah er in diesem Eingriff einen päderastischen Akt und in dem Arzt fortan einen homosexuellen Verfolger. Hier finden wir in einem Beispiel die Äußerung des homosexuellen Partialtriebes, dessen Verschiebung von der analen Zone auf eine andere erogene Zone ("Verlegung nach oben" Fre ud's) und den erogenen Ursprung einer Verfolgungsidee.

Ein abnormes Persistieren der Partialtriebe ist auch den Neurosen eigen. Auch diese weisen also eine Hemmung in der psychosexuellen Entwicklung auf. Dieser fehlt jedoch die autoerotische Tendenz. Die Störung bei der Dementia praecox greift viel tiefer; das Individuum, das vom tiefsten Stađium der psychosexuellen Entwicklung nie völlig losgekommen war, wird mit der Progression des Krankheitsprozesses mehr und mehr in das autoerotische Stadium zurückgeworfen.

Die Annahme einer abnormen psychosexuellen Konstitution im Sinne des Autoerotismus scheint mir einen großen Teil der Krankheitserscheinungen der Dementia praecox zu erklären und die neuerdings erörterten Toxin-Hypothesen entbehrlich zu machen.

Natürlich ist es unmöglich, die zahllosen Krankheitsphänomene, welche auf diese Entwicklungshemmung zurückzuführen sind, in einem kurzen Vortrag zu erschöpfen. Auch eine ausgedehnte Abhandlung wäre hierzu heute nicht imstande. Denn die Analyse der Psychosen auf Grund der F r e u d'schen Lehren ist noch in den Anfängen begriffen. Sie scheint mir aber berufen, uns Aufklärungen zu bringen, die auf keinem andern Wege $\mathrm{zu}$ erzielen sind. Ich habe hier in erster Linie die differential-diagnostische Abgrenzung der Dementia praecox gegen Hysterie und $Z$ wangsneurose im Auge. Sodann erscheint mir die Genese der verschiedenen Wahnformen der analytischen Erforschung zugänglich. Vielleicht verhilft uns die Methode aber auch zur Klarheit über die intellektuellen Störungen im Krankheitsbilde der Dementia praecox, von deren Verständnis wir heute noch weit entfernt sind. 


\section{Die psychologischen Beziehungen zwischen Sexualität und Alkoholismus'.}

Es ist eine unbestrittene Tatsache, daB im allgemeinen das männliche Geschlecht dem Alkoholgenuß mehr zuneigt, als das weibliche. Wenn auch in manchen Gegenden täglicher Alkoholgenuß den Frauen ganz wie den Männern etwas Selbstverständliches ist, wenn auch mancherorts betrunkene Frauen eine häufige Erscheinung im StraBenbild sind, so ist doch der Alkohol mit dem geselligen Leben der Frauen nie in derjenigen Weise verknüpft, wie mit dem der Männer. Trinkfestigkeit gilt bei uns in weiten Kreisen als Zeichen der Männlichkeit, ja als Ehrensache. Von der Frau verlangt die Gesellschaft das Trinken nie in rigoroser Weise. Unsere landläufige Moral neigt eher dazu, das Trinken für unweiblich zu erklären. Unter normalen Frauen ist das Trinken auch nie Gegenstand der Renommage wie unter Männern.

Es scheint mir der Untersuchung wert, ob dieses verschiedene Verhalten der Geschlechter zum Alkohol in den Unterschieden der Sexualität seine Begründung finde. Eine solche Untersuchung muß auf die neueren Auffassungen der psychosexuellen Konstitution des Mannes und Weibes zurückgehen, wie sie besonders in den Arbeiten Freuds 2 niedergelegt sind.

Unser Körper enthält, wie die Entwicklungsgeschichte nachweist, die Anlage $z \mathbf{u}$ den Genitalorganen beider Geschlechter. Eine der beiden Anlagen wird im Verlauf der normalen Entwicklung reduziert oder übernimmt anderweitige Funktionen. Die andere hingegen entwickelt sich weiter, bis sie funktionsfähig wird. Ein ganz analoger Vorgang spielt sich auf psychosexuellem Gebiet ab. Die Differenzierung der Geschlechter nimmt auch hier von einem ursprünglichen Zustande der Bis exualität ihren Ausgang. Im Kindesaiter haben die Äußerungen des Sexualtriebes bei Knaben und Mädchen noch große Ähnlichkeit.

${ }_{1}$ Zuerst veröffentlicht in "Zeitschrift fur Sexualwissenschaft", I. Jahrg., 1908.

- Drei Abhandlungen zur Sexualtheorie, 1905. 
Wie wir besonders durch $\mathrm{Fr}$ e uds Forschungen erfahren haben, fehlen der Kindheit die sexuellen Regungen keineswegs. Nur die Fortpflanzungsfunktion ist noch aufgeschoben, und der Trieb erhält erst allmählich seine definitive Richtung. Wie Freud darlegt, ist die infantile Libido objektlos, "autoerotisch ". Sie strebt nach Lustgewinnung durch Reizung gewisser Körperstellen, welche als e ro g e n e $Z$ on en dienen. Doch werden nicht alle sexuellen Energien in der Vorpubertätszeit zur autoerotischen Lustgewinnung verbraucht; zu einem wesentlichen Teil werden sie aus dem Bewußtsein verdrängt, um nicht mehr sexuelle Verwendung zu finden, sondern um wichtige soziale Funktionen zu übernehmen. Die "Verdrangung" ist ein von Freud eingeführter Begriff, der zum Verständnis vieler - normaler und krankhafter - psychologischer Vorgänge nicht entbehrt werden kann. Die Ablenkung verdrängter sexueller Vorstellungen und Gefühle auf soziale Ziele bezeichnen wir mit Freud als Sublimierung. Durch diesen Proze日 werden bei beiden Geschlechtern die Schranken des Geschlechtstriebes errichtet.

Mit dem Eintritt der Reifung gewinnt der Knabe wie das Mädchen die ausgesprochenen körperlichen und physischen Charaktere seines Geschlechtes. Auf psychosexuellem Gebiet findet der wichtige ProzeB der Objektfindung statt. Die Libido richtet sich nun auf das andere Geschlecht. Aber nicht nur in dieser Hinsicht differenzieren sich männliche und weibliche Libido; uns interessiert hier namentlich noch e in e Differenz. Die weibliche Sexualität zeigt größere Neigung zur Verdrängung, zur Bildung von Widerständen. Die infantile Sexualverdrängung erfährt beim Weibe in der Pubertät, gleichsam durch einen neuen Schub, eine mächtige Verstärkung. Daraus resultiert der mehr passive Sexualtrieb des Weibes. Die männliche Libido ist mehr aktiver Natur. Sie überwindet die psychischen Widerstände, denen sie beim Sexualobjekt begegnet, vermöge ihrer aggressiven Komponente. Zwei Ausdrücke der deutschen Sprache charakterisieren den psychosexuellen Unterschied der Geschlechter : der Mann erobert, das Weib gibt sich hin.

Die alkoholischen Getränke wirken auf den Geschlechtstrieb, indem sie vorhandene Widerstände aufheben und die sexuelle Aktivität erhöhen. Das sind allbekannte Erfahrungen; aber man pflegt auf ihr eigentliches Wesen nicht einzugehen.

Je länger die Forschung sich mit dem sexuellen Problem befaßt, desto mehr zeigt sich die Kompliziertheit des Geschlechtstriebes. Er umfaßt neben der "normalen" heterosexuellen Liebe eine Reihe von "perversen" Regungen. Der Sexualtrieb des Kindes zeigt uns das bunte 
Chaos dieser Triebe; er ist "polymorph-pervers" (Freud). Nur allmählich ordnen sich die "Partialtriebe“ dem einen, heterosexuellen, unter. Sie verfallen der Verdrängung und Sublimierung. Aus ihnen entstehen Scham und Ekel, moralische, ästhetische und soziale Gefuhle, Mitleid und Grauen, die Pietăt des Kindes gegen die Eltern, die fürsorgende Liebe der Eltern für das Kind. Künstlerische und wissenschaftliche Tatigkeit beruhen zu einem wichtigen Teil auf der Sublimierung sexueller Energien ${ }^{1}$. A ú diesen Produkten der Sublimierung beruht unser soziales Leben, unsere gesamte Kultur. Unter ihnen ist keines, das nicht durch die Wirkung des Alkohols beeinträchtigt oder aufgehoben würde.

Beim normalen Individuum verfällt die homosexuelle Komponente des Sexualtriebes der Sublimierung. Die Gefühle der Harmonie und Freundschaft unter Männern sind alles BewuBt-Sexuellen entkleidet. Der gesund empfindende Mann hat einen Widerwillen gegen jede zärtliche Berührung mit Männern. Eine Reihe ähnlicher, aus der gleichen Quelle stammender Regungen des Widerwillens oder Ekels ließe sich hier anführen. Der Alkohol hebt sie auf. Beim Trinken fallen Männer einander um den Hals und küssen sich. Trinkende Männer fühlen sich durch besonders innige Bande vereinigt, sind darob zu Tränen gerührt und sind schnell mit dem intimen "Du" bei der Hand. Im nüchternen Zustande nennen die gleichen Männer ein solches Gebaren "weibisch" Ereignisse der jüngsten Zeit gaben den Anlaß, daß man viel von „abnormer Männerfreundschaft" hörte. Die GefühlsäuBerungen, die da als etwas Krankhaftes oder Unmoralisches gebrandmarkt wurden, kann jeder Sehende bei jedem Trinkgelage beobachten. Durch jede Kneipe geht ein Zug von Homosexualităt. Die gleichgeschlechtliche Komponente, die wir unter den Einflüssen der Erziehung verdrängen und sublimieren gelernt haben, kommt unter der Wirkung des Alkohols unverkennbar wieder zum Vorschein.

Ein Paar von Partialtrieben, dessen Bedeutung erst von Fre ud richtig eingeschätzt worden ist, wird durch die sexuelle Schau- und Exhibitionslust reprăsentiert. Mit ihnen steht die sexuelle WiBbegierde in engem Zusammenhang. Die Sublimierung dieser Triebe erzeugt das Schamgeflihl. Das Kind kennt in seinen ersten Lebensjahren kein Schamgefuhl; es muß das "Genieren" erst lernen. Erfolgt die Sublimierung nicht, so entsteht eine Perversion (Voyeurs, Exhibitionisten). Das Schamgefühl erstreckt sich nun nicht nur auf die körperliche Entந̋löBung, sondern richtet für den gesellschaftlichen Umgang, für die Konversation usw.

1 Vergl. F reud, drei Abhandlungen, und Ra nk, „Der Künstler, Ansătze zu einer Sexualpsychologie", Wien und Leipzig 1907. 
wichtige Schranken auf. Gerade diese fallen dem Alkohol zum Opfer. Untrennbar vom AlkoholgenuB ist der öbszöne Witz, der nach Fre ud ${ }^{1}$ ausgezeichneter Analyse eine psychische Entblößung darstellt. Fore ${ }^{2}$ hat mit Meisterhand geschildert, wie unter der Wirkung des Alkohols der "Flirt" rohe, widerwärtige Formen annimmt.

Ein anderes, ebenfalls im Verhältnis von Aktivität und Passivität stehendes Paar von Partialtrieben drängt nach der Herrschaft über das Sexualobjekt, resp. nach Unterwerfung unter dessen Willen.-Durch Sublimierung dieser Tendenzen entstehen die Gefühle des Mitleids, des Grauens usw. Bleibt die Sublimierung aus, so haben wir die als Sadismus, resp. Masochismus bezeichneten Perversionen vor uns. DaB zahlreiche Roheitsdelikte im Alkoholrausch ausgeführt werden, bedarf kaum der Erwähnung. Die verdrängten Partialtriebe brauchen sich jedoch nicht in dieser krassen Form zu äußern. Auch in mehr larvierter Form erkennen wir sie wieder. Seit Urzeiten kennt man Trinksitten und -gesetze; der Trinkkönig bei einem Gelage ist unumschränkter Herrscher. Ich erinnere an den noch heute gebräuchlichen, studentischen "Komment ${ }^{\text {" }}$ mit seinem rigorosen Trinkzwang, an das stolze Vergnügen, mit welchem der ältere Student den jüngeren zum Trinken zwingt, und an die blinde Unterwerfung des letzteren unter das Kommando. Ich weiß, daB ich mit dieser Auffassung der Gebräuche auf Widerspruch stoße; ich weise deshalb noch darauf hin, daß die studentischen Trinksitten sich aus einem Treiben von unglaublicher Roheit ganz allmählich $\mathrm{zu}$ den heutigen, zivilisierteren Formen entwickelt haben. Noch eine wichtige Schranke des Sexualtriebes müssen wir erwähnen. Das normale heranwachsende Kind überträgt seine Libido zuerst auf die andersgeschlechtlichen Personen seiner nächsten Umgebung: der Knabe auf Mutter und Schwester, das Mädchen auf Vater und Bruder. Einer langen kulturhistorischen Entwicklung bedurtte es, bis die nächsten Blutsverwandten von der Objektwahl ausgeschlossen wurden. Die Verwerfung des Inzestes führte zur Sublimierung der Elternliebe; die Liebe des Kindes wurde zur pietätvollen Verehrung der Eltern. Jedes Kind muß diese Entwicklung wiederholen; es überträgt zu einer gewissen Zeit seine erwachenden sexuellen Wünsche auf den andersgeschlechtlichen Teil der Eltern. Diese Regungen werden verdrängt, wie denn unsere Moral auch eine nicht sublimierte Neigung des Vaters zur Tochter verwirft. Auch diese Sublimierungen verschont der Alkohol nicht. Schon Lots Töchter wußten, daß der Alkohol die

${ }^{1}$ Freud, Der Witz und seine Beziehungen zum Unbewußten. Wien und Leipzig 1905.

2 Forel, Die sexuelle Frage. 
Inzestschranke niederreißt; sie erreichten ihr Ziel, indem sie ihrem Vater zu trinken gaben.

Man liest gewöhnlich, daß der Alkohol psychische Hemmungen beseitigt. Wir haben jetzt das Wesen dieser Hemmungen kennen gelernt: sie sind die Produkte der Sublimierung sexueller Energien.

Während nun verdrängte sexuelle Regungen wieder auftauchen, wird zugleich die dem Manne normalerweise eigne sexuelle Aktivität erhöht, woraus ein Gefühl gesteigerter sexueller Leistungsfähigkeit resultiert. Der Alkohol wirkt als Reiz auf den "Komplex “ der Männlichkeit ${ }^{1}$. Der Stolz des Männchens ist uns aus vielen Beispielen des Tierreichs bekannt. Mutatis mutandis begegnen wir den gleichen Erscheinungen beim Menschen. Der Mann fühlt sich stolz als der Zeugende, Gebende; das Weib „empfängt“. Wie tief dieser Größenkomplex im Manne wurzelt, das beleuchtet in uberraschender Weise die Analyse der Schöpfungsmythen. In einer demnächst erscheinenden Schrift ${ }^{2}$ werde ich den ausfihrlichen Nachweis erbringen, daß die Schöpfungssagen der verschiedenen Völker ursprünglich eine Vergötterung der männlichen Zeugungskraft darstellen, daß sie also die letztere als Prinzip alles Lebens proklamieren. Männliche Zeugungskraft und göttliche Schöpferkraft werden im Mythus identifiziert und eine an Stelle der andern gebraucht. Wir stoßen hier auf einen psychologischen Vorgang von außerordentlicher Wichtigkeit. Wir können seine Wirkungen in allen Gebilden der menschlichen Phantasie erkennen, seien es nun Werke der Individual- oder der Massenphantasie, seien sie normaler oder krankhafter Natur. Wir bezeichnen ihn als I dent if ikation.

Eine Frage, die von jeher die Menschen beschäftigen muBte, die wir aber auch heute noch nicht in befriedigender Weise zu beantworten vermögen, ist das Zustandekommen der ,sexuellen Erregung“. Die Annahme, daß die Erregung beim Manne vom Samen ausgehe, lag sehr nahe. Die naive Vorstellung des Volkes identifiziert nun das berauschende Getränk, weil es sexuell erregt, mit dem Samen oder mit dem sonstigen unbekannten Etwas, das (bei Abwesenheit künstlicher Reizmittel) die sexuelle Erregung hervorruft. Diese populäre Theorie findet in der Bezeichnung "Liebesrausch" ihren Ausdruck.

'Mit dem abgeklirzten Ausdruck .Komplex der psychologischen Arbeiten aus der Züricher psychiatrischen Klinik) einen Komplex von Vorstellungen nebst den ihnen anhaftenden Gefühlen, der unter gewissen Verhältnissen ins Unbewußte verdrängt wird, unter verănderten Verhältnissen sich aber wieder ins Bewußtsein eindrăngen kann.

Heft 4.

"Traum und Mythus." In: "Schriften zur angewandten Seelenkunde*, 
Die Wirkungssphäre gerade dieser Identifikation ist besonders groß. Durch die indogermanisch Mythologie ziehen sich Erzăhlungen vom Göttertrank und von seiner Entstehung. Dieser Trank, den man sich belebend und begeisternd vorstellt, wird mit den berauschenden Getränken der Menschen identifiziert. Die Identifikation geht aber noch weiter. An der Hand der alten indischen Mythen fuhre ich in der erwähnten Schrift den Nachweis, daß der Göttertrank dem menschlichen Samen gleichgestellt wird. Die lebenspendende Wirkung des Samens hat die Veranlassung dazu gegeben. Es ist bemerkenswert, daß die Sagen von der Zeugung (Erschaffung) des ersten Menschen (PrometheusSage u. a.) mit den Sagen vom Göttertrank in den denkbar engsten Beziehungen stehen. Es ist an dieser Stelle nicht möglich, auf die psychologische Analyse der genannten Mythen genauer einzugehen. Erwähnt sei nur, daß die griechischen Sagen von der Geburt des Weingottes Dionysos dieselbe Identifikation erkennen lassen.

In der gesamten Sagenwelt spielen die $\mathrm{L}$ i ebestränke eine große Rolle. Ihre erotische Wirkung ist zweifellos von den alkoholischen Getränken entlehnt. Rauschwirkung und sexuelle Erregung werden auch hier identifiziert. Dem gleichen Gedankengange begegnen wir in zahllosen Gebräuchen. Die dem Gotte des Weines gewidmeten Feste sind stets zu gleicher Zeit erotische Feste. In vielen Gebräuchen ist der Wein das Symbol der Zeugung oder Befruchtung. In einem von Riklin ${ }^{1}$ erwähnten Gebrauch ist die symbolische Vertretung des Samens durch den Wein ganz durchsichtig: in einer bestimmten Gegend ist es üblich, beim Frühlingsfest den Mädchen Wein in den Schoß zu gießen. Ein allgemeiner Gebrauch ist das Zutrinken. Hier vertritt das alkoholische Getränk wegen seiner erregenden Wirkung die Lebenskraft. Trinkt man auf das Wohl eines andern, so heißt das: die im Wein enthaltene belebende Wirkung solle ihm zugute kommen.

Die uns interessierende Identifikation muß überaus fest begründet sein. Der Respekt vor Trinkleistungen und derjenige vor sexuellen Leistungen sind fest miteinander verbunden. Wer nicht trinkt, gilt als Schwächling. Der Alkoholgenuß des Mannes beginnt in der Pubertätszeit, also dann, wenn man als Mann gelten möchte. Wer nicht mittrinkt, gilt bei seinen Altersgenossen nicht als reif. Das Renommieren mit Trinkleistungen ist in keinem Lebensalter so ausgeprägt, wie in der Zeit der beginnenden Männlichkeit. Erlischt in späteren Jahren die Potenz, so greift der Mann gern zum Lustbringer Alkohol, der ihm nun zum Surrogat der schwindenden Zeugungskraft wird.

1 Riklin, Wunscherfüllung und Symbolik im Märchen. Schriften zur angew. Seelenkunde. Heft 2. Wien und Leipzig 1908. 
Der Mann hăngt am Alkohol, weil dieser ihm ein erhöhtes Gefühl der Männlichkeit verleiht, seinem Männlichkeitskomplex schmeichelt. Das Weib erhält durch seine psychosexuelle Konstitution weit weniger Anlaß zum Alkoholgenuß. Die Aktivităt des weiblichen Geschlechtstriebes ist geringer, die Widerstände gegen die Regungen des Triebes sind gröBer. Wir führten dieses abweichende Verhalten auf den Verdrängungsschub der Pubertät zurück. Durch seine psychischen Widerstände reizt das Weib den Mann, wie ihm selbst am Manne energische Initiative gefällt. Das Mädchen hat keinen Anlaß, sich in der Pubertät dem Alkohol zuzuwenden. Dieser hebt ja die Verdrängungswirkungen, die Widerstände auf. Gibt das Weib sie preis, so verliert es an Reiz für den Mann. Weibliche Personen, die eine starke Neigung zum Alkohol zeigen, dürften bei genauer Beobachtung stets eine starke homosexuelle Komponente aufweisen.

Der Alkohol ruft seine Wirkungen - Erleichterung der Sexualübertragung und Aufhebung der Verdrängungswirkungen - nicht nur vorübergehend hervor, sondern bekanntermaßen auch chronisch. Chronische Trinker zeigen einen charakteristischen Gefühlsüberschwang, sind plump vertraulich, sehen jedermann als alten Freund an und zeigen eine unmännliche Rührseligkeit. Sie büßen das Schamgefühl ein; was für Szenen die Kinder eines Trinkers ansehen müssen, braucht bier nicht ausgeführt $\mathrm{zu}$ werden. Kurz, jedes der feineren Gefühle, die der Sublimierung ihre Entstehung verdanken, wird vernichtet.

Es sind nicht die Sublimierungen des Sexualtriebes allein, welche beim Trinker zugrunde gehen. Schon der akute Alkoholrausch setzt ja die sexuelle Leistungsfähigkeit in Wirklichkeit herab. Wir kennen des weiteren die Giftwirkung des Alkohols auf die Keimzellen (Blastophthorie) ${ }^{2}$. Wir wissen, daß ein großer Teil der Trinker impotent wird. Der Alkohol hat sie betrogen. Sie glaubten ihm, dab er ihre Männlichkeit erhöhe, weil er ihnen ein sexuelles Kraftgefühl gab. Statt dessen raubte er ihnen die Kraft; sie aber bemerken den Betrug auch jetzt nicht. Sie lassen nicht vom Alkohol, identifizieren ihn auch weiter mit ihrer Sexualität und gebrauchen ihn als Surrogat der letzteren. Ich erblicke hierin eine Analogie zu gewissen sexuellen Perversionen, bei welchen ein sexueller $R$ eiz, der normalerweise als $E$ inleitung des sexuellen Aktes dienen könnte, a n Stelle des letzteren gesetzt wird. Freud bezeichnet dies als "Fixierung eines vorlaufigen Sexualziels“. Beispielsweise bildet das Beschauen des Sexualobjekts unter

$2 \mathrm{Vgl}$. Forel und Juliusburger, Über Blastophthorie in Zeitschrift für Sex. Wiss. I, 1908, p 346. 
normalen Verhältnissen nur eine Quelle der Vorlust, während erst der sexuelle Akt selbst die Befriedigungslust herbeiführt. Gewisse Perverse begnügen sich dagegen mit dem Betrachten allein. Ganz analog verhält sich der Alkoholiker. Der Alkohol wirkt sexuell erregend; dieser Erregung jagt der Trinker nach und büBt dabei die Fähigkeit zur normalen Sexualbetätigung ein.

Zwischen Akolholismus und sexueller Perversion können wir noch weitere Analogien auffinden. Durch $\mathrm{F}$ re $\mathrm{uds}$ Forschungen haben wir die intimen Beziehungen zwischen Perversion und Neurose kennen gelernt: $\mathrm{Freu \textrm {d } ^ { 1 }}$ hat erwiesen, daB viele Symptome der Neurosen den Ausdruck verdrängter pervers-sexueller Phantasien und somit eine Art von Sexualbetätigung des Patienten bilden. Dem Versuch einer psychologischen Analyse seiner Symptome setzt der Patient stets einen außerordentlichen Widerstand entgegen, der sich aus der Verdrängung sexueller Komplexe erklärt. Beim Versuch der psycho-analystischen Auflösung der Krankheitserscheinungen tönt dem Arzt immer nur ein Nein entgegen, und wenn seine Frage noch so begrindet ist. Statt der wirklichen Ursachen bringt der Patient Deckmotive vor. Auch der Alkoholiker negiert bis aufs Blut Tatsachen, welche gar nicht bestritten werden können. Er hat für seinen Alkolholismus Deckmotive in reicher Auswahl. Jeden Versuch ernstlichen Eingehens wehrt er ab. Der Neurotische wehrt sich für seine Symptome, weil sie ihm seine Sexualbetätigung sind. Aus demselben Grunde - so glaube ich schließen zu müssen - wehrt der Trinker sich für seinen Alkoholismus.

Noch ein Gesichtspunkt scheint mir der Erwähnung wert. Unter den krankhaften Veränderungen des Vorstellungslebens der Alkoholiker spielen solche von unbestreitbar sexuellem Inhalt eine auffallende Rolle. Ich meine die bekannte Eifersucht der Trinker, die sich bis zum Wahne steigert. Auf Grund vieier Erfahrungen, die ich hier nicht im Detail anführen kann, sehe ich als Ursache der Eifersucht des Alkoholikers das Gefühl abnehmender Potenz an. Der Trinker benutzt den Alkohol als Quelle müheloser Lustgewinnung; er wendet sich vom Weibe ab dem Alkohol zu. Dieser Tatbestand ist seinem Selbstbewußtsein im höchsten Grade peinlich; er verdrängt ihn, ganz wie der Neurotiker es tut, und nimmt zugleich eine Verschiebung vor, wie wir sie im Mechanismus der Neurosen und Psychosen $z$ u finden gewohnt sind. Er verschiebt sein Schuldgefühl als Anklage auf die Frau: sie ist ihm untreu.

. Zwischen Alkoholismus, Sexualität und Neurose bestehen also

1 Fre ud, Hysterische Phantasien und ihre Beziehung zur Bisexualităt. Zeitschrift für Sex. Wiss. I, 1908; abgedruckt in Sammlung kleiner Schriften zur Neurosenlehre, II. Folge. 
mannigfache Beziehungen. Es scheint mir notwendig, das von Fre u d ausgebildete psychoanalystische Verfahren, das uns das Eindringen in die Struktur der Neurosen ermöglicht, auch zur Analyse des Alkoholismus nutzbar zu machen. Aus mündlichen Mitteilungen von Kollegen weiß ich, daß in Fällen von Morphinismus die Psychoanalyse überraschende Beziehungen zwischen Sexualität und Mißbrauch des Narcoticums ergeben haben. Ich erwähne hier auch das so rätselhafte Verhalten vieler nervöser Personen gegenüber den Narcotica. Hysterische bitten den Arzt oft, ihnen nur ja kein Morphium oder Opium zu verordnen, da sie es nicht vertrügen; sie erzählen dann von unangenehmen, früheren Erfahrungen. Aller Anschein spricht dafür, daß jene Mittel bei gewissen Hysterischen eine sexuelle Erregung hervorrufen; diese wird infolge der eigentümlichen psychosexuellen Konstitution der Hysterischen in körperliche Symptome und Angstgefühle konvertiert. Vielleicht hat die bei Nervösen so häufige Intoleranz gegen Alkohol eine ähnliche Wurzel. Endlich will ich einer merkwürdigen Erfahrung gedenken, die ich wiederholt bei Geisteskranken gemacht habe. Wenn man den Kranken ein narkotisches Mittel unter die Haut einspritzte, so faßten sie dies als eine sexuelle Vergewaltigung auf. Sie deuteten Injektionsspritze und Flüssigkeit symbolisch um.

Wie man sieht, bietet die psychologische Erforschung des Alkoholismus noch genügend ungelöste Probleme. Äußere Einwirkungen, wie soziale Einflüsse, Erziehungsfehler, erbliche Belastung usw., genügen a 11 e i n nicht zur Erklärung der Trunksucht. Ein individuelles Moment muß hinzukommen. Dieses zu erforschen ist die nächste Aufgabe. Sie erscheint mir nur dann lösbar, wenn man sich die Zusammenhänge zwischen Alkoholismus und Sexualität stets vor Augen hält. 


\section{Die Stellung der Verwandtenehe in der Psychologie der Neurosen ${ }^{1}$.}

Die Anschauung, daß die Ehe unter Blutsverwandten auf die Nachkommenschaft einen nachteiligen EinfluB auslibe, ist sehr alt. Besonders daß die Konsanguinität der Eltern den Grund $z \mathfrak{u}$ den verschiedenartigsten Nerven- und Geisteskrankheiten lege, wird in der medizinischen Literatur wie auch im Volksglauben allgemein angenommen. $\mathrm{DaB}$ in vielen Familien Inzucht und nervöse oder psychische Störungen zusammentreffen, kann keinem Zweifel unterliegen. Daraus folgt aber nicht ohne weiteres, daß beide Erscheinungen in dem einfachen Verhältnis von Ursache und Wirkung zueinander stehen müssen. Es fragt sich vielmehr, ob das Vorkommen von Verwandtenehen in gewissen Familien nicht seinerseits eine spezifische Ursache hat, ob nicht gerade in neuropathischen Familien eine eigentumliche Veranlagung dazu drängt, daß die Familienmitglieder untereinander heiraten. Versucht man, die Verwandtenehe als psychopathologisches Phänomen $z \mathbf{u}$ betrachten, so bemerkt man, daß sie sich als solches von einer Reihe anderer Phänomene nicht sondern läßt, mit welchen sie bestimmte psychologische Wurzeln gemein hat.

Die Ansichten über die Psychologie der Verwandtenehe, die ich im folgenden mitteile, erheben keinen Anspruch auf allgemeine Gültigkeit. Natürlich kann eine Ehe unter Blutsverwandten ebenso wie eine andere aus rein praktischen Gründen geschlossen werden. Oder äußere Gründe, wie z. B. das Abgeschlossensein vom allgemeinen Verkehr, lassen eine Verbindung mit fremden Familien nicht zustande kommen. Auch dürfte nach Rassen und gesellschaftlichen Schichten die Neigung zur Inzucht verschieden groß sein. Für diejenigen Fälle aber, in welchen Verwandte nur durch individuelle Sympathie zusammengeführt werden, nehme ich an, daB die Fähigkeit, die Liebesneigungen auf fremde Personen $z \mathbf{u}$ lubertragen, unzureichend ist, wăhrend die

1 Mit Benutzung eines Vortrages (Sitzung der Berliner Gesellschaft für Psychiatrie und Nervenkrankheiten am 9. November 1908). Zuerst veröffentlicht im .Jahrbuch für psychoanalytische und psychopathologische Forschungen*, I. Band, 1909. 
Zuneigung $z u$ Mitgliedern der eigenen Familie das normale Maß übersteigt.

Ein solches Verhalten läßt sich von den Eigentümlichkeiten 'der Sexualität bei den Neurotikern herleiten. Abweichungen von der Norm treten bei ihnen ja schon in der Kindheit hervor. Neuropathische Kinder zeigen schon früh ein übermäßiges erotisches Verlangen. Das übertriebene Liebesbedürfnis der neuropathischen Kinder bedeutet freilich nur eine Steigerung der normalen Verhältnisse ${ }^{1}$. Auch das normale Kind überträgt seine Neigung naturgemäß zuerst auf die Personen, mit welchen es ständig zusammenlebt. Daß es sich hier um eine Äußerung der Sexualität handelt, kann schon deshalb keinem $Z$ weifel unterliegen, weil sich die Zuneigung des Knaben vorzugsweise auf Mutter oder Schwester, die des Mädchens auf Vater oder Bruder richtet ${ }^{2}$. In der $z$ weiten Kindheitsperiode lassen die ÄuBerungen dieser Liebe oft auch keinen Zweifel an ihrer Natur aufkommen. Neurotische Kinder zeigen mit Bezug auf die geliebte Person eine starke Eifersucht, verlangen sie allein zu besitzen und sehen in den übrigen Familienangehörigen nur Rivalen, ganz nach Art verliebter Erwachsener. Es sei übrigens bemerkt, daB neurotische Kinder in dieser ihrer Eigenart oft noch von den Eltern bestärkt werden, indem diese die Kinder verzärteln, ihre Anspriche auf Liebesbeweise steigern und gelegentlich wohl auch vorzeitig geschlechtliche Sensationen bei ihnen hervorrufen.

Unter normalen Verhältnissen verfällt die infantile Sexualübertragung auf den andersgeschlechtlichen Teil der EItern (resp. auf Geschwister des anderen Geschlechtes) der Sublimierung, d. h. der Umwandlung in Gefähle der Verehrung, der Pietät usw. Durch diesen ProzeB wird, wie Freud ausgeführt hat, die Liebe zu Eltern und Geschwistern des BewuBt-Sexuellen entkleidet. Nur in gewissen Träumen lebt die infantile Inzestphantasie fort 3.

Die Pubertät mit ihren psychischen Umwälzungen führt eine je nach der Individualität verschieden weitgehende Ablösung des Kindes

1 Vgl. Freud, Drei Abhandlungen zur Sexualtheorie, 1905.

2 Unter den Autoren, welche die Anschauungen Freuds im allgemeinen ablehnen, verweist Oppenheim (Lehrbuch der Nervenkrankheiten, 5. Auflage, Seite 1256) auf die besondere Zärtlichkeit, die überschwengliche Liebe der hysterischen Kinder; er etblickt in diesen Erscheinungen jedoch keine Außerungen der kindlichen Sexualităt (Vgl. den Sitzungsbericht der Berliner Geselischaft für Psychiatrie und Nervenkrankheiten vom 9. November $1908 \mathrm{im}$ Neurolog. Zbl. 1908, Heft 23).

${ }^{3}$ Bezüglich des "Odipusmotivs" Im Traume vgl. besonders Freud, Die Traumdeutung, 2. Auflage, 1909, Seite 185. 
von der elterlichen Autorität herbei. Die Libido wird frei, um auf fremde Personen des anderen Geschlechtes übertragen zu werden; die Personen đer nächsten Familie sind fortan von der Objektwahl ausgeschlossen. Im Unbewußten bleibt freilich der verdrängten infantilen Neigung ein wichtiger Einfluß erhalten. Vielfach läßt sich z. B. deutlich erkennen, daß der Mann durch solche weibliche Personen angezogen wird, bei welchen er Eigenschaften seiner Mutter (oder Schwester) wiederfindet.

Bei neuropathischen Individuen ist der Ablauf dieses wichtigen Entwicklungsvorganges gestört. Die abnorme Stärke der infantilen Sexualübertragung hindert die vollkommene Verdrängung der Inzestphantasie. Sie erschwert ferner die Ablösung von der elterlichen Autorität. Bei vielen Neurotischen bleibt daher eine kindliche Unselbständigkeit bestehen. Bleibt der Sohn nun in der Pubertät unter dem ungeschmälerten EinfluB der Eltern, bleibt seine Libido auf das infantile Sexualobjekt ubertragen, so entstehen daraus für ihn doppelte Folgen. Erstens wird ihm die normale Übertragung auf fremde weibliche Personen zeitlebens erschwert, ja auf Jahre hinaus unmöglich gemacht, zweitens wird die Neigung zu einer so nahen Angehörigen von der herrschenden Moral verworfen. So kommt es zur Triebunterdrü ckung. Der neurotisch Veranlagte schwankt ja stets hin und her zwischen der abnormen Stärke seiner Libido und seiner Tendenz zur Triebverdrängung. Hier bietet sich ihm der Anlaß zu einer weitgehenden Unterdrückung seiner Triebe. Als Paradigmen dieses Vorganges nenne ich die Mustersöhne und -töchter, denen wir gerade in neuropathischen Familien begegnen; ihre Liebe zu den Eltern bewahrt auch nach der Pubertät den infantilen Charakter ${ }^{1}$.

Aus dieser eigentümlichen psychosexuellen Entwicklung können für den Neurotischen sehr verschiedenartige praktische Konsequenzen hervorgehen. In der Reihe dieser Möglichkeiten nimmt auch die uns besonders interessierende Erscheinung, die Verwandtenehe, ihren Platz ein. Wenn ich die der Verwandtenehe psychogenetisch nahestehenden Erscheinungen aufzähle, so muß ich mit derjenigen beginnen, die streng genommen nicht hierher gehört, nämlich mit dem wirklichen Inzest. Kommt es tatsächlich zum inzestuösen Verkehr, so fehlt ja die Triebunterdrückung. Ein kurzer Hinweis scheint mir aber gerechtfertigt. Einmal erfährt man aus der Anamnese nervöser Personen nicht selten, daB in der Kindheit zwischen den Geschwistern sexuelle Handlungen vorgekommen sind. Sehr bemerkenswert ist aber die starke

1 Vgl. hierzu Freud, .Die kulturelle Sexualmoral " usw. in der Zeitschrift „Sexualprobleme“, 1908, Seite 123. 
Neigung zum Inzest unter den an Dementia praecox leidenden Geisteskranken. Ich verfüge über eine Anzahl einwandfreier Beobachtungen dieser Art, die sich auf das Zusammenleben geisteskranker Geschwister (resp. von Vater und Tochter) beziehen.

Ich gehe auf die Frage des wirklichen Inzestes nicht näher ein, sondern wende mich zu den neuropathischen Personen, deren Neigung im Unbewußten an das infantile Sexualobjekt fixiert bleibt und denen deshalb die Applikation an fremde Personen des andern Geschlechtes erschwert ist. Dem $\mathrm{Ma}$ an e stehen zunächst zwei Möglichkeiten offen: er bleibt unverehelicht oderer heiratet eine Blutsverwandte ${ }^{1}$. Die Betrachtung dieser beiden Fälle läßt sich nicht trennen, weil sie tiberraschend oft in der gleichen Familie zusammentreffen. Familien, in denen sich die Verwandtenehen häufen, pflegen auch viele ehelose Personen aufzuweisen². Ich erwähne z. B. eine Familie, in welcher während mehrerer Generationen Verwandtenehen vorkamen. In einer Generation blieben die meisten Geschwister ledig und von den zwei Brüdern, welche heirateten, wählte einer eine Verwandte.

Offenbar liegt in solchen Familien eine verminderte sexuelle Aktivität vor. Die Wahl einer Verwandten erfordert geringere Initiative; man ist der Schwierigkeit enthoben, einer Fremden näherzutreten. Ein Mädchen aus der Verwandtschaft kennt man entweder von Jugend auf oder die Bekanntschaft wird doch sehr erleichtert. Wichtiger aber erscheint mir noch, daß man bei einer Verwandten am leichtesten gewisse Eigenschaften wiederfindet, die man bei Mutter oder Schwester besonders liebte. So wird namentlich die Cousine zum Ersatze der Schwester. Mir sind zwei Fälle bekannt, in welchen der Mann seine Cousine heiratete, weil er der festen Überzeugung war, daß er keine andere, als eine Verwandte wählen könne. Der eine dieser beiden Herren, der wegen nervöser Beschwerden in meiner Behandlung stand, war zu Studienzwecken ins Ausland gegangen und besuchte dort Verwandte, die er vorher nie gesehen hatte. Während er sonst eine sehr spröde Natur war, verliebte er sich sofort in seine Cousine und heiratete sie.

Ein Teil der Männer mit solcher Veranlagung heiratet erst sehr spät. In solchen Fällen trifft die Wahl mit Vorliebe auf eine Nichte. Ich habe eine kleine Anzahl solcher Ehen eruiert. Sie haben unter eineinder eine merkwtirdige Äbnlichkeit, indem stets der Mann völlig

1 Ich spreche hier vorwiegend vom Manne, weil er hăufiger der Wählende ist. •

- Diese Beobachtung wurde mir u. a. auch von Herm Professor Op p e $\mathrm{n}$ h e im aus seiner Erfahrung bestätigt. 
unter der Herrschaft der Frau steht. Es handelt sich in allen mir bekannten Fällen um sehr unselbständige Männer, die als der schwächere Teil in die Ehe eintraten, weil sie auf diese eine Frau angewiesen waren.

Die $H a ̈ u f u n g$ der Verwandtenehen in manchen Familien spricht natürlich sehr für das Vorhandensein einer eigentümlichen Veranlagung. Mir sind Familien bekannt, in welchen durch mehrere Generationen eine merkwlirdig konsequente Inzucht getrieben wurde. In einem Falle z. B. heirateten drei Brüder ihre drei Cousinen, die untereinander Schwestern waren. Diese Familie leistete an Inzucht Derartiges, daß ihr Stammbaum kaum entwirrbar ist ${ }^{1}$.

In manchen Familien tritt die Ehelosigkeit auffallender hervor, als die Neigung zur Inzucht. Nach den wenigen Erfahrungen, die mir in dieser Hinsicht zu Gebote stehen, scheint es sich hier um schwer neuropathische Sonderlinge zu handeln, die sich auch sonst von der Welt abschlieben. Ich erwähne eine Familie, in welcher sämtliche acht Brtider unverheiratet blieben. Ob hier noch anderweitige psychosexuelle Abnormitäten im Spiele sind, kann ich leider nicht entscheiden ${ }^{2}$.

Den Neuropathen, welche dauernd ehelos bleiben, steht eine andere Gruppe nahe. Sie umfaßt solche Individuen, welche außerstande sind, selbs t eine Wahl zu treffen. Interessant ist es nun, daß solche Männer es vielfach ihrer Mutter oder Schwester ubberlassen, eine Frau für sie auszuwählen. Diese Unselbständigkeit zeigt die außerordentliche Macht der infantilen Ubertragung. Ein beruhmtes Beispiel dieser Art werde ich noch erwähnen.

Es gibt unter den Neuropathen ferner Männer, die zwar außerhalb ihrer Familie eine Wahl treffen, aber ihre Liebe auf eine bedeutend ältere weibliche Person richten. Nicht selten gelingt der Nachweis, daß ein Ersatz für die Mutter gesucht wurde.

Allen diesen Gruppen aber ist eine psychosexuelleEigentlimlichkeit gemeinsam, die ich als $\mathrm{m}$ on $\mathrm{og}$ a $\mathrm{m}$ is $\mathrm{ch}$ en $\mathrm{Zug}$ bezeichnen möchte. Bei den meisten anderen Männern ist es die Regel, daß die Neigungen der Pubertätszeit nicht von Bestand sind, daß vielmehr die Neigung sich verschiedenen Personen zuwendet, bevor eine endgültige Wahl erfolgt. Es kommt außerdem sehr gewöhnlich zu

' Hern Dr. M. Hirschfeld verdanke ich die sehr interessante Mitteilung, daß Mănner mit homosexueller Veranlagung hăufig ihre Cousinen heiraten. Da bei soichen Männern die sexuelle Aktivităt gegenüber dem weiblichen Geschlecht minimal ist, so ist für sie die Wahl einer Verwandten eine besondere Bequemlichkeit.

2 Selbstverständlich soll nicht behauptet werden, daB jedem Falle von Ehelosigkeit Ursachen wie die hier geschilderten zugrunde liegen. 
intimen Beziehungen, welche wieder gelöst werden. Bei vielen Angehörigen solcher Familien, welche eine Neigung zur Inzucht erkennen lassen, ist die Entwicklung eine andere. Es fehlt ihnen die polygamische Neigung. Sie eignen sich nicht zum Flirt, zum raschen Anknüpfen und zum raschen Wechseln persönlicher Beziehungen. Wie es ihnen schwer wird, die früheste Fixierung ihrer Libido zu lösen, so ergeht es ihnen auch späterhin. Obertragen sie ihre Neigung auf eine Person des anderen Geschlechtes, so pflegt diese Neigung dauernd und endgültig zu sein. Kommt es bei diesen Personen nicht zur Heirat mit einer Verwandten, so ist doch die Beschränkung in der Auswahl auch hier kenntlich.

Bis hierher hatten wir es mit Außerungen der neurotischen Libido zu tun, die man gewöhnlich nicht als krankhaft bezeichnet, obschon eine Abweichung vom Normaltypus vorliegt. Es gibt nun auf der gleichen psychologischen Grundlage eine Reihe anderer Erscheinungen, die unbedingt als pathologisch erscheinen. Für sie ist aber mit Nachdruck zu betonen, daß an ihrer Entstehung noch andere, ebenso wichtige psychologische, vielleicht auch somatische Faktoren beteiligt sind. Hierher gehört beim Manne die psychische Impotenz. Die abnorme Fixierung der Libido an Mutter oder Schwester, d. h. eine verdrängte Inzestphantasie, legt den Grund zu diesem Krankheitszustande. Andere konkurrierende Faktoren treten hinzu. Ich verweise in dieser Beziehung besonders auf die von Stek el veröffentlichten Analysen. Ich habe selbst verschiedene Falle dieser Art beobachtet, in denen sich dieser Faktor als sehr bedeutsam herausstellte. Ich erwähne z. B. zwei Brüder, welche beide an psychischer Impotenz leiden. Beide waren in einem entschieden abnormen Grade in ihre Schwester verliebt.

Weibliche Personen, die ihre Neigung im Ubermaße auf Vater oder Bruder übertragen haben, sind sehr häufig $\mathrm{frigid}$ in der Ehe. Bei solchen Personen wirkt also ihre infantile Sexualübertragung mit anderen Faktoren zusammen, um sie im späteren Leben $z u$ einer erfolgreichen Übertragung unfähig zu machen.

Andere Personen bestreben sich, die Inzestphantasien gewaltsam zu unterdrücken. Während sie ihnen ausweichen, werden sie nun leicht auf die Bahn homosexueller Neigungen gedrängt. Sie wenden sich von der Mutter ab dem Vater zu. Auch hier fehlt es nie an anderen Ursachen, die in der gleichen Richtung wirken. Ich möchte hier auf die Tatsache verweisen, daß nach den Beobachtungen der erfahrensten Autoren viele Homosexuelle, die sonst kein Interesse für weibliche 
Personen zeigen, mit einer vergeistigten, sublimierten Liebe an ihrer Mutter hängen ${ }^{1}$.

Bei ausgesprochener Neurose bestehen noch weitere Ausdrucksmöglichkeiten für die uns beschäftigenden sexuellen Infantilismen, auf die ich kurz hinweisen will. Nicht selten drücken hys terische Sy m tome den Wunsch des Patienten aus, sich mit einer bestimmten, geliebten Person zu identifizieren. Ein Patient, den ich wegen psychischer Impotenz behandle und bei dem eine abnorme Verliebtheit in die Mutter deutlich hervortritt, kopiert z. B. diese in einer Anzahl von Symptomen².

Bei chronischen, in das Gebiet der Dementia praecox gehörenden Geisteskrankheiten sind mir besonders zwei Arten aufgefallen, in denen die infantile Inzestphantasie zum Ausdruck kommt. Ein Teil der Kranken bildet einen Wahn, der die Vereinigung mit der in der Kindheit geliebten Person als vollzogen darstellt. Ich erwähne kurz ein Beispiel aus einer meiner früheren Publikationen ${ }^{3}$ : Bei dem Patienten stand im Mittelpunkte seiner Wahnbildungen eine Schwester, die er in seinem zehnten Lebensjahre durch den Tod verloren hatte. Sie erschien auch beständig in seinen Halluzinationen. Einmal fand ich den Patienten ganz einer Vision hingegeben. Er sah - so teilte er mir mit - wie ein sehr schöner Jüngling in den Besitz einer schönen Jungfrau zu gelangen suchte. Es waren Apollo und Diana. Die Diana trug die Züge der verstorbenen Schwester des Patienten, Apollo glich dem Patienten selbst. Apollo und Diana sind ja im Mythus Geschwister. So sprach sich die infantile Fixierung der Libido noch in den Halluzinationen des Erwachsenen aus.

Eine andere Möglichkeit bei der Dementia praecox ist das Umschlagen der übermäßigen Ubertragung in Negativismus und Verfolgungswahn gegen die früher geliebte Person. Ich habe diesen Hergang in einer früheren Arbeit genauer behandelt 4 .

Zum Schluß möchte ich ein paar berühmte Beispiele anführen, die mir sehr zugunsten meiner Ansichten zu sprechen scheinen. Sie

1 Zwischen Konsanguinität und Homosexualität dïrften noch andere Beziehungen bestehen. Herr Dr. M. Hirschfeld teilte mir eine wertvolle Beobachtung mit: Der aus einem Inzest von Vater und Tochter hervorgegangene Sohn ist homosexuell.

2 Vgl. hierzu besonders F r e d, Bruchstück einer Hysterieanalyse. Monatsschrift für Psychiatrie und Neurol. 1905, Bd. 18 und neu herausgegeben in seiner ,Sammlung kleiner Schriften zur Neurosenlehre II.*

s A r a ham. Über die Bedeutung sexueller Jugendtraumen für die Symptomatologie der Dementia praecox. Zentralblatt für Nervenheilkunde. 1907. S. 409 f.

$4 \mathrm{Abr}$ a ha m. Die psychosexuellen Differenzen der Hysterie und der Dementia praecox. Zentralblatt fiur Nervenheilkunde. 1908. S. $521 \mathrm{f}$. 
ließen sich gewiß vermehren. Aber auch aus diesen wenigen Beispielen durfte hervorgehen, daß meine Anschauungen nicht auf künstlichen Deutungsversuchen beruhen.

Ein Beispiel für den reellen Inzest ist Lord Byron. Er konnte sich nie von der Neigung zu seiner Schwester befreien. Seine Ehe mit einer Fremden nabm daher einen unglücklichen Ausgang. Der Dichter Konrad Ferdinand Meyer hing mit einer abnormen Verliebtheit an seiner Mutter und Schwester ${ }^{1}$. Er heiratete in vorgeschrittenem Alter ein Mädchen, das seine Schwester für ihn ausgewählt hatte. Endlich sei Mörike erwähnt, dessen Neigung in außerordentlichem Grade seiner Schwester galt; er ging erst mit 47 Jahren eine Ehe ein.

Die hergebrachte Lehre, daB die Ehe unter Blutsverwandten nervöse und psychische Erkrankungen der Nachkommenschaft zur Folge habe, trägt der Kompliziertheit der Verhältnisse nicht genügend Rechnung.

Die eigentümliche psychosexuelle Konstitution, welche nach Freud die Grundlage der Neurosen bilidet, ist selbst die wichtigste Ursache der Verwandtenehe. Letztere wird erst sekundär zum belastenden Moment, indem durch sie die bereits vorhandene neurotische Veranlagung g e $\mathrm{z} \mathrm{u} \mathrm{chtet}$ wird. Die Verwandtenehe ist also in erster Linie eine Folge neuropathischer Veranlagung und erst sekundär ein die nervöse Disposition steigerndes Moment.

Die ihr gebuhrende Stellung kann man der Verwandtenehe unter den Phänomenen der Neurosenpsychologie nur dann anweisen, wenn man sie mit einer Reihe anderer Erscheinungen unter gleichen Gesichtspunkten betrachtet. In ihrer Gesamtheit zeigen sie, welch auBerordentliche Bedeutung den sexuellen Infantilismen im Seelenleben des Erwachsenen zukommt.

${ }^{1}$ Vgl. Sa dger, Konrad Ferdinand Meyer. In: Grenzfragen des Nervenund Seelenleberis. Wiesbaden, 1908. In dieser Schrift findet auch die homosexuelle Komponente Berücksichtigung. 


\section{Über hysterische Traumzustände'.}

In einem kürzlich erschienenen Aufsatz "Uber traumartige und verwandte Zustände" hat $L$ ö w e n f e $1 \mathrm{~d}^{2}$ eigentümliche, bei Neurotikern auftretende Störungen behandelt, die bisher in der Literatur keine gentigende Wurdigung gefunden haben. Zur Orientierung zitiere ich Lö we $n f$ el $\mathrm{ds}$ allgemeine Beschreibung dieser Zustănde.

"Die Außenwelt macht nicht den gewöhnlichen Eindruck, das wohl Bekannte und täglich Gesehene erscheint verändert, wie unbekannt, neu, fremdartig, oder die ganze Umgebung macht den Eindruck, als sei sie ein Phantasieprodukt, ein Schein, eine Vision. In letzterem Falle besonders ist es den Patienten, als ob sie sich in einem Traum oder Halbschlaf befänden, hypnotisiert oder somnambul seien, und sie sprechen dann auch zumeist von ihren Traumzuständen." - Der Autor erwähnt ferner, daB diese Zustände dem Grade nach sehr verschieden sein können und in der Dauer groBe Schwankungen aufweisen, daB sie oft mit dem Affekte der Angst verknüpft sind und daB sich neben ihnen in der Regel noch andere nervöse Symptome nachweisen lassen.

Löwenfeld gründet seine Beschreibung auf eine beträchtliche Anzahl von Krankengeschichten. Ich selbst bin bei einer ganzen Reihe meiner Patienten, die ich psychoanalytisch behandelte, auf diese Zustände gestoßen. $\mathrm{Da}$ die bisherigen psychoanalytischen Arbeiten sich mit den Traumzuständen noch nicht beschäftigt haben, so teile ich meine hauptsächlichsten Resultate mit. Sie bilden eine Ergänzung derjenigen Aufschlitsse, die uns die Psychoanalyse uber das Wesen der anderen episodischen Erscheinungen im Krankheitsbilde der Hysterie gebracht hat.

Ein einfaches Beispiel möge zunächst zeigen, bis zu welchem Grade wir das Wesen der Traumzustände zu begreifen vermögen, wenn wir von der Psychoanalyse keinen Gebrauch machen. Die

1 Aus "Jahrbuch für psychoanalytische und psychopathologische Forschungen", Band II. 1910.

2 Zentralblatt für Nervenheilkunde, 1. und 2. Augustheft 1909. 
Exploration eines Patienten, den ich nur ein einzelnes Mal in der allgemein getibten Art explorieren konnte, ergab nach der hier interessierenden Richtung folgendes ${ }^{1}$ :

\section{Beobachtung A.}

Der in jugendlichem Alter stehende Patient A neigt zu T agtră u m e r e i en von großer Lebhaftigkeit. Wie er angibt, reizen ihn namentlich aktuelle Ereignisse $z \mathfrak{u}$ wachen Träumen. Die Nachricht von der Entdeckung des Nordpols z. B. gab ihm AnlaB zu der Phantasie, er wäre an einer großen Expedition beteiligt. Er malte sich diese mit allen Einzelheiten aus, besonders in bezug auf seine eigene Tätigkeit. Derartige Phantasien nahmen ihn schon seit längerer Zeit fast ganz in Anspruch. Er brauchte nur etwa auf der Straße aus der Unterhaltung Vorübergehender ein Wort wie z. B. "Zeppelin" aufzufangen und schon geriet seine Einbildungskraft in die lebhafteste Tätigkeit. Haben nun diese Träumereien eine große Intensităt erreicht, so fühlt Patient sich mehr und mehr der Wirklichkeit entrü ckt. Eine traumhafte Benommenheit kommt ubber ihn. Dann tritt für eine kurze Zeit eine "Leere" im Kopf ein, auf welche rasch ein lebhaftes $S \mathrm{ch}$ windelgefühl folgt, das sich mit A ngst und Herzklopfen verbindet. Patient bezeichnet den Zustand bis zum Eintreten des Schwindelgefühles als lustvoll.

Neben diesen Erscheinungen bestehen nervöses Erbrechen, nervöse Diarrhöen, Anfalle von Kopfschmerz, ferner Reizbarkeit, Schreckhaftigkeit usw.

Der mitgeteilte Fall - und, wie sich zeigen wird, auch jeder der folgenden - läßt den Zusammenhang der Traumzustände mit den Tagträumereien ohne weiteres erkennen. Ich betone diese , Tatsache, weil Löwenfeld ihr keine besondere Beachtung geschenkt hat. Die typische Einleitung des Traumzustandes bildet ein Stadiu m der phantastischen Exaltation, dessen Inhalt ein durchaus individuelles Gepräge zeigt.

Es folgt der Zustand traumhafter Entrückung? In ihm erscheint den Patienten, wie Lö we n f eld treffend schildert, die ihnen wohlbekannte Umgebung unwirklich, fremd, verändert. Sie selbst fühlen

${ }^{1}$ Die Krankheitsfalle, die ich im folgenden bespreche, sind in alphabetischer Reihenfolge mit den Buchstaben $A$ bis $F$ versehen. Alle für das Verständnis der Sache entbehrlichen Angaben über Alter, Beruf und sonstige persönliche Verhältnisse der Patienten habe ich fortgelassen.

2 Den Ausdruck, Entrü ckung* entlehne ich von Breuer (cf. Breuer und F r e ud, Studien über Hysterie, Seite 191 der 2. Auflage). 
sich "wie im Traum". Die Bezeichnung "Traumzustand", die von vielen Patienten spontan gebraucht wird, gründet sich auf die phantastische Gedankenrichtung im ersten und auf die Alteration des Bewußtseins im zweiten Stadium.

Ich unterscheide weiter ein drittes Stadium der BewuBtseinsle ere. Es wird charakterisiert durch das von den Patienten bemerkte "Stillstehen der Gedanken" (auch: "Leere im Kopf" oder ähnlich benannt).

Den Abschluß bildet ein depressiver Zustand, dessen wichtigstes Kennzeichen der Affekt der Ang st mit seinen gewohnten Begleiterscheinungen (Schwindel, Herzklopfen usw.) bildet. Die meisten Patienten beschreiben überdies Phantasien von depressivem Charakter.

Die Abgrenzung der einzelnen Stadien gegeneinander ist nicht absolut scharf. Im Gegenteil lassen sich Übergänge $z$ wischen ihnen erkennen. Die praktische Brauchbarkeit und Wichtigkeit der Einteilung wird erst bei der Besprechung der genau analysierten Fälle hervortreten. Alsdann wird die obige, summarisch gehaltene Schilderung der einzelnen Stadien auch eine ausgiebige Vervollständigung erfahren.

Den Höhepunkt des Zustandes bildet ohne Zweifel das dritte Stadium. Auf ihm findet, sozusagen, die Peripetie statt, nicht nur insofern, als die phantastische Produktion beim Eintritt dieses Stadiums eine jähe Unterbrechung erfăhrt. Von ebenso großer Bedeutung ist es, $\mathrm{da} B$ das dritte Stadium die Grenze zwischen zwei entgegengesetzten Affektbesetzungen bildet. Es ist keine spezielle Eigentümlichkeit des skizzierten Falles, daß der Traumzustand bis zum dritten Stadium als lustvoll geschildert wird, während dem letzten Stadium ein starker Unlustaffekt zugeschrieben wird.

Wir vermögen so durch die Exploration des Patienten mancherlei Kenntnisse über Vorstellungen und Gefühle im Traumzustand, über den auslösenden AnlaB, über die Schwankungen des Bewußtseins zu erhalten. Würden wir eine Reihe weiterer Fälle in derselben Weise betrachten, so könnten wir noch dazu gelangen, die individuelle Mannigfaltigkeit in den genannten Beziehungen kennen zu lernen; wir würden auch Löwenfelds Angaben uber die Differenzen in bezug auf Intensität und zeitliche Ausdehnung der Zustände bestätigen können. Damit sind wir aber an der Grenze der Erkenntnismöglichkeiten angelangt, sofern wir uns auf das dem Patienten Bew u Bte als einzige Quelle unseres Wissens beschränken. Unerklärt bleibt die U rs a ch e des Auftretens der Traumzustände. Im allgemeinen begnügt sich der Neurotiker mit wachen Träumereien. Es bleibt dunkel, warum diese gelegentlich eine Steigerung zu akuten, anfallsähnlichen, mit einer leichten Alteration 
des BewuBtseins verbundenen Zuständen erfahren. Unklar bleibt in ihrem ganzen Wesen die Entrückung, speziell das Gefühl des Fremdartigen, Unwirklichen. Vollends in Dunkel gehüllt bleiben die temporäre Bewußtseinsleere und endlich das Auftreten der Angst mit ihren Begleiterscheinungen. Alle diese Erscheinungen sind tiberdies der individuellen Variation unterworfen. Jeder einzelne Fall bietet seine Rätsel. Insbesondere die Phantasien des Anfangsstadiums (und auch die des SchluBstadiums) sind ohne eingehende Analyse nur in ganz beschränktem Umfange verständlich.

Den Schlüssel zur Lösung dieser Rätsel gibt uns die Kenntnis

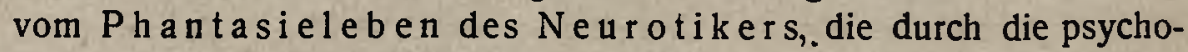
analytischen Forschungen gewonnen wurde.

Wir haben durch F re u d gelernt, daß unsere Phantasien Verlautbarungen unserer Triebe sind. Wünsche, deren Erfüllung verhindert ist, sucht unsere Einbildungskraft als erfüllt oder in Erfüllung begriffen darzustellen. Beim Neurotiker ist nun das gesamte Triebleben, sind alle Partialtriebe von ursprünglich abnormer Stärke. Gleichzeitig ist die Neigung zur Triebverdrängung besonders groB. Aus dem Konflikte zwischen Trieb und Verdrängung geht die Neurose hervor. Dềr Vielgestartigkeit und đer Macht seines Trieblebens, der Fülle verdrängter Wünsche entspricht es, daß der Neurotiker e in $\mathrm{Ph}$ antast ist. Er neigt darum, wie die Erfahrung lehrt, in hohem Grade zur Tagträumerei; auch sein Schlaf pflegt reich an lebhaften Träumen zu sein. Die Triebkraft seiner verdrängten Winsche ist aber so gewaltig, daß der Neurotiker mit diesen auch dem Normalen eigenen Ausdrucksmitteln nicht sein Auskommen findet. Die Neurose selbst steht ganz und gar im Dienste dieser Tendenzen. Der neurotische Traumzustand ist, wie in dieser Arbeit gezeigt werden soll, nur eines der mannigfachen Phänomene, durch welche das Heer der verdrängten Wünsche sich manifestiert.

Der Krankheitsfall, aus dessen umfangreicher Analyse ich das zum Verständnis der Traumzustände Notwendige nun zunächst mitteile, eröffnet klärende Einblicke in das Gewirr der einander verstärkenden oder unter sich widerstreitenden Triebregungen. Die Analyse läßt die alles beherrschende Bedeutung der Sexualphantasie erkennen; es wird vollkommen durchsichtig, daB die bewuBten, dem äuBeren Anscheine nach nicht sexuellen Phantasien durch den Prozeß der Sublimierung aus sexuellen Wünschen hervorgegangen sind. Die von der Zensur zum Bewußtsein zugelassenen Phantasien dienen lediglich zur Vertretung verdrängter Wünsche; ihre Triebkraft haben sie von den letzteren entlehnt. 


\section{Beobachtung B.}

Der Patient B leidet an einer ungewöhnlich schweren Hysterie mit Phobien und $Z$ wangserscheinungen. Seine Angst, allein das Haus zu verlassen, macht ihn seit fünf Jahren zur Ausubung seines Berufes und überhaupt $\mathrm{zu}$ fast jeder sozialen Betätigung unfähig. Neben schweren Angstzuständen treten mit großer Häufigkeit Traumzustände bei ihm auf.

Den ersten derartigen Zustand erlebte Patient, wie er sich erinnert, im Alter von zehn Jahren, als er sich einmal zurückgesetzt fühlte. Es bemächtigte sich seiner ein "Gefühl des Weltschmerzes", dem rasch Kontrastvorstellungen folgten: „Später, wenn ich erst groß bin, werde ich euch schon imponieren." Er geriet dabei in eine ekstatische Begeisterung und empfand eine traumartige Veränderung seines Bewußtseins. Seither fuhrt jede Situation, in der ihm die Überlegenheit anderer und seine eigene Tatenlosigkeit besonders zu Bewußtsein kommen, einen Traumzustand herbei. Durch seine Lage ist er also zu solchen Zuständen fortwährend disponiert. Es genligt $z$. B., daß man in seiner Gegenwart die Tüchtigkeit oder die Erfolge eines Altersgenossen erwähnt; sofort reagiert er mit einem Traumzustand. Im Laufe der Zeit hat sich eine größere Variabilität in bezug auf den auslösenden Anlaß herausgebildet. Der Anblick weiblicher Personen, Theater, Musik, Lektüre wirken in diesem Sinne, indem sie bei dem Patienten ehrgeizige oder erotische Phantasien hervorrufen. Weniger leicht verständlich ist schon die auslösende Wirkung, welche von lebhafter Körperbewegung (z. B. Gehen auf der Straße) oder vom Hören starker Gerăusche (z. B. Fahrt eines Eisenbahnzuges über eine Brücke) ausgeht. Am häufigsten tritt der Zustand auf der Straße ein.

Alle diese Anlässe rufen zunächst eine lebhafte Tätigkeit der Phantasie hervor und zugleich den Vorsatz, mit aller Energie an der Verwirklichung der phantastischen Wünsche $z u$ arbeiten. Patient rührt, wie er sich ausdrückt, seine ganze Willenskraft auf. Im Mittelpunkt steht immer der Gedanke, dereinst aus der Absonderung hervorzutreten und aller Welt zu imponieren. Er wird einst durch großes Wissen Aufsehen erregen, wird als Autor eines Dramas vor den Vorhang gerufen werden und aller Blicke auf sich ziehen; oder er wird ein Meister im Schachspiel werden und als Simultanspieler im Café von Tisch zu Tisch gehen, die Figuren ziehen und dabei von bewundernden Menschen beobachtet werden. In anderen Fällen erdenkt er sich die Idealgestalt eines groBen Feldherrn, hinter der er seine ehrgeizigen Wünsche verbirgt. Die energischen Vorsätze dokumentieren sich 
äußerlich darin, daß Patient im Zimmer hastig umhergeht oder auf der Straße einen Sturmschritt anschlägt.

Patient selbst bezeichnet den geschilderten Vorgang als einen immer höher gehenden "Enthusiasmus". Dieser geht bald und unmerklich in das zweite Stadium über. Die Schilderung des Patienten ist sehr bezeichnend : es findet eine völlige "Nachinnenkehrung" statt, eine Ausschaltung aller äußeren Eindrücke. „Man verliert beim Phantasieren den Boden unter den Füßen." Das soll heißen, daß er die Herrschaft über den Flug seiner Gedanken verliert und sich völlig vom realen Boden entfernt. Nun kommt er sich wie im Traume vor, die ganze Umgebung, sogar der eigene Körper erscheint ihm fremd und es treten Zweifel an dessen wirklicher Existenz auf. Alsbald folgt das typische dritte Stadium: der Gedankenstillstand. Rasch tritt dann der Angstaffekt auf und leitet das vierte Stadium ein. Patient wird von Schwindel ergriffen; er hat das Gefühl, daß er nicht mehr vorwärts kommen, die Beine nicht mehr heben kann, als wenn er gleitet, fällt, versinkt. Diese Sensationen sind mit höchster Angst verbunden. Die Menschen erscheinen ihm merkwürdig groß; dies gilt auch von den ihn umgebenden Gegenständen. Er selbst kommt sich klein vor, hat auch den Wunsch, es zu sein, um nur nicht gesehen zu werden; er möchte „als nichts gelten, ganz in die Erde sinken“. Er beschreibt ferner das Gefühl, als müsse er auf allen Vieren kriechen, um nach Hause zu kommen.

Patient bezeichnet die ersten Stadien als lustvoll; doch tritt, wie er sich ausdrückt, schon während des Enthusiasmus eine entgegengesetzte Nebenströmung auf, die sich zuerst durch ein Kältegefühl bemerkbar macht. Wir treffen hier auf Parästhesien und vasomotorische Symptome als Begleiterscheinungen des Traumzustandes, die bisher nicht genügend beachtet worden sind. Im Stadium der Gedankenleere wird das Kältegefühl intensiv. Mit der Angst setzt manchmal eine plötzliche "Hitzewelle" ein, eine Kongestion nach dem Kopfe. Macht die Angst schließlich dem Gefühl der Schwäche Platz, so ist das Gefüh] der Kälte stets sehr lebhaft; zugleich besteht die Sensation, daB Teile des Körpers abgestorben seien.

Das Eintreten eines Traumzustandes ist dem Patienten wegen der begleitenden Lust erwanscht. Er versucht jedoch manchmal, bevor der Höhepunkt, d. h. die Bewußtseinsleere, erreicht ist, den Vorgang za unterbrechen. "Ich will mich vom Enthusiasmus losreißen, ich versuche, wie aus einer Wolke herauszukommen. " Der Ausdruck "Wolke" ist zu beachten ; er deutet das Gefuhl einer Umnebelung des Bewußtseins, also das Traumhafte an. Bei vorzeitiger Unterbrechung tritt Angstund Schwächegefühl ein. 
Das letzte Stadium ist bei diesem Patienten sebr protrahiert. Um sich von der Angst, die nicht weichen will, zu befreien, bedient er sich eines eigentümlichen Mittels: er zündet sich eine Zigarre an. Ubrigens taucht auch schon im Stadium des Enthusiasmus der Wunsch zum Rauchen auf.

Als ich auf die Analyse seiner Traumzustände einging, gab mir der Patient spontan die Erklärung, er halte diese Zustände schon seit langer Zeit für eine Art Vergeistigung des Sexualtriebes. Unsere Nachforschungen sollten diese Auffassung durchaus bestätigen.

Patient gehört za den Neurotikern, die sich in früher Kindheit der $M$ a sturbation ergeben und später mit ihrer masturbatorischen Neigung in einem steten Kampfe leben. Die Abgewöhnung der Onanie, oft mißlungen und immer wieder versucht, hat dem Patienten die bekannten Enttäuschungen, Selbstvorwürfe und hypochondrischen Sorgen eingetragen. Eine Reihe von Symptomen seiner Neurose steht unter dem determinierenden Einflub dieses Vorganges; doch soll auf diese hier nicht eingegangen werden. Der Konflikt zwischen Wunsch und Verdrängung hat, wie so oft in der Neurose, seinen AbschluB in einem Kompromiß gefunden. Der Patient hat oft für längere Zeit auf die Onanie verzichtet. Er meidet dann die körperliche Selbsterregung mitsamt ihrem Endziel, der Ejakulation. Für eine oberflăchliche Betrachtung hat er damit die gewohnte Sexualbetätigung aufgegeben. Aber sein Unbewußtes verlangt eine Ersatzbefriedigung, deren Wesen und Ziel dem Bewußtsein entgeht, die daher ungehindert von hemmenden Einflüssen vor sich gehen kann.

F re $\mathfrak{u d}^{1}$ hat den Nachweis erbracht, daß gewissen episodischen Erscheinungen der Hysterie die Bedeutung einer Ersat $z$ befriedigung für die aufgegebene Masturbation zukommt; wir müssen später dieser Anschauung unsere Aufmerksamkeit zuwenden. Eine Ersatzbefriedigung in dem angegebenen Sinne ist nun a uch der Traumzustand. Bevor ich diese Auffassung begründe, muß ich noch erwähnen, daß der Patient besonders neuerdings den Traumzuständen auch zu solchen Zeiten unterworfen ist, in denen er dem Drange nach Masturbation häufig nachgibt. Doch spricht dies nur scheinbar gegen die Auffassung der Traumzustände als Ersatzbefriedigung. Denn gerade $z u$ solchen Zeiten sind lebhafte Gegenvorstellungen vorhanden, die den Patienten hindern, dem Drange ganz ungehemmt nachzugeben. Die Triebstärke ist außerdem so groB, daB eine volle

1 ,Allgemeines über den hysterischen Anfall.“ Zeitschrift für Psychotherapie und medizinische Psychologie, 1909, auch in der zweiten Folge der "Kl. Schriften zur Neurosenlehre', Wien 1909. 
Befriedigung schwer zu erzielen ist. Auch bei häufiger Ausubung der Masturbation werden daher Surrogate nicht entbehrlich. Endlich bilden diese selbst eine Lustquelle und es ist bekannt, wie schwer namentlich der Neurotiker eine solche wieder aufgibt.

Patient hat sich in der frühen Jugend gewöhnt, Tagträumereien nachzuhängen und auf der Höhe lebhafter Phantasietätigkeit der angesammelten Erregung durch Masturbation Abfuhr zu verschaffen. Als er sich von der Masturbation zu entwöhnen suchte, bedurften die Tagträumereien eines andern Abschlusses; sie bilden seither die Einleitung zum Traumzustand wie früher zum Masturbationsakt. Das zweite und dritte Stadium - Entrlickung und Bewußtseinsleere entsprechen der steigenden Sexualerregung und ihrer Akme im Moment der Ejakulation. Das Endstadium mit Angst und Schwäche ist unverändert vom masturbatorischen Vorgang herübergenommen; diese Symptome sind uns ja als jedesmalige Folgen der Masturbation bei Neurotikern geläufig.

Diese Auffassung bedarf bezuglich des zweiten und dritten Stadiums noch einer weiteren Begründung. Ein der "Entrückung " im Traumzustand analoges Stadium findet sich auch im masturbatorischen Akt. Die steigende sexuelle Erregung führt $z \mathfrak{u}$ einer Absperrung gegen alle äußeren Eindrücke. Dieser Vorgang findet sich im Traumzustande mehr ins Psychische übersetzt. Der Patient empfindet eine absolute "Nachinnenkehrung". Durch diese autoerotische AbschlieBung von der Außenwelt erhalt er das Gefühl der Is oliertheit. Er "tritt aus der Gemeinschaft heraus"; seine Vorstellungen versetzen ihn in eine andere, seinen verdrängten Wünschen entsprechende Welt. So groB ist die Macht der verdrängten Wünsche, wenn sie einmal dem UnbewuBten entsteigen, daß ihre phantasierte Erfüllung als Wirklich́keit, die Wirklichkeit aber als ein nichtiges Traumgebilde erscheint. Die gesamte Umgebung, selbst der eigene Körper, erscheint dem Patienten fremd und unwirklich.

Das Gefuhl des Isoliertseins ist vielen Neurotikern eigen, die sich zur einsamen Sexualbetätigung von der Welt zurückziehen. Unser Patient erinnert sich aus der frühen Jugend einer von ihm bevorzugten Phantasie von einem verborgenen Zimmer, das irgendwo im Walde unter der Erde versteckt sei: dahin wünschte er mit seinen Phantasien zu flüchten. Der Wunsch machte später einer Angst Platz: der Angst, allein im geschlossenen Raume zu sein, die ihn noch als Erwachsenen beherrscht.

Das dem dritten Stadium eigentumliche Schwinden der Gedanken, die Bewußtseinsleere, entspricht dem mehr oder weniger 
erheblichen „BewuBtseinsentgang" (F re u $\mathrm{d}^{1}$ ), wie er sich besonders ausgesprochen beim Neurotiker auf der Höhe jeder sexualen Erregung einstellt. Gleichzeitig setzt ein heftiges Schwindelgefühl oder eine andere, dem Schwindel ähnliche, aber schwer zu beschreibende Sensation ein. Unser Patient gibt mit Bestimmtheit an, daB das nämliche Gefuhl bei der Masturbation im Augenblick der Ejakulation eintrete. Die kurze, der Entleerung der Sexualprodukte entsprechende Bewußtseinspause findet sich auch im hysterischen Anfall.

Nunmehr ist es nicht länger verwunderlich, daß der Traumzustand bis zum Stadium der Bewußtseinsleere lustvoll ist. Er verleugnet dadurch nicht seine Herkunft von der Masturbation, die bis zu dem entsprechenden Stadium lustvoll, beim Neurotiker oft die lebhaftesten Unlustgefühle nach sich zieht. Sehr interessant ist es, daB der Patient, wie erwähnt, manchmal den Traumzustand vorzeitig, d. h. vor dem Eintritt der Bewußtseinsleere unterbricht. Das ist gleichsam ein Versuch, sich die Traumzustände abzugewöhnen. Ganz das gleiche tun Neurotiker sehr häufig, wenn sie sich von der Masturbation entwöhnen wollen ${ }^{2}$. Sie sind oft der Meinung, der Samenverlust sei das eigentlich Schädliche an der Masturbation und begntigen sich daher mit einer vor der Ejakulation abgebrochenen Masturbation. Sie geben sich dann der beruhigenden- Vorstellung hin, in Wirklichkeit n icht masturbiert zu haben. Diesem Sophismus kann man bei Nervösen häufig begegnen. Den Verzicht auf die Endlust suchen sie durch sehr ausgiebigen Vorlustgenuß wettzumachen. Der abschließenden Angst freilich vermögen sie nicht zu entgehen. Die zu einer gewissen Höhe angewachsene Sexualerregung, der die Abfuhr versagt wird, verwandelt sich in Angst.

Wenn wir nun in dem Traumzustand die Ersatzbefriedigung für eine aufgegebene Form der Sexualbetätigung erkennen, so sind wir doch noch entfernt von einem vollen Verständnis seiner Eigentumlichkeiten. Die Phantasien im ersten und vierten Stadium sind so individueller Natur, daB wir sie nur aus einer genauen Kenntnis des Trieblebens des Patienten werden begreifen können.

Bei dem Patienten haben sich in der dem Psychoanalytiker geläufigen Art die infantilen Neigungen in solchem Grade an die ihm am nächsten stehenden Personen fixiert, $\mathrm{daB}$ in der Pubertät die normale Ablösung nicht gelingen konnte. Es handelt sich im vorliegenden Falle um eine ausgesprochen bisexuelle Fixierung. Die

1 ,Allgemeines über den hysterischen Anfall ", 1. c.

2 Vgl. hiezu Rohleder, Ober Masturbatio interrupta. Zeitschrift für Sexualwissenschaft, 1908. 
heterosexuelle Komponente seiner Libido hat zum Objekt die Mutter. Ihr gegenüber identifiziert er sich mit dem (übrigens verstorbenen) Vater. Mit seiner homosexuellen Komponente hängt er dem Vater an und identifiziert sich ihm gegenüber mit der Mutter. So spielt er in der Neurose bald den Vater, bald die Mutter. Im allgemeinen ist das Verhalten des Patienten als ein auBerst passives zu bezeichnen; er ergibt sich in das Elend seiner Neurose. Auch seine Liebe zum Vater, der eine sehr energische Persönlichkeit war, trägt den Charakter der Unterwerfung unter eine unbedingt überlegene Person. Patient bietet die typische Eifersucht des Neurotikers, die sich aus seiner Kindheit erhalten hat. Als Knabe betrachtete er den Vater als seinen Rivalen bei der Mutter, während die Mutter seiner Neigung zum Vater im Wege stand. Daraus ergaben sich feindselige Wünsche, die - wie so oft bei neurotischen Kindern - in der Phantasie, Vater oder Mutter zu töten, gipfelten. Diese Äußerungen des Sadismus fanden eine intensive Verdrängung. Von der Fortdauer dieser Wünsche im Unbewußten legt eine große $Z$ ahl von Träumen, in denen er den Tod des Vaters oder der Mutter erlebt, Zeugnis ab. Dazu kommen häufige Tagesphantasien der gleichen Art sowie plötzliche aggressive Impulse. Die Vorstellung, verbrecherisch $\mathrm{zu}$ sein, sowie eine Menge psychischer $Z$ wangserscheinungen beruhen auf jenen verdrängten Regungen und auf gewissen Fällen aggressiver Betätigung im Kindesalter und in der Pubertät.

Die Aggressionsneigungen wurden in weitem Umfang sublimiert. Sie könnten nun Verwendung finden als impulsive Energie und als Neigung $z \mathfrak{u}$ hochfliegenden Plänen auf anderem als erotischem Gebiet. Aber dieser Wall genügt nicht gegen eine solche Impulsivität der Triebe. Zu ihrer wirklichen Unschädlichmachung müssen sie geradezu in ihr Gegenteil verkehrt werden. Die gewalttätigen Regungen gegen die Mutter werden ersetzt durch völlige Passivität, durch eine absolute Abhängigkeit von der Mutter, die bei dem längst erwachsenen Patienten fortdauert. Er ist nun gänzlich an sie und an das Haus gefesselt wie ein kleines Kind. Dies ist die wichtigste Quelle der Angst, die ihn hindert, allein das Haus zu verlassen. Man vermißt diese Abhängigkeit von einer bestimmten Person (oder auch von mehreren) in keinem Falle von Straßenangst. Der Versuch, sich allein vom Hause zu entfernen, würde eine dem Patienten verbotene Aktivität in sich begreifen, er wärde symbolisch eine Ablösung von der Mutter bedeuten und - wie die Analyse ergibt - zugleich eine Hinwendung nach der väterlichen (homosexuellen) Seite. Will Patient sich von den heterosexuellen Inzestphantasien losreißen, so verfällt er den homo- 
sexuellen, die wiederum vom Bewußtsein energisch abgewiesen werden. Es findet also eine umfassende Triebunterdrickung statt; ihr entspricht die besondere Heftigkeit der nervösen Angst in unserem Falle.

Der Patient korrigiert nun, wie jeder Neurotiker, die unbefriedigende Wirklichkeit mit Hilfe seiner Phantasie. Er macht von diesem Mittel besonders dann Gebrauch, wenn ein äußerer AnlaB ihm vor Augen führt, wie sehr er sich durch seine kindliche Abhängigkeit und durch sein passives Verhalten, namentlich aber durch seinen Hang zur Masturbation von gesunden Altersgenossen unterscheidet. Schon als Knabe litt er unter diesem Empfinden; sein heftiger Wunsch war es, sein zu können "wie die andern“. Er quälte sich mit Vorwürfen, daß er sich durch seine Neigungen von den „andern“ entferne, daß er dadurch unfähig werde, mit den anderen zu konkurrieren. Besonders peinigte ihn die Befürchtung, den anderen lächerlich oder verächtlich zu erscheinen. Aus diesen Gründen erklärt sich die ubermäßige Empfindlichkeit für eine Zurücksetzung gegenuber "andern“. In der Zurücksetzung sah er ein Zeichen dafür, daß man ihn nicht achte. Das mußte alle seine unterdrückte Aktivität in Aufruhr bringen. Seine ursprünglichen Aggressionsneigungen hätten ihn auf eine Zurücksetzung mit einem Gewaltakt antworten lassen. Aber sie wurden ja frühzeitig durch "Reaktionsbildung" unschädlich gemacht und wagten sich nur noch als geheime Phantasien hervor. Auf eine Beeinträchtigung, die ihm seiner Meinung nach zuteil geworden war, reagierte er mit sublimierten Aktivitätswünschen, mit $\mathrm{Gr}$ ö $\mathrm{B}$ e n p h a n ta s i en, deren Erfüllung er in die Zukunft verlegte: „wenn, ich nur erst einmal erwachsen bin ....“

Je mehr Patient heranwuchs, um so mehr trat das Gefühl bei ihm hervor, er bleibe ein Kind. Es entging ihm, daß es der stärkste Wunsch seines UnbewuBten war, diesen kindlichen $Z$ ustand $z$ u erhalten. Sein Bewußtsein reagierte darauf mit der entgegengesetzten Tendenz. Jeder Traumzustand diente dem Wunsch, e rw a c h s e n zu sein. Das bedeutete für ihn ein Vielfaches: unabhängig, selbständig, energisch zu sein (wie der Vater), frei von der ihn beherrschenden Gewohnheit und vor allem fähig zu sexueller Aktivität. Denn die Angst vor Impotenz beherrscht ihn wie jeden Neurotiker, der von der infantilen Sexualbetätigung und von den Objekten der infantilen Sexualphantasie nicht lassen kann.

Mit den Größenphantasien, die wir von der Sublimierung "sadistischer" Regungen ableiteten, verbindet sich bei dem Patienten regelmäßig die Vorstellung, sich vor Zuschauern hervorzutun, aller 
Blicke auf sich zu lenken. Sie erklärt sich aus der Sublimierung verdrängter Exhibitionswünsche. Bei Neurotikern, die einen krankhaft gesteigerten Ehrgeiz aufweisen, konnte ich stets den Nachweis erbringen, $\mathrm{daB}$ in diesem Charakterzuge die verdrängten sadistischen und exhibitionistischen Wünsche sich gewissermaßen einen gemeinsamen Ausweg suchen. In unserem Falle läßt sich nun feststellen, daß es in der Jugend wirklich $z \mathfrak{u}$ sadistisch-exhibitionistischen Handlungen gekommen ist, aus denen der Patient schwere Selbstanklagen herleitet. Die immer wieder notwendige Verdrängung dieser Triebe ist eine stetige Quelle der Angst. Er vermag z. B. nicht die Straßenbahn zu benutzen, weil oft plötzlich der Impuls auftaucht, vor den anwesenden Personen zu exhibieren oder auf eine weibliche Person einen sexuellen Angriff zu machen. Ähnliche Impulse treten auch sonst, z. B. in der Unterhaltung mit Frauen auf. Der Sublimierungsprozeß führt nun zu einem partiellen oder gänzlichen Verzicht auf das ursprüngliche Ziel des Exhibitionstriebes, die EntblöBung. Die unerlaubte Exhibition wird durch Phantasien ersetzt, die sich mit einem weit harmloseren Ziel begntigen. Der Patient zieht die Blicke der Menschen auf sich, aber nicht die sexuell begehrenden oder neugierigen, sondern die bewundernden Blicke.

Wir hatten verschiedenartige Eindrücke kennen gelernt, welche bei dem Patienten zum Auftreten der Traumzustände Anlaß geben. Ihre Wirkung beruht, wie wir nunmehr sagen können, darauf, daB sie Wünsche der sexuellen Aggression oder der Exhibition bei ihm wachrufen, die in sublimierter Form zum Ausdruck gebracht werden. $\mathrm{DaB}$ der Anblick weiblicher Personen einen Traumzustand auslösen kann, ist nun leicht verständlich: Wird dem Patienten anderen, tatkräftigen Menschen gegenüber seine Passivität allzu fühlbar, so korrigiert er die Wirklichkeit, indem er sich mit Hilfe seiner Einbildungskraft zu einem sehr aktiven Manne macht, der die Aufmerksamkeit auf sich zieht. Starke Körperbewegung kann zur auslösenden Ursache dadurch werden, daß sie dem Patienten das Gefühl der Aktivität gibt. Das Poltern eines Eisenbahnzuges erregt in ihm den Wunsch nach Kraftentfaltung. Auch die sich nun anschließenden Phantasien gehören ganz in das Gebiet der erwähnten Betriebe. Als Simultan-Schachspieler im Café von Tisch zu Tisch zu schreiten, das ist allerdings eine besonders gute Gelegenheit, sich den Blicken anderer zu exponieren. Das Schachspiel selbst bietet liberdies dem Patienten, wie die Analyse ergeben hat, vollauf Gelegenheit zur Betătigung sublimierter Triebe. $\mathrm{DaB}$ auf dem Brett zwei Parteien kămpfen, daB man angreift, schlägt, die feindliche Stellung zertrümmert usw., das sind Vorstel- 
lungen, die den Patienten seiner eigenen Aussage nach geradezu faszinieren. Er schwelgt in diesen technischen Ausdrücken; er befriedigt in einsamen Schachübungen seinen Aggressionstrieb.

Während die phantasierte Erfüllung seiner ehrgeizigen Wünsche, d. h. die Befriedigung sublimierter Triebe, mit Gefühlen der Lust verbunden ist, weist das Schlußstadium des Traumzustandes den entgegengesetzten Affekt der Angst auf. Es läßt sich nun dartun, daß auch der Inhalt der Phantasien im Schlußstadium in einem gegensätzlichen Verhältnis zum Inhalt der einleitenden Phantasien steht.

Im Beginn des Traumzustandes erhebt sich der Patient aus seiner habituellen Passivität zur Aktivität. Das Schlußstadium leitet wieder zu dem alten Zustand hinliber. An Stelle der großen Pläne finden wir jetzt Mutlosigkeit und Niedergeschlagenheit. Der Patient, der vorhin voller Kraftgefühl war und in Sturmschritt verfiel, fühlt sich jetzt schwach und in seinen Bewegungen gehemmt. Er glaubt, nicht mehr vorwärts kommen zu können - eine treffende, symbolische Charakteristik seiner tatsächlichen Situation. Er wird wieder zum kleinen Kinde, das ja nicht allein laufen kann ${ }^{1}$. Die unbewußte Tendenz, die den infantilen Zustand aufrecht erhalten will, hat den Sieg davongetragen. Darum kommt Patient sich so winzig vor, erscheinen ihm Menschen und Dinge so gro ${ }^{2}$. Wie ein Kind, das noch nicht laufen gelernt hat, möchte er auf allen Vieren kriechen, nach Hause zur Mutter. Wollte er vor wenigen Augenblicken noch aller Blicke auf sich lenken, so möchte er jetzt verschwinden, in den Boden sinken, um nur nicht gesehen zu werden.

Das sehr intensive Gefühl der Schwäche im vierten Stadium ist mehrfach determiniert. Es bedeutet zunächst die befürchtete sexuelle Schwäche. Nahm Patient im Beginn des Traumzustandes einen Anlauf zur kraftvollen Aktivităt, so fällt er nun wieder in die Passivität zurück; es fehlt ihm die männliche Kraft. Das Gefühl, vor Schwäche nicht stehen zu können, enthält einen symbolischen Hinweis auf die Impotenz. Eine weitere Determinierung für diese Hinfalligkeit geben die. Todesphantasien, die ja niemals fehlen, wenn Aggressionspläne gegen Angehörige unterdrïckt werden mußten. Diese Todesphantasien des SchluBstadiums stehen in einem beachtenswerten Gegensatze zu der energischen Vitalităt im einleitenden Stadium.

1 Auf die anderweitigen Determinierungen des "Gleitens" und "Fallens" will ich hier nicht eingehen.

2 Dies die wichtigste Ursache des als "Makropsie" beschriebenen Symptoms. Ich habe es in ganz gleicher Weise in den Angstanfalle $n$ einer Patientin beobachtet. 
Aggressionstrieb und Exhibitionstrieb sind nun wieder der Unterdrückung verfallen. Aus dem zurückbleibenden Zustand der Depression sucht Patient sich, wie erwähnt wurde, durch Rauchen einer Zigarre zu befreien. Es ist aber nicht so sehr die Nikotinwirkung, der die Depression allmählich weicht. Vielmehr hat auch das Rauchen für den Patienten die Bedeutung einer Ersatzbefriedigung. Es ist ein Zeichen der Männlichkeit, die er entbehrt ${ }^{1}$. Das Rauchen ist ihm ein Trost in dieser Situation.

Die vasomotorischen und parästhetischen Begleiterscheinungen erfordern ein gesondertes Eingehen. Das von diesem Patienten (und wie sich zeigen wird, auch von anderen) beschriebene Hitzegefuhl gehört zu den normalen Begleiterscheinungen der Sexualerregung; es wurde aus dem masturbatorischen Akt in den Traumzustand übernommen. Es ist bemerkenswert, daß Patient auch sehr leicht errötet; sobald er unter Menschen kommt, tritt seine außerordentlich erregbare Sexualphantasie in Tätigkeit und außert sich im Körperlichen durch die Hitzewelle. Es kann uns nicht verwundern, daß diese kongestive Blutwelle auch die Aktivitätsphantasien des Patienten begleitet, denn letztere vertreten ja nur unbewubte Sexualphantasien.

Schon wăhrend der phantastischen Exaltation nimmt der Patient neben der aufsteigenden Hitze eine „Unterströmung“ von Kälte und Angst wahr. Im abschließenden Stadium der Angst ist das Kältegefühl vorherrschend. Im allgemeinen also tritt das Hitzegefühl auf, wenn Patient sich zur sexuellen Aktivität aufschwingen möchte, während das Kältegefühl erscheint, wenn mit der Umwandlung der Triebregungen in Angst die Verdrängungstendenz wieder die Oberhand gewinnt. Das Blut wird nun nicht mehr mit der vorherigen Heftigkeit nach der Peripherie getrieben. Das nun einsetzende Kältegefahl ist jedoch noch anderweitig determiniert. Patient fühlt, wie ihm Körperteile absterben; er glaubt, im nächsten Augenblick zusammenzubrechen, hinzuschwinden. Es kommt also im vierten Stadium zu einem symbolischen Sterben, welches u. a. in dem Kältegefühl seinen Ausdruck findet. Die weiter fortgesetzte Analyse ergibt dann, daB auch dieses Sterben eine doppelte Bedeutung hat. Es erhält einen besonderen Sinn durch die vom Patienten befürchtete Impotenz; die eigentliche Lebenskraft fehlt ihm.

Dient das erste Stadium des Traumzustandes den Phantasien von der kraftvollen Mănnlichkeit, so weist das letzte Stadium eine Verdichtung zweier Vorstellungsreihen auf, welche den Männlichkeits-

1 Ich gehe der Kürze halber auf die anderen Deferminationen des Rauchens (Betätigung der Mundzone; Identifikation mit dem Vater) nicht năher ein. 
phantasien entgegengesetzt sind: 1. ein Kind bleiben und 2. sterben. Der erwachsene Mann mit seiner energischen Vitalität steht in der Mitte zwischen Kindheit und Tod.

Die Traumzustände dieses Patienten gewähren uns Einblicke in den Kampf zwischen Trieb und Verdrängung, wie er sich in jeder Neurose abspielt. Verdrängte Triebe von ursprünglich abnormer Stärke ringen sich vom Unbewußten los, um rasch den verdrängenden Mächten wieder zu erliegen. Jeder solche Zustand dieses Patienten stellt eine Revolution gegen die Neurose dar, freilich eine stets vergebliche. Schon der nächste Fall wird aber zeigen, daß die Traumzustände nicht bei allen Patienten die nämliche Tendenz haben.

\section{Beobachtung C.}

Die Traumzustände entstehen bei der Patientin $\mathrm{C}$ ebenfalls, wenn sie sich durch eine aktuelle Situation, der sie nicht entgehen kann, gequält, deprimiert, erniedrigt fühit. Ein Gespräch mit peinlichem Inhalt gibt den Anlaß, oder ein körperliches Ubelbefinden. In dieser Beziehung kommt besonders der Menstruation die Rolle des auslösenden Anlasses zu. Die Patientin äußert: „Während der Periode geht mir jede Realităt verloren." Ganz wie bei dem vorigen Patienten findet auch hier im Traumzustand eine Isolierung von der Außenwelt statt. Man könnte nun nach Analogie jenes Falles erwarten, der Traumzustand entführe die Patientin der quälenden Wirklichkeit. Das Gegenteil trifft $z u$. Tatsächlich versetzt Patientin sich durch ihre Phantasien in einen Zustand noch größeren Leidens, in absolute Passivităt, und zieht daraus masochistischen Lustgewinn. Aus ihrer Kindheit ließen sich interessante Details aber wirkliche masochistische Betätigung mitteilen. Aber auch jetzt ist diese Triebrichtung deutlich erkennbar. Die Patientin versteht es nämlich, ganz wie ich es auch bei verschiedenen anderen Patienten sah, den Traumzustand a u ch willkür $l$ ich herbeiz uführen. "Manchmal verlockt mich etwas, den Traumzustand herbeizufähren." Sie rezitiert $z u$ diesem Zwecke aus dem Gedächtnis eine Stelle aus $\mathrm{Hebbels} \mathrm{"Maria}$ Magdalena" (III. Akt, 2. Szene). Es sind folgende Worte der Kla ra : "Ich will dir dienen, ich will für dich arbeiten, und zu essen sollst du mir nichts geben, ich will mich selbst ernähren, ich will bei Nachtzeit nähen und spinnen für andere Leute, ich will hungern, wenn ich nichts $z u$ tun habe, ich will lieber in meinen eigenen Arm hineinbeißen, als zu meinem Vater gehen, damit er nichts merkt. Wenn du mich schlägst, weil dein Hund nicht bei der Hand ist oder weil du 
ihn abgeschafft hast, so will ich eher meine Zunge verschlucken, als ein Geschrei ausstoßen, das den Nachbarn verraten könnte, was vorfällt. Ich kann nicht versprechen, daß meine Haut die Striemen deiner GeiBel nicht zeigen soll, denn das hängt nicht von mir ab, aber ich will lügen, ich will sagen, daß ich mit dem Kopf gegen den Schrank gefahren oder daB ich auf dem Estrich, weil er zu glatt war, ausgeglitten bin, ich wills tun, bevor noch einer fragen kann, woher die blauen Flecke rühren. Heirate mich - ich lebe nicht lange. Und wenn's dir doch zu lange dauert und du die Kosten der Scheidung nicht aufwenden magst, um von mir loszukommen, so kauf' Gift aus der Apotheke und stell's hin, als ob's für deine Ratten wäre, ich will's, obne daß du auch nur $z u$ winken brauchst, nehmen und im Sterben $z \mathfrak{u}$ den Nachbarn sagen, ich hätt's flur zerstoßenen Zucker gehalten !“

Die Patientin gerät, wenn sie diese typisch masochistischen Vorstellungen in sich eingesogen hat, in einen Zustand traumhafter Entrückung. Sie empfindet als lustvoll einerseits die masochistische Unterwerfung der Klara, mit welcher sie sich identifiziert, andererseits ihre eigene Isolierung von der Welt. Sie betont mit großem Nachdruck das Lustvolle dieser Abgeschiedenheit; in ihren Trăumen durchlebt sie ähnliche Situationen, Die Welt ist ihr fern, der eigene Körper erscheint ihr verändert, die eigene Stimme fremd. „Der Mensch, der da spricht, ist mir ganz fremd." Um die Qual noch zu erhöhen, nehmen alle Dinge bizarre, verzerrte Formen an, so daß sie an Zeichnungen von $\mathrm{Ku} \mathrm{b}$ in erinnern. "Alles ist grausamer, schwärzer als in Wirklichkeit." Diese masochistischen Phantasien gipfeln in Vorstellungen vom Tode, in der Idee, zum Fenster hinausspringen zu müssen usw. Nach Überschreitung des Höhepunktes setzt heftige Angst ein. Dazu gesellen sich angstvolle Vorstellungen, die entsprechend der momentanen Lage variieren. Macht Patientin z. B. auf der Straße den Zustand durch, so hat sie das Gefühl, sie müsse fallen, sie könne nicht allein nach Hause gelangen, müsse irgend einen beliebigen Mann ansprechen. "Fallen" und "einen beliebigen Mann ansprechen" sind doppelsinnige Ausdrücke. Sie charakterisieren nicht nur den Zustand der Hilflosigkeit und Hilfsbedürftigkeit, sondern sie deuten auf die bei hysterischen Frauen so häufigen, aber streng geheim gehaltenen Prostitutionsphantasien hin ${ }^{1}$. Patientin empfindet den Trieb, sich dem ersten besten Manne hinzugeben und hat dies zu Zeiten, in denen Zustände wie die geschilderten häufig auftraten, wirklich getan. Die Prostitutions-

${ }^{1}$ Diese kommen bei der Patientin in hăufigen Trăumen zum deutlichsten Ausdruck, desgleichen in verrăterischen Symptomhandlungen. 
gelüste erscheinen hier nur als eine spezielle Form des Masochismus; sie begreifen fur die Patientin, die im allgemeinen selbstbewußt, ja herrschsüchtig ist, die tiefste Erniedrigung in sich.

Bei dieser Patientin lernen wir auch das Vorkommen sehr protrahierter Tra u $\mathrm{m} z$ ustände kennen, wie ihrer Lö wenfeld ebenfalls Erwähnung tut. Bei manchen Neurotikern dauert das Gefühl, in einem Traum befangen zu sein, mitsamt den $Z$ weifeln an der Realität der Umgebung durch Monate und noch darüber. Patientin litt sehr lange unter dem Eindruck, alles um sie sei nur ein Schauspiel, sie selbst sei körperlich tot, sei nur ein geistiges Wesen, das die wirkliche Welt beobachte, ohne mit ihr irgend etwas gemein zu haben. Sie erklärt, dieser langdauernde Zustand sei eigentlich eine Qual gewesen, aber eben dadurch habe er ihr den Zugang zu Dingen verschafft, die ihr sonst verschlossen geblieben wären. Diese Zustände gestatteten es der Patientin, sich aus der Welt, die ihre Wünsche unbefriedigt ließ, in eine Traumwelt zu flüchten.

\section{Beobachtung D.}

Der noch jugendliche Patient D leidet seit seiner Kindheit an einer schweren Hysterie, die ihn fast völlig unsozial macht. Er spricht z. B. mit anderen Menschen kaum das Nötigste und vermeidet es, in Gegenwart Fremder zu essen, weil er bei jeder solchen Gelegenheit schwere Angst ausstehen muB. Schon durch seine Art zu leben schlieBt er sich also gegen die Außenwelt ab. Dieser Tendenz dienen auch seine Traumzustände.

Das Sonderlingsleben eines so jungen Mannes ist motiviert durch eine ganz ausnahmsweise starke Fixierung der Libido an die nächsten Angehörigen. Patient ist außerordentlich fest an den engen Kreis dieser Personen gebunden; jedes Hinaustreten aus diesem erregt Angst. Geht er aus dem Hause, will er Fremden einen Besuch machen, will er mit einem Vorgesetzten sprechen, stets tritt Angst ein. Die ungewöhnlich starke Sexualphantasie des Kranken hängt an seiner Familie, und zwar sind nicht nur seine heterosexuellen Wünsche an Mutter und Schwester fixiert, sondern in ganz besonderem Grade beschäftigt er sich in homosexuell-masochistischem Sinne mit der Person seines Vaters. Nähert sich Patient nun irgend einem fremden Menschen, so beschäftigt sich seine Sexualphantasie sofort mit diesem. Der Versuch einer "Übertragung" erfăhrt aber ebenso rasch eine Unterdrackung. Patient wollte einen Augenblick lang aus dem engen Kreise heraustreten, aber die Fixierung seiner Libido auf die Angehörigen ist zu stark und so folgt 
jedem Versuche, den er in dieser Richtung unternimmt, die Angst auf dem Fuße.

Die erwähnten sexuellen Phantasien bildeten für den Patienten stets die Einleitung zur Masturbation. Er betreibt nun die Masturbation in einer raffinierten Weise, indem er nie brüske Manipulationen anwendet, sondern im Gegenteil ganz leichte, dafür aber lange fortgesetzte Reize appliziert (leichtes Zusammenpressen der Schenkel, Manipulationen durch die Kleider hindurch). Unter diesen körperlichen Reizen und den sie begleitenden Phantasien tritt nun die traumbafte Entrückung ein. Es kommt beim Patienten nie zur Ejakulation, dagegen zu einem sehr ausgeprägten Stadium der Bewußtseinsleere. Wir sehen in diesem Falle die Traumzustände noch in ihrer direkten und ursprünglichen Verknüpfung mit der Masturbation. Doch treten sie auch ganz spontan auf, und zwar namentlich in Anwesenheit des Vaters des Patienten. Dann regen sich eben jene Phantasien, denen Patient in der Einsamkeit nachhängt. Sie leiten jetzt den Traumzustand wie sonst die Masturbation ein.

Jahrelang hat Patient diese für ihn in hohem Grade lustvollen Zustände während des Schulunterrichtes genossen. Er war, wie seine Lehrer bemerkten, ohne Teilnahme für den Unterricht und meist wie geistesabwesend. Ihn beherrschten eben Phantasien, die vom Unterrichte weit abseits lagen. Wurde er nun durch eine Frage des Lehrers aus seinem Dämmern aufgescheucht, so trat heftige Angst ein. Im Laufe der Jahre hat sich in dieser Hinsicht bei ihm nichts geändert. Der Traumzustand dient ihm auch jetzt dazu, sich in völliger Einsamkeit abzuschließen. Er ist ganz in sich gekehrt und es fallt ihm schwer, sich auf irgend etwas, das außerhalb des Kreises seiner Phantasien liegt, zu konzentrieren. Befindet der Patient sich in einer ihm unerwünschten Situation, so ruft er nicht selten den Traumzustand willkürlich durch ein einfaches Mittel hervor, das den Abschluß gegen äußere Eindrücke in deutlichster Weise symbolisiert: er schließt die Augen. Wahrend der psychoanalytischen Sitzungen schloß er die Augen stets, wenn wir auf ein Gebiet kamen, tiber das er nicht zu reden wünschte. Dann war es unmöglich, auch nur ein Wort aus dem Patienten herauszubringen, der wie erstarrt und geistesabwesend dasaß. Als ich ihm erklärte, die Traumzustände erforderten ein genaues psychoanalytisches Eingehen, trat sofort ein Traumzustand ein, der natürlich ein solches Eingehen zunächst unmöglich machte. Öbrigens ist Patient auch imstande, den Traumzustand selbst zu unterbrechen. Er tut dies durch einen plötzlichen Ruck des Kopfes.

Eine besondere Verwendung findet der Traumzustand noch, wenn 
Patient unter einem eigentumlichen, psychisch bedingten Schmerz zu leiden hat. Er ruft dann durch sexuell erregende Manipulationen den Traumzustand hervor. Der Schmerz verwandelt sich dann ganz allmählich in ein Lustgefühl.

\section{Beobachtung E.}

Auch bei dem Patienten $\mathrm{E}$ begegnen wir einer tuberaus starken infantilen Sexualübertragung auf beide Eltern und vermissen nicht die stets zugehörigen, vom BewuBtsein streng abgelehnten Todeswünsche. "Diese letzteren waren besonders aui die Mutter gerichtet, durch den Vorgang der Reaktionsbildung aber in eine lubergroBe Anhänglichkeit von durchaus kindlichem Charakter verwandelt. Dem längst erwachsenen Manne kommt es noch jetzt sonderbar vor, daß er erwachsen ist; er hat das Gefühl, eigentlich noch ein Kind zu sein. Es ist sehr bemerkenswert, daB der Tod der Mutter bei diesem Patienten den ersten Traumzustand auslöste, welcher einen sehr protrahierten Verlauf nahm. Patient hatte viele Monate hindurch beständig das Gefühl, im Traum umher zu gehen; nur die Intensität dieses Gefühles bot große Schwankungen. Ganz spontan äußert Patient: „I ch kann mir die Realität nicht vorstellen, wenn ich nicht Seite an Seite mit ihr (der Mutter) bin." An die Stelle der verdrängten Phantasien, die sich einst gegen das Leben der Mutter gerichtet hatten, ist also im BewuBtsein die Vorstellung getreten, das eigene Lebeh des Patienten hänge vom Leben der Mutter $a b$ und höre auf, wenn das ihrige aufhöre. Die Todesphantasien haben sich gegen den Patienten selbst gekehrt. Er äußert weiter wörtlich: ${ }_{n}$ Hand in Hand damit geht die Vorstellung vom Unwert alles Vorhandenen". Mit dem Tode der Mutter hat die Welt aufgehört, für den Patienten Wert zu haben! Seine Libido zieht sich zeitweise von den Dingen zurück. Nun erscheint ihm, ganz wie wir es bei den anderen Kranken sahen, alles fremd, als hätte er es nie gesehen. Die Menschen, mit denen er spricht, scheinen ihm gar nicht wirklich zu existieren. Alle früheren Erlebnisse - d. h. diejenigen, welche sich zu Lebzeiten seiner Mutter zugetragen haben - sind weit von ihm abgerückt: "Rückwärts hat alles etwas Traumhaftes, als wäre es unendlich lange her."

Der geschilderte Zustand herrscht auch jetzt öfter, ohne daß sein Kommen und Gehen dem Patienten besonders auffält. Patient ist auch im allgemeinen imstande, die in seinem Berufe notwendige, sehr intensive geistige Arbeit $z u$ leisten. In den letzten Jahren sind 
nun Traumzustände von kurzer Dauer und akutem Verlaufe hinzugetreten. Sie haben eine sehr eigenartige Entstehungsgeschichte.

Patient leidet an periodischen Kopfschmerzen von quälendster Heftigkeit, über deren Ursprung später einiges erwähnt werden soll. Vor ungefähr drei Jahren entschloß er sich, die Hilfe eines Nervenarztes in Anspruch zu nehmen, der sich speziell mit hypnotischer Therapie beschäftigte. Da eine Reihe von Versuchen nicht zu einer Hypnose führte, gab Patient die Behandlung auf, versuchte nun aber selbst, sich in einen von dem gewöhnlichen abweichenden BewuBtseinszustand $z \mathfrak{u}$ versetzen, in der Hoffnung, dadurch den Kopfschmerz zu verlieren. Es gelang ihm eine Anzahl von Malen, einen solchen höchst lustvollen $Z$ ustand hervorzurufen, den er selbst als eine "Autohypnose" auffaßt. Der Kopfschmerz wurde freilich dadurch nicht beeinflußt.

Patient hat den Wunsch, hypnotisiert zu werden, auch mir wiederholt und auffallend eindringlich geäußert. Die Unterordnung unter den Willen eines andern liegt in der Richtung seines Masochismus. Er spricht es selber aus, daß sein höchstes Ideal sei, sich völlig passiv verhalten zu können, daß er es als eine Qual empfinde, im Leben alle seine Energie anstrengen zu müssen. Seine Sexualität bietet unverkennbare masochistische Züge in Menge. Lange Zeit masturbierte er unter masochistischen Phantasien, bis er sich unter schweren Kämpfen halbwegs von der Masturbation befreite. Ein für das Verständnis der Traumzustände ausschlaggebendes Symptom der sexuellen Passivität ist aber seine psychische Impotenz. Sie ist bei dem Patienten in der gleichen Zeit entstanden, als er die Traumzustände hervorrief. Patient hat sich ubbrigens, wie er spontan erklärt, schon früher gewünscht, sexuell passiv sein zu können. Er möchte sich der sexuellen Lust passiv hingeben können wie ein Weib.

Der Traumzustand bringt die Erfüllung dieser Ideale unter hoher Lust. Dem Wunsche nach dem Ende aller Aktivität entspricht es, daß Patient sich, um den Zustand herbeizuführen, mit aller Gewalt darauf konzentriert, $\mathrm{nichts} z \mathrm{u}$ den $\mathrm{ken}$. Sein Leben dient im allgemeinen der angestrengten Denkarbeit; er wünscht das Gegenteil dieses Zustandes herbei. Wir sahen bereits bei den anderen Patienten auf der Höhe des Traumzustandes eine "Gedankenleere" eintreten. Im vorliegenden Falle finden wir ein ganz bewußtes Tendieren nach diesem Stadium, das ja dem Moment der höchsten Lust entspricht.

Hören wir nun die eigene Beschreibung, die der Patient unter den Zeichen eines starken Affektes spontan gegeben hat; sie ist uns nach dem Gesagten ohne weiteres verständlich. „Zuerst ist es eine 
Anstrengung, wie beim sexuellen Verkehr; wenn ich es jetzt machen wollte, ich müBte mich hinlegen und müBte arbeiten. Es ist die strengste Konzentration darauf, nichts zu denken. Ich schliebe die Augen. Nichts von der Außenwelt darf zu mir dringen. Dann kommt das kurze Stadium der Wonne, der vollständig umgekehrten Lebensgefühle, die gröBte physische Veränderung, die ich kenne. Ich glaube, ich kann die Worte nicht extrem genug gebrauchen. Das kurze Stadium der Lust ist doch wie eine Unendlichkeit." Auf dem Höhepunkte des Erregungsvorganges - als einen solchen mulssen wir ihn bezeichnen - ist das Denken unterbrochen.

Der Patient vervollständigt seine Schilderung wie folgt: "Man hat die Idee im Leben, als wenn alles vorwärts drängt; ich meine z. B. den Blutkreislauf. Mit einem Schlage ist alles anders; nun ebbt alles zurück, als wenn es nicht mehr vorwärts, sondern rückwärts ginge. Es ist, als wenn ein Zauber in Kraft getreten wäre. Während sonst alles aus dem Körper hinaus will, wird es nun in den Körper zurlickgetrieben. Ich strahle nicht aus, sondern ich ziehe ein." Dann nach einer kleinen Pause fortfahrend: "Es liegt darüber eine absolute, harmonische Ruhe, eine wohltuende Passivităt, im Gegensatze zu meinem wirklichen Leben. Die Wogen strömen uber mich hin. Es wird etwas mit mir gemacht. Wenn der Zustand nicht aufhörte, ich würde mich bis ans Ende der Tage nicht bewegen."

Diese Traumzustände dienen dem Patienten dazu, in seiner Phantasie uneingeschränkte Lust aus sexueller Passivität zu gewinnen. Er möchte ein Weib sein; im Traumzustand erlebt er die Erfüllung dieses Wunsches. Er hat vollkommen recht, wenn er von der "denkbar größten physischen Veränderung" spricht. Eine eingreifendere Veränderung als die Verwandlung in ein Wesen des anderen Geschlechtes kann ja nicht erdacht werden. Für den Patienten bedeutet sie nicht nur eine Veränderung seines Geschlechtes, sondern eine Umkehrung seiner gesamten Lebensführung.

Der Wunsch, Weib zu sein, weist uns auf die homosexuelle Triebkomponente bei dem Patienten hin. Da wir von der intensiven Obertragung der infantilen Libido auf den Vater bereits erfahren haben, so wird die Annahme nahegelegt, der Patient identifiziere sich, wenn er ein Weib sein will, mit seiner Mutter, um beim Vater ihren Platz einzunehmen. Diese Annahme wird gesichert durch die Ätiologie des schon erwähnten Kopfschmerzes, der in erster Linie der Identifizierung des Patienten mit seiner Mutter dient. Die Mutter litt schon in der Kindheit des Patienten an Anfällen von Kopfschmerz, welchen die seinigen auffallend gleichen. Der Kopfschmerz der Mutter kam stets 
mit der Periode; sie war gleichzeitig einige Tage lang sehr empfindlich gegen jeden Reiz und mußte sich vollkommen schonen. A u ch bei dem Patienten wiederholte sich der Kopfschmerz jahrelang in vierwöchentlichen Intervallen und da uerte jeweilen drei bis vier Tage. Patient ist während des Kopfschmerzes äußerst empfindlich gegen jeden Reiz, muß die Arbeit aussetzen und einen bis zwei Tage im Bette zubringen. Patient identifiziert sich also durch den Kopfschmerz mit seiner Mutter. Dał er eine dunkle Ahnung von diesem Zusammenhange hatte, geht daraus hervor, daß er in der ersten Zeit der Behandlung einmal scherzend sagte: "Ich habe augenblicklich meine Periode."

Kopfschmerzanfälle und Traumzustände dienen bei dem Patienten der Metamorphose zum Weibe. Die vierwöchentliche Periode und die sexuelle Passivität sind zwei hervorragend wichtige Züge im Geschlechtsleben des Weibes. Patient handelte aus einem ganz richtigen Instinkt heraus, als er den Kopfschmerz durch den Traumzustand zu vertreiben oder - wie wir jetzf richtiger sagen werden - zu ersetzen suchte. Denn beide dienen ja dem gleichen Ziele, der sexuellen Passivität. Wäre ihm sein Plan gelungen, so hätte er eine unlustvolle Krankheitserscheinung durch eine gleichsinnige 1 us tbet onte ersetzt gehabt. $\mathrm{Daß}$ seine Erwartung getäuscht wurde, vermögen wir freilich auch $z u$ erklären. Der Kopfschmerz beruht eben nicht nur auf dem einen erwähnten Motiv, sondern er steht noch im Dienste anderer verdrängter Wünsche, die durch den Traumzustand keinen adäquaten Ausdruck gefunden hätten. Der Traumzustand konnte daher nur neben den Kopfschmerz, nicht aber an seine Stelle treten.

Die beabsichtigte Unlustverhütung ist dem Patienten mißlungen; aber er hat eine neue Lustquelle gewonnen. Vermag der Traumzustand den Patienten auch nicht von seinem Schmerze zu befreien, so entschädigt er ihn doch durch eine Lust, die ihn den ausgestandenen Schmerz verwinden läßt.

\section{Beobachtung F.}

Ubergänge $z$ wischen Tagträumereien und eigentlichen Traumzuständen.

Ich schließe hier ein Fragment einer weiteren Psychoanalyse an; dieser Fall weist keine ausgesprochenen Traumzustände im Sinne der bisher beschriebenen auf, macht uns aber mit einer Art Vorstufe $z \mathfrak{u}$ diesen bekannt. Er demonstriert in besonders einleuchtender Weise die Abkunft der Traumzustände von den Wachträumen und aberdies 
die nahe Verwandtschaft $z$ wischen den neurotischen Traumzuständen und den nächtlichen Träumen.

Der Patient $F$ wird von gewissen, häıfig wiederkehrenden Phantasien in so hohem Grade beherrscht, $d a B$ er sie als seine "Zwangsvorstellungen" bezeichnet. Namentlich Lektüre gibt ihm die Anregung $z u$ seinen Träumereien. Er identifiziert sich sofort mit dem Helden der Erzählung. „Wenn ich einen Liebesroman lese, glaube ich der Held zu sein, den die Frauen umschwärmen." In Wirklichkeit ist die geschlechtliche Aktivität des Patienten sehr reduziert. Neben den erotischen Träumereien beschätigen den Patienten Größenphantasien. Hat er von gewissen historischen Persönlichkeiten gelesen, so kommt die Vorstellung, er sei der Held. Er durchlebt dann in der Phantasie die Rolle seines Helden. "Ich lese z. B. gern von Napoleon. Den Jubel, den er hörte, empfinde ich auch." Ja, Patient braucht nur an Jubel, Ruhm und Beifall zu denken, so überläuft ihn ein Schauern. Auch Musik (z. B. Militärmusik) wirkt begeisternd auf ihn und ruft ein "Schauern" hervor. In dem Wachtraum, der durch solche erregende Anlässe ausgelöst wird, erlebt der Patient, der von Beruf Kaufmann ist, wie er ein bedeutender oder reicher Mann wird, "etwa ein Fabrikant wie Krupp." Er malt sich dannaus, wie ergegen seine Angestellten rucksichtslos vorgehen, ihnen seinen Willen a $u f z$ ingen wit $\mathrm{d}$ e. (Napoleon!) Es wird ihm schwer, sich von diesen Vorstellungen frei zu machen. "Wenn ich die Zwangsvorstellungen (= Tagträume) habe, rezitiere ich ein Gedicht, um mich abzulenken, meist die ,Lorelei', ,Heil dir im Siegeskranz' oder ein anderes Gedicht aus meiner Schulzeit." Er muß das Aufsagen soicher Gedichte aber oft wiederholen, ehe er die Wirkung erzielt.

Im Mittelpunkte der Phantasiegebilde des Patienten steht entweder ein Sexualheld oder ein rücksichtsloser Despot oder Kriegsheld. Man errät unschwer, daß Patient in diesen Wachträumen diejenigen Wünsche zu befriedigen sucht, die aus der "Verschränkung" des Sexualtriebes mit dem Aggressionstrieb hervorgehen, also seine "sadistischen" Regungen.

Patient hat im allgemeinen das Gefühl, als erwecke er nicht den Eindruck der Männlichkeit, als behandle man ihn wie ein Kind. Dieses Gefühl beruht auf der Unterdrückung seines Sadismus. In seinen Träumen wird er zum energischen, despotischen Manne, um sich hernach wieder in das abhängige, schwache "Kind" zurlick zu verwandeln. Die Gedichte aus der Schulzeit sind geeignet, die Phantasien zu unterbrechen, weil Patient sich durch sie in die Kindheit zurückversetzt fühlt. Die inhaltliche Ähnlichkeit der Phantasien dieses Patienten mit denjenigen 
des ausführlich beschriebenen Falles B fällt sofort auf. Die Äbnlichikeit erstreckt sich übrigens noch auf ein besonderes Symptom. Bei dem Patienten B konstatierten wir eine auffällige Neigung zum Erröten. Patient $F$ leidet an Erröten und ausgesprochener Erythrophobie.

Es handelt sich in diesem Falle nicht um Traumzustände von dem früher geschilderten Charakter, denn es fehlt die Entrückung, die Bewußtseinsleere und die nachfolgende Angst. Auch der Verlauf ist ein anderer. Aber es handelt sich um sehr intensive, über das Gewöhnliche hinausgehende Tagträumereien, die mit dem Traumzustand (sensu strictiori) einen wichtigen Zug gemeinsam haben. Der Patient verliert während, des Phantasierens die Herrschaft uber seine Gedanken; er kann sie nicht ohne weiteres nach seinem Belieben unterbrechen. Er muBte, ganz wie wir es bei anderen Patienten sahen, ein Mittel erfinden, um die Träumereien unterbrechen $z \mathfrak{u}$ können, und $m u B$ von diesem einen ausgiebigen Gebrauch machen, bevor es wirkt. Besonders ist noch $z \mathfrak{u}$ erwähnen die große visuelle Lebhaftigkeit der Tagträumereien in diesem Falle; sie wird noch eine genauere Besprechung finden.

Der gleiche Fall zeigt nun außerdem sehr schön, daß die Tagesphantasien auch die Vorstufe der nächtlichen Träume bilden. Der Patient berichtet über einige Träume, die seit seiner Kindheit öfter wiederkehren. In einem dieser Träume wird er im Bett von einem bärtigen Manne überfallen. Dieser sticht mit einem Dolch auf ihn ein. Er selbst liegt ruhig da, als wären ihm die Hände gelähmt. Er erwacht aus dem Traum mit großer Angst. Noch häufiger wird Patient im Traum von einem Löwen verfolgt. In großer Angst schlüpft er schließlich durch einen Mauerspalt, durch welchen der Löwe ihm nicht folgen kann ${ }^{1}$. Der Mann mit dem (symbolischen) Dolch ist der Vater, dessen "Überfall" auf die Mutter der Patient als kleiner Knabe beobachtet hat. Der Traum verrät den verdrängten Wunsch des Patienten, beim Vater die Stelle der Mutter einzunehmen. Auch der Traum vom Löwen gehört diesem Komplex an.

Forderte ich diesen Patienten, der nur kurze Zeit in meiner Behandlung stand, auf, in der zur Analyse notwendigen Weise mitzuteilen, was ihm einfiele, so schloß er gewöhnlich die Augen und berichtete über Bilder, die vor seinen Augen erschienen. Zu dem Traum vom Erdolchtwerden ließ er sich folgendermaßen vernehmen ${ }^{2}$ : "Ich

1 Ähnliche perennierende Träume berichtet auch Patient B. Die Analyse solcher Träume habe ich aber der Darstellung des Falles B nicht eingereiht, um die Ubersicht nicht zu erschweren.

2 Die oben gegebene Deutung des Traumes war dem Patienten unbekannt, als er seine Visionen mitteilte. 
sehe, wie ein Mann von einem anderen gestochen wird; der eine liegt auf dem Diwan, der andere kniet auf ihm und sticht zu in die Brust. Der Liegende hält mit der linken Hand die rechte des Gegners fest. Der Kniende mag etwa 30 Jahre alt sein, er sieht sehr wild aus, hat einen dunklen Bart. Der Liegende ist vornehm, wie von altem Adel, er hat ein Seidenwams mit Spitzenkragen."

$\mathrm{DaB}$ diese Bilder den erwähnten perennierenden Träumen inhaltlich gleichen, ist ohne weiteres ersichtlich. Der Liegende ist Patient selber; er liegt übrigens während der Vision auf dem Diwan in meinem Sprechzimmer. Sehr zu beachten ist die Form der Darstellung durch das Passivum: ein Mann w i r d von einem anderen gestochen. Patient selbst ist das Subjekt. Der Vater war zur Zeit, als Patient das Schlafzimmer der Eltern teilte, ungefähr 30 Jahre alt und trug einen Bart. Daß Patient den Liegenden als Adeligen vornehm ausstattet, wird aus den typischen $\mathrm{Abkunftsphantas} \mathrm{i} \mathrm{e} \mathrm{n}^{1}$ verständlich, die beim neurotischen Kinde mit großer Lebhaftigkeit auftreten. Das Seidenwams mit Spitzenkragen hat er einem tiber dem Diwan hängenden Bilde entnommen (der "lachende Kavalier" von Franz Hals); er hatte es eifrig betrachtet, bevor er die Augen schloß, weil es den infantilen Vornehmheitskomplex traf. Als er es jetzt nochmals betrachtet, bemerkt er, die Kleidung erinnere an ein vornehmes Frauenkleid. Das Bild hatte also noch einen weiteren Komplex - den homosexuellen - berührt.

Biol. Jag.

Einen Tag später produzierte Patient, wiederum auf dem Diwan liegend, noch folgende Visionen:

„Ein Zentaur - jetzt kommt ein kleines Kind ... ein kleiner Zentaur hinzu." (Vater und Patient selbst. Zu beachten die sexuelle Symbolik im Vergleich mit dem wilden Zentauren oder dem Hengst!) „Ein Wettrennen ... wie die Reiter die Hürde nehmen." (Die Rivalität mit dem Vater. Patient hat überhaupt den Charakterzug, den Patient B bei sich selbst als "Wetteifergefühl" bezeichnet.)

"Ein gestürztes Pferd vor einem Wagen." (Patient gibt an, auf dem Wege zu mir ein gestürztes Pferd gesehen zu haben. Die tiefere Begründung dieses Bildes liegt in den typischen Phantasien vom Tode des Vaters ${ }^{2}$.

1 Vgl. meine Schrift ,Traum und Mythus" (Seite 40) sowie Rank, Der Mythus von der Geburt des Helden*, beide in ,Schriften zur angewandten Seelenkunde".

2 Die gleiche Phantasie vom gestürten Pferd habe ich kürzlich wieder in einem anderen Falle gefunden. Ihre Analyse bei einem Knaben findet man in Fre uds "Analyse der Phobie eines fünfjăhrigen Knaben" in Band I des Jahrbuches f. psa. Forschungen. 
"Der Mann mit dem Helm, das Bild von Rembrandt." (Dieses Bild hängt nicht in meinem Zimmer; es ist aber ein Lieblingsbild des Patienten. Der Vater des Patienten war eine große, kraftvolle Erscheinung; er hatte zwei Kriege als Gardist mitgemacht. Patient hat den Wunsch, ein Krieger zu sein wie der Vater; dieser ist auch das Vorbild der Napoleon-Phantasien.)

Es folgten dann noch weitere Erscheinungen von ähnlichem Charakter.

Phantasien aus der Kindheit des Patienten geben in gleicher Weise seinen Wachträumereien und seinen nächtlichen Träumeıl den Inhalt. Sogar die halluzinatorischen Bilder sind beiden gemeinsam. Eine der "Traumarbeit" analoge psychische Leistung formt auch in den Traumzuständen aus dem verdrängten (latenten) Gedankenmaterial den manifesten Inhalt. Ich verweise hier nur auf die ausgiebige Verwendung der Symbolik sowie auf die sehr intensive Verdichtungsarbeit. Wir sind zahlreichen Beispielen begegnet, welche zeigen, daß irgend ein Detail des Traumzustandes (und dieser selbst, als Ganzes betrachtet) sehr verschiedenen, ja entg egengesetzten Phantasien zum Ausdruck dient.

Träume und neurotische Traumzustände sind nicht die einzigen Abkömmlinge der Tagträumereien. Wir können ihnen zwei weitere, durch eine tiefergehende Störung des BewuBtseins ausgezeichnete Gebilde anreihen. Aus dem Traum geht der so $\mathrm{m} \mathrm{n}$ a $\mathrm{m}$ b u le Tr a u m hervor; in ihm setzt der Neurotiker seine Phantasien in mehr oder weniger komplizierte $\mathrm{Handlung}$ en um, für welche er später keine Erinnerung hat.

$Z u$ den Traumzuständen stehen in ganz analogem Verhältnis die

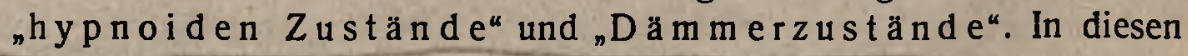
letzteren finden wir Erscheinungen wieder, die uns von denTraumzuständen her geläufig sind; ich nenne mit denWorten Breuers ${ }^{1}$ die ${ }_{n}$ Entrückung", das "Verdămmern der umgebenden Realität" und das "affekterfüllte Stillestehen des Denkensu. In den Dämmerzuständen werden oft komplizierte Handlungen ausgeführt. Dem Grade der Bewußtseinsstörung entspricht die den Dämmerzuständen folgende Amnesie; den von uns betrachteten Traumzuständen ist diese nicht eigentümlich.

Diesen episodischen Erscheinungen im Krankheitsbild der Hysterie, sind noch andere, nahe verwandte Phanomene anzureihen, deren Beziehungen $z u$ den Tagträumereien bereits durch frühere Untersuchungen erwiesen sind. Ich nenne zunächst die hysterischen Anfälle. Fre u d ${ }^{2}$ hat kurzlich seine Anschauungen von ihrem Wesen in sehr

1 "Studien über Hysterie" von B r e u e r und F r e ud, Seite 191 der 2. Auflage.

2 Vgl. Zitat auf Seite 59. 
knapper Form zusammengefaßt. Aus seinen Ausführungen, auf die ich schon früher zu verweisen hatte, zitiere ich einige Stellen wörtlich:

„Die Erforschung der Kindergeschichte Hysterischer lehrt, daB der hysterische Anfall zum Ersatz einer ehemals geübten und seither aufgegebenen a utoe rotischen Befriedigung bestimmt ist." Wir sind durch dieAnalyse derTraumzustände zu analogen Resultaten gelangt.

"Die Anamnese der Kranken ergibt folgende Stadien: a) autoerotische Befriedigung ohne Vorstellungsinhalt, b) die nämliche im Anschlusse an eine Phantasie, welche in die Befriedigungsaktion ausläuft, c) Verzicht auf die Aktion mit Beibehaltung der Phantasie, d) Verdrängung dieser Phantasie, die sich dann entweder unverändert oder modifiziert und neuen Lebenseindrlicken angepaßt im hysterischen Anfalle durchsetzt und $e$ ) eventuell selbst die ihr zugehörige, angeblich abgewöhnte Befriedigungsaktion wiederbringt. Ein typischer Zyklus von infantiler Sexualbetătigung - Verdrängung - Mißglücken der Verdrängung und Wiederverkehr des Verdrängten." Die ersten drei Entwicklungsstadien sind also dem Traumzustand und dem hysterischen Anfalle gemeinsam.

Der BewuBtseinsverlust, die Absence des hysterischen Anfalles geht aus jenem flüchtigen, aber unverkennbaren BewuBtseinsentgang hervor, der auf der Höhe einer jeden intensiven Sexualbefriedigung (auch der autoerotischen) zu verspliren ist.... "Der Mechanismus dieser Absencen ist ein relativ einfacher. Zunächst wird alle Aufmerksamkeit auf den Verlauf des Befriedigungsvorganges eingestellt, und mit dem Eintritte der Befriedigung wird diese ganze Aufmerksamkeitsbesetzung plötzlich aufgehoben, so daß eine momentane Bewußtseinsleere entsteht. Diese sozusagen physiologische BewuBtseinslücke wird dann im Dienste der Verdrăngung erweitert, bis sie all das aufnehmen kann, was die verdrängende Instanz von sich weist."

Aus gleichen Anfang sstadien hervorgegangen und den gleichen $Z$ wecken dienend, differieren Traumzustand und hysterischer Anfall in den Mitteln der Darstell ung und meist auch im Verhalten des BewuBtseins. Während die Absence im Traumzustand fast stets von kurzer Dauer ist, namentlich im Vergleiche mit der Ausdehnung der anderen Verlaufsstadien, erweitert sich beim hysterischen Anfalle die "BewuBtseinslücke" je nach Bedarf. Zur Darstellung der verdrängten Phantasien bedient sich der hysterische Anfall des "Reflexmechanismus der Koitusaktion" und bew irkt so die "motorische Abfuhr der verdrängten Libido." Im Traumzustande spielt sich der Vorgang auf dem Gebiete der Phantasie ab, wenn wir von gewissen motorischen Äußerungen 
(wie z. B. Veränderung der Körperhaltung oder des Ganges) absehen, die zur Koitusaktion keine Beziehung haben.

Nächst den motorischen Anfällen der Hysterie stehen die Angs ta nfälle in naher genetischer Beziehung zu den Traumzuständen. Auch in dieser Art episodischer hysterischer Erscheinungen haben wir umgewandelte sexuelle Erregungsvorgänge $z u$ erblicken ${ }^{1}$. Ich möchte hier erwăhinen, daB die Patienten, über deren Traumzustände ich ausfuhrlich berichtet habe, sämtlich mehr oder weniger häufig auch an Angstanfällen, nicht dagegen an motorischen Anfällen leiden. Hier liegen individuelle Differenzierungen im Krankheitsbilde vor, in die wir noch keinen gentugenden Einblick gewonnen haben.

Ich will hier erwähnen, daß Traumzustände von ganz anaioger Struktur auch bei Geisteskranken (Dementia praecox) vorkommen. Ihre Entstehung aus den Wachtrăumen konnte ich kürzlich bei einem jungen Hebephrenen mit Sicherheit fesstellen. In diesem Falle war der Zustand der Entrückung besonders ausgesprochen; in den Traumzuständen schien es dem Patienten, "als wäre alles nur ein Theater". Ich erinnere daran, daB im Verlaufe der Dementia praecox auch Dämmerzustände vorkommen, die wichtige $Z$ üge mit den hysterischen gemeinsam haben. Traumarlige Zustände von 'protrahiertem Verlauf mit besonderem Hervortreten des Fremdheitsgefühles sind von Wernicke, Juliusburger u. a. Autoren beschrieben worden ${ }^{2}$. Die analysierten Fälle gehören sämtlich zu den $s c h w e r e n$ Psychoneurosen. Es darf daraus aber nicht der Schluß gezogen werden, daB Traumzustände bei leicht Neurotischen nicht vorkämen. Sicherlich ist eine große Zahl Leichtkranker wie Schwerkranker mit ihnen behaftet. Zur Tagtrăumerei neigen sie alle; es will ihnen nicht gelingen, das Heimweh nach der autoerotischen Betätigung ihrer Kindheit zu überwinden. Die einfachen Wachträume oder die von diesen ableitbaren komplizierteren Gebilde dienen ihnen dazu, sich zeitweise aus der Wirklichkeit in ihr Kinderland $\mathrm{zu}$ flüchten. Ist ein Individuum zur Produktion von Traumzuständen disponiert, so genügt ein sehr geringer Reiz, der die verdrängten Komplexe berührt, zur Hervorrufung des Zustandes.

Besonders bei leicht Neurotischen entziehen sich die Traum-

1 Vgl. hiezu St e k e 1, Nervöse Angstzustände und ihre Behandlung, Berlin und Wien, 1908.

2 Ich konnte kürzlich bei einer Patientin eine Serie $k$ at at o $n$ is cher A nf ălle beobachten. Sie wurden durch heftige KuBbewegungen des Mundes eingeleitet und stellten im weiteren unverkennbar einen sexuellen Akt dar. Also auch hier Analogie zum hysterischen Anfall. 
zustände oft der ärztlichen Beobachtung, oder sie werden nicht in ihrer eigentlichen Bedeutung erkannt. Nicht selten erklärt z. B. eine Patientin dem Arzt - und zwar keineswegs nur bei der Psychoanalyse -, daß sie sich von ihm hypnotisiert fühle. Das ist ein durchsichtiges Phänomen der "Ubertragung“. Die Patientin ist unbewußt dazu bereit, sich dem Willen des Arztes unterzuordnen, d. h. bereif zum passiven Verhalten gegenüber einem von ihrem Unbewußten gewünschten Angriff des Arztes. Ihre Phantasie bearbeitet intensiv die Erfüllung dieses Wunsches. Es kommt dann zur traumhaften Entrückung und zu den bekannten weiteren Erscheinungen. Die Patientin macht, während sie beim Arzt weilt, einen Traumzustand durch. Andere Hysterische fühlen sich durch die Gegenwart eines beliebigen Mannes hypnotisiert. Ich behandelte eine Patientin, die in der Straßenbahn stets von Angst befallen wurde. Sie hatte das Gefühl, sie werde von den Blicken eines beliebigen ihr gegenüber sitzenden Mannes "durchbohrt". Daraus ging jedesmal ein Zustand hervor, den sie als eine Art Hypnose bezeichnete, und der mit Angst abschloB.

Andere neurotische Mädchen berichten, daß sie mitten im Gespräche mit einem Manne sich plötzlich entrückt fühlen, ihrer eigenen Stimme zuhören, als spräche eine Fremde. Dann tritt die „Gedankenleere" ein, der schließlich Angst und ein Gefübl der Beschämung folgt. Durch die Analyse erfährt man, daß solche Individuen sich in ausgiebiger Weise mit Tagträumereien beschåftigen. Besonders lieben sie es, morgens im Bette liegend sich den Phantasien hinzugeben. Bei geeignetem Anlaß wird der Faden dieser Träumereien wieder aufgenommen, und es folgen dann die anderen typischen Stadien des Traumzustandes.

In seiner oben zitierten Abhandlung hat $\mathrm{F}$ re u d eine gedrängte Übersicht auch über Anlaß und Zweck des Auftretens hysterischer Anfälle gegeben. Der hysterische Anfall wird as soziativ hervorgerufen, wenn der Komplex durch eine Anknüpfung des bewußten Lebens angespielt wird; organisch wird er dann hervorgerufen, wenn die Libido, durch äußere oder innere Gründe gesteigert, keine Abfuhr hat. Es liegt auf der Hand, daß in der Regel beide Anlässe gleichzeltig vorliegen. Die $\mathrm{näm} \mathrm{lichen} \mathrm{a} \mathrm{uslösenden} \mathrm{Faktoren}$ wirken a ch bei der Entstehung der Traumzustände.

Die hysterischen Anfälle dienen nach Freud zunächst der primären T endenz der Krankheit (Flucht in die Krankheit), bilden also eine Tröstung für den Patienten; außerdem stehen sie im Dienste der sekundären Krankheitstendenzen, wenn das Kranksein praktisch nützt. Von den Traumzuständen laßßt sich durchaus das 
Nämliche erweisen. Ein ausgezeichnetes Beispiel einer Flucht in die Krankheit bietet der Patient E, der nach dem Tode der Mutter in einen langdauernden Traumzustand geriet. $\mathrm{DaB}$ die Traumzustände auch einem aktuellen, praktischen $Z$ weck dieneñ, zeigt jeder einzelne der mitgeteitten Fälle. Bei mehreren Patienten stellt sich in peinlicher Situation der Traumzustand "wie gerufen " ein. Besonders aber muB hier angeführt werden, daß manche Patienten ihn bewußt und absichtlich herbeirufen, um Unlustgefüblen zu entgehen oder Lust zu gewinnen. Man wird hier wieder an die genetischen Beziehungen der Traumzustände zur Onanie erinnert; auch der letzteren bedient sich der Neurotiker hăufig zum Trost, um z. B. eine Verstimmung zu beseitigen. Gemeinsam mit dem Traume ist den neurotischen Traumzuständen die Funktion der Unlustverhütung '. Aber die letzteren dienen darüber hinaus auch positiv der Lustgewinnung. Der Patient $B$, welcher durch den Traumzustand aus dem Zustande der Passivität entrückt wird, entgeht dadurch nicht nur der Unlust, sondern er zieht in den ersten Stadien des Vorganges positive Lust aus phantasierter Aktivität.

Ein W e chselde s S e x u a $1 \mathrm{z}$ i els, wie er in den Traumzuständen des Patienten B stattfindet, ist nicht die Regel. Es gibt einen andern T y p u s, der z. B. durch die Patientin C vertreten wird. Die Phantasien bewegen sich hier in der Richtung der schon herrschenden Passivität. Den masochistischen Gefühlen wird hierdurch eine auBerordentliche Intensität verliehen.

Die Traumzustände bieten dem Neurotiker, ganz wie die ubrigen Phänomene der Neurose, Ersatz für eine ihm versagte Sexualbetätigung. Sein Unbewußtes macht von diesem Surrogat Gebrauch, solange die Befriedigung bestimmter Wünsche ausbleibt. Erfährt dagegen die Libido eine ausreichende Befriedigung, so treten die Traumzustände zurück, ja sie verschwinden gãnzlich. Letzteres geschah einer leicht neurotischen Dame meiner Beobachtung, sobald sie in der Ehe sexuell befriedigt wurde. Bei einem jungen Manne, der wegen psychischer Impotenz in meiner Behandlung stand, ging die ruhelose Tătigkeit seiner Sexualphantasie auf ein normales Maß zurück, als er wieder potent wurde und eine genügende Befriedigung erzielen konnte.

Die Analyse der Traumzustände beweist aufs neue die auBerordentliche Fruchtbarkeit der F r e u d schen Ideen. Seit es eine psychoanalytische Forschung gibt, sind wir nicht mehr darauf beschränkt, die Symptome der Neurosen lediglich zu beschreiben, ohne zugleich hhr Wesen erfassen und ihr individuelles Gepräge im Einzelfalle 
erklären zu können. Wir vermögen die Bedingungen und Motive ihrer Entstehung zu begreifen, die in ihnen wirksamen Triebkrăfte und die in ihnen verborgenen Tendenzen aufzuzeigen. Wir vermögen die individuelle Eigenart eines Krankheitsfalles $\mathrm{zu}$ verstehen, indem wir nicht nur das gegenwartige Triebleben des Neurotikers berücksichtigen, sondern seinen verdrängten Kindheitswünschen nachforschen. Denn sein innerstes Dichten und Trachten strebt nach der Wiederholung infantiler Befriedigungssituationen, deren Erinnerung sein Unbewußtes bewahrt. 


\section{Bemerkungen zur Psychoanalyse eines Falles von Fuß- und Korsettfetischismus ${ }^{1}$.}

Die psychoanalytische Forschung hat bis in die letzten Jahre den Problemen des Fetischismus keine besondere Aufmerksamkeit zugewandt. Noch in der ersten Auflage der "Drei Abhandlungen zur Sexualtheorie“ wies Fre ud ihm eine Sonderstellung zu, sowohl gegenüber den anderen sexuellen Abirrungen als auch gegenüber den Neurosen. Die fortschreitenden Erfahrungen haben aber gelehrt, daB in nicht wenigen Fällen Fetischismus und Neurose bei dem gleichen Individuum zusammentreffen. Die zweite Auflage der genannten Schrift enthält einen kurzen Hinweis darauf, dab $F r$ ud die Entstehung der fetischistischen Phänomene jeizt auf eine eigentümliche Abart der Verdrängung ( (Partialverdrängung “) zurückführt. Der früher betonte Gegensatz ist somit aufgehoben.

Die Analyse eines Falles von Schuh- und Korsettfetischismus, über die ich im folgenden berichte, ergab mir bestimmte Resultate uber die Psychogenese dieser Form des Fetischismus; andere Fälle haben diese Ergebnisse vollauf bestätigt.

Als Grundlage muß eine eigentümliche sexuelle Konstitution angenommen werden, welche durch die ursprunglich a b n o r m e S tä rke bestimmter Partialtriebe charakterisiert ist. Auf dieser Basis ist der uns interessierende Komplex von Erscheinungen entstanden durch das Zusammenwirken zweier Faktoren: der bereits erwähnten Partialverdrängung uud eines näher zu erörternden Verschiebungsvorganges ${ }^{2}$.

Der Patient, über den ich nunmehr in möglichster Kürze berichte, war zur Zeit der Analyse 22 Jahre alt und studierte an einer Hochschule. Er tubergab mir bei Beginn der Behandlung eine Autobiographie, die besonders seine Sexualität eingehend berücksichtigte. Von diesen Aufzeichnungen ist zunächst erwähnenswert, daß Patient

1 Aus "Jahrbuch für psychoanalytische und psychopathologische Forschungen", 1911, Band III.

2 Über den Begriff der Verschiebung vgl. Freud, Traumdeutung, S. $209 \mathrm{f}$. 
sich in der Pubertät von seinen Altersgenossen deutlich unterschied, indem ihm deren sexuelles Interesse für das weibliche Geschlecht durchaus fremd blieb. Aber auch für männliche Personen spürte er keine Liebesneigung im gewöhnlichen Sinne. Er gelangte auch auffallend spăt $z \mathrm{u}$ bewußter Kenntnis der wichtigsten Tatsachen des Geschlechtslebens; als er sie aber erworben hatte, stieg ihm alsbald die Vermutung auf, er werde impotent sein. Gegen die von gleichaltrigen jungen Leuten geübte manuelle Selbstbefriedigung fühlte er eine starke Antipathie.

Sein Sexualinteresse wandte sich nach anderer Richtung. Mit 14 Jahren begann er sich selbst zu fesseln; er wiederholte dies, so oft er zu Hause ungestört war. Er fand Gefallen an Büchern, in denen von Fesselungen die Rede war, so namentlich an Indianergeschichten, in denen die Gefangenen an den Marterpfahl gebunden und dann gepeinigt wurden. Er versuchte aber niemals, einen anderen $z u$ fesseln, noch reizte es ihn, von anderen dergleichen in Wirklichkeit zu erđulden.

Als er zirka 15 Jahre alt war, sah er in einem Kurort einen etwa acht- bis zehnjährigen Knaben, der seine Aufmerksamkeit sofort durch elegante Schuhe auf sich zog. "Bei jedem Zusammentreffen - so schreibt Patient in seiner Selbstbiographie - wo ich auf seine Stiefel achten konnte, empfand ich Freude, und ich sehnte die Gelegenheit dazu herbei." Aus den Ferien zurückgekehrt, achtete er auch in der Heimatstadt auf elegante Schuhe, besonders bei seinen Mitschülern. Bald verschob sich dieses Interesse aber auf we iblich e Schuhe und wurde nun zur Leidenschaft. ${ }_{n}$ Meine Augen wurden wie von magischer Gewalt auf weibliche Schuhe gezogen... Ein uneleganter Schuh stöBt mich ab und flöBt mir Abscheu ein." Beim Anblick schöner Damenschuhe erlebt er seither eine "innere Freude“. Dieses Wohlgefühl geht manchmal in heftige Erregung über, besonders wenn er Lackstiefel mit hohen Absätzen sieht, wie sie vielfach von Halbweltdamen getragen werden. Was ihn erregt, ist aber nicht nur der Anblick der Schuhe, sondern er malt sich lebhaft aus, wie unbequem das Gehen in solchen Schuhen sein müsse. Um das Gefühl eines quälenden Druckes an den Füßen aus eigener Erfahrung kennen zu lernen, hat er öfter seine eigenen Stiefel miteinander vertauscht und den rechten FuB in den linken Stiefel, den linken FuB in den rechten Stiefel gezwängt.

Bald nach dem Interesse für die Fußbekleidung entstand dasjenige für Korsetts. Mit 16 Jahren nahm er ein altes Korsett seiner Mutter an sich, schnürte sich fest darin ein und trug es verschiedentlich auf der 
Straße unter seinem Anzuge. Charakteristisch ist folgende Schilderung in der Lebensbeschreibung: "Sehe ich enggeschnürte Frauen und Mädchen und vergegenwärtige ich mir den Druck des Korsetts auf ihre Brust und Unterleib, so kann ich Erektionen erzielen. Schon öfters ist mir dann der Wunsch aufgetaucht, ein Weib zu sein, um mich tüchtig schnüren zu können, Damenstiefel mit hohen Hacken tragen und, ohne aufzufallen, vor Korsettläden stehen bleiben $z \mathrm{u}$ können. Da das nicht geht, so ist es mitunter mein sehnlicher Wunsch, Frauenkleider, Korsetts und entsprechendes Schuhwerk tragen zu können."

Das Ausschauen nach eleganten Schuhen oder nach enggeschnürten Tailfen wurde zur hauptsächlichsten Sexualbetätigung des Patienten. Dieses Interesse nahm auch in seinen lebhaften Tagträumereien den ersten Platz ein. Nächtliche erotische Träume handelten oft von Korsetts, vom Schnüren usw. Als Lektüre wählte Patient, wie erwähnt, mit Vorliebe Erzăhlungen von sadistischem Charakter.

Alles auf seine Neigungen Bezügliche hatte Patient streng geheim gehalten, bis er den Rat eines Spezialarztes suchte, der ihn zum Zwecke der Psychoanalyse an mich wies. In bezug auf den therapeutischen Erfolg verhielt ich mich von vornherein skeptisch.

Akzidentelle Ursachen, denen in der älteren Literatur eine große ätiologische Bedeutung für die Entstehung fetischistischer Neigungen zugeschrieben wurde, konnten in unserem Falle nicht eruiert werden. DaB Patient als Knabe zu öfteren Malen seiner Mutter zusah, wenn sie ihr Korsett anlegte, kann nicht im Sinne eines psychischen Traumas gewirkt haben. Das Interesse, welches er dem Korsett der Mutter oder spater den Schuhen eines Knaben zuwandte, war zweifellos schon eine Äußerung seiner Perversion. Ein ätiologischer Wert kann diesen Vorkommnissen nicht beigelegt werden.

Was in unserem und in jedem gleichartigen Falle am schärfsten hervortritt, das ist die außerordentliche Herabsetzung der sexuellen Aktivität. Von sexuellen Handlungen kann eigentlich kaum geredet werden, wenn man davon absieht, daB Patient in früherer Zeit Schnür- und Fesselungsversuche an sich selbst verübt hat. An anderen Personen hat er nie ein sadistisches oder sonstiges Gelüste betätigt; seine dahin zielenden Wünsche befriedigte er lediglich in der Phantasie. In der Praxis hat er nie die Grenzen des A u toerotismus uberschritten.

So wenig von geschlechtlicher Aktivität bemerkbar ist, so lebhaft ist der sexuelle $\mathrm{Sch}$ autrieb. Aber auch er ist von seinem eigent- 
lichsten Interessengebiet abgekehrt. Er richtet sich nicht auf den Gesamteindruck des Körpers anderer Personen, noch auch auf die primären und sekundären Geschlechtscharaktere bei diesen, sondern auf gewisse Teile der Bekleidung. Nicht also auf den nackten Körper, sondern auf dessen Verhüllung. Hier wiederum hat er sich auf die Fußbekleidung und auf die einengende Bekleidung des Oberkörpers beim weiblichen Geschlechte spezialisiert. Über das Betrachten dieser Objekte geht das sexuelle Verlangen nicht hinaus. Es handelt sich also um die Fixierung eines vorläufigen Sexualziels. (Vgl. "Drei Abhandlungen zur Sexualtheorie".) Der Anblick weiblicher Schuhe erregt jedoch nur dann Lust, wenn sie in Form und Ausführung elegant sind; plumpe, häBliche FuBbekleidung erregt Ekel. Man findet hier also neben der Neigung zur Sexualüberschätzung des Fetisches eine ausgesprochene Neigung zu affektiver Ablehnung, ganz wie der Neurotiker sie bietet. Die hohen Anforderungen, die der Schuhfetischist in bezug auf ästhetische Werte an sein Sexualobjekt zu stellen pflegt, beweisen ein starkes Bedürfnis nach Idealisierung des Objektes.

Ist die sexuelle Aktivität derartig reduziert wie im vorliegenden Falle, und findet der Trieb sein Genügen in der Erreichung vorläufiger Sexualziele, so darf daraus keineswegs der Schluß gezogen werden, $\mathrm{da} B$ eine primäre Schwäche der Libido vorliege. Die Analyse der Neurosen zeigt aufs deutlichste, wie ein ursprünglich ubbermäßig starker Trieb durch Verdrängung paralysiert werden kann. Für den in Rede stehenden Fall von Fetischismus ergibt die Analyse einen ganz analogen Hergang. Ein reiches Tatsachenmaterial, das hier nur zum Teil referiert werden kann, läßt den sicheren Schluß zu, daß die aktiv-sadistische Triebkomponente und die sexuelle Schaulust ursprünglich von abnormer Stärke waren. Beide Triebe, die sich in inniger "Verschränkung" (Adler) befanden, fielen gemeinsam der Verdrängung anheim.

In diesen Verdrängungsproze $B$ waren jedoch, wie sich erwies, noch andere Teiltriebe einbezogen. Das besondere Bedürfnis des Fetischisten nach ästhetischen Werten bei seinem Sexualobjekt ließ erwarten, daß die Libido ursprünglich nach gewissen Zielen drängte, die dem normalen Erwachsenen itm allgemeinen besonders unästhetisch erscheinen und seinen Ekel erregen. Meine Aufmerksamkeit wurde, bevor ich in die Analyse eintrat, auf ein bestimmtes Gebiet des Trieblebens gelenkt. Aus einer privaten Mitteilung Prof. Freuds erfuhr ich, daB nach seinen Beobachtungen die Verdrängung der koprophilen Riechlust eine eigentümliche Rolle in der Psychogenese des FuBfetischismus spiele. Meine eigenen Untersuchungen brachten 
alsbald die volle Bestätigung dieser Anschauung. Es ergab sich, daB auch in diesem Falle von Fetischismus die Lust an "ekelhaften" Körpergerüchen primär von ungewöhnlicher Stärke gewesen war. Die gemeinsame Verdrängung der k oprophilen Riechlust, der Schaulust und der sexuellen Aktivität hat zur Entstehung von Ersatzbild un gen geführt; eben diese bilden die charakteristischen Eigentümlichkeiten des FuBfetischismus.

Es gibt Fälle von Fetischismus, in denen sich die sexuelle Anomalie durch eine unverdrängte, also vollkommen bewußte Lust an ekelhaften Gerüchen äußert. Bei diesem sogenannten Geruchsfetischismus bezieht sich die Riechlust besonders häufig auf die Ausdünstungen des ungereinigten Fußes. Dieser zieht gleichzeitig auch die Schaulust auf sich. In dem von mir analysierten Falle ergab sich, da $B$ der Patient ein Stadium durchlaufen hatte, das dem soeben geschilderten Geruchsfetischismus entsprach. Danach hatte sich die eigenartige Umwandlung vollzogen: die Riechlust wurde verdrängt und die Schaulust zur Lust an einer ästhetisch wirkenden Fußbekleidung sublimiert.

Wie aber konnten sich Schautrieb und Riechtrieb in solchem Maße dem Fuße zuwenden, anstatt sich auf die Sexualorgane, respektive deren Sekrete zu richten?

Auf Grund gewisser Erfahrungen ließ sich die Vermutung hegen, daB das Interesse beider Triebe ursprünglich auch der Genitalzone gegolten habe, daß aber andere erogene Zonen frühzeitig mit dieser in Konkurrenz getreten seien. Eine solche Bevorzugung anderer erogener Zonen (Mund, After usw.) ist uns aus der Lehre von den sexuellen Abirrungen ebenso geläufig wie aus der Analyse der Neurosen und der Träume.

Tatsächlich ergab die Analyse, daß der genitalen Zone vonseiten der analen frühzeitig eine starke Konkurrenz erwachsen war; daß das eigentliche Sexualinteresse in der ersten Kindheitsperiode zurücktrat zugunsten des Interesses an den Exkretionsvorgängen; daß in der Pubertăt ein in gleicher Richtung zielender (weiblicher) Verdrängungsschub stattfand. Der Patient verharrte auffallend lange bei gewissen infantilen Anschauungen, die den Exkretionsvorgängen die Bedeutung von Sexualfunktionen zuschreiben. Seine Träume weisen eine dementsprechende Symbolik auf. Seine Schau- und Riechlust blieben soweit sie nicht auf den Fuß verschoben wurden - in hohem Maße auf die Vorgänge der Urin- und Stuhlentleerung, respektive deren Produkte gerichtet,

Die Erinnerungen des Patienten an seine frühe Kindheit beziehen 
sich vorzugsweise auf Eindrlicke des Geruchsinnes, erst in zweiter Linie auf Gesichtseindrücke. Erwähnt seien zunächst gewisse obsedierende Einfälle, die sich häufig vordrängten, wenn Patient auf seine frühe Kindheit gelenkt wurde. Dann fiel ihm zuerst der Geruch von Jodoform und Holzessig ein, zwei Substanzen, die sich in seiner Kindheit im Gebrauche der Mutter befanden. Ein anderer wiederkehrender Einfall betraf eine Szene, die sich in einem Badeorte abgespielt hatte. Dem Patienten trat jedesmal seine Mutter vor Augen, wie sie ins Wasser watete. Die eigentliche Bedeutung dieser Erscheinung wurde erst durch ergänzende Einfälle geklärt. Der Knabe hatte sich zu jener Zeit einige Male verunreinigt; die Mutter führte ihn deswegen in den See, um ihn zu reinigen.

Auch aus der späteren Kindheit brachten die Einfälle des Patienten auffallend viele Reminiszenzen an Gerüche: wie er z. B. im Zimmer der Mutter ein Paket mit Haaren fand, deren Geruch ihm angenehm war; wie er die Mutter zärtlich umarmte, um den Geruch ihrer Achsel einzuatmen. Auf die frühere Kindheit führt noch eine Erinnerung zurück: wie die jüngere Schwester an der Brust der Mutter lag, wie er selbst mit dem Munde die andere Brust berührte und dabei den Körpergeruch der Mutter angenehm empfand.

Die Zärtlichkeit gegenluber der Mutter währte bis gegen das zehnte Lebensjahr des Patienten. Bis dahin hatte er häufig das Bett der Mutter aufgesucht. Jetzt machte die Zuneigung einer Abneigung Platz. Er wurde äußerst empfindlich gegen den Körpergeruch weiblicher Personen. Mit der Verdrängung der Riechlust wandte sich sein Sexualinteresse vom weiblichen Geschlechte $a b$ und wandte sich dem nächstliegenden männlichen Objekt - dem Vater - zu.

In diese Ubertragung spielt nun das Interesse für die Körperentleerungen in auffälligster Weise hinein. Freilich wurde durch gewisse Eigenheiten des Vaters die Aufmerksamkeit des Knaben besonders auf diese Vorgänge gelenkt. Der Vater pflegte z. B. öfter vor den Augen der Kinder zu urinieren. Die Phantasie des Knaben befaßte sich im höchsten Maße mit allem, was diese Funktionen bei ihm selbst und seinem Vater betraf .

Mit der Ubertragung auf den Vater steht der Wunsch, selbst W e i b $z$ u s e in, in innigem Zusammenhange. Er erhielt sich, wie schon eingangs erwähnt wurde, auch nach der Pubertät. Dieser Wunsch richtete sich aber, soweit er bewußt war, nicht darauf, die geschlecht-

1 Es entwickelte sich im Anschluß daran eine mit der von Fre ud beschriebenen absolut identische Pferde- und Giraffensymbolik (vgl. Die Analyse der Phobie eines fünfjährigen Knaben). 
lichen Funktionen des Weibes zu erfullen. Vielmehr erschien dem Patienten das Wünschenswerte, wie ein Weib "Schnürschuhe und Korsetts tragen und entsprechende Schaufensterauslagen unauffällig ansehen zu können". Während der Pubertätszeit hat er - wie bereits berichtet - tatsächlich ein paarmal ein Korsett unter seinen Kleidern getragen. Unbewußt äuBerte sich der Wunsch, Weib zu sein, durch mancherlei Erscheinungen, uber welche noch zu berichten ist.

Die Regungen der infantilen Auflehnung und Eifersucht muBten sich bei dem Patienten wechselnd gegen Vater und Mutter richten. Mit diesen Erscheinungen stehen in dem uns geläufigen Zusammenhange Todes- und Kastrationsphantasien. Diese letzteren sind bald aktiver, bald passiver Natur. Die aktiven Kastrationsphantasien haben auch die Mutter zum Objekte, welcher die infaritile Phantasie ein männliches Geschlechtsorgan andichtet. Die passiven Kastrationsvorstellungen entsprechen dem Wunsche des Patienten, Weib zu sein. Sie entstammen einer Zeit, in der die Anschauung herrschte, das weibliche Geschlecht sei des ihm ursprünglich eigenen Penis durch Kastration beraubt. Alle die genannten Vorstellungen spielen eine große Rolle in seinem Traumleben. Er muB etwa einer Frau einen Finger amputieren. Oder er muß an einem Manne (Vater) eine Operation vollziehen; nachher hilft die Mutter ihm beim Vernähen der Wunde. In anderen Träumen soll ein Kind geköpft werden. Unter den perennierenden Trăumen des Patienten ist die Verfolgung durch einen Mann, der ein Messer in der Hand trägt, erwähnenswert. Die besondere Ausprägung des Kastrationskomplexes zeigt die ursprüngliche Gewalt der sadistisch-masochistischen Triebregungen.

Die Kastration hat in der Phantasie des Patienten nicht nur die selbstverständliche Bedeutung der Entmannung, sondern sie weist daneben auf eine bestimmte Vorstellung hin, die von jeher sein besonderes Interesse in Anspruch genommen hat. Es ist die Idee, infolge der Kastration nicht mehr urinieren zu können. Von hier führen Fäden zu einem anderen Vorstellungskomplex hinüber.

Bei allen Neurotikern, deren Anal- und Urethralzone in besonderem MaBe erogen sind, besteht die Neigung zur Retention der Exkrete. Für den vorliegenden Fall gilt dies in ungewöhnlichem Maße. Die Erinnerungen aus der Kindheit beschäftigen sich großenteils mit einstmals geübten lustvollen Betätigungen in dieser Richtung. Ein nervöses Symptom - das Harnstottern - steht ebenfalls mit solcher Betătigung in Zusammenhang.

In seiner Phantasie hat Patient sich von jeher Situationen ausgemalt, in denen man zur Zurlickhaltung der Bedürfnisse gezwungen 
ist. Mit Vorliebe malte er sich aus, wie er von Indianern gefesselt und an den Marterpfahl gebunden würde und dann zur Zurlickhaltung des Blasen- und Darminhaltes gezwungen wäre. Hier tritt ein stark masochistisches Element hinzu. Ebenso war es eine seiner Lieblingsvorstellungen, er wäre Polarforscher und würde durch entsetzliche Kälte verhindert, auch nur für kurze Zeit zum Zwecke der körperlichen Entleerungen die Kleidung zu öfnen.

Auch die Versuche, sich selbst zu fesseln, waren u. a. durch solche Motive determiniert; sie fanden bezeichnenderweise im Klosett statt. Uberhaupt gewann die Fesselung, welche im Vorstellungsleben der Sadisten und Masochisten die bekannte Rolle spielt, bei dem Patienten wesentlich ihre Bedeutung durch die assoziative Verknüpfung mit den Funktionen der Körperentleerung. Das Einschnüren des Körpers übte einen Druck auf Darm und Blase aus, den der Patient lustvoll empfand. Als er zum ersten Male ein Korsett anlegte, traten Erektionen ein, die von einer Urinentleerung gefolgt waren.

Eine wichtige Determinierung des Einschnurens (Korsett, Schnurstiefel) liegt in gewissen autoerotischen Gewohnheiten des Patienten, die mit einer Einklemmung der Genitalien einhergingen.

Die außergewöhnlich starke Betonung der Analzone findet ihren Ausdruck darin, daß diese Körperstelle in der Kindheit des Patienten einer eigentümlichen autoerotischen Betätigung diente: Patient pflegte sich so niederzulassen, daß die Ferse des einen Fußes einen Druck auf die Analgegend ausübte. In den entsprechenden Erinnerungen finden wir die unmittelbare assoziative Verknüpfung von FuB und After. Die Ferse dient gewissermaßen als männliches, der Anus als weibliches Organ.

Diese Verknüpfung wird jedoch außerordentlich verstärkt durch die koprophile Riechlust des Patienten. Sein Autoerotismus findet eine ausgiebige Befriedigung in den Gerüchen seiner eigenen Körperabsonderungen. Die Ausdlunstungen der Haut, der Genitalgegend und des Fußes erregten schon früh besondere Lust. So konnte der FuB in der unbewußten Phantasie des Patienten Genitalbedeutung erlangen.

Hinsichtlich der koprophilen Riechlust sei erwähnt, daß häufige Träume des Patienten entweder im Klosett spielen oder in durchsichtiger Symbolik analerotische Wunscherfullungen bringen. Charakteristisch ist besonders ein Traumbild, in dem er seine Nase zwischen zwei große Halbkugeln steckt.

$\mathrm{DaB}$ auch der Schautrieb vorzugsweise auf das Exkrementelle gerichtet ist, wurde bereits erwähnt. In den Träumen treten Vater und Bruder des Patienten häufig in entsprechenden Situationen auf. 
In weitaus den meisten Träumen kommt das Wasser als Symbol vor. Von Interesse ist ein Traum des Patienten, in dem er mit seinem Bruder auf einem Schiffe durch einen Hafen făhrt. Um aus dem Hafen $\mathrm{zu}$ kommen, müssen sie einen eigentümlichen, wie ein Haus über dem Wasser gebauten Durchlaß passieren. Sie fahren dann durch freies Wasser, sind dann aber plötzlich auf dem Lande und fahren mit dem Schiffe durch eine Straße, ohne jedoch den Boden zu berühren. Sie fahren in der Luft; ein Schutzmann sieht ihnen dabei zu. - Zur Erklärung dieses Traumes nur einige Bemerkungen! Zunächst ist auf den Doppelsinn des Wortes Hafen (in gewissen Dialekten = Topf) und auf den Anklang des Wortes "Schiff" an einen vulgären Terminus für "Urinieren“ hinzuweisen. Der Durchlaß, welchen man an der Hafenausfahrt passieren muß, erinnert ihn an die abgeschrägten Säulen des Tempels von Philae. Ein weiterer Einfall lautet: "KoloB von Rhodos“. Der Koloß stellt einen Mann dar, der mit auseinander gestellten Beinen über dem Hafeneingang von Rhodos steht. Er erinnert den Patienten an seinen Vater, den er als Knabe in entsprechender Körperhaltung urinieren sah. Das nachherige gemeinsame Schiffahren mit dem Bruder - wobei das Schiff durch die Luft fährt - knüpft an eine Kindheitserinnerung an, nämlich an einen unter Knaben nicht seltenen Wettstreit in bezug auf das Urinieren. Von Bedeutung ist auch das exhibitionistische Moment in diesem Traume: das Urinieren geschieht vor den Augen eines Schutzmannes; die Erfahrung lehrt, daß aufsichtführende Personen im Traume den V ater bedeuten.

Das außerordentlich reiche Traummaterial, welches der Patient im Laufe der Analyse lieferte, enthält ähnliche Anspielungen in großer Menge. Die erstaunliche Variabilităt dieser Träume läßt darauf schließen, daß die koprophile Schaulust in ganz ungewöhnlichem Maße die Phantasie des Patienten beschäftigt.

Erwähnt sei, daß der Patient die typischen Charakterzeichen sublimierter Analerotik bietet; insbesondere treten eine pedantische Sparsamkeit und Ordnungsliebe hervor.

In welchem Maße für den Patienten der Fuß dem männlichen Genitale substituiert ist, geht in bemerkenswerter Weise aus gewissen Träumen hervor, von denen zwei kurz wiedergegeben seien. Einmal trägt Patient im Traume Pantoffeln an den FüBen; die Schuhe sind hinten niedergetreten, so daß seine Fersen sichtbar sind. Dieser Traum entpuppt sich als Exhibitionstraum; die Ferse wird zur Schau gestellt wie in den gewöhnlichen Exhibitionsträumen die Sexualorgane. Der Affekt war der gleiche, wie wir ihn aus den typischen, mit Angst einhergehenden Exhibitionsträumen kennen. 
In einem anderen hierher gehörigen Traume berührt Patient eine Frau mit seinem Fuße und beschmutzt sie dadurch. Dieser Traum ist ohne weiteres verständlich.

In diesem Zusammenhange wird klar, warum den Patienten besonders die hohen Absätze an Frauenschuhen interessieren. Der Absatz des Schuhes entspricht der Ferse; gerade diese aber hat durch den besprochenen Verschiebungsvorgang die Bedeutung eines männlichen Genitale erhalten. So lebt in der Vorliebe für den weiblichen Fuß und seine Bedeckung, besonders aber für den Absatz das infantile Sexualinteresse fort, das der Patient einst dem von ihm supponierten Penis des Weibes entgegenbrachte.

Das angeführte Tatsachenmaterial stellt nur einen geringen Bruchteil dessen dar, was die Analyse zutage gefördert hat. Es scheint mir aber ausreichend, um den Nachweis zu erbringen, d a B d e m F u Be die Bedeutung eines Genitalersatzes zukommt. Schautrieb und Riechtrieb, von jeher in auffälligem Maße auf das Exkrementelle gerichtet, wurden einer weitgehenden, freilich sehr ungleichen Umwandlung unterworfen; der Riechtrieb wurde in weitem Ausmaße verdrängt, der Schautrieb hingegen um so stärker betont, freilich von seinem ursprünglichen Interessengebiet abgelenkt und idealisiert. Dieser Vorgang, dem nur der eine der beiden in Frage kommenden Triebe zum Opfer fällt, verdient den ihm von Freud gegebenen Namen "Partialverdrängungu.

Seit der ausführlichen Analyse dieses Falles hatte ich mehrfach Gelegenheit, bei Neurotikern fetischistische Züge, welche gewissermaßen einen Nebenbefund bildeten, der Analyse zu unterwerfen. In allen Fällen erhielt ich die gleichen Resultate bezüglich der Bedeutung derjenigen Triebe, die in dem mitgeteilten Falle als Grundlagen des Fetischismus ermittelt wurden. Wegen dieser Gleichförmigkeit der Resultate unterlasse ich• es, Einzelheiten aus diesen Analysen mitzuteilen.

Es erübrigt noch, einiges über die therapeutische Wirks a mkeit der Psychoanalyse im obigen und in anderen Fällen von Fetischismus hinzuzufügen. $\mathrm{Zu}$ einer Beseitigung des Fetischismus bin ich in dem geschilderten Falle nicht gelangt. Wohl aber hat die Aufklärungsarbeit der Analyse der sexuellen Abnormität sehr viel von der Macht genommen, die sie bis dahin über den Patienten gehabt hatte. Seine Widerstandskraft gegenüber den Reizen weiblicher Schuhe usw. war wesentlich gewachsen. Während der Analyse tauchten des öfteren normal-sexuelle Regungen auf. Ich halte es nicht für unmöglich, $\mathrm{daB}$ eine konsequent fortgesetzte Behandlung allmählich zu einer Stärkung der normalen Libido geführt hätte. 
Günstiger scheinen die Chancen mir da, wo es sich um weniger ausgeprägte Falle handelt; wenn z. B. Erscheinungen fetischistischer Art neben einer Neurose bestehen. Ein klirzlich von mir analysierter Fall dieser Art scheint mir den Beweis zu liefern, daB die Symptome der Neurose und des Fetischismus mitsammen durch die Psychoanalyse zum Schwinden gebracht werden können, um einem normalen geschlechtlichen Verhalten Platz zu machen. 


\section{Ansätze zur psychoanalytischen Erforschung und Behandlung des manisch-depressiven Irreseins und verwandter Zustände'.}

Während die nervösen Angstzustände in der psychoanalytischen Literatur eingehend behandelt worden sind, haben die Depressionszustände nicht die gleiche Berücksichtigung gefunden. Und doch ist der depressive Affekt uber alle Formen der Neurosen und Psychosen ebenso verbreitet wie der Angstaffekt. Oft findet man beide Affekte bei dem gleichen Individuum nebeneinander oder in zeitlicher Folge. Der an Angstneurose Leidende ist depressiven Stimmungen unterworfen; der tief verstimmte Melancholiker klagt liber Angst.

Eines der frathesten Ergebnisse der Freud'schen Neurosenforschung lautete: die neurotische Angst stammt von der Sexualverdrängung. Durch diese ihre Herkunft ist die neurotische Angst von der Furcht geschieden. Ganz entsprechend trennen wir den Affekt der Trauer oder Niedergeschlagenheit von der unbewußt motivierten, d. h. auf Verdrängung beruhenden neurotischen Depression.

Zwischen Angst und Depression besteht ein analoges Verhältnis wie zwischen Furcht und Trauer. Wir furchten ein kommendes Unheil; wir trauern uber ein eingetretenes. Der Neurotiker wird von Angst befallen, wenn sein Trieb einer Befriedigung zustrebt, die zu erreichen seine Verdrängung ihm verbietet. Die Depression setzt ein, wenn er erfolglos, unbefriedigt sein Sexualziel aufgibt. Er fühlt sich liebesunfähig und ungeliebt; darum verzweifelt er am Leben und an der Zukunft. Dieser Affekt hält an, solange seine Ursachen nicht in Wegfall gekommen sind, - sei es durch tatsăchliche Änderung der Situation, sei es durch psychische Verarbeitung der unlustbetonten Vorstellungen. Jeder neurotische Depressionszustand enthalt die Tendenz zur Lebensverneinung, ganz wie der ihm wesensverwandte Angstzustand.

1 Mit Benutzung eines Vortrages auf dem IIl. psychoanalytischen KongreB in Weimar (21. September 1911). Zuerst verơffentlicht im .Zentralblatt für Psychoanalyse * II. Jahrgang, Heft 6, 1912. 
Mit den obigen Bemerkungen sage ich denjenigen, welche die Neurosen unter den Gesichtspunkten der F r e u d'schen Lehren betrachten, kaum etwas Neues, obwohl die Literatur auffallend wenig über die Psychologie der neurotischen Depression enthält. Der depressive Affekt im Rahmen der Psychosen harrt dagegen noch der genaueren Untersuchung. Die Aufgabe seiner Erforschung wird dadurch kompliziert, daß ein Teil der in Frage kommenden Krankheiten „zirkulär " verläuft, einen Wechsel melancholischer und manischer Zustände erkennen läßt. Die wenigen bisher erschienenen Vorarbeiten ${ }^{1}$ beschäftigen sich aber jeweilen nur mit einer der beiden Phasen.

Im Laufe mehrerer Jahre konnte ich in der psychotherapeutischen Privatpraxis sechs einschlägige Fälle beobachten. Zwei davon waren leicht manisch-depressive Patienten, deren einen ich freilich nur vorübergehend behandelte (Fälle von sogenannter Zyklothymie); eine dritte Kranke litt an kurzen, aber rasch aufeinander folgenden Depressionszuständen mit typisch-melancholischen Erscheinungen. Bei zwei Patienten handelte es sich um erstmalige depressive Psychosen; schon früher hatte bei ihnen die Neigung zu Teichten manischen und depressiven Stimmungsschwankungen bestanden. Ein Patient endlich war mit 45 Jahren an einer schweren und hartnäckigen Psychose erkrankt.

Die Depressionszustände des fünften Dezenniums werden nach $\mathrm{K}$ ra e peli n's Vorgang von den meisten Psychiatern nicht dem manischdepressiven Irresein zugerechnet. Wegen der weitgehenden Übereinstimmung der psychischen Struktur, wie sie durch die Analyse aufgedeckt wurde, reibe ich den letztgenannten Fall hier denjenigen an, deren Zugehörigkeit zum manisch-depressiven Irresein keinem Zweifel unterliegen kann. Zur Frage der Abgrenzung dieser Psychosen gegeneinander will ich damit nicht Stellung genommen haben.

Auf die Depressionszustände im Krankheitsbilde der Dementia praecox beabsichtige ich nicht einzugehen.

Schon zu Beginn der ersten Analyse einer depressiven Psychose fiel mir auf, wie sehr diese in ihrem Aufbau der Zwangsneurose ähnelte. Beim $Z$ wangsneurotiker ${ }^{2}$ - ich habe hier die schweren,

1 Maeder, Psychoanalyse bei einer melancholischen Depression. Zentralblatt für Nervenheilkunde und Psychiatrie. 1910.

Brill, Ein Fall von periodischer Depression psychogenen Ursprungs. (Übersetzung.) Zentralblatt für Psychoanalyse, Bd. I. p. 158.

J on es, Psycho-Analytic Notes on a Case of Hypomania. Bulletin of the Ontario Hospitals for the Insane. 1910.

2 Die folgende kurze Charakteristik hält sich eng an die Darstellung Freud's in den .Bemerkungen uber einen Fall von $Z$ wangsneurose ". (Jahrbuch für psychoanalyt. Forschungen. Bd. I.) 
ausgeprägten Falle im Auge - kann die Libido sich nicht in normaler Weise entfalten, weil $z$ wei verschiedene Tendenzen - Haß und Liebe - einander dauernd beeintrăchtigen. Die Neigung zur feindseligen Einstellung auf die AuBenwelt ist so groB, daB die Liebesfähigkeit aufs äuBerste herabgemindert ist. Gleichzeitig aber wird der Zwangsneurotiker durch Verdrängung des Hasses (oder allgemeiner gesagt: der ursprünglich ubberwiegenden sadistischen Komponente seiner Libido) schwach und energielos. Eine ahnliche Unsicherheit besteht bei der Objektwahl in bezug auf das Geschlecht des Objektes. Die Unfähigkeit, der Libido eine bestimmte Einstellung zu geben, führt zu einem allgemeinen Gefühl der Unsicherheit, weiterhin zur Zweifelsucht. Der Zwangsneurotiker vermag keinen Entschluß $z u$ fassen, keine klare Entscheidung zu treffen; er leidet in jeglicher Situation unter Gefühlen der Insuffizienz und steht dem Leben hilflos gegenuber.

Ich teile nun in möglichster Kürze die Geschichte eines Zyklothymen mit, wie sie sich nach erfolgter Analyse darstellt.

Der Patient erinnert sich, daB der Geschlechtstrieb bei ihm sehr frühzeitig, d. h. schon vor dem sechsten Lebensjahre, mit großer Heftigkeit hervorbrach. Als sein erstes Sexualobjekt aus dieser Zeit nannte er eine Kindergärtnerin, deren Gegenwart ihn erregte. Auch in der Phantasie beschäftigte er sich lebhaft mit ihr. Die damalige Erregung führte zur Onanie, die er ausubbte, indem er sich auf die Bauchseite legte und dann reibende Bewegungen ausfuhrte. In dieser Betatigung wurde er durch die Kinderfrau (früher Amme) gestört. Sie verbot ihm sein Tun eindringlich, prügelte ihn wiederholt, wenn er dem Verbot zuwiderhandelte und stellte ihm in Aussicht, er werde sich auf diese Weise für sein ganzes Leben unglücklich machen. Während der Schuljahre hatte Patient eine mehrere Jahre dauernde erotische Schwärmerei für einen Mitschüler.

Im elterlichen Hause fuhlte Patient sich während der Kindheit und auch später nie zufrieden. Er hatte stets den Eindruck, daB die Eltern den ältesten Bruder bevorzugten, weil dieser sich als besonders intelligent erwies, während er selbst nur mittelmäßig veranlagt war. Ebenso war er der Ansicht, daß' der jüngere Bruder, der kränklich war, von der Mutter mit gröBerer Aufmerksamkeit bedacht wurde als er. Daraus ging eine feindselige Einstellung gegenliber den Eltern hervor, wăhrend die Brüder seine Eifersucht und seinen $\mathrm{Haß}$ erregten. Wie intensiv diese HaB-Einstellung war, geht aus ein paar impulsiven Handlungen in seiner Kindhejt hervor. Aus AnlaB eines geringen Streites wurde er gegen den jüngeren Bruder zweimal so gewalttătig, daB dieser zu Fall kam und beide Male ernstliche Verletzungen davontrug. 
Diese Gewalttätigkeit fällt besonders auf, wenn wir hören, daB Patient während der Schulzeit stets der Kleinste und Schwächste unter seinen Mitschulern war. Er fand nie rechten AnschluB, hielt sich meist allein. Er war fleiBig, brachte es aber nicht zu entsprechenden Erfolgen. In der Pubertät erwies sich dann deutlich, daß seine Triebe, die sich zuerst so stark gezeigt hatten, durch Verdrängung lahm gelegt waren. Er fülilte sich - im Gegensatz zu seinem Verhalten in der Kindheit! - vom weiblichen Geschlecht nicht angezogen. Seine Sexualbetätigung war die schon in der Kindheit geübte, die sich aber nicht im wachen Zustande, sondern nur im Schlaf oder Halbschlaf vollzog. Freunde hatte er nicht. Er bemerkte selbst, wenn er sich mit anderen verglich, das Fehlen der rechten Lebensenergie. $\mathrm{Zu}$ Hause fand er keine Ermutigung; im Gegenteil bekam er vom Vater geringschätzige Bemerkungen $\mathrm{zu}$ hören. $\mathrm{Zu}$ allen diesen deprimierenden Momenten gesellte sich noch ein besonderes psychisches Trauma. Ein Lehrer beging die Roheit, ihn vor versammelter Klasse als einen körperlichen und geistigen Krüppel zu bezeichnen. Bald danach brach der erste Depressionszustand aus.

Auch später fand er nicht den Anschluß an andere Menschen, hielt sich aber auch absichtlich von ihnen zurück, weil er fürchtete, doch nur für beschränkt gehalten zu werden. Einen guten gemütlichen Rapport hatte er nur mit Kindern, denen gegenüber ihn nicht die sonst gewohnten Insuffizienz-Gefühle befielen. Im ubrigen hielt er sich isoliert. Vor Frauen hatte er geradezu Angst. Zum normalen Sexualverkehr war er făhig, empfand aber eigentlich keine Neigung dazu und entbehrte auch der Befriedigung durch ihn. Die Schlafonanie blieb auch in späteren Jahren die hauptsächlichste Sexualbetätigung des Patienten. Im praktischen Leben zeigte er sich wenig energisch; besonders fiel es ihm immer schwer, in zweifelhafter Situation zu einem Entschluß oder einer Entscheidung zu gelangen.

Diese Vorgeschichte deckt sich in allen Einzelheiten mit derjenigen, wie wir sie bei den $Z$ wangsneurotikern ermitteln. Aber wir finden bei unserem Patienten nicht Zwangserscheinungen, sondern zirkuläre Stimmungsschwankungen, die sich seit nunmehr etwa 20 Jahren viele Male wiederholt haben.

In der de pressiven Phase ist die Stimmung des Patienten - je nach der Schwere des Zustandes - "deprimiert" oder "apathisch". (Ich gebe hier die vom Patienten selbst gebrauchten Bezeichnungen wieder.) Er ist gehemmt, muß sich auch $z \mathfrak{u}$ einfachen Verrichtungen mühsam zwingen, spricht langsam und leise, wünscht sich den Tod und hegt Selbstmordgedanken. Seine Vorstellungen haben einen 
depressiven Inhalt. Oft sagt er zu sich selbst: "Ich bin ein Ausgestoßener", "ein Verfluchter", "ein Gezeichneter"; "ich habe keine Zugebörigkeit zur Welt “. Er hat ein unbestimmtes Gefähl, als treffe der Depressionszustand ihn als Strafe. Er hat das Gefühl der Nichtigkeit; er malt sich häufig aus; wie er spurlos vom Erdboden verschwände. Während dieser Stimmungslage leidet er an Mattigkeit, Angst und Druckgefuhlen im Kopf. Die Dauer der depressiven Phase betrug meist einige Wochen; manchmal war sie kürzer. Die Intensität der Depression schwankt ebenfalls zwischen den einzelnen Attacken; Patient hatte im Laufe eines Jahres etwa zwei oder drei schwerere melancholische und etwa sechs oder noch mehr leichtere Zustände. Im Verlauf jeder einzelnen Attacke war ein allmähliches Ansteigen, ein Verweilen auf der Höhe der Depression und ein allmähliches Absinken der Verstimmung sowohl dem Patienten fühlbar als auch objektiv deutlich wahrnehmbar.

Ungefähr im 28. Lebensjahre des Patienten traten Verstimmungen entgegengesetzter Art hinzu; seither findet ein ständiger Wechsel hypomanischer und depressiver Zustände statt.

Im Beginn der manischen Phase erwacht Patient aus seiner Apathie, wird geistig rege, allmählich sogar überrege. Er ist vielgeschäftig, kennt keine Ermüdung, erwacht früh vor Tag und beschätigt sich dann mit beruflichen Plänen. Er ist unternehmend, traut sich groBe Leistungen $z \mathfrak{u}$, ist redselig und zum Lachen und Scherzen geneigt. Er neigt zu Wortspielen und Wortwitzen. Er bemerkt selbst, daß seine Gedanken etwas Flächtiges an sich haben; objektiv läßt sich ein leichter Grad von Ideenflucht nachweisen. Er spricht in schnellerem Tempo, lebhafter und lauter als sonst. Die Stimmung ist heiter und leicht gehoben. In den höheren Graden der manischen Verstimmung pflegt die Euphorie in Reizbarkeit und impulsive Heftigkeit überzugehen. Stört ihn z. B. jemand bei der Arbeit, tritt ihm jemand in den Weg, fährt ein Automobil rasch an ihm vorüber, so macht sich ein heftiger Wutaffekt bemerkbar. Patient möchte den Missetäter am liebsten auf der Stelle niederschlagen. Er bekommt in diesem Zustand öfter auch wirklich Streitigkeiten, in denen er sich dann sehr schroff benimmt. - Während in den Depressions-Zeiten der nächtliche Schlaf ruhig ist, tritt während der manischen Phase, besonders in der zweiten Hälfte der Nacht, eine lebhafte Unruhe ein. In den meisten Nächten macht sich eine explosive sexuelle Erregtheit bemerkbar.

Der Kranke, dessen Libido sehr frühzeitig und mit großer Energie hervorgetreten war, hat die exekutive Fähigkeit zu Liebe und $\mathrm{HaB}$ gröBtenteils eingebüBt. Auf gleichem Wege wie die $\mathrm{Zwangsneurotiker}$ 
ist er lebensunfähig geworden. Freilich liegt keine Impotenz bei ihm vor; allein er entbehrt des eigentlichen Sexualgenusses. Die Pollution bringt ihm größere Befriedigung als der Koitus. Seine Sexualbetätigung ist im wesentlichen auf den Schlaf verwiesen. Es zeigt sich hier das auch den Neurotischen eigene autoerotische Bestreben, sich von der AuBenwelt zu isolieren. Solche Menschen können nur in gănzlicher Abgeschlossenheit Lust genießen. Jedes lebende Wesen, jeder tote Gegenstand wird störend empfunden. Erst wenn ein völliger AbschluB gegen jeden von auBen kommenden Eindruck erzielt ist - wie dies im Schlaf der Fall - erleben sie träumend die Befriedigung ihrer sexuellen Wünsche. Unser Patient äußert sich dazu mit den Worten : "Ich fühle mich im Bett am wohlsten; da bin ich wie im eigenen Hause ${ }^{41}$.

In der Pubertätszeit mußte Patient in besonderem Maße bemerken, $\mathrm{daB}$ er in wichtigen Beziehungen hinter seinen Altersgenossen zurückstand. Körperlich hatte er sich diesen nie ebenbürtig gefühlt. In geistiger Hinsicht fürchtete er - besonders im Vergleich mit seinem älteren Bruder - ebenfalls inferior zu sein. Jetzt kam das Gefühl sexueller Unzulänglichkeit hinzu. Gerade in dieser Zeit traf ihn die Kritik des Lehrers ("geistiger und körperlicher Krüppel ") wie ein Keulenschlag. Ihre Wirkung erklärt sich zu einem wesentlichen Teil daraus, daB sie, wie Patient angibt, die Prophezeiung der Amme in seine Erinnerung zuruckrief. Sie hatte ihm ja gedroht, er werde sich durch seine Masturbation fürs ganze Leben unglücklich machen. Gerade in dem Zeitpunkt also, da er zum Mann werden und sich männlich fühlen sollte wie seine Altersgenossen, erhielten die schon früher in ihm wohnenden Gefahle der Insuffizienz eine bedeutende Verstärkung. Im AnschluB daran entstand der erste dem Patienten erinnerliche Depressionszustand.

Der Ausbruch der eigentlichen Krankheit erfolgte - ganz wie wir es bei der $Z$ wangsneurose so oft erweisen können - als über die Einstellung des Patienten auf die Außenwelt, über die zukünftige Verwendung seiner Libido die endgaltige Entscheidung getroffen werden sollte. In den anderen analysierten Fällen hatte ein Konflikt der gleichen Art den AnlaB zum ersten Ausbruch eines Depressionszustandes gegeben. So hatte sich z. B. einer der Patienten verlobt. Bald darauf ubberwaltigte ihn das Gefühl mangelnder Liebesfähigkeit; er verfiel in eine schwere melancholische Depression.

I Ich bemerke hier, daß die anderen männlichen Patienten, deren depressive Psychosen Ich analysieren konnte, sich ganz ahnlich verhielten. Impotent war keiner von ihnen. Aber fur alle war das autoerotische Verhalten von jeher lustvoller, wăhrend ihnen jede Applikation an weiblichen Personen beschwerlich und lastig war. 
In sämtlichen Fällen batte die Krankheit erweislich ibren Ausgang genommen von einer das Liebesvermögen paralysierenden Haßeinstellung. Ganz wie in der Psychogenese der Zwangsneurose erwiesen sich aber auch hier noch andere Konflikte im Triebleben der Patienten als krankmachende Faktoren. Ich betone hier besonders die Unsicherheit in bezug auf die Geschlechtsrolle. In Maeders Fall trat dieser Konflikt $z$ wischen männlicher und weiblicher Einstellung besonders hervor. Bei zweien meiner Patienten erhob ich einen Befund, der dem von $M$ a eder geschilderten taberraschend ähnlich war.

In der weiteren Entwicklung aber entfernen die beiden Krankheiten sich voneinander. Die $Z$ wangsneurose schafft an Stelle der unerreichbaren Sexualtriebe Ersatzziele; die Betătigung im Sinne dieser letzteren ist mit den Erscheinungen des psychischen $Z$ wanges verbunden. Anders ist der Vorgang bei der Entstehung der depressiven Psychosen. Zu dem VerdrängungsprozeB gesellt sich hier der Vorgang, welcher uns, besonders aus der Psychogenese gewisser Geistesstörungen, unter dem Namen "P rojektion* geläufig ist.

In den ${ }_{n}$ Bemerkungen zu einem autobiographisch beschriebenen Fall von Paranoia" (Jahrb. f. psychoanalyt. Forschungen, Bd. III) gibt Fre ud eine bestimmte Formulierung über die Psychogenese der Paranoia. In kurzen Formeln präzisiert er die Stadien, welche bis zur Bildung des paranoischen Wahnes durchlaufen werden (l. c. S. 55 f.). Auf Grund meiner Analysen depressiver Geistesstörungen möchte ich hier eine ähnliche Formulierung für die Genese der depressiven Psychosen zu geben versuchen.

F r e u d sieht - mindestens in einem großen Teil der Fälle von paranoischer Wabnbildung - den Kern des Konfliktes in der homosexuellen Wunschphantasie, ein Individuum des gleichen Geschlechtes zu lieben. [Formel: Ich (ein Mann) liebe ihn (den Mann).] Der Verfolgungswahn erhebt Widerspruch gegen diese Einstellung, "indem er laut proklamiert: ich li e be ihn nicht, ich hasse ihn ja." Da die innere Wahrnehmung bei der Paranoia durch eine Wahrnehmung von außen ersetzt wird, so wird der eigene $\mathrm{HaB}$ als eine Folge der von außen her erduldeten Gehässigkeiten hingestellt. Die dritte Formel lautet nun: "Ich liebe ihn ja nicht - ich hasse ihn ja - weil er mich verfolgt."

In den uns hier beschäftigenden Psychosen verbirgt sich ein anderer Konflikt. Er nimmt seinen Ausgang von einer tiberwiegenden Haß-Einstellung der Libido, die sich zuerst den nächsten Angehörigen gegenuber geltend macht, sich dann aber verallgemeinert. Sie läßt sich durch folgende Formel ausdrúcken: 
1. Ich kann die Menschen nicht lieben; ich muB sie hassen.

Von dieser unlustvollen ,inneren Wahrnehmung " nehmen die schweren Insuffizienzgefuhle dieser Kranken ihren Ausgang. Wird nun der lnhalt der Wahrnehmung verdrängt und nach auBen projiziert, so gelangt das Individuum zu der Auffassung, von seiner Umgebung zunăchst sind es wieder die Eltern usw., dann ein weiterer Kreis von Personen - nicht geliebt, sondern gehaßt zu werden. Diese Auffassung wird aus ihrem ursprünglichen ursächlichen Zusammhang mit der eigenen HaB-Einstellung des Individuums losgelöst und mit andern psychischen oder körperlichen - Mängeln in Zusammenhang gebracht ${ }^{1}$. Es scheint, daß ein reichliches Vorhandensein solcher Minderwertigkeiten die Entstehung depressiver Zustände begünstigt.

So ergibt sich die zweite Formel:

2. Die Menschen lieben mich nicht; sie hassen mich ... weil ich mit angeborenen Mängeln behaftet bin' ${ }^{2}$. $\mathrm{a} \mathrm{rum} \mathrm{b}$ in ich unglü cklich, deprimiert.

Die verdrängten sadistischen Regungen aber ruhen nicht. Sie zeigen die Tendenz, ins BewuBtsein zurtickzukehren und erscheinen in mancherlei Formen wieder: in Träumen und Symptomhandlungen, besonders aber in quälerischen Neigungen gegen die Umgebung, in heftigen Rachegelüsten oder kriminellen Impulsen. Derartige Anwandlungen kommen gewöhnlich nicht zur direkten Beobachtung, weil sie meist unausgefuhrt bleiben. Bei intimerem Eingehen auf die Kranken - eventuell in der Katamnese - erfährt man genug daräber. Wer sie in der depressiven Phase ubersehen hat, findet abrigens reichlichere Gelegenheit, sie in der manischen Phase zu beobachten. Daruber später.

Gerade hinsichtlich dieser Gelüste nach Rache, gewalttätigen Handlungen usw. tritt die Neigung hervor, sie von dem qualenden Gefúhl körperlicher oder seelischer Unvollkommenheit abzuleiten, anstatt von dem eigenen, mangelhaft verdrängten Sadismus. Jeder Kranke der manisch-depressiven Gruppe neigt $z \mathbf{u}$ den Folgerungen Richards des Dritten. Der enthallt mit schonungsloser Grausamkeit gegen sich selbst alle seine Gebrechen und zieht daraus das Fazit:

\section{"Therefore, since I cannot prove a lover \\ I am determined to prove a villain."}

1 In manchen Fällen - anscheinend besonders in den leichteren - geht der ursprüngliche Zusammenhang nur teilweise verloren. Doch bleibt die Verschiebungstendenz auch dann deutlich erkennbar.

2Man beachte in der deutschen Sprache die Etymologie von ,hablich": was den $\mathrm{HaB}$ erregt. 
Wegen seiner Gebrechen kann Richard nicht lieben; er wird um ihrer willen gehaBt. Dafür will er Rache nehmen. Ganz ebenso wollte jeder unserer Kranken; aber er kann nicht, weil die Aktivităt seiner Triebe durch Verdrängung paralysiert ist.

Firr ihn gehen aus der Unterdrückung dieser oft genug auftauchenden Regungen des Hasses, der Rache usw. neue krankhafte Erscheinungen hervor: die I deen der Verschuldung. Nach den bisherigen Erfahrungen glaube ich sagen zu dürfen: je heftiger die unbewußten Regungen der Rache sind, umso ausgeprägter ist die Neigung, Wahnideen der Verschuldung zu bilden. Dieser Wahn kann, wie bekannt, ins Ungeheure gehen, so daB der Kranke etwa angibt, er allein habe seit Weltbeginn alle Sünden verschuldet, oder alles Böse in der Welt stamme allein von ihm. Es handelt sich hier um Individuen mit einem ins UnbewuBte verdrängten unersättlichen Sadismus, der sich gegen alle und alles richten möchte. Freilich ist die Vorstellung einer so ungeheuren Schuld dem BewuBtsein im höchsten Maße qualvoll; einem solchen Grade des verdrängten Sadismus entspricht eine besondere Schwere des depressiven Affektes. Dennoch enthalt die Verschuldungsidee die Erfüllung eines Wunsches: des verdrängten Wunsches, ein Verbrecher allergröBten Stiles zu sein, mehr Schuld auf sich zu laden als alle anderen Menschen zusammengenommen. Auch hier werden wir an gewisse psychische Vorgänge bei den Zwangsneurotikern erinnert. Ich nenne nur die Vorstellung dieser Kranken bei der - Allmacht" ihrer Gedanken. Sie leiden häufig an der Angst, durch Gedanken an den Tod gewisser Personen deren Tod tatsächlich verschuldet $\mathrm{zu}$ haben. Auch beim $\mathrm{Zwangsneurotiker} \mathrm{sind} \mathrm{die} \mathrm{sadistischen}$ Triebregungen unterdrückt. $\mathrm{Da}$ er nicht gemäß seinem ursprünglichen Triebe handeln kann, gibt er sich unbewußt der Phantasie hin, durch Gedanken töten zu können; dem Bewußtsein wird dieser Wunsch nicht als solcher, sondern als quälende Beăngstigung. bemerkbar.

Aus der Verdrängung des Sadismus sehen wir Depression, Angst und Selbstvorwirfe hervorgehen. Wird aber die wichtige Lustquelle der aktiven Triebbetätigung versperrt, so ist die Hinwendung zum Masochismus die selbstverständliche Folge. Der Patient stellt sich passiv ein; er zieht Lust aus seinem Leiden, aus der beständigen Selbstbespiegelung. Im tiefsten melancholischen Elend ist so noch ein versteckter Lustgewinn enthalten.

Manche Kranke sind, bevor ein eigentlicher Depressionszustand bei ihnen einsetzt, besonders tătig im Berufsleben oder auf anderen Gebieten. Sie sublimieren - oft gewaltsam - die Libido, die sie 
ihrem eigentlichsten Zwecke nicht zuftuhren können. Sie tăuschen sich damit uber die Konflikte in ihrem Innern hinweg und wehren den depressiven Stimmungen, die in ihr BewuBtsein einbrechen wollen. Das gelingt oft recht lange Zeit hindurch, freilich nie vollkommen. Wer dauernd mit der Abwehr störender Einflüsse zu tun hat, kommt nie. zu innerer Ruhe und Sicherheit. Eine Situation, welche eine bestimmte Entscheidung in Sachen der Libido zur Notwendigkeit macht, hebt dann plötzlich das mühsam erhaltene psychische Gleichgewicht auf. Mit dem Beginn des Depressionszustandes kommen die vorherigen Interessen (d. h. Sublimierungen) des Patienten plötzlich in Wegiall; daraus resultiert die Einengung des geistigen Gesichtskreises, die bis zum sogenannten "Monideïsmus" gehen kann.

Ist die depressive Psychose manifest geworden, so tritt als Kardinalerscheinung die allgemeine psychische Hemmung hervor. Sie erschwert den Rapport zwischen dem Kranken und der AuBenwelt. Unfăhig zu einer nachhaltigen, positiven Applizierung seiner Libido, sucht der Kranke unbewußt die Abgeschlossenheit von der Welt. Dieses autoerotische Streben gibt sich in der Hemmung des Kranken kund. Nun stehen freilich in der Symptomatik der Neurosen und Psychosen auch andere Mittel zurVerfuggung, die einer autoerotischen Tendenz Ausdruck verieihen können. $\mathrm{DaB}$ gerade die Hemmung und nicht ein beliebiges anderes Ausdrucksmittel hier in die Erscheinung tritt, erklărt sich einwandfrei daraus, daB die Hemmung gleichzeitig noch anderen, unbewuBten Tendenzen zu dienen vermag. - Ich nenne hier besonders die Tendenz. der Lebensvern einung. Namentlich die hơheren Grade der Hemmung, die man als depressiven Stupor bezeichnet, stellen ein symbolisches Sterben dar. Der Kranke bleibt selbst auf Applikation starker außerer Reize reaktionslos, als gehörte er nicht mehr zur lebenden Welt. Ausdrlicklich sei bemerkt, daß im vorstehenden nur zwei durchgängige Ursachen der Hemmung behandelt worden sind. Die Analyse ergibt in jedem Falle noch weitere, mit den individuellen Verhăltnissen zusammenhängende Determinationen.

Gewisse Einzelerscheinungen des Depressionszustandes werden uns verständlich, wenn wir auf gut gegrandete psychoanalytische Erfahrungen zurúckgreifen. Genannt sei hier die so hăufige Idee der Verarmung. Der Patient klagt etwa, er und seine Familie seien dem Verhungern preisgegeben. Ist dem Ausbruch der Krankheit tatsăchlich ein pekuniärerVerlust vorausgegangen, so behauptet der Patient, diesen Schlag unmöglich überstehen zu können; er sei vollkommen ruiniert. Diese eigentumlichen, den Kranken oft gänzlich beherrschenden Gedankengänge erklären sich aus einer uns gelaufigen Identifizierung 
von Libido und Geld, von sexuellem und pekuniărem "Vermögen“. Für den Kranken ist, sozusagen, die Libido aus der Welt gegangen; während andere mit ihrer Libido die Objekte der AuBenwelt besetzen können, fehlt ihm dieses Kapital. Die Idee der Verarmung entspringt aus der vercrängten Wahrnehmung der Liebesunfähigkeit.

Befurchtungen oder ausgesprochene Wahnideen mit derartigem Inhalt begegnen uns besonders häufig in den Depressionszuständen des Involutionsalters. Soweit meine noch nicht sehr umfangreichen analytischen Erfahrungen über diese Zustände einen Schluß zulassen, handelt es sich um Personen, deren Liebesleben dauernd unbefriedigend verlaufen ist. In den vorausgegangenen Jahrzehnten hatten sie diesen Tatbestand verdrängt, hatten ihre Zuflucht $\mathbf{z u}$ allerhand Kompensierungen genommen. Der klimakterischen Revolution ist die Verdrängung nicht gewachsen. Diese Menschen halten jetzt gleichsam Rückschau über ihr verlorenes Leben und empfinden gleichzeitig, daß es nun für eine Änderung zu spät ist. Gegen alle hierher gehörigen Vorstellungen străubt sich ihr Bewußtsein mit größter Heftigkeit; zu schwach, um sie völlig zu bannen, muß es ihnen den Zutritt in maskierter Form gewähren. In der Verhullung des Verarmungswahnes sind sie immer noch peinvoll, aber nicht mehr unerträglich in dem vorherigen Maße.

In der äußeren Erscheinung ist die $\mathrm{m}$ anische $\mathrm{Ph}$ ase der zirkulären Störungen das volle Gegenteil der depressiven. Far die oberflăchliche Betrachtung sieht eine manische Psychose sehr lustig aus; verzichtet man auf ein tieferes Eindringen mit Hilfe der Psychoanalyse, so kann man zu dem Schluß gelangen, die beiden Phasen ständen auch inbaltlich im Gegensatz zueinander. Die Psychoanalyse aber läbt mit Sicherheit erkennen, daß beide Phasen unter der Herrschaft der gleichen nicht etwa entgegengesetzter - Komplexe stehen. Verschieden ist nur die Einstellung des Kranken auf die sich gleichbleibenden Komplexe. Im depressiven Zustand läßt er sich vom Komplex niederdracken und sieht keinen anderen Ausweg aus seinem Elend als den Tod ${ }^{1}$; im manischen Zustand setzt er sich über den Komplex hinweg.

Zum Ausbruch der Manie kommt es dann, wenn die Verdrängung dem Ansturm der verdrängten Triebe nicht mehr standzuhalten vermag. Der Kranke wird, besonders in den Fallen schwererer manischer Erregung, von seinen Trieben wie im Taumel mitgerissen. Hier sei ganz besonders betont, daß positive und negative Libido (Liebe und $\mathrm{HaB}$, erotisches Verlangen und aggressive Feindseligkeit) sich gleichermaßen ins Bewußtsein drăngen.

1 Manche Kranke verfechten auch die Meinung, geheilt werden zu können durch die Erfülung einer auBeren Bedingung, die allerdings unerfullbar zu sein pflegt. 
Gerade dadurch, daß libidinöse Regungen von beiderlei Art wieder Zutritt zum BewuBtsein erhalten, wird ein Zustand geschaffen, wie der Patient ihn schon einmal durchlebt hat: in seiner frühen Kindheit. Während in der depressiven Phase alles zur Lebensverneinung, zum Tode drängt, făngt der Manische das Leben von Neuem an. Er kehrt in ein Stadium zurück, in dem die Triebe der Verdrängung noch nicht anheimgefallen waren, in dem er von dem heraufziehenden Konflikt noch nichts ahnte. Charakteristischerweise äußern die Patienten öfter, - so auch in dem oben beschriebenen Fall - sie fühlten sich "wie neugeboren". Die Manie birgt in sich die Erfüllung des Wunsches:

"Gib ungebändigt jene Triebe,

Das tiefe schmerzenvolle Glück,

Des Hasses Kraft, die Macht der Liebe,

Gib meine Jugend mir zurück."

Die Stimmung des Maniacus ist, gegenüber dem normalen oder dem depressiven Zustand verăndert, teils im Sinne einer sorglosen oder ausgelassenen Heiterkeit, teils im Sinne erhöhter Reizbarkeit und gesteigerten SelbstbewuBtseins. Je nach der Individualităt herrscht diese oder jene Veränderung vor; auch in verschiedenen Krankheitsstadien kann diese oder jene Stimmungslage vorherrschen.

Der Lustaffekt der Manie läbt sich aus denselben Quellen ableiten wie die Witzeslust. Die folgenden Ausführungen können sich daher aufs engste an die von Freud gegebene Theorie des Witzes ${ }^{1}$ anschließen.

Während der Melancholische sich im Zustand allgemeiner Hemmung befindet, kommen mit dem Ausbruch der Manie auch die beim Normalen vorhandenen Hemmungen der Triebe teilweise oder ganz in Wegfall. Die hierdurch bedingte Hemmungsersparnis wird zur Lustquelle, und zwar zu einer dauernd flieBenden, wahrend der Witz nur eine vorübergehende Aufhebung von Hemmungen mit sich bringt. Die Ersparnis an Hemmungsaufwand ist jedoch keineswegs die alleinige Quelle der manischen Lust. Durch Wegfall von Hemmungen werden alte Lustquellen wieder zugänglich, auf denen die Unterdrückung lag; gerade hierin zeigt es sich, wie sehr die Manie im Infantilen wurzelt. Als dritte Lustquelle ist die Technik der manischen Gedankenproduktion zu nennen. Die Aufhebung des logischen $Z$ wanges und das Spielen mit Worten - zwei wesentliche Züge des manischen Vorstellungsablaufs bedeuten eine weitgehende; Wiederherstellung infantiler Freiheiten". 
Der melancholischen Hemmung des Gedankenablaufs entspricht als gegensätzliches Symptom in der manischen Phase die Ideenflucht. Dort Einengung des Ideenkreises, hier schnelles Wechseln des BewuBtseinsinhaltes. Der haupsächlichste Unterschied zwischen Ideenflucht und normalem Denken liegt darin, daB der Gesunde, während er denkt oder spricht, dem Ziel der Denkoperation konsequent zustrebt, der Manische dagegen die Zielvorstellung sehr leicht verliert ${ }^{1}$. Damit ist das Formale der Ideenflucht gekennzeichnet, nicht aber ihre Bedeutung für den Manischen. Es muB betont werden, daß die Ideenflucht dem Kranken bedeutende Möglichkeiten der Lustgewinnung bietet. Daß durch den Wegfall des logischen Zwanges, durch die Einstellung auf den Wortklang statt auf den Wortsinn psychische Arbeit erspart wird, wurde bereits erwähnt. Darüber hinaus hat aber die Ideenflucht noch eine zweifache Funktion. Sie ermöglicht das spielende Hinweggehen über solche Vorstellungen, welche dem BewuBtsein peinlich sind, so z. B. über die Vorstellungen der Insuffizienz. Sie beglinstigt also ähnlich wie der Witz - das Hineingelangen in einen anderen Vorstellungskreis. Und ferner erlaubt die Ideenflucht, das sonst unterdrückte Lustvolle scherzend zu streifen.

In einer Anzahl von Zügen prägt sich die Ähnlichkeit der manischen und der kindlichen Psyche aus. Hier sei nur noch ein einzelner Hinweis nach" dieser Richtung gegeben. In den Zuständen leicht manischer Exaltation findet man eine Art der sorglosen Heiterkeit, die einen offensichtlich kindlichen Charakter trägt. Der Psychiater, der viel mit solchen Kranken zu verkehren hat, bemerkt deutlich, daB sein gemullicher Rapport mit ihnen ein ganz gleichartiger ist wie der mit einem etwa fünjährigen Kinde.

Die höheren Grade der Manie gleichen einem Freiheitsrausch. Die sadistische Triebkomponente ist ihrer Fesseln entledigt. Alle Zurückhaltung schwindet; statt dessen zeigt sich die Neigung zu rücksichtslosem, aggressiven Verhalten. Auf einen geringen AnlaB hin reagiert der Manische in diesem Stadium mit heftigen Wutausbrüchen, mit ubertriebener Rache. Der zyklothyme Patient, von dem oben die Rede war, spärte, wenn die Exaltation eine gewisse Höhe erreicht hatte, den Impuls, jemanden niederzuschlagen, der ibm auf der Straße nicht sogleich Platz machte. Die Kranken pflegen gleichzeitig ein übertriebenes Kraftgefühl zu äußern; sie messen ihre Kraft nicht an den wirklichen Leistungen, sondern an der Heftigkeit der Triebe, die ihnen jetzt in ungewohnter Weise fühlbar wird. Nicht selten finden 
sich Größenideen, die dem Renommieren eines Kindes mit seiner Kraft oder seinem Können äußerst ähnlich sehen.

Eine sehr wichtige Frage, die sich aus dem ausführlicher beschriebenen Fall von Zyklothymie ergibt, wage ich nicht bestimmt $z \mathfrak{u}$ beantworten. Es bleibt $z \mathfrak{u}$ erklären, warum $z u$ den schon lange vorher aufgetretenen depressiven Zuständen ungefähr im 28. Lebensjahre des Patienten manische Exaltationen hinzutraten. Ich vermute, es handle sich hier um eine der körperlichen Reifung verspätet nachfolgende psychosexuelle Pubertät. Wir sehen bei Neurotikern die Entwickelung des Trieblebens oft in so verspäteter Weise erfolgen. Der Patient hätte also in der Pubertát nicht eine Verstärkung seines Trieblebens erfahren, sondern einen weiblichen Verdrängungsschub durchgemacht, während erst gegen Ende des dritten Dezenniums ein gewisses Erwachen der Triebe in Gestalt des ersten manischen Zustandes erfolgte. Tatsăchlich hat in dem bezeichneten Alter sein Sexualinteresse sich mehr als früher dem weiblichen Geschlecht zugekehrt und vom Autoerotismus mehr abgewandt.

Ich habe nunmehr noch tiber die therapeutische Wirkung der Psychoanalyse $z u$ berichten.

Der Krankheitsfall, über den ich am ausführlichsten berichtet habe, war zur Zeit meines Referates in Weimar soweit analysiert, daB seine Struktur im ganzen durchsichtig wurde. Im einzelnen blieb dagegen noch manches zu tun. Ein therapeutischer Erfolg war erst in den Anfängen erkennbar; er ist in den seither verflossenen $21 / 2$ Monaten deutlich geworden. Ein abschließendes Urteil kann in dieser Hinsicht naturlich noch nicht gefällt werden; denn nach zwanzigjährigem Kranksein, das überdies gelegentlich durch freie Intervalle von verschiedener Dauer unterbrochen war, bedeuten zwei Monate der Besserung noch sehr wenig. Immerhin sei das bisherige Ergebnis mitgeteilt. In der genannten Zeit ist kein Depressionszustand mehr eingetreten, nachdem schon der letztvorausgegangene auffallend leicht verlaufen war. Infolgedessen war Patient wăhrend dieser Zeit dauernd arbeitsfähig. Nach der manischen Seite hat in gleichem Zeitraum zweimal eine Stimmungsschwankung stattgefunden, die der sorgfältigen Beobachtung zwar nicht entgehen konnte, aber dem Grade nach hinter früheren Exaltationen ganz erheblich zurackblieb und gewisser sonst regelmäBig beobachteter Erscheinungen uberhaupt entbehrte. Zwischen diesen beiden manischen Phasen lag nicht wie sonst - eine depressive, sondern ein Zustand, den man mangels aller zyklothymen Erscheinungen als normal bezeichnen durfte.- Hier muB uns der fernere Verlauf belehren. Nur eine Bemerkung sei 
hinzugefügt. Wenn es in diesem Falle lediglich gelănge, einen Zustand wie den der letzten zwei Monate dauernd aufrecht $\mathrm{zu}$ erhalten, so wäre für den Patienten auch ein partieller Erfolg dieser Art von Wert. - In dem andern, eingangs erwähnten Fall von Zyklothymie wàr die Beobachtungszeit zu kurz, um über die therapeutische Einwirkung ein Urteil zu gestatten, während sich bezüglich der Struktur der Krankheit von Anfang an überraschende Analogien mit dem ersten Fall herausstellten.

Der eingangs angeführte dritte Fall erwies die Wirksamkeit der Analyse in schlagendster Weise, trotzdem äußere Verhältnisse den Abbruch der Behandlung nach etwa 40 Sitzungen erzwangen. Schon in der ersten Zeit der Behandlung gelang es einmal, eine frisch entstandene melancholische Depression zu kupieren, was früher auf keine Art zu erzielen gewesen war. Die Einwirkung wurde im Laufe der Zeit nachhaltiger; sie äußerte sich in einer deutlichen Hebung der Stimmungslage und in einer bedeutenden Zunahme der Arbeitsfähigkeit. Nach Unterbrechung der Behandlung ist in den folgenden Monaten die Stimmung nicht wieder auf das frühere Niveau herabgesunken. An dieser Stelle sei bemerkt, daB der Fall mit besonderer Deutlichkeit das Uberwiegen der Haßeinstellung, das Gefühl der Liebesunfahigkeit, die Verknupfung der Depression mit dem Insuffizienzgefïhl erkennen lieB.

Die oben erwähnten zwei Fälle von erstmaliger melancholischer Depression gestatteten eine konsequente Durchfuhrung der Analyse nicht, weil ihr von auBen her Schwierigkeiten in den Weg gelegt wurden. Die Einwirkung war dennoch unverkennbar. Vor allem gelang es durch die psychoanalytische Klarstellung gewisser Tatsachen und Zusammenhänge, einen psychischen Rapport mit den Patienten -zu gewinnen, wie ich ihn friher niemals zu erlangen vermocht hatte. Die Herstellung der Obertragung ist bei diesen Kranken, die sich in ihrer Depression von aller Welt abkehren, außerordentlich erschwert; die Psychoanalyse, die mir bisher allein ermöglicht hat, das Hindernis zu überwinden, erscheint mir deshalb als einzige rationelle Therapie der manisch-depressiven Psychosen.

Der sechste oben angeführte Fall gibt zu dieser Auffassung eine noch gröBere Berechtigung, besonders deswegen, weil die Behandlung bis zum SchluB durchgeführt werden konnte. Sie endete mit einem außerordentlich schönen Erfolg. Der Kranke kam nach $11 / 4$ jähriger Dauer seines Leidens in meine Behandlung; vorher hatte der Aufenthalt in verschiedenen Sanatorien nur palliativ gewirkt, resp. einzelne Krankheitserscheinungen günstig beeinflußt. 
Einige Wochen nach Beginn der Psychoanalyse fühlte der Kranke sich zeitweise erleichtert. Nach vier Wochen. begann die schwere Depression zu weichen. Patient äußerte, es komme ihm zuweilen ein Hoffnungsgefühl, als werde er doch noch wieder arbeitsfähig werden. Er gelangte $z \mathfrak{u}$ einem gewissen Grad von Einsicht: "Ich bin ja jetzt so egoistisch, daB ich mein Geschick für das tragischeste halte. " Im dritten Monat der Behandiung war die Stimmung im ganzen freier; alle psychischen Äußerungen trugen nicht mehr im früheren Grade den Charakter der Hemmung. Es kamen bereits halbe oder ganze Tage vor, an denen Patient sich gut befand und sich mit Zukunftsplänen befaßte. Er sagte in dieser Zeit einmal in bezug auf seine Stimmung: "Wenn sie gut ist, so bin ich so sorglos und zufrieden wie nie zuvor." Im vierten Monat erklärte er, von der eigentlichen Depression sei keine LRede mehr. Während des fünften Monats, in welchem die psychoanalytischen Sitzungen nicht mehr täglich stattfanden, waren noch deutlich Schwankungen des Befindens bemerkbar, die Tendenz zur Besserung aber ließ sich nicht verkennen. Im sechsten Monat konnte Patient die Behandlung verlassen; die Veränderung seines Wesens im günstigen Sinne fiel auch seinen Bekannten auf. Seither ist ein halbes Jahr verflossen, ohne daß ein Rückfall eingetreten wäre.

Diagnostisch liegt der Fall insofern durchaus. klar, als es sich mit Sicherheit um eine depressive Psychose und nicht etwa um eine Neurose des klimakterischen Alters handelte. Ich bin leider nicht in der Lage, die Einzelheiten des Falles zu veröffentlichen; sie sind so eigenartig, daß das Inkognito des Patienten sich nicht genügend wahren ließe. Auch andere Rücksichten liegen vor, die zu ganz besonderer Diskretion nötigen, wie sie mir im Interesse der Wissenschaft durchaus nicht erwunscht sind. Nur einem Einwand in therapeutischer Hinsicht habe ich zu begegnen. Es könnte der Eindruck entstehen, als hätte ich einen Fall von Melancholie, - der auch ohne mein Zutun geheilt wäre - gerade in dem Stadium erwischt, als er sich zur Rekonvaleszenz wandte. Daraus ergäbe sich der Einwand, der Psychoanalyse komme der Heilwert, den ich ihr beilegen wolle, nicht $z \mathbf{u}$.

Demgegentiber betone ich, daB ich von Anfang an darauf bedacht war, mich vor derartigen Selbsttäuschungen zu schützen. Als ich die Behandlung übernahm, hatte ich einen dem Anschein nach ganz unbeeinflußbaren Kranken vor mir, der unter seiner Krankheit zusammengebrochen war. Ich stand dem Erfolg der Behandlung sehr skeptisch gegenüber. Um so erstaunter war ich, als ich nach Oberwindung betrăchtlicher Widerstände zur Aufklärung gewisser, den Patienten völlig beherrschender Ideen gelangte und đie Wirkung dieser Aufklärungs- 
arbeit beobachtete. Unmittelbar an die Auflösung ganz bestimmter Verdrängungsprodukte schloß sich sowohl diese erste als auch jede fernere Besserung an. Während des gesamten Verlaufs der Analyse ließ sich mit aller Deutlichkeit beobachten, daB sich die Fortschritte der Besserung an die Fortschritte der Analyse anschlossen. -

Indem ich die wissenschaftlichen und praktischen Ergebnisse meiner bisherigen Psychoanalysen bei exaltativen und depressiven Psychosen mitteile, bin ich mir der Unvollständigkeit des Gebotenen durchaus bewußt. Ich hebe diese Mängel meiner Arbeit selbst hervor. Ich war nicht in der Lage, meine Anschauungen in dem MaBe, wie ich es gewünscht hätte, durch ausführliche Wiedergabe der analysierten Fälle zu belegen. In bezug auf einen unter ihnen wurden die Gründe bereits erwähnt. In drei weiteren, sehr instruktiven Fällen, bin ich ebenfalls durch besondere Pflichten der Diskretion an der Mitteilung irgendwelcher Einzelheiten verhindert. Eine einsichtsvolle Kritik wird mir nach dieser Richtung hin keinen Vorwurf machen. Diejenigen, welche an der Psychoanalyse ein ernstes Interesse nehmen, werden den Mangel meiner Publikation durch Untersuchungen an eigenem Material ersetzen.

Das weitere Untersuchungen efforderlich sind, soll ebenfalls ausdrücklich betont werden. Gewisse Fragen sind im obigen überhaupt nicht berührt oder nur gestreift worden. Erinnert sei besonders daran, $\mathrm{daB}$ wir $\mathrm{zwar} z \mathrm{u}$ erkennen vermochten, bis $\mathrm{zu}$ welchem Punkt ihrer Psychogenese $Z$ wangsneurose und zirkuläre Psychose miteinander lubereinstimmen; daß wir aber nichts über die Ursachen ermittelt haben, warum von diesem Punkt an die eine Gruppe von Individuen diesen, die andere jenen Weg beschreitet.

In therapeutischer Beziehung sei noch ein Wink gegeben. Es dürfte sehr vorteilhaft sein, bei solchen Kranken, welche zwischen ihren einzelnen manischen oder depressiven Attacken längere, freie $Z$ wischenzeiten haben, die Psychoanalyse während dieser letzteren Zeiten vorzunehmen. Der Vorteil liegt auf der Hand. An schweŕ gehemfinten melancholischen und unaufmerksamen manischen Kranken wird man sie nicht durchführen können.

Mögen unsere Resultate gegenwärtig unvollkommen und lückenhaft sein - die Psychoanalyse allein ist es dennoch, die uns die bisher verborgene Struktur einer groBen Gruppe von psychischen Erkrankungen enthüllt. Oberdies berechtigen uns die ersten therapeutischen Ergebnisse auf diesem Gebiet zu der Erwartung, der Psychoanalyse werde es vorbehalten sein, die Psychiatrie von dem Alp des therapeutischen Nihilismus zu befreien. 


\section{Über die determinierende Kraft des Namens ${ }^{1}$.}

In seinem Aufsatz "Die Verpflichtung des Namens"2 hat $S$ tekel auf verborgene Beziehungen zwischen Namen und Beruf, sowie zwischen Namen und Neurose hingewiesen. Wie der Autor durch eine Fulle von Beispielen beweist, wirkt der Name auf seinen Trăger in vielen Fällen verpflichtend, oder er ruft gewisse psychische Reaktionen (Trotz, Stolz, Scham) hervor. Die von Stekel angeschnittene Frage verdient sicherlich Beachtung; ich möchte im nachstehenden zu ihrer Klärung einen Beitrag liefern.

Aus Erfahrungen bei meinen neurotischen Patienten kann ich Stekels Beobachtungen bestatigen. Ich erwähne beispielsweise, daB ich bei $z$ wei $Z$ wangsneurotikern eine Ubereinstimmung zwischen der Bedeutung ihres Namens und dem Inhalt ihrer $Z$ wangsideen gefunden habe, und daB ich einen Homosexuellen behandelte, dessen Name vollkommen seinem femininen Wesen entsprach. Ich füge hinzu, daB in einzelnen Familien sich ein bestimmter, im Namen ausgedrückter Charakterzug forterbt; so kenne ich eine durch besonderen Stolz ausgezeichnete Familie, deren Name ihrem Wesen vollkommen angepaBt ist. In derartigen Fällen hat wohl ein Vorfahre den Namen wegen einer solch auffalligen Eigenschaft erhalten oder angenommen. Der Charakterzug würde sich auch ohne Mitwirkung des Namens vererben; der letztere wirkt jedoch insofern verpflichtend, als er den Nachkommen den AnlaB gibt, ihre Eigentümlichkeit besonders zur Schau zu tragen.

Ein klassisches Beispiel für die bestimmte Wirkung des Namens findet sich in Goethes "Wahlverwandtschaften " (1. Teil, 2. Kapitel): Mittler erzăhlte von seinen heutigen Taten und Vorhaben. Dieser seltsame Mann war früherhin Geistlicher gewesen und hatte sich bei einer rastlosen Tătigkeit in seinem Amte dadurch ausgezeichnet, daß er alle Streitigkeiten, sowohl die häuslichen, als die nachbarlichen, erst der einzelnen Bewohner, sodann ganzer Gemeinden und mehrerer

1 Zentralbl. f. Psa. Bd. II, 1912, S. 133.

2 Zeitschr. f. Psychotherap. u. med. Psychol. Bd. III, 1911, H. 2. 
Gutsbesitzer zu stillen und zu schlichten wuBte. Solange er im Dienste war, hatte sich kein Ehepaar scheiden lassen, und die Landeskollegien wurden mit keinen Händeln und Prozessen von dorther behelligt. Wie nötig ihm die Rechtskunde sei, ward er zeitig gewahr. Er warf sein ganzes Studium darauf und fühlte sich bald den geschicktesten Advokaten gewachsen. Sein Wirkungskreis dehnte sich wunderbar aus, und man war im Begriff, ihn nach der Residenz zu ziehen, um das von oben herein $\mathrm{zu}$ vollenden, was er von unten herauf begonnen hatte, als er einen ansehnlichen Lotteriegewinst tat, sich ein mäBiges Gut kaufte, es verpachtete und zum Mittelpunkt seiner Wirksamkeit machte, mit dem festen Vorsatz, oder vielmehr nach alter Gewohnheit und Neigung, in keinem Hause zu verweilen, wo nichts $z \mathfrak{u}$ schlichten und nichts zu helfen wäre. Diejenigen, die auf Namensbedeutungen abergläubisch sind, behaupten, der Name Mittler habe ihn genötigt, diese seltsamste aller Bestimmungen $z u$ ergreifen."

Eine sicherlich häufige Erscheinung ist es, daß ein Knabe, der den gleichen Vornamen trägt wie ein berühmter Mann, diesem nacheifert oder ihm sonstwie ein besonderes Interesse entgegenbringt. Der Vorname Alexander wird beispielsweise seinem Träger AnlaB bieten, sich speziell far Alexander den Großen zu interessieren, respektive sich in seiner Phantasie mit diesem zu identifizieren. Bemerkenswert ist das Beispiel des Historikers Ottokar Lorenz, der eine Geschichte des Königs Ottokar von Böhmen verfaßte.

Auch darin kann ich Stekel beipflichten, daB sich in der Liebeswahl oft ein determinierender EinfluB des Namens kundgibt; doch muB ich es mir versagen, die mir bekannten Beispiele hier mitzuteilen.

Von Interesse ist auch der Hinweis auf die Gewohnheit mancher Menschen, ihren Namen in spielerischer Weise umzugestalten. Stekel erwăhnt hier $\mathrm{St}$ e $\mathrm{nd}$ h a l. Die deutsche Literatur weist einen besonders merkwtirdigen Fall dieser Art auf: Johann Fis ch a rt, der mit seinem Namen die seltsamsten Verwandlungen vornahm und ihn zur Herstellung wunderlicher assoziativer Vorstellungen benutzte.

Einen Einwand hatte ich nur gegen den von Stekel gewählten Terminus zu erheben; die Bezeichnung "Verpflichtung des Namens" erscheint mir nicht gentigend klar und auch formell nicht einwandirei. Ich möchte diejenige empfehlen, welche ich in der Oberschrift dieser Mitteilung gebraucht habe. 


\section{Über ein kompliziertes Zeremoniell neurotischer Frauen ${ }^{1}$.}

Vor mehreren Jahren hat $\mathrm{Fr}$ e ud in einem kleinen Aufsat ${ }^{2}$ die Beziehungen zwischen $Z$ wangsneurose und Religions übung behandelt. Die tägliche Beobachtung lehrt uns, daß sebr viele Neurotiker - und nicht nur $Z$ wangsneurotiker - privatim einen Kultus betreiben, dessen Formen durchaus an die religiösen Riten und Zeremonien erinnern. Ein Teil dieser Gepflogenheiten wiederholt sich im Leben des Neurotikers täglich mit der gleichen Regelmäßigkeit, mit welcher sich etwa die Gebetsübungen einer Religionsgemeinschaft an jedem Morgen und Abend unter Einhaltung bestimmter Formen abspielen.

Obgleich der Spielraum für eine individuelle Gestaltung derartiger privater Kulte sehr weit ist, so treffen wir bei Personen, die aus gänzlich verschiedenen Kreisen stammen und in ihren Lebensverhältnissen, ihren Schicksalen, ihren geistigen Anlagen, ihren Anschauungen bedeutend differieren, dennoch oft übereinstimmende oder doch sehr ähnliche neurotische Zeremonien. Das gilt insbesondere für die einfachsten Formen. So ist z. B. der Zwang, beim Gehen auf der Straße die Trottoirplatten in einer bestimmten Weise zu betreten, ubberaus verbreitet; ich gehe auf die Bedeutung dieses $Z$ wanges nicht ein, weil von anderer Seite eine Untersuchung darüber geplant ist. Ähnlich häufig ist der Zwang, beim Gehen oder beim Treppensteigen die Schritte zu zählen und das Ziel mit einer Schrittzahl zu erreichen, die durch zwei teilbar sein muB. Hier handelt es sich um eine MaBregel der ausgleichènden Gerechtigkeit, um die Uberkompensierung gewisser unerlaubter Triebregungen, auf die hier jedoch ebenfalls nur hingedeutet werden soll.

Weit auffälliger ist es, wenn wir bei einer neurotischen Frau ein recht kompliziertes Zeremoniell antreffen, und bald danach fast das nämliche bei einer zweiten, anders gearteten und sicherlich mit der ersten nicht bekannten Patientin wiederfinden. Ober ein derartiges, bisher nicht beschriebenes Zeremoniell will ich hier berichten, indem

1 Aus dem ,Zentralblatt für Psychoanalyse`. Zweiter Jahrgang, Heft 8, 1912.

\&gl. "Kleine Schiiften zur Neurosenlehre*. Bd. II. 
ich aus der Psychoanalyse des ersten Falles das zum Verständnis Erforderliche mitteile; des zweiten werde ich nur insoweit Erwähnung tun, als charakteristische Abweichungen vom ersten in Betracht kommen.

Aus einem bestimmten, später $z \mathfrak{u}$ erwähnenden Anlaß im Verlauf der Psychoanalyse machte mir die Patientin, welche wir Frau Z. nennen wollen, spontan folgende Mitteilung: Wenn sie abends schlafen gehe, so mache sie sich peinlich ordentlich und in einer genau geregeiten Weise zurecht. Besonders sorge sie für die Korrektheit ihrer Frisur. In das gelöste Haar binde sie eine weiBe Schleife. Dieser ersten, unvollständigen Schilderung ihres Zeremoniells fügte sie als Begründung hinzu: Es könne doch sein, daß sie in der Nacht plötzlich stürbe; man solle sie dann nicht in einem unordentlichen oder unästhetischen Zustande auffinden.

In der folgenden Sitzung ergänzte sie die Schilderung wie folgt: Die Frisur, welche sie sich abends mache, sei die, welche sie als ganz junges Mädchen getragen habe. Nach Überwindung deutlicher Widerstände fuhr sie fort: Wenn sie sich niederlege, sorge sie dafür, daB ihr Bett in möglichster Ordnung bleibe. In der Nacht wache sie oftmals auf; sie ziehe dann ihr Hemd und die Bettwäsche, die etwa in Unordnung geraten seien, zurecht. Sie könne dann wieder einschlafen, erwache aber immer nach einiger Zeit von neuem, um die nämliche Korrektur vorzunehmen. Irgend einen Teil dieser Ubung zu unterlassen, sei ihr bisher nicht möglich gewesen.

Die Motive dieses sonderbaren Verhaltens liegen zum größten Teil im UnbewuBten und lassen sich daher nicht ohne weiteres erraten. Zunăchst vermögen wir nur einiges aus der symbolischen Ausdrucksweise in unsere Sprache zu übersetzen: Frau Z. erwartet in jeder Nacht den Tod. Sie versetzt sich dabei in ein sehr jugendliches Alter zurlick. Sie schmückt ihr Haar mit einer Schleife, deren weiße Farbe zugleich auf die bräutliche Unschuld und auf den Tod anspielt. Sie trägt Sorge, daß, wenn sie gestorben, an ihr und ihrem Lager kein Zeichen der Unordnung gefunden werde, an ihrer bräutlichen Unberührtheit also kein Zweifel entstehen könne.

Weitere Aufklärung über den Sinn des Zeremoniells empfangen wir aus dem $\mathrm{Z}$ u samme $\mathrm{nh}$ a $\mathrm{ng}$, in welchem die Patientin zum ersten Male die geschilderte Gepflogenheit erwähnte. Nachdem sie schon fruher aber eine sehr ausgesprochene Schlangen-Phobie berichtet hatte, teilte sie eines Tages einen Traum mit, in welchem sie ein kleines Madchen mit einer Schlange hatte spielen sehen. Aus bestimmten Eigentumlichkeiten des Mädchens schloß sie nach dem Erwachen, daß síe selbst das Mädchen sei, das mit der Schlange spiele. Bald darauf 
folgte die Angabe, sie sei in letzter Zeit fast allnächtlich aus dem Schlaf aufgeschreckt und habe dann schreckliche Angst gehabt, daB in ihrem Bett eine dicke Schlange sei. Während der anschliebenden Analyse dieser Angst sprach sie immer von der "großen Schlange“.

Die zu dem obigen Traum produzierten Einfälle führten zunächst auf den verstorbenen alteren Bruder der Patientin, den sie auBerordentlich geliebt hatte. Sie berichtete, wie sie als Kinder - und zwar nicht nur in den fruhen Kindheitsjahren - einander täglich nackt gesehen hătten, so beim Aus- und Ankleiden und beim Baden; wie sie im gleichen Zimmer schliefen und einander oft im Bett besuchten. Weitere Assoziationen führten auf den späteren Ekel der Patientin vor dem männlichen Körper.

Sie erzählte weiter vom Bruder, wie er phantastisch gewesen sei und ganz in seinen Indianergeschichten lebte, wie er sich abends beim Schlafengehen auf seinen von ihm selbst verfertigten Schild legte, wie er sich den Namen eines bestimmten jungen Indianers beilegte. Hier trat eine Sperrung ein: der Name des "letzten Mohikaners" ("Unkas") wollte ihr nicht einfallen. Diese Erinnerungsstörung konnte nur die Funktion haben, ein weiteres Vordringen auf dem eingeschlagenen Wege zu verhindern. Es war aber in diesem Falle nicht schwer, den assoziativen Zusammenhang herzustellen, gegen dessen Herstellung der Widerstand gerichtet war. In Co opers Indianergeschichte trägt Unkas' Vater den Namen "Chin-gach-gook", zu deutsch: „die grobe Schlange".

Der Traum, in welchem die Patientin als kleines Mädchen mit einer Schlange spielt, setzt der Deutung nun keine Schwierigkeiten mehr entgegen. Sie spielt mit dem Genitale des Bruders, das noch klein, infantil ist. Eine Frage, welche Knaben und Mädchen in gleicher Weise $z u$ interessieren pflegt, ist diejenige, ob wohl beim erwachsenen Manne (gemeint ist zunächst der Vater!) der Penis sehr viel größer als beim Kinde sei. Es besteht die Neigung, sich von seinen Dimensionen eine tubertriebene Vorstellung $z \mathfrak{u}$ machen. Auf diese Tenden $z$ hat fraher schon Stekel in seiner Monographie tuber die nervösen Angstzustände hingewiesen. In Fre uds "Analyse der Phobie eines fünfjăhrigen Knaben“ spielt die Vorstellung des Kindes von der riesigen Größe des Penis beim Manne eine bedeutende Rolle.

Die "große" oder "dicke" Schlange wird nun - im Gegensatz zu dem noch infantilen Penis des Bruders - als Penis des erwachsenen Mannes verständlich. Hat die Patientin Angst, es sei ,die große Schlange" in ihrem Bett, so erblicken wir darin zunächst die typische Angst neurotischer Frauen vor dem mannlichien Genitale. Die als 
ständiger Terminus wiederkehrende Bezeichnung "die große Schlange" aber weist uns mit Bestimmtheit auf die Person des Vaters.

Nach dieser Richtung hatte die Analyse schon vorher genug Material ergeben, das nunmehr noch ergänzt wurde. Die Patientin war seit fruher Kindheit, besonders aber seit dem zeitigen Tode der Mutter, an den Vater innig fixiert. Ihre verdrängten Sexualphantasien hatten ihn zum hauptsächlichsten Objekt. In ihren Augen war der Vater der einzige wirkliche Mann. Ein anderer, davon war sie überzeugt, könne ihr niemals genügen. Sie hatte sein Verhalten zu anderen Menschen mit großer Eifersucht beobachtet. Lebhafte Affekte traten auf, als sie berichtete, wie sie nach dem Tode der Mutter kurze Zeit neben dem Vater geschlafen habe, oder wie er später gelegentlich durch ihr Schlafzimmer ging. Der Vater starb, als sie im Pubertätsalter stand. Ihre Frisur aus dieser Zeit ist es, welche sie jeden $A$ bend mit so peinlicher Sorgfalt herstellt. Wir verstehen nun ihr Zeremoniell bereits zu einem großen Teil: Sie versetzt sich in eine Zeit zurück, da der Vater noch lebte. Er ist es, den sie allnăchtlich erwartet. Wenn sie aus dem Schlaf erwacht und die "große Schlange" in ihrem Bette wăhnt, so erlebt sie darin die Erfüllung ihres auf den Vater gerichteten Inzestwunsches, die freilich nur unter lebhafter Angst vor sich gehen kann. - In anderem Zusammenhang kommt übrigens der verdrängte Wunsch, vom Vater ein Kind zu haben, deutlich zutage.

Die Patientin ist tatsächlich verheiratet. Ihr UnbewuBtes lehnt jedoch die Ehe mit einem anderen Manne als dem Vater ab; alle nur erdenklichen Zeichen der Sexualablehnung lassen dies deutlich erkennen. Ihre Phantasie entfuhrt sie so weit aus der Wirklichkeit, daß sie sich allabendlich als junges Mädchen und als Braut zu schmlicken vermag. Dem toten Vater, den sie erwartet, liefert sie damit den Beweis ihrer Treue; in ihrem Unbewußten hängt sie ihm allein an.

B e w u Bt freilich erwartet sie nicht den Vater, sondern den Tod. Die Analyse ergibt aber, daB beide Vorstellungen identisch sind. Im Phantasieleben, besonders in den Träumen der Patientin, spielen Oberfalle und Gewalttaten eine große Rolle. Sie stellt sich in diesen Phantasien masochistisch ein; sie erwartet vom sexuellen Angriff des Mannes - des Vaters! - den Tod. Sie erlebt in der Phantasie das Schicksal der Asra, "welche sterben, wenn sie lieben“. So werden Brauthemd und Totenhemd, Brautbett und Totenbett für die Patientin $\mathrm{zu}$ identischen Vorstellungen, die in den Gebilden ihrer unbewuBten Phantasie einander vertreten können.

$\mathrm{Zu}$ bemerken ist, $\mathrm{daB}$ an der Bildung des uns beschäftigenden Zeremoniells neben den verdrängten Inzestwünschen auch die 
verdrängende Instanz beteiligt ist. Während die Patientin unbewußt beständig den sexuellen Angriff erwartet, muB sie immer wieder Bett und Nachtgewand in Ordnung bringen, damit deutlich zu erkennen sei, daB ihrem Tode keine Sexualhandlung voraufgegangen sei.

Das Symbol der Schlange, das zwar nicht im Zeremoniell selbst, wohl aber in dem zugehörigen Vorstellungsmaterial einen so wichtigen Platz einnimmt, ist vielfach determiniert. Es ist nicht lediglich symbolischer Ersatz des männlichen Genitale. Die Schlange vermag durch ihren giftigen $\mathrm{BiB}$ zu töten. Das Symbol kann daher gleichzeitig einer Koitusphantasie und einer Todesphantasie Ausdruck verleihen. $\mathrm{Zu}$ beachten ist in dieser Beziehung auch, daß die Schlange ihr Opfer umschlingt und erdrückt; der Tod durch die Schlange ist ein Tod in der Umschlingung! In der unbewußten Phantasie liegen ferner die Vorstellungen "Schlange" und "Wurm " nahe beieinander. Der Wurm erscheint ebenfalls als männliches Sexualsymbol ${ }^{1}$ und als Todessymbol. In unserem Falle spielt eine Kindheitserinnerung in diese Angst hinein. Die Patientin hatte als neunjähriges Mädchen einmal gemeinsam mit einem Knaben einen Stein auf dem Kirchhof zu bewegen versucht und hatte sich aufs heftigste entsetzt, als sie unter dem Stein eine Menge von Würmern erblickte. Der Gedanke an diese Szene erregt ihr noch jetzt die höchste Angt.

Die Angst vor der Schlange hat jedoch noch einen besonders wichtigen Grund. Die Schlange ist für sie das den verstorbenen Vater vertretende Totemtier. Die kindliche Angst vordem Vater ist auf dieses Symbol tubertragen. Dabei scheint noch eine bestimmte Kindheitserinnerung in Betracht $z u$ kommen. Mit etwa neun Jahren hatte die Patientin einmal große Angst vor den Augen ihres Vaters; aus vielen Tatsachen der Völkerpsychologie aber wissen wir, daB der Blick der Schlange besonders gefürchtet wird. Die Identifizierung von Vater und Schlange erfăhrt dadurch noch eine weitere Öberdeterminierung.

Aus den Angaben der zweiten Patientin geht hervor, daß auch sie während längerer Jahre allabendlich ein strenges Zeremoniell befolgte. Sie brachte nach dem Entkleiden ihre abgelegten Kleidungsstucke in eine penible Ordnung. Sie legte sich in Rlickenlage nieder, strich Bett- und Leibwäsche in tubertrieben sorgsamer Weise zurecht, kreuzte dann die Arme uber der Brust und zwang sich, möglichst unbeweglich $z \mathbf{u}$ liegen, damit die Ordnung ihres Lagers nicht gestört warde. Sie begrundete - ganz wie die erste Patientin - ibr Tun

1 Bei Neurotikern pflegt neben der Schlangen- auch eine Würmerphobie zu bestehen. 
damit, daß sie in der Nacht sterben könne; man solle dann nichts unordentlich oder unästhetisch bei ihr finden. Das Kreuzen der Arme habe sie vorgenommen, weil man Toten die Arme so zu legen pflege. Auch die Frisur wurde in ganz bestimmter Weise hergerichtet. Diese letztere Prozedur begründete die Patientin aber ganz bewuBt damit, daß sie sich überzeugen wollte, in welcher Haartracht sie einem Manne wohl am besten gefallen würde, wenn sie sich später verheirate. Diese Erklärung ist befriedigend, insofern als sie den erotischen Untergrund des Zeremoniells zugesteht. Sie verlegt aber die erotische Erwartung in eine unbestimmte Zukunft, während die Erwartung des Todes in die allernächsten Stunden verlegt wurde. Der Verschiebungsvorgang liegt hier ganz offen zutage. Leider war es nicht möglich, in diesem Falle eine eingehende Psychoanalyse vorzunehmen. Ober die Beziehungen des Zeremoniells zum Vaterkomplex vermag ich daher nichts Bestimmtes $z u$ sagen; doch scheinen ganz ähnliche Verhältnisse wie im ersten Falle vorzuliegen.

Vermutlich werden sich komplizierte Handlungen von ganz ahnlichem Charakter wie die hier beschriebenen bei Neurotischen offer finden, nachdem einmal die Aufmerksamkeit darauf gelenkt ist. Besonders hege ich diese Erwartung in bezug auf diejenigen Personen, welche dem Zwang unterliegen, vor dem Schlafengehen ihre Kleidungsstücke in einer ganz bestimmten Weise anzuordnen, die nicht uberschritten werden darf.

Dér oben analysierten Form des Zeremoniells möchte ich den Namen "Todesbrautzeremoniell" beilegen. 


\section{Ohrmuschel und Gehörgang als erogene Zone ${ }^{1}$.}

Auf die Bedeutung der Ohrmuschel und des äußeren Gehörganges als erogene Zone wurde ich vor mehreren Jahren durch eine Beobachtung aufmerksam, die ich hier zunächst mitteilen will.

Ein Neurotiker litt an eigentümlichen "Anfällen“, die sich täglich zehn- bis zwanzigmal und selbst öfter einstellten. Im Laufe der langdauernden psychoanalytischen Behandlung konnte ich diese Zustannde oftmals beobachten. Der Patient sprang etwa während eines Gespräches plötzlich auf, wurde bleich, griff mit beiden Händen nach seinen Ohren, lief dabei zur Tür des Zimmers, steckte dann unter Zeichen der heftigsten Erregung den Zeigefinger der rechten Hand in das recbte Ohr, um ihn nun heftig darin auf- und abzustoBen. Dabei verzog er sein Gesicht wie zur höchsten Wut, krümmte sich und stampfte mit den FüRen, bis die motorische Entladung unter keuchenden Atemzügen ihr Ende fand. Der Patient ließ sich dann erschöpft niedersinken. Nach wenigen Augenblicken war er wieder imstande, den vorherigen Gedankengang fortzusetzen; nur die unmittelbar vor dem Anfall gesprochenen Worte muBte ich ihm jeweils in die Erinnerung zurückrufen. Während des Anfalles war das Bewußtsein stets getrübt. Der Patient hatte das Gefühl, nach dem Anfall aus einem veränderten Zustand in die Wirklichkeit zurlickzukehren. Er wuBte hernach jedesmal, daß auf der Höhe der Erregung ganz bestimmte Gedanken auftauchten, doch vermochte er sich dieser niemals im einzelnen zu entsinnen. Die Analyse dieser Anfälle, die hier nicht ausführlich mitgeteilt werden soll, ergab unter anderem, daB im Beginn jedes Anfalles ein intensiv juckendes Gefühl im Gehörgang auftrat, dessen sich der Patient unter allen Anzeichen großer Erregung entledigte. Für ihn waren diese Anfalle ein Surrogat gewisser ihm versagter Arten der Sexualbetätigung. Von besonderem Interesse ist die Tatsache, daß die geschilderten Anfälle und die meisten anderen Krankheitserscheinungen einmal für Monate verschwanden. Der Patient hatte damals ein junges Mädchen kennen gelernt. Es kam nicht zum

1 Aus „Internationale Zeitschrift für ärztliche Psychoanalyse“, 1. Jahrgang, 1913. 
Sexualverkehr zwischen beiden. Sie fanden vielmehr ihre Lust daran, einander unter großer Erregung und bis zur Erschlaffung zu kit z el $\mathbf{n}$.

Offensichtlich lag in diesem Falle eine ungewöhnlich starke Erogeneităt der Haut im allgemeinen vor. Der Ohrmuschel und dem Gehörgang kam diese Eigenschaft aber in einem ganz exzessiven Maße zu. DaB manche Neurotiker eine auBerordentliche Lust aus kitzelnden Beruhrungen der Haut ziehen, ist bekannt. Sind andere Wege der Sexualbefriedigung versperrt, so tritt nicht selten das kneurotische Symptom auf, welches wir als Pruritus bezeichnen. Es nötigt den davon Befallenen zu scheuernden oder kratzenden Manipulationen, deren Ausübung bisweilen zum Orgasmus führt. So beobachtete ich zum Beispiel bei einer Patientin einen Pruritus am linken Oberarm. Das Kratzen dieser Partie, welches sich zu einer förmlichen Wut steigerte, löste einen vollständigen Orgasmus aus. Vor der Masturbation, die früher geubbt wurde, hatte dieses Verfahren den Vorzug, daß an ihm nicht die Selbstvorwürfe hafteten wie an der ersteren. Daß man sich wegen eines nervösen Hautjuckens, respektive wegen des hinzugetretenen Ekzems kratzt, erscheint als eine Notwendigkeit und nicht als moralische Verfehlung.

$\mathrm{DaB}$ das äuBere Ohr im frühen Kindesalter zur autoerotischen Lustgewinnung gebraucht wird, ist längst bekannt. Ich brauche nur auf die häufige Gewohnheit lutschender Kinder hinzuweisen, während des "Wonnesaugens" eine Hand ans Ohr $z u$ fuhren und das Ohrläppchen rhythmisch zu ziehen. Sodann ist daran zu erinnern, daß nicht wenige Personen im Kindesalter und später im Gehörgang zu bohren, Gegenstände hineinzuführen und mit dem Gehörgangssekret sich zu beschäftigen lieben. Speziell erwähne ich einen Knaben, der eine Fliege fing und sie in sein Ohr setzte. Infolge seiner Manipulation gelangte der „Fremdkörper" so tief in den Gehörgang, daB ein ärztlicher Eingriff nötig wurde. Kleinere Gegenstände, wie z. B. Erbsen, werden von Kindern oft in den Gehörgang gesteckt ${ }^{1}$.

Erst neuerdings wurde es mir jedoch zur GewiBheit, daB dem äußeren Ohr eine viel allgemeinere Bedeutung als erogene Zone zukommt. Die folgenden, zuverlässigen Beobachtungen verdanke ich Herrn Kollegen Dr. H. He m p e l, Ohrenarzt in Berlin. Ich gebe sie hier wieder, weil solche Feststellungen das Interesse des Psychoanalytikers in hohem Maße verdienen und bisher nicht genügend gewturdigt worden sind.

Kinder leiden oft an nässenden Ekzemen der Ohrmuschel und des äußeren Gehörganges. Dieses Leiden ist mit intensivem Jucken

- Bei Geisteskranken wird die Neigung, allerhand Dinge in die Ohren zu stecken, oft beobachtet. 
verbunden. Sobald der Arzt nun einmal an dem Ohr manipuliert hat, verhalten solche Kinder sich bei seinem jedesmaligen Erscheinen umgekehrt wie sonst bei einem bevorstehenden ärztlichen Eingriff. Das Kind, welches vorher wegen der Ekzembeschwerden schrie, wird auffälligerweise bei Annäherung des Arztes ruhig und sträubt sich nicht im geringsten. Solange der Arzt sich mit der juckenden Partie beschaftigt, ist das Kind ruhig, ja es gibt ein behagliches Schnurren von sich und schreit erst wieder, wenn der ärztliche Eingriff beendigt ist. Ich bemerke, daß diese Beobachtungen ohne nähere Kenntnis der Freudschen Auffassung von der kindlichen Sexualität angestellt worden sind, daß der Beobachter aber gleichwohl zu dem Resultat gelangt war, das geschilderte Verhalten sei dem Verhalten des Kindes bei masturbatorischer Reizung durchaus gleichzusetzen. Ergänzend sei binzugefügt, daß auch erwachsene Personen bei Behandlung eines Ohrekzems unverkennbare Zeichen des Wohlbehagens von sich geben. Mein oben genannter Gewăhrsmann sah übrigens einen Mann, der sich beide Ohrmuscheln ganz zerkratzt hatte, dem Arzt aber erklärte, von einer Behandlung der Affektion nichts wissen zu wollen.

Welch wichtige Rolle das äußere Ohr in der Sexualität des Kindes zu spielen vermag, geht auch aus manchen Phantasieprodukten unzweideutig hervor.

Eine Patientin berichtet mir aus ihrer Kindheit von der Neigung, sich phantastische Geschichten auszudenken. Mit etwa neun Jahren (doch wahrscheinlich auch schon früher) malte sie sich gern aus, wie sie wegen eines Vergehens bestraft würde. Besonders gern stellte sie sich folgenden Hergang vor:

Sie ging mit ihrer jüngeren Schwester spazieren. Da kam der Kaiser im Wagen dahergefahren und ließ sie beide wegen eines unbestimmten Vergehens festnehmen. Dann folgte eine Bestrafung. Sie bestand darin, daß beiden Kindern - die Ohren gereinigt wurden. Diese Prozedur enthielt für das Kind gleichzeitig Lust und Angst. Die darauf bezuglichen Phantasien stellten nicht nur eine halb ersennte, halb gefürchtete Reizung einer erogenen Zone dar, sondern überdies eine Befriedigung masochistischer Tendenzen.

Ganz ähnliches beobachten wir bei Kindern oder Erwachsenen, die sich in der Phantasie Szenen ausmalen, in welchen sie an ihren empfindlichsten Körperstellen gekitzelt werden. Die Verschmelzung sadistisch-masochistischer Regungen mit der Lust am Kitzeln oder Gekitzeltwerden ließe sich durch mannigfache Tatsachen belegen. Hier mag der Hinweis genügen, daB in den Anfällen eines Neurotikers, die ich eingangs beschrieb, Zeichen eines heftigen Wutaffektes 
unverkennbar waren, ebenso auch bei jener Patientin, die sich den Oberarm zerkratzte.

Es ist nun noch auf einige bisher wenig berücksichtigte Tatsachen zu verweisen. Zunächst auf die Rötung der Ohrmuscheln, zu welcher viele neurotische Personen neigen. Auf den Zusammenhang dieses Symptoms mit sexuellen Erregungsvorgängen beabsichtige ich später einmal genauer einzugehen.

Sodann scheint mir ein Hinweis darauf berechtigt, daB bei manchen Personen die dem Ohre benachbarten Partien des Halses, speziell der Winkel zwischen Hals und Unterkiefer, von besonderer erogener Bedeutung sind.

Die erogene Bedeutung des äuBeren Ohres scheint auch für die Erklärung des neurotischen Ohrensausens und anderer subjektiver Ohrgeräusche in Betracht zu kommen.

Endlich sei noch auf die dem Psychoanalytiker bekannte Tatsache verwiesen, daß das äußere Ohr von altersher häufig als Genitalsymbol verwertet wird.

Ich glaube annehmen zu düren, daß jeder Psychoanalytiker uber Erfahrungen verfügt, die den hier mitgeteilten ähneln. S a dge $\mathrm{r}$ hat eine Reihe interessanter Beobachtungen mitgeteilt, die sich mit den meinigen vortrefflich ergänzen (vgl. Jahrb. für psychoanal. Forsch., Bd. III.). In einer in Heft 5 des I. Jahrganges der Internat. Zeitschrift für Psa. erschienenen Arbeit von Je ke ls findet sich (pag. 442) ein Hinweis auf das Vorkommen mutueller Reizung des Gehörganges bei Invertierten. 


\section{Zur Psychogenese der Straßenangst im Kindes- alter'.}

Bei Neurotischen, welche sich ängstigen, ohne die Begleitung bestimmter Personen die Straße zu betreten, findet man sehr gewöhnlich eine zweite Phobie: die Angst vor dem Alleinsein im Hause. Es handelt sich um Menschen, denen ihr UnbewuBtes nicht gestattet, sich aus dem Bannkreis derjenigen Personen zu entfernen, an welche ihre Libido sich fixiert hat. Jeder Versuch dieser Kranken, dem Verbot ihres Unbewußten zuwiderzuhandeln, rächt sich durch einen Angstzustand.

Ein fünfjähriger Knabe, mit beiden genannten Phobien behaftet, lieferte kürzlich ganz spontan - also nicht etwa auf ärztliches Befragen - eine Bestătigung dieser psychoanalytischen Erfahrung. Die AußBerung des Kleinen ist in ihrer Bestimmtheit und lapidaren Kürze so erstaunlich, daB ich sie hier mitteilen und mit einigen Worten kommentieren möchte.

Der Knabe ist infolge seiner heftigen Angst nicht $\mathrm{zu}$ bewegen, die elterliche Wohnung allein zu verlassen, um die im Nebenhause wohnenden Verwandten zu besuchen, obwohl er zu diesem Behuf nicht einmal die Straße zu uberschreiten braucht. Ebenso ängstigt er sich, wenn seine Mutter die Wohnung verläBt, obwohl dann das Kinderfrăulein bei ihm bleibt. Neuerdings weigert er sich auch, in Begleitung des Kinderfräuleins spazieren zu gehen.

Als nun die Mutter den Knaben einmal aufforderte, in Begleitung des Kinderfräuleins einen Spaziergang zu machen, widersetzte er sich und erklärte in bestimmtem Tone: "I ch will kein Spazierkind sein, ich will ein Mutterkind sein."

Der Ausspruch ist nach mehreren Richtungen hin bemerkenswert. Der Knabe betont den Wunsch nach einer möglichst innigen Verknapfung mit seiner Mutter ( ${ }_{n}$ Mutterkind“). Er lehnt es ab, an der Hand einer von ihm nicht geliebten Person zu gehen ("Spazierkind" zu sein). Besonders muB aber auffallen, daB der Knabe nicht von

${ }^{1}$ Aus ,Internationale Zeitschrift für ärztliche Psychoanalyse", I. Jahrgang, 1913. 
seiner Angst, sondern von einem Wolle $\mathrm{n}$ redet. Man wird die Bedeutung der Fixierung des Knaben an seine Mutter nicht verkennen; aber man wird die Frage aufwerfen, wie denn die Phobie zustande komme, wenn doch der Wunsch, "ein Mutterkind zu sein", dem BewuBtsein des Knaben so wenig entfremdet sei.

Der Einwand ist unschwer zu entkräften. Nach Freuds Neurosenlehre ist es nicht sowohl der Wunsch des Kindes nach dem Beisammensein mit der Mutter, der der Verdrängung verfält, als vielmehr der inzestuöse Wunsch nach sexueller Inbesitznahme der Mutter. Eine zweite ÄuBerung des Knaben, welche aus denselben Tagen wie die obige stammt, bringt die Bestätigung dieser Auffassung. Sie zeigt, daB der Kleine im Kampfe mit dem Ödipuskomplex liegt, und daB ihn der Wunsch, die Mutter allein zu besitzen, beherrscht.

Der Vater des Kleinen war für mehrere Tage verreist. Während dieser Zeit durfte der Knabe zur Seite der Mutter, im Bett des Vaters, schlafen. Als ihm die Mutter eines Morgens mitteilte, der Vater werde an diesem Tage zurückkehren, erwiderte er: „Es wăre doch viel schöner, wenn der Papagarnichtvonder Reise $z$ uräckkäme." Er brachte in diesen Worten den Todeswunsch gegen den Vater und den Anspruch, neben der Mutter zu schlafen, in unzweideutiger Weise zum Ausdruck.

Beide angeführten ÄuBerungen des Knaben enthalten ein naives Zugeständnis infantiler Wünsche. Beide tragen dennoch schon deutlich den Stempel der Verdrängung, und es läbt sich erweisen, daB unter den offen geăußerten eine tiefere Schicht unausgesprochener Wtunsche lagert. Diese entspricht dem Ödipuskomplex.

Solche Beobachtungen aus frühen Entwicklungsstadien der Neurose sind im besonderen MaBe geeignet, die Anschauungen $\mathrm{zu}$ stützen, die wir durch die Psychoanalyse voll entwickelter Neurosen unter großen Schwierigkeiten gewonnen haben. 


\section{Sollen wir die Patienten ihre Träume aufschreiben lassen ${ }^{1}$ ?}

In einem kleinen Aufsatz über "Die Handhabung der Traumdeutung in der Psychoanalyse" hat Freud mit wenigen Worten zu der Frage Stellung genommen, ob es zweckmäBig sei, die Patienten ihre Träume gleich nach dem Erwachen schriftlich fixieren zu lassen. Er kommt zu dem Resultat, daß eine solche MaBregel überflüssig sei. „Hat man nămlich auf solche Weise mühselig einen Traumtext gerettet, der sonst vom Vergessen verzehrt worden wäre, so kann man sich doch leicht überzeugen, daß für den Kranken damit nichts erreicht ist. Zu dem Text stellen sich die Einfälle nicht ein, und der Effekt ist der nämliche, als ob der Traum nicht erhalten geblieben wäre." Ich kann dieser Ansicht aus eigener Erfahrung nur in vollem MaBe beipflichten. Die Frage scheint mir aber für den Psychoanalytiker, der von der Traumdeutung täglich praktischen Gebrauch macht, von erheblichem Interesse zu sein. Das veranlabt mich, einige Vorkommnisse aus der Praxis mitzuteilen. Ich erlebte sie gerade mit solchen Patienten, die ich bereits auf die Zwecklosigkeit eines sofortigen Niederschreibens der Träume aufmerksam gemacht hatte.

Beobachtung 1: Patient hat einen sehr ausgedehnten, ereignisreichen und mit starken Affekten verbundenen Traum. Er erwacht und greift noch schlaftrunken nach den Schreibmaterialien, die er, entgegen der ärztlichen Weisung, neben sein Bett gelegt hat. Am anderen Morgen bringt er etwa zwei Quartseiten voll Notizen. Es stellt sich aber sogleich heraus, daB das Geschriebene fast völlig unleserlich ist. Die Tendenz, den Traum vor dem Vergessenwerden zu bewahren, ist in diesem Falle offensichtlich von der entgegengesetzten Tendenz (Verdrängung) durchkreuzt worden. Es kommt zu einer KompromiBbildung: der Traum wird zu Papier gebracht, aber die Niederschrift ist unleserlich und vermag nichts $z u$ verraten.

Beobachtung 2: Patient, der auf seine Frage von mir den Bescheid erhalten hat, das Aufschreiben der Träume sei zu widerraten, produziert

${ }^{1}$ Intern. Zeitschr. f. ärzt. Psa. Bd. I. 1913, S. 194. 
in einer der nächsten Nächte eine ganze Serie von Träumen. Beim Erwachen - mitten in der Nacht - sucht er auf ingeniöse Weise die Träume, die ihm sehr wichtig erscheinen, der Verdrängung zu entreißen. Er besitzt einen Apparat zur Aufnahme von Diktaten und spricht nun die Träume in den Schalltrichter. Charakteristischerweise läßt er dabei auBer acht, daß der Apparat schon seit einigen Tagen nicht gut funktioniert. Das Diktat des Apparates fällt daher undeutlich aus. Patient muß vieles aus seinem Gedächtnis ergänzen. Das Diktat bedurfte also der Ergänzung durch die Erinnerung des Träumers! Die Analyse des Traumes geschah ohne erheblichen Widerstand, so dab man annehmen darf, der Traum wäre in diesem Falle auch ohne jede Fixierung in gleichem Umfang erhalten geblieben.

Der Patient ließ sich aber durch diese Erfahrung noch nicht überzeugen, sondern wiederholte den Versuch noch einmal. Der inzwischen reparierte Apparat gab am Morgen nach der Traumnacht ein dem Ohre gut verständliches Diktat. Inhaltlich aber war es nach der eigenen Äußerung des Patienten so verworren, daß er mit Mühe einige Ordnung herstellen muBte. Da die folgenden Nächte ein sehr reichliches Traummaterial lieferten, welches die nämlichen Komplexe behandelte und ohne Kunsthilfe ausreichend reproduziert werden konnte, so zeigt sich auch in diesem Falle die Nutzlosigkeit einer sofortigen Fixierung des Geträumten.

Wie vergeblich es ist, einer starken Verdrängungstendenz auf solche Weise entgegenzutreten, zeigt in schlagendster Weise die

Beobachtung 3: Die Patientin klagt während mehrerer Wochen über ihre Unfähigkeit, einen bestimmten Traum im Gedächtnis zu behalten. Sie habe in letzter Zeit allnächtlich den gleichen Traum. Sie schrecke dann auf, nehme sich sogleich vor, mir den Traum am Morgen zu erzählen, habe ihn aber jedesmal dennoch vergessen. Eines Tages erklärte sie, für die nächste Nacht Schreibmaterial bereithalten $\mathbf{z u}$ wollen, um den Traum fixieren $z \mathbf{u}$ können, sobald sie aus ihm erwache. Ich widerriet es ihr mit dem Bemerken, eine Tendenz, die sich allnächtlich Träume schaffe, werde auch ohne diese Nachhilfe den Weg ins BewuBtsein finden; gegenwärtig sei nur der Widerstand noch zu groB. Sie sah das ein und verzichtete auf ihr Vorhaben. Beim Schlafengehen tauchte jedoch der Wunsch, den Traum in dieser Nacht festzuhalten, von neuem auf. Patientin legte sich Papier und Bleistift bereit.

Wirklich erwacht sie mit einem Schreck aus dem gleichen Traum, zündet Licht an und schreibt etwas nieder. Mit dem beruhigenden Gefŭhl, den Traum nun nicht verlieren zu können, schläft sie wieder 
ein. Am Morgen verschlät sie die Zeit und erscheint verspătet zur Behandlung (Widerstand!). Sie tuberreicht mir ein Blatt und bemerkt dazu, sie habe es am Morgen in der Eile gar nicht năher angesehen.

Es machte wegen der undeutlichen Schrift (vergl. Beobachtung 11) einige Mühe, die wenigen Worte zu entziffern. Sie lauteten:

"Traum auf chreiben gegen Vereinbarung."

Der Widerstand hatte gesiegt. Die Patientin hatte nicht den Traum, sondern nur den Vorsatz zum Niederschreiben notiert. Dann war sie zufrieden wieder eingeschlafen!

Etwa eine Woche nach diesem erfolglosen Versuch konnte sie mir den Traum, der noch mehrmals aufgetreten war, erzählen. Sein Inhalt entsprang einer lebhaften Ubertragung. Patientin trăumte, $\mathrm{daB}$ ich mich ihr annahere, und schrak dabei jedesmal auf. Nachdem andere Symptome der Ubertragung zu einer eingehenden Analyse dieses Vorganges genötigt hatten, fiel der Grund, den Traum noch länger als Geheimnis $z \mathrm{u}$ wahren, hinweg.

Ich möchte noch in Kürze auf die Motive verweisen, welche den Patienten dazu fuhren, auf sofortige Niederschrift seiner Träume Gewicht zu legen. In vielen Fälen handelt es sich um eine Erscheinung der Ubertragung. Der Patient, der einen Traum schriftlich zur Behandlungsstunde mitbringt, möchte (unbewuBt) dem Arzt dadurch zeigen, dab ihn (den Arzt) dieser Traum besonders angehe. In manchen Fällen trägt ein geschrieben uberreichter Traum geradezu den Charakter eines Geschenkes an den Arzt, als wollte der Patient damit ausdricken: ich bringe dir mein Wertvollstes dar.

Dabei spielt offensichtlich die neurotische Eitelkeit mit. Manche Patienten mit ausgeprägtem $\mathrm{NarziBm}$ us sind in die Schönheit ihrer Trăume geradezu verliebt. Sie bewahren sie vor der Vergessenheit, weil sie in ihnen Kostbarkeiten sehen.

Wie der autoerotisch eingestellte Neurotiker seine Körperprodukte aufzusparen liebt, wie er ängstlich besorgt ist, daß von seinem körperlichen Besitzstand so wenig wie irgend möglich verloren gehe, ebenso wacht er auch daraber, daß von seinen geistigen Produkten nichts abhanden komme. 


\section{Einige Bemerkungen über die Rolle der Groß- eltern in der Psychologie der Neurosen'.}

In meiner psychoanalytischen Tătigkeit fiel mir von jeher auf, daB manche Neurotiker und Geisteskranke immer wieder das Gesprăch auf den GroBvater oder auf die Großmutter brachten, obwohl die Großeltern in keinem der einschlägigen Fälle die Lebensschicksale jener Individuen entscheidend beeinflußt hatten. So verschieden untereinander nun die Krankheitsfalle waren, welche diese Erscheinung darboten, so fahrte die Psychoanalyse doch $z \mathfrak{u}$ einem gleichförmigen Ergebnis: die besondere Hervorhebung des Großvaters oderder Grobmutter wurzelte stets in einer heftigen Ablehnung des Vaters, respektive der Mutter.

Die tieferen Ursachen der eigenartigen Erscheinung werden uns, wie so vieles andere im Wesen der Neurotiker, begreiflich, wenn wir das Verhaiten der Kinder zum Vergleich heranziehen. Zwei Beispiele aus dem Leben eines gesunden oder doch nur leicht neurotischen Knaben mögen den Beweis liefern.

Der Knabe gibt sich der typischen Phantasie hin, der Prinz eines von ihm erdachten Reiches zu sein. Den König des Reiches stattet er mit ganz denjenigen Eigenschaften aus, die ihm bei seinem Vater besonderen Respekt einflöBen. Später setzt er diesem König noch einen Vater (sich selbst also einen GroBvater) vor, den er mit der Fähigkeit, durch sein Wort Dinge zu erschaffen, das heißt also mit göttlicher Allmacht ausstattet. Der Effekt ist klar: dem Vater, der in den Augen des kleinen Kindes allmächtig gewesen war, wird ein Höherer vorgesetzt, den auch er respektieren muB; damit wird seine ihm fruher zugeschriebene Omnipotenz bestritten. Es ist $z u$ bemerken, daB der Knabe seine beiden Großvăter nicht gekannt, die großväterliche Gestalt in seinem Fabelreiche also im wesentlichen aus eigener Phantasie geschaffen hatte.

Derselbe Knabe wird einmal von seiner Mutter bestraft. Unter Tränen erklärt er ihr: ${ }_{n} J$ etzt heirate ich die GroBmama!“ Er

${ }^{1}$ Aus Internationale Zeitschrift flir ărztliche Psychoanalyse“. I. Jahrg. 1913. Vgl. dazu die ergănzenden Mittellungen von J o n e s ebda. 
gibt also bei dieser Gelegenheit dèr Mutter in negativer Form die Erklärung, daB er eigentlich sie habe heiraten wollen. Wegen der ihm widerfahrenen, als ungerecht empfundenen Behandlung verschmäht er sie (natirlich nur vorübergehend) und zeigt ihr, daB noch eine Mächtigere, Gütigere und zugleich ihm Gewogenere uber ihr stehe.

Der Knabe spielt seine Großeltern gegen seine Eltern aus. Er gibt damit der Vorstellung Ausdruck, daB es Wesen gebe, die an Macht, bezw. an Güte noch uber den Eltern stehen. Vielleicht ist der Hinweis nicht überflussig, daß dem Kinde eine soiche Auffassung durch die Sprache besonders nahe gelegt wird. "Großvater", "grandfather", "grandpère" und andere analoge Bezeichungen lassen uns vermuten, daB das Kind in dieser Wertschätzung der Großeltern nur wiederholt, was die Menschheit seit Urzeiten getan hat. Das Kind faßt hier, wie in so vielen anderen Fällen, das Wort in seiner vollen ursprünglichen Wertigkeit auf.

An das Verhalten dieses Kindes werden wir erinnert, wenn wir den folgenden Ausschnitt aus einer Krankengeschichte unter psychoanalytischen Gesichtspunkten betrachten. Es handelt sich um einen sehr fruhzeitig an Dementia praecox erkrankten jungen Mann. In seinen Halluzinationen und Wahnvorstellungen spielte seine GroBmutter (von mütterlicher Seite) eine zunächst nicht verständliche Rolle. Oft sprach der Kranke von einer immer wiederkehrenden Vision auch als von seiner "Urgroßmutter".

Der Kranke war als kleiner Knabe in ganz ungewöhnlichem Maße an seine Mutter attachiert gewesen. Er hatte sie mit gröBter Eifersucht bewacht und sie kaum für einen Augenblick dem Vater oder seinen Geschwistern gegönnt. Als später die Psychose nach und nach manifest wurde, hatte er sich in äuBerster Feindseligkeit gegen die Mutter verschlossen. Wie der Kranke nun vordem in seinem gesamten Wesen völlig von seiner Mutter abhängig gewesen war, so fühlte er sich in der Psychose beherrscht durch die "Großmutter". Sie erschien ihm, um ihm Befehle und Verbote zu geben. Er selbst überhäufte ihre Erscheinung mit den unflätigsten Schimpfwörtern, so wie er seine Mutter, wenn sie ihn einmal besuchte, in schroffster Art zurückzuweisen pflegte.

Der Patient befindet sich in einer dauernden feindlichen Einstellung seiner Mutter gegenüber. Er tut dauernd, was der im ersten Beispiel erwähnte (gesunde) Knabe in einer Affektaufwallung vorubergehend tat: er ersetzt die Mutter durch die GroBmutter. Hier zeigt sich die Oberdeterminiertheit psychischer Reaktionen. Der Kranke kann seine wlisten Schimpfreden weit ungehemmter gegen die Großmutter oder UrgroBmutter richten, die für ihn kein Wesen von Fleisch und Blut 
ist, als gegen seine Mutter, an die er im Grunde noch ebenso wie früher fixiert ist. Der Ersatz der Mutter durch die Großmutter erlaubt dem Patienten ferner eine kindliche Einstellung $z u$ der von ihm halluzinierten Person, und einer solchen Einstellung vermag er offenbar nicht zu entraten.

Ein $Z$ wangsneurotiker, bei welchem sich die Ablehnung des Vaters in mannigfacher Weise und mit größter Heftigkeit äußert, stellt seinem Vater den GroBvater von mütterlicher Seite gegenuber. Der Patient wurde von seinem Vater, der in bescheidenen Verhältnissen lebte, puritanisch erzogen. Er besuchte dann einmal mit seiner Mutter den GroBvater an dessen Wohnort. Der alte, wohlhabende Mann, der liber den Besuch seines Enkels liberaus erfreut war, liberhäufte ihn mit Geschenken und vorausgabte dafür Betrăge, die dem Knaben ungebeuer groß vorkamen. Von nun an nahm sein Widerstand gegen den Vater eine bestimmte Form an. Der Vater erschien ihm noch mehr als vorher lediglich als Tyrann, während der freigebige Großvater zum Vater-Ideal erhoben wurde. Während der psychoanalytischen Behandlung hatte der Patient u. a. einen Traum, in welchem er mit seiner Mutter nach dem Wohnort des (jetzt längst verstorbenen) Großvaters reiste.

In den Ideengängen eines anderen Neurotikers geht neben der Gestalt des Vaters diejenige des Großvaters (von mütterlicher Seite) beständig wie ein Schatten einher. Die Psychoanalyse wies nach, daB die feindselige, revolutionäre Einstellung des Sohnes gegenüber dem Vater in dieser Erscheinung einen sehr gemilderten Ausdruck fand. Der Patient brachte neben anderen hierher gehörigen Materialien vor, daß ihm in seiner frühen Jugend der Großvater, der sich bereits ins Privatleben zurückgezogen hatte, immer wie ein entthronter Gott, wie Kronos erschienen sei. Indem der Knabe den entthronten Großvater neben den herrschenden, noch jugendlichen Vater stellte, sprach er sich in versteckter Weise den Trost zu, auch der Vater werde nicht ewig regieren, sondern eines Tages entthront sein wie der Großvater.

Es kommt auch vor, daB ein Neurotiker sich mit einem starken Affekt des Hasses von seinem Vater abwendet, zum Ersatz aber in der Phantasie Beziehungen zwischen sich selbst und den fernsten Vorfahren (den "Vätern") herstellt. Ich beobachte augenblicklich einen solchen Fall, muB mir aber aus äuBeren Gründen die Mitteilung von Einzelheiten versagen ${ }^{1}$. Ich habe übrigens in meiner Studie uber Amenhotep IV. bereits ahnliches nachgewiesen ${ }^{2}$.

1 Die heftigste Wat des Patienten knipite sich an ein Erlebnis, das thn aufs höchste erregt hatte, d. h. an eine Beobachtung des sexuellen Verkehres der Eltern.

2 Im a g o, Bd. I., 1912, Heft 4. 
Die Psychoanalyse lehrt uns zahlreiche Wege kennen, die von der neurotischen Phantasie eingeschlagen werden, um die Macht des Vater- oder Mutterkomplexes zu paralysieren. Man kann diese Phantasien der Neurotiker in drei Gruppen teilen. Die am weitesten gehenden unter diesen Phantasien sind BeseitigungsVorstellungen. Es ist bekannt, in wie mannigfaltiger Form Todeswünsche 'gegen Vater oder Mutter in der Neurose Ausdruck finden.

Eine zweite Gruppe von Vorstellungen dient der Verleugnung der Eltern, besonders hăufig des Vaters: sogenannte Abstammungsphantasien.

Endlich sucht der Neurotiker sich des Elternkomplexes zu erwehren, indem er die Macht des Vaters, respektive der Mutter herabsetzt. Eine Herabsetzung geschieht aber auch dadurch, daB dem Vater ein Machtigerer vorgesetzt wird.

In letzterer Hinsicht sei noch daran erinnert, $\mathrm{daB}$ manche Neurotiker die Gepflogenheit haben, bewuBt oder unbewuBt gegen jedwede Autorität eine andere auszuspielen. Widerstände gegen den Arzt auBern sich während der psychoanalytischen Kur nicht selten in dieser Weise.

Auch die Religiosität mancher Neurotiker wird im wesentlichen aus diesen Quellen gespeist. Der Glaube an eine göttliche Allmacht, oder an eine das menschliche Leben prädestinierende Schicksalsmacht gibt dem Neurotiker den Trost, daß auch der Vater, dem er sich infolge seiner unbewußten Fixierung gänzlich unterworfen fahlt, nicht allmächtig sei, sondern noch eine höhere Macht über sich habe.

Am Schluß sei es gestattet, noch kurz auf ein analoges Phănomen in der Völkerpsychologie zu verweisen. Eine Verschiebung der Autorität vom Vater auf entferntere Vorfahren durfte auch dem Ahnenkultus zugrunde liegen. Freilich verehrt hier nicht mehr der einzelne einen bestimmten Ahnen, sondern eine gröBere Gemeinschaft von Menschen stattet einen gemeinsamen Stammvater mit einer Macht aus, die in der väterlichen Autorităt ihr Vorbild hat. 


\section{Eine Deckerinnerung, betreffend ein Kindheits- erlebnis von scheinbar ätiologischer Bedeutung ${ }^{1}$.}

Die nachfolgende kasuistische Mitteilung entstammt einem Krankheitsfalle, den ich äuBerer Gründe halber nur sehr kurze Zeit beobachten und daher nicht lege artis analysieren konnte. Die Analyse einer Deckerinnerung des Patienten trägt daher einen fragmentarischen Charakter; denn in den wenigen Sitzungen konnten nicht alle Zusammenhänge durch die vom Patienten gebrachten Einfälle geklärt werden. An einigen Stellen mußte ich Zusammenhänge - die freilich dem psychoanalytisch Erfahrenen ohne weiteres durchsichtig sind durch eigene Kombination herstellen; ich werde ausdrlicklich erwähnen, wo ich derartige Ergänzungen vorgenommen habe.

Der 47jährige Patient klagte über einen seit seiner Jugend bestehenden Zwang, alle Gegenstände in minutiöser Weise zu betrachten und zu untersuchen, speziell aber die Rückseite jedes Gegenstandes seinen Augen zugänglich zu machen. Hatte er einen Gegenstand genau betrachtet, so muBte er des weiteren tiber dessen Herkunft oder Entstehung grübeln. Ferner bestand - ebenfalls seit der Kindheit ein Zwang zum Beten sowie zum Grubbeln luber religiöse Fragen. Diese $Z$ wangserscheinungen waren von solcher Heftigkeit, daB der Kranke an jedem Gegenstand sozusagen hängen blieb. Er konnte nicht mehr in seinem Beruf tätig sein und schließlich nicht einmal mehr vom Hause fortgehen, weil jeder Gegenstand auf der Straße ihn auf lange Zeit festhielt. Er bedurfte der ständigen Begleitung seiner Frau, die ihn vorwärts ziehen mußte, damit er nicht grübelnd und Selbstgespräche führend bei dem ersten, seinem Blicke begegnenden Objekt für unbestimmte Zeit verweilte. Als Beispiel diene sein Verhalten bei Gelegenheit seines ersten Erscheinens in meiner Sprechstunde.

Vor dem Hause, in welchem ich damals wohnte, befand sich ein Vorgarten, an dessen Gitter mein Namensschild angebracht war. Der Patient begnügte sich nicht damit, die Aufschrift zu lesen, sondern

1 Aus Internationale Zeitschrift flir årztliche Psychoanalyse*, I. Jahrgang 1913. 
beleuchtete, nachdem er in den Vorgarten eingetreten war, mit Hilfe eines Zündhölzchens die Rückseite des Schildes. Dann brachte er (nach der Schilderung seiner Frau) längere Zeit damit zu, laut vor sich hin sprechend über die Herstellung solcher Schilder nachzugrubeln. Als seine Frau ihn endlich bis in mein Sprechzimmer gebracht hatte, fabte er alsbald eine kleine Bronzefigur ins Auge, nahm sie vom Tisch, drehte sie und betrachtete besonders eingehend die Rlickseite des Körpers. Nur mit Muhe ließ er sich dann von dem Vorstellungskreis, in den er hineingeraten war, wieder ablenken.

Erst in der zweiten Besprechung, bei welcher die Ehefrau nicht anwesend war, wurde Patient mitteilsamer. Er brachte nun sogleich ein Erlebnis aus seiner Kindheit vor, das ihm in lebhaftester Erinnerung geblieben sei. Er erklärte spontan mit Bestimmtheit, daB von diesem Vorfall sein ganzes Leiden den Ausgang genommen habe.

Mit sieben Jahren, so erzählte der Patient, ging er durch eine Straße in der Nähe der elterlichen Wohnung. Er kam an einem Hause vorliber, in dessen Keller sich ein kleiner Laden befand. Er bemerkte, daB die Inhaberin des Geschäftes sich mit anderen Personen stritt. Plötzlich sah er, wie sie ihren Gegnern den Rücken zuwandte, ihre Röcke hob und ihnen das bloße Gesäß zeigte. Der Patient ging dann nach Hause und erzählte das Erlebte sogleich dem Dienstmädchen, einer ihm vertrauten älteren Person. Sie wies ihn zurecht: er sei sehr unanständig und hätte dergleichen nicht ansehen sollen; jetzt werde ihn der Schutzmann holen. Der Patient schilderte nun lebhaft, wie er durch diese Worte ganz verängstigt worden sei; er sei ${ }_{n}$ krank vor

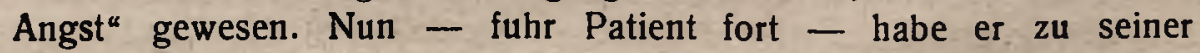
Beruhigung angefangen zu beten. Daraus sei bald ein Zwang geworden, dem er nicht widerstehen konnte. Er muBte ungezählte Male beten, Gott solle ihn einen guten, großen, schönen, braven . . . usw. ... Menschen werden lassen. Um ja nicht etwa ein Wort seiner immer lănger werdenden Gebetsformeln auszulassen, schrieb er sich eine ganze Litanei auf einen Zettel, den er dann täglich vielmal herunterlas.

Die mitgeteilte Reminiszenz bezog sich auf einen Vorgang, der auf den Schautrieb des Knaben einen starken Eindruck gemacht haben mochte. Die pathogene Bedeutung des Erlebnisses muBte dennoch von vornherein in Zweifel gezogen werden, obwohl der Patient aufs bestimmteste angab, daB sich Selbstvorwürfe und zwangsmäBiges Beten unmittelbar an den Vorfall angeschlossen hătten. ÄuBerlich muBte schon auffallen, daB der Patient die Geschichte fließend und ohne jede Hemmung vortrug. Wir sind gewohnt, daB Reminiszenzen, mit welchen die Krankheit eng verwoben ist, erst nach Uberwindung betrăchtlicher 
Widerstände zur Kenntnis des Arztes gebracht werden. Der vom Kranken so bestimmt behauptete ursächliche Zusammenhang zwischen dem Erlebnis und der Zwangsneurose litt aber vor allem an innerer Unwahrscheinlichkeit. Eine Drohung wie diejenige des Dienstmädchens in unserem Falle pflegt auf einen Knaben keinen solch erschütternden Eindruck zu machen. Von einem Knaben im achten Lebensjahr, der dem Mittelstand entstammt und in einem Hause aufwächst, in welchem neben der Familie Gesellen und Dienstboten leben, darf man als natürliche Reaktion erwarten, daB ein solches Erlebnis und die nachfolgende Drohung ihn eher belustigen oder doch gleichgültig lassen werden. Ferner ist in keiner Weise ersichtlich, wie ein einmaliges, an sich geringfügiges Vorkommnis eine so ungewöhnlich schwere, mit den Jahren an Umfang zunehmende Neurose hervorgerufen haben sollte. Somit war von vornherein anzunehmen, es liege eine Reminiszenz vor, die ihren "Gedächtniswert" von anderen - ins UnbewuBte verdrängten - Erinnerungen entlehnt habe. Es muBte sich um eine sogenannte Deckerin ner ung handeln ${ }^{1}$.

Bei weiterem Eingehen auf seine Kindheit versich erte der Patient, $\mathrm{daB}$ er als Knabe sonst keinerlei Erlebnisse von sexuellem Charakter gehabt habe. Er betonte mit besonderem Nachdruck, er und seine Geschwister seien "sehr sittlich erzogen worden". Speziell sei auch nie etwas mit den Dienstboten vorgefallen. Bei einem genaueren Bericht über die Verhältnisse im Elternhause kam auch die Frage zur Sprache, mit welchen Personen der Patient als Knabe das Schlafzimmer geteilt hatte. Hier machte sich bei dem Patienten eine Unsicherheit bemerkbar. Er berichtete dann, er habe eine Zeit lang im gleichen Zimmer wie seine Schwestern geschlafen; doch sei auch dort niemals etwas vorgefallen. Hier setzte deutlicher Widerstand ein. Dann folgte als nächster Einfall die Erinnerung, er habe als Knabe der älteren Schwester einmal đen Nacken klopfen müssen, weil sie dort Schmerzen oder sonst etwas hatte ${ }^{2}$. Dann tauchte eine andere Situation in seiner Erinnerung auf. Die Amme, welche ihn genăhrt hatte, "eine schöne Person", sei nach seiner Entwöhnung im Hause seiner Eltern geblieben. Aus seinem funften Lebensjahr erinnere er sich, im gleichen Bett mit der Amme geschlafen zu haben. Wieder folgte die stereotype Versicherung, "da

1 Vgl. Fre u d, Über Deckerinnerungen. Monatsschrift für Psychiatrie, Bd. 6, 1899.

2 Dieser Einfall deckt offenbar anderes, verđrängtes Material. Es war leider nicht moglich, die Spur weiter zu verfolgen. Es mag darum nur darauf hingewiesen werden, daB Nacken und Hinterkopf in den neurotischen Phantasiegebilden nicht selten das GesäßB vertreten. (Verlegung nach oben.) Vgl, hiezu: S a d g e r, Die sexualsymbolische Verwertung des Kopfschnerzes. Zentralblatt f. Psychoanalyse, Bd. II, 1912. 
sei auch nichts vorgekommen." Gleich darauf zwang ein Einfall ihn, sich zu korrigieren: er habe sich immer so gern mit dem Leib an den Körper der Amme, besonders gegen ihr GesäB gelegt. Es falle ihm nun wieder ein, daß er manchmal ihr Hemd hinaufgestreift habe, um jenen Körperteil unmittelbar $\mathrm{zu}$ beruhhren ${ }^{1}$.

Endlich schloB sich eine weitere Reminiszenz an. Der Patient berichtete, er sei mit etwa sieben Jahren einmal krank gewesen. Damals habe die Mutter ihn zu sich ins Bett genommen. Bei solcher Gelegenheit habe er das Hemd der Mutter gern hinaufgestreift. Die früheren Vorgänge bei der Amme fanden hierin ihre Fortsetzung.

Die soeben mitgeteilte Reminiszenz verlegte der Patient in das gleiche Lebensalter wie die zuerst beschriebene Szene.

Diese fragmentarischen Angaben gestatten uns zwar keineswegs, uns ein vollständiges Bild von der Entstehung des Krankheitszustandes zu machen. Immerhin lassen sie uns in der Kindheit des Patienten diejenigen Phänomene des Trieblebens erkennen, von welchen nach Fre u d ${ }^{2}$ die als Grubelsucht bezeichnete Form der $Z$ wangsneurose ihren Ausgang nimmt. Besonders sei auf den stark betonten sexuellen Schautrieb verwiesen. Der Knabe begnügt sich jedoch nicht damit, zu beschauen, was sich seinem Auge zufällig darbietet, sondern er sucht die ihn reizende Körperpartie aktiv zu entblößen.

Soweit sich die Erinnerung in wenigen Sitzungen wiedererwecken lie日, hatte er entsprechende Handlungen mit vier Jahren bei der Amme, mit sieben Jahren bei der Mutter vorgenommen. Diese Reminiszenzen tauchten freilich erst allmählich auf, während der Patient eine andere Szene aus seiner Kindheit viel detaillierter wiedergegeben und sie in offenbar tendenziöser Weise von Anfang an in den Vordergrund gerückt hatte.

Es ist nicht $\mathrm{zu}$ kühn, den folgenden Hergang zu vermuten. Der Knabe hatte seinen tibermächtigen Schautrieb an seiner Mutter befriedigt. Derartige Handlungen von inzestuösem Charakter pflegen, wie die Psychoanalyse der Zwangsneurose uns gelehrt hat, zu den schwersten Selbstvorwürfen und weiterhin zu komplizierten Sühneaktionen zu führen. Unser Patient litt in hohem MaBe unter Selbstvorwürfen, die er jedoch mit einer relativ sehr harmlosen Szene in ursächlichen

1 Feststehende psychoanalytische Erfahrungen berechtigen uns zu der ergänzenden Annahme, das GesăB der Amme habe flir die Sexualităt des Patienten erst sekundär die Bedeutung gewonnen, welche primär ihren Brüsten zukam. Doch drang die Analyse nicht bis zum Nachweis dieses Herganges vor.

2 Bemerkungen liber einen Fall von $Z$ wangsneurose. Jahrbuch f. psychoanalyt. Forschungen, Bd. I. 
Zusammenhang brachte. Hier liegt eine offensichtliche Ver s ch i e b ung vor, deren Motive unschwer zu erkennen sind. Der Mutter war der Patient aktiv zu nahe getreten; der Szene in dem Kellerladen hatte er dagegen ohne Vorwissen als unfreiwilliger $Z$ uschauer beigewohnt. Er verdrängt die erste Tatsache ins UnbewuBte und befreit sich auf diesem Wege von der für ihn peinlichsten Erinnerung. Dagegen behält er ein weit harmloseres Erlebnis mit größter Schärfe im Gedächtnis und verkntipft mit ihm den schweren Vorwurfsaffekt. Der Gewinn, der für den Patienten aus diesem Vorgang entspringt, braucht wohl nicht weiter hervorgehoben $\mathrm{zu}$ werden. Mit welcher Intensität der Patient die eigentlich quälende Erinnerung von seinem BewuBtsein abgedrängt hatte, geht daraus hervor, daB ihm durch viele Jahre zwar oft die Kellerladenszene lebhaft vor Augen trat, daB dagegen die wichtigeren Vorkommnisse aus seiner Kindheit zum erstenmal in den Tagen der Psychoanalyse wieder auftauchten.

Der äußere AnstoB zu dem angenommenen Verschiebungsvorgang ist uns nicht unbekannt. Als der Knabe der Dienstmagd von seinem Erlebnis erzählte, schalt sie ihn wegen seiner Unanständigkeit und malte ihm aus, welche Folgen sein Verhalten haben werde. Diese Worte können nur dadurch so stark auf den Knaben gewirkt haben, daß sie in ihm plötzlich den Gedanken wachriefen, er habe ja weit Schlimmeres begangen. An diese plötzliche Erkenntnis konnten sich unmittelbar die Selbstvorwürfe, das zwangsmäBige Beten usw. anschlieBen; dem Anschein nach waren sie freilich die Folge der belanglosen Kellerladenszene.

Diese stellt sich somit als eine Deckerinnerung heraus, welche bis ins kleinste der von Freud im Jahre 1899 gegebenen Definition entspricht. Nach Freud sind Deckerinnerungen solche Reminiszenzen, denen trotz ihres gleichgültigen Inhalts ein großer Gedächtniswert zukommt. Sie verdanken diesen Gedächtniswert jedoch nicht ihrem eigenen Inhalt, sondern seinen Beziehungen zu einem anderen, verdrängten Inhalt. Die Deckerinnerung ist etwa ein losgerissenes Stück einer wichtigen Erinnerung oder sie vertritt symbolisch eine solche.

Hinter der harmlosen Kindheitsszene suchen sich - wie F r eud weiter ausführt - Vorstellungen von peinlichem Inhalte zu verbergen, die im aktuellen Leben des Neurotikers eine Rolle spielen. Es kann keinem Zweifel unterliegen, daB der Patient auch zur Zeit unserer Beobachtung noch ganz von seinem auf die "Rückseite“ gerichteten Schautrieb beherrscht wurde. Die hiedurch bedingten Selbstvorwurre fanden eine teilweise Ablenkung (Verschiebung) auf jenes scheinbar pathogene Kindheitserlebnis. 
Die der Kellerladenszene gegebene Deutung als Deckerinnerung erfährt aus anderer Quelle noch eine erwähnenswerte Bestätigung.

Der Patient lieferte nämlich noch weitere, besonders auf das Pubertätsalter und die nachfolgenden Jahre bezugliche Erinnerungen. Er kam dabei auf eine Zeit, in welcher die seit der Kindheit bestehenden Krankheitserscheinungen sich außerordentlich verschlimmert hatten. Diesem neuen Krankheitsschub war, wie sich herausstellte, ein sexuelles Erlebnis vorausgegangen, das dem ausführlich analysierten auffallend ähnelte. Der Patient berichtete: Als er achtzehn Jahre alt war, sei seine Mutter einmal des Nachts zu irgend einem $Z$ weck durch sein Schlafzimmer gegangen. Dabei habe sie ihn wohl für schlafend gehalten. Er habe aber gesehen, wie sie hinten ihr Hemd aufhob, so daB ihr GesäB entblöBt war.

Bemerkenswert ist auch an diesem Vorgang, daB der Patient seiner Schilderung nach wiederum nur der unfreiwillige Zuschauer war, während eine Frau sich selbst entblößte. Man darf vermuten, daß der Schautrieb des Patienten um jene Zeit besonders rege war und sich in inzestuöser Richtung bewegte. Ob der Kranke damals irgend eine entsprechende Handlung beging, ließ sich nicht feststellen. Es liegt aber wohl auf der Hand, daß die an seinen inzestuösen Triebregungen haftenden Selbstvorwürfe auf die geschilderte nächtliche Szene verschoben wurden. Demnach läge auch hier eine Deckerinnerung vor.

Freilich nötigt uns die vom Patienten gegebene Darstellung zu einem kritischen Einwand. Sie erweckt den Eindruck tendenziöser Bearbeitung. Es ist nicht recht ersichtlich, warum die Mutter des Patienten sich beim Durchschreiten seines Zimmers in der beschriebenen Weise entblöBt haben sollte. Der wirkliche Sachverhalt ist naturlich nicht feststellbar. Ohne Zweifel aber war das Verlangen des Patienten, die Mutter entblößt zu sehen, geeignet, seine Wahrnehmung in dem Augenblick zu verfälschen, als die Mutter nachts durch sein Zimmer ging. Vermutlich wähnte er dann, das zu sehen, was er zu sehen begehrte. In der irrtümlichen Wahrnehmung oder Erinnerung wäre also eine klare Wunscherfüllung enthalten.

Die vorstehenden Ausführungen sollen einerseits einen Beitrag zur Psychologie der Erinnerungsstörungen liefern. Anderseits mögen sie den Praktiker daran erinnern, mit wie großer Skepsis er gerade denjenigen Angaben seiner Patienten gegenübertreten muB, welche sich auf die Ätiologie der Neurose beziehen. Deckerinnerungen der geschilderten Art, die vom Patienten so eifrig in den Vordergrund geschoben werden, dienen stets zur Irreführung des Arztes, zur Ablenkung seiner Aufmerksamkeit von den tieferen seelischen Schichten. 


\section{Psychische Nachwirkungen der Beobachtung des elterlichen Geschlechtsverkehres bei einem neunjährigen Kinde ${ }^{1}$.}

Der Herausgeber dieser Zeitschrift hat zur Mitteilung solcher, in der Kindheit vorgefallener Träume aufgefordert, deren Deutung zum Schlusse berechtigt, daß die Träumer in frühen Kinderjahren Zuschauer sexuellen Verkehres gewesen sind. Der nachfolgende Beitrag entspricht diesen Anforderungen insofern nicht ganz, als die Beobachtung des elterlichen Koitus in diesem Falle nicht in die fruhesten Kindheitsjahre fällt, sondern mit gröBter Wahrscheinlichkeit unmittelbar vor dem Auftreten des mitzuteilenden Traumes und der neurotischen Angst stattgefunden hat. Dennoch halte ich die Veröffentlichung für berechtigt, weil der Fall mit seltener Deutlichkeit erkennen läbt, wie ein zur Neurose disponiertes Kind auf ein Erlebnis wie das genannte reagiert.

Ich wurde zu einem $93 /$ Jahre alten Mädchen gerufen, welches seit kurzem an Angstzuständen litt.

Zehn Tage vor der Konsultation war die Kleine am Abend in gewohnter Weise zu Bette gebracht worden. Nach mindestens einstündigem Schlaf rief sie durch Angstschreie ihre Mutter, welche sich im anstoBenden Wohnzimmer aufhielt, herbei. Sie erzăblte der Mutter mit allen Anzeichen des Entsetzens einen Traum: ${ }_{n}$ Ein Mann hat dich in deinem Bettermorden wollen, ich habe dich aber gerettet." Während dieser Mitteilung vermochte sie zwischen Traum und Wirklichkeit noch nicht zu unterscheiden. Als die Mutter ihr beruhigend zusprach, antwortete sie mit entsetztem Ausdruck: "Ach, du bist ja gar nicht meine Mutter." Hernach äußerte sie Angst vor Gegenstănden im Zimmer, die sie als Tiere verkannte. Erst nach geraumer Zeit trat Beruhigung ein. Die Kleine schlief bis zum Morgen, erklärte dann, in der Nacht gut und ungestört geschlafen zu haben und sich ganz wohl zu fühlen.

'Aus „Internationale Zeitschrift fur ärztliche Psychoanalyse“, I. Jahrgang, 1913. 
Auf vorsichtiges (und daher nur oberflächliches) Befragen vonseiten der Eltern wußte sie sich des oben geschilderten Vorganges anscheinend nicht zu erinnern.

Bei der Patientin hatte sich an einen schweren Angsttraum ein Dämmerzustand angeschlossen. Epileptische Antezedentien fehlten gänzlich; Symptome, welche eindeutig für eine Geisteskrankheit (im engeren Sinne) gesprochen hätten, lagen nicht vor. Die weitere Entwicklung des Zustandes und der nachfolgende von mir erhobene Befund ließen einen hysterischen Dämmerzustand annehmen.

Die Patientin bot in den folgenden Tagen mannigfache Krankheitserscheinungen. Sie war schreckhaft und neigte zum Zusammenzucken. Mehrfach bot sie in der Unterredung mit der Mutter Symptome dar, die dem "Vorbeireden" (Ganser) sehr ähnelten. Abends trat wiederholt starke Angst auf. Patientin hatte einigemal Tiervisionen; u. a. wurde sie, wie sie mir bei Gelegenheit meines Besuches erzählte, von einer Schlange erschreckt, die in ihr Bett kroch und sie ins Bein beißen wollte. Sie ängstigte sich, das Klosett aufzusuchen, weil dort schwarze Männer erschienen, die ihr mit dem Finger drohten. Sodann fand sich bei der Patientin eine ausgesprochene Astasie und Abasie und, als Begleiterscheinung, Angst vor dem Fallen. Suggestiv ließ sich diese Störung schnell soweit beeinflussen, daB ich die Patientin durch das Zimmer führen konnte, sie nur ein wenig am Ärmel haltend. Sie konnte schließlich, zwar noch taumelnd, aber ohne zu fallen allein zum Bett zurückkehren. Symptome einer organisch bedingten Lähmung fanden sich nicht vor.

Patientin berichtete auf mein Befragen, daß sie in letzter Zeit oft Angstträume gehabt habe. Als ich sie bat, einen solchen zu erzählen, brachte sie sofort den oben angefuhrten Traum vor, obwohl sie in den vorausgegangenen Tagen von den Eltern nicht an ihn erinnert worden war. Die Amneslie für den Abend, an welchem die Krankheit ausgebrochen war, konnte also höchstens eine partielle sein.

Da ich nur zu einer Konsultation zugezogen war, muBte ich mich der Patientin gegentuber mit der Erhebung des Befundes und einigen beruhigenden psychotherapeutischen MaBnahmen begnugen. Mit Hilfe des Vaters der Patientin suchte ich in ätiologischer Richtung weiter vorzudringen.

Der Angsttraum der Patientin hatte in mir sogleich die Vermutung erweckt, sie sei Zeugin des elterlichen Geschlechtsverkehres gewesen, habe den Eindruck in typisch kindlicher Weise ( ${ }_{n}$ sadistische ${ }^{\text {"Theorie }}$ des Koitus) verarbeitet und dann im Traum eine Wiederholung der Szene erlebt. 
$\mathrm{Da}$ das Zimmer, in welchem die Kleine lag, auch die Betten der Eltern enthielt, so teilte ich dem Vater meine Vermutung mit und begründete sie kurz. Ich fand sofort Verstăndnis. Der Vater erklärte, er könne meiner Ansicht nur zustimmen. Er fügte hinzu, die Kleine werde auBer dem Koitus in letzter Zeit auch gelegentliche heftige Auseinandersetzungen der Eltern angehört haben, die nach dem Schlafengehen stattfanden. Hiedurch würde die "Ermordung" der Mutter neben der sexuellen noch eine weitere Determination erhalten.

Die dem Ödipuskomplex des Sohnes analoge Einstellung der Tochter zeigt sich im vorliegenden Fall in nicht zu verkennender Weise. Die Tochter trăumt von einem Mordanschlag auf die Mutter. Der Sinn dieser Phantasie wird dadurch nicht geändert, $\mathrm{daB}$ die Träumerin ihre Mutter "rettet". Ginge dies nicht schon aus der bekannten Bedeutung der Rettungsphantasien hervor, so brauchte nur darauf verwiesen zu werden, daß die Patientin unmittelbar nach dem Traum die Mutter verleugnete; sie entledigte sich ihrer also in einer Form, wie sie uns besonders von den "Abstammungsphantasien" her wohlbekannt ist. Ihr selbst nähert sich - als halluzinatorische Erscheinung im Wachen - die Schlange, die als mănnliches Symbol offenbar den Vater vertritt ${ }^{1}$. Die Angabe, daß die Schlange sie habe ins Bein beißen wollen, machte die Patientin unter deutlichem Zögern und mit verăndertem Gesichtsausdruck; sie schien mir hier etwas zu verschleiern. Wahrscheinlich nannte sie das Bein an Stelle des Genitale, nach Analogie der Fabel vom Storch, der die Frauen ins Bein beiBt.

Eine so akut einsetzende, so intensive und in ihren Erscheinungen für den Psychoanalytiker so durchsichtige Verarbeitung des Elternkomplexes berechtigt, wie ich meine, zu der Annahme, ein affektbetontes, mit den Eltern in Zusammenhang stehendes Erlebnis habe auf das Kind eingewirkt. Die äußeren Umstände sowie die Angaben des Vaters sind wohl geeignet, zu dem Schlusse zu führen, das Kind habe unmittelbar vor dem Auftreten der geschilderten Erscheinungen den Verkehr der Eltern beobachtet. Eine direkte Befragung der Patientin war natürlich bei dieser einmaligen Unterredung nicht angăngig.

Allein zur Begründung eines so ernsten Krankheitszustandes konnte ein solches Erlebnis des Kindes nicht ausreichen; auch war der Zusammenhang gewisser Symptome mit dem erlittenen psychischen Trauma zum mindesten unsicher ${ }^{1}$. Eine Befragung des Vaters förderte

1 Vg1. hiezu meine Ausführungen ,Über ein kompliziertes Zeremoniell neurotischer Frauen". Seite $114 \mathrm{f}$.

1 Ich habe eine Deutung gewisser Symptome im obigen absichtlich unterlassen, well mir genligende Grundlagen dafur zu fehlen schienen. 
einiges weitere Material zutage. Die Patientin pflegte mit einer Nachbarstochter umzugehen, von der es hieB, daB sie mit anderen Mädchen mutuelle Masturbation treibe. Es ergibt sich nun die Vermutung, daß die Patientin, durch sexuelle Handlungen und Gespräche mit dieser Freundin aufgeregt, deswegen viel heftiger auf das im elterlichen Schlafzimmer Erlebte reagiert habe, als sie es sonst getan haben würde.

Die Angst vor Gestalten mit drohender Gebärde läßt ohne weiteres auf ein Verschuldungsgefuhl schließen, und dieses wlirde sich nach uns geläufigen Erfahrungen am wahrscheinlichsten auf die Verübung unerlaubter sexueller Handlungen zurückführen lassen. DaB jene Gestalten der Patientin gerade im Klosett erschienen, ist gewiB nicht ohne Belang; ist doch dieses der häufigste Schauplatz heimlicher Verbotsübertretungen der Kinder.

Die mitgeteilte fragmentarische Analyse läBt uns besonders nach einer Richtung hin unbefriedigt. Wir werden durch die Assoziationen der Patienten in der Regel auf früh-infantile Wünsche und Eindrücke aufmerksam gemacht, von welchen die neurotischen Symptome ihren Ausgang genommen haben. Ein Vordringen bis in die tiefen Schichten des UnbewuBten war im vorliegenden Falle nicht möglich. Ich vermute, es wirde ergeben haben, daB der aktuelle Eindruck, unter dem die Patientin stand, seine wichtigste Verstärkung aus dem UnbewuBten bezog, d. h. von verdrängten, der ersten Kindheitsperiode angehörigen Erinnerungen verwandter Art. Doch lieB sich, wie gesagt, ein bezuglicher Nachweis nicht fahren.

Ich halte den SchluB für berechtigr, daB die Beobachtung des elterlichen Koitus den AnstoB zum Ausbruch der Psychoneurose gegeben habe, deren erstes merkbares Symptom ein schwerer Angsttraum mit anschlieBendem Dämmerzustand bildete. 


\section{Kritik zu:}

C. G. Jung, Versuch einer Darstellung der psychoanalytischen Theorie. Neun Vorlesungen, gehalten in New-York im September 1912. Jahrb. f. psychoanalyt. Forsch., Bd. V. Buchausgabe: Wien, F. Deuticke $1913^{1}$.

Der Titel dieser neuesten Arbeit Jungs und die Vorrede der Buchausgabe erregen in dem Leser die Erwartung, eine Darstellung der Theorien Fre uds und seiner Schule $z u$ finden. Der Autor will - wie er uns sagt - zu den bisherigen Anschauungen auf Grund seiner eigenen Erfahrungen Stellung nehmen, will durch eine „bescheidene und maßvolle Kritik" die psychoanalytische Bewegung fördern und den Formulierungen $\mathrm{Freuds}$ seine eigenen gegentuberstellen, soweit sie $\mathrm{ihm}$ den beobachteten Tatsachen besser gerecht $\mathrm{zu}$ werden scheinen.

Würde die Schrift inhaltlich diesem Programm entsprechen, so wäre sie als eine Bereicherung unserer Literatur zu begrißen. Eine kurze und klare Einfuhrung in das Studiengebiet der Psychoanalyse wäre uns erwünscht; nicht minder aber sind wir dankbar für jede sachliche Kritik. Daß es geteilte Meinungen in der psychoanalytischen Schule gibt, brauchen wir nicht zu verhehlen; haben doch die "Diskussionen des Wiener psychoanalystischen Vereins" den Streit der Meinungen in unserem Lager dem Forum der Öffentlichkeit unterbreitet.

Allein die Dinge liegen anders. Der Kritiker kann sich in diesem Falle nicht damit begnugen, des Autors Ansichten wiederzugeben und zu beurteilen; es erwăchst ihm außerdem die ungewohnte und nicht eben erireuliche Aufgabe, nachzuweisen, daß Jung den Lehren Freuds eine in tatsächlicher Hinsicht gänzlich unrichtige Darstell u $\mathrm{n} g$ zuteil werden läßt.

Bevor ich mich dem Detail dieser beiden Aufgaben zuwende, muB ich einige allgemeine Eigenschaften der $\mathrm{Ju} \mathrm{ng}$ schen Arbeit hervorheben, die mit den Vorzligen seiner früheren Schriften auffallig kontrastieren. Wie schon die "Wandlungen und Symbole der Libido", enthall sie eine ganze Anzahl innerer Widersprüche, so daB der Leser 'Aus ,Internat. Z. f. årztl. Psychoanalyse", I. 1913. 
über das gleiche Thema an zwei Stellen in entgegengesetzter Weise unterrichtet wird. Mancherorts ist die Darstellung so unklar, dab man dem Gedankengange kaum zu folgen vermag. Bestimmte Lehrsătze werden vom Autor lediglich dekr eti ert, ohne daB ein hinreichender Beweis hinzugefügt wird. Auffällig ist ferner, wie $\mathrm{J}$ u $\mathrm{ng}$ mehrfach seine Grundsătze wissenschaftlicher Forschung und Kritik verkündet, um selber in der gleichen Arbeit gegen sie in der krassesten Weise zu verstoßen. Diese allgemeinen Mängel der Schrift müssen dem kritischen Leser zum AnlaB werden, den speziellen Ausführungen des Autors mit großer Skepsis gegenüberzutreten.

Ich wende mich zunächst $z u$ den Ausführungen $\mathrm{J} u \mathrm{ng} \mathrm{s}$ über Sexualtheorie und infantile Sexualität.

$\mathrm{J}$ ung verteidigt die Erweiterung des Sexualbegriffes, zu welcher Freud sich genötigt sah, in einer anfechtbaren Weise: die psychoanalytische Schule meine mit Sexualität den Trieb der Arterhaltung (Seite 16) ${ }^{1}$. Nur im Vorlubergehen sei hier bemerkt, daB der Trieb der Arterhaltung" nichts ist als eine teleologische Fiktion. Die Triebe des Individuums, und keineswegs nur der Sexualtrieb, dienen i ndire kt a $u$ ch der Arterhaltung; mehr von ihnen in dieser Hinsicht auszusagen, sind wir nicht berechtigt. Ferner liegt es auf der Hand, daß gewisse Manifestationen des Sexualtriebes keinerlei arterhaltende Tendenz in sich tragen; man denke nur an die Homosexualităt. Faktisch aber hat Freud den Sexualbegriff gerade nach der entgegengeset $z$ ten Richtung erweitert: die infantile Sexualität in seinem Sinne strebt lediglich nach Lustgewinnung; die Sublimierungen des Sexualtriebes und die neurotischen Symptome sind nach Freud Derivate des Geschlechtstriebes, die mit der Arterhaltung entweder nur indirekt oder gar nichts $z$ u schaffen haben.

Jung gesteht dann Freud ausdrucklich das Recht zu, die "andeutenden und vorbereitenden Phänomene" der Kinderzeit als sexuell zu bezeichnen; nur "gewissen Konklusionen" möchte er sich nicht anschlieBen (Seite 16). ${ }_{n} \mathrm{~F} \mathrm{reud} \mathrm{ist} \mathrm{geneigt,} \mathrm{auch} \mathrm{im} \mathrm{Akte} \mathrm{des}$ Saugens an der mütterlichen Brust eine Art sexuellen Aktes zu erblicken. Diese Ansicht hat Fre ud schwere Vorwurfe eingetragen, sie ist aber, wie wir gestehen müssen, sehr sinnreich, wenn wir mit Freud annehmen, daß der Trieb zur Arterhaltung, d. h. also die Sexualităt gewissermaßen abgetrennt vom Selbsterhaltungstrieb, d. h. der Ernahrungsfunktion existiere und so auch eine besondere Entwicklung ab ovo durchlaufe. Diese Denkweise scheint mir aber biologisch nicht zulassig zu sein." (Seite 16-17.)

- Die Seitenzahlen bei den Zitaten bezlehen sich auf die Buchausgabe. 
Die zitierten Sătze wlurden uns nicht in Erstaunen setzen, fănden wir sie in der Kritik eines Gegners, der sich mit Fre uds Schriften nicht gentigend vertraut gemacht hat. Denn sie enthalten eine nach $\mathrm{z}$ we i Richtungen hin fälschliche Darstellung, wie man sie von Jung nicht erwarten sollte. Erstens: Freud sieht im Saugeakt selbstverständlich einen Ernährungsakt, welcher jedoch g l e i ch z e itig zur lustvollen Reizung des Mundes (als e rogene $Z$ one) AnlaB gibt. Was $\mathrm{J}$ ung zitiert, deckt sich mit $\mathrm{Fr}$ e uds Ansicht von der Bedeutung des $L$ utschens des Kindes. $Z$ weitens: Freud nimmt selbst eine ursprüngliche Vergesellschaftung und eine erst sekundäre Trennung beider Triebe an ${ }^{1}$.

Nachdem J u ng den ersten Schlag gegen die infantile Sexualität mit sehr fragwürdigen Argumenten gefuhrt hat, holt er $\mathrm{zu}$ einem zweiten aus. -Auf Seite 17 erscheint in Sperrdruck die Proklamation: "Diese $Z$ eit," d. h. die früheste Kindheit, "ist durch das Fehlen sexueller Funktionen gekennzeichnet." So steht es plötzlich da, nur wenige Zeilen entfernt von dem Zugeständnis, das man der Sexualterminologie Freuds nichts vorwerfen könne, indem sie konsequent alle Vorstufen der Sexualität mit Recht als sexuell bezeichnet ${ }^{2}$. Jung begnigt sich mit einigen allgemeinen biologischen Belegen für seine Ansicht; luber eine eigentliche Beweisführung setzt er sich hinweg.

Mit neuem Erstaunen vernimmt man aber auf Seite 18, daß dem

1 Ich zitiere wortlich (Drei Abhandlungen zur Sexualtheorie, Seite 37):

.Es ist ferner deutlich, daB die Handlung des lutschenden Kindes durch das Suchen nach einer - bereits erlebten und nun erinnerten Lust bestimmt wird .. . Es ist auch leicht zu erraten, bei welchen Anlässen das Kind die ersten Erfahrungen dieser Lust gemacht hat, die es nun zu erneuern strebt. Die erste und lebenswichtigste Tătigkeit des Kindes, das Saugen an der Mutterbrust.... muß es bereits mit dieser Lust vertraut gemacht haben. Wir würden sagen, die Lippen des Kindes haben sich benommen wie eine erogene $Z$ one, und die Reizung durch den warmen Milchstrom war wohl die Ursache der Lustempfindung. Anfangs war wohl die Befriedigung der erogenen Zone mit der Befriedigung des Nahrungsbedürfnisses vergesellschaftet. Wer ein Kind gesăttigt von der Brust zurücksinken sieht, mit geröteten Wangen und seligem. Lächeln in Schlaf verfallen, der wird sich sagen müssen, daß dieses Bild auch fur den Ausdruck der sexuellen Befriedigung im späteren Leben maßigebend bleibt.

Nun wird das Bedürnis nach Wiederholung der sexuellen Befriedigung von dem Bedürinis nach Nahrungsaufnahme getrennt.*

J u ng behauptet übrigens weiter, Fre ud leite von der Änlichkeit, die zwischen der Erregung und Befriedigung beim Saugakt und den analogen Erscheinungen beim Sexualakt bestehe, die sexuelle Qualitat des Saugaktes her! Ich uberlasse es dem Leser, die Richtigkeit dieser Darstellung an der Hand vorstehenden Zitates zu prüfen.

2 Vom Ref. in Sperrdruck gesetzt. 
Lutschen des Säuglings "schon viel eher" sexuelle Qualität zugesprochen werden düre, als dem Saugakt. Nichts anderes war ja von Freud behauptet worden! Jungs unbestimmte Ausdrucksweise hängt innig mit der Schwäche seiner Beweisführung zusammen; sie wird uns noch öfter wieder begegnen. Aus der schwierigen Lage, in die er sich gebracht hat, zieht er sich mit sehr schwachen Argumenten heraus und entscheidet ("beweist" wäre zu viel gesagt), daB das Lutschen nicht Sexuallust, sondern "Ernährungslust" sei.

Doch es kommt noch besser! Jung erkennt plötzlich, indem er von der Masturbation ausgehend, die Entwicklung zu den frühkindlichen "Unarten" (Nägelkauen etc.) und endlich zum Lutschen $\mathrm{rä} \mathrm{ckwärts}$ verfolgt, alle diese Erscheinungen als Vorstufen der Masturbation und damit als sexuell an (Seite 18); nur bezüglich des Lutschens drückt er sich in einem späteren Satz wieder reservierter aus.

Was heiBt das anderes, als in den klaren und vorsichtigen Aufstellungen $\mathrm{F} r \mathrm{e} u \mathrm{~d} \mathrm{~s}$ eine heillose Verwirrung anrichten? Keinem Leser ist es möglich, aus den widerspruchsvollen Ausfährungen die eigentliche Meinung des Autors zu entnehmen. Jung aber, der es auf Seite 8 für ungerecht erklärt hat, „einem Geiste, wie F r e u d, plumpe Lehrlingsfehler zuzumuten", wirft - gänzlich blind für die Mängel seiner eigenen Beweisführung - auf Seite 18 seinem "verehrten Lehrer" den groben logischen Fehler der petitio principii vor. Oder er argumentiert mit Sătzen wie: "Lustgewinnung is t ke ineswegs ident isch $m$ it Sexualita t." Bisher hatten wir derartige Einwände nur von Gegnern gehört, die damit etwas $z \mathfrak{u}$ widerlegen meinten, was Fr e u d behauptet haben sollte.

Einige weitere Willkürlichkeiten $\mathrm{J}$ u $\mathrm{ng} \mathrm{s}$ in seinen Ausführungen über die frühesten Sexualäußerungen übergehe ich und komme zu seiner Kritik der „polymorph perversen“ Anlage des Kindes.

Die einschlägigen Anschauungen $\mathrm{Freuds}$ (Erogene Zonen, Partialtriebe) finden eine höchst mangelhafte Wiedergabe, aus der sich niemand eine wirkliche Orientierung $\mathrm{zu}$ holen vermag. J u ng gibt dann folgendes Resumee:

"Nach dieser Betrachtungsweise setzte sich also die spătere normale und monomorphe Sexualität aus verschiedenen Komponenten zusammen. Zuerst zerfällt sie in eine homo- und eine heterosexuelle Komponente, dann gesellt sich dazu eine autoerotische Komponente, dann die verschiedenen erogenen Zonen usw."

So viele Worte, so viele Unrichtigkeiten! J u ng vernachlässigt in seiner Darstellung vollkommen, daB es sich um Entwicklungsstadien handelt. F r e u d hat die frühesten Äußerungen der Libido autoerotisch 
(objektlos) genannt, und hat ausgefuhrt, wie die Libido sich mehr und mehr, aber nie absolut, von den erogenen Zonen, an die sie zuerst gebunden ist, frei macht, wie die ursprtinglich autonomen erogenen Zonen sich dem Primat der Genitalzone unterordnen, und wie auf diesem Wege die "normale" Sexualităt des Erwachsenen 'entsteht; vor allem hat $\mathrm{Fre} \mathrm{u}^{-\mathrm{d}}$ auch den ProzeB der Objektfindung eingehend gewürdigt. Unter Weglassung alles Wesentlichen gibt $\mathrm{J}$ u $\mathrm{n} \mathrm{g}$ nur die verkehrte Darstellung, daB nach F re u d die Sexualität "zuerst" (sic!) in eine homosexuelle und heterosexuelle Komponente "zerfalle". Freud spricht übrigens überhaupt nicht von einer autoerotischen Komponente; noch weniger sagt er aus, daB sie sich früheren Formen der Sexualität "hinzugeselle". J u n g stellt hier die Ansichten Fre u d s geradezu auf den Kopf.

$\mathrm{J}$ u $\mathrm{ng}$ gibt seinen Lesern ein durchaus unrichtiges Bild, wenn er behauptet, F r e u d habe die Sexualitat kunstlich zerspalten. Das gerade Gegenteil ist der Fall. F r e ud hat eine große Zahl von Erscheinungen, die früher völlig unverstanden waren, unter dem Gesichtspunkt der Sexualităt vereinigt. Er hat durch die Erforschung der infantilen Sexualităt $z$ wischen dem Triebleben des Kindes und dem des Erwachsenen eine Kontinuität hergestellt, die vorher fehlte. Er hat nachgewiesen, -daB vielerlei Triebregungen, die in unvereinbarem Gegensatz zueinander zu stehen schienen, tatsächlich einander ergänzen und sich zur Einheit zusammenschließen. Kurz, er hat die großen, vereinigenden Gesichtspunkte in die Sexualtheorie und Neurosenlehre erst eingefuhrt.

Ferner hat niemand die Transformationsfähigkeit der Libido je in dem MaBe gewlirdigt wie Freud. Man denke nur an seine Theorie von der Entstehung neurotischer Symptome, an seine Lehre von der Sublimierung und Reaktionsbildung, an seine Termini: Objektbesetzung und Zurückziehung der Libido vom Objekt usw. Doch er muß es sich gefallen lassen, daB $\mathrm{J} u \mathrm{ng} \mathrm{ihm}$ vorwirft, die Libido in feste, starre Komponenten zerlegt zu haben. Jungs Prătentionen gehen an dieser Stelle derart aber das berechtigte $\mathrm{MaB}$ hinaus, daB ein entschiedener Protest am Platze ist. Nicht nur, daB er die Einfuhrung einigender Gesichtspunkte in die Psychologie sich selbst zuschreibt; er vergleicht dieses sein Werk sogar mit der Einführung des Energie-Begriffes in die Physik - als ob die energetische Auffassung der Psychoanalyse bisher völlig iremd gewesen wäre. Neu ist in Wirklichkeit nur ein bedenklicher Fehler: die Vermeng ung psychologischer, biologischer und physikalischer Gesichtspunkte '. J u n g aber fordert: Sowie in der

1 Wie vorsichtig F re u d im Gegensatz zu J ung nach dieser Richtung verfăhrt, zeigt sein Artikel über „das Interesse an der Psychoanalyse*. (In „Scientia*, 1913.) 
Physik die Optik, Mechanik etc. ihre Selbständigkeit eingebüBt hătten, so müsse es auch mit den "festen" Sexualkomponenten geschehen. Freuds "Partialtriebe" seien den "Seelenvermögen" der alteren Philosophie an die Seite $z u$ stellen.

Was setzt nun Jung an Stelle dessen, was er beseitigt? Seinen gänzlich vagen Libidobegriff und die "Anwendungsmöglichkeiten" der Libido. Auf eine Kritik des $\mathrm{J}$ ung schen Libido-Begriffs brauche ich hier nicht einzugehen, sondern verweise nur auf Ferenczis treffende Ausführungen in Nr. 4 des I. Jahrgangs der Zeitschrift f. Psa., denen ich nur gewisse Ergänzungen hinzufügen werde.

Was aber die "Anwendungsmöglichkeiten" der Libido betrifft die ja labrigens längst Gemeingut der Psychoanalyse waren - so entbindet deren Feststellung nicht von der Aufgabe, die "Möglichkeiten“ zu erklären. Fre ud bat sich hier auf Beobachtungen, auf biologische Tatsachen gestutzt, unter denen ich nur die Bisexualitat als Beispiel erwăhnen will. Die V e r d ră n g u n g erklărt dann weiter die Herrschaft einer Gattung von Triebregungen im BewuBtsein, während die entgegengesetzten ins Unbewußte verdrăngt sind. $\mathrm{J}$ u $\mathrm{n} g$ begnügt sich dagegen mit Worten, die uns nichts bedeuten können. Aus einem von ihm kurz wiedergegebenen Krankheitsfall zitiere ich: ${ }_{\text {}}$ Die Enttãuschung trieb seine (des Patienten) Libido von der heterosexuellen Anwendungsweise weg, so dab sie wieder in die ho mosexu ell e Form geriet." $\mathrm{J}$ u $\mathrm{n} \mathrm{g} \mathrm{s}$ Ausdrucksweise ist hier wieder äußerst unklar. Was soll man sich unter der "homosexuellen Form" vorstellen? Vor allem aber sollte der Autor, der mit solchen Worten umspringt, eine Erklärung geben, woher denn die Libido die Fahigkeit hat, andere „Formen“ zu wählen. Es ist zu betonen, daB F r e u d in seinen "Drei Abhandlungen" gerade zuerst das b i o lo g i s ch e Fundament herstellt, um seine Sexualtheorie darauf aufzubauen. J ung dagegen führt seinen Libido-Begriff, d. h. eine philosophische Konstruktion ein und legt die Tatsachen im Sinne dieser Theorie aus.

Wie vage $\mathrm{J}$ u $\mathrm{n}$ g s Begriff von der Libido und deren "Anwendungsmöglichkeiten" ist, illustriert eine spätere Stelle der Schrift (Seite 79). In einem Beispiel führt $\mathrm{Jung}$ dort aus: Ein Bergsteiger, der eine ersehnte Bergspitze nicht $z u$ erklimmen vermochte, werde fortan nseine Libido zu nützlicher Selbstkritik verwenden". Wie der Alpinist das macht, fügt $J u n g$ leider nicht hinzu. Wenn er es aber weiB, so möchte man wünschen, daß er selbst in Zukunft von dieser Anwendungsmöglichkeit der Libido ausgiebigen Gebrauch mache.

Die "polymorph-perverse Anlage" des Kindes kann J u n g nicht wegleugnen. Er druckt sich aber zu diesem Thema sehr gewunden und 
schwankend aus (Seite $25 \mathrm{f}$ ). Einmal fallen jene Äußerungen im Kindesalter sehr in die Augen, sind sogar reichhaltiger als beim Erwachsenen, dann wieder handelt es sich nur um "Andeutungen". Von diesen Andeutungen aber sagt $J$ ung, daß sie $n$ noch ganz den Charakter der kindlichen, unschuldigen und harmlosen $\mathrm{Naivität}$ tragen ${ }^{1}$.

Diese "Harmlosigkeit" des Kindes betont Jung immer von neuem; ja er setzt später hinzu, das Kind sei planmäßiger Absichten nicht fähig! (Seite 63).

$\mathrm{J}$ u n $\mathrm{g}$ setzt sich damit nicht bloß über seine früher geäußerten Ansichten hinweg (was ja selbstverständlich jedem freisteht), sondern er miBachtet $\mathrm{T}$ at $\leqslant$ a $\mathrm{ch}$ en, die er früher selbst publiziert hat. Was aber will er mit dem bestandigen Hervorheben der kindlichen "Harmlosigkeit" sagen?

Es ist eines der großen Verdienste $\mathrm{Freuds}$, die ethische Bewertung der kindlichen Triebregungen aus der Psychologie beseitigt zu haben. Diese Regungen sind für den Psychoanalytiker Naturerscheinungen, die er beobachtet, und die er zu verstehen sucht. Sie sind ebenso wenig harmlos wie etwa böse zu nennen. Konsequent hat Freud auch die Amoralität des UnbewuBten angenommen. Denn den Grundstock des UnbewuBten bilden ja nach unserer Anschauung die verdrängten kindlichen (primitiven) Triebregungen. Jung bahnt einen bedenklichen wissenschaftlichen Rückschritt an, indem er seinen Lesern immer wieder die Harmlosigkeit der kindlichen Triebe versichert. Schlimmer freilich ist es, daß er hernach dem Unbewußten sogar moralische Tendenzen zuschreibt.

Die von Jung aufgestellten drei Stadien der Libido-Entwicklung sind von Ferenczi bereits kritisiert worden. Ich gehe, unter Bezugnahme auf Ferenczis Ausführungen, sogleich $z \mathbf{u}$ weiteren Behauptungen Jungs uber, die in den "Wandlungen" noch nicht in gleicher Weise enthalten waren, und die doch Jungs Vorgehen gegen die Freudsche Lehre vortrefflich charakterisieren.

Ganz unrichtig ist Jungs Behauptung, Freud erkläre den Unterschied $z$ wischen kindlicher und reifer Sexualität „aus dem Diminutiv des Infantilen".

Weiterhin sucht Jung (Seite 38-39) den ursprünglichen Polymorphismus der Sexualität daraus zu erklären, daß Ernährungslibido vom Munde aus in andere Bahnen überwandere. Er meint, ein betrăchtlicher Teil der Hungerlibido setze sich in Sexuallibido um. 
Der Versuch, den Mund allein zum Ausgangspunkt dieser völlig hypothetischen - Libido-Wanderung zu machen, zeigt die ganze Einseitigkeit der Jung schen Ideen. Jung vernachlässigt die ubrigen erogenen Zonen (mit Ausnahme des Mundes) vollstăndig, und dies ist sicher einer der größten wissenschaftlichen Rückschritte. Aber handelt es sich denn nur um körperliche Erscheinungen der Libido? Wie will Jung denn z. B. die sexuelle Neugierde und die Exhibitionslust des Kindes erklären?

Eine der angreifbarsten Partien der Jung schen Arbeit ist die den "Odipus-Komplex“ behandelnde. Die Ausführungen (Seite $62 \mathrm{f}$ ) leiden an großer Unklarheit. Vergebens sucht man aus den vagen Ausdrücken etwas Bestimmtes zu entnehmen. Der Grund dieser Unklarheit ist leicht genug zu erkennen. Er liegt in der Vernachlässigung der Verdrängung und des Unbewußten. Das Wort "Verdrängung" kommt zwar hir und wieder in Jungs Schrift vor, aber stets wird es in einer ganz unbestimmten Weise angewandt; es hat eben seinen Inhalt verloren. Das Unbewaßte gibt in dieser "Darstellung" der Psychoanalyse ebenfalls nur gelegentliche Gastrollen. Nirgends finden wir eine klare Stellungnahme $z \mathfrak{u}$ den fundamentalen Problemen des Unbewußten. J u n $\mathrm{g}$ stellt unvermittelt gewisse Behauptungen auf, wie etwa: „Im Unbewußten des Kindes vereinfachen sich die Phantasien beträchtlich", oder: "Im Unbewußten gewinnen diese Wünsche und Absichten eine konkretere und drastischere Form ". Aber er bleibt jede Erklärung des Unbewußten und der unbewußten Phänomene schuldig.

$\mathrm{Daß}$ Jung in der Ödipus-Einstellung nur ein Symbol erblickt, und den inzestuösen Regungen jede reale Bedeutung abspricht, ist schon aus dem II. Teil seiner "Wandlungen und Symbole der Libido" bekannt; ich beziehe mich hier wieder auf Ferenczis Kritik. Nirgends wird es so klar wie an dieser Stelle des Buches, daB Jung sich auf dem Rückweg von der Psychoanalyse zur OberflächenPsychologie befindet. Dafür nur ein Beispiel. Wir finden auf Seite 63 die Behauptung, im frühen Alter habe die Mutter für das Kind "natürlich keinerlei irgendwie nennenswerte Sexualbedeutung". Es ist noch nicht gar lange - ich verweise auf den ersten Teil seiner "Wandlungen" - daß J u n g das Gegenteil des nunmehr Ausgesagten ebenso natürlich fand. Zum Beweise seines jetzigen Lehrsatzes beruft sich der Psychoanalytiker $\mathbf{J}$ u $\mathbf{n g}$ aber auf eine amerikanische Ärztin, die von Kindern durch eine Umfrage erfuhr, daB die Mutter gern als diejenige definiert wird, die das -Essen gibtl Also nachdem Jung - wie er in der Einleitung des Buches bemerkt - zehn Jahre lang Psychoanalyse betrieben hat, genügen ihm plötzlich Angaben 
der Kinder, die nichts anderes enthalten können, als nur das Bewußte und Konventionelle! Wozu dann noch die mühsamen Psychoanalysen? $\mathrm{J} u \mathrm{ng}$ bemerkt es nicht im geringsten, daB er auf diese Weise in die nächste Nachbarschaft der psychologischen Sammelforscher (wie W. Stern u. a.) gerät.

$\mathrm{J} u \mathrm{n} g$ benutzt diese Gelegenheit, um nochmals auf die Bedeutung der Ernährungslust hinzuweisen. Dabei versteigt er sich $z \mathfrak{u}$ folgenden Sätzen: „Die großen Schmausereien des dekadenten Rom beruhten meinetwegen auf allem anderen, nur nicht auf verdrängter Sexualität, denn diese könnte man den damaligen Römern am wenigsten vorwerfen. $\mathrm{DaB}$ auch diese Exzesse ein Ersatz waren, ist nicht $\mathrm{zu}$ bezweifeln, aber nicht für die Sexualität, sondern für die vernachlässigten moralischen Funktionen ...."

Bei dem unkundigen Leser muB hier der Eindruck entstehen, als habe Fre u d - dem man freilich keine logischen Lehrlingsfehler zuschreiben wollte! - einmal solch handgreiflichen Unsinn behauptet. Wer aber jemals in Freuds Schriften irgend eine Stelle las, die sich mit kulturhistorischen Fragen beschäftigte, der wird sich erinnern, daß dort ein anderer Geist weht. Jungs oben zitierte Bemerkung fällt somit in ihrer ganzen Plattheit ohne weiteres auf ihren Urheber zurück.

Für das Ausbleiben des Inzestes in der Kulturmenschheit gibt $\mathrm{Jung}$ die höchst unzulängliche Begründung, daß das Alltägliche seinen Reiz für den Menschen verliere. Alle kulturhistorischen Tatsachen und nicht minder die individual-psychologischen geben dieser Anschauung Unrecht.

Die "Ödipus-Phantasie" bildet sich nach J un g "mit wachsender Reifung" aus und tritt in der "Nachpubertätszeit" "mit der nunmehr erfolgten Abtrennung von den Eltern in ein neues Stadium", dessen Symbol das in den "Wandlungen" ausführlich behandelte "Opfer" ist. Nach $\mathrm{Jung}$ erscheint in dieser Zeit die unbewuBte Phantasie des Opfers, d. h. der Vorsatz zum "Aufgeben der Infantilwünsche".

Vergeblich suchen wir nach einer Erklärung dieses Phänomens. Das UnbewuBte hat moralische Tendenzen erhalten, es opfert. Alle bisherigen Erfahrungen, von denen $\mathrm{J} u \mathrm{n} g$ keine widerlegt, zeigten uns die Amoralität des Unbewußten, das rücksichtslos-egoistische Drängen der ins UnbewuBte versunkenen Triebe. Freuds Lehre schuf neben der Verdrängung den wertvollen Begriff der Sublimierung. Durch diesen letzteren ProzeB wird es den verdrängten, vorher unsozialen Triebregungen ermöglicht, in verwandelter, d. h. sozial verwertbarer Form ins Bewußtsein zurückzukehren. Jung $s$ "Darstellung " würdigt diesen Vorgang keiner Erwähnung. In $\mathrm{J} u \mathrm{n} g \mathrm{~s}$ Ausführungen ist das 
Unbewußte, wie schon oben gesagt, etwas völlig Unbestimmtes; aber nicht nur das. Indem es in einem bestimmten Lebensalter plötzlich eine Phantasie produziert, der $\mathrm{Jung}$ mit dem Namen "Opfer" eine ausgesprochen religiöse Färbung gibt, wird dieses UnbewuBte zu einer Art von mystischem Urgrund. An dieser Stelle hört Jung faktisch auf, Psychoanalytiker zu sein und wird Theologe.

Einen weiteren Rückfall in die Oberflächenpsychologie muB ich darin erblicken, daß $\mathrm{Ju} n \mathrm{~g}$ zwischen den seelischen Konflikten des Kindes und denen des Erwachsenen eine scharfe Grenze zu ziehen sucht (Seite 67-68). Ich zitiere: "Jene Fälle, die schon seit Kindheit an einer chronischen Neurose leiden, leiden nicht mehr am selben Konflikt wie in der Kindheit. Die Neurose brach vielleicht aus, als das Kind zur Schule mußte. Damals war es der Konflikt $z$ wischen verwöhnter Zärtlichkeit und Lebenspflicht, d. h. zwischen der Liebe zu den Eltern und dem Zwang zur Schule. Heute ist es der Konflikt $z$ wischen den Freuden einer bequemen burgerlichen Existenz und den rigorosen Anforderungen des Berufslebens. Es scheint nur, als ob es noch derselbe frühere Konflikt wäre." Leider vergißt $\mathrm{Jung}$ hier, den Unterschied wirklich $z u$ präzisieren. $\mathrm{DaB}$ der erwachsene Neurotiker, der der Schule entwachsen ist, durch eine Neurose sich nicht mehr der $\mathrm{Sch}$ ul e entzieht, ist eine banale Selbstverständlichkeit. Der Konflikt hat also höchstens sein äußeres Gewand gewechselt. Fr e u ds Verdienst ist es gerade, in den verschiedensten Metamorphosen die gleichen Konflikte wiedererkannt zu haben. Jung s Auffassung ist hier so reaktionär, wie die der "oppositionellen " Kritiker, uber die er sich in der Einleitung der Schrift so erhaben dünkte.

Die Einwände $\mathrm{J}$ ungs gegen die Bedeutung der Inzestwünsche als Kernkomplex der Neurose waren teilweise längst zurückgewiesen, ehe Jung sie erhob. Im labrigen hat Ferenczi bereits zu dieser Frage Stellung genommen. Ich gehe daher auf $\mathrm{Jungs}$ Ansicht betreffend die rein regressive Bedeutung dieses Phänomens nicht ein. Nur einer von Jungs Einwänden mag hier herausgegriffen werden. Die Ödipusphantasie könne, so meint $\mathrm{Jung}$, nicht pathogen sein, weil sie allgemein menschlich sei; sie bedürfe, um pathogen zu werden, erst "einer besonderen Aktivierung “. Die tatsächliche Stellungnahme der Psychoanalyse zu dieser Frage ist zu bekannt, als $\mathrm{daB}$ es sich lohnte, sie hier auseinander $z u$ setzen! Ich habe diesen Einwand Jung s auch nicht hierher gesetzt, um ihn zu widerlegen, sondern nur darum, weil er geeignet ist, die innere Haltlosigkeit der Beweisführung Jungs klarzustellen. J ung erklärt (Seite 116), der Inzestkomplex werde "wiederbelebt" durch die Bequemlichkeit 
des Menschen, die ihn vor Anpassungsleistungen zurückschrecken lasse. Er muB aber an gleicher Stelle die "Bequemlichkeit“ als allgemein menschlich bezeichnen! Damit führt Jung sich selbst ad absurdum. Er versprach, an Stelle der zu allgemeinen Ursache der inzestuösen Einstellung eine spezifische zu geben, und dann verfällt er auf die "Trägheit", bekanntlich die allgemeinste Eigenschaft der Materie überhaupt!

Besonders scharf wendet sich $\mathrm{J} u n g$ gegen den Begriff der "Latenzzeit“; nirgends sind in Wirklichkeit seine Angriffe weniger berechtigt als hier. Fre ud hat (Seite 35 der "Drei Abhandlungen“) die "hypothetische Natur und die mangelhafte Klarheit unserer Einsichten in die Vorgänge der kindlichen Latenz- oder Aufschubsperiode" ausdrücklich zugestanden. Ju ng, der auf Seite 19 erklärt, Theorien seien nur Vorschlage, wie man Dinge betrachten könne, verliert diesen seinen Grundsatz gegentuber dieser Theorie Fre uds ganz aus den Augen. Freud sah sich, ubrigens in Anlehnung an FlieB, genötigt, eine Latenzperiode anzunehmen und hat ihr - was Jung ganz verschweigt - die wichtige Aufgabe zugewiesen, Hemmungen gegen die primitiven Triebe auszubilden. Freud hat ferner betont, daB Äußerungen der Libido in der Latenzzeit keineswegs fehlen, und sie als "Durchbrüche" bezeichnet. Danach ist also auch Jungs Vergleich mit der Blume, die sich in eine Knospe zurückverwandelt, hinfällig. Die inneren Widersprüche sind übrigens gerade in diesem Teil der $\mathbf{J}$ u $\mathrm{n} g$ schen Arbeit besonders in die Augen springend.

$\mathrm{Jung}$ erhebt Widerspruch gegen Freuds Auffassung der infantilen und neurotischen Amnesie, welch letztere nach $F_{\text {r }}$ u d dem Vorbild der kindlichen Amnesie folgt. $\mathrm{J}$ u $\mathrm{ng}$ findet hier einen schroffen Gegensatz und erklärt den Ausdruck "Amnesie" für die frühe Kindheit für "absolut unrichtig". Die von Jung gegebene Unterscheidung beider Phänomene (ich verweise auf Seite 73) entspricht aber den Beobachtungen an Kindern und Neurotikern nicht im geringsten; er stellt hier wieder einmal eine Behauptung aus eigener Mach tvollkommenheit auf. Ich brauche zur Widerlegung $\mathrm{J}$ ung $\mathrm{s}$ nur auf diejenigen Neurosen zu verweisen, in denen die Erinnerungslosigkeit für die erste Kindheit sich nicht wie gewöhnlich bis ins fünfte oder sechste Jahr erstreckt, sondern bis ins elfte Jahr, oder noch darüber hinaus. Hier geht die infantile Amnesie in die neurotische unmittelbar uber; von einem absoluten Gegensatz zu sprechen, ist darum ganz unstatthaft.

lch bin hier bei den Fragen der Neurosenlehre angelangt. Hier kann ich mich kürzer fassen, da sich im Grunde nur das gleiche Spiel wiederholt. Freuds Theorie der Hysterie wird in einer ganz 
mangelhaften Weise dargestellt. Jung verweilt mit größter Ausfuhrlichkeit bei der alten "Trauma-Theorie" (die er ubrigens fälschlich als eine

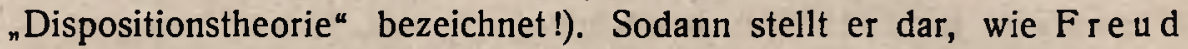
dazu gelangte, den neurotischen $\mathrm{Ph}$ a $\mathrm{n}$ t a s i en eine größere Bedeutung beizulegen. Über die Lehre von der besonderen psychosexuellen Konstitution der Neurotiker, von den verdrängten Wünschen als treibenden Kräften der Neurose, von der Ambivalenz der Gefühlsregungen bei den Neurotikern usw. erfährt der Leser aber kein Sterbenswörtchen. In der Darstellung eines Hysteriefalles führt Jung (Seite $41 \mathrm{f}$ ) aus, wie die "alte Theorie" es sich dachte. Er stellt es hier, und später noch zu wiederholten Malen (vgl. Seite 46, Seite, 76 und 77) so dar, als beharre Freud noch in der Traumalehre uns suche die Ursachen der Neurose lediglich in der Vergangenheit. Dieses Verfahren Jung s ist um so anfechtbarer, als er es vorher den "oppositionellen" Kritiken ausdrücklich verwiesen hatte.

Die mangelhafte Anpassung des Neurotikers an die Realität, auf die Jung mit Recht so großen Wert legt, ist von Fr e u d (vor allem in dem Aufsatz uber die „zwei Prinzipien des psychischen Geschehens “) eingehend gewürdigt worden. Um Spezielleres zu nennen, so hat F r e u d (cf. "Bruchstück einer Hysterieanalyse") besonders betont, daß der Neurotiker vor den realen Anforderungen, die an seine Sexualităt herantreten, zurückscheut. In der Arbeit über die Zwangsneurose (1909) behandelt er speziell das Ausweichen des Kranken vor jeder Entscheidung. Ganz besonders aber zeigt der Artikel "Neurotische Erkrankungstypen" (1912), daB F r e u d den aktuellen Konflikt im Neurotiker in vollem Maße berücksichtigt. Aber er erkannte, daß dieser nur eine Neuauflage früherer Konflikte sei und betonte darum die Bedeutung der letzteren. Wenn Jung nun den Aktualkonflikt als allein wesentlich für das Verständnis der Neurose bezeichnet, so ist das nicht etwa eine originelle Idee seinerseits, sondern er schlägt nur den Irrweg der nichtanalytischen Neurologie wieder ein, den Fre ud uns vermeiden gelehrt hatte.

Nachdem Jung die Methode Freuds als rein historisch verworfen hat, kann er nicht umhin zu gestehen, daß Freud "die finale Orientierung der Neurosen in gewissem MaBe anerkennt" (Seite 77). Vielleicht ist dieses das stärkste Stück, das $\mathrm{J}$ u $\mathrm{n} \mathbf{g}$ sich in seiner "Darstellung" der Psychoanalyse geleistet hat. Ist es denn nötig, auf das zu verweisen, was $\mathrm{Fr}$ e u d in Wirklichkeit über die T e n d e n z e $\mathrm{n}$ der Neurose, über die Symptome als Darstellungsmittel unbewuBter W ansche gelehrt hat? Allerdings hat $\mathrm{Fr}$ u d sich nicht dazu verstiegen, diese Tendenzen der Neurose mit einer metaphysisch $\mathbf{z u}$ verstehenden Finalităt zu verquicken. Es widersteht mir, in dieser Sache 
weitere Worte zu verlieren. Alles wirklich Geleistete ist hier F re uds ausschlieBliches Eigentum, während $\mathrm{J} \mathfrak{u} \mathrm{ng}$ nichts anderes als die uberflüssige Vokabel "finale Orientierung" hinzugetan hat ${ }^{1}$.

Nach J u n g ist der Neurotiker von den "Pflichten " zurückgewichen, die er im Leben zu erfüllen hat. Den Tatsachen wird diese Auffassung aber keineswegs gerecht. Statt vieler Gegengründe nenne ich nur einen. Wir finden unter den Neurotikern eine große Zahl der ausgesprochensten ${ }_{\text {"Pflichtmenschen }}$, die in ihrer Arbeit oder in sonstigen Aufgaben völlig aufgehen, Geht man auf solche Neurotiker genauer ein, so stellt sich regelmäBig heraus, daB bestimmte Hemmungen der Libido (ich meine natürlich den sexuellen Sinn dieses Wortes) ihnen die Befriedigung versagen, und daß die Arbeit ihnen als Ersatzbefriedigung dient. Jungs Auffassung ist nicht etwa ein originelles Produkt, sondern lediglich die alte Freudsche Auffassung vom Zurückweichen vor der realen Sexualforderung; Jung hat sie nur "desexualisiert", um ein von ihm geschaffenes Wort zu gebrauchen.

Die Bedeutung des UnbewuBten in der Neurose sinkt bei Jung fast auf Null herab. So lesen wir: "Sie (d. h. die neurotischen Phantasien), sind öfter nur als gefühlsmäBige Erwartungen, Hoffnungen, Vorurteile usw. vorhanden. Man nennt die Phantasien in diesem Falle unbewußt." Es bedarf kaum des Hinweises, daB es sich hier um eine volllige Verwässerung des „Unbewußten" handelt. Eine Begründung für diese Änderung der psychoanalytischen Auffassung des Unbewußten gibt Jung nicht.

Jung scheint den Terminus "Verdrăngung" geflissentlich zu vermeiden. Wir finden statt seiner allerhand unklare Wendungen, wie: "Die Libido wurde nicht anerkannt" (Seite 72) u. a. m.

Von der "Ubertragung " ist ausführlich die Rede, ohne daß Jung Wesentliches $\mathrm{zu}$ dem Bekannten hinzufügte. Dagegen findet das Phänomen des "Widerstandes" fast gar keine Berücksichtigung.

Ein wichtiger Gesichtspunkt Freuds, den Jung der ${ }_{n}$ Regression" vollkommen zum Opfer bringt, ist das $\mathrm{Haften}$ ble ibe n des Neurotikers im Infantilen.

Gegen den Schluß der Schrift gibt Jung eine Psychoanalyse wieder, die an einem elfjährigen Mädchen angestellt wurde. Die Vernachlässigung des Unbewußten trägt auch hier zur Verwirrung Erhebliches bei. Übrigens ist es bemerkenswert, daß dieses Kind sich den $\mathrm{Jungschen}$ Anschauungen in wesentlichen Beziehungen widersetzt. Ich erwähne nur, daß es im fünften Lebensjahre eine groBe sexuelle

1 Auf die ,fördernde und vorübende" Tendenz der neurotischen Phantasien werde ich an anderer Stelle eingehen. 
Neugierde entfaltete und im gleichen Alter gewisse Strampelbewegungen ausführte, denen nach $\mathrm{Jung}$ "einè sexuelle Unterströmung zuerkannt werden muBa. Der letztere Ausdruck leistet wieder das möglichste an Unklarheit.

Die letzte Grundlage der Neurose sieht $\mathrm{J}$ ung in der nangeborenen Empfindsamkeit" (Seite 92). Da er selbst darin "nur ein Wort" sieht, so erübrigt sich jede Diskussion. Ich meine, auch hier hat $F$ reud uns Greifbareres geboten.

Ganz kurz fasse ich mich bezuglich der Ausführungen $\mathrm{J}$ ung s zur Frage der Dementia praecox; ich kann mich auch hier wieder nur dem Urteil Fe r e n $\mathrm{z} z$ is anschließen. Bei der Frage des "Realitätsverlustes" nimmt Jung die gleiche Stelle aus Freuds ParanoiaAnalyse zum Ausgangspunkt wie schon in seiner früheren Arbeit. Jung hatte dort von den zwei Möglichkeiten, die Freud zur Aufklärung des "Weltunterganges" vorschlug, gerade diejenige unberücksichtigt gelassen, welcher Freud sich zuneigte. Er versucht sich nunmehr auch mit dieser zweiten Erklärung des Verlustes der "fonction du réel " auseinanderzusetzen. Eine Widerlegung Freuds gelingt ihm dabei jedoch meines Erachtens in keiner Weise.

$\mathrm{J}$ un $\mathrm{g} \mathrm{s}$ Ausführungen über $\mathrm{T} \mathrm{r}$ a u $\mathrm{m}$ müssen unseren Widerspruch in mehrfacher Hinsicht erregen. Auch hier gibt Jung F re uds Theorie mangelhaft wieder, wenn er sagt, die Deutungstechnik bestehe darin, daß "man sich zu erinnern suche, woher die Traumstücke stammen". (Seite 55).

$\mathrm{Jung}$ ist ferner im Irrtum, wenn er Freuds Traumdeutung als eine "absolut historische Methode“ kennzeichnet. Freud sucht ja gerade nach den $W$ ü $\mathrm{nschen}$, die sich in mancherlei Verkleidung im Traume verbergen. Diese Verkleidung ist aber nur aus historischer Forschung zu verstehen. Die Tendenz des Traumes ist etwas in die Zukunft Weisendes; nur kommt hinzu, daB der Träumer sich die Zukunft in seinen unbewuBten Phantasien nach dem Bilde der frühesten Vergangenheit gestaltet.

Jung verlangt eine weitergehende Berlicksichtigung der „teleologischen" Funktion der Träume gegenüber der bloBen Berücksichtigung der historischen Determinierung durch Freud. Dieses "prospektive" Element im Traum ist uns nun aber längst bekannt. Jeder Psychoanalitiker begegnet ihm täglich bei seinen Traumanalysen. Fre ud hat schon in seiner "Traumdeutung" (1900) darauf hingewiesen, daB Vorsätze und dergleichen im Traum nur eine Oberschicht darstellen; die Psychoanalyse hat gerade die Aufgabe, die tiefere Schicht bloßzulegen. In einer späteren Schrift ( ${ }_{n}$ Bruchstück einer 
Hysterieanalyse", Kleine Schriften zur Neurosenlehre II, Seite 76f.) hat F r e u d seine Ansicht über diesen Punkt noch genauer auseinandergesetzt. Die "prospektive Tendenz" ist also gleichfalls keine originelle Entdeckung Jungs oder Maeders, sondern lediglich ein neuer Straßenname für einen Irrweg, den $\mathrm{F} r \mathrm{eu} d$ von vornherein vermieden hat. Das gleiche gilt für die analoge Funktion, welche $\mathrm{Jung}$ der Neurose zuschreibt.

Ich habe im obigen eine ganze Reihe von anfechtbaren Positionen J ung $s$ unberücksichtigt gelassen, besonders da, wo F e r e n c z i mir bereits vorgearbeitet hat. Ich erwähne noch speziell, daB ich aus diesem Grunde ein Eingehen auf $\mathrm{J}$ ungs psychotherapeutische Technik unterlassen habe.

Ich glaube aber, den Nachweis erbracht zu haben, daß J u ng nicht - wie er es behauptet - eine organische Weiterentwicklung (Seite 135) der F r e udschen Gedanken gibt. Um einen Ausdruck von ihm selbst (Seite 135) zu gebrauchen, stellt er sich faktisch nur "mit möglichst veränderter Nomenklatur auf einen möglichst gegensătzlichen Standpunkt". Und wenn Jung im Vorwort erklärt, er sei „weit entfernt, in einer bescheidenen und maßvollen Kritik einen ,Abfall' oder ein ,Schisma' zu erblicken", so will ich gern glauben, $\mathrm{daB}$ er sich dieser Sẹlbsttäuschung hingibt. Ich jedoch sehe keinen Grund, die genannten Ausdrücke zu vermeiden. Ich gehe sogar darliber hinaus und behaupte, daB $\mathrm{Jung}$ kein Recht mehr hat, die von ihm vertretenen Ansichten mit dem Namen "Psychoanalyse" zu belegen.

Die Gründe, die mich hierzu veranlassen, liegen darin, daB Jung alle wesentlichen Bestandteile der Freudschen Lehre wieder beiseite geschoben hat.

Die infantile Sexualität, das Unbewußte, die Verdrängung, der Begriff des Psychosexuellen, die Wunschtheorie des Traumes und der Neurose - alle diese unerläBlichen Bestandteile der Psychoanalyse sind teils verschwunden, teils zur Bedeutungslosigkeit herabgedrückt. Von wichtigen Einzelheiten der Lehre, die von dem gleichen Schicksal betroffen wurden, nenne ich nur Autoerotismus und NarziBmus, die Ambivalenz der Gefahle, die Sublimierung und Reaktionsbildung. Ich kann aber auch nicht unerwăhnt lassen, daß wichtige Bestandteile der psychoanalytischen Theorie in $\mathrm{J}$ ungs Arbeit überbaupt keiner Erwahnung gewürdigt werden. Ich nenne beispielsweise die Theorie der Zwangsneurose, der Angst und der Depressionszustände.

Unter diesen Umständen wird niemand in meiner radikalen Ablehnung der $\mathrm{J} u \mathrm{n} \mathrm{g}$ schen Ideen das starre Festhalten eines engherzigen Parteistandpunktes erblicken. Vielmehr glaube ich den Nachweis 
gefuhrt zu haben, daB Jungs "Darstellung im Effekt auf eine völlige Entstelluug der psychoanalytischen Theorie hinausläuft. Ich sehe in $\mathrm{Jungs}$ Arbeit im wesentlichen destruktive und rackschrittliche Tendenzen am Werke; irgendeine positive, aufbauende Leistung vermag ich in ihr nicht zu erblicken.

Ich muB endlich noch betonen, daB $\mathrm{J}$ u $\mathrm{n} g$ gegen seinen Grundsatz (cf. Seite 13), nur die Wahrheit und nicht das moralische Sentiment zur Richtschnur zu nehmen, arg verstöBt, indem er mit ethisch-theologischen Wertungen an die infantile Sexualität und das UnbewuBte herantritt. Gerade nach dieser Seite möchte ich zum SchluB noch die Abwehr richten. Hier gilt es die Psychoanalyse gegen Einflusse zu schützen, die aus ihr machen möchten, was die Philosophie in vergangenen Zeiten war: ancilla theologiae. 


\section{Über eine konstitutionelle Grundlage der lokomotorischen Angst ${ }^{1}$.}

Wer Gelegenheit hatfe, die Psychogenese dec lokomotorischen Angst mit Hilfe der Freudschen Methodik zu untersuchen, dem sind gewisse, in der Entstehung des Leidens wirksame Faktoren von Fall zu Fall wieder begegnet, so daß er in ihnen etwas Typisches erblicken mußte. Es ist ihm geläufig, daß bei den Neurotikern, welche der bestăndigen Begleitung bestimmter Personen bedürfen, die inzestuöse Fixierung der Libido besonders aufdringlich hervortritt. Er ist damit vertraut, daB jeder Versuch, sich vom Liebesobjekt räumlich zu trennen, dem UnbewuBten dieser Kranken einen Versuch zur Ablosung der Libido bedeutet. Nicht minder ist es dem Psychoanalytiker bekannt, daB diese Kranken unter ihrer Angst einerseits le ide $n$, anderseits aber mit Hilfe der Angst ihre Umgebung beherrschen. Weitere typische Determinierungen der "Topophobien" sind die Angst vor dem Leben - das symbolisch durch die StraBe dargestellt wird - und insbesondere die Angst vor den Versuchungen, die dem Patienten entgegentreten. sobald er das schützende Obdach des elterlichen Hauses verlabt. Ich nenne auch noch die Angst vor dem Tode, der den Patienten fern von seinen Lieben luberraschen könnte.

Die Kenntnis aller dieser Determinierungen - und es wären ihnen noch manch andere hinzuzufügen - rlickt die Straßenangst unserem Verständnis năher, bringt uns aber keine vollständige Lösung des Problems. Die Frage, warum bei einer nicht eben kleinen Gruppe von Neurotikern gerade die Fortbewegung durch Angst erschwert werde, bleibt ung eklärt.

Die Fixierung der Libido des Kranken an bestimmte Personen seiner nächsten Umgebung hat für sich allein nicht diese determinierende Kraft. Sonst müBten wir erwarten, daB eine sehr viel gröBere Zahl von Neurotischen, als tatsächlich der Fall, an Straßenangst litte. Die sonstigen, oben erwähnten psychosexuellen Faktoren wirken bei der

1 Aus „Internationale Zeitschrift für ärztliche Psychoanalyse“, II. Jahrgang 1914. 
Entstehung anderer neurotischer Erkrankungen ebenfalls mit, ohne da'B es zur Produktion lokomotorischer Angst kommt.

Wir werden so zu der Annahme genötigt, daB in der sexuellen Konstitution derjenigen Neurotiker, die an lokomotorischer Angst leiden, eine besondere, nicht allen Neurotikern in gleicher Weise eigene Vorbedingung liegen müsse, die beim Hinzutreten anderer psychosexueller Faktoren (von der Art der oben angefuhrten) die Straßenangst und ähnliche Affektionen hervortreten ließe.

Die Psychoanalyse eines Falles von schwerer StraBen- und Platzangst hat mich $z u$ einer bestimmten Auffassung gefuhrt, die ich im folgenden $z u$ begrlanden versuchen will.

Der Patient, welcher schon seit dem Pubertätsalter, d. h. seit einer langen Reihe von Jahren mit diesem Leiden behaftet ist, vermag nur in Begleitung seiner Mutter oder ein paar anderer, ihm ebenfalls sehr vertrauter Personen, die Straße zu betreten. Er äußerte einmal, als ich Aufklärungen dieser Art gar nicht erwartete, das Gehen an sich sei für ibn eine sehr angenehme Tätigkeit, sobald nur durch geeignete Begleitung der Angst vorgebeugt sei. Beim Gehen auf der StraBe fuhle er sich gleichsam tanzend. Es stellte sich weiter heraus, daB dem sexuell völlig enthaltsamen Manne das Tanzen große Lust bereitete, so daB seine Pollutionstrăume oft Träume vom Tanzen waren; $d a B$ er in einer Dichtung die Prostitution einmal allegorisch durch ein Weib dargestellt hatte, das mit jedem beliebigen Manne tanzt.

Ein näheres Eingehen auf die erotische Bedeutung des Tanzes oder auf seine Eignung, erotische Absichten mimisch darzustellen, ist hier nicht erforderlich. In dem kurz skizzierten Falle handelt es sich jedoch nicht um den banalen Tatbestand einer Lust am Tanzen, sondern die Geh- und Tanzbewegungen bieten dem Patienten einen Ersatz für die Sexualbefriedigung, die ihm durch neurotische Hemmungen im übrigen versagt ist.

DaB die Tätigkeit des Gehens eine sexuelle Miterregung, speziell eine Genitalerregung zur Folge hat, ist bei Neurotikern nicht selten. Ich verdanke Herrn Kollegen Dr. Eiting on die sehr interessante Mitteilung eines besonders prägnanten Falles, den man wohl mit dem Namen "Geh- $Z$ wang" belegen kann. Es handelt sich um einen Neurotiker, der - einem heftigen Impulse folgend - Märsche machte, die ihn bis zum Orgasmus erregten.

Das „N e g a t i v" zu dieser eigentümlichen Perversion - im Sinne der Auffassung Freuds in den "Drei Abhandlungen zur Sexualtheorie" - scheint mir nun die Neurose zu sein, die wir unter dem 
Namen der Straßenangst kennen. Eine Reihe von Krankheitsfallen meiner Beobachtung ist geeignet, diese Auffassung zu stützen.

Eine von mir psychoanalytisch behandelte Patientin wird, sobald sie sich vom elterlichen Hause entfernt, von heftiger Erregung befallen, die alsbald einer lähmenden Angst Platz macht. Auch in diesem Falle besteht eine ausgesprochene Lust an körperlicher Bewegung. Speziell das Gehen war ursprünglich lustbetont. Es ist sehr charakteristisch, daB diese Patientin zu Hause, weln sie in ihrem Zimmer ist, mit großem Vergnugen $\tan z t, d$. h. ohne Partner. Tanzt sie dagegen bei einem Balle mit einem Herrn, so bemächtigt sich ihrer sogleich eine Erregung, die mit heftigstem Herzklopfen einhergeht und in Angst umschlägt, mit der ein lähmungsartiges Gefluhl verbunden ist. Die Krankheit macht es ihr faktisch unmöglich, mit einem fremden Menschen zu tanzen. Aber nicht nur dies ist ihr verboten: auch gehen darf sie nicht mit einem beliebigen anderen Menschen; denn auch dabei würde sie von ihrer Angst verfolgt werden. Sie kann in Begleitung ihrer năchsten Angehörigen Wege zurücklegen, ist aber auch dann der Angst in einem gewissen (freilich gemilderten) Grade ausgesetzt. Völlig frei von Angst ist sie auf der Straße nur in Begleitung des Vaters. Ist sie aber frei von Angst, so kann sie auch die Lust des Gehens genießen, die für ihr Unbewußtes ein Äquivalent der sexuellen Lust (im engeren Sinne) bildet. Sie genießt die Lust des Gehens gemeinsam mit dem Vater; dieses gemeinsame Gehen stellt somit eine symbolische Erfüllung des Inzestwunsches, einen Ersatz für die wirkliche Vereinigung dar. Durch die Fixierung an den Vater ist es ihr verboten, mit anderen Personen zu gehen. Jede Abweichung von diesem, durch die Neurose gegebenen Gesetz hätte den Wert einer Untreue gegen den Vater.

Es mag an dieser Stelle darauf verwiesen werden, daB in den verschiedensten Sprachen der Geschlechtsakt durch einen Ausdruck bezeichnet wird, der ein gemeinsames Gehen zweier Personen bedeutet (z. B. coire im Lateinischen).

Wie ich glaube, ist diese Bedeutung des gemeinsamen Gehens den Psychoanalytikern, die je einen Fall von lokomotorischer Angst untersucht haben, ebenfalls geläufig. Ich begnüge mich jedoch nicht mit dem Hinweis auf die symbolische Bedeutung des Gehens, sondern betone den Lustwert des Gehens selbst.

Auf Grund der kurz geschilderten und anderer analoger Erfahrungen komme ich $z u$ der Auffassung, es liege bei den Neurotikern, die an lokomotorischer Angst erkranken, ursprtinglich eine konstitutionelle, uberstarke Lust an B ew egung en vor; aus 
der mißglückten Verdrängung dieser Tendenz gingen neurotische Hemmungen der Köperbewegung hervor.

Auf die Bedeutung der Bewegungslust hat mit besonderem Nachdruck Sadger ${ }^{1}$ aufmerksam gemacht. Er spricht von der "Muskelerotik" als von einer besonderen Quelle sexueller Lust und stellt sie neben die von ihm sogenannte "Hauterotik" und "Schleimhauterotik". Sadger gibt interessante Nachweise betreffs positiver Lust an körperlicher Bewegung. Ich könnte seine Beobachtungen durch manche analoge stätzen, will aber an dieser Stelle nur auf das zum Verständnis der Straßenangst Nötige eingehen.

Wir finden die Bewegungslust? bei den Neurotikern, von denen hier die Rede ist, nicht völlig verdrängt. Wie schon aus den kurz erwähnten Beispielen hervorgeht, können die Kranken unter gewissen Bedingungen (die eben durch die Krankheit diktiert werden) diese Lust genieBen. Ich habe, seit ich auf die Bedeutung dieses konstitutionellen Faktors aufmerksam geworden bin, mein früheres, relativ umfangreiches Material an analysierten Fällen von Straßenangst gesichtet und war liberrascht, wie stark dieser Faktor hervortritt. Ich hatte früher schon entsprechendes Tatsachenmaterial in meinen Psychoanalysen zutage gefördert, ohne das $\mathrm{T}$ y p is ch e zu erkennen. Ich fand dann bald gewisse, mit großer RegelmäBigkeit wiederkehrende Äußerungen der Bewegungsiust heraus, uber die ich hier noch einige Mitteilungen folgen lassen möchte. Es handelt sich teils um Erscheinungen der Bewegungslust, denen von den Kranken selbst ein sexueller Charakter zugeschrieben wurde, teils um lustvolle Bewegungsantriebe von scheinbar nicht sexuellem Charakter. Diese Erscheinungen dürften geeignet sein, weiteres Licht auf diejenigen neurotischen Symptome zu werfen, die ich von einer dem Bewubtsein ent fremdeten Bewegungslust herzuleiten versucht habe.

Von besonderem Wert erscheinen mir wiederholte Beobachtungen, welche erkennen lassen, daB die in Rede stehenden Kranken dem Rhythmus der Bewegung ein eigentumliches Interesse entgegenbringen. Sie fahren, soweit nicht außBere Hindernisse es unmöglich machen, ihre Bewegungen in einem bestimmten Rhythmus aus, den sie besonders lieben. Fuhlen sie sich unbeachtet, so durchschreiten sie in diesem Rhythmus das Zimmer, dabei etwa eine entsprechende Melodie vor sich hin pfeifend. Ein Patient erklärte ohne weiteres, dieser

1 -Haut-, Schleimhaut- und Muskelerotik." Jahrbuch für psychoanalytische Forschungen Bd. III. 1912.

- Ich ziehe diesen Ausdruck dem Terminus ,Muskelerotik“ vor, weil ersterer eine Lokalisation der Lust vermeidet. 
Rhythmus erinnere ihn an sexuelle Rhythmen. Es scheint sich dabei teils um den Rhythmus masturbatorischer Handlungen, teils um den Rhythmus der Ejakulation zu handeln. Der genannte Patient zeichnete den Rhythmus in folgender Weise auf:

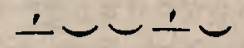

Eine Patientin gab folgenden Lieblingsrhythmus an:

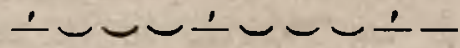

Sie hatte tbrigens eine Prosadichtung verfabt, die von nichts anderem handelte als von FüBen und ihrer tanzenden Gehbewegung.

Manche Patienten, die an lokomotorischer Angst leiden, haben eine ausgesprochene Lust an kräftigem oder raschem Ausschreiten ${ }^{1}$. Manchen Neurotikern ist ein rasches Bergablaufen lustvoll; sie empfinden dabei z. B. einen Harndrang, der von sexuellen Gefahlen begleitet ist. Eine meiner Patientinnen dagegen, die im erwachsenen Alter an Straßenangst erkrankte, litt als Kind an der Angst, bergab fuhrende Wege zu gehen, die keineswegs allein aus der Furcht vor einem Sturz in die Tiefe erklärt werden konnte. Ich habe wiederholt bei Neurotischen die Angst beobachtet, beim Gehen in allzu rasche Bewegung $z u$ geraten. Es handelt sich dabei um die Verdrăngung lustvoller Triebregungen, die mit dem Menschen "durchgehen " könnten. Es ist bezeichnend, daB die Sprache hier einen Vergleich mit der Hemmungslosigkeit des dahin rasenden Pferdes anwendet.

Die Lust an Körperbewegungen beschränkt sich bei den Kranken natürlich nicht auf die unteren Extremitäten allein, obwohl, wie gesagt, das $\mathrm{Ge}$ h en besonders lustbetont ist. So beobachtete ich z. B. bei einem an Straßenangst leidenden jungen Manne die Neigung, beständig die Fäuste zu ballen, die Armmuskeln zu kontrahieren und namentlich die Kiefer aneinander zu pressen, zu welchem Zwecke er die Kaumuskeln aufs außerste kontrahierte ${ }^{2}$. Eine Patientin muBte zwangsmäBig die Fäuste ballen, forcierte Atemzuge tun, oder bäumende Bewegungen mit dem Oberkörper ausführen. Auch sie litt an Straßenangst. Es scheint bei dieser Gruppe von Neurotikern auch öfter vorzukommen, daB sie ein Gefahl allgemeiner Steifigkeit oder Starre des Körpers empfinden.

Neben diesen Erscheinungen auf körperlichem Gebiet habe ich nun mit großer RegelmäBigkeit bei den gleichen Patienten einen

${ }^{1}$ Es gibt Neurotiker, die, wenn sie einen Weg in großer Hast zurücklegen, lebhafte Angst produzieren und dabei eine Pollution erleiden.

2 Hier bestand gleichzeitig eine ungewöhnliche erogene Bedeutung der Mundschleimhaut. 
psychischen Zustand gefunden, den ich aus den nämlichen Quellen herleiten möchte. Es ist bemerkenswert, daB manche Patienten für beide Erscheinungskomplexe spontan die nämliche Bezeichnung wählen, indem sie sowohl von "Spannungen" im Körper als von einem Zustand seelischer "S pannung " sprechen.

Der Patient, der an lokomotorischer Angst feidet, befindet sich in einem in schweren Fällen nahezu permanenten Zustand seelischer Spannung. Erwacht er am Morgen, so ist er bereits in banger Erwartung der Notwendigkeit, im Laufe des Tages irgend einen Weg machen zu müssen. Je năher die Zeit des Aufbruches rückt, um so mehr nimmt die Spannung zu; während des Weges hält sie an. Ist der Kranke wieder daheim angelangt, so ängstigt er sich schon wieder in der Erwartung dessen, was der nächste Tag bringen wird.

Viele Patienten belegen diesen Zustand mit einem Ausdruck, der jedem Neurologen geläufig ist. Sie sprechen von der "Angst vor der Angst “. Mir ist von jeher aufgefallen, daB die Kranken sich dieses Ausdruckes mit einer gewissen Emphase bedienen, als sagten sie mit ihm etwas besonders Tiefsinniges, als gäben sie dem Arzt die wichtigste Aufklärung über ihren Zustand. Sie sind damit tatsächlich im Recht. Oberflächlich angesehen ist der Ausdruck nAngst vor der Angst". freilich eine Banalität. Der psychoanalytischen Betrachtung kann es jedoch nicht entgehen, $d a B$ diese der eigentlichen Angst voausgehende Spannung in jeder Beziehung der, Vorlust" analog is t, die dem Eintritt der Befriedigungslust vorausgeht.

Manche der uns hier speziell beschäftigenden Neurotiker äußern, daß sie sich ihr Leben ohne jenen Zustand permanenter Angsterwartung gar nicht vorzustellen vermöchten. Lernt man nun die Sexualität solcher Patienten näher kennen, so bemerkt man bei ihnen des weiteren eine exzessive Neigung $z \mathrm{um} \mathrm{Haftenbleiben} \mathrm{an} \mathrm{einer}$ protrahierten Vorlust. Gerade unter den an Straßenangst Leidenden finden sich auffallend viele Personen, die infolge ihrer neurotischen Hemmungen der normalen sexuellen Befriedigungslust gänzlich entsagen. Sie sind ausgesprochene Autoerotiker, und als solche schieben sie die Erreichung der Endlust gern ins Unbestimmte hinaus. Ich erwähne als eine Form protrahierter Vorlustgewinnung die sogenannten "Traumzustände ${ }^{*}$, denen ich früher eine eingehende Bearbeitung gewidmet habe ${ }^{1}$. Unter den Patienten, bei denen ich diese Zustände studierte, litt ein beträchtlicher Prozentsatz an Straßen-

1 Jahrbuch für psychoanalytische Forschungen, Bd. 2, 1910. 
angst! Eben die Traumzustände zeigen aber auch in deutlichster Form den Ubergang erotischer Tendenzen in Angst und andere neurotische Symptome.

Wie wir auf Grund der Psychoanalyse der "Topophobien" sagen dürfen, haben wir mit Kranken zu tun, die sich vor der Erreichung des Zieles ihrer Libido ängstigen. Die Angst hindert sie, von sich selbst und den Liebesobjekten ihrer Kindheit loszukommen und den Weg zu den Objekten der Außenwelt zu finden. Jeder Weg, der sie aus dem Bannkreis der Personen, an die sie fixiert sind, hinwegfuhrt, ist verboten. Die Kranken dürfen ihre Bewegungslust nur in Begleitung eben dieser Personen genieBen. Handeln sie dem von der Neurose diktierten Verbot zuwider, indem sie sich ohne die ihnen vorgeschriebene Begleitung auf den Weg machen, so verwandelt sich die Bewegungslust in B ew egungsangst. Es ist den Kranken unmöglich, ihre Bewegungslust in derjenigen Weise in den Dienst der Objektliebe $z \mathbf{u}$ stellen, wie beim gesunden Menschen die ursprunglich autonomen Partialtriebe in den Dienst einer zentralen Tendenz treten.

Nachdem es uns gelungen ist, die Angst vor der selbständigen Fortbewegung auf einen bisher nicht gentigend gewürdigten Faktor in der sexuellen Konstitution des Patienten zurückzuführen, beantwortet sich die Frage nach dem Ursprung des "Verbotes" von selbst. Schon die Tatsache, daß die Gegenwart des Vaters oder der Mutter den Patienten von der Angst entbindet, laßst deutlich genug erkennen, daß die inzestuöse Fixierung die Quelle der Bewegungshemmungen ist. Es bedarf kaum der Erwähnung, daß meine sämtlichen Psychoanalysen von Topophobien bezüglich dieses Resultates völlige Obereinstimmung ergaben.

Die vorstehenden Ausfuhrungen bedürfen nach einer bestimmten Richtung der Ergänzung. Ich sprach oben aus Gründen der leichteren Obersicht nur von der Lust an aktiven Bewegungen und der Umwandlung dieser Lust in Angst. In der Regel aber ängstigen sich die gleichen Kranken auch vor der passiven Fortbewegung, sobald diese sie aus der Nähe gewisser Personen entfuhrt. Meine Erfahrung nötigt mich nun zu der Annahme, daB auch das F a hre n fü diese Kranken ursprünglich einen besonderen Lustwert hatte. Jeder, der sich in die T ră u me dieser Patienten vertieft, wird bemerken, wie häufig sie vom Fahren handeln, neuerdings besonders vom Fahren mit dem Luftschiff. Es gibt nicht, wenige Neurotiker, die am Fahren eine ausgesprochene körperliche Lust haben ${ }^{1}$. Als besonders charakteristisch

- Auf die Lust der Kinder am Fahren sei ebenfalls verwiesen. Ich kannte 
erwăhne ich die Neigung eines meiner Patienten, lange Eisenbahnfahrten zu machen und sich wăhrend der längsten Reise stets wach zu halten, um nichts von der Lust des Fahrens zu verlieren. Er reiste hauptsăchlich wegen der Lust des Fahrens. Erwähnt sei ferner, daß bei manchen Personen eine lăngere Eisenbahnfahrt stets eine Pollution in der nächsten Nacht zur Folge hat.

$\mathrm{DaB}$ bei der uns beschäftigenden Gruppe von Neurotikern eine Verdrăngung dieser passiven Bewegungslust vorliege, bestătigte mir ktirzlich eine Patientin durch eine spontane Angabe. Sie hatte anfangs die Fahrt von ihrer Wohnung zu der meinigen nur mit Aufbietung aller ihrer Krăfte zurücklegen können. Unter der Einwirkung der Psychoanalyse war die Angst zunächst quantitativ zurlickgegangen. Eines Tages erschien die Patientin in einer deutlich gehobenen Stimmung und berichtete mir, sie sei ganz erstaunt gewesen, dab die heutige Fahrt ihr einen Gen u B bereitet habe. Die Angst hatte also einer ausgesprochenen Lust am Fahren Platz gemacht!

Vor einigen Jahren gelang es $\mathrm{mir}$, in einem Falle schwerer StraBen- und Platzangst einen sehr schönen und vollständigen Heilerfolg zu erzielen. Die Patientin, die vorher nur unter gröBter Angst ihr Haus verlassen konnte, fand nach ihrer Heilung nicht nur eine ausgesprochene $\mathrm{L}$ u s $\mathrm{t}$ am Reisen, sondern meldete sich auch zur Teilnahme an einer Luftschiffahrt. Die Lust an Bewegungen war ihr nicht mehr durch neurotische Verbote verschlossen.

Gerade die Erfahrung, daB sich die Angst vor der Fortbewegung in eine auf die gleiche Tatigkeit gerichtete Lust zurluckverwandeln läBt, scheint mir die oben gegebene Auffassung der Bewegungsangst zu bestătigen.

Die Zurückfluhrung der Bewegungsangst auf eine ursprünglich ubermăchtige $\mathrm{L}$ ust an der Fortbewegung reiht sich anderen, durch die Erfahrung gesicherten Ergebnissen der Psychoanalyse an. Beispielshalber nenne ich nur die Berührungsangst, die wir auf ursprüngliche lustvolle Antriebe zur Beruhrung zurückführen gelernt haben.

Seit langem beschäftigt uns die schwierige Frage nach der individualpsychologischen Bedingtheit der neurotischen Erkrankungsformen. Es ist, als ständen verschiedene Formen der Erkrankung zur Auswahl, das Individuum schlage aber - unbekannten Antrieben folgend - einen bestimmten Weg ein.

Durch neueste Forschungen - ich habe Fre uds Mitteilungen

einen Knaben, der sein Taschengeld von 1 Mark, sobald er es erhalten hatte, regelmäBig in der Weise verausgabte, daß er einen ganzen Nachmittag hindurch mit der Trambahn fuhr. 
über die Entstehung der Zwangsneurose ${ }^{1}$ und $\mathrm{J}$ on e ${ }^{\prime}{ }^{2}$ Beitrăge zum gleichen Thema im Auge - sind wir dem Problem der "N e uros enwahl" um einen Schritt näher gerückt. Es scheint mir, daß die in der vorliegenden Arbeit vertretene Anschauung von der Psychogenese der. Bewegungsangst“ geeignet sei, zur Lösung der Frage der Neurosenwahl einen kleinen Beitrag zu liefern.

1 Vortrag, gehalten auf dem IV. KongreB der Internationalen Psychoanalytischen Vereinigung in München im September 1913.

' Internat. Zeltschrift flir ärztliche Psychoanalyse. I. Jahrgang, Heft 5, 1913. 


\section{Über Einschränkungen und Umwandlungen der Schaulust bei den Psychoneurotikern nebst Bemerkungen über analoge Erscheinungen in der Völkerpsychologie ${ }^{1}$.}

Die Schaulust als sexueller "Patrialtrieb" ist, gleich ihrem passiven Gegenstück - der Zeigelust (Exhibitionslust) - mannigfachen Einschränkungen und Umwandlungen unterworfen. Beide Triebe, die sich im frthen Kindesalter außern durfen, ohne durch Verbote gehemmt zu werden, unterliegen später unter normalen Verhältnissen in erheblichem Maße der Verdrängung und Sublimierung. Bei den Psychoneurotikern gehen die Hemmungen und Transformationen dieser Triebe weit uber das normale Maß hinaus, während zu gleicher Zeit die verdrängten Regungen einen beständigen Kampf gegen die Verdrängung führen.

Eine kleine Publikation Freuds $s^{2}$ uber die ${ }^{2} p s y c h o g e n e$ Sehstörungu enthält diejenigen leitenden Gesichtspunkte, die uns zu einem tieferen Verständnis der neurotischen Hemmungen und Umwandlungen der Schaulust führen können. Fre u d nimmt in dieser Arbeit Bezug auf seine Lehre von den erogenen Zonen und den Partialtrieben und äußert sich uber den uns hier interessierenden Partialtrieb - die Schaulust - und die in Betracht kommende erogene Zone das Auge - wie folgt: „Die Augen nehmen nicht nur die fur die Lebenserhaltung wichtigen Veränderungen der Außenwelt wahr, sondern auch die Eigenschaften der Objekte, durch welche diese zu Objekten der Liebeswahl erhoben werden, ihre "Reize". Es bewahrheitet sich nun, daB es für niemand leicht wird, zweien Herren zugleich zu dienen. In je innigere Beziehung ein Organ mit solch doppelseitiger Funktion zu dem einen der großen Triebe tritt, desto mehr verweigert es sich dem andern."

1 Aus .Jahrbuch der Psychoanalyse*. Band VI, 1913.

- Árztliche Standeszeitung, Wien 1910. Abgedruckt in .Kleine Schriften zur Neurosenlehre*, Bd. III, Wien. 1913. 
Stellt der Schautrieb Ansprüche, die quantitativ zu hoch sind oder sich auf verbotene Objekte richten, so ergibt sich ein Konflikt im Triebleben. Es heißt darluber in der erwähnten Schrift weiter (KI. Schriften, Bd. III, S. 318/319): „Wenn der sexuelle Partialtrieb, der sich des Schauens bedient, die sexuelle Schaulust, wegen seiner ubergroßen Ansprüche die Gegenwehr der Ichtriebe auf sich gezogen hat, so daB die Vorstellungen, in denen sich sein Streben ausdrückt, der Verdrängung verfallen und vom Bewußtwerden abgehalten werden, so ist damit die Beziehung des Auges und des Sehens zum Ich und zum BewuBtsein überhaupt gestört. Das Ich hat seine Herrschaft über das Organ verloren, welches sich nun ganz dem verdrăngten sexuellen Trieb zur Verfligung stellt. Es macht den Eindruck, als ginge die Verdrängung vonseiten des Ichs zu weit, als schüttete sie das Kind mit dem Bade aus, indem das Ich jetzt taberhaupt nichts mehr sehen will, seitdem sich die sexuellen Interessen im Sehen so sehr vorgedrängt haben. Zutreffender ist aber wohl die andere Darstellung, welche die Aktivität nach der Seite der verdrängten Schaulust verlegt. Es ist die Rache, die Entschädigung des verdrängten Triebes, daß er, von weiterer psychischer Entfaltung abgehalten, seine Herrschaft uber das ihm dienende Organ nun zu steigern vermag. Der Verlust der bewuBten Herrschaft tuber das Organ ist die schädliche Ersatzbildung für die mißglückte Verdrängung, die nur um diesen Preis ermöglicht war."

Zur Erklärung einer so weitgehenden Verdrängung der sexuellen Schaulust zieht Fre ud (1. c. S. 319) als Motiv die Talion - d. h. Selbstbestrafung für genossene Schaulust am verbotenen Objekt heran.

Damit ist der erste VorstoB in ein großes, von der Psychoanalyse noch wenig durchforschtes Gebiet unternommen, dessen weiterer Erschließung die vorliegende Abhandlung dienen soll. Eine Fulle von Erscheinungen harrt einer eindringlichen Untersuchung. Die von Freud als Paradigma der neurotischen Sehstörungen gewählte hysterische Blindheit ist nur eine, freilich eine besonders auffällige Form neurotischer Störung im Bereich des Schautriebes. Sie kommt in der ärztlichen Praxis nicht eben hăufig zur Beobachtung; mir wenigstens ist in den letzten sechs Jahren nervenärztlicher Praxis kein einziger einschlägiger Fall begegnet, während ich gewisse andere Störungen - die zum Teil in der Literatur taberhaupt noch keine Berlicksichtigung gefunden haben - verhältnismäßig häufig beobachtete.

Es handelt sich in klinischer Hinsicht teils um Transformationen der Schaulust in eine spezifische Angst vor der Betătigung dieses Triebes, teils um Störungen der Sehfunktion, teils um neurotische 
Symptome, welche sich am Sehorgan abspielen, ohne den Gesichtssinn direkt zu betreffen. Im folgenden beabsichtige ich nicht nur, die Ergebnisse meiner psychoanalytischen Untersuchungen mitzuteilen und damit die Symptomatologie zu fördern. Uber diesen rein medizinischen Interessenkreis hinausgehend, möchte ich versuchen, die gewonnenen individualpsychologischen Einsichten zur Aufklärung gewisser Phänomene der Völkerpsychologie zu verwerten.

Aus Gründen der Knappheit und Ubersichtlichkeit werde ich mich auf die Äußerungen der $\mathrm{Sch}$ a ul u st beschränken, auf eine gleichzeitige Berücksichtigung der " $Z$ e ig el us t" (Exhibitionslust) also im allgemeinen verzichten. Ich weiß wohl, daß es prinzipiell richtiger wäre, beide Triebe nebeneinander und in ihrem Zusammenwirken $z \mathfrak{u}$ behandeln, so wie es z. B. Rank in seiner vortrefflichen Arbeit uber "das Motiv der Nacktheit in Sage und Dichtung" (Imago 1913, Bd. Il) getan hat. $\mathrm{Da}$ aber die neurotischen Symptome, die im folgenden behandelt werden, vorwiegend aus verdrängter Schaulust zu erklären sind, so erscheint mir eine gesonderte Untersuchung dieser e in en Seite der Phănomene berechtigt.

\section{Die neurotische Lichtscheu.}

Eine Störung, deren Analyse uns besonders instruktive Einblicke eröffnet, ist diejenige, welche ich mit dem Namen "neurotische Lichtscheu* belegen möchte. Es handelt sich um eine Affektion, die keineswegs selten ist und früher bereits in der nichtanalytischen Literatur einige Beachtung gefunden hat. Ich konnte eine kleine Reihe einschlägiger Fälle beobachten und sie gröBtenteils eingehend analysieren. $\mathrm{Da}$ die mit der Lichtscheu behafteten Patienten stets noch andere, ebenfalls von der Verdrängung der Schaulust herrührende Störungen darboten, so werde ich die psychoanalytische Erklärung dieser letzteren in die nun folgenden Ausführungen uber die Lichtscheu einfügen. Die "Lichtscheu" auBert sich darin, daB die mit ihr Behafteten das Sonnenlicht, resp. Tageslicht, meist auch das künstliche Licht, als unangenehm empfinden. Sie fühlen sich selbst durch mattes Licht geblendet; manche klagen aber mehr oder weniger heftige Augenschmerzen, sobald sie dem Licht nur kurze Zeit ausgesetzt sind. Sie schützen ihre Augen durch allerhand Mittel gegen das Licht. Doch liegt nicht nur eine Empfindlichkeit des Auges gegen Belichtung vor, sondern die betreffenden Patienten reagieren auf Lichtreize mit einer Scheu, die durchaus den Charakter der neurotischen Angst trăgt; in ausgesprochenen Fälien schlutzen sie ibre Augen in ebenso sorgsamer Weise vor jedem Lichtstrahl, wie etwa ein an Berührungsangst leidender 
Zwangsneurotiker seine Hände vor dem Kontakt mit irgend einem Gegenstand bewahrt. Die Angst hat $z$ um Inhalt die Gefahr der Blendung.

Die hier in kurzen Umrissen geschilderte Störung bat bisher keine spezielle Bearbeitung in der psychoanalytischen Literatur gefunden. Und doch existiert in dieser ein Hinweis, der zur Aufklärung der uns beschaftigenden Affektionen einen wichtigen Fingerzeig gibt.

In dem "Nachtrag zu dem autobiographisch beschriebenen Falle von Paranoia" unterwirft Freud eine paranoische Wahnidee der psychoanalytischen Deutung. Der Geisteskranke S ch r e b e r (cf. dessen Denkwürdigkeiten eines Nervenkranken, S. 139, Anm.) behauptete, minutenlang ohne erhebliche Blendung das Licht der S onne ertragen $z$ u $k o ̈ n n e n^{2}$. Aus dem ganzen, in seinen merkwürdigen Einzelheiten geschilderten Verhältnis des Patienten zur So nn e lieb sich entnehmen, daB für ihn die Sonne ein ${ }_{n}$ sublimiertes Vatersymbol" bedeutete. Unter Bezugnahme auf die bei manchen Völkern verbreiteten Abkunftsproben" (Ordale) gelangte F r e u d zu der Annahme: "Wenn Schreber sich rühmt, daB er ungestraft und ungeblendet in die Sonne schauen kann, hat er den mythologischen -Ausdruck für seine Kindesbeziehung zur Sonne wiedergefunden, hat er uns von neuem bestätigt, wenn wir seine Sonne als Vater auffassen."

Die Wahnidee $\mathrm{Schrebers}$ bildet auf psychotischem Gebiet ein vollkommenes Gegenstück zur neurotischen Lichtscheu. Wăhrend der gesunde Mensch auf die Belichtung seiner Augen innerhalb gewisser Grenzen ohne besondere Empfindlichkeit reagiert, sich vor dem Anblick zu grellen Lichtes aber instinktiv in ausreichender Weise schützt, wăhnt der Geisteskranke, der Blendung durch hellstes Sonnenlicht nicht $\mathrm{zu}$ unterliegen, indessen der Neurotiker sich in tabertriebenem Maße vor der Gefahr der Blendung angstigt. Man darf daher geradezu von einer S o n n en phobie sprechen.

Ich werde nun zunăchst aus der Psychoanalyse eines jungen Mannes diejenigen Tatsachen und Ergebnisse mitteilen, welche eine Erklarrung der Lichtscheu sowie gewisser, mit ihr in engem Konnex stehender Erscheinungen anbahnen können.

Der Patient, den ich "A" benennen will, hatte mich aufgesucht wegen einer Störung der sexuellen Potenz und einer tiefgreifenden Verstimmung. Er befand sich zur Zeit des Beginnes der Behandlung

1 Jahrb. f. psychoanalyt. Forschungen, 1912, Bd. III, S. 588.

2 Der gleichen Wahnidee bin ich übrigens auch bei anderen Geisteskranken begegnet. 
in einem Zustande der Niedergeschlagenheit. Früher voll lebhafter Anteilnahme für alles, was um ihn vorging, hatte er jetzt jedes Interesse an den Menschen, an seinem Beruf, an Vergnügungen usw. verloren. Seine geistige Tătigkeit beschränkte sich mehr und mehr auf neurotische Grübeleien. Bei etwas genauerem Eingehen auf die Symptome des Patienten stellte sich dann heraus, daB in seinen Vorstellungen das Auge, die Sehkraft und das Sehen eine auffallende Rolle spielten, daB mit gewissen Vorstellungen dieser Art deutliche Angst verbunden war, daB eine bei dem Patienten vorhandene sexuelle Perversion sich ebenfalls auf das Auge bezog und endlich, daB er an einer ausgesprochenen $\mathrm{Lich}$ t $\mathrm{ch}$ e u litt.

Die Intensität einer solchen Störung kann man ermessen, wenn man die SchutzmaBregeln kennen lernt, die der Patient gegen das Objekt seiner Angst anwendet. Im vorliegenden Falle schützte der Patient sich gegen helles Tageslicht durch krampfhaftes SchlieBen der Augen und ähnliche Maßnahmen, die an sich uber das Verhalten Gesunder höchstens quantitativ hinausgingen. Bei Abend schützte er sich in ähnlicher Weise gegen das künstliche Licht. Auffälliger und entschieden krankhaft aber waren die Prozeduren, durch die er sich bei Nacht (d. h. vom Augenblick des Schlafengehens an) gegen jeden Lichtschein absperrte. Er hatte in seinem Schlafzimmer die Fenster durch dreifache Vorhänge verdeckt, so daß am Morgen kein Lichtstrahl eindringen konnte. Zum Schutz gegen kunstliches Licht hatte er in der Tür seines Zimmers nicht nur das Schltisselloch verstopft, sondern jeden kleinsten Spalt im Holz sorgfältig ausgefüllt.

Im Beginn der Psychoanalyse drängten sich zunächst andere Materialien in den Vordergrund. Erst nach mehr als einem Monat war ein Eingehen auf die vielfältigen Gedanken möglich, die um das Auge kreisten. Schon aus dieser Zögerung ließ sich entnehmen, daß die hierher gehörigen Gedankengänge besonders peinlicher Natur waren. Der weitere Verlauf der Psychoanalyse brachte denn auch die Bestätigung dieser Erwartung; es ergab sich, daB sie in engstem Zusammenhang mit den verdrängten inzestuösen Wünschen des Patienten standen.

Im Anschluß an die Schilderung seiner Lichtscheu machte der Patient folgende weitere Angaben. Er stehe unter einer zwangartigen Angst, $\mathrm{daB}$ er oder einer seiner Angehörigen ein Auge verlieren könnten. Er sei äuBerst empfindlich gegen jede Annäherung an sein Auge. Bei anderen Menschen interessierten ihn, wie er weiter erklärte, Augenleiden sehr. "Menschen, die etwas am Auge haben, zwingen mein Interesse auf sich." Er interessierte sich für Mädchen besonders dann, wenn sie 
ein Pincenez trugen, ferner fahndete er nach solchen, die auf einem Auge blind waren. Bei Frauen mit durchaus gesunden Augen begegnete es ihm, dab er "sich einredete, sie seien einseitig blind". Von einem einseitig blinden Mädchen, das er kennen gelernt hatte, träumte er einmal, daß ihr Vater ihr das Auge ausgeschlagen habe, also an ihrer einseitigen Erblindung schuld sei.

Die Angst um das Augenlicht anderer Personen bezog sich, wie sich bald herausstellte, in erster Linie auf den Vater des Patienten. Schon vorher hatte sich ergeben, daB seine Einstellung zum Vater durchaus ambivalent war. Die erste hierher gehörige Äußerung des Patienten sprach von seiner "glühenden Verehrung" für den Vater; als er aber diese Worte ausgesprochen hatte, trat ein plötzliches "Abbrechen der Gedanken", eine kurze BewuBtseinspause ein. Bald zeigten sich denn auch Vorstellungen von entgegengesetztem Charakter, z. B. Phantasien vom Tode und Begräbnis des Vaters. Es folgten Klagen über sein (des Patienten) verfehltes Leben; sein Vater laste förmlich auf ihm. Er müsse die überragende Intelligenz des Vaters anerkennen, der in seiner Heimat eine hohe Stellung einnehme; es sei ausgeschlossen, daB er ihn je erreichen oder ubertreffen werde. Oft habe er gewünscht, einmal irgend etwas besser zu können oder $z \mathfrak{u}$ wissen als der Vater; doch immer habe er die Uberlegenheit des letzteren anerkennen müssen. Dazu fühle er selbst sich vom Vater kontrolliert; es sei ihm immer unmöglich gewesen, vor dem Vater etwas $\mathrm{zu}$ verheimlichen. De $\mathrm{n} \mathrm{de} \mathrm{r} \mathrm{sehe} \mathrm{jad} \mathrm{och}$ alles.

Von diesem Punkt aus ergaben sich zunächst zwangslos ein paar assoziative, aber dem Patienten nicht bewußte Zusammenhänge zwischen "Vater" und "Sonne". Das beobachtende Auge des Vaters wurde mit der Sonne identifiziert; eine Identifizierung, die weiterhin durch reichliche Belege bestätigt wurde.

Die Angst des Patienten um das Augenlicht seines Vaters ist. uns nun nicht mehr ganz unverständlich; sie ist für uns zunächst der entstellte Ausdruck seines Wunsches, dem überwachenden Auge des Vaters entzogen $z \mathfrak{u}$ sein.

Von den reichlichen Bestätigungen, welche die Identifizierung von Vater und Sonne in diesem Sinne noch ferner erfuhr, sei nur noch ein Einfall des Patienten erwähnt, der unter lebhaftem Affekt zutage gefördert wurde. Ihm sei in der Schule ein Gedicht ganz "ekelhaft" gewesen. In dem Gedicht, das von der späten, unverhofften Entlarvung eines Verbrechers handelte, schloß jede Strophe mit dem Refrain: "Die Sonne bringt es an den Tag 1."

1 Die Ambivalenz seiner Einstellung zum Vater hatte der Patient in einer 
Der Sonne mußte jedoch noch eine zweite, vatervertretende Bedeutung zukommen; denn die Einstellung des Patienten zum Vater lie日 sich aus dessen tiberwachender Rolle, - seiner "Allwissenbeit", möchte man sagen - allein nicht ableiten. Als zweite Determinierung ergab sich die vom Sohne mit enthusiastischen Ausdrucken hervorgehobene Größe des Vaters, d. h. seine Intelligenz, seine Kenntnisse, sein "Können"1; kurz, alles das, was für den mit Insuffizienzgefühlen beladenen Sohn die Macht und die Uberlegenheit des Vaters ausmachte, wurde mit dem Glanz der Sonne verglichen. Der Glanz des Vaters mußte des Patienten eigene Bedeutung für immer überstrahlen, so wie die Sonne die anderen Gestirne uberstrahlt. Trotz dieser uberschwänglichen Lobpreisung des Vaters war die E ifers u cht des Patienten gegenlbber seinem Vater unverkennbar². Wenn das Unbewußte des Patienten die Vorstellung des văterlichen Auges mit der des văterlichen Glanzes verdichtete, um beiden gemeinsam im Sonnensymbol Ausdruck zu verleihen, so hatte es damit nichts anderes getan, wie die Völker von altersher.

Die uberwachende Tätigkeit ist eine dem Sonnengott vielfach zugeschriebene Funktion. Helios z. B. fahrt in den homerischen Gedichten ständig den Beinamen: der alles beobachtet und alles belauscht" 3 .

Ähnlich heißt es in dem biblischen Psalm 19 (der offenbar die Reste eines alten Sonnenhymnus enthält): $\mathrm{Er}$ (d. h. die Sonne, urspranglich der Sonnengott) gehet auf an einem Ende des Himmels und lauft bis an sein anderes Ende, und nichts bleibt vor seiner Glut verborgen."

Zur Identifizierung des Auges des Vaters mit dem Glanz oder Licht der Sonne finden sich reichlich völkerpsychologische Parallelerscheinungen. Ich erwähne hier einige Beispiele aus dem Gebiet der

bemerkenswerten Form auch auf die Sonne tibertragen. Das Licht der Son ne war ihm unsympathis $c h$, die Warmeder Sonnedagegen liebte er.

1 Es genügt, hier auf dle eingangs erwähnte Stơrung der Potenz hinzuweisen, um die Eifersucht auf das $K o ̈ n n$ e $n$ des Vaters verständlich $z$ machen. Deutlicher noch als in dem hier beschriebenen Fall konnte ich in anderen (vgl. weiter unten Fall B) konstatieren, daB die Sonne nicht nur die Größe, respektive die Potenz des Vaters darstellte, sondern daß sie ein Symbol des văterlichen Phallus war. Die Scheu vor dem Anblick des letzteren ist uns auch als Phănomen der Vollkerpsychologie bekannt. (Vgl. die biblische Erzählung von Noahs Söhnen.)

Es wird spăter gezeigt werden, daß die Erhebung des Vaters zur Sonne keineswegs nur eine Erhohhung bedeutet, sondern gleichzeitig eine Herabsetzung seiner Macht.

3 Bemerkenswert ist namentlich Odyssee, VIII, $266 \mathrm{f}$., wo Helios das verbotene Beisammensein des Ares und der Aphrodite beobachtet. 
Linguistik. Owohl es sich um Erscheinungen handelt, die in den verschiedenen Sprachen sehr verbreitet sind, beschränke ich mich auf einige, nur die deutsche Sprache betreffende Hinweise.

Auch die Sprache identifiziert vielfach Auge und Licht; es liegt am nächsten, auf das Wort "A u genlicht" zu verweisen. In Wirklichkeit nehmen die Augen das Licht wahr; die Sprache aber verhalt sich so, als ob das Licht dem Auge angehöre oder entspringe. Interessant ist namentlich der Gebrauch des Wortes "blind". Wir nennen "blind" nicht nur einem Menschen, der die Sehkraft eingebüBt hat, der nicht sehen $\mathrm{kann}$, sondern wir sprechen auch $z$. B. von einem "blinden Passagier", d. h. wir gebrauchen das gleiche Wort auch mit Bezug auf einen Menschen, der nicht gesehen wird. Es ist ferner auch gebräuchlich, einen Gegenstand, der seinen Glanz verloren hat, als "blind" zu bezeichnen. Daraus geht hervor, daB auch die Sprache "sehend" und ,glänzend" identifiziert. Die hier erwăhnten sprachlichen Phänomene sind wohl ohne Zweifel aus dem ursprünglichen "Gegensinn der Urworte" (Abel) abzuleiten. Fre ud hat in einem kleinen Aufsatz ${ }^{1}$ gezeigt, daB im UnbewuBten des Individuums die Gegensätze in ähnlicher Weise gepaart sind, wie in den primitiven Entwicklungsstadien der Sprache, welche in der spateren Sprache gewisse Spuren hinterlassen haben.

Die Scheu vor dem beobachtenden Auge des Vaters fand eine wichtige Ergänzung in der Scheu des Patienten, seine Mutter zu betrachten. Er hatte sich geradezu ein Schauverbot in bezug auf die Mutter bewuBt auferlegt. Von Jugend auf vermied e r es - wie er sich ausdrückte - seine Mutter schön $z$ u finden. Er scheute sich zur Zeit der Behandlung noch heftig, irgend eine Korperpartie der Mutter auBer Gesicht und Händen unbedeckt zu sehen. Schon eine Bluse, die in der Halsgegend durchbrochen war, bereitete ihm das größte Unbehagen.

Es stellte sich im weiteren heraus, daß die Sonne, vor deren Anblick der Patient sich scheute, für ihn ein $S$ y $m$ bol v on bi s e $x u-$ eller Bedeutung war. Es stellte sich nicht bloß den Vater dar (resp. dessen uberwachendes Auge oder seinen Glanz), sondern auch die Mutter, welche der Sohn nicht ansehen darf, wofern er nicht den Zorn des Vaters auf sich laden will. Das allgemeine Verbot, die Mutter anzuschauen, entspringt, wie es sich in diesem und anderen Fällen ergibt, dem spezielleren, die Mutter nackt zu sehen, und besonders, ihr Genitale zu betrachten. Die Vorstellung, die Mutter 
nicht anschauen zu dürfen, setzt sich um in die Angst, das Licht der Sonne nicht anschauen $z u k$ ö nne $n$.

Diese Bisexualität des Sonnensymbols lät sich aber auch in den Ideengängen $\mathrm{Schrebers}$ nachweisen. In den "Denkwürdigkeiten" findet sich eine Stelle, in der Schreber die Sonne anschreit und sie beschimpft mit den Worten: "Die Sonne ist eine Hure." Hier kann liber die Weiblichkeit des Sonnensymbols kein Zweifel aufkommen.

Ohne schon an dieser Stelle auf die Verbote, den Körper der Mutter zu schauen, năher einzugehen, erwăhne ich hier nur, daß nach meinen Feststellungen eine besondere Scheu, sogar indifferente Partien des mütterlichen Körpers $z u$ sehen, auf eine verdrängte Schaulust zurückgeht, die sich ursprünglich im Obermaß der Mutter zugewandt, sich aber speziell auf das Genitale bezogen hatte.

Auf andere weibliche Personen richtete die Schaulust des Patienten sich eher im Ubermaß. Aber sie wandte sich nicht denjenigen weiblichen Körperteilen $z \mathfrak{u}$, die normalerweise als Reize wirken. Speziell bestand eine áusgesprochene Scheu vor dem Genitale. Die Schaulust richtete sich in erster Linie auf zwei Körpergegenden des Weibes, die vom Genitale weit entfernt liegen: Auge und FuB. Aber selbst diese Teile durften die Rolle, die ihnen durch einen Verschiebungsvorgang zugefallen war, nicht selbst spielen, sondern mußten sie noch an akzessorische, nicht zum Körper selbst gehörige Dinge abgeben; so kam es, daß Mädchen, welche ein Pincene $z$ trugen oder einen $k$ lunstlichen $\mathrm{F} u B$ hatten, den hauptsächlichsten Reiz auf ihn ausübten. Auch hinkender Gang, der auf ein steifes Bein oder eine kunstliche Prothese schließen ließ, reizte ihn sehr. Seine Scheu vor dem Genitale des Weibes fand den deutlichsten Ausdruck darin, daß er in Wirklichkeit nie ein Mädchen berührte, das etwa hinkte oder ein kunstliches Bein hatte.

Die Scheu vor dem weiblichen Körper, oder - richtiger gesagt vor dem Genitale erwies sich als abhängig von mehrfachen Determinierungen, unter denen als die wichtigste die Kastrations-Angst zu erwähnen ist. Von besonderem Interesse war eine Assoziationskette, die enge Beziehungen aufdeckte $z$ wischen folgenden affektbesetzten Vorstellungen:

1. Erstaunen des Patienten in der Kindheit über das Fehlen des Penis bei seiner kleinen Schwester.

2. Ängstliche Vermeidung der Berührung des eigenen Penis.

3. Abkehrung des Interesses vom weiblichen Genitale.

4. Interesse für Frauen, bei denen eine Amputation vorgenommen ist.

Gerade dieses letztgenannte Interesse verriet die außerordentliche Betonung der Kastrationsvorstellung; handelt es sich doch um das 
Weib, "dem ein Glied abgeschnitten ist". Wir finden hier, wie so oft in unseren Psychoanalysen, daB das UnbewuBte die Vorstellung des Kindes festhält, nach welcher auch dem Weibe ein Penis zukommt. Oft steht dann der Kastrationsangst eine Vorstellung aktiver Art Frauen zu kastrieren - gegenüber. Ich habe auf diese Erscheinungen in einer früheren Arbeit gelegentlich der Analyse des FuBfetischismus bereits hingewiesen ${ }^{1}$; auch in dem hier mitgeteilten Falle handelt es sich ja um ausgesprochenen Fetischismus. Ich unterlasse aber der Kürze halber ein genaueres Eingehen hierauf; nur auf den Zusammenhang des FuB- und Pincenez-Fetischismus mit dem sadistischen Partialtrieb muB ich wenigstens mit einigen Worten eingehen.

Eine der lustvollsten Phantasien des Patienten bestand in der Vorstellung, einem kurzsichtigen (womöglich einäugigen) Mädchen das Pincenez wegzunehmen, oder einer Amputierten ihr künstliches Bein zu rauben, sie auf diese Weise hilflos zu machen?. DaB es sich hier um verschobene Kastrationsphantasien handle, ließen die Einfalle des Patienten mehr und mehr erkennen. Besonders wichtig aber wurde nach dieser Richtung ein schon erwähnter Traum des Patienten; er bezog sich auf ein ihm vom Ansehen bekanntes Mädchen, das nur auf einem Auge sehen konnte. Seine Vorstellung im Traum war nun, $d a B$ dieser Person das fehlende Auge vom Vaterausgeschlagen worden sei. Von hier fuhrten die Fäden weiter zu der Angst des Patienten vor dem Verlust des eigenen Auges.

Diese Angst erwies sich als zwiefach determiniert: durch die Idee der Bestrafung für verbotenes Schauen und durch die Verschiebung der Kastrationsangst vom Genitale auf das Auge. Diese Verschiebung ist der oben erwähnten - vom weiblichen Genitale auf das Auge völlig analog. Beide Vorstellungen aber trugen deutlich den Charakter der Talion. Ich muB mit Befriedigung konstatieren, daß diese Ergebriisse meiner Psychoanalyse sich in voller Obereinstimmung befinden nicht nur mit den eingangs zitierten Anschauungen $\mathrm{Fr}$ e u ds, sondern auch mit denjenigen anderer Autoren, auf die ich hier kurz referierend eingehen möchte, ohne dabei Vollständigkeit anzustreben.

Ferenczi (vgl. Imago 1912, Bd. I, S. 281 f.) betonte in der Selbstblendung des Ödipus den symbolischen Ersatz der Selbstentmannung, d. h. der dem Inzest adaqquaten Selbstbestrafung.

1 Bemerkungen zur Psychoanalyse eines Falles von FuB- und Korsettfetischismus. Bd. III des Jahrbuches für psychoanalyt. Forsch. S. 563.

${ }^{2} \mathrm{Zu}$ erwăhnen ist, daB diese sadistischen Regungen auf das Gebiet der Phantasie beschränkt waren; im wirklichen Leben war der Patient in hohem MaBe mitleidig. 
$\mathrm{Rank}^{1}$ lieferte verschiedene Beiträge zu dieser Frage; er und andere Autoren ${ }^{2}$ lieferten reichliches, namentlich aus Traumanalysen stammendes Beweismaterial, aus dem hervorgeht, daB das Auge bald männliche, bald weibliche Genitalbedeutung haben kann. Besonders Eder zeigte, $\mathrm{daB}$ im Traum Eingriffe am Auge - ähnlich wie solche an den Zähnen - Kastrationsbedeutung haben ${ }^{3}$.

Die Richtigkeit der Annahme wurde übrigens bestätigt durch weitere Träume, in welchen die Kastration durch andere Symbole von unzweifelhafter Bedeutung ausgedrückt war. Ich erwähne nur einen Traum, in dem jemand erschien, um dem Träumer die Schamhaare abzuschneiden.

Die ${ }_{n}$ Strafe" der Blendung erwies sich als Vergeltung verbotener, der Mutter zustrebender Schaugeluste und der aktiven Kastrationsoder Blendungsphantasie gegentuber dem Vater.

Aus den Ergebnissen der Psychoanalyse ist weiter zu betonen, $\mathrm{da} B$ in den Phantasien des Patienten auch die letztgenannte Untat selbst eine Rolle spielte. Ich erwähne in diesem Zusammenhang nur eine obsedierende Vorstellung, von der der Patient als Schuler durch lange Zeit verfolgt wurde. Während des Unterrichtes bei einem bestimmten Lehrer muBte er sich immer von neuem ausmalen, wie er dem Lehrer eine Kugel mitten in die Stirn schießen würde. Es ergab sich zwangslos, daB dieser Lehrer eine Ersatzfigur für den Vater bildete.

Der SchuB in die Stirn wäre freilich nicht ohneweiteres als Kastrationssymbol erkennbar. Auch brauchte ihm im Rahmen dieser Abhandlung keine besondere Aufmerksamkeit geschenkt zu werden, wenn nicht reichliche Beweise es über jeden Zweifel klarstellten, daB die genannte Körperstelle sehr gewöhnlich das A u ge ersetzt.

Hier muß in erster Linie auf die Sage von der Blendung des Kyklopen durch Odysseus hingewiesen werden. Wesen, die nur ein

' R a nk, Inzestmotiv, S. 271, A. 2, und eine noch nicht beschriebene Form des Odipustraumes.

2 E der, Augentrăume.

Beide Arbeiten im Jahrgang I, Heft 2 der Internat. Zeitschr. f. ärztl. Psychoanalyse, Man vergleiche ferner: S to rf e r (Zentralbl, f. Psychoanalyse, Bd. II, S. 201); Gebsattel (Zeitschr. f. Pathopsychol,, 1912); Die Bedeutung des Auges als weiblich es Genitalsymbol würdigte $J$ ung im Indra-Mythus; ich selbst habe in Anlehnung an Kleinpaul dem Auge, speziell der Pupille, ebenfalls weibliche Genitalbedeutung zuerkannt (.Traum und Mythus", 1909).

B l e u les (Dementia praecox oder Gruppe der Schizophrenien) erwähnt ebenfalls das Auge als weibliches Genitalsymbol in den Wahnideen Geisteskranker.

Jo n e s (Jahrbuch Bd.V, S.67) zeigt die männliche Genitalbedeutung des Auges.

- In den Trăumen der Frauen kann ein Eingriff am Auge Koitusbedeutung haben. Ein junges Mădchen trăumt z. B., daß jemand ihr mit einem langen Instrument das Auge offne. 
Auge besitzen, das sich mitten auf der Stirn befindet, sind in den Sagen sehr verbreitet. Interessant ist, daB sich auch in Trä ume n zuweilen Ähnliches vollzieht wie in der Polyphemsage. Einen derartigen Traum hat z. B. Eder (l. c.) mitgeteilt. Ich selbst hatte mehrfach Gelegenheit, ähnliche Feststellungen zu machen. Ich kann Eders Bemerkung, daß der Kyklop dem Vater des Träumenden entspreche, und daß die Blendung des Riesen eine Kastration des Vaters vorstelle, nach meinen Erfahrungen nur bestätigen.

Es scheint mir von besonderem Interesse $z u$ sein, dab die Mitte der Stirn, die zunächst einem von der Phantasie angenommenen Aug e entspricht, sowohl das männliche wie das weibliche Genitale symbolisch vertreten kann. In ersterer Hinsicht möchte ich auf eine Mitteilung von Reitler ${ }^{1}$ verweisen, um für die zweite Behauptung einen Beleg aus eigener Erfahrung zu bringen.

Reitler bespricht gewisse, als obszöner Scherz dienende Figuren, deren Abbildung er beigibt; sie werden von der Landbevölkerung im Salzkammergut hergestellt. Der Scherz besteht darin, daB bei Druck auf den Kopf der Figur ein großer Penis sichtbar wird. Auf der Stirn des hölzernen Männchens ist in roher Zeichnung ein drittes Auge dargestellt. Reitler ermittelte nun, daB dieses Auge ein von der Bevölkerung jener Gegend ohneweiters verstandenes Penissymbol darstellt.

Ich stelle in Parallele mit dieser eigentümlichen volkspsychologischen Tatsache eine eigene Beobachtung. Eine von mir behandelte Patientin unterlag dem Zwange, ihre Stirn in der Mitte zu einer senkrecht verlaufenden Falte $z u$ runzeln. Sie rieb diese Falte dann heftig mit dem Zeigefinger der rechten Hand. In einem Zusammenhang, dessen genaue Mitteilung ich mir hier versagen muB, kam ihr wie eine Erleuchtung plötzlich die Einsicht, daB es sich bei dieser Prozedur lediglich um eine verschobene, $d$. h. nach oben verlegte Masturbation handle, daB also die senkrechte Stirnfalte der Vulva entspreche. Beweisend für diese Auffassung war noch besonders, daß die Patientin, während sie die Stirnfalte rieb, ein "Druckgefuhl im Unterleib" versplirtes.

Die Autoren, welche die Genitalbedeutung des Auges nachwiesen, haben, wie mir scheint, diese symbolische Verwendung des Auges nur insoweit erklärt, als das Symbol das weibliche Genitale vertritt.

1 Reitler, Zur Augensymbolik. Internat. Zeitschr. f. ärztl. Psychoanalyse, 1913, Bd. I, S. 159.

- Ich möchte hier auf Sadgers Mitteilung, daB auch die Schlafe Genitalbedeutung habe, verweisen. Cf. Zentralbl. f. Psychoanalyse, 1911, Bd. II. 
Erst vor kurzem wurde mir die männliche Bedeutung des Auges aus einer Traumanalyse erklärlich. Die Träumerin gab nämlich an, daB die Glans penis ihr wie ein Auge erscheine.

Ich kehre zu der Angst des Patienten A. um sein Augenlicht zurïck. Nachdem wir die Kastrationsvorstellung als eine wichtige Determinierung derselben erkannt haben, verlohnt es sich, auf eine Einzelheit hinzuweisen, die zunächst als ganz belanglos erscheinen könnte. Nicht nur in dem vorliegenden Falle, sondern auch bei anderen Patienten fiel es mir auf, daß sie immer von ihrer Angst um das Auge des Vaters sprachen oder von ihrer Scheu vor jeder Berührung des Auges usw. Nie war von den Augen die Rede, sondern mit einer RegelmäBigkeit, die jeden Zufall ausschlieBt, sprachen die Patienten so, als gäbe es nur e in Auge. Unter dem Gesichtspunkt der "Verlegung nach oben" wird diese Redeweise leicht verständlich. "D a s" Auge ersetzt ein Organ, das nur in der Einzahl vorhanden ist ${ }^{1}$.

Die Angst um das Auge des Vaters entspricht also der verdrăngten, auf den Vater gerichteten Kastrationsphantasie. Nachdem wir aber die Identität von Auge und Sonne kennen gelernt haben, kann kaum mehr ein Zweifel übrig bleiben, daB auch der Sonne die gleiche phallische Bedeutung zukommt wie dem Auge des Vaters. Die Scheu vor dem Anblick der Sonne enthält damit die weitere Bedeutung einer Scheu vor dem Anblick des Penis des Vaters, die übrigens auch völkerpsychologisch $\mathrm{zu}$ belegen ist.

Es ist nicht möglich, in diesem Zusammenhang näher auf die Kastrationsangst einzugehen. Nur einige, zum Verständnis gewisser Erscheinungen des vorliegenden Falles unentbehrliche Bemerkungen muß ich noch hinzufugen.

Als Vergehen, wegen deren die Kastration vonseiten der Erzieher angedroht oder vom Knaben selbst befürchtet wird, lernten wir bereits das Verlangen des Knaben nach dem Anblick des mütterlichen Genitale sowie die gegen den Vater gerichtete Kastrationsphantasie kennen. Hier wäre weiter die Masturbation zu nennen, die besonders durch begleitende Phantasien zur schweren Vorwurfshandlung wird. Wie wir

1 Ich möchte bemerken, daß hier noch weitere Determinierungen vorliegen. Ich verweise nur auf die oben besprochene Identifizierung des Auges des Vaters mit der Sonne, welche ja auch nur in der Einzahl vorhanden ist. Man darf hier wohl eine spezielle Form der Verdichtung, eine Unifizierung annehmen, die weitgehende Gleichsetzungen ermorglicht: e in Genitale, e in Vater, e in e Sonne und darum auch "e in" -Auge. Man könnte noch hinzusetzen, „e in Gott“; ich verweise auf spătere Ausführungen in dieser Arbeit. 
aber aus reicher psychoanalytischer Erfahrung wissen, gibt es noch gewisse andere Erlebnisse des Kindes, welche häufig der AnlaB heftiger Selbstvorwirfe werden. Ich meine die Beobachtung des Geschlechtsverkehres der Eltern. Bezüglich aller dieser "Sünden" ist der Knabe oft genug in Angst, vom wachenden Auge des Vaters entdeckt zu werden ${ }^{1}$.

Gerade wegen dieses verbotenen Sehens leiden manche Neurotiker an Erblindungsangst. Diese letztere Art der neurotischen Reaktion soll uns jedoch an dieser Stelle nicht beschäftigen. Ich möchte vielmehr darauf hinweisen, daß die Lust am nächtlichen Beobachten und Belauschen der Eltern in nicht seltenen Fällen dazu führt, daß neurotische Personen an einer Uberempfindlichkeit gegen $\mathrm{L}$ ic $\mathrm{ht}$ und daneben an einer solchen gegen $\mathrm{G}$ e $\mathrm{r} \ddot{\mathrm{u}} \mathrm{sch}$ e leiden ${ }^{2}$. In dem oben besprochenen Falle bestand auch eine deutliche Geräuschempfindlichkeit. Beide Eigentümlichkeiten treten in solchen Fällen - aus leicht erklärlichem Grunde - vorwiegend bei Nacht auf. Auf diesem Wege wird die Scheu des Patienten vor dem künstlichen Licht und vor dem geringsten Lichtschein, der etwa durch eine Türspalte drang, vollkommen begreiflich. Die ubertriebenen Maßregeln zur Absperrung des von außen kommenden Lichtes tragen den Charakter von Prohibitivmaßnahmen.

Das sorgsame Verschließen jedes feinsten Spaltes hatte aber noch die weitere Bedeutung, anderen Personen die Beobachtung des Patienten unmöglich zu machen; es liegt auf der Hand, daB hier wieder die Scheu vor dem beobachtenden Vater die treibende Kraft ist.

Die Prozeduren zur Verdunkelung des Zimmers finden jedoch nicht ihre volle Erklärung in der negativen Absicht, das Licht abzusperren und jeder Beobachtung zu entgehen. Vielmehr hat die so hervorgebrachte absolute Dunkelheit auch einen positiven Wert fur den Patienten. Doch soll dies an einem andern Krankheitsfall demonstriert werden.

Ebenso versage ich es mir zunächst, auf gewisse Umwandlungsprodukte des Schautriebes einzugehen. Ich erwähne nur folgende psychologische Eigentümlichkeiten des Patienten : zwangartige Neugierde, Hang zum Grübeln, übertriebene Neigung für alles Rätselhafte. Auf diese Phänomene werde ich später zurückkommen. Endlich sollen

${ }^{1}$ Auch die Lust des Kindes, Erwachsene beim Urinieren zu beobachten, gibt zu neurotischen Selbstvorwürfen den AnlaB. Vgl. auch die FuBnote auf Seite 185.

2 Über die Genese der neurotischen Geräuschempfindlichkeit haben mir verschiedene Psychoanalysen Aufklärung gebracht. Die Resultate sollen später veroffentlicht werden. 
hier noch einige Zeichen erwähnt werden, die erkennen lassen, daB das Auge nicht nur als Sehorgan eine wichtige erogene Bedeutung far diesen Patienten hatte. Auch Berlihrungen des Auges wurden als lustvoll empfunden. Er neigte sehr dazu, die Augen zu reiben, die oberen Augenlider herabzuziehen, hatte in fruherer Zeit auch ofter die Augenbrauen abgeschnitten ${ }^{1}$.

In therapeutischer Hinsicht sei bemerkt, daß der Patient durch die Psychoanalyse in vollkommenem Umfang wiederhergestellt wurde. Von Einzelheiten interessiert hier, daß die Lichtscheu und Geräuschempfindlichkeit ganz verschwanden. Die Einstellung des Patienten zu seinen Eltern wurde diejenige eines Gesunden im gleichen Lebensalter, dies zeigte sich, als er nach Abschluß der Behandlung in seine Heimat zurïckkehrte. Die sexuellen Abirrungen machten einem normalen Sexualinteresse Platz; speziell verschwanden die fetischistischen Interessen bis auf geringe, praktisch durchaus unwesentliche Spuren. Während der Rekonvaleszenz traten bei dem Patienten Träume auf, in welchen der weibliche Körper, speziell das Genitale, Gegenstand der Schaulust waren; bald darauf zeigte sich auch im wachen Zustand die normal gerichtete Schaulust. Die unfruchtbare Neugierde und die pathologischen Grubeleien wichen gleichzeitig einer intensiven Wißbegierde, die auf die verschiedensten Gebiete tibergriff; d. h. die Sublimierung des Schautriebs gelang in einer vollkommenen Weise. Mit der Herstellung einer durchaus normalen Sexualfunktion ging die soziale Anpassung (Leistungsfähigkeit im Beruf usw.) Hand in Hand. Seit dem Abschluß der Behandlung sind $1 \frac{1}{2}$ Jahre verstrichen, ohne daß ein Rückfall eingetreten wäre.

Die Psychoanalyse der neurotischen Lichtscheu bei anderen Patienten ergab mir die volle Bestätigung der mitgeteilten Resultate und Auffassungen. Nur aus einer meiner Analysen werde ich hier das Hauptsächlichste in gedrängter Kürze mitteilen. Es handelt sich um eine diagnostisch sichere Dementia praecox (Schizophrenie). Ich erhielt die Gelegenheit zur psychoanalytischen Behandlung des Kranken nur dadurch, daß er mir als Neurotiker zugeführt wurde; erst bei gründlichem Eingehen auf seine Symptome lieB sich die Art seines Leidens feststellen. Die Erfahrung hat uns nun oft gelehrt, daB die Psychose weit unverhullter als die Neurose die Geheimnisse des Unbewußten preisgibt. So geschah es auch in diesem Falle. Zu den auffălligsten Erscheinungen stellten sich, meist ohne erheblichen Widerstand, die

I Man erinnere sich an den erwähnten Traum, in dem jemand dem Patienten die Schamhaare abschneidet. Das Abschneiden der Augenbrauen bedeutet offenbar auch eine symbolische Kastration. 
Einfalle ein, welche den gesuchten Zusammenhang oft tuberraschend schnell enthüllten.

Dieser Patient, den wir "B" nennen wollen, fiel schon bei der ersten Konsultation dadurch auf, daß er bat, sich so setzen zu dürfen, $\mathrm{daB}$ sein Gesicht vom Fenster abgewandt wäre; er hielt, nachdem er diese Stellung eingenommen hatte, die Augen noch meist geschlossen und bedeckte sie außerdem mit den Händen ${ }^{1}$. Wäbrend der psychoanalytischen Sitzungen pflegte er, obwohl sein Gesicht vom Fenster abgewandt war, diesen VerschluB der Augen streng zu bewahren, bis die Besserung der Lichtscheu solche Prozeduren unnötig machte.

Die Antezedentien waren denjenigen des ersten Falles auffallend ähnlich. Auch der Patient B. war der Sohn eines tatsächlich besonders intelligenten und tüchtigen Mannes. In der Vorstellung des Sohnes aber waren die Leistungen des Vaters schlechtweg unerreichbar. Fast mit den gleichen Worten wie Patient A. drackte B. sich aus: er habe lange, aber immer vergeblich gehofft, den Vater einmal in irgend einer Beziehung übertreffen zu können. Die Ambivalenz der Einstellung zum Vater war wiederum die gleiche, nur trat sie aus dem oben erwähnten Grunde in diesem Falle weit unverhullter zutage.

Der Vater war dem Patienten, wie dieser sich ausdrückte, immer als ein "machtvoll-gütiges Wesen" erschienen. Schon dieser Ausdruck trägt einen religiösen Charakter; wäre er hier nicht mit Bezug auf einen Menschen gebraucht, so wurde man ohneweiters annehmen, daB von Gott (oder überhaupt von einem religiös verehrten Wesen) die Rede sei. Schon als Knabe - so erzählte B. weiter habe er die Auffassung gehabt, daB der Vater alles sehe. Wir brauchen uns nur an das allsehende Auge Gottes zu erinnern, um zu bemerken, daß hier eine Tendenz vorliegt, den Vater zu einem höheren Wesen zu erheben. Durch freie Assoziationen stellte sich tuberraschend schnell einer der Anlässe heraus, die dem Sohne die Oberzeugung gegeben hatten, daB sein Vater alles sähe. Der Vater hatte mit wachsamem Auge die Masturbation des Knaben entdeckt und ihm das Versprechen abgenommen, fortan von dieser Neigung abzusehen. Beí jedem Ráckfall in späterer Zeit fühlte der Patient das Auge des Vaters gleichsam auf sich gerichtet. DaB dieses Gefühl des Beobachtetseins noch andere und wohl wichtigere Quellen hatte, wird sich noch zeigen. Im BewuBtsein des Patienten aber wurde der Entdeckung der Masturbation durch den Vater das gröBte Gewicht beigelegt.

1 Ich bemerke, daB diese Attittide der Neurotischen nicht selten ist und am leichtesten das Vorhandensein der neurotischen Lichtscheu verrät. 
Im Alter von ungefahhr 20 Jahren verlor der Patient seinen Vater durch den Tod. Bald danach bildete sich die Vorstellung, der Vater stehe am Himmel neben der Sonne und sehe auf ihn herab, um sein Tun und Lassen zu beobachten. Es handelte sich hier noch nicht um eine fixe Wahnidee; nicht lange nachher traten jedoch unzweifelhafte Wahnbildungen hervor. Die Versetzung des Vaters an den Himmel ist hier ganz evident. Sein Posten unmittelbar neben der Sonne läbt erkennen, daß er der Sonne gleichgesetzt wurde, ohne noch mit ihr zu ein e $m$ Wesen verschmolzen $z u$ werden.

Dieser - uber den Tod hinaus fortdauernden - Verehrung und Vergőttlichung des Vaters stand eine äußerst affektvolle, aber durch lange Zeit dem BewuBtsein ferngehaltene Feindschaft gegenüber. Sie äuBerte sich während der Behandlung u. a. in einem Traume, in welchem der Patient seinen Vater im Zweikampf erschlug, um gleich darauf von der Mutter symbolisch Besitz zu nehmen. Die Tötung des Vaters im Zweikampfe und der endliche Besitz der Mutter sind die beiden großen Ereignisse der Ödipussage und vieler verwandter Erzählungen.

Die Kastrationsangst fand in diesem Falle einen sehr ähnlichen Ausdruck wie beim Patienten A. Ich brauche daher nur ein paar Einzelheiten hervorzuheben. Auch in diesem Falle bestand die uns schon verständlich gewordene Angst um das Auge des Vaters. Im Zusammenhang mit dieser Angst ist eine Kindheitserinnerung Von Interesse. Der Patient hatte als neunjähriger Knabe einmal seinen Vater nackt gesehen und mit großem Interesse dessen Genitalien betrachtet. Seine Phantasie, die sich in diesem Alter männlichen Personen zuwandte, kehrte oft $\mathbf{z u}$ jener Szene zurlick. Doch waren die daran anknüpfenden Gedanken keineswegs nur lustvoll. Im Gegenteil wurde er dauernd von der unruhigen Erwartung gequalt, ob er in der Entwicklung der Genitalien wohl den Vater erreichen werde. Als er dann erwachsen war, unterlag er der peinigenden, bei Neurotikern so uberaus häufigen Idee, einen $z u$ kleinen Penis zu haben.

Wir begegnen also hier wiederum der Eifersucht auf das Können des Vaters; im vorliegenden Falle galt die scheue Anerkennung des Sohnes gleichzeitig dem tiberlegenen Genitalorgan des Vaters und seinem Auge ${ }^{1}$. Hier finden wir also keine so weitgehende Verdrängung des sexuellen Charakters der Scheu vor dem Vater. Nur die Lust am Betrachten des văterlichen Genitales ist verdrăngt.

1 Ich verweise an dieser Stelle auf die Bezeichnung ,das Gemăcht" für die männlichen Genitalien; hier hat die Sprache die Macht des Mannes in seine Genitalien verlegt. 
Gelegentlich hatte der Patient "blitzartige" Halluzinationen, die ihm den Gegenstand des Interesses für einen Augenblick zeigten.

Auch in seinem Verhältnis zur Mutter glich Patient B. dem A. in auffälliger Weise. Er scheute sich in höchstem Maße vor dem Anblick seiner Mutter (in ähnlicher Weise auch der Schwester), auch wenn sie vollständig bekleidet waren. Im Gespräch mit der Mutter be deckte er die Augen mit den $\mathrm{Händen.} \mathrm{Die} \mathrm{inzestuöse} \mathrm{Richtung} \mathrm{seiner}$ Wunsche verriet er schon in der ersten psychoanalytischen Behandlungsstunde durch die sonderbare Wahl eines Ausdruckes. Nachdem er berichtet hatte, daB er nach dem Tode des Vaters mit seiner Mutter und seinen Schwestern zurückgeblieben sei, hob er hervor, daB er sich gewissermaßen als Nachfolger des Vaters betrachten muisse; denn er sei doch nun "das einzige männliche Glied" in der Familie. Sehr bald kamen dann die Wunschphantasien zutage, welche die Wahl des Ausdrucks determiniert hatten. Der Patient litt an der Angst, seine Mutter und Schwestern unbeabsichtigt schwängern zu können. Besonders wenn er nach einer Pollution ein Bad nahm, ängstigte er sich, es könnten Reste von Samen an der Badewanne haften, durch die seine Mutter oder Schwester bei späterem Gebrauche der Wanne geschwängert werden könnten. Aus dieser Angst darf man auf einen gleichlautenden verdrängten Wunsch des Patienten schließen : die weiblichen Angehörigen $\mathrm{sau} \mathrm{m} \mathrm{l} \mathrm{lich}$ zu besitzen.

Die auf die Mutter gerichteten libidinösen Wunsche waren auf andere, und zwar hauptsächlich auf reife, ältere Frauen ubergegangen, waren aber auch hier verhindert, sich in ihrer wirklichen Gestalt zu zeigen. Sie äußerten sich vielmehr in einer $\mathrm{Sch}$ e u, solch e $\mathrm{Fr}$ a u e $n$ a nzublicken². Diese Scheu war mit einem für den Patienten sehr lästigen neurotischen Symptom verbunden; beim Anblick reifer Frauen, die ihn oft bewuBt an seine Mutter erinnerten, wurde ihm schwarz v or de $n$ A u ge n. Wir begegnen hier einer Einschränkung der Schaulust, die - soweit mir bekannt - bisher nicht in diesem Sinne aufgefaBt worden ist. Das von Nervösen so oft, namentlich als Begleiterscheinung von Schwindelanfällen geschilderte "Schwarzwerden" vor den Augen dürfte regelmäBig der Unterdrückung einer libidinösen Tendenz entsprechen. Die mit jeder Sexualerregung verbundene Steigerung der Blutzirkulation fuhrt bei Neurotikern oftmals zu einem vermehrten ZufluB des Blutes nach dem Kopf, besonders auch nach

1 Ich verdanke Herrn Dr. de Bruine in Leiden die interessante Mitteilung, daß nach einem hollăndischen Volksglauben erblindet, wer einer alten Frau beim Verrichten eines Bedürnisses zusieht. 
den Augen, wodurch unter anderen Symptomen auch die Verdunkelung des Gesichtsfeldes hervorgerufen wird.

Der Anblick der für ihn reizvollen Frauen wurde dem Patienten auf diese Weise im wirklichen Leben versperrt. Es entspricht ganz der Psychologie der Dementia praecox, daß der Patient für diese ihm auferlegte Entbehrung Ersatz auf halluzinatorischem Wege fand. Er sah z. B. eine im reifen Alter stehende Frau nackt vor sich liegen; sie hatte, wie der Patient spontan hinzufügte, Formen und Gestalt wie seine Mutter.

In eindrucksvoller Weise bestätigte der Patient B., daß seine Scheu vor dem Anblick weiblicher Personen im Grunde genommen eine Scheu vor dem weiblichen, richtiger gesagt vor dem mütterlichen Genitale war.

Zu der Zeit, als schon deutliche Erscheinungen der Rekonvaleszenz zu bemerken waren, besuchte der Patient einmal seine Mutter. Bei ihrem Anblick hatte er, wie er berichtete, die Augen wieder mit den Händen bedecken müssen; seine Empfindlichkeit gegen das Licht war damals bereits in deutlichem Abnehmen begriffen. Wăhrend ich eine Bemerkung dazu machte, legte der Patient wiederum die Hände auf die Augen und sagte dann spontan: "Ich habe die Scheibe mit dem Draht in der Mitte gar nicht ansehen wollen." Diese Worte waren im Tone einer Rechtfertigung gesprochen - als befürchtete der Patient, ich könne ihm etwas in falschem Sinne auslegen. Doch blieb die zitierte Äußerung mir zunächst vollkommen unverständlich. Die Erklärung folgte aber der ersten Äußerung auf dem Fuße. Der Patient, der sich wahrend der Behandlung in Ruhelage befand, hatte seinen Blick nach der Zimmerdecke gerichtet, an welcher eine runde, blanke Messingscheibe angebracht war; aus der Mitte der Metallscheibe kam ein Leitungsdraht der elektrischen Beleuchtung hervor. Dieser Eindruck hatte in dem Augenblicke, als von der Scheu des Patienten vor dem Anblick der Mutter die Rede war, genügt, um die Assoziation der Vulva (Scheibe) und des Penis (Draht in der Scheibe) hervorzurufen.

Feindschaft und Eifersucht gegenüber dem Vater hatten mit der Zeit einer bewundernden Anerkennung seiner GröBe und Macht Platz gemacht. Doch vermochte die unterdrückte feindliche Strömung zuweilen noch Storrungen der zur Herrschaft gelangten Gegenströmung zu erzeugen. Der Patient hatte in einem ekstatischen Moment einmal einen Sonnenhymnus dichten wollen. Er vermochte aber nur wenige Worte zu produzieren. Sie lauteten: 
Danach trat eine solche Störung des Gedankenablaufes (Sperrung) ein, daß der Patient uber die ersten Worte nicht mehr hinauskam. Charakteristisch ist der Eintritt der Sperrung in dem Augenblick, als der Sohn seiner Verehrung für die Kraft der Sonne, d. h. des Vaters, Ausdruck verleihen will. Ich erinnere hier an ein vollkommen analoges Vorkommnis aus der Krankengeschichte des Patienten A., bei welchem eine Sperrung gleicher Art eintrat, als er begonnen hatte, von seiner gltuhenden Verehrung des Vaters zu sprechen.

Der Wunsch, dem Vater gleich zu werden, kam einmal in einer Form zum Ausdruck, die die Gleichsetzung von Vater und Sonne deutlich erkennen läßt. Der Patient unterlag nămlich einmal der Sensation, daB seine beiden Augen zu ein em würden. Dieses Auge sah er halluzinatorisch vor sich, als wäre es "draußen", d. h. außerhalb seines Körpers. Es wurde dann zu einer strahlenden Sonne; der Patient erhob sich damit zur gleichen Höhe wie den Vater. Daß es gerade das Auge und nicht ein anderer Teil des Körpers war, der die Umwandlung erfuhr, ist teils aus dem früher über Auge und Sonne Gesagten verständlich, teils handelt es sich wieder um einen symbolischen Ersatz des Penis durch das Auge. Die erwähnte Halluzination läBt demnach insbesondere noch die Tendenz erkennen, die eigene Zeugungskraft des Patienten der befruchtenden Kraft der Sonne gleichzusetzen.

Ich bin einem inhaltlich ganz ahnlichen, symptomatologisch allerdings andersartigen Vorgang auch in der Psychoanalyse einer Zwangsneurose begegnet. Der Patient hatte nach dem Tode seines Vaters lebhafte Angst vor dessen wachsamem Auge. Das beobachtende Auge versetzte er stets an den Himmel; auch in gewissen Träumen kam das unzweideutig zum Ausdruck. Diese Anerkennung und Erhebung des Vaters war jedoch nur die eine Seite seiner ambivalenten Einstellung zu diesem. Zuzeiten regte sich ein intensiver Trotz gegen den verstorbenen Vater; dann unterlag der Patient dem $Z$ w a ng, di e Sonne frech und herausfordernd anzuseben. Gleichzeitig trat die obsedierende Grübelei auf: "Vielleicht bin ich Gott."

Einen merkwürdigen historischen Versuch eines Menschen, sich selbst mit der Sonne $z u$ identifizieren, habe ich in meinem Aufsatz ${ }^{1}$ über den ägyptischen König Amenhotep IV. analysiert. Ich möchte hier nur den kurzen Hinweis geben, daB die ambivalente Einstellung des Königs $\mathrm{zu}$ seinem verstorbenen Vater die hauptsächlichste Erklärung für die Einführung des Atonkultes abgibt, in welchem die Kraft der Sonne verehrt wurde.

1 Imago Bd. I, 1912. 
Die Angst des Patienten vor der Blendung durch die Sonne wird auch im Falle B. erst dann vollkommen verständlich, wenn man berücksichtigt, dab dem Sonnensymbol nicht nur Vater-, sondern auch - Mutterbedeutung zukommt. Wie im Falle A., so stellte sich die Notwendigkeit dieser Annahme auch hier heraus. Die vorhin erwăhnte blanke Messingscheibe mit dem Beleuchtungskörper an der Zimmerdecke war eine Art von Sonne am Himmel ${ }^{1}$.

Seine Neigung, ein weibliches (d. h. far ihn: "mutterliches") Symbol an den Himmel zu versetzen, äuberte sich in einer spontan mitgeteilten Phantasie. Als sich während der Behandlungsstunde der vorher klare Himmel stark bewölkte, ăußerte der Patient: „Es wä re eine Wollust, sich mitdem Kopf in eine Wolke hinein$z$ ubohren." Diese Phantasie entspricht vollkommen gewissen mythischen Vorstellungen, die ich in meiner Schrift "Traum und Mythus" gelegentlich der Analyse der Prometheussage erwähnt habe. In den altesten Schichten dieses Mythus wird das Bohren in der Wolke (die Erzeugung des himmlischen Feuers) mit dem Sexualakt identifiziert.

Ich habe zum Fall B. nur noch kurz zu bemerken, daB die Lichtscheu im Laufe der Behandlung verschwand, wie denn der Fall sich liberhaupt als therapeutisch sehr dankbar erwies?

Ich sehe an dieser Stelle von der Mitteilung weiterer psychoanalytischer Erfahrungen uber die neurotische Lichtscheu ab. Die Reihe der Falle lieBe sich leicht vermehren; denn nach meiner Erfahrung handelt es sich um eine keineswegs seltene Affektion. Leichtere Grade, wie $z$. B. eine gesteigerte Empfindlichkeit gegen grelles Sonnenlicht, beobachtet man bei leicht neurotischen Personen ziemlich oft.

Eine einzelne Tatsache greife ich aus der Psychoanalyse einer schweren Zwangsneurose heraus. Der Patient litt an einer im allgemeinen nicht sehr erheblichen Lichtscheu. Als seine Assoziationen inn einmal auf gewisse, von der Vater-Imago ausgehende Verbote gebracht hatten, bedeckte er plötzlich seine Augen mit den Händen. Zur Erklärung dieses Verhaltens dienten mehrere ergänzende Einfälle. Der Patient hatte seinem Vater gegenüber immer ein schlechtes Gewissen gehabt; er konnte ihn nie recht ansehen. Seine

${ }_{1}$ Die Identifizierung von Zimmerdecke und Himmel trăgt einen echt infantilen Charakter. Kürzlich hörte ich einen $31 / 2$ jăhrigen Knaben die Decke des BadezImmers den "Badehimmel" nennen.

${ }^{2}$ Zur Erklärung des schönen Erfolges der Psychoanalyse in diesem Falle von Dementia praecox bemerke ich, daB der Patient sich bald als genügend fähig zur - Obertragung" erwies. Seine Psychose war wen ig in der Richtung der Wahnbildung vorgeschritten, wăhrend die Halluzinationen eine überwiegende Rolle spielten. 
Auflehnung gegen den Vater hatte $u$. a. in der Phantasie, den Vater zu blenden, ihren Ausdruck gefunden.

In diesem Fall ergab sich noch eine spezielle Bedeutung des Bedeckens der Augen. Es stellte - abgesehen von den abrigen, uns bereits bekannten Bedeutungen - eine Selbstbestrafung dar: sich blind machen. Es handelte sich also um eine Talion für die erwähnte, auf den Vater gerichtete Absicht ${ }^{1}$.

\section{Andere Formen neurotischer Störungen im Bereich des Schautriebes.}

Sobald man sich einmal eingehender mit den neurotischen Einschränkungen und Unwandlungen der Schaulust beschaftigt, ist man erstaunt taber die Mannigfaltigkeit der Störungen, die aus den genannten Vorgängen herzuleiten sind. Diese Störungen finden sich bald bei den gleichen Personen, welche an Lichtscheu leiden, bald treten sie selbständig auf.

Bei der Darstellung des Krankheitsfalles B. habe ich eine derartige Störung, welche neben der Lichtscheu bestand, nur kurz erwăhnt und komme hier zunächst mit einigen Worten auf sie zurück.

Der Patient klagte über unscharfes Sehen. Er sah die Gegenstände nicht klar, sondern verschwommen, undeutlich. Eine Störung des Sehapparates war nicht nachzuweisen ${ }^{2}$; dab die Affektion neurotischen Charakter trug, wurde noch dadurch erhärtet, daB sie auf psychoanalytische Behandlung gleichzeitig mit der Lichtscheu verschwand. Um Wiederholungen zu vermeiden, gehe ich sogleich zu einem andern Fall über, aus dessen Psychoanalyse ich einiges über eine ganz ăhnliche Affektion mitteilen möchte.

Die Patientin C. beschäftigte sich mit Malerei. Obwohl sie dieser Kunst mit ausgesprochener Liebhaberei ergeben war, bemerkte sie doch, dab es ihr namentlich in Zeiten stärkerer neurotischer Erregtheit schwer fiel, die Formen von Gegenständen richtig aufzufassen und sie ihrem Gedächtnis einzuprägen. Auf diese Störung kam sie zu sprechen, als die Psychoanalyse bei der Aufklärung gewisser motorischer Anfälle angelangt war. Die Störung erwies sich als vorzugsweise determiniert durch eine verdrängte, inzestuös fixierte Schaulust, die sich namentlich auf den Vater (Körperformen!) richtete. Eine spezielle Determinierung

1 Vgl. Ödi p us' Selbstblendung.

2 Ich erwähne an dieser Stelle, daß die in diesem Aufsatz beschriebenen Affektionen solche Personen betrafen, die einen durchaus intakten Sehapparat hatten. Eine einzige Ausnahme wird im folgenden noch Erwähnung finden. 
ergab sich aber noch aus der Analyse besonderer Anfälle, die ich einige Male auch selbst $\mathrm{zu}$ beobachten Gelegenheit hatte.

Auf dem Sofa liegend, begann die Patientin sich unter Anzeichen heftiger psychischer Erregung zu strecken und erhob sich in einem (nicht sehr ausgesprochenen) "Arc de cercle“ von ihrem Lager; dann geriet der ganze Körper, besonders die Extremitäten in ein lebhaftes Vibrieren und Zucken, das die Patientin mit ächzenden Lauten begleitete, bis eine allgemeine Erschlaffung eintrat. Wahrend des Anfalles pflegte die Patientin sich einmal hastig aufzurichten und den Kopf für einen Augenblick nach der Seite zu drehen, um dann wieder zurückzusinken.

Die Analyse dieser Anfalle vollzog sich unter ungeheuren Widerständen; mehrmals begonnen und immer wieder aufgegeben, gelang sie erst am Schluß der Behandlung. Die Anfälle entpuppten sich als mimische Darstellung eines mit äußerst heftigen Affekten verbundenen Erlebnisses aus der Kindheit der Patientin, über dessen Realităt aus bestimmten Grunden kein $Z$ weifel obwalten kann. Sie war eines Morgens fruher als sonst erwacht und war, da sie im gleichen Zimmer wie die Eltern schlief, Zeugin des sexuellen Verkehres geworden. Sie hatte sich - wie die allmählich hervorkommenden Einfälle ergaben im Bett einen Augenblick aufgerichtet und dann erschrocken wieder niedergelegt. Diese ihre eigene aktive Beteiligung an dem damaligen Vorgang drückte sich im späteren Anfall durch das plötzliche Aufrichten des Oberkörpers aus. Das aufregende Erlebnis selbst wurde verdrängt, die Erinnerung machte sich aber bei bestimmten, hier nicht weiter $\mathrm{zu}$ verfolgenden Gelegenheiten in verhüllter Form bemerkbar. Die eigentliche schwere Nachwirkung des Erlebnisses aber bestand in heftigen Selbstvorwürfen und in bestimmten Einschränkungen des Trieblebens, unter welchen hier nur die Einschränkung des Schautriebes interessiert. Sie äußerte sich zunăchst durch eine Scheu vor allem sexuellen Schauen und Wissen, u. a. durch ängstliches Meiden von Lektüre, die der Patientin irgendwelche Aufklärung laber das Liebesleben bringen konnte. Die Scheu breitete sich aber, wie die Psychoanalyse ergab, auf das Sehen im allgemeinen aus, selbst wenn es keinen manifest-sexuellen Charakter hatte und bezog sich speziell auf die Formen der Objekte.

Dieser Fall zeigt mit besonderer Klarheit, wie die Beobachtung des elterlichen Geschlechtsverkehres bei einem neurotisch veranlagten Kinde wirkt. Die Schaulust wird durch derartige Eindrücke an die Eltern in ungewöhnlichem Maße fixiert, so daß die späteren Ablösungsversuche miBlingen müssen. Gleichzeitig kommt es zu einer, weit 
über das eigentliche Gebiet der Sexualität hinausgehenden Einschränkung der Schaulust. Die ,Talion" kann sehr verschieden weit gehen; sie kann zur neurotischen Blindheit führen, kann sich aber auch mit gewissen Einschränkungen des Sehens begnügen. Oder sie kann zur Bildung von Phobien AnlaB geben. Die Patientin litt an gelegentlichen Zwangsgedanken, sich selbst die Augen ausstechen zu müssen.

Kurz erwähnen will ich hier zwei mir bekannte Krankheitsfälle, die ich nicht psychoanalytisch behandelt habe, die aber ein symptomatologisches Interesse bieten und die Mannigfaltigkeit der neurotischen Sehstörungen demonstrieren mögen.

Eine neurotische Frau leidet zeitweise an einer Sehstörung, die sie hindert, ohne Brille ein Buch zu lesen. Sie hat eine ausgesprochene Scheu vor dem Anblick von Illustrationen in Blichern; sie meidet solche daher nach Möglichkeit.

Ein jungerer Mann, der von Kindheit an mit Angst vor der Dunkelheit und mit einer hartnäckigen Erblindungsphobie behraftet war, erkrankte an einer Sehstörung, die von augenärztlicher Seite sofort als neurotisch erkannt wurde. Er beschrieb sie mir in einem Brief mit folgenden Worten: "Seit ungefähr 10 bis 14 Tagen sehe ich schlecht, d. h. es flimmert mir vor den Augen, so als ob es mir beständig schwindelig wäre, und ich sehe nur wie durch einen Schleier. Es fing eines Nachmittags mit einem Flimmern an, ich sah z. B. Zickzackbänder flimmern, so ungefahr wie wenn man lange in die Sonne oder in grelles Licht geblickt hat. Es dauerte etwa eine halbe Stunde; dasselbe wiederholte sich drei Tage später und seitdem habe ich es beinahe unaufhörlich. Es ist jetzt weniger Flimmern als trubes Sehen, be i g ro Bem Angstgef $u$ h 1 natürlich. Zuerst hatte ich die Angst vor Erblindung." Zum Verständnis dieser Störung, die ich, wie erwähnt, nicht analysiert habe, konnte ich nur ermitteln, daB der Patient sich in einem sexuellen Konflikt befand, der eine völlige Wiederholung seiner infantilen Ödipuseinstellung bildete.

Es gibt eine, freilich seltenere Störung auf dem Gebiet der Schaulust, welche den beschriebenen Störungen der Wahrnehmung in ihrer äußeren Erscheinung vollkommen entgegengesetzt und dennoch gleicher Herkunft ist und den nämlichen Tendenzen dient. Es handelt sich um ein übertriebenes Achtgeben auf die Dinge und Vorgange in der Außenwelt, womit sich dann auch ein auffallend getreues Gedächtnis für minutiöse Details verbindet. Diese stetige Spannung der optischen Aufmerksamkeit, dieses Notiznehmen von Dingen, welche von anderen Menschen als belanglos mit Recht keiner besonderen Beachtung gewürdigt werden, täuscht eine rege Schaulust vor. 
Solche Menschen sind uber tausend Kleinigkeiten innerhalb ihres Gesichtskreises glănzend orientiert. Aber dieser Gesichtskreis ist in Wirklichkeit erschreckend eng; er beschränkt sich auf das, was mit dem Interessenkreis der Kindheit, der Familie oder der engen Heimat zusammenhängt. Dagegen besteht eine Scheu, kennen zu lernen, was jenseits dieser Sphäre liegt. Besonders meiden solche Personen das sexuelle Schauen und jede sexuelle Aktivität. Wie leicht ersichtlich, handelt es sich um einen Verschiebungsvorgang. Dasjenige, was den Schautrieb am stärksten zu reizen vermag, wird gleichsam als etwas Verbotenes gemieden; das Interesse verschiebt sich auf das unbedingt erlaubte Indifferente.

Bei einem Patienten meiner Beobachtung lieB sich dieser ProzeB bis auf die fruhe Kindheit zurückverfolgen. Der Patient, welcher vor Eintritt in die Behandlung etwas Unbestimmtes dartiber vernommen hatte, daB in der Psychoanalyse die frihesten Kindheitserlebnisse reproduziert werden mthbten, teifte $\mathrm{mir}$ in der ersten Sitzung vor allem anđêrn mit, daß er außergewöhnlich vollständige und getreue Erinnerungen aus seiner fruhesten Kindheit habe. Er gab dann sogleieh einige Beispiele, denen spater eine große Zahl weiterer folgte, welche sich auf das vierte bis siebente Lebensjahr bezogen. Von Ereignissen dieser Zeit wubte er eine unbegreifliche Menge von Einzelheiten. Am erstaunlichsten war dieses minutiöse Gedächtnis für zwei Zeitpunkte in seinem vierten und siebenten Jahre. Die letzteren bezogen sich auf den Aufenthalt in einem Badeort, wo er als sechsjähriger Knabe mit seinen Eltern geweilt hatte. Er kannte eine große Menge von Personennamen aus jener kurzen Zeit, beschrieb minutiös das Äußere seiner Spielgefährten, erinnerte sich, was diese und jene Person gesagt hatte, wuBte von jedem Möbel der Wohnung, in der seine Eltern mit ihm wohnten. Die Erinnerungen waren so lebhaft und machten den Eindruck solcher Frische, daß man mit Recht von einer ausgesprochenen Hypermnesie reden konnte.

Dieses Phänomen blieb mir zunächst rătselhaft. An eine solch ausgeprägte Ausnahme, von der allgemeinen Amnesie für die frùhen Kindheitsjahre vermochte ich nicht zu glauben. Erinnerungsfälschungen anzunehmen lag aber ebenfalls kein Grund vor. Die vom Patienten gemachten Angaben trugen in keiner Weise den Stempel des Phantastischen, bewegten sich vielmehr im Rahmen der nuchternsten Alltäglichkeit. Man hätte vergeblich geraten, was wohl die Phantasie des sehr intelligenten Mannes hätte veranlassen sollen, seine Kindheit mit dieser Menge uninteressanter Details auszuschmücken. Irgend welche affektstarken Eindrücke oder irgend welche Erinnerungen, die 
đen Größenwänschen des Kindes oder des Erwachsenen hätten schmeicheln können, fanden sich unter all dem mitgeteilten Material nicht vor.

Diese Hy perm nesie klärte sich aber auf, sobald sich in ihrer Nahe eine - scheinbar nicht sehr wichtige - umschriebene Am nesie herausstellte. Der Patient wußte, außer dem geschilderten indifferenten Material nur eine Tatsache aus der Zeit jenes Badeaufenthaltes mitzuteilen, die mit großem Affekt verbunden war: in jener Zeit waren lebhafte Selbstvorwürfe bei ihm aufgetreten. Die Ursache dieser - Selbstvorwlirfe war ihm aber vollig a us dem Gedächtnis e $\mathrm{ntschw}$ w nden. Es ergab sich dann, daß der Patient auch in seinem vierten Lebensjahr bereits eine Periode der heftigen Selbstvorwurfe durchgemacht hatte; der AnlaB zu den letzteren lag ebenfalls im Dunkeln.

Der Hebung einer solchen, seit der frühen Jugend bestehenden Amnesie pflegen sich stets ganz besondere Widerstande in den Weg zu stellen. So auch in diesem Falle. Ganz allmählich wurden aber, besonders durch Trắume, die Anhaltspunkte zutage gefördert, die mit Sicherheit darauf schlieBen lieBen, daB auch bei diesem Patienten die in früher Kindheit erfolgte Beobachtung des elterlichen Sexualverkehres zu schweren Verdrängungen Anlaß gegeben hatte; sie muß gerade in die Zeit gefallen sein, die dem Auftreten der Selbstvorwturfe vorausging. Die sexuelle Neugierde verfiel der Verdrăngung; an ihre Stelle trat das ubertriebene Achtgeben auf indifferente Einzelheiten im tăglichen Leben.

Die Erforschung der frühen Kindheit förderte bei dem nămlichen Patienten Materialien zutage, die bewiesen, daB sich sein Interesse frühzeitig in einem ungewöhnlichen Maße auf den Körper seiner Mutter gerichtet hatte. Seine Fixierung an die Mutter hielt auch nach der Pubertăt an und äußerte sich in einer schweren Neurose (Angsthysterie). Es ist nun bemerkenswert, daß der Patient eine große Scheu empfand, seine Mutter anzusehen. Das Verbot des Schauens auf die Nacktheit der Mutter hatte sich in eine Scheu vor ihrem Anblick uberhaupt umgewandelt. Fremden weiblichen Personen blickte der Patient mit Vorliebe ins Gesicht, namentlich in die Augen; das hatte für ihn einen ausgesprochen erotischen Reiz. Faktisch war dieses seine einzige Sexualbetätigung gegenüber dem weiblichen Geschlecht. Ich erinnere hier an die früheren Erörterungen, welche uns die Genitalbedeutung des Auges ergaben. Jene sehr reduzierte Sexualbetătigung des Patienten war also eine, von ihrem ursprünglichen Ziel - dem Genitale - abgelenkte, "nach oben verlegte" Schaulust. Bei dieser Gelegenheit mag daran erinnert werden, daB der Ausdruck des Auges 
leicht eine erotische Erregung verrät. Männer -mit herabgesetzter sexueller Aktivität suchen oft gerade dieses Zeichen der Geneigtheit bei weiblichen Personen; sie beschränken sich manchmal darauf, dieses Zeichen hervorzurufen, unter Verzicht auf jede sonstige Annäherung. Diese Erscheinungen werden unten eine genauere Besprechung finden. Hier genügt es, auf die eigentümliche Verschiebung des Schautriebes hinzuweisen.

Bei dem gleichen Manne bestand aber eine Scheu, männliche Personen anzublicken; sie bezog sich sogar auf ihm ganz vertraute Menschen. Die homosexuelle Schaulust war also in bedeutend weiterem Umfang der Verdrängung verfallen als die heterosexuelle.

Eine ähnliche Unterdrückung der Schaulust ist von erheblicher Bedeutung für die Entstehung eines sehr verbreiteten motorischen Symptoms im Bereich der Augen, nämlich des $z$ wangartigen $Z$ uckens der Augenlider. Soweit meine psychoanalytische Erfahrung reicht, entspringt diese Zwangsbewegung einem e r $\mathrm{Ch} \mathrm{rockenen}$ VerschlieBen der Augen. Diese ist zunächst ein Ausdruck der Kastrationsangst. Das Liderzucken scheint regelmäBig mit einer Angst vor Beschädigung der Augen verbunden zu sein, welche nach unseren früheren Ausführungen einer Angst um das Genitale gleichkäme. Das zwangsmäßige Zusammenkrampfen der Lider entspricht des weiteren einem Grauen vor gewissen Phantasien, welche sich dem Patienten mit visionärer Deutlichkeit aufdrängten und verbotenen Schaugelüsten Ausdruck gaben. Es scheint sich dabei teils um erotische Vorstellungen zu handeln, teils um solche sadistischer Art (Phantasien vom Tode Angehöriget). Diese Vorstellungen drängten sich dem Patienten eines Tages in Form von Bildern (Zwangshalluzinationen) auf, wurden unter Zeichen des Grauens abgewiesen und verfielen der Verdrängung. Das zwangsmäßige krampfartige Schließen der Augenlider zeigt aber an, daß jene verpönten Phantasien im Unbewußten des Patienten noch existieren, und daB ein fortdauernder Verdrängungsaufwand erforderlich ist, um sie vom BewuBtsein fernzuhalten ${ }^{1}$.

Eine eigentlimliche Transformation der sexuellen Schaulust stellt diejenige Störung dar, welche ich mit dem Namen $\mathrm{Sch}$ a u $\mathrm{z}$ wang belegen möchte. Ich behandelte einen $Z$ wangsneurotiker, der neben dem Zwange, uber die Herkunft jedes Gegenstandes zu grübeln, an dem krankhaften Antrieb litt, die Rückseite jedes Gegenstandes seinen Augen $z$ ugänglich $z u$ machen und sie

1 Ich bemerke ausdrücklich, daß ich hier keine erschöpfende Erklărung des Phänomens gebe; die obigen Andeutungen entstammen gelegentlicher Beobachtung, nicht ausführiicher Analyse. 
dann zu betrachten. Ich habe einiges über diesen merkwürdigen Fall mitgeteilt ${ }^{2}$. In diesem Zusammenhange sind folgende Tatsachen von Interesse.

Vor dem Hause, in welchem ich damals wohnte, befand sich ein Vorgarten, an dessen Gitter mein Namensschild angebracht war. Der Patient begnügte sich bei seinem ersten Besuch, der an einem Abend stattfand, nicht damit, die Aufschrift des Schildes zu lesen, sondern beleuchtete, nachdem er in den Vorgarten eingetreten war, mit Hilfe eines Zündhölzchens die Rückseite des Schildes. Dann brachte er (nach Schilderung seiner ihn begleitenden Frau) längere Zeit damit zu, laut vor sich hinsprechend, über die Herstellung solcher Schilder nachzugrübeln. Als seine Frau ihn endlich bis in mein Sprechzimmer gebracht hatte, faBte er alsbald eine kleine Bronzefigur ins Auge, nahm sie vom Tisch, drehte sie und betrachtete besonders eingehend die Rückseite des Körpers.

Die sehr fragmentarische Psychoanalyse ergab, daB der Patient in der Kindheit ein übergroßes Interesse für das $G$ esä $B$ bekundet hatte. Im Anschluß an den unverhofften Anblick des GesäBes einer Frau waren seine ersten $Z$ wangssymptome aufgetreten. Das Interesse am Gesäß hatte sich dann auf leblose und indifferente Gegenstände verschoben, deren $\mathrm{R}$ u $\mathrm{cks}$ eite der Patient $z$ wangsmäBig betrachten muBte. Warum die Schaulust in diesem Falle (und in mancher anderen Neurose) vorwiegend auf das GesäB anstatt auf das Genitale gerichtet ist, kann hier nicht genauer untersucht werden.

Eine, wie es scheint, speziell bei weiblichen Neurotischen vorkommende Störung ist die Angst, durch den Blick Personen des anderen Geschlechtes sinnlich $z$ u erregen. Sie führt in manchen Fallen $z u$ einer Scheu vor jeder Begegnung mit Menschen, so daß die von dieser Störung befallenen Personen ganz unsozial werden.

Die Eigentümlichkeit dieser und gewisser noch zu erwähnender Falle besteht darin, daB dem Auge respektive dem Blick eine Macht zugeschrieben wird, als wäre das Individuum im Besitz zauberhafter Kräfte. Es entspricht dieser Úberschätzung des Auges und seiner Macht, daB solche Menschen in ihrem Denken sich in auffalliger Weise auf diesen Vorstellungskreis einengen. Auf Grund mehrfacher Erfahrungen glaube ich, die hieher gehörigen Fälle diagnostisch nach zwei Seiten sondern zu können.

1 .Eine Deckerinnerung betreffend ein Kindheitserlebnis von scheinbar ätiologischer Bedeutung." Internationale Zeitschr. für ärztl. Psychoanalyse, 1913, Bd. I, S. 247. 
Die Angst, durch den Blick in jedem Menschen sexuelle Erregung wachzurufen, findet sich bei Neurotischen neben anderen Phobien oder Zwangsgedanken. Die Störung erscheint mir durchaus ein Analogon der Vorstellung von der "Allmacht der Gedanken" zu sein; dem Blick wird hier eine solche "Allmacht" zugeschrieben.

Diagnostisch anders zu bewerten sind dagegen jene Fälle, in denen die Angst besteht, durch den Blick Wirkungen zu erzielen, die über das Erregen von Verliebtheit usw. weit hinausgehen. Hier handelt es sich um Psychosen von paranoidem Charakter, die oft durch lange Zeit äußerlich unter dem Bilde einer Neurose verlaufen.

Bei einem jungen Mädchen bestand die Angst, durch ihren Blick andere Menschen in solchem Maße zu entsetzen, daB sie erstarren und auf der Stelle sterben müßten. Die Obereinstimmung mit einem antiken Sagenstoff ist hier ganz frappant; die Patientin verglich auch selbst ihren Blick mit dem der Gorgo. Diese Angst verstärkte sich im Laufe der Jahre immer mehr und nötigte die Patientin, sich von aller Gesellschaft zurückzuziehen. In einem ihrer Träume befand sie sich in einem riesigen Raume, der etwa einer Bahnhofshalle glich. Unter den Tausenden von Menschen, die dort versammelt waren, erscholl plötzlich der Schreckensruf, die "Totenstarre" sei ausgebrochen, worauf die Menschen in panischem Entsetzen vor der Träumerin flohen.

Ganz ăhnliche Phantasien fand ich bei einem anderen jungen Mådchen. Die Vorstellung, durch ihren Blick zahllose Menschen zu töten, setzte sich bei ihr nicht bloB in den Träumen, sondern auch in Sinnestäuschungen wăhrend des Wachens durch. Als sie z. B. an einem Ball teilnahm, bemerkte sie zu ihrem Entsetzen, wie jeder Mensch, den sie ansah, im Gesicht eine weißgrunliche Leichenfarbe annahm, wodurch für sie der Eindruck entstand, daß sie sich unter lauten Toten befand.

Beide Personen, von welchen zuletzt die Rede war, ergingen sich in mablosen sadistischen Phantasien. Die eine zerbrach im Traum ihrer Mutter sämtliche Knochen, die andere phantasierte unaufhörlich von räuberischen Überfăllen auf ihre Familie, deren Mitglieder gemordet oder gefoltert wurden; diese Beispiele ließen sich beliebig vermehren. Das Auge war in diesen Fallen sozusagen ein Instrument des $S$ adis mus.

Es ist bemerkenswert, daß es sich in den Fällen dieser Art, welche ich beobachten konnte, immer um weibliche Personen handelte. Die Psychoanalyse in den beiden zuletzt erwähnten Fallen war mit sehr großen, in der Krankheit begrundeten Schwierigkeiten verbunden. 
Ich kann deshalb nur mit einer gewissen Reserve aussagen, daß für beide Patientinnen, die in ihren Phantasien die männliche Geschlechtsrolle zu ubernehmen liebten, das Auge die Bedeutung eines Penis zu haben schien, mit dem man die Menschen erschrecken und töten konnte. Diese Auffassung, die zunächst befremdend und unwahrscheinlich klingt, findet ihre Bestätigung in den nicht seltenen Beängstigungen neurotischer Frauen, vom Blick des Mannes "durchbohrt" zu werden. So wich 2. B. eine meiner Patientinnen dem Blick jedes Mannes aus, weil sie sich von ihm im eigentlichsten Sinne - durchbohrt fuhlte, d. h. sie verspurte, sobald der Blick eines Mannes sie traf, einen stechenden Schmerz im Unterleib.

Andere Neurotische spüren stechende oder bohrende Sch merzen im A uge. In manchen solchen Fällen handelt es sich um eine Verlegung der soeben erwähnten Genitalsensationen "nach oben". Es gibt jedoch seltene Fälle von schwerem, ne urotischem A u g ens ch m e r z, die eine sehr komplizierte psychologische Struktur aufweisen. Ich werde uber die Psychoanalyse eines solchen Falles genauer berichten; hier war der Augenschmerz mit einer extremen Lichtscheu kombiniert. Die Patientin brachte längere Zeit in vollkommenem Dunkel zu. Dieser Fall eignet sich besonders dazu, di e Be d e u t ung der Dunkelheit im Seelenleben der an Lichtscheu Leidenden aufzuklären. Wir müssen $z u$ diesem $Z$ wecke wieder an die oben mitgeteilten Resultate aus der Analyse der Lichtscheu anknüpfen.

\section{Zur Bedeutung des Dunkels in der Psychologie der} Neurosen.

Bei der Analyse der neurotischen Lichtscheu ergab sich, daß der Sonne vorzugsweise die Bedeutung eines Vatersymbols, daneben freilich auch diejenige eines Muttersymbols zukomme. In Hinblick auf diese zweite, entschieden untergeordnete Bedeutung darf man sagen, daB das nur in der Einzahl vorhandene Sonnensymbol der Darstellung der Vaterimago diene, welch letztere die Mutterimago sozusagen in sich aufgesogen habe. Ich denke dabei an einen Vorgang solcher Art, wie wir ihn in deutlichen Spuren z. B. in der biblischen Schöpfungsgeschichte finden. Unterwirft man diesen Mythus, der ja Spuren ganz außerordentlicher Umarbeitungen und Entstellungen aufweist, einer genaueren Analyse, so fällt in hohem Maße auf, wie sehr das weiblichmütterliche Element im männlich-väterlichen aufgegangen ist. Findet man in den uns sonst bekannten Kosmogonien stets ein sogenanntes "Welt-Elternpaar", so erschafft in der biblischen Genesis der 
einzige (männliche) Gott allein die Welt, alle Wesen und endlich auch den Menschen, oder - richtiger gesagt - den Mann. Erst aus diesem entsteht das Weib. Beide zeugen zusammen wiederum Söhne, keine Töchter. Diese weitgehende Ausschaltung des weiblichen Elementes erweist sich jedoch als eine ganz sekundäre Erscheinung, auf die später noch zurückzukommen sein wird.

Wenn nun im Sonnensymbol vorwiegend die Vaterimago ihren Ausdruck findet, so wird man sich fragen, ob die Imago der Mutter nicht etwa doch auch durch ein besonderes Symbol in den Phantasiegebilden unserer Patienten vertreten sei. Denn die Mutter spielt in den unbewußten Phantasien dieser Patienten eine bedeutende Rolle; die ihr geltenden Vorstellungen haben unbedingt den gleichen Anspruch ătú einen ihnen adäquaten symbolischen Ausdruck wie die auf den Vater bezüglichen Phantasien. Zur Lösung dieser Frage gelangte ich auf einem Umweg, nämlich als ich einer anderen, ebenfalls ungelösten Frage im Bereich der neurotischen Lichtscheu năher zu kommen versuchte. Die neurotische Lichtscheu wurde nicht in vollem Umfang verständlich, solange nicht die Frage, warum die Patienten das Dunkel aufsuchen, allseitig geklärt war. Ich selbst war anfänglich geneigt, in diesem Verhalten lediglich eine Flucht vor dem Licht zu erblicken. Bei genauerem Studium dieser Falle wurde mir aber immer klarer, daB dem Dunkel nicht bloB eine negative Bedeutung zukomme. Durch eine Mitteilung von Dr. A. Stegmann in Dresden wurde ich auf den positiven Lustwert des Dunkels aufmerksam gemacht. Erst dadurch wurden mir die manchmal so komplizierten Maßregeln zur Herstellung völliger Dunkelheit verständlich, wie diese Patienten sie, besonders am Abend, $z \mathfrak{u}$ treffen pflegen. Ich habe, der größeren Übersichtlichkeit halber, in den zwei mitgeteilten Auszügen aus Psychoanalysen (Kap. I) diese wichtige Seite des Zustandes zunächst auBer acht gelassen. Ich werde das Nötige nunmehr nachtragen und mich dabei auf die schon bisher herangezogenen Fälle, auBerdem aber namentlich auf die Psychoanalyse einer Frau beziehen, die an einer extrem schweren Lichtscheu erkrankt war.

Die Patientin - dieselbe, auf deren. Krankheitsgeschichte ich im vorstehenden schon einige Male verweisen mußte - lebte zu der Zeit, als sie in psychoanalytische Behandlung trat, Tag und Nacht im absoluten Dunkel. Sie litt - wie erwăhnt - nicht nur an einer sehr ausgeprägten Lichtscheu, sondern empfand jede Belichtung als heftigen Schmerz in den Augen. Die Sehorgane waren, bis auf einen mäBigen Grad von Astigmatismus, durchaus gesund. Eine Reihe namhafter Ophthalmologen hatte sich übereinstimmend dahin 
ausgesprochen, daB es sich bei der Patientin nicht lediglich um die Schmerzen handle, welche oftmals den Astigmatismus begleiten. Der atiologische Zusammenhang des Leidens mit schweren Gemütserregungen wurde von der Patientin selbst betont.

Jeder Besuch der Patientin in meiner Wohnung war durch ihr Leiden aufs ăußerste erschwert. Am hellen Tage konnte sie den Weg nicht machen; ebensowenig am Abend, wenn die Straßen elektrisch beleuchtet waren. So war sie auf die Dämmerstunde angewiesen. Sie schützte dann ihre Augen durch ein Pincenez mit ganz dunkeln Gläsern; darüber setzte sie eine ebenfalls dunkle Automobilbrille, die besonders den seitlichen Lichteinfall vom Auge fernhielt. Dann folgte als weiterer Schutz ein dichter Schleier; damit nicht genug, bog sie die sehr breite Krempe ihres Hutes tief herab. So geschlitzt, bestieg sie eine geschlossene Droschke und begab sich zur Behandlung. In ihrer Wohnung schutzte sie sich in ahnlich komplizierter Weise gegen das Licht.

$\mathrm{DaB}$ auch in diesem Falle Licht und Leben identisch waren, ergab sich bald; die ungeheuer starke Betonung des Willens, im Dunkeln zu leben, stellte sich bald als ein Todessehnen heraus. In einem ihrer Gedichte hatte die Patientin, die einșt mit großem Ehrgeiz ins Leben getreten war, ihr Dasein mit einem Kirchhof verglichen. Sie war in ihrem dunklen Zimmer, wo sie auch noch zumeist im Bette lag, gleichsam lebendig begraben. Die in diesem Begrabnis liegende Selbstbestrafung liegt für den Psychoanalytiker auf der Hand, der weiB, wie häufig die verdrăngte Phantasie vom Lebendigbegraben zur neurotischen Symptombildung Anlaß gibt.

Von ausschlaggebender Wichtigkeit war aber, wie sich des weiteren zeigte, die $\mathrm{Phantasie} v$ on der Ruckkehr in den Mutterleib. Die Fixierung der Tochter an die Mutter war so außergewöhnlich stark, daß die Patientin, eine Frau von großem psychologischen Scharfblick, mit Bezug darauf einmal außerte, die "psychologische Nabelschnur" zwischen ihr und ihrer Mutter sei nicht durchschnitten worden! Unter ihren Gedichten fand sich eines, in dem sie die Mutterleibsphantasie in anschaulicher Weise zur Darstellung gebracht hatte.

Von den mannigfachen Determinierungen der Lichtscheu und des Augenschmerzes kann ich aus besonderen Rücksichten nur einiges andeuten. Im Phantasieleben der Patientin lagen schwerwiegende Motive, wegen deren sie sich jeder Lust am Schauen begeben hatte und sich für jeden Versto $B$ gegen dieses selbstgegebene Verbot mit heftigen Schmerzen bestrafte. Neben anderen Phantasien handelte es 
sich um solche, die gegen eine Person ihrer nächsten Umgebung gerichtet waren, weil jene die Patientin an Glanz weit aberstrahlte. Zur Erklärung der sonderbaren Prozeduren, welche die Patientin vor dem Verlassen des Hauses treffen muBte, trug in hohem MaBe bei, daß sie durch Brillen und Schleier hindurch auf keinen Mann "ein Auge werfen" konnte, daß sie sich durch ihre Vermummung für jeden Mann abschreckend machte, freilich auch für den eigenen Mann.

Ohne des weiteren auf die Determinierungen der Symptome einzugehen - besonders die sadistischen Determinierungen habe ich nicht genauer berücksichtigt - erwähne ich, daß im Laufe einiger Monate eine so weitgehende Besserung der Lichtscheu eintrat, daB die Patientin unter Anwendung relativ geringer SchutzmaBregeln an abendlichen Gesellschaften in hell erleuchteten Räumen teilnehmen konnte. Einmal brachte sie vier Stunden in einem hell erleuchteten Saal zu. Diese schönen Erfolge, welche natürlich zu einem Teil auf Obertragungswirkungen beruhten, wurden durch eine Periode des intensivsten Widerstandes abgelöst. Die Psychoanalyse hatte der Kranken zum Eintritt ins Leben verholfen, hatte die "psychologische Nabelschnur" nahezu durchtrennt. Aber die Patientin durfte sozusagen das Licht der Welt nicht erblicken. Der nun einsetzende Widerstand erweckte die Mutterleibphantasien von neuem. Die Patientin zog sich mit heftigen Schmerzen wieder in ihren kaum verlassenen Kerker zurück und weigerte sich gegen eine Fortsetzung der Behandlung; diese wurde tatsăchlich nicht wieder aufgenommen.

Die symbolische Bedeutung des Dunkels hat einen durchaus ambivalenten Charakter. Ganz wie die Erde oder das Wasser hat auch das Dunkel gleichzeitig eine symbolische Bedeutung im Sinne der Geburt und des Todes. Diese doppelte Bedeutung kommt in der Symbolik der Träume und der Neurosen allen Höhlen $z u$, in welche kein Licht eindringt, und zwar sowohl den Höhlen des menschlichen Körpers als auch Hohlräumen anderer Art.

Die dunkle Höhle, welche in dieser Symbolik den Mutterleib repräsentiert, ist oftmals nicht als Uterus, sondern als Da rm aufzufassen. Für den psychoanalytisch Erfahrenen genügt hier der Hinweis auf die bekannte infantile Sexualtheorie, welche die Geburt der Kinder aus dem Anus der Mutter erfolgen läbt, und die oft liberlebhafte Betonung des kindlichen (respektive neurotischen) Interesses an Darm und Darmfunktionen. Durch die Ergebnisse meiner Psychoanalysen bin ich aber mehr und mehr darauf aufmerksam gemacht worden, daB das Interesse mancher Neurotiker am Alleinsein in einem engen, dunkeln Raum noch weitere Determinierungen analerotischer Natur 
aufweist. Besonders kommt in ihren Phantasien, wie leicht zu vermuten, diesem Raum oft die Bedeutung des Klosetts zu. Oberraschender, aber für den Kundigen durchaus erklärlich ist die nicht seltene Vorstellung neurotischer Personen, in einer Klosettgrube eingeschlossen zu sein. Bald ist diese der Ort ihrer heimlichen, lustbetonten Wünsche, bald ihrer unheimlichen Befurchtungen.

Ich muBte zum SchluB dieses Abschnittes ausführlicher auf das infantile und das neurotische Interesse an geschlossenen dunkein Răumen eingehen, weil uns dadurch andere psychologische Erscheinungen verständlich werden, $z u$ denen wir nun ubergehen mulssen. Die bei vielen Neurotischen, insbesondere bei Zwangskranken, so sehr hervortretende Neigung zu allem "Dunkeln", d. h. Geheimnisvollen, Ubersinnlichen, Mystischen darf nicht nur aus verdrängter Schaulust im allgemeinen erklärt werden, sondern ist spezieller determiniert durch jenes lustbetonte Interesse an dunkeln Höhlen, welches uns aus der infantilen Sexualităt verständlich wurde.

\section{Beiträge zur Psychologie des Zweifelns und Grübelns. Völkerpsychologische Parallelen.}

In den "Bemerkungen luber einen Fall von $Z$ wangsneutose“ (1909) hat Freud den Nachweis gefuhrt, daB gewisse Symptome - der Zwangsneurose von einem Verdrängungs- und Verschiebungsvorgang herruhren, welcher den Schautrieb betroffen hat. Er verwies dabei namentlich auf die Beziehungen zwischen Schaulust, $W$ i

Im folgenden beabsichtige ich, an Hand meines analytischen Materials den von $\mathrm{Freud}$ erkannten ProzeB genauer zu verfolgen, und F r e u d s Aufstellungen in gewisser Hinsicht zu ergănzen; uberdies werde ich gewisse völkerpsychologische Parallelerscheinungen in den Kreis der Betrachtung ziehen.

Bei den Neurotikern, welche an Frage- und Grubelsucht leiden, finden wir regelmäBig eine Herabsetzung der sexuellen Aktivităt; in extremen Fällen ist die letztere dem grüblerischen Denken vollständig zum Opfer gefallen'1. Solche Menschen stehen den wichtigen Fragen der Sexualităt ratlos wie Kinder gegentiber; ihr Interesse hat sich vom sexuellen Gebiet in folgenschwerer Weise entfernt und sich auf andere Fragen verschoben.

Is handelt sich hier vorwiegend um mannliche Patienten. Bei Frauen ist die Grübelsucht viel seltener. Wo ich aber bei Frauen Symptome von Fragesucht oder ahnliche Erscheinungen fand, stellte sich regelmäBig auch elne außergewbhnlich weitgehende Sexualablehnung heraus. 
Die primitive sexuelle Neugierde richtet sich im Kindesalter zuerst auf den Körper und speziell auf die Genitalien der Eltern, sodann auf den Zeugungsvorgang und auf die Geburt. DaB sich beim Knaben, dessen Verhalten uns hier in erster Linie beschäftigen muB, das Interesse in weit höherem Maße der Mutter zuwendet als dem Vater, ist nicht bloß aus dem Geschlechtsunterschied $z \mathfrak{u}$ erklären, sondern hauptsächlich auch aus dem Interesse für die Herkunft der Kinder aus dem Körper der Mutter.

Die primitive kindliche Neugierde will diese Organe oder Vorgänge sehen; das Verlangen, von ihnen $z \mathfrak{u}$ wissen, läßt bereits auf eine Eindämmung der Schaulust schließen. Bei vielen Neurotikern gebt die Einschränkung bedeutend weiter, indem auch das Wissen auf. sexuellem Gebiet gleichsam einem Interdikt verfällt. Alsdann kommt es zu mannigfaltigen Transformationen der Schaulust, deren wichtigste von Fre ud in der genannten Schrift bereits behandelt worden sind. Wertvolle Beiträge zu diesen Fragen hat v. Winterstei $\mathbf{n}^{1}$ geliefert.

Mit diesen Prozessen der Transformierung und ibren Produkten müssen wir uns nunmehr beschäftigen.

Wir nehmen mit Freud an, daß die sexuelle Schaulust des gesunden Menschen im Kindesalter in einem erheblichen Umfang der Verdrängung und Sublimierung verfällt. Von wichtigen psychologischen Erscheinungen, welche größtenteils diesem Vorgang ihre Entstehung verdanken, nenne ich hier nur Wißbegierde (im allgemeinen Sinne), Forschungsdrang, Interesse an der Naturbeobachtung, Reiselust sowie den Trieb zur kunstlerischen Verwertung des vom Auge Wahrgenommenen (z. B. in der Malerei).

Bei Neurotischen müssen wir in vielen Fällen sicherlich eine konstitutionelle Verstärkung der Schaulust annehmen; doch kann auch durch Einschränkung der sexuellen Aktivität der Schaulust eine vergröBerte Bedeutung zufallen. An die Stelle aktiver sexueller Leistungen tritt dann ein verstärkter Drang zum tatenlosen Schauen aus der Ferne. Das Schicksal dieser neurotischen Schaulust kann sehr vielfältig sein. $\mathrm{Zu}$ einem Teil kann sie in ihrer ursprünglichen Gestalt erhalten bleiben; $z \mathfrak{u}$ einem anderen Teile wird sie durch Sublimierung im oben beschriebenen Sinne umgewandelt; ein dritter Teil endlich wird zur neurotischen Symptombildung verwandt. Je lebhafter der Trieb, desto intensiverer Sublimierungsarbeit bedarf es, um den Ausbruch neurotischer Störungen $\mathrm{zu}$ verhüten; desto schwerer pflegen freilich auch diese Störungen auszufallen, wenn es zur Symptombildung kommt.

1 „Psychoanalytische Anmerkungen zur Geschichte der Philosophie". Imago, 1913, Bd. II. 
Der Sublimierungsprozes vermag seinerseits verschiedene Richtungen einzuschlagen. Ich wende mich zunächst $z \mathrm{u}$ solchen Neurotikern, welche ein lebhaftes Interesse für konkretes Wissen oder Forschen an den Tag legen.

In den Interessen der Neurotiker, welche einer solchen Sublimierung der Schaulust ihre Entstehung verdanken, vermag man oft den ursprünglichen Trieb - bald ohne besondere Hilfsmittel, bald erst auf psychoanalytischem Wege - wieder zu erkennen. Ich gebe aus einer meiner Beobachtungen ein paar besonders instruktive Beispiele ${ }^{1}$.

Ein sehr intelligenter und gebildeter Neurotiker hatte ein ausgesprochenes Streben nach wissenschaftlicher Universalităt in sich. Bei seiner regen geistigen Tătigkeit hatte er bemerkt, daB ihn in jeder Wissenschaft, der er sein Interesse zuwandte, immer ein einzelnes Problem ganz besonders fesselte. Als ich ihn um Beispiele bat, nannte er mir u. a. die folgenden:

In der Chemie interessiere ihn am meisten der $\mathrm{St}$ a $\mathrm{t}$ u $\mathrm{s} \mathrm{n}$ a $\mathrm{s}$ c e $\mathrm{ndi}$. Bei genauerem Eingehen ergab sich, daß der Augenblick, in dem ein Stoff sich bildet, oder in dem zwei Stoffe sich zu einem neuen vereinigen, ihn förmlich $z \mathbf{u}$ faszinieren vermochte. Das Interesse fär Z e u g ung (Vereinigung zweier Stoffe zur Bildung eines neuen) und Geburt (Status nascendi!) war hier in erfolgreicher Weise auf ein wissenschaftliches Problem verschoben. Der Patient fand in jeder Wissenschaft unbewuBt dasjenige Problem heraus, welches sich zur verhüllten Darstellung seiner Kindheitsinteressen am besten eignete.

Ein weiteres, besonders instruktives Beispiel für diese Sublimierungstendenz entnahm der Patient aus dem Gebiet der Paläontologie. Hier habe ihn das als "Pli o za a" bezeichnete Zeitalter am meisten gefesselt. Es handelt sich um das Zeitalter, in welches $d$ a s erste Auftreten des Menschen fallt. Die typische Frage des Kindes nach seiner eigenen Entstehung ist hier zum allgemeinen Interesse für die Entstehung des Menschengeschlechtes sublimiert.

Es wäre leicht, die Zahl dieser Beispiele zu vermehren. Die mitgeteilten zeigen, daB diese Form der Sublimierung fur den Neurotiker einen sehr wichtigen Vorzug hat: daB sie ihn nämlich in nahe Futhlung mit den Phänomenen der Außenwelt bringt. In anderen Fallen verwandelt sich die verdrăngte Schaulust in einen unproduktiven

- Es gibt auch ein unproduktives Interesse an Konkretem, das man bel Neurotischen nicht selten findet, und das nichts anderes darstellt als eine $\mathbf{N e}$ u $\mathrm{g}$ i e r de von infantilem Charakter. In dem oben beschriebenen Falle A gelang es, diese Neugierde aufzulösen; an ihre Stelle trat ein durchaus produktives, tătiges Interesse an den Erscheinungen der AuBenwelt. 
Wissensdrang, der sich nicht den realen Phänomenen zuwendet ${ }^{1}$. Wir haben dann mit der neurotischen Grabelei zu tun, die gleichsam eine Karikatur des philosophischen Denkens bildet.

Wir verdanken v. Winterste in (1. c.) schöne Aufschlüsse liber. die unbewuBten Triebfedern des philosophischen Denkens. Der Philosoph möchte, wie der Autor ausführt, seine eigenen Gedanken schauen. Die Libido richtet sich hier nicht mehr auf das verbotene (inzestuöse) Ziel, nicht mehr auf das, was man nicht sehen $\mathrm{d}$ a rf, sondern auf das, was man nicht seheqn $\mathrm{k}$ a $\mathrm{n}$. Gleichzeitig hat sie sich auf das Ich in einer Form zurückgewandt, die wir nur als eine Regression in die Bahnen des kindlichen NarziBmus verstehen können (v. Winters te i n). Ich werde später aus einer meiner Analysen einschlägiges Material mitteilen, aus welchem hervorgeht, daß beim neurotischen Grübler ein ähnlicher Prozeß stattfindet.

Im folgenden werde ich, um die Grenzen meines Themas nicht zu überschreiten, die Fragen des Narzißmus aus der Untersuchung möglichst ausschalten. Ich werde mich im ganzen darauf beschränken, in den neurotischen Grlibeleien und Zweifeln die Spuren der verdrängten inzestuösen Schaulust nachzuweisen.

Als Beispiel der neurotischen Grübeleien wähle ich die besonders häufige, mit $Z$ wangsgewalt sich dem Patienten immer wieder aufdrängende Grübelfrage nach der Herkunft der Gedanken. Ein schon in vorgerïckterem Alter stehender $Z$ wangsneurotiker, den ich behandelte, befaBte sich seit vielen Jahren mit dieser Grübelei. Es ließ sich ermitteln, daß ihrer Entstehung eine andere Grabelei zeitlich unmittelbar vorausgegangen war, nämlich der Gedanke: Wo $\mathrm{h}$ i n werde ich nach meinem Tode kommen? Diese Frage war in dem Patienten während einer Seereise aufgetaucht, kurze Zeit nachdem sich bei ihm gewisse hypochondrische Besorgnisse um sein Leben gezeigt hatten. Es befiel ihn die Angst: wenn ich jetzt während der Fahrt sterbe, wird man meine Leiche dann nach dem alten Seemannsbrauch ins Wasser versenken? Er verlangte also GewiBheit darüber, wohin er nach seinem Tode kommen werde. Bald darauf zeigte sich dann die zweite Grubbelei nach der Herkunft der Gedanken, welche jedoch die erste niemals ganz beiseite $z \mathfrak{u}$ drängen vermochte.

.Der ersten Grabelei versuchte der Patient durch eine praktische $\mathrm{MaBregel} z \mathfrak{z}$ entgehen. Als seine Mutter gestorben war, legte er ein Mausoleum an. Nun wuBte er, wo er nach seinem Tode liegen werde,

1 Erwahnenswert ist die Beobachtung, daB unter solchen Bedingungen in der Regel die Freude am Anblick der Natur gering ist, ebenso das Interesse an Produkten der bildenden Kunst zu fehlen pflegt. 
wofern nicht ganz besondere Umstände seine Beisetzung im Erbbegrăbnis verhindern wïrden: an der Seite der Mutter ${ }^{1}$.

Ohne auf alle ihre verschiedenen Determinierungen einzugehen, hebe ich nur hervor, daB die Frage: „Wohin komme ich nach dem Tode?" die typische Umkehrung einer anderen, dem Kinde näher liegenden Frage enthălt: "Wo war ich vorder Geburt?" Als eine andere Umgestaltung dieser Frage aber entpuppt sich in der Psychoananalyse der hauptsăchlichste $Z$ wangsgedanke des Patienten nach der Herkunft der Gedanken.

Der Patient begnuigt sich nicht mit grtibelndem, abstraktem Denken allein, sondern er sucht sich eine sinnliche Vorstellung davon zu machen, wie die Gedanken im Gehirn entstehen, und wie sie aus dem Gehirn "hervorkommen“. Er verlangt eigentlich, diesen Vorgang zu s e he n. Ein junger Philosoph, den ich psychoanalytisch behandelte, brachte die aberraschend einfache Erklärung: "I ch vergle iche das Gehirnmit dem Multerleib. "Will er nun die Entstehung der Gedanken beobachten, so können wir in diesem Wunsch nur eine Verschiebung des typischen Kinderwunsches erblicken: Zeugung und Geburt mit Augen zu sehen. Ich bemerke hier, daB der Vergleich der geistigen Produktion mit der sexuellen uns auch im allgemeinen durchaus nicht fernliegt; wir sprechen etwa von der Konzeption eines Dichtwerkes usw. Dringt man analytisch noch weiter vor, so stöBt man auf die Identifizierung von Geburtsakt und Defäkationsakt, und damit weiter auf eine Gleichsetzung der Gehimprodukte (Gedanken) und Darmprodukte.

Es ist nun interessant, daB der Patient, welcher sich in seinen Grabeleien mit der Herkunft der Gedanken und mit dem Verbleib seines Körpers nach dem Tode beschäftigte, auffallend ununterrichtet über gewisse Hauptsachen des Geburtsvorganges war. Er hatte die Unwissenheit auf diesem Gebiete nie ganz aufgegeben; sein Wissensdrang hatte sich auf jene Grübelfragen verschoben.

Eine weitere, sehr verbreitete Grabelei ersetzt das Begehren, das menschliche Leben entstehen zu sehen, durch eine andere Umkehrung. Sie fragt nicht nach der Herkunft, sondern nach dem $Z$ weck des menschlichen Lebens. Auch diese obsedierende Frage ist

1 Ich verfüge über mehrere, einander sehr ahnliche Beobachtungen, in denen ein Sohn durchaus neben der Mutter, oder eine Tochter neben dem Vater bestattet zu werden verlangte, wobei dann der andere Elternteil von seinem ihm zukommenden Platz verdrăngt werden sollte. Ein interessantes Beispiel für diese Art der Besitznahme von der Mutter bietet der altägyptische König Echnaton; vgl. meine Abhandlung Imago, 1912, Bd. I. 
unlösbar, trotz aller Versuche, ihr vom religiösen Standpunkt aus eine das Gemut befriedigende Beantwortung zu geben. Ein junger Mann, den ich behandelte, wurde im Pubertätsalter von dieser Grubelfrage durch längere Zeit obsediert. Es ergab sich, daB er gleichzeitig eine förmliche Angst davor hatte, über den Bau des weiblichen Körpers und über die Geschlechtsfunktionen Genaueres zu erfahren. Auch in späteren Jahren, als sich ihm Gelegenheit bot, den weiblichen Körper zu betrachten, hielten ihn Angst und Ekel davon zurluck; diese Affekte bezogen sich aber ganz speziell auf das Beschauen der Genitalgegend. Als der Patient in meine Behandlung trat und erfahren hatte, daß in der Psychoanalyse die geschlechtlichen Vorgänge zur Sprache kämen, richtete er an mich die ausdrückliche Bitte, ihm vorläufig keine "Aufklärungen" uber das zu geben, was er bisher nicht wisse. In der Psychoanalyse ergab sich mit großer Klarheit, daB die Schaulust, welche mit so starken Affekten abgelehnt wurde, sich im UnbewuBten auf die Mutter des Patienten bezog.

Die Grübelfragen der $Z$ wangsneurotiker sind stets unbeantw ortbar. Das Rătsel, welches sie eigentlich lösen möchten, da rf niclıt gelöst werden; die Grubelei, welche an seine Stelle tritt, $k$ an $n$ nicht gelöst werden. So bleibt das Geheimnis erhalten. Im Patienten besteht ein dauernder Konflikt zweier Parteien, deren eine forschen, wissen möchte, während die andere die Unwissenheit zu erhalten strebt.

Es wird hieraus erklärlich, warum sich Grübelsucht und sexuelles Nichtwissen so regelmaBig beieinander finden. Es kommt aber für die Erklärung dieses Zusammentreffens weiter in Betracht, daß für viele Neurotiker das Geheimnis selbst mehr Lustwert hat als seine Enthüllung. Ich habe darauf schon oben hingewiesen. Gelegentlich begegnet man Patienten, die unter ihrer Unwissenheit ernstlich leiden und dennoch sich nicht von ihr freimachen können. Ich beobachtete $z$. B. einen 28 jäbrigen Mann, der an schweren Aufregungszuständen litt. Der gedankliche Inhalt dieser Zustände war ganz bewuBt: Alle Menschen wissen, nur ich allein bin vom Wissen ausgeschlossen. Für ihn bedeutete freilich "Wissen“ nicht nur die Kenntnisse auf sexuellem Gebiet, sondern vor allem "sehen" und weiterhin die sexuelle Aktivität! Es leuchtet ohneweiters ein, daß derjenige, welcher die sexuelle Aufklärung meidet, sich damit vollends der sexuellen Aktivität entzieht. Der Patient verlor in meinem Sprechzimmer einmal einen Zettel, der mit allerlei unverständlichen, abgebrochenen Redewendungen beschrieben war. In der Mitte des Zettels waren mit großer Schrift die Worte zu lesen: I d o n't know. In diesem Satz pflegte der Patient die ganze 
Qual seiner Unwissenheit auszudrücken. In seinen Aufregungszuständen lief er im Zimmer umher und schrie die gleichen Worte. Ebenso schrieb er sie auf Papierblätter und umgab sie mit allerhand Verwünschungen. Die Psychoanalyse konnte in diesem Falle nur durch einige wenige Sitzungen fortgeführt werden; diese kurze Zeit genligte aber, um mir einen gewissen Einblick in das Unbewußte des Patienten zu gewähren. Es ließ sich feststellen, daß die Libido des Patienten in einem Maße, das selbst den Psychoanalytiker staunen machte, in inzestuöser Richtung fixiert war. Ich ziehe hier zum Vergleich eine völkerpsychologische Tatsache heran, auf die auch schon v. Winterste in (1. c.) Bezug genommen hat. Im biblischen Hebräisch wird die gleiche Vokabel für "wissen", "erkennen" und für die Begattung gebraucht. Ein Mann "erkennt" sein Weib. Die vorläufige Sexualhandlung des Beschauens, durch welche er das Weib kennen lernt, wird in diesem Sprachgebrauch an die Stelle der definitiven Handlung gesetzt. Besonders interessant ist aber die Wahl des Ausdruckes in der mosaischen Gesetzgebung gegen den Inzest. Hier wird niemals in all den vielen Verboten der Verkehr unter Blutsverwandten untersagt, sondern dem Manne wird nur verboten, dieses oder jenes Weibes "Scham zu entblöBen". Das Verbot des EntblöBens und Beschauens ist gegenliber dem einfachen Verbot des inzestuösen Verkehrs eine we it e r g e h e n de Einschränkung. Sie entspricht in dieser Hinsicht durchaus den strengen Schauverboten, mit welchen sich manche Neurotiker nicht bloß vor dem Anblick des Verbotenen, sondern auch vor jeder sexuellen Aktivität schützen.

Eine Untersuchung der Einschränkungen des Schauens und Wissens bleibt durchaus unvollständig, wenn sie nicht das Phänomen des Zweifels hinreichend berücksichtigt. Ich kann hier wiederum auf die grundlegenden Ausführungen Freuds Bezug nehmen.

Freud schreibt dem Zwangsneurotiker ein $B$ edu $\mathrm{r} f \mathrm{n}$ is $\mathrm{nach}$ Unsicherheit zu. Der Kranke weicht vor der Realität, vor allem Greifbarem, Sicherem aus und wird von einem unbewuBten Bestreben dazu geführt, die Unsicherheit zu erhalten, zu kultivieren und neue Unsicherheiten künstlich herzustellen. Der Zweifel nimmt seinen Ausgang von der innern Wahrnehmung der eigenen $Z$ wiespältigkeit seitens des Kranken. Dieser zweifelt also eigentlich an der Zuverlässigkeit seiner eigenen Gefühle, er verschiebt jedoch die Unsicherheit mit großer Vorliebe auf Objekte und Vorgänge in der Außenwelt. Dabei pflegt er sich an solche Dinge zu klammern, die tatsăchlich dem Zweifel unterworfen sind, wie etwa das menschliche Gedächtnis oder die Dauer des menschlichen Lebens. 
Wir werden hier an die Erscheinungen der Grübelsucht erinnert, welche denjenigen der $Z$ weifelsucht in weitem Umfange analog sind. Wir konstatierten auch beim Grübler, daB er sein Interesse von der Welt des Konkreten, des sinnlich Wahrnehmbaren zurückgezogen und es solchen Fragen zugewandt hat, die im Dunkel bleiben mussen. Wie der Zweifler die Unsicherheit, so sucht der Grabler unbewuBt das Nichtwissen zu konservieren. Das macht es uns begreiflich, daB Zweifel und Grubbeleien in der Regel im gleichen Individuum beieinander wohnen. Auch liegt es auf der Hand, daB jede Einschränkung der Schaulust und - was für uns nicht davon zu trennen ist - der WiBbegierde nicht bloß dem abstrakten Grübeln, sondern in gleicher Weise dem Zweifel Vorschub leisten muß. Die Zweifelsucht findet sozusagen vermehrte Angriffspunkte, wenn das Individuum seine Sinne und sein Denken nicht auf das Reale zu richten vermag. Andererseits wird der Neurotiker durch seine Unsicherheitsgefuble zur ständigen Erneuerung seiner Gräbeleien gedrăngt; er muß den tausendmal durchgemachten Gedankengang wieder und wieder prüfen.

In der Neurose gibt es mancherlei Methoden, den Qualen der Unsicherheit und des Zweifels, respektive der Grübelsucht zu entgehen. Der Zweifelnde, Grabelnde, der, wie wir sahen, unbewuBt bestrebt ist, die Grundlagen seines Leidens zu erhalte $n$, zeigt doch gleichzeitig die entgegengesetzte Tendenz, die Unsicherheit zu be s e itige n, den Zweifel und das Nichtwissen zu bannen. Freilich kann ihm dies nicht aus eigener Kraft und mit eigenen Mitteln gelingen. $\mathrm{Er}$ ist darauf angewiesen, sich an Autorităten zu halten, deren Wissen oder Ansicht er sich fügt, denen er aber auch die Verantwortung aufbürdet. Manche Zwangsneurotiker lieben es, ihrem Arzt eine solche Verantwortung zu uberbinden. Sind sie unfähig, in irgend einer Angelegenheit selbst die Entscheidung zu treffen, so lassen sie den Arzt gern eine Art von Machtwort sprechen, das den Zweifel ausschalten soll. Sie ăndern auf diese Weise die Situation dergestalt um, $\mathrm{da} B$ dem Anschein nach ein $Z$ weifel uberhaupt nicht existiert.

Ich bin hier zu einem Exkurs genötigt, der uns auf gewisse völkerpsychologische Phänomene führt, die dem Anschein nach in keinem direkten Zusammenhang mit dem Schautrieb stehen, deren Verständnis uns aber fulr den weiteren Gang der Untersuchung unentbehrlich sein wird.

Auch in der Völkerpsychologie finden sich Erscheinungen, welche der Beseitigung des $Z$ weifels in ganz gleicher Weise dienen, wie es soeben am Verhalten gewisser Neurotiker gezeigt wurde. 
Ich gehe von der eigentumlichen und, wie ich glaube, wenig beachteten Tatsache aus, daß in der hebräischen Sprache der biblischen Schriften ein Wort für "zweifeln " fehlt ${ }^{1}$. Dabei ist zu beachten, daB die verschiedenen Schriften aus sehr verschiedenen Epochen stammen. Es muß auffallen, daß gerade die Sprache eines Volkes, in welchem sich der Monotheismus zuerst durchsetzte, einer solchen Vokabel entbehrt. Die Erscheinung wird noch auffalliger dadurch, daß die Sprachen respektive Dialekte der Nachbarvölker entsprechende Ausdrücke besitzen, so daß also eine Entlehnung leicht hätte stattfinden können. Durch Jahrhunderte dauerte das Schwanken zwischen dem monotheistischen Kultus und dem Dienst des Baal, der Astarte und der anderen vorderasiatischen Gottheiten. Endlich siegte der Kultus eines einzigen mãnilichen Gottes. Es wurde schon oben darauf hingewiesen, daB im biblischen Schöpfungsmythus die Tendenz bestehe, alle Leistungen dem männlichen Gott und dem Manne zuzuschreiben, das Weib aber zu einer nebensächlichen Bedeutung herabzudrücken. Dies entspricht nun vollkommen dem patriarchalischen System, in welchem dem männlichen Familienoberhaupt die alleinige Macht zukommt ${ }^{2}$. Ihm gehören die Frauen und Kinder ganz wie die lebende und leblose Habe.

Ich muß nun auf die Ausführungen Fre uds ${ }^{3}$ Bezug nehmen, welcher in uberzeugender Weise die Entstehung des männlichen Gottes aus der Einstellung der Söhne zum Vater dargetan hat. Die Sympathie des Sohnes gehört ursprünglich der Mutter, während er dem Vater Gefühle der Auflehnung und Feindschaft entgegenbringt. Eine der fruhesten Verdrängungsleistungen, welche die Kultur verlangt, ist das Aufgeben dieser Einstellung. Der Sohn stand zunächst zwischen Vater und Mutter; die Verdrängung der Ödipuseinstellung führt dazu, daß er sich zugunsten des Vaters entscheidet und dessen Macht rückhaltlos anerkennt. Gerade der Patriarchalismus stellte rigorose Forderungen in dieser Hinsicht an den Sohn. So wie aber in der patriarchalischen Familie der Konflikt im Sohne unbedingt zugunsten des Vaters entschieden wurde, ganz so auch in der monotheistischen Religion des alten Testamentes.

Man könnte nun das Fehlen eines Wortes für den Zweifel in der hebräischen Sprache als ein vereinzeltes Phänomen ohne wesentliches

1 Auf eine Ausnahme werde ich weiter unten zurückkommen.

2 Mit diesem Prozeß der Ausschaltung des weiblichen Elementes beschäftigt sich auch $v$. W interste in in seiner oben zitierten Arbeit (S. 204). Zur Zeit ihres Erscheinens war ich bereits zu den obigen Resultaten gelangt, für die ich bei v. W in terste in eine volle Bestatigung fand.

3 ,Totem und Tabu*, Kap. IV (Wien und Leipzig, 1913). 
Interesse abtun, wenn nicht die gleiche Sprache einen zweiten charakteristischen Defekt aufwiese. Sie entbehrt nämlich auch eines Wortes, welches Göttin bedeutet, während doch andere Sprachen eine entsprechende Vokabel besitzen. Man möchte sagen, der Konflikt des Sohnes, welcher durch seine ursprüngliche zweifelnde Stellung zwischen Vater und Mutter bedingt ist, sei ausgemerzt, in gleicher Weise sei das Schwanken, ob nur ein männlicher Gott oder auch eine Göttin verehrt werden solle, abgetan und die Sprache benehme sich nun, als gabe es nicht nur diese $Z$ weifel nicht, sondern als existierten $Z$ weifel in der menschlichen Seele uberhaupt nicht.

Ein besonders helles Licht fält auf dieses sprachpsychologische Problem, wenn man beachtet, daß in einer großen $Z a h l$ von Sprachen das Wort für "zweifeln" mit der Zahl "zwei“ zusammenhängt. Diese anderen Sprachen verleugnen den $Z$ weifel also nicht, ja manche Sprachen treiben da, wo der $Z$ weifel zum Ausdruck gebracht werden soll, einen besonderen grammatischen Aufwand. Ich erinnere beispielshalber nur an die Mannigfaltigkeit der grammatischen Formen im Lateinischen; das Verbum des $Z$ weifels verlangt besondere Formen des Ausdruckes, die sonst kaum tablich sind.

Erst in einem der späten biblischen Dokumente, dem Psalm 119, findet sich ein Wort, das man wohl mit Recht als "Zweifler" übersetzt. Genau genommen bedeutet es: "gespalten “. Dieser Psalm stammt nach Ansicht berufener Forscher aus später Zeit, in der sich schon die hellenistischen Einflusse geltend machten ${ }^{1}$. Ein zweites Wort von gleicher Bedeutung findet sich dann in der späthebräischen Literatur, das vielleicht ursprünglich die gleiche Bedeutung der Teilung, Spaltung hat. Es ist sehr bemerkenswert, daB die Sprache sich vor mehr als 2000 Jahren so ausdrickte wie die heutige Psychologie, die von psychischer Spaltung spricht. "Spalten" enthalt den innern Gegensatz im Menschen noch deutlicher als diejenigen Bezeichnungen des $Z$ weifels, die mit "zwei" zusammenhängen ${ }^{2}$.

Nachdem einmal durch Aufnahme zweier Lehnwörter die Existenz des Zweifels anerkannt war, sah man sich genötigt, den Zweifel auf andere Weise auszumerzen. Es fand sich ein einfacher Weg. Wenn es z. B. zweifelhaft war, ob eine bestimmte Handlung erlaubt oder verboten sei, so entschied man regelmäig im strengeren Sinne,

1 Cf. Ba ethgen, Die Psalmen. Göttingen, 1897.

2 Wohl den eigentümlichstell, im Sinne der Psychoanalyse treffendsten Ausdruck findet die ,innere Wahrnehmung der Unsicherheit" (Fre ud) in einer alten amerikanischen Kultursprache, dem Nahuatl. Diese Sprache diückt den Zweifel aus durch ,omeyolloa*. ,z wei Herzen". 
d. h. im Sinne des Verbotes, das für ähnliche Fälle von der höchsten (göttlichen) Autorität gegeben war. Im Grunde kommt diese Praxis auch wieder auf eine Verleugnung des Zweifels hinaus.

Nach diesen Bemerkungen gehe ich dazu über, einige besonders eigentümliche Beobachtungen mitzuteilen und $\mathrm{zu}$ analysieren, welche der Psychoanalyse eines komplizierten Falles von Grubel- und $\mathrm{Z}$ we if e $\mathrm{ls} \mathrm{u} \mathrm{ch}$ t entstammen. Ich werde mich jedoch darauf beschränken, diejenigen Wurzeln der Erscheinungen zu berücksichtigen, welche mit der Verdrängung des Schautriebes zusammenhängen. Andere wichtige Quellen der Symptomenbildung - ich nenne nur Narzißmus und Sadismus - werde ich nur streifen können.

Schon früh zeigten sich bei dem Patienten Gefühle von Unsicherheit. Als Knabe quälte er seine Umgebung mit einer hartnăckigen Frages uch $t$, später sich selbst durch $Z$ weifel, von denen kein Gebiet des Lebens verschont blieb. Er zweifelte an seiner Intelligenz, an seinem „Können“ in jeder Hinsicht, an seinem Gedächtnis, an seiner Urteilsfähigkeit. Er zweifelte an seiner Männlichkeit, zweifelte schon als Knabe, ob er sich knabenhaft oder mädchenhaft benehmen solle. Er schwankte mit seiner Zuneigung $z$ wischen Vater und Mutter hin und her. Als er zuerst Bekanntschaft mit zwei jungen Mädchen machte, wuBte er nicht, welche von beiden er liebte. Sein ganzes Leben war fur ihn ein Labyrinth von $Z$ weifeln, die er vergebens durch Denkarbeit zu bewäligen versuchte. $\mathrm{Er}$ fand die uns bereits bekannte Ausflucht, alle Entscheidungen auf eine Autorität abzuschieben. In einem besonderen Falle suchte er seine Zweifel in einer höchst merkwürdigen Weise zu töten. Als er studierte, trat in der Universitătsstadt ein Redner auf, den er schon in Berlin gehört hatte. Die Reden und Schriften dieses Mannes hatten ihm fruher schwere $Z$ weifel und Grubeleien verursacht. Es war ihm gelungen, sich dem Einfluß in einem gewissen Maße zu entziehen; er fürchtete aber, wenn er den Mann abermals hörte, seinem Einfluß von neuem $z u$ verfallen. Aus seinem Dilemma suchte er sich zu retten, indem er seine Bekannten anstiftete, den Redner in der Versammlung $z \mathbf{u}$ verhöhnen. Ich kann nur nebenbei darauf verweisen, daß es sich hier gleichzeitig um eine ÄuBerung des Hasses handelte, der sich gegen jede Autorität richtete, wie er sich zuerst gegen den Vater des Patienten gerichtet hatte.

Die Tatsachen, welche die Psychoanalyse aus der Kindheit des Patienten zutage förderte, ließen erkennen, daß die sexuelle Neugierde und Schaulust ursprünglich von außergewöhnlicher Stärke gewesen waren und erst allmählich der Frage- und Grtbelsucht Platz gemacht hatten. Bei diesem Vorgang waren erzieherische Einflüsse in hohem 
Maße beteiligt gewesen, die ihren stärksten Ausdruck in einem eigentlichen Frageverbot fanden, welches ihm von der Mutter im Pubertätsalter gegeben wurde, als sich die sexuelle WiBbegierde von neuem in ihm regte. Der Unterdrückung der Wißbegierde in den folgenden Jahren-wurde dadurch Vorschub geleistet. Als dann die Neurose ausbrach, zeigte eine ganze Reihe von Symptomen an, daß die inzestuöse Schaulust die Verdrängung $z u$ durchbrechen trachtete. Auch die Träume verrieten die gleiche Tendenz. Im Beginn der Behandlung berichtete der Patient, welcher sich viel mit philosophischen Studien befaßt hatte, daB er schon als Gymnasiast den Pythagoras beneidet habe. Der Grund zum Neid bestand darin, daß Pythagoras nach seiner uberlieferten Behauptung dreimal seine eigene Geburt geschaut hatte. Das intensivste Interesse des Patienten verband sich noch immer mit der Frage des Kindes: Woher bin ich gekommen?

Wie oben ausgeführt, wünscht das Kind eigentlich zu sehen, woher es gekommen ist. Der griblerische Neurotiker hatte dieses infantile Interesse in ein späteres Lebensalter mit hinübergenommen; sein sehnlichster Wunsch wäre es gewesen, die eigene Geburt aus dem Körper der Mutter mit sehenden Augen zu erleben.

Die frühe Abdrängung der Schaulust von ihren eigentlichsten Objekten und Zielen führte nicht nur zu den typischen Grlubeleien, sondern $u$. a. auch zu einem krankhaften Hang zum Geheimnisvollen, Mystischen. Die früher besprochene Tendenz, das Geheimnisvolle zu pflegen, zu konservieren, äußerte sich darin, daß der Patient in sehr jugendlichem Alter mystische, theosophische, spiritistische Schriften förmlich verschlang. Mit dieser Tendenz lag die entgegengesetzte im Konflikt: er wollte mit Augen sehen, was nur gedacht werden kann. Ganz besonders war in diesem Falle das fruher bereits erwähnte Verlangen, die Gedanken zu schauen, ausgesprochen. Der Patient stellte sich den Denkproze日 in naivster Form körperlich und răumlich vor. Im Gehirn gab es Kasten und Fächer, in denen die Gedanken lagen, um gelegentlich hinauszuspazieren. Seine Grübeleien befaßten sich hauptsächlich mit diesen Vorgängen. Selbstverständlich reizte es ihn, auch, das Obersinnliche zu schauen. Endlose Grübeleien richteten sich darauf, wie wohl die Geister und Gespenster aussähen, wie Gott aussähe usw. Dann traten wieder Hemmungen hervor, die es dem Patienten verboten, sich dergleichen vorzustellen.

Es bedarf kaum des Hinweises auf die zahlreichen verwandten Erscheinungen in der Völkerpsychologie: auf Geheimkulte, Mysterien, okkultistische Bewegungen einerseits, andererseits auf die religiösen Verbote, nach dem Geheimsten $z \mathfrak{u}$ forschen. 
Beztiglich der Bedeutung der Gespenster, welche in den Gedankengängen des Patienten eine sehr große Rolle spielten, ergab sich $\mathfrak{u}$. a. eine Erklärung, die uns auch sonst aus den Psychoanalysen geläufig ist. Wie in anderen Fällen, so hatten auch hier nächtliche Eindrícke der Kindheit zu den Grübeleien uber Gespenster den Grund gelegt. Die Eltern, welche im weißen Nachtgewand von den Kindern beobachtet werden, sind die Vorbilder für die kindliche Auffassung jener geheimnisvollen Gestalten.

So kraus und phantastisch das Beobachtete von seiner Phantasie aber auch ausgestaltet wurde, so läßt sich doch erkennen, daß das Kind sich auf dem Wege zu durchaus richtigen SchluBfolgerungen befunden hatte. Als später die Verbote des Schauens und Wissens uber den Patienten Gewalt bekommen hatten, verschob sich der verdrängte Wunsch nach Wiederholung der lustvollen Kindheitseindrücke auf die "Gespenster “. Der Patient verlangte beständig, d i e G e s p e n s te r $z$ u sehen. Er ging aber noch weiter und transponierte all seine Wißbegierde, die dem Zeugungsrätsel galt, auf die Gespenstergrübeleien.

Eines der Probleme, die ihn mit $Z$ wangsgewalt durch Jahre in ihrem Bann hielten, lautete: "Wi e k ommen Gespenster in einen geschlossenen Raum ?" Ich ubergehe die höchst interessanten Determinierungen der Lösungsversuche, welche der Patient dieser Frage zuteil werden ließ, und erwăhne nur, daB zwei Probleme, deren Lösung verboten war, sich in dem unlösbaren Ersatzproblem versteckten, nämlich die Fragen: Wie dringt der Mann in den weiblichen Körper und wie kommt das Kind in den Mutterleib? Das Verbotene der Probleme liegt in ihrer Zuspitzung auf Vater und Mutter und besonders in der ursprünglichen Lust, das Geheime $z$ u schauen.

Die verdrängte Schaulust suchte sich aber nicht nur in den Grübeleien eine Ersatzbefriedigung zu verschaffen, sondern es wurden noch andere Wege zu diesem Behufe eingeschlagen. Sie verdienen unser höchstes Interesse; es ist daher notwendig, ausführlicher auf sie einzugehen, zumal uns auf diesem Wege wichtige Einblicke in die Entstehung gewisser völkerpsychologischer Phänomene erschlossen werden können.

Der Patient war, gleich sehr vielen anderen Menschen, imstande, Personen, Vorgănge usw., mit denen er sich in Gedanken beschăftigte, mit bildlicher Deutlichkeit vor seinem Auge erscheinen zu lassen. Bei manchen Neurotikern genugt schon das einfache Schließen der Augen, um derartige Visionen auftreten zu lassen. Andere rufen die "Bilder" absichtlich hervor und vergnügen sich damit wie mit einem Theater. Diese Fähigkeit scheint im Kindesalter bei allen Menschen 
vorhanden zu sein, verschwindet aber bei manchen mit den Jahren. Man darf also aus dem Fehlen dieser visionären Illustrationen des phantastischen Denkens bei einem Menschen nicht ohneweiters schließen, daß er nicht zum "visuellen" Typus gehöre. Vielmehr handelt es sich oftmals um Einschränkungen der Schaulust, die auf dem Wege der Verdrängung zustande gekommen sind.

$\mathrm{Da}$ dem Patienten der Wunsch, die "Gespenster" zu sehen, versagt bleiben mußte, so versuchte er nun, sich auf dem Wege willkürlich hervorgerufener Visionen einen Ersatz zu verschaffen. Es ist nun höchst bezeichnend, daß er sich bemühte, die Bilder seiner Eltern vor seinen Augen entstehen zu lassen. Allein dies gelang ihm nicht in der gewünschten Weise. Das Bild der Mutter erschien uberhaupt nicht, dasjenige des Vaters nur in ganz verzerter Form. Dagegen gelang es leicht, die Erscheinung anderer Angehöriger hervorzurufen. Dieser Versuch, der inzestuösen Schaulust eine Ersatzbefriedigung zu geben und der negative Ausgang des Versuches sind gleich bemerkenswert.

Nachdem ich Ähnliches in einer Reihe anderer Falle beobachtet habe, bin ich dazu gelangt, der Erscheinung größere Bedeutung beizulegen. Manche Neurotiker versuchen, wie soeben geschildert, die Bilder der Eltern visionär hervorzurufen, oder sie begnügen sich damit, sich deren Aussehen nur möglichst lebhaft in Gedanken vorzustellen. Einer meiner Patientinnen, die im höchsten Maße an ihren Vater fixiert war, gelang es nicht, sich das Aussehen des Vaters vorzustellen. In einem andern Fall war es dem Patienten sehr schwer, sich die Gesichtszüge der Mutter klar vorzustellen. Eher gelang es ihm bezuglich seines Vaters; allein kaum entstand in ihm die Vorstellung, so verzerrte sich das Gesicht des Vaters; besonders die Augen nahmen einen Ausdruck der Erstarrung an. Es erwies sich, daB in diesem Falle die der Mutter zugewandte Schaulust eine sehr intensive Verdrängung erfahren hatte, während die dem Vater zustrebenden Todesphantasien nicht mit gleichem Erfolge verdrängt waren: sie fanden in der Starre der Augen ihren Ausdruck.

Es ist, als wirkte in diesen Personen ein Verbot, das ihrem Schautrieb strenge Grenzen setzte. Einen schönen Beleg für diese Auffassung Tieferte mir der Traum eines neurotischen ijungen Mädchens. Die Träumerin befindet sich in einer Kirche unter vielen anderen Menschen. Diese betrachten ein Madonnenbild. Sie alle in $\mathrm{kann}$ das Bild nichtsehen. Die Psychoanalyse deckte bei dieser Patientin eine starke, homosexuelle Neigung zur Mutter auf. Im allgemeinen war diese Neigung in einen intensiven Widerwillen verwandelt, um 
gelegentlich unter heftigen Affekten in ihrer ursprünglichen Form wieder aufzutreten. Die Mutter galt als eine besonders schöne Frau; die Tochter muBte sich gegen die verbotenen Reize durch ein förmliches Schau-Verbot sichern.

Durch eine der hierhergehörigen Veröffentlichungen $\mathrm{Freuds}$ sind wir auf gewisse ,Ubereinstimmungen im Seelenleben der Neurotiker und der Wilden" aufmerksam geworden. An dieser Stelle interessiert uns speziell die Analogie gewisser Zwangsverbote bei den Neurotikérn mit den sogenannten Tabu-Vorschriften gewisser Völker. Diese Vorschriften haben die charakteristische Eigentümlichkeit, daß ihnen seitens derer, die sie befolgen, keine Begründung gegeben werden kann. Ganz entsprechend vermögend die Neurotker, welche dem hier in Frage kommenden Zwangsverbot unterliegen, ihm eine Begründung nicht zu geben. Von besonderem Interesse ist in diesem Zusammenhang die Ubereinstimmung $z$ wischen dem geschilderten neurotischen Schauverbat und dem zweiten Gebot des biblischen Dekalogs, welches die Herstellung eines Abbildes des einzigen (väterlichen) Gottes streng untersagt. Eine Erklärung dieser Vorschrift hatte $\mathrm{Fre} \mathrm{ud^{1 }}$ kürzlich bereits auf anderem Wege zu geben versucht; die hier vorgeschlagene steht mit der von Freud gegebenen nicht im Widerspruch, ergänzt sie vielmehr entsprechend der uns geläufigen Uberdeterminierung aller psychologischen Produkte. Als die vorliegende Arbeit bereits inhaltlich abgeschlossen war, fand ich in einer soeben erschienenen Publikation von S torfer („Marias jungfräuliche Mutterschaft “, Berlin, 1914, S. 32) eine Erklärung des zweiten Gebotes, die von den gleichen Uberlegungen ausgeht wie die meinige. Storfer sucht das Verbot, Bildnisse Gottes herzustellen, auf die Scheu vor dem väterlichen Phallus zuruckzufuhren, unter dem Hinweis, daB so viele Götterbilder und kultische Zeichen phallischen Charakter tragen. Mir scheint diese Erklärung in guter Ubereinstimmung mit vielen hier mitgeteilten Auffassungen $z \mathfrak{u}$ stehen; doch wäre noch eine gewissenhafte, vergleichend mythologische Nachprüfung am Platze. Wir können diesen Parallelismus der individual- und völkerpsychischen Erscheinungen noch um einen Schritt weiter verfolgen. Von dem Patienten habe ich bereits mitgeteilt, $\mathrm{daB}$ er von beständigen Zweifeln beunruhigt war; diese bezogen sich, wie erwähnt, u. a. auch auf seine Eltern. In seiner Beziehung zu den Eltern spielte demnach sowohl der Zweifel als auch das Verbot, ihr Abbild zu schauen, eine wichtige Rolle. Unterwerfen wir aber den Dekalog einer eindringenderen Untersuchung, so muB uns auffallen, daB das Gebot, nur e in en Gott anzuerkennen und das Gebot, sich von ihm kein Abbild zu machen,

1 . Animismus, Magie und Allmacht der Gedanken". Imago, 1913, Bd. II. 
in unmittelbare Nachbarschaft gerückt sind. Wir haben aus der Analyse der verschiedenartigsten Produkte des menschlichen Seelenlebens die übereinstimmende Erfahrung gewonnen, daB die unmittelbare Nachbarschaft zweier Elemente auf deren Zusammenhang hinweist. $\mathrm{Da}$ ist es nun bemerkenswert, daB das Bilderverbot dem Gebot, nur einen Gott anzuerkennen - dem Gebot also, welches die Zweifel zwischen Vater und Mutter ausschließen soll, unmittelbar folgt. Von der Analyse individualpsychologischer Produkte her fällt auf diese Erscheinung ein neues Licht.

Kehren wir zu dem Patienten zurlack, der sich kein Bildnis der Eltern machen durfte, und hören wir, was er tat, um für das Verbotene einen Ersatz zu bekommen.

Er suchte sich mit ganzer Einbildungskraft das A us se h en de $r$ $G$ espenster vorzustellen, die ja in seinem Grubelsystem die Eltern vertraten. $\mathrm{DaB}$ es sich im Grunde für ihn darum handelte, sich den Sexualverkehr der Eltern vorzustellen, ging mit gröBter Sicherheit hervor aus der Vorstellung, die er sich vom Aussehen der Gespenster bildete. Er dachte sie sich - ich zitiere seine Äußerungen wörtlich als "groBe, nackte Wesen", als "wollüstige Gestalten"1.

Die Grubeleien des Patienten fanden, wie schon erwähnt, reichliche Nahrung in gewissen Schriften, namentlich in solchen mit theosophischem Inhalt. Im AnschluB an dort Gelesenes identifizierte er die Eltern nicht bloB mit Gespenstern, sondern auch noch mit ${ }$ Ri esen ${ }^{*}$. Er hatte in einem dieser Bücher die Angabe gefunden, $\mathrm{daB}$ die Bewohner des untergegangenen Erdteiles Atlantis Riesen gewesen seien und eine höhere Form des Bewußtseins gehabt hătten als die jetzt lebenden Menschen, nämlich das AstralbewuBtsein. Sie seien daher im Geheimnisse eingeweiht gewesen, die uns verschlossen seien. Es hieb in dem Buche: ihr Wissen war so gewaltig, dab die Erde davon dröhnte.

Für den Patienten nahmen diese Riesen sofort die Bedeutung der Eltern an. Die Eltern "wuBten“ ja mehr als er, d. h. sie waren im Besitz des sexuellen Geheimnisses. Das Kind aber versuchte das Geheimnis der Eltern nicht nur mit dem Auge zu schauen, sondern auch mit dem Ohr zu belauschen. Der Patient hatte offenbar dieselbe Gleichung vorgenommen, die uns als sprachliches Phänomen begegnet ist; er hatte "W is se $n^{\prime}$ und Sexualverkehr identifiziert.

1 Das Hervorrufen solcher Vorstellungen respektive visionärer Erscheinungen dient noch anderen Tendenzen, die ich hier nur kurz andeuten kann. Unter anderem dient es der Befriedigung der infantilen Größenvorstellung, alles aus der eigenen Einbildungskraft erschaffen zu können. (Allmacht der_fedanken) 
Charakteristisch ist ferner, daB der Patient auch versuchte, sich von Gott eine materielle Vorstellung zu machen. Es wundert uns nicht, daB er sich auch Gott als Riesen dachte. Die Phantasie des Kindes schreibt dem Vater außerordentliche Macht zu: sie vergleicht den Vater, der dem Kinde an Größe so sehr überlegen ist, gern mit einem Riesen. Die Träume Erwachsener legen davon oft noch Zeugnis ab. Wenn das Kind etwas von Gott vernommen hat, so ist es genötigt, ihn sich im Bilde des Vaters vorzustellen; es tut damit nichts anderes als die religionsbildenden Völker, die einen väterlichen Gott verehren. Unser Patient, der liber das Aussehen Gottes nachgrübelte, beging auch damit wieder nur einen Versuch, das auf den Vater bezigliche Schauverbot $\mathrm{zu}$ durchbrechen.

Wie sehr das neurotische Verbot, den Vater (respektive die Eltern) sich im Bilde darzustellen, und das biblische Verbot, Gott abzubilden, in ihrem innersten Wesen libereinstimmen, wird daraus ersichtlich, dab beide Verbote in ganz abereinstimmender Weise durchbrochen werden.

Ich habe hier eine der typischen Gribelfragen im Auge, wie sie in den talmudischen Schriften so reichlich enthalten sind. Das Verbot einer bildlichen Darstellung Gottes durfte nicht ubertreten werden. Wo die Menschen sich aber durch irgend welche Motive gedrängt fühlten, ihrer Gottesvorstellung einen lebendigeren materiellen Inhalt zu geben, da waren sie auf das Gribeln angewiesen. Aus dem genannten Bedürfnis und der strengen Einhaltung des Bilderverbotes erklärt sich nun die talmudische Frage nach den Körperdimensionen Gottes. Sie durfte aber auch nur dann beantwortet werden, wenn man sich streng an bereits in den biblischen Schriften vorhandenen Angaben hielt. Da fand sich nun die Stelle, an welcher Gott die Worte in den Mund gelegt werden: ${ }_{n} \mathrm{Der} \mathrm{Himmel}$ ist mein Thron und die Erde der Schemel meiner F a Be." Daraus wurde gefolgert, Gottes Beine seien so lang, daB sie vom Himmel bis zur Erde reichten. Diese Grubelei ähnelt derjenigen unseres Patienten in erstaunlichem MaBe. Nicht nur, daB auch in ihr der verdrängte Wunsch, sich von Gott ein Bild zu machen (d. h. ihn zu schauen), wiederkehrt. Die Ähnlichkeit geht noch weiter insofern, als auch in der talmudischen Grübelei die infantile Vorstellung von der Riesengestalt des Vaters oder Gottes wiederersteht.

Existiert somit eine unverkennbare Analogie zwischen den Einschränkungen der Schaulust bei neurotischen Individuen und bei Volkern, so soll nun im folgenden gezeigt werden, daB wir mit Hilfe der Psychoanalyse in das Wesen dieses Parallelismus noch tiefere Einblicke gewinnen. 


\section{Die Herkunft der Sonnen- und Gespensterphobie aus dem infantilen Totemismus.}

Im Laufe der Untersuchung sind uns zwei $\mathrm{S}$ y $\mathrm{m}$ b o le begegnet, denen wir eine vorwiegende $V$ aterbedeutung zuerkennen muBten: es sind die Sonne and das Gespenst. Gewisse Neurotiker, so erfuhren wir, ängstigen sich vor dem Anblick des Sonnenlichtes oder reagieren in einer andern, vom Verhalten der Gesunden abweichenden Weise mit Affekten der Auflehnung, des Trotzes auf die Erscheinung der Sonne. Es ergab sich, daß jeder dieser Neurotiker eine ambivalente Gefühlseinstellung zur Sonne aufwies; daB er die Sonne liebte (verehrte) und gleichzeitig Angst vor ihr empfand. Ich habe in letzterem Sinne geradezu von einer So n n e n ph obie gesprochen. Unter den Grüblern fanden wir das besondere Interesse für Gespenstererscheinungen. Das Gespenst oder die Vorstellung von einem solchen rief aber ebenfalls ambivalente Reaktionen hervor: den Wunsch, es zu sehen, und wiederum die Angst vor seiner Erscheinung, die man als Gespensterphobie bezeichnen darf. Erblicken wir in Sonne und Gespenst Symbole des Vaters und sind wir mit der ambivalenten Einstellung des Neurotikers zu seinem Vater vertraut, so wundert es uns nicht, diese Zwiespältigkeit der Gefühle auch auf die den Vater vertretenden Symbole ubertragen zu finden. Der Psychoanalyse ist es aber nicht erlaubt, sich mit dieser Erkenntnis zufriedenzugeben; als eine Entwicklungslehre, weiche die strenge Bedingtheit alles Psychischen erweisen will, muB sie der Herkunft der Phänomene weiter nachgehen. Um den Zugang zum Ursprung der uns interessierenden Symbole $z \mathbf{u}$ finden, bedarf es desjenigen Schltussels, den Fre ud uns in seinen Abhandlungen tuber "Totem und Tabu" gegeben hat.

Wir finden bei gewissen Völkerschaften mit primitiver Kultur bis zum heutigen Tag eine Organisation, welche das religiöse und soziale Leben regelt; sie wird als Tote $\mathrm{m}$ is $\mathrm{m}$ us bezeichnet. Es handelt sich um eine Form des Abnenkultus. Im Mittelpunkte des Kultus steht der Totem, meist ein Tier, welches als Stammvater der betreffenden Sippe ( ${ }$ Clan") betrachtet wird. Wir verdanken Freud u. a. die wichtige Erkenntnis, dab jene Primitiven zu ihrem Totem ambivalent eingestellt sind; d. h. das Totemtier nicht jagen, töten, verzehren oder auch nur beruhren, es also im allgemeinen schonen, es unter besonderen Umständen aber mit feierlichem Zeremoniell dennoch töten und verzehren. Der Totem ist ebensowohl Objekt der Liebe wie der Angst. Viele Gewohnheiten jener Menschen lassen die $z$ wiefache Einstellung zum Totem deutlich erkennen. 
Die psychoanalytische Forschung (vgl. die Quellenangaben bei Freud 1. c.) hat nun die merkwürdige Tatsache eruiert, das unter unseren heutigen Kulturbedingungen der Totemismus im Seelenleben des Kindes immer von neuem wiederersteht und im Unbewubten des Individuums unverkennbare Spuren zurlickläbt. Gewisse Phantasieprodukte der Kinder ăhneln dem totemistischen System der Primitiven auBerordentlich. Das Kind, das zum Vater oder zur Mutter eine oft handgreiflich ambivalente Stellung einnimmt, verschiebt vielfach seine Gefuhle vom Vater oder von der Mutter auf ein bestimmtes Tier, respektive auf eine Tierart, manchmal auch auf mehrere solche. Für dieses dem Totem durchaus gleichwertige Tier zeigt das Kind einerseits ein liebevolles Interesse; andererseits spielt das Tier in den Wachträumereien und năchtlichen Träumen des Kindes die Rolle eines Angsttieres. Kommt es, wie in der Kindheit so oft, zur Bildung einer Phobie, so ist das gleiche Tier meist das Objekt, auf welches sich die Angst bezieht. In nicht wenigen Fällen behält das Tier seine Bedeutung auch noch weiter bei, um in den Phobien und Träumen erwachsener Neurotiker ganz so wie in der Kindheit zu erscheinen.

Ich verflige taber eine beträchtliche Zahl einschlägiger Beobachtungen. Hier ist jedoch nicht der Ort, sie ausfuhrlich mitzuteilen. Nur einige Angaben lasse ich folgen, um im weiteren auf ihnen fuBen $z u$ können.

Zunächst erwähne ich, daß die Ambivalenz der Einstellung zum Totem (Angsttier) manchen Patienten selbst auffallt. Einer meiner Kranken, der an einer schleichend verlaufenden Hebephrenie litt, hat mir tiber diesen und andere wichtige Punkte des Individualtotemismus mit der Hemmungslosigkeit, die diesen Patienten eigen ist, den besten Aufschlub gegeben. Eine Hauptrolle als Angsttier spielte bei ihm die Fliege. Der Patient auBerte einmal spontan, er stehe der Fliege einerseits "liebevoll" gegenuber, andererseits habe er den Drang in sich, das Tier zu töten.

Von Wichtigkeit für das Verständnis des Weiteren ist sodann, daB ein bestimmtes Tier (namentlich in den Träumen der Patienten) nicht nur den Vater (oder die Mutter) vertritt, sondern oft auch den Trăumer selbst. Ich verflige uber einen interessanten Traum dieser Art, in welchem der Vater des Träumers, der Träumer selbst und dessen Sohn - also drei Generationen - alle durch das gleiche Symboltier (Hund) bezeichnet werden. Das entspricht vollkommen der bei den Primitiven herrschenden erblichen $Z$ ugehörigkeit $z u$ einem bestimmten Totem.

Sodann erwähne ich eine Parallelerscheinung zu dem bei Primitiven 
gelegentlich (seltener als der Tiertotemismus) beobachteten Pflanzentotemismus. Ein Neurotiker, der sich sozusagen beständig auf der Flucht vor dem Mutterinzest befindet, bietet in wachen Phantasien wie in Trăumen alle Erscheinungen eines Baumtotemismus. Im Garten eines SchlöBchens, welches seine Eltern bewohnten, betrachtete er schon als Knabe einen sehr großen, alten Baum mit religiöser Scheu, betete vor ihm und empfing aus seinem Rauschen Orakel ${ }^{1}$. Die Abwehr der Inzestwünsche war für den Patienten mit schwerer Angst verbunden; wie erwähnt, ist er von einer ständigen Unruhe geplagt und wird nirgends seßhaft. In seinen Wachträumen steht er als Baum im elterlichen Garten, umgeben von den anderen Bäumen (seinen Angehörigen), nahe dem großen Orakelbaum ( = Vater) und hat dort feste Wurzeln geschlagen. Wie mir scheint, erforderte die Inzestverdrängung in diesem Falle auBerordentliche Maßnahmen, und so durfte kein animalisches Wesen die symbolische Elternvertretung lbernehmen, sondern diese mußte dem sexuell indifferenten Baume zufallen. Vielleicht fallt von hier aus auch einiges Licht auf den Totemismus gewisser primitiver Stămme, in dessen Mittelpunkt nicht - wie in den meisten Fallen - ein Tier, sondern eine Pflanze steht.

Im Bereich der kindlichen Tierphobien und der totemistischen Erscheinungen in der Neurose mub eine Tatsache auffallen, die bisher noch wenig oder keine Beachtung gefunden hat. Als Totem figuriert in einem Teil der Fälle, wie bereits erwähnt, eines der vierfüßigen Tiere, deren Größe und Kraft es uns ohneweiters begreiflich macht, daB sie vom Kinde mit dem starken Vater identifiziert werden. In einer betrăchtlichen Zahl von Fällen finden wir dagegen als "Angsttiere" gerade die kleinsten, dem Kinde bekannten Tiere: Fliege, Wespe, Schmetterling, Raupe usw.; für eine Anzahl von Neurotikern gilt das gleiche. Die objektive Gefährlichkeit solcher Tiere kann für diese Form des kindlichen Totemismus nicht als ausreichende Erklärung dienen, denn sie trifft nur auf einzelne dieser Tiere zu; andere sind gerade ganz harmlos, so daß das Kind sie ungefährdet zu töten vermag. Nach meinen Psychoanalysen bei Neurotikern erscheint mir eine andere, einfache Erklärung besser begründet. Jene Tiere haben die Eigenschaft des plötzlichen Erscheinens. Sie nähern sich schnell und unversehens und berlihren ganz unerwartet den menschlichen Körper; ebenso schnell aber verschwinden sie auch wieder. In jedem Einzelfalle treten weitere individuelle Begründungen hinzu. So war bei einem meiner Patienten die Wespe an die Stelle eines andern Tieres - des Tigers - getreten. Farbe und Zeichnung der Wespe erinnerten den Patienten an den Tiger.

1 Vgl. hierzu das Orakel von Dodona. 
Das Brummen der Wespe konnte das Gebrüll des Tigers vertreten; letzteres. wieder erwies sich als determiniert durch die Angst des Kindes vor der tiefen, drobenden Stimme des erztirnten Vaters. Wie der Patient sich spontan ausdrückte, assoziierte sich bei ihm an den Eindruck der Wespe, die mit drohendem Brummen umherflog, die Vorstellung eines Wutaffektes. Auf Grund meiner analytischen Resultate nehme ich an, daB jenen kleinen Tieren eine mehrfache Bedeutung zukommt. Sie repräsentieren den Vater, der das Kind uberrascht, indem er plötzlich in seiner körperlichen Nähe ist oder es mit drohender Stimme schreckt. Dazu kommt aber die Eigenschaft dieser Tiere, daß sie schnell verschwinden und daB man sie leichter als die großen Tiere töten kann. In den kleinen Fliegetieren ${ }^{1}$ wird also einerseits die gefährliche Macht des Vaters anerkannt, andererseits dienen sie zum Ausdruck der Beseitigungsvorstellungen, welche sich gegen den Vater richten. Es sind die gleichen Tiere, welche uns in den Mythologien als "Seelentiere" begegnen.

Der schon mehrfach erwähnte Patient E., der mir hemmungslos eine große Menge wichtiger Aufschlusse tuber die in ihm erhalten gebliebenen Infantilismen gab, der u. a. auch die ambivalente Einstellung zur Fliege selbst hervorgehoben hatte, vergnügte sich während seiner Kindheit oft mit dem Töten von Fliegen und Wespen. An dieser Stelle muB ich aus seiner Psychoanalyse einige weitere Einzelheiten berichten; ich bemerke, daß gewisse Phänomene, die auch bei anderen Patienten nachzuweisen sind, in diesem Falle lediglich in einer unverhullteren Form zum Ausdruck kommen.

Wenn der Patient eine Fliege oder Wespe getötet hatte, so befiel ihn regelmäßig die Angst, die to te Fliege könne sich rächen.

Dieser spontan gemachten Angabe des Patienten kommt eine große Tragweite zu. Es handelt sich nämlich um e in en in di vidua lpsychologischen Vorgang, dersichvollkommen mitder Angst der Primitiven vor ihren Toten deckt. Freud hat in seinen Ausführungen über das $\mathrm{T}$ abu der $\mathrm{T}$ oten diese rätselhafte Scheu analysiert. Die feindlichen Regungen, die man einem Menschen bei seinen Lebzeiten entgegenbrachte, werden nach seinem Tode durch das Aufkommen entgegengesetzter Regungen (Trauer) verdrängt und durch einen Projektionsvorgang dem Verstorbenen selbst zugeschoben. Nun ist er selbst gefährlich für die Überlebenden geworden; er könnte sie sozusagen nach sich ziehen. Bei dem Patienten zeigte

1 Kleine kriechende Tiere (Raupen usw.) sind den fllegenden insofern gleichzusetzen, als sie auch plötzlich am Körper des Kindes erscheinen und dadurch Furcht erregen. 
sich für das von ihm getötete Tier ebenfalls ein "liebevolles" Gefuhh; gleichzeitig aber wurde die Absicht des Tötens dem getöteten Tiere zugeschoben, so daB eine Angst vor seiner Rache die Folge war.

Der gleiche Patient hatte während der Behandlung einen Traum, in welchem er einen Tiger mit einer Stange erstechen sollte. Alle anderen Details des Traumes tibergehend, fuge ich nur hinzu, $d a B$ das Tier plötzlich an den Himmel versetzt war. Der Patient kam im Traum nicht dazu, das Tier zu töten.

Hier begegnen wir dem wichtigen Vorgang der Versetzung an den Himmel; er betrifft ein Objekt, zu dem der Tră umer sich in einer ambivalenten Einstellung befindet. Dieser Vorgang ist uns aber keineswegs fremd. Ich brauche nur an den Patienten B. zu erinnern (vergl. S. 184), der seinen verstorbenen Vater in einer an das Wahnhafte streifenden Phantasie direkt an den Himmel, neben die Sonne versetzte. Es drängt sich uns die Schlußfolgerung auf, daß die Symbolisierung des Vaters durch die Sonne einer solchen Versetzung an den Himmel entspreche, deren Motivierung uns nun keine Schwierigkeit mehr bereitet. Wir sind in der Lage, sie aus der ambivalenten Einstellung des Sohnes zum Vater zu erklären.

Auch hier folge ich zunächst wieder den spontanen, in Form von Einfällen gemachten Angaben des Patienten E.; sie motivierten die Versetzung des Vaters (Tiger, Wespe) an den Himmel zunăchst damit, daß man auf diese Weise von dem gefährlichen Tier möglichst weit entfernt sei. Sofort folgte ein Einfall, der die Berechtigung dieser Motivierung erhärtete. Der Patient berichtete nämlich jetzt, wie er als Knabe. verfuhr, um Wespen und Fliegen a us möglichst weiter Entfernung zu töten. Zu ängstlich, die Tiere direkt anzugreifen, befestigte er eine Kerze an einer langen Stange, zündete die Kerze an und näherte sie einem an der Fensterscheibe sitzenden Insekt; das Tier fiel dann tot oder wehrlos herab ${ }^{1}$.

Je weiter das Tier, d. h. der Totem oder Vater, entfernt ist, um so weniger Gefahr geht von ihm aus. Gleichzeitig aber wird der Totem auf diesem Wege erhöht, er wird von dem irdischen Niveau auf ein höheres erhoben. Dieser Vorgang muß in seinen Einzelheiten nunmehr genauer verfolgt werden.

Die ambivalente Bedeutung der Versetzung des Totem an den Himmel veranschaulicht in besonders instruktiver Weise das folgende Beispiel aus der Kinderstube. Zwei Geschwister mit stark phantastischer Anlage beobachten die Wolken und gewöhnen sich daran, ihnen

1 Durch diese Angabe wird auch die "Stange" erklărt, mit welcher der Patient in dem oben mitgeteilten Traum den am Himmel befindlichen Tiger töten soll. 
Namen zu geben. In diesen Namen, die ich, aus Gründen der ärztlichen Diskretion, mitzuteilen mir leider versagen muß, ließ sich mit Leichtigkeit eine Verdichtung zweier Elemente nachweisen. Sie enthielten eine durchsichtige Entstellung der Wörter "Papa" respektive "Mama", die mit dem Wort "Tier" verschmolzen war. Hier sind also in naiver Weise Vater und Mutter $z$ unächst als Tiere dargestellt und dann als auberirdiscbe Gebilde (Wolken) an den Himmel versetzt. Das mitgeteilte Beispiel gewinnt an Interesse noch dadurch, daB die beiden Geschwister nachweislich ambivalent auf ihre Eltern eingestellt waren, indem sie ihnen einerseits Zärtlichkeit und Verehrung entgegenbrachten, anderseits dazu neigten, insbesondere den Vater zu einer lächerlichen Figur zu stempeln.

In einem Traum einer neurotischen Frau fand ich kürzlich bewundernde Verehrung des Vaters (als Sublimierung einer starken erotischen Fixierung) und Todeswünsche in sehr charakteristischer Weise ausgedrückt. Hier repräsentierte ein ungeheurer Kronleuchter, der sich am Himmel befand und aus lauter Sternen zusammengesetzt war, den Vater; die Erscheinung dés Kronleuchters war übrigens von einer Menge phallischer Symbole umgeben.

In allen diesen Produkten der individuellen Phantasie, mag es sich um spielende Gedanken der Kinder, um Träume Erwachsener oder um Beängstigungen Neurotischer handeln, erblicken wir das gleiche seelische Geschehen wie in den völkerpsychischen Prozessen, die der Religionsbildung zugrunde liegen. Ich darf mich darauf beschränken, hier in aller Kürze auf jene mythologischen Gebilde zu verweisen, welche die Spuren der Versetzung des Totem an den Himmel fast unverhtillt erkennen lassen. Ich nenne den Blitzvogel der indischen, die Sonnenkuh der ägyptischen, den Wolkenbaum der gesamten indogermanischen Mythologie.

Die Wirkungen der Versetzung des Vaters (respektive der Mutter) an den Himmel sind sehr vielseitig. Ich beschränke mich hier zunächst auf die Darstellung des Vaters durch das Sonnensymbol. Mit Rücksicht auf den uns bekannten ambivalenten Charakter des ganzen Vorganges darf man seine Wirkungen in zwei Gruppen sondern.

Die erste Gruppe entspricht den freundlichen, liebevollen Gefuhlsregungen, die dem Vater zugewandt waren, der Anerkennung der văterlichen Macht.

Wird der Vater durch das Symbol der Sonne dargestellt, so bedeutet dies, wie leicht ersichtlich, eine gewaltige Erhöhung seiner Macht. Von der Sonne ist alles Leben, das uns umgibt, abhängig. Durch die Identifizierung mit der Sonne wird der Vater geradezu zum Prinzip 
alles Leben erhoben, wobei auf die Anerkennung der zeugenden Kraft des Vaters ein besonderer Akzent zu legen ist. Zweifel und Unglauben vermögen der Macht des Vaters nunmehr keinen Abbruch zu tun. Da aber der Sonne auch die Eigenschaft zukommt, die irdischen Wesen zu ubberdauern, so wird dem Vater durch die Identifizierung mit der Sonne ewiges Leben, Unsterblichkeit zugeschrieben. Als Sonne an den Himmel versetzt, vermag der Vater alles $z \mathfrak{u}$ schauen, während er durch die blendende Wirkung seines Lichtes dem Blicke des Sohnes entzogen ist. Zugleich aber ist der an den Himmel versetzte Vater den aggressiven Gelüsten des Sohnes entzogen; er ist ubber sie erhaben, wie im Sprichwort der Mond, den das Bellen des Hundes nicht zu kümmern braucht.

Aber all diese Machtfülle ist nur Schein. Denn die Versetzung an den Himmel, die Erhebung zur Gottheit wird - wie Freud in seinem Aufsatze uber den Totemismus uberzeugend nachgewiesen hat - dem toten (rectius: getöteten) Vater zuteil. Die Ergebnisse der Psychoanalyse beim Individuum berechtigen uns zu der ganz analogen Auffassung, dab es der als tot gedachte (eigentlich vom Sohne tot gewtinschte) Vater ist, dem die Erhöhung zur Sonnengottheit gilt. Die Regungen von $\mathrm{HaB}$, Feindschaft, Eifersucht sind es, die in den Todesphantasien ihren Ausdruck finden. Sie berauben den Vater seiner Macht, so daß er eigentlich o hnma chtig, unschadlich wird. Durch nachträgliche Kompensierung wird ihm dann eine a $11 \mathrm{ma} \mathrm{ch}$ tige Gewalt eingeräumt.

Ich verweise an dieser Stelle darauf, daB die Völker nicht nur ihre Gottheiten und andere höhere Wesen an den Himmel versetzen, sondern dab es nach einer bis zur Gegenwart herrschenden Vorstellung die Menschen selbst sind, die nach dem Tode, in den Himmel kommen". Das Seelenleben des einzelnen bringt völlig analoge Produkte hervor. Ein Traumbeispiel möge dies erläutern.

Einer meiner Patienten brachte wăhrend einer bestimmten Periode der Behandlung eine Menge von Träumen hervor, die seinen unbewußten inzestuösen Regungen Ausdruck verliehen. Nachdem er viele Male im Traum gewaltsam von seiner Stiefmutter Besitz ergriffen hatte, folgte ein Traum, welcher inhaltlich von den bisherigen Träumen scheinbar abwich, in Wirklichkeit aber eine Ergänzung $z \mathfrak{u}$ innen bildete. In diesem Traume stieg der Patient auf einer Leiter in den Himmel. Er fand dort Gott auf dem Throne sitzend; die Gesichtsztíge waren aber diejenigen seines Vaters. Aus den Ergebnissen der Analyse erwähne ich nur als hier interessierend, daB der Patient seinen Vater in den Himmel versetzt hat, $d$. h. ihn aus der Liste der 
Lebenden gestrichen hat. Gleichzeitig erhöht er den Vater zum Gott. Aber die Macht des Vaters wird dadurch nur scheinbar erhöht. Denn der Patient steigt ja selbst zur Höhe des Vaters hinauf. Das Besteigen der Leiter ist ein häufiges Koitussymbol, das hier im Sinne des Inzestwunsches angewandt ist. Der Patient nimmt symbolisch von der Stiefmutter Besitz, weil der Vater nicht mehr am Leben ist. Die göttliche Macht des Vaters ist unwirksam; sie kann ihn an der Ausführung seines Vorhabens nicht hindern.

Gerade in Hinblick auf diesen Traum, in welchem der Sohn nach den Rechten des zum Gott erhobenen Vaters greift, erscheint mir die Bemerkung notwendig, daß der Sohn durch jede solche Erhöhung des Vaters sich selbst erhöht, jenem also an Macht ahnlich wird. Es genügt, an die Herrscher- und Priestergeschlechter zu erinnern, die sich, zur Erhöhung ihrer eigenen Macht als Söhne der Sonne bezeichneten ${ }^{1}$.

Nachdem es gelungen ist, die Sonnenphobie zu verstehen, läßt die Gespensterphobie sich ohne besondere Schwierigkeit auflösen. Das Gespenst ist der tote (oder tot gedachte) Vater. Wird der Vater durch die Sonne vertreten, so ist sein Anblick unerträglich. Ist er zum Gespenst umgewandelt, so ist er dem Anblick im allgemeinen entzogen. Sein unerwarteter Anblick erregt heftige Angst. Nach meinen Beobachtungen, welche nach dieser Richtung hin jedoch der Ergänzung bedürfen, scheinen manche Neurotiker zuerst eine Scheu vor dem Sonnenlicht, respektive dem Lichte luberhaupt zu haben, um später noch die Angst vor Gespenstern zu produzieren. Mit dem Fortschreiten des gegen den Schautrieb gerichteten Verdrängungsprozesses muß das Symbol, welches den Vater oder die Mutter vertritt, immer unmaterieller werden.

Einer meiner Patienten produzierte innerhalb eines kurzen Zeitraumes zwei Träume, in deren einem der Vater als Licht erschien, während er im andern als Gespenst auftrat. Im ersten dieser Träume befindet der Patient sich in der Schule (die er schon vor mehreren Jahren verlassen hat). Der Schuldirektor, welchem auch in anderen Trăumen eine ausgesprochene Vaterrolle zukam, betritt das Klassenzimmer und redet den Patienten an. Dieser widersetzt sich zunächst in trotziger Weise den Anordnungen des Direktors, muß aber dann gehorchen, während liber dem Kopf des Direktors ein blendend helles Licht erscheint, bei dessen Anblick der Patient in Ohnmacht fällt.

${ }^{1}$ Kurz erwähnen möchte ich, daß bei manchen Neurotikern der Vater nicht durch die Sonne, sondern durch den Blitz repräsentiert wird, also durch eine andere Lichterscheinung am Himmel. Der Blitz repräsentiert hier besonders die strafende (tötende) Macht des Vaters. 
Repräsentiert hier das blendende Licht die văterliche Macht, so gilt das Gleiche vom Gespenst in dem anderen Traum. Bemerkenswert ist in diesem Falle, daB das Gespenst den Träumer durch seine weiBe Gestalt blendet. Im allgemeinen werden die Gespenster als weiße, aber fahle, blasse Erscheinungen gedacht. Die Gespensterphobie findet sich am ausgeprägtesten bei den neurotischen Griblern, welche, wie früher ausgeführt, überhaupt die Tendenz zeigen, das sinnlich Wahrnehmbare, das Klare und Greifbare durch Unbestimmtes, Verschwommenes, Unmaterielles zu ersetzen.

Wer über eigene psychoanalytische Erfahrung verfügt, wird unschwer erkennen, daB die vorstehenden Ausführungen das umfassende Gebiet, auf welches sie sich beziehen, keineswegs zu erschöpfen vermögen. Sicherlich läßt sich den hier analysierten Phänomenen manches Weitere an die Seite stellen, besonders aber muB hervorgehoben werden, daß diese Studie sich gedrängtester Kürze befleißigt hat. So mußte manches, was zur Aufklärung der Symptome hätte beitragen können, unerwähnt bleiben; anderes konnte nur angedeutet werden. Der fragmentarische Charakter des Gebotenen mag aber gerade zeigen, wie sehr uns symptomatologische Untersuchungen not tun. Der Weg, den sie zu gehen haben werden, ist vorgezeichnet durch die uns unentbehrlich gewordene Aufstellung der "Partialtriebe $e^{\alpha}$ und der "erogenen $Z$ on en“. Im Vorstehenden habe ich mich bemüht, das an dem Beispiel eines Partialtriebes und e iner erogenen Zone zu erweisen. 


\section{Über neurotische Exogamie.}

Ein Beitrag zu den Obereinstimmungen im Seelenleben der Neurotiker und der Wilden ${ }^{1}$.

Während man früher der Ehe unter Blutsverwandten nur insoweit ein Interesse entgegenbrachte, als man in ihr ein hereditär belastendes Moment erblickte, habe ich in einem Aufsat ${ }^{2}$ darauf hingewiesen, daß die Verwandtenehe selbst als Phänomen der Neurosen-Psychologie gewürdigt werden müsse. Ausgehend von den Eigentumlichkeiten der Sexualität bei den Neurotikern, welche uns durch die Psychoanalyse bekannt geworden sind, gelangte ich zu der Auffassung, daß bei vielen solchen Personen die Übertragung der Libido auf blutsfremde Personen miBlinge, weil sie auch nach der Pubertät in inzestuöser Gebundenheit verharre. Für den Neurotiker, der sich dem Objekt seiner ursprunglichen inzestuösen Wünsche ebenso fern halten muß wie dem blutsfremden Weibe, bedeutet die Ehe mit einer Verwandten ein KompromiB. Schon in der erwähnten Schrift machte ich darauf aufmerksam, $\mathrm{da} B$ man die Neigung zur Inzucht in eine Reihe mit gewissen anderen Erscheinungen stellen mutsse, um ihr psychologisch gerecht zu werden. An dem einen Ende dieser Reihe hat der reale Inzest seinen Platz; er ist in psychopathischen Familien nicht gar so selten, wie man anzunehmen pflegt. Das entgegengesetzte Extrem ist die völlige und dauernde Ablehnung aller Beziehungen zum andern Geschlecht.

Dem erstgenannten Extrem steht psychologisch nahe die Neigung zu solchen blutsverwandten Personen, welche nicht dem allernächsten Verwandtschaftsgrade angehören. In einem ganz ähnlichen Verhältnis $z u$ dem oben genannten andern Extrem der Reihe steht eine Erscheinung, welche ich mit dem Namen "neurotische Exogamie

1 Aus „Imago", Zeitschrift für Anwendung der Psychoanalyse auf die Geisteswissenschaften. III. Jahrgang 1914, 6. Heft.

"Die Stellung der Verwandtenehe in der Psychologie der Neurosen." Vgl. S. 45 dieses Buches. 
belegen möchte. Sie besteht darin, daß der Mann ${ }^{1}$ eine unüberwindliche Scheu empfindet, in nahe Beziehungen zu einem Weibe zu treten, das der gleichen Rasse oder Nationalität angehört wie er selbst, oder richtiger gesagt - wie seine Mutter. Hier werden also gegen die Möglichkeit des Inzestes ganz besondere Maßregeln getroffen. Der Neurotiker flieht vor dem mütterlichen Typus zu solchen Frauen, welche in Erscheinung und Wesen der Mutter (oder Schwester) möglichst entgegengesetzt sind. Diese Flucht ist eine Folge seiner übermäßigen In $z$ estscheu.

Ein Beispiel möge zunächst den geschilderten Sachverhalt erläutern:

Ein dem blonden, norddeutschen Typus angehöriger Neurotiker zeigt die höchste Antipathie gegen den gleichen Typus bei Frauen. Nichts darf ihn beim Weibe an sein ursprüngliches Liebesobjekt, die Mutter, erinnern. Er erträgt bei Frauen nicht einmal den heimischen Dialekt. Nur dunkelhaarige, brunette fremdrassige Frauen ziehen ihn an. Er hat im Laufe der Jahre verschiedenen Frauen seine Sympathie geschenkt; sie gehörten stets fremder Rasse oder Nationalität an. Dabei trat mit gröBter Deutlichkeit die von F r e u d hervorgehobene Neigung zur ${ }_{n}$ Reihenbildung " hervor. Der Patient erwies sich als unfähig, seine Libido nachhaltig und erfolgreich auf eine bestimmte weibliche Person zu richten. Die Fixierung an die früheste Liebe erwies sich als übermächtig.

Ich habe eine ganze Anzahl ähnlicher Fälle analysieren können und bin allmählich $z u$ der Auffassung gelangt, $\mathrm{daB}$ in dieser Abneigung gegen Frauen des eigenen (oder mütterlichen) Typus resp. der eigenen Rasse etwas Gesetzmäßiges liege. Eine interessante Beobachtung ganz derselben Art hat Dr. Karl We i 2 $^{2}$ veröffentlicht. In seiner Mitteilung handelt es sich um einen Mann, der unfähig ist, ein Mädchen aus seiner Heimatstadt und Heimatprovinz, oder aus der Heimatgegend seines Vaters oder seiner Mutter zu heiraten. Ebenso empfindet er eine Scheu vor Mädchen, die ähnliche Augen oder Haare haben wie seine Schwestern.

Die Motivierung dieser sexuellen Scheu ist manchen Neurotikern durchaus unbewußt, anderen dagegen voll bewußt.

Ein Patient erklärte mir, er - der selbst Jude war - werde nie eine Jüdin heiraten können, weil er in jeder Jüdin unwillkürlich seine Schwester erblicke. Tatsächlich befand sich dieser Patient in einer ungewöhnlich starken inzestuösen Fixierung an Mutter und Schwester,

1 Wie in der zitierten früheren Arbeit berücksichtige ich auch hier wieder in erster Linie die Erscheinungen, wie sie sich beim männlichen Geschlecht äußern; die Begründung dafür habe ich am erwähnten Orte gegeben.

2 Internat. Zeitschr. f. ärztl. Psychoanalyse, Bd. II., p. 161. 
wovon auch seine Neurose (Straßenangst) Zeugnis ablegte. Im Pubertätsalter war es zu einer sexuellen Annäherung der Geschwister gekommen.

Ein zweiter Patient, ebenfalls von jüdischer Abkunft, machte hinsichtlich seiner Neigungen ganz ähnliche Angaben wie der Vorerwähnte. Er verliebte sich wiederholt in Mädchen, welche dem jüdischen Typus in ihrer Erscheinung ganz entgegengesetzt waren, so z. B. in eine blonde Dänin.

In einem dritten Falle war der Sachverhalt ganz der gleiche; nur befand sich der Patient über die Herkunft seiner Rassenneigung und -abneigung im Unklaren.

In allen von mir genauer untersuchten Fällen bestand neben der übermäBigen positiven Fixierung der Libido an die nächsten Angehörigen gleichzeitig ein ausgesprochener $\mathrm{Ha} \mathrm{B}$ gegen die eigene Familie. Dieser richtet sich bald vorwiegend auf die Mutter und erklärt sich dann aus enttäuschter inzestuöser Neigung; bald gilt er mehr dem Vater und leitet sich dann zwanglos aus der ÖdipusEinstellung des Sohnes her.

Ein solcher $\mathrm{HaB}$ wird fur den Sohn zum wirksamen Motiv, sich von seinesgleichen $z u$ trennen. Er sucht nun nicht bloß den Zusammenhang mit seinen Blutsverwandten, sondern auch denjenigen mit seinen Stammesgenossen aufzuheben.

Zweierlei häufige Erscheinungen werden durch diese Betrachtungsweise in ein neues Licht gerückt.

Ich habe zunächst einen Teil der sogenannten $M$ ischehen im Auge. In den christlichen Ländern handelt es sich namentlich um Mischehen zwischen Christen und Juden. Bald ist es mehr die Flucht vor dem Inzest, bald mehr die feindliche Ablehnung der eigenen Familie, welche in nicht wenigen Fällen zur Schließung einer Mischehe treibt. Ich könnte für diesen Hergang zahlreiche Belege beibringen.

Sodann verdient unser Interesse jener Typus von Männern, welche frühzeitig, meist im Unabhängigkeitsdrang des Pubertätsalters, aus ihrer Heimat auswandern und irgendwo in einem exotischen Lande mit einem fremdrassigen Weibe die Ehe eingehen. Ich verfüge über eine Reihe sehr instruktiver Beobachtungen dieser Art.

Durch die neuesten Untersuchungen Freuds sind wir auf gewisse Übereinstimmungen im Seelenleben der Neurotiker und der Primitiven aufmerksam geworden. An dieser Stelle ist in erster Linie an die verstärkte Inzestscheu der Neurotiker und der Primitiven zu erinnern. Diese Inzestscheu kommt am stärksten zum Ausdruck in der Gesetzgebung jener Völker, deren wichtigste Sorge augenscheinlich die Inzestverhutung ist. Die wirksamste und 
weitreichendste Maßregel dieser Art ist diejenige bei vielen primitiven Stämmen bestehende Einrichtung, welche man als Ex o ga mi e bezeichnet. Sie verbietet die geschlechtlichen Beziehungen nicht nur unter Blutsverwandten im eigentlichen Sinne, sondern sogar unter Angehörigen des gleichen Stammes.

Wir sahen, daß manche Neurotiker, einer inneren Nötigung folgend, ihre Neigung lediglich solchen Personen zuwenden, welche einem anderen Stamme angehören. Die innere Nötigung hat bei diesen Individuen den gleichen Effekt wie der äußere, gesetzliche Zwang bei den primitiven Völkern. Wir durfen also mit Fug und Recht die uns beschäftigende Erscheinung bei Neurotischen als Exogamie bezeichnen. Das neurotische und das ethnologische Phänomen, die wir mit gleichem Namen belegen, stimmen bezüglich ihres Ursprungs und ihres Zieles vollkommen überein. 


\section{Untersuchungen über die früheste prägenitale Entwicklungsstufe der Libido ${ }^{1}$.}

I.

In den "Drei Abhandlungen zur Sexualtheorie“, welche zuerst im Jahre 1905 erschienen, hatten Freuds Anschauungen von der Sexualität des Kindesalters eine zusammenfassende Darstellung gefunden, die wir auch heute noch als grundlegend betrachten dürfen. In neuester Zeit haben diese Anschauungen eine Vervollständigung erfahren, von der auch die dritte Auflage (1915) der genannten Schrift Zeugnis ablegt.

Die Fortschritte der psychoanalytischen Erfahrung nötigen $z \mathfrak{u}$ der Annahme gewisser Stadien in der frühen Entwicklung der kindlichen Libido. Fre ud bezeichnet sie, weil sie eine vorherrschende Bedeutung der Genitalorgane noch nicht erkennen lassen, als "prägenitale Organis ationen" der Libido.

Die folgenden Ausführungen beschäftigen sich mit der frühesten der von uns angenommenen Entwicklungsstufen. Sie stützen sich auf ein umfangreiches Beobachtungsmaterial, welches ausschlieBlich einer Zeit entstammt, welche der theoretischen Aufstellung der erwăhnten Entwicklungsstadien vorausging. Eine vorgefaßte Meinung im Sinne der Theorie von den prägenitalen Organisationen kann also bei der Gewinnung des Materials nicht beteiligt gewesen sein. Es scheint mir nicht luberflüssig, darauf hinzuweisen; denn jede weitere Ausgestaltung der Sexualtheorie dürfte mit ähnlichen Einwänden aufgenommen werden, wie sie nach dem ersten Erscheinen der "Drei Abhandlungen "laut wurden.

Meine Beobachtungen und die Schlüsse, welche sich aus ihnen ergeben, kann ich jedoch nicht mitteilen, ohne einen Rluckblick auf die Grundlagen zu werfen, auf welchen die Lehre von den prägenitalen Stufen der Libidoentwicklung entstanden ist.

In seinen Ausführungen uber die frühesten Phänomene des kindlichen Geschlechtslebens konnte Fre ud sich auf einen Gewährsmann berufen, der lange vor ihm zu neuartigen und kühnen, aber uberzeugenden

${ }^{3}$ Aus "Internationale Zeitschrift für ărztliche Psychoanalyse", IV. Jahrgang 1916. 
Schlüssen auf diesem Gebiet gelangt war. Diese wichtige Vorarbeit hatte $L$ indner 1879 mit seiner Studie tiber das Lutschen der Kinder geleistet. Dem genannten Autor war der libidinöse Charakter des Vorganges nicht entgangen; er machte darauf aufmerksam, wie das Lutschen, obwohl es nicht dem Zweck der Sättigung diene, vom Kinde mit einer Intensität betrieben werde, welche dessen Aufmerksamkeit gänzlich absorbiere. $\mathrm{L}$ in d n e r beobachtete ferner eine mit dem Lutschen einhergehende Erregung, die sich zu einer Art von Orgasmus steigerte, und er bewertete das Einschlafen des Kindes nach diesem Vorgang als einen Effekt der erreichten Befriedigung. Ferner betonte er die Erscheinungen des Greiftriebes, welche sich mit dem Lutschen verbinden, und erkannte die fließenden Übergänge vom Lutschen zur Masturbation, also zu einer unzweifelhaften Sexualbetätigung.

Freud schloß sich Lindners Auffassungen an. Er vindizierte der kindlichen Sexualität bestimmte Eigentümlichkeiten, die sich gerade an dem Beispiel jener primitiven Triebäußerung, des Lutschens, besonders deutlich erkennen ließen. Erstens sei der Trieb nicht auf ein fremdes Objekt gerichtet, sondern er betätige sich a u to e r o ti s ch. Zweitens sei die primitivste Sexualäußerung keine selbständige Erscheinung; sie lehne sich vielmehr an eine zur Erhaltung des Lebens wichtige Funktion - das Nahrungsaugen - an, sei also eigentlich die Reproduktion eines lustvollen Reizes, welchen das Kind beim Nahrungsaugen kennen gelernt habe. Drittens sei die Erzielung der Lust an eine "e rogene Zon e" - die Lippenschleimhaut - gebunden. Die Befriedigung des Nahrungsbedürfnisses und die Befriedigung der erogenen Zone seien in ihren Ursprüngen nicht voneinander zut trennen. Die Lippenschleimhaut müsse ubrigens eine dem Grad nach wechselnde, von Kind zu Kind schwankende Erogeneität besitzen, da die Neigung zum Lutschen in sehr verschiedener Intensität auftrete.

Eine ähnliche Doppelfunktion wie dem Eingang des Darmkanals schrieb Freud dem Darmausgang zu. Auch dieser diene im frühen Kindesalter nicht lediglich der Exkretion, sondern er stehe als erogene Zone ebenfalls im Dienst der kindlichen Sexualität. Die mit der Darmentleerung notwendigerweise verbundenen Reizempfindungen suche das Kind wieder zu erleben; durch Anhalten des Darminhaltes vermöge das Kind diese Reize zu verstärken. Wie für die Lippenzone, so sei eine individuell schwankende Erogeneität auch für die Analzone anzunehmen. Die gewollte Steigerung des Lustnebengewinnes bei der Defäkation sei, ganz wie das Lutschen, als Reizung einer erogenen Zone gleichwertig der genitalen Masturbation, welche ebenfalls bereits dem frühen Kindesalter eigentümlich ist. 
Neben den autoerotischen Phänomenen der frühen Kindheit beschrieb F r e u d gewisse Triebkomponenten, welche bereits auf andere Personen als Sexualobjekte angewiesen seien (Schau- und Zeigelust, aktive und passive Grausamkeitskomponente). Diese "Partialtriebe“ seien zunächst noch nicht zu einem festen Verbande organisiert, sondern sie gehen selbständig auf Lustgewinn aus. Erst später ordnen sich die erogenen Zonen und die Partialtriebe dem Primat der Genitalzone unter; indem die Sexualität in den Dienst der Fortpflanzung trete, erreiche die Entwicklung ihren normalen Abschluß.

Diejenigen Entwicklungsstadien der Libido, welche der Einsetzung des Primates der Genitalzone vorausgehen, hat F r e u d nun neuerdings

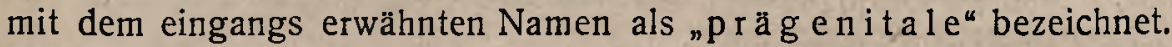
Es handelt sich um Vorstufen der späteren, "normalen" Sexualität, welche in der Regel von der Libido des Kindes durchlaufen werden, ohne daß die Umgebung von den sich vollziehenden Veränderungen Notiz nimmt. Dieselben Vorgänge, welche unter normalen Verhältnissen keine besondere Aufmerksamkeit auf sich ziehen, werden in pathologischen Fällen „aktiviert und für grobe Beobachtung kenntlich“ (Fre u d).

Aus der Psychoanalyse der Neurosen konnten bisher zwei prägenitale Organisationen erschlossen werden. Die früheste ist die o ra le Organisation; man könnte sie - fügt F r e u d hinzu - auch die $\mathrm{k}$ a n $\mathrm{n}$ ibalis $\mathrm{che}$ nennen. Wie früher ausgeführt wurde, ist in diesem Stadium die Sexualtätigkeit von der Nahrungsaufnahme noch nicht getrennt. "Das Objekt der einen Tätigkeit ist auch das der anderen, das Sexualziel besteht in der E in verl e ib un g des Objektes. " (S. 60). Freud fügt eine für das Verständnis des Lutschens wichtige Bemerkung hinzu: „Als Rest dieser fiktiven, uns durch die Pathologie aufgenötigten Organisationsphase kann das Lutschen angesehen werden, indem die Sexualtätigkeit, von der Ernährungstätigkeit abgelöst, das fremde Objekt gegen eines am eigenen Körper aufgegeben hat."

Eine weitere Form der prägenitalen Organisation wurde aus der Psychoanalyse der Zwangsneurose erschlossen. F re ud sagt von ihr: ${ }_{n}$ Eine zweite prägenitale Phase ist die der sadistisch-analen Organisation. Hier ist die Gegensätzlichkeit, welche das Sexualleben durchzieht, bereits ausgebildet; sie kann aber noch nicht $\mathrm{ma} n \mathrm{nlich}$ und weiblich, sondern muB aktiv und passiv benannt werden. Die Aktivität wird durch den Bemächtigungstrieb vonseiten der Körpermuskulatur hergestellt, als Organ mit passivem Sexualziel macht sich vor allem die erogene Darmschleimhaut geltend; fur beide Strebungen sind Objekte vorhanden, die aber nicht zusammenfallen. 
Daneben betätigen sich andere Partialtriebe in autoerotischer Weise. In dieser Phase sind also die sexuelle Polarität und das fremde Objekt bereits nachweisbar. Die Organisation und die Unterordnung unter die Fortpflanzungsfunktion stehen noch aus."

Mit den bisherigen Ausfuhrungen ist der heutige Stand der Sexualtheorie, soweit er unser Thema angeht, in großen Umrissen skizziert. Während nun in der psychoanalytischen Literatur die Beobachtungen, welche zur Aufstellung der sadistisch-analen Organisation geführt haben, eine spezielle Berlicksichtigung gefunden haben, besonders ist hier auf Jones' wichtige Mitteilungen hinzuweisen harrt die früheste, "orale" Entwicklungsstufe der Libido noch der eingehenderen Untersuchung.

Ihre Annahme ist uns, wie Freud sich ausdrückt, von der $\mathrm{Pathologie} \mathrm{aufgenötigt} \mathrm{worden.} \mathrm{Damit} \mathrm{ist} \mathrm{bereits} \mathrm{zum} \mathrm{Ausdruck}$ gebracht, daß es sich um Entwicklungsvorgänge handelt, die der direkten Beobachtung im Kindesalter wenig zugånglich sind. Das Kind kann in dieser frthen Zeit keinen AufschluB tuber die Vorgänge seines Trieblebens geben. Unter normalen Verhältnissen spielt die Entwicklung in den ersten Lebensjabren sich auch so ruhig ab, daß meistens keine augenfälligen Erscheinungen dem Beobachter die sich vollziehenden Veränderungen kundgeben. Später, wenn erst die Verdrăngung ihre Macht entfaltet hat, kann das Individuum naturgemäß über die fruhesten Ereignisse am wenigsten Auskunft geben.

Die Tatsachen der normalen Erotik zeigen zwar deutlich, daß der Mund seine Bedeutung als erogene Zone keineswegs aufgibt. Mehr noch läbt das Studium der sexuellen Perversionen erkennen, daB der Mund vollkommen die Bedeutung eines Sexualorganes eine Genitalrolle - ubernehmen kann. Und weiter zeigt die Psychoanalyse der Neurosen, daß häufig der Mund seine Bedeutung als erogene Zone nur im Bewußtsein verloren hat, daß diese im Unbewußten dagegen fortdauert und sich dem Bewußtsein durch Ersatzbildungen kundgibt, die wir als neurotische Symptome kennen. Der Psychoanalyse verdanken wir die Kenntnis, daß diesen Erscheinungen der Wert von Infantilismen zukommt; sie erklären sich teils aus einem Fortbestehen infantiler Triebe im Unbewußten, teils sind sie der Ausdruck einer nachträglichen Rückkehr $\mathrm{zu}$ bereits uberwundenen Entwicklungsstadien der Libido. $\mathrm{DaB}$ jene verdrängten Infantilismen durch mannigfache Umwandlungen unkenntlich gemacht, ja in ihr gerades Gegenteil verkehrt sein können, erwähnte $\mathrm{F}$ r e u d 1905 gerade im Zusammenhang mit den Erscheinungen, welche sich an der Mundzone abspielen. Neurotische, deren Mundzone ursprünglich durch besondere Erogeneität ausgezeichnet gewesen sei, 
die sich etwa durch jahrelang fortgesetztes Lutschen äußerte, seien im späteren Alter oft mit nervösem Erbrechen behaftet.

Mögen alle diese Erfahrungen uns nun auch ein gutes Recht geben, Rückschlüsse auf ein frühes, „orales" Stadium der Libido zu ziehen, so geben sie uns doch kein greifbares Bild, keine unmittelbare Anschauung dieses archaischen Zustandes, von welchem sich das Triebleben des normalen Erwachsenen außerordentlich weit entfernt hat. Ich möchte deshalb im folgenden auf Erscheinungen psychopathologischer Natur hinweisen, die bisher nahezu unbekannt oder doch unbeachtet geblieben sind. Sie zeigen, daß bei erwachsenen Menschen ein positives und unverkennbares Verharren im Triebleben des Säuglings vorkommt, und $\mathrm{da}$ die Libido dieser Personen ein Bild darbietet, welches dem von Fre u d angenommenen oralen oder kannibalischen Stadium bis in die letzten Einzelheiten entspricht. Ich werde zunächst die äußerst krassen Erscheinungen eines derartigen Falles mitteilen, soweit sie in diesem Zusammenhange von Interesse sind. Von ihnen aus wird alsdann ein Licht auf eine ganze Reihe von psychopathologischen Erscheinungen fallen, denen bisher noch keine spezielle Untersuchung zuteil geworden ist. Endlich wird auf eine Frage einzugehen sein, die sich aus den neuen Veröffentlichungen zur Psychogenese der Zwangsneurose ergibt. Die Untersuchungen von Fre $\mathrm{d}^{1}$ und Jone $\mathrm{s}^{2}$ haben gezeigt, daß aus der Abwehr sadistischanaler Triebregungen Zwangserscheinungen hervorgehen. Die Erwartung liegt nahe, daß die Abwehr eines drohenden Rückfalles in die orale Organisation ebenfalls zur Bildung ganz bestimmter typischer Symptome führe. Die Richtigkeit dieser Erwartung scheint in gewissen Ergebnissen der Psychoanalyse ihre Bestätigung zu finden. Es soll versucht werden, auf Grund der Ermittelungen uber die früheste prägenitale Organisation einen zwiefachen Beitrag zur psychoanalytischen Theorie zu liefern, nämlich zur Frage der Entstehung psychischer Depressionszustände und zum Problem der "Neurosenwahl“.

II.

Was ich hier zunächst an Materialien wiedergebe, entstammt der Psychoanalyse eines Falles von Dementia praecox ("Schizophrenie" Bleulers). Der Patient bot jedoch nicht das allbekannte Bild einer Psychose mit Wahnvorstellungen, Sinnestäuschungen, usw., sondern jene Spielart der Krankheit, welche man als "einfache" Dementia Bd. I, 1913.

1 .Die Disposition zur Zwangsneurose." Internat. Zeitschr. f. ărztl. Ps.-A., 2. HaB und Analerotik in der $Z$ wangsneurose." Ebenda erschienen. 
praecox bezeichnet hat. Die Kranken dieser Gruppe, dié auch B l e u l e r neuerdings wieder als "Schizophrenia simplex" gesondert behandelt hat, lassen die bereits erwähnten groben Symptome der Geistesstörung vermissen. Sie weisen dagegen bestimmte assoziative Störungen und namentlich Veränderungen des Gefühls- und Trieblebens auf, wie man sie in ausgeprägten Fällen des Leidens neben den Wahnbildungen usw. findet. Die assoziative Tätigkeit solcher Kranken vollzieht sich insoweit in geordneten Bahnen, daß man mit ihnen die Psychoanalyse ebensowohl wie mit einem Psychoneurotiker durchführen kann. Ja, diese Arbeit wird sogar durch den Wegfall mancher Hemmungen bei diesen Patienten erleichtert. Vieles, was beim Neurotiker durch intensive Verdrängung vor dem Bewußtwerden und damit vor der Aussprache behütet wird, liegt bei solchen Kranken dem Bewußtsein ganz nahe und wird unter Umständen widerstandslos ausgesprochen.

Mein Patient entstammte einer Familie, in welcher bereits Fälle von schwerer, katatonischer Dementia praecox vorgekommen waren. Intellektuell keineswegs schlecht begabt, hatte er eine höhere Schule absolviert. Dem Zwang der Schule entwachsen, kam er im akademischen Studium in keiner Weise vorwärts; vielmehr bildeten sich an ihm gewisse Eigenschaften, durch welche er schon als Schüler aufgefallen war, immer stärker aus. Als er in meine Behandlung trat, glich sein Verhalten in vielen Beziehungen demjenigen eines albernen Kindes. Weder sein Studienfach noch irgend welche Vorgänge in der Außenwelt vermochten ein ernstes Interesse in ihm zu erregen. Er belustigte sich höchstens an Kleinigkeiten und Äußerlichkeiten, wandte aber seine Aufmerksamkeit hauptsächlich in stark narzißtischer Weise dem eigenen Ich zu. Kleine Einfälle, Wortspielereien u. dgl. konnten ihn intensiv und lange beschäftigen. Mehr als alles andere aber $z 0 g$ die eigene Körperlichkeit sein Interesse auf sich. Seine genitalen und analen Sensationen hatten für ihn die höchste Wichtigkeit. Er war übrigens ebenso der analen wie der genitalen Masturbation ergeben. In den Pubertätsjahren vergnügte er sich mit Kotspielereien, beschäftigte sich auch später viel mit seinen Körperabsonderungen, hatte $z$. B. auch Lust daran, das eigene Sperma zu genießen. Eine ganz besondere Rolle als erogene Zone spielte aber bei ihm der Mund. Wie man es in solchen Fällen oft erlebt, so war auch diesem Patienten der sexuelle Charakter gewisser Erscheinungen bewußt, welche der objektive Beobachter nicht sogleich in diesem Sinne bewertet haben whrde. Der Patient lenkte meine Aufmerksamkeit auf die erogene Bedeutung des Mundes, als er eines Tages von "Mundpollutionen" berichtete, als wären diese etwas Selbstverständliches und Bekanntes. Er schilderte auf Befragen einen 
Vorgang, der sich bei ihm häufig wiederhole. Er erwache nachts aus einem erregenden Traum und bemerke, daß ihm der Speichel aus dem Munde laufe. Seinen Assoziationen freien Lauf lassend, ging der Patient dazu über, mir eine Fúlle weiteren Materials über die erogene Bedeutung des Mundes vorzutragen; ich gebe die besonders beweisenden Tatsachen hier wieder.

Aus den Angaben des Patienten ging hervor, daß er sich als Knabe nicht vom Milchgenu $B$ zu trennen vermochte. Als Schüler - so berichtete er - habe er nie genug Milch zu trinken bekommen können. Die Neigung sei auch jetzt noch vorhanden, habe sich aber in gewisser Hinsicht verändert.

Bis zu seinem fünfzehnten Lebensjahre habe er die Milch nicht einfach aus dem Gefäb getrunken, sondern er habe eine besondere Methode gehabt, sie einzusaugen. Er trank, indem er die Zunge aufwărts krümmte und sie hinter den Oberzähnen an den Gaumen preBte und dann die Milch einsog. Die Milch durfte weder kalt noch heiß, sondern sie mußte körperwarm sein. Auf diese Weise habe er ein besonders angenehmes Gefühl erzielt. Spontan fügte er hinzu: „Es ist so wie ein Lutschen an der Brust." "Ich sauge an meiner eigenen Zunge wie an der Brustwarze." Mit 15 Jahren habe er sich diese Art des Saugens abgewöhnt, habe auch angefangen, Getränke in kaltem Zustande zu sich zu nehmen.

-Das Verlangen nach Milch war damit jedoch keineswegs tiberwunden; ja, seine sexuelle Determinierung wurde in den folgenden Jahren überdeutlich durch häufige Vorkommnisse, von welchen der Patient wie von etwas ganz Selbstverständlichem berichtete. Er erwache nachts oft mit heftigem sexuellen Drang. Dann trinke er Milch, die er im Schlafzimmer bereitstehen habe. Oft sei er auch schon nachts aufgestanden und habe in der Küche nach Milch gesucht. Fand er einmal keine Milch vor, so setzte er seiner sexuellen Erregung durch Masturbation ein Ziel; andernfalls befriedigte er sich durch MilchgenuB. Er selbst empfand das Verlangen, Milch zu saugen, als den tiefsten und ursprünglichsten Trieb. Die genitale Masturbation, so stark sie ihn auch beherrschte, erschien ihm wie etwas erst Hinzugekommenes.

Die Tatsachen sprechen in diesem Falle, soweit ich ihn bereits mitgeteilt habe, für sich selbst. An der sexuellen Bedeutung des Milchsaugens, an der Rolle des Mundes als erogene Zone kann auch nicht der geringste Zweifel bestehen. Das nächtliche Verhalten des Patienten, wie er es selbst geschildert hat, ist aber, wie sich leicht ersehen läßt, eine Fortsetzung desjenigen Verhaltens, welches neurotisch veranlagte Kinder im ersten und zweiten Lebensjahr darbieten. Solche 
Kinder pflegen der Gewöhnung an einen ununterbrochenen Nachtschlaf große Schwierigkeiten $z u$ bereiten. Sie erwachen wăhrend der Nacht einmal oder mehrmals und geben durch ihr Geschrei, oder wenn sie dazu bereits imstande sind, durch andere Zeichen zu erkennen, daB sie nach der Brust oder Milchflasche verlangen. Gibt man einem solchen Kinde Milch $z u$ saugen, so tritt alsbald ein Zustand der Befriedigung und Ruhe ein; andernfalls vermag das Kind sich selbst eine Ersatzbefriedigung zu verschaffen, indem es den Mund durch den eingeführten Finger reizt, oder einer anderen erogenen Zone, etwa der Genitalzone, ihr adăquate masturbatorische Reize zuteil werden läßt.

Das Verhalten unseres Patienten deckt sich mit dem des Săuglings vollkommen. Indem er aber noch als Erwachsener diejenige Form der Befriedigung am intensivsten empfindet, welche den Charakter der Einverleibung trägt, gibt er deutlich kund, daB seine Libido in dem frühesten prägenitalen Stadium, dem oralen oder kannibalischen, eine starke Fixierung erfahren hat. Das Saugen dient dem Patienten als Methode der Nahrungsaufnahme und als Methode der sexuellen Lustgewinnung. Die erstere Bedeutung des Saugens tritt freilich zurück gegenluber der letzteren. Es muß hier an die bereits erwähnten, vom Patienten so genannten "Mundpollutionen" erinnert werden. Wir betrachten den Speichelfluß im allgemeinen als Zeichen der EBlust. Bei dem Patienten aber, desseh Mundzone in so hohem Maße der Sexualităt dienstbar war, war sie die Begleiterscheinung eines im Schlafe aufgetretenen sexuellen Dranges. Die Libido zeigte also die Neigung, auf dem Wege der im frühesten Kindesalter bevorzugten erogenen Zone abzuströmen.

Von hohem Interesse ist nun, was die Psychoanalyse uiber die weitere Entwicklung der Libido bei dem Patienten ergeben hat.

Seine Assoziationen glitten vom Milchsaugen zwanglos hinuber auf die entwicklungsgeschichtlich spätere Form der Nahrungsaufnahme, auf das Essen. Der Patient brachte in diesem Zusammenhang eine Reminiszenz, an welche sich dann weitere wichtige Einfalle anschlossen. Als kleinem Knaben sei ihm die Vorstellung, jemanden lieb zu haben, ganz gleichbedeutend gewesen mit der Vorstellung, etwas Gutes zu essen. Er habe seit seiner Kindheit "kannibalistische Vorstellungen ${ }^{1}$.

1 Vielleicht ist es nicht uberflissig $z a$ betonen, daß sowohl der hier wiedergegebene Gedanke wie der Ausdruck vom Patienten stammen. Der Ausdruck "kannibalistische Vorstellungen* ist nicht etwa aus der Lektüre der. Drei Abhandlungen zur Sexualtheorie" entnommen. Die Psychoanalyse, aus welcher ich hier berichte, fand 1912 statt, während die dritle Auflage der Freudschen Abhandlungen, welche den Ausdruck zuerst enthalt, erst 1915 erschienen ist. 
Diese ließen sich auf assoziativem Wege zunächst bis in das vierte Lebensjahr zurückverfolgen. In diesem Alter - die Richtigkeit der zeitlichen Angabe ließ sich bestätigen - hatte er eine Pflegerin gehabt, der er sehr zugetan war. Sie war es, die im Mittelpunkt der kannibalistischen Phantasien stand. Der Patient wünschte sich noch in späterer Zeit oft, in sie hineinzubeißen und sie "mit Haut, Haaren und Kleidern zu verschlingen“. Die Psychoanalyse vermochte jedoch noch tiefer einzudringen.

Eine weitere Assoziation des Patienten besagte, daß der Geschmack des Fleisches ihn an denjenigen der Milch erinnere. Beides sei "fett und $\mathrm{süB}^{\mathrm{u}}$. Wie er manchmal ein plötzliches Verlangen nach Milch verspüre, so auch nach Fleisch. Es kom me ihm vor, als suche er einen Ersatz für Menschenfleisch. Von hier führte die assoziative Bahn weiter zu der Phantasie, in die weibliche Brust zu.beiBen. Hier war die unmittelbare Verkntupfung von Fleisch und Milch gegeben. Dazu muß bemerkt werden, daß die Säuglingsperiode für unseren Patienten ungewöhnlich reich an eindrucksvollen Erlebnissen gewesen war. Verschiedene Umstände hatten dazu genötigt, eine Reihe von Malen die Amme zu wechseln und ihm die Ernährung durch die Brust sehr lange zuteil werden zu lassen. Bei einem Kinde, in dessen Sexualkonstitution die Mundzone so stark betont war, konnten diese Vorgänge nicht ohne Folgen bleiben; sie muBten die Fixierung auf einer fruheren Stufe der LibidoEntwicklung, resp. die spätere Regression auf diese Stufe erleichtern.

Zum SchluB sei aus der Geschichte des Kranken noch erwähnt, daß auch das Essen für ihn eine starke Lustqualităt hatte; seine Neigung $z \mathfrak{u}$ unmäßigem Essen legte Zeugnis davon ab. Diese Lustbetonung des Essens trug aber für das Gefühl des Kranken nicht den gleichen, sexuellen Charakter, erschien ihm auch als etwas erst Hinzugekommenes. Doch zeigt auch diese Erscheinung die Neigung des Patienten, seinen erogenen Zonen Reize aller Art zuzuführen. Fand seine Libido neue Lustquellen, so wurden dadurch die früheren in ihrer Bedeutung nicht geschmälert. Auch in der weiteren Entwicklung des Trieblebens trat bei dem Patienten diese Eigentümlichkeit sehr hervor. Sie macht es begreiflich, daB seine Libido im erwachsenen Alter niemals eine einheitliche Tendenz erhielt. Während er zu keiner normalen Gefühlseinstellung gegenüber anderen Personen, zu keiner Objektwahl gelangen konnte, behielten die verschiedenen erogenen Zonen nebeneinander ihre alte Bedeutung. Unter ihnen war es aber die Mundzone, deren Reizung der Patient weitaus am lustvollsten empfand und von deren Bedeutung er mit besonderem Affekt sprach. 
Die Eigentümlichkeiten des geschilderten Krankheitsfalles lassen sich folgendermaßen zusammenfassen:

1. Die orale Zone überwiegt an Bedeutung die anderen erogenen Zonen. Insbesondere tritt die Saugelust hervor. Milchsaugen führt einen Zustand der Befriedigung herbei.

2. Sexualfunktion und Ernährungsfunktion sind im Saugeakt miteinander verknüpt.

3. Dem Objekt gegenüber, welches die Wunschphantasien des Patienten auf sich gezogen hat, besteht das Verlangen nach Einverleibung. (Vom Patienten selbst als kannibalische Regung bezeichnet.)

Das sind aber die gleichen Merkmale, welche Freud dem frubesten Stadium der Libido-Entwicklung im Kindesalterzuzusprechen genötigt war.

Die Übereinstimmung ist vollkommen, überrascht aber denjenigen nicht, der aus eigener psychoanalytischer Arbeit erkannt hat, wie sehr die Theorien Fre ud $\mathrm{s}$ aus der unmittelbaren Beobachtung hervorgehen und wie weit sie von weltfremder Spekulation entfernt sind.

Ein Erwachsener, dessen Libido sich in einem Zustande wie dem oben geschilderten befindet, weicht in ganz außerordentlichem Maße von der Norm ab. Das überaus Krasse der Erscheinungen eines solchen Falles eröffnet uns das Verständnis verwandter Phänomene, wenn sie uns bei anderen Personen in geringerer Ausprägung oder in stärkerer Vërhüllung wiederbegegnen.

\section{III.}

Schon bei gesunden Kindern gibt es beträchtliche Unterschiede hinsichtlich des Zeitpunktes der Entwöhnung. Diese Unterschiede sind zwar zu einem Teil in äußeren Verhältnissen begründet, zum Teil aber lassen sie sich nur aus individueller Verschiedenheit der Kinder erklären. So erfolgt der Obbergang von der saugenden Nahrungsaufnahme zum Trinken im engeren Sinne des Wortes bald früher, bald später.

Von äußeren Gründen kommen ethnologische, soziale und familiäre in Betracht. Bei nicht wenigen kulturärmeren Völkern werden die Kinder erst mit vier oder gar mit sechs Jahren entwöhnt. Auch innerhalb der Bevölkerung eines Landes, ja einer Gegend erfolgt die Entwöhnung zu recht verschiedenen Zeiten. In den unteren Volksschichten ist es sogar bei uns nichts Seltenes, daß ein Kind von mehreren Jahren noch zeitweise die Brust der Mutter erhält, wenn diese wieder ein jüngeres Kind zum Stillen hat. Neurotische Mütter schieben manchmal die Entwöhnung ihrer Kinder lange hinaus, weil das Stillen ihnen die stärksten körperlichen Lustgefühle bereitet. Insbesondere 
sind es Frauen mit genitaler Frigidität, bei welchen die Brust eine übergroße Bedeutung als erogene Zone gewonnen hat.

Mehr interessieren uns hier jedoch die Fäle, in denen das Kind aus Gründen, die in ihm selbst liegen, der Entwöhnung Schwierigkeiten bereitet. Schon innerhalb des Zeitraums der saugenden Nahrungsaufnahme kann man bei einem Kinde diese Widerstände kennen lernen, wenn es von der Mutter- oder Ammenbrust zur Saugflasche übergehen soll. Hier beobachtet man sehr merkwürdige Unterschiede im Verhalten der Kinder. Viele gewöhnen sich im Laufe einiger Tage an die Veränderung. Manche Kinder, die es beim Trinken aus der Brust an der genügenden Energie des Saugens fehlen ließen, ziehen die Flasche sehr bald vor, weil ihnen die Nahrung mühelos aus ihr zufließt. Endlich aber gibt es Kinder, die sich mit großer Hartnäckigkeit gegen den Übergang zur Flasche sträuben. Vollends wird dies Widerstreben deutlich, wenn dem Kinde der endgültige Verzicht auf die saugende Nahrungsaufnahme zugemutet wird. Es kommt bei neurotisch veranlagten Kindern nicht selten vor, daß sie auf den Versuch der Entwöhnung mit so mangelhafter Nahrungsaufnahme reagieren, daB die Mutter zum vorläufigen Nachgeben gezwungen wird. Derartige Schwierigkeiten erstrecken sich in ausgeprägten Fällen bis in das schulpflichtige Alter. Ičh erwähne beispielsweise ein neunjähriges Mädchen, das nicht $z u$ bewegen war, am Morgen vor dem Schulgang sein Frühstück mit den Eltern und Geschwistern einzunehmen. Um die Kleine den Weg zur Schule nicht nüchtern antreten zu lassen, bringt die Mutter ihr allmorgendlich eine Saugflasche mit warmer Milch ins Bett. Die sonstigen Mahlzeiten des Tages nimmt die kleine Widerspenstige in normaler Weise mit der Familie. In einem von Gött mitgeteilten Fall mußte ein dreizehnjähriger Knabe von der Flasche entwöhnt werden. Wir werden hier an die besonders krasse Beobachtung erinnert, welche ich oben ausfuhrlicher mitgeteilt habe.

Ein solches Verhalten des Kindes kann nicht anders erklärt werden, als aus einem zähen Festhalten an dem Lustgewinn, welchen das Saugen dem Kinde durch Vermittlung der Lippen als erogene Zone gewährt. Die Erfahrung lehrt uns nun, daß Personen, welche an der kindlichen Saugelust festhalten, regelmäBig in der Entwicklung ihrer Sexualität schwer gehemmt werden. Nahrungstrieb und Sexualität bleiben bei ihnen in einem gewissen Umfang miteinander verflochten. Ihre Libido findet nicht in normaler Weise den Weg zum lebenden, menschlichen Objekt, sondern sucht ihre Befriedigung in erster Linie bei Gelegenheit einer saugenden Stoffaufnahme in den Mund. 
Der Anteil der Sexualität an einer noch in späteren Jahren persistierenden Saugelust tritt vollends zu Tage bei jenen Personen, welche im erwachsenen Alter den Drang empfinden, an der weiblichen Brust zu saugen. Diese Art der Sexualbetätigung reizt sie stärker als die normale Kohabitation. Einer meiner Patienten erklärte mir, daß er sich bei einer solchen Liebesbetätigung in einem sonderbaren $Z$ wiespalt der Gefühle befinde. Einesteils habe er Angst davor, daß aus der Brust Mileh kommen könnte, anderseits sei er ärgerlich und enttäuscht, wenn sich keine Milch entleere. In diesem Falle ist das Sexualinteresse am Saugen das weitaus uberwiegende; von der anderen Bedeutung des Saugens ist nichts ubrig geblieben als ein neugieriges, gespanntes Warten, ob die Brust Milch hergeben werde.

Bekanntlich bleibt beim Kinde nach der Entwöhnung eine Neigung zum Aufsaugen ("Lutschen") süßer Stoffe bestehen. Bei neurotischen Männern mit stark unterdrückter Libido findet sich nun nicht selten ein intensives, triebhaftes Verlangen nach Süßigkeiten. Sie haben eine besondere Lust daran, die Süßigkeiten langsam aufzusaugen. In zwei sehr ausgeprägten Fällen konnte ich mit aller Sicherheit feststellen, daß die vom kindlichen Autoerotismus stammende Saugelust es war, welche die aktiven Regungen der Libido beiseite drängte und den betreffenden Patienten das stärkste Wohlbehagen brachte. Von dem einen Patienten erwähne ich hier, daß er mit Vorliebe abends im Bett Süßigkeiten lutschte, worauf er dann mit dem Gefühl der Befriedigung einschlief. Die Anlehnung an das Verhalten des Kindes im Säuglingsalter ist hier ganz unverhulllt zu erkennen. Die normale männliche Liebesbetätigung war in diesem Falle völlig unterdrückt. Der andere Patient bot infantile Züge in ungewöhnlicher Menge dar. Die männliche Aktivităt fehlte seiner Libido vollkommen; um so intensiver nutzte er alle autoerotischen Lustquellen. Wenn er sich morgens auf den Weg zu seiner beruflichen Tätigkeit machte, pflegte er ein charakteristisches Spiel aufzuführen. Er tat, als ob er noch ein kleiner Knabe wäre, und sagte zum Abschied seiner Frau: „Bubi geht jetzt in die Schule." Auf dem Wege kaufte er sich dann - wie Kinder zu tun pflegen - SüBigkeiten und hatte große Lust daran, sie gemächlich aufzusaugen. Von diesen kindlichen Belustigungen sprach der Patient mit lebhaftem Gefühlston, während das Geschlechtliche im Sinne normaler Männlichkeit mit abnorm geringem Interesse besetzt war. Im Laufe dieser Psychoanalyse lieB sich aus vielen Anzeichen mit Sicherheit entnehmen, daß das libidinöse Interesse, das der normalen Geschlechtsfunktion gebührt, durchaus den autoerotischen Vorgängen anhaftete. Daß gerade das Aufsaugen sußßer Substanzen mit dem Munde eine so starke libidinöse Betonung zeigte, läßt die 
mangelnde Trennung der Nahrungs- und Geschlechtsfunktion auch hier deutlich erkennen.

Zeigt der soeben kurz skizzierte Fall ein Haftenbleiben des Patienten an der kindlichen Saugelust, so möge ein anderes Beispiel die nachträgliche Regression zu dieser Lustquelle demonstrieren.

Ein neurotisches junges Mädchen wird, nach jahrelang geübter Masturbation, eines Tages durch Lektture darliber "aufgeklärt", wie schädlich und sündhaft ihr Handeln sei. Sie wird von Angst ergriffen und gerät in eine langdauernde Verstimmung. Der Masturbation enthält sie sich vollkommen. In dieser Zeit der sexuellen Abstinenz und der Verstimmung wird sie nun öfter von einem heftigen Verlangen nach Süßigkeiten befallen. Sie kauft und verzehrt die Süßigkeiten mit größter Heimlichkeit und unter Gefühlen der Lust und Befriedigung, deren Intensität sie selbst in Erstaunen versetzt. Die Patientin, welche von jeher den äußersten Ekel vor der normalen Verbindung mit dem Manne empfand, hat durch das strenge Selbstverbot der Masturbation ihre genitale Sexualität völlig verworfen. So wird es begreiflich, daß ihre Libido den regressiven Weg einschlägt und sich in der geschilderten Weise der Munđzone bemächtigt. Dazu muß noch bemerkt werdèn, daB die Psychoanalyse viele Anhaltspunkte für das Vorhandensein verdrängter Wunschregungen lieferte, die sich auf das Saugen am männlichen Genitale bezogen.

Nachdem sich uns ergeben hat, daB die saugende Aufnahme von Stoffen mit Hilfe des Mundes bei gewissen Menschen als sexuelle Handlung zu bewerten ist, werden gewisse andere, bei Neurotikern recht häufige Erscheinungen in ein neues Licht gerlickt.

\section{IV.}

Viele Neurotiker leiden an abnormen $\mathrm{Hungergefuhlen.}$ Besonders Frauen sind mit diesem Symptom häufig behaftet, und wohl jedem Nervenarzt sind jene Patientinnen bekannt, die auf der Straße oder an anderen Orten plötzlich von Hunger befallen werden und Vorsorge halber stets EBwaren bei sich tragen. Auch aus dem Schlaf werden sie durch nagenden Hunger geweckt und stellen darum am Abend einige Nahrungsmittel neben dem Bette bereit. Für diesen neurotischen Hunger ist charakteristisch, $\mathrm{da} B$ er ganz unabhängig vom Fällungszustande des Magens auftritt, $\mathrm{da} ß$ er in unregelmäßigen Zeitabständen kommt, und $\mathrm{daß}$ er anfallsweise und unter quälenden Begleiterscheinungen einsetzt, wie sie dem normalen Nahrungsbedurfnis nicht zugehören. Besonders sind hier Angstgefuhle zu erwähnen. 
Die Kranken klagen selbst liber ihre "Anfälle von Heißhunger“. Sie spüren den Unterschied des normalen Hungers und dieses "Heißhungers", neigen aber nichtsdestoweniger dazu, beide Zustände miteinander zu konfundieren. Sie legen die heftigsten Widerstände an den Tag, wenn die Psychoanalyse den Zusammenhang des neurotischen Heißhungers mit verdrängter Libido aufdeckt. Verräterisch weisen gewisse Anzeichen uns dennoch den richtigen Weg. Auffällig ist beispielsweise die große Häufigkeit dieser Hungeranfälle bei frigiden Frauen. Einer meiner Patienten, der das Symptom des neurotischen Hungers in ausgeprägter Weise darbot, hob hervor, daß das Hungergefühl nach den Hoden ziehe.

Starke libidinöse Regungen, gegen deren unverhülltes Auftreten das BewuBtsein sich wehrt, können sich besonders gut hinter einem Hungergefühl - wie hinter einer Maske - verbergen. Hunger, und auch einen übermäBigen, darf man sich selbst und anderen eingestehen. Keiner, auch der Patient selbst nicht, ahnt, aus welcher Quelle das neurotische Symptom seine Macht bezieht. Diese letztere ist in einzelnen Fällen so groß, daß die Kranken genötigt werden, dem krankhaften Nahrungsbedürfnis ihre ganze Lebensführung anzupassen und unterzuordnen. Ebendiese Gewalt, welche der neurotische Hunger uber die Kranken erlangt, gestattet uns Rückschlüsse auf die Heftigkeit der verdrängten Triebregungen, die sich in ihm einen Ausdruck gesucht haben. Ich gebe hier beispielshalber aus einer meiner Psychoanalysen einige Tatsachen wieder, die nicht anders als monströs genannt werden können.

Eine von mir behandelte, schwerleidende Kranke wurde von Heißhunger befallen, sobald sie sich um wenige Schritte von ihrer Wohnung entfernte. Sie verlieB niemals das Haus, ohne etliche Nahrungs mittel mit sich zu nehmen. Waren diese verzehrt, so suchte sie eine Konditorei oder sonst ein Lokal auf, um ihren Hunger $z \mathfrak{u}$ stillen. Am stärksten wurde sie von diesem Bedürfnis jedoch bei Nacht bedrängt. Sie war im Laufe der Jahre dazu gelangt, in jeder Nacht zwei bis drei größere Mahlzeiten zu halten. Obwohl sie sich nicht mit der Abendmahlzeit begnügte, sondern unmittelbar vor dem Schlafengehen nochmals ausgiebig $a B$, wurde sie doch im Laufe jeder Nacht durch nagenden Hunger geweckt, dem sie regelmäßig nachgab. Die Folge der gehäuften Mahlzeiten war natürlich eine bedeutende Zunahme des Körpergewichtes. Die Patientin genoß - angeblich weil sie dadurch am wenigsten Fett ansetzte - bei Nacht hauptsächlich Gemüse. Zur Zeit der psychoanalytischen Behandlung wohnte sie in einem Pensionat. Dort hatte sie große Vorräte von Gemüsekonserven aufgehäuft. Allabendlich bereitete sie sich die im Laufe der Nacht einzunehmenden Mahlzeiten. 
War sie etwa um $10 \mathrm{Uhr}$ schlafen gegangen, so erwachte sie etwa um 1,3 und 5 Uhr. Jedesmal nahm sie eine starke Mahlzeit zu sich. Früh zwischen 6 und 7 Uhr eilte sie bereits in die Küche und bat um ihr Fruhstiuck. Das Verbalten der Patientin erinnerte lebhaft an dasjenige "verwöhnter" kleiner Kinder, welche nachts wiederholt erwachen und nur dadurch zu beruhigen sind, daß die Mutter ihnen zu trinken gibt. Ubrigens war die Kranke das einzige Kind ihrer Eltern. Das Verhalten solcher Kranker, die in kurzen Abstanden nach Nahrung begehren und Qualen erleiden, wenn ihr Verlangen nicht befriedigt wird, erinnert anderseits in überraschender Weise an dasjenige der Morphinisten und mancher Trunksüchtiger. Hinsichtlich dieser Zustände ist der Psychoanalyse der Nachweis gelungen, daß das berauschende Gift dem Kranken eine Ersatzbefriedigung für ihm versagte Betätigungen seiner Libiđo gewährt. Das tibermäßige, unter einem krankhaften Zwange erfolgende Ess en mancher Neurotiker muß in ganz gleicher Weise bewertet werden.

Der zuletzt geschilderte Fall ist von den früher besprochenen dadurch unterschieden, daß die Kranke nicht nach dem Einsaugen von Milch oder sonstigen saugenden Betătigungen verlangte, sondern einen krankhaften Drang nach sehr häufiger Aufnahme fester Nahrung zeigte. Das gesamte Verhalten einer solchen Kranken wird uns erst verständlich, wenn wir den Lustwert erkennen, den das Essen für sie - bewuBt oder unbewuBt - hatte. Obwohl sie sich in keiner Nacht eines ruhigen, ununterbrochenen Schlafes erfreuen durfte, setzte sie der Analyse ihrer Hungeranfälle und der Entwöhnung von den nächtlichen Mahlzeifen den äuBersten Widerstand entgegen. Auch war nicht bloß das Essen selbst bei der Patientin mit so starken Affekten betont; vielmehr genoB sie schon beim Einkauf ihrer Vorräte, bei der Zubereitung der Mahlzeiten usw. eine gewisse Vorlust ${ }^{1}$.

V.

Die Neurotiker, deren Sexualität in solchem Maße verkümmert ist daß sie mehr oder weniger an das Nahrungssaugen oder auch an das Essen gebunden bleibt, zeigen als Erwachsene nach meinen bisherigen Erfahrungen keine besondere Neigung zum Lutschen am Daumen.

1 Zur Ergänzung des obigen Auszuges aus einer Psychoanalyse, der weit von Vollstăndigkeit entfernt ist, sei hier noch auf die Bevorzugung der vegetabilischen Kost für die năchtlichen Mahlzeiten hingewiesen. Die von der Patientin selbst gegebene rationelle Erklarung ist unzureichend und nicht einmal sachlich richtig. Erblicken wir in dem ganzen Tun der Patientin eine Form autoerotischer Befriedigung, so wird das nächtliche Meiden des Fleisches leicht verständlich. 
Diejenigen erwachsenen Neurotiker hingegen, welche ausgesprochene Daumenlutscher geblieben sind, zeigen in der Regel keine besondere libidinöse Betonung der Nahrungsaufnahme. Sehr häufig ist vielmehr bei ihnen der Ekel vor der Nahrung - und zwar besonders vor Milch und Fleisch - sowie Ubelkeit und Neigung zum Erbrechen.

Es mag seltsam klingen, aber man darf dennoch behaupten, daB die erwachsenen Daumenlutscher, gegentiber derjenigen $G r u p p e$ von Neurotikern, die uns bisher beschäftigt hat, ein fortgeschritteneres Stadium der Libido-Entwicklung repräsentieren. Ihre Libido hat sich gegenüber dem Nahrungstrieb insoweit eine gewisse Selbständigkeit verschafft, als die Lustgewinnung nicht mehr an das Nahrungssaugen gebunden ist. Die Mundzone bat freilich ihre vorherrschende Rolle auch bei ihnen belbehalfen, und von einer erfolgreichen Ubertragung ihrer Libido auf Objekte sind auch sie weit genug entfernt. Im Gegenteil bieten sie im wirklichen Leben vielerlei Anzeichen der stärksten Sexualablehnung. In ihren Phantasiegebilden spielt anderseits die Verwendung des Mundes zu sexuellen Zwecken (Fellatio, Cunnilinguus) eine beherrschende Rolle, freilich meistens - wenn auch nicht immer - mit dem negativen Affekt des Ekels und Grauens versehen.

Die Zähigkeit, mit welcher diese Neurotiker in praxi an der autoerotischen Reizung der Lippenschleimhaut und - mindestens in ihrer uppigen Phantasietätigkeit - an der erotischen Verwendung des Mundes festhalten, wird uns leicht verständlich, wenn wir unseren Blick zu dem Verhalten des kleinen Kindes zurlickwenden. Wir brauchen uns nur der Intensität zu erinnern, mit der das Kind sich schon in den frühesten Lebenstagen dem Wonnesaugen hingibt. Der Eifer des Säuglings, beide Hände in den Mund zu drängen, das heftige Schnappen nach den eigenen Fingern, die völlige Hingabe an das rhythmische Saugen und die endliche befriedigende Wirkung des ganzen Vorganges lassen uns erkennen, welche Macht den frühen Triebregungen innewohnt. Diese Macht offenbart sich besonders deutlich darin, daB manche Menschen ihr noch im erwachsenen Alter untertänig bleiben.

Das Verhalten solcher Neurotiker ähnelt aber noch in anderer Hinsicht dem des Säuglings. Nach meiner Erfahrung neigen die Neurotiker, welche das Lutschen nicht tuberwunden haben, auch in besonders hohem Maße zur autoerotischen Reizung anderer Zonen, besonders der Genitalien. Auch beim kleinen Kinde finden wir neben der Saugelust die Neigung, nach einer Stelle des eigenen Körpers zu greifen und an ihr thythmisch zupfende Bewegungen auszuführen. Wir erinnern uns der Gewohnheit lutschender Kinder, während des Saugens am Daumen der einen Hand mit der anderen Hand am Ohrläppchen 
zu ziehen. Sehr gewöhnlich sucht auch die andere Hand die Genitalgegend auf, um sie durch ähnliche Bewegungen zu reizen.

Das Daumenlutschen erwachsener Personen, das uns so seltsam anmutet, wird uns noch erklärlicher, wenn wir uns der Tatsache erinnern, daB auch beim normalen Erwachsenen der Mund seine Rolle als erogene Zone nicht ganz verloren hat. Den Kuß betrachten wir als eine durchaus normale Äußerung der Libido. Freilich ist hier die erogene Zone in den Dienst der Objektliebe getreten. Auch beansprucht der Kuß nicht die Bedeutung eines eigentlichen Sexualzieles, sondern er stellt nur eine vorbereitende Handlung dar. Und doch sind auch hier die Grenzen fließend. Gewisse Formen des Kusses können das wesentliche Ziel des sexuellen Strebens ausmachen. Namentlich aber übernimmt mit einer Häufigkeit, die nicht unterschătzt werden darf, die Lippenzone eigentliche Genitalfunktionen.

Ich lasse nun wieder ausführlichere Mitteilungen aus zweien meiner Psychoanalysen folgen: sie zeigen die Schicksale des kindlichen Hanges zum Lutschen in besonders instruktiver Weise und ergänzen einander in mancherlei Beziehungen.

Ein Mann in mittleren Jahren litt an einer chronisch verlaufenden Neurose, unter deren Symptomen ihn die hartnäckige Schlaflosigkeit am meisten belästigte. Bei dem Versuch, den psychosexuellen Ursachen dieser Störung nachzugehen, kam über die Schicksale seiner Libido oder - was das gleiche besagt - uber die Entwicklung seiner Neurose unter anderem folgendes zu Tage.

Der Patient neigte in der frühesten Kindheit in ungewöhnlichem Maße zum Lutschen am Daumen. Als er größer wurde und von seiner Gewohnheit nicht abließ, wurden die bekannten Mittel der Kinderstube zur Anwendung gebracht, und wirklich unterließ der Knabe das Saugen an dem Finger, der mit einer bitter schmeckenden Flussigkeit bestrichen war. Doch der Erfolg war nur scheinbar. Tatsächlich benutzte der Kleine jetzt einen Zipfel seines Kissens oder seiner Bettdecke, um daran saugend und kauend einzuschlafen. Seine Erzieher mußten gegen diese neue Gewohnheit einschreiten, doch geschah dies wiederum mit dem Effekt, daB der Knabe sich zum Schein fugte, um sich eine neue Ersatzlust zu suchen. Bald entdeckte man Spuren seiner Zähne an dem hölzernen Bettgestell. Er hatte die Gewohnheit angenommen, abends das $\mathrm{Holz} z \mathrm{zu}$ benagen.

Im Laufe der Vorpubertätsjahre befestigte sich das Bedürfnis, vor dem Einschlafen dem Munde seine lustvollen Reize zu gewăhren, immer mehr, und diese letzteren wurden zur Bedingung des Einsch la fens. Unter den autoerotischen Schlafmitteln des Patienten 
spielte jahrelang die Masturbation eine wichtige Rolle. Nach der Pubertät, besonders um das zwanzigste Lebensjahr des Patienten, fanden lebhafte Abgewöhnungskämpfe statt, bei welchen alte Verbote aus der Kindheit wieder in Wirksamkeit traten. Die Abgewöhnung der Masturbation gelang oftmals für längere Zeit, doch muBte der Patient diesen Erfolg durch ebenso lange Perioden hartnäckiger Schlaflosigkeit erkaufen. Von ärztlicher Seite erhielt er sodann Schlafmittel: an ihren Gebrauch gewöhnte er sich bald dermaßen, daß auch gegen sie ein Abgewöhnungskampf geführt werden mußte, welcher sich dann - abwechselnd mit dem Kampf gegen die Masturbation - im Laufe der Jahre öfter wiederholte. Als der Patient endlich in meine Behandlung getreten war und eine gewisse Besserung verspürte, verzichtete er an zwei aufeinander folgenden Abenden auf den Schlafmittelgebrauch. Am Tage, welcher der zweiten schlafmittelfreien Nacht folgte, erschien er in der Sprechstunde unter deutlichen Äußerungen des Unwillens. Als er sich dann in gewohnter Weise zur Behandlung niedergelassen und mir vom Verlauf der letzten Nacht erzählt hatte, beobachtete ich, wie der Patient den rechten Daumen zum Mund führte und, anstatt weiter zu sprechen, am Daumen lutschte. Sein Widerstand hätte. sich kaum deutlicher äußern können. Dieser Widerstand, ursprünglich gegen die Eltern und anderen Erzieher, jetzt - durch Ubertragung - auf den Arzt gerichtet, besagte etwa: "Wenn ihr mir das Nagen am Betttuch, die Masturbation oder die Schlafmittel verbietet, so kehre ich zk meiner altesten Befriedigung zurück. Da seht ihr, daß ihr bei mir nichts erreichen könnt!“ Daß das Lutschen gerade vor den Augen des Arztes geschah, ist ein unverkennbares Zeichen des Trotzes.

LaBt diese Beobachtung mit unubertrefflicher Deutlichkeit erkennen, in welchen Beziehungen das Daumenlutschen zur Sexualität steht, so möge der folgende Auszug aus einer anderen Psychoanalyse zeigen, welch komplizierte Erscheinungen sich von der kindlichen Saugelust ableiten.

Es gibt eine nicht eben kleine Gruppe von Neurotikern, bei welchen die Saugelust von jeher abnorm stark betont ist, die im erwachsenen Alter zu perverser Verwendung des Mundes neigen und dennoch die heftigsten Widerstände gegen Handlungen dieser Art produzieren, und die endlich nervöse Symptome darbieten, welche sich im Gebiet der Mundzone abspielen. Dieser Gruppe gehörte der Patient an, von dem ich $z \mathfrak{u}$ berichten habe.

Der siebzehnjahrige Patient, welcher mich auf Veranlassung seines Hausarztes aufsuchte, zeigte sich bei der ersten Konsultation äußerst einsilbig und verschlossen. Während ich nur mit Muhe einzelne 
kurze Antworten von ihm erhalten konnte, bemerkte ich, daß der Patient fast unausgesetzt etwas mit seinem Mund und den umgebenden Teilen vornahm. Bald biß er die Ober- oder Unterlippe, bald leckte er sie mit der Zunge. Oft sah man, daß er die Wangen saugend nach innen zog; dann wieder biß er die Kiefer so fest aufeinander, daß das Relief der Kaumuskeln deutlich vorsprang. Zuweilen riß der Patient den Mund weit auf, dann wieder schloß er ihn; andere Male war zu erkennen, daß er an den Zähnen oder am Zahnfleisch sog. Als es der Behandlung gelungen war, die Sprachhemmung des Patienten wenigstens zeitweise aufzuheben, berichtete er liber eine Menge weiterer, an die Mundhöhle gebundener Vorgänge, denen allen ein lustvoller Charakter zukam. Besonders trat ein $\mathbf{u n b e z a ̈ h m - ~}$ barer Hang zum Sa ug n hervor. Der Patient machte - gleichviel, ob er allein oder unter anderen Menschen, ob er beschäftigt oder untätig war - beständig Saugbewegungen. Wegen einer Anomalie der Zahnstellung war ihm, als er ca. 13 Jahre alt war, ein Richtapparat angelegt worden. Der Druck des Apparates auf das Zahnfleisch war dem Patienten schmerzhaft; er verschwieg seine Beschwerden aber und reagierte auf den Reiz lieber mit einem fortwährenden Saugen an der betreffenden Kieferpartie. Weiter gestand der Patient, daß er sich noch auf sonstige Art Lustgefühle verschaffe. Er benutzte die Zunge, um am Gaumen streichende und kitzelnde Berbhrungen vorzunehmen, die er als wollustig empfand. Dem Kranken war die sexuelle Natur seines Handelns durchaus nicht unbekannt. Man ist berechtigt, in derartigen Fallen von einer oralen Masturbation zu sprechen.

Gewisse Symptome des Patienten standen mit der Erogeneität der Mundhöhle in engstem Zusammenhang. Zunächst hatte das schon erwähnte Aufsperren des Mundes, das einen zwangartigen Charakter trug, zweifellos eine solche Herkunft. Sobald nämlich der Patient mit einer männlichen Person zusammen war, stellte sich bei ihm zwangartig die Phantasie ein, den Penis des anderen in den Mund zu nehmen. Während er sich nun unter einem Schauergefluhl dieser Phantasie halb hingab, halb sie abzuwehren versuchte, kam es zu der schnappenden Mundbewegung, an deren Sinn kein Zweifel aufkommen kann.

Wir machen nun regelmäßig die Erfahrung, daß ein Organ, welches in zu hohem Maße als erogene Zone in Anspruch genommen wird, seine sonstigen Funktionen nicht mehr genligend $z u$ erfülen vermag ${ }^{1}$. In dem

1 Fre u d hat diesen Vorgang besonders am Beispiel des Auges in seiner kleinen Arbeit liber die ,psychogene Sehstörung" behandelt. Vgl. „Kleine Schriften“, Bd. IIl, S. 314. 
geschilderten Falle versagte der Mund diejenigen Funktionen, welche keinen sexuellen Charakter hatten. Sobald sich der Patient in Gesellschaft anderer Personen befand, war es ihm nahezu u n m ögli ch, zu sprechen oder zu essen. So war er beispielsweise außerstande, sich mit seinen Kollegen in dem gemeinsamen Arbeitsraum zu unterhalten. Holten die anderen im Laufe des Vormittags ein mitgebrachtes Frühstück hervor und verzehrten es, so war dem Patienten solches unmöglich. Er nahm sein Brot jeden Mittag, ohne einen Bissen genossen $z u$ haben, wieder mit sich und warf es dann irgendwo auf der Straße fort. Letzteres tat er, um zu Hause keinen Fragen ausgesetzt zu sein. Bemerkenswert war hier die Wirkung der psychoanalytischen Behandlung. Kaum hatte die zwangartige, mit ständiger Angst verbundene homosexuelle Einstellung des Patienten einem normalen Interesse am weiblichen Geschlecht Platz gemacht, als er auch fähig war, gemeinsam mit seinen Kollegen zu essen und mit ihnen zu sprechen.

Die beiden mitgeteilten Fälle lassen erkennen, welchen beherrschenden Einfluß die im erwachsenen Alter persistierende Saugelust gewinnen, wie sie auf das gesamte Verhalten eines Menschen bestimmend wirken kann. Neben einer Minderheit von derart krassen Fällen gibt es in weit größerer Zahl Personen, die ihrer Mundzone fortdquernd einen gewissen Tribut zahlen müssen, ohne daß es bei ihnen zur Bildung schwerer neurotischer Symptome kommt. Der Widerstreit zwischen ihrem Autoerotismus und anderen Lebensinteressen ist durch Kompromißbildungen zum Ausgleich gebracht. Solche Menschen sind beispielsweise in ihrem Beruf tüchtig und leistungsfähig - sie vermögen einen Teil ihrer Libido mit Erfolg zu sublimieren -, aber ihr Autoerotismus schreibt ihnen Bedingungen vor, von deren Erfullung ihre Leistungen abhängen. Ich behandelte einmal einen Neurotiker, der sich nur dann zu geistiger Arbeit sammeln konnte, wenn er vorher masturbiert hatte. In ahnlicher Weise können manche Personen nur dann intensiv nachdenken, wenn sie gleichzeitig einen Finger in den Mund stecken oder an den Fingernägeln kauen oder einen Federhalter benagen können. Wieder andere müssen bei intensiver Tätigkeit auf ihre Lippen beißen oder sie belecken. Ihr Autoerotismus läßt ein ununterbrochenes Arbeiten nur dann $z \mathfrak{u}$, wenn ihm gleichzeitig ein gewisses $M a B$ von Befriedigung zu teil wird. $\mathrm{DaB}$ bei nicht wenigen Männern das Rauchen zur Arbeitsbedingung wird, erklärt sich zu einem Teil auf diesem Wege; doch liegen hier kompliziertere Verhältnisse vor.

Eine scharfe Trennung $z$ wischen normaler Neigung und Gewöhnung einerseits und pathologischem Zwange anderseits wird sich auf diesem Gebiet nicht durchführen lassen. Für praktische $Z$ wecke aber wird man 
sich im allgemeinen an ein Kriterium halten durfen: an die Art, wie das Individuum die zeitweise Entbehrung des gewohnten Reizes erträgt. Die Reaktion auf das Versagen einer Lustquelle, an welche das Individuum krankhaft fixiert war, trägt einen pathologischen Charakter. Sie besteht in neurotischer Symptombildung.

VI.

Es ist nicht zweifelhaft, daß die Befriedigung der sexuellen Bedürfnisse beim normalen Menschen einen starken Einfluß auf das Gleichmaß seiner Stimmung ausübt. Doch ist der Gesunde fähig, den zeitweisen Mangel der gewohnten Befriedigung innerhalb gewisser Grenzen zu ertragen. Er vermag sich auch auf dem Wege der Sublimierung gewisse Ersatzbefriedigungen zu verschaffen. Das gleiche darf man auch von einem großen Teil der Neurotiker aussagen. Andere unter ihnen sind jedoch äußerst intolerant gegen jede Minderung der gewohnten Lust, und zwar um so mehr, je weniger sich ihr Triebleben von dem Niveau der fruheren Kindheit entfernt hat. Sie gleichen in hohem Maße den „verwöhnten“ Kindern. Ihre Libido verlangt unablässig die gewohnte Befriedigung. Sie werden infolgedessen vollkommen abhängig und reagieren mit großer Unlust, wenn sie ihrer gewohnten Lust entraten sollen. Diese Unlust aber geht in ausgesprochene Verstimm ung über.

Dieser Ursprung neurotischer Verstimmungen scheint mir oft nicht genügend gewürdigt $\mathrm{zu}$ werden.

Für den Neurotiker hat die gewohnte autoerotische Befriedigung praktisch eine zweifache Bedeutung: sie dient zur Verhltung drohender und zur Beseitigung eingetretener Verstimmungen.

In ersterer Hinsicht diene als Beispiel, daß viele Neurotiker früh am Morgen sofort zu dem gewohnten Mittel der Befriedigung greifen, um sich vor einer Verstimmung zu schützen. Es handelt sich um Inđividuen, die sich morgens schwer vom Schlafe lösen können. Jeder Tag, jede Rückkehr in das wache Leben beginnt für sie mit lebhafter Unlust. Diese würde anhalten und ihnen den ganzen Tag verstören, wenn sie nicht $z u$ der gewohnten Art der Befriedigung - als zum Prophylaktikum gegen ihre neurotischen Verstimmungen - greifen würden. Gerade die verschiedenen, bereits ausführlicher besprochenen Reizungen der Mundzone sind in dieser Hinsicht von besonderer Bedeutung.

Ein solches Verhalten neurotischer Personen kann nicht besser erklärt werden, als durch den Hinweis auf ein bereits erwähntes Beispiel. Ich erinnere an die neunjährige Kleine, die am Morgen nicht zun 
Verlassen des Bettes zu bewegen war, bevor sie ihre geliebte Saugflasche mit Milch erhalten hatte.

Ausführlicher muB ich mich mit denjenigen Neurotikern beschäftigen, welche eine eingetretene Verstimmung durch einen lustvollen oralen Reiz verscheuchen. Ich gehe dabei absichtlich nicht auf den Alkohol als Stimmungskorrigens ein, weil hier die narkotische Wirkung das Bild kompliziert.

Besonders instruktiv ist der Fall einer jungen zyklothymen Kranken, die ich beobachtet habe. Sie fand auBerordentlich schwer einen seelischen Kontakt mit anderen Menschen, zog sich vielmehr von ihnen zurück und ergab sich ganz ihren autoerotischen Neigungen. Kam sie in deprimierte Stimmung, so half sie sich durch verschiedene Mittel, unter denen das hauptsächlichste hier von Interesse ist: sie kaufte sich etwas zu essen und spürte während des Essens alsbald eine Aufheiterung ihrer Stimmung. Bezeichnend für ihren Autoerotismus war auch ein anderes Mittel, das auf ihre Stimmung wirkte: sie fuhr stundenlang auf der Straßenbahn und zog daraus eine sehr ausgesprochene Bewegungslust ${ }^{1}$. Fuhlte sie sich deprimiert, so verbrachte sie einen großen Teil des Tages mit Straßenbahnfahrten und mit dem Verzehren von $E$ Bwaren, die sie bei sich trug.

Wie sehr alle solche Erscheinungen im Infantilen wurzeln, darüber belehrte mich die Psychoanalyse eines jungen Mannes, den ich wegen einer neurotischen Verstimmung behandelte. Stark an seine Mutter fixiert, vermochte er auch längere Jahre nach der Pubertăt seine Libido nicht auf andere weibliche Personen zu tibertragen. Geraume Zeit hindurch fand er in seiner beruflichen Arbeit eine Ersatzbefriedigung, bis ihn gewisse Umstände in einen inneren Zwiespalt brachten, dessen er sich freilich nicht bewußt war. Die Fixierung an die Mutter und die Tendenz zur Ablösung von ihr gerieten in einen heftigen Widerstreit; die Arbeit hörte auf, den Patienten zu befriedigen. Das nächste Ergebnis war eine Verstimmung, in deren Beginn ihn ein eigentumliches Vorkommnis tiberraschte. Von starker Lebensunlust befallen, schlafslichtig und appetitlos, legte er sich eines Tages zu Bett. Seine Mutter brachte ihm eine Tasse mit Milch. Als er die Tasse an den Mund setzte und seine Lippen mit dem Getränk in Berührung brachte, hatte er, wie er sich ausdruckte, "e ine Mischem pfindung von warm, weich und $s$ a $B^{*}$; sie befremdete ihn und kam ihm dennoch wie etwas aus ferner Vergangenheit Bekanntes vor, gleichzeitig aber ubte sie eine ihm unerklärliche beruhigende Wirkung auf ihn aus. Die Psychoanalyse

${ }^{2}$ Vgl. hiezu meinen Artikel: Uber eine konstitutionelle Grundlage der lokomotorischen Angst". S. 159 u. ff. 
brachte bald die Lösung des Rätsels. Der Patient war während seines ganzen ersten Lebensjahres von seiner Mutter gestillt worden und hatte - wie sich durch nachherige Befragung der Eltern ergab - mit besonderer Intensität gesogen. In den folgenden Kindheitsjahren hatte er noch oft nach der Brust der Mutter gegriffen und von ihr mit zärtlichen, der Kindersprache angehörigen Ausdrücken gesprochen. Als nun der erwähnte Ablösungsversuch gescheitert war und der Patient unter einer heftigen Verstimmung litt, wandte er sich unbewu $B t$ der ältesten Lustquelle seines Lebens wieder $z$ u. Die von der Mutter gereichte Milch rief alteste, lustvolle Erinnerungsspuren wach und vermochte so, die Verstimmung vortibergehend zu mildern.

Ein dem Nervenarzt wohlbekanntes Phänomen wird in diesem Zusammenhang verständlich. Verstimmte oder erregte Neurotiker werden oft - freilich immer nur vorübergehend - durch das bloße Verschlucken eines Medikamentes günstig beeinflußt, auch dann, wenn dem Mittel keine sedative Wirkung zukommt. Man beruft sich zur Erklärung dieser Tatsache gern auf die suggestive Wirkung der ärztlichen Verordnung. Vielfache Erfahrung zeigt aber, daß der Neurotiker ein Irgendetwas durch den Mund zu sich nehmen kann - ohne ärztliche Verordnung - und damit für den Augenblick eine beruhigende Wirkung erzielt. Man ubersieht hier leicht einen wichtigen Faktor. In jedes Menschen Leben gab es eine Zeit, da er von aller Erregung durch die Aufnahme einer Flüssigkeit befreit wurde. Die „suggestive“ Wirkung der Arzneiflasche liegt keineswegs nur in dem behandelnden Arzt, sondern mindestens ebenso sehr in ihrer Eigenschaft, dem Munde des Kranken etwas zu spenden, was in ihm die ältesten lustvollen Erinnerungen zum Mitschwingen bringt.

Die Neigung Nervöser, sich eine Diät und immer wieder eine neue Diät vorschreiben $z u$ lassen, die sich möglichst einem rein flussigen Regime nähert, erfährt ihre Erklärung zum Teil ebenfalls aus dieser Quelle. Es sei besonders an jene Kranken erinnert, die sich mit Vorliebe im Bett von einer Pflegerin päppeln lassen.

Vergessen wir aber darüber nicht die große'Häufigkeit der $\mathrm{Nahrungsablehnung} \mathrm{bei} \mathrm{unseren} \mathrm{Patienten.} \mathrm{Sie} \mathrm{tritt} \mathrm{im} \mathrm{Rahmen}$ der neurotischen Erkrankungen in mancherlei Gestalt und vielfach in verhullter Form auf. Ich erinnere nur an Appetitlosigkeit, Ekel vor dem Essen, Obelkeit und Erbrechen. Uber die Herkunft dieser Symptome ist dem bereits fruher Gesagten nichts prinzipiell Neues hinzuzufugen.

Bei seelisch Verstimmten findet sich oft eine bewuBte, auch offen ausgesprochene Tendenz zur Nahrungsverweigerung. Am ausgeprägtesten beobachtet man diese Erscheinung bei denjenigen Verstimmungen, die 
wir den Psychosen zurechnen. Die Erwartung ist daher berechtigt, daß die Psychoanalyse dieser Erkrankungen uns tuber die tieferen Ursachen der Nahrungsverweigerung Aufschluß geben werde.

\section{VII.}

Unter den wichtigsten und hervorstechendsten Äußerungen depressiver Geistesstörungen finden sich zwei Symptome, welche auf die Nahrungsaufnahme unmittelbaren Bezug haben: di e Verwe igerung der Nahrungsaufnahme und die Angst vor dem Verhungern.

Als ich vor mehreren Jahren einen ersten Versuch ${ }^{1}$ unternahm, die Struktur der depressiven Geistesstörungen auf psychoanalytischem Wege aufzuklären, habe ich den soeben genannten beiden Symptomen nicht die Beachtung geschenkt, die sie mir jetzt $z \mathfrak{u}$ verdienen scheinen. Ich glaube, im folgenden einen weiteren Beitrag zur Psychogenese der Depressionszustände liefern zu können, bin mir aber wohl bewußt, wie weit ich von einer umfassenden und endguiltigen Lösung. des Problems entfernt bleibe.

Wer einen melancholisch Deprimierten aufmerksam beobachtet, wird bald den Eindruck gewinnen, daB der Kranke das Leben verneint. Es liegt darum sehr nahe, in der Verweigerung der Nahrung den Ausdruck einer Selbstmordtendenz zu erblicken. Gegen die Richtigkeit dieser Erklärung ist an sich nichts einzuwenden. Der Psychoanalytiker kann sich jedoch nicht mit ihr zufrieden geben, weil sie unvollständig und einseitig ist. Ihm drängt sich die Frage auf, warum denn der zum Sterben entschlossene Kranke den langsamen und unsicheren Weg des Hungertodes wähle. Auch schützt die psychoanalytische Erfahrung davor, allzu bereitwillig eine Auffassung zu akzeptieren, welche ein psychopathologisches Phänomen auf bewußte, logische Gründe zurückzuführen sucht.

Auch die Entstehung des zweiten der oben erwähnten Symptome der Angst vor dem Verhungern - ist nicht durch ein paar einfache Öberlegungen aufzuklären. Die Angst vor dem Verhungern findet sich mit besonderer Häufigkeit in den Depressionszuständen des Rückbildungsalters. Eine primitive psychologische Auffassung dieser Krankheitserscheinung wlirde etwa lauten: der Mensch, der sich altern fühlt, mache sich Sorgen um seine weitere Existenz. Da im Rückbildungsalter die Neigung zu nervösen und psychischen Störangen besonders groß sei, so finde die erwähnte Sorge - je nach der Disposition des Individuums -

1 "Ansătze zur psychoanalytischen Erforschung und Behandlung des manischdepressiven Irreseins und verwandter Zustände ${ }^{u}$. S. 95 u. ff. dieses Bandes. 
in einer krankhaften Angst oder auch in einer depressiven Wahnidee ihren Ausdruck.

Eine solche Auslegung trifft nicht das Wesen des Zustandes. Sie hält sich lediglich an den Wortlaut der krankhaften Vorstellung - an ihren manifesten Inhalt. Weder die treibenden Kräfte der Psychose noch der tiefere Gehalt der Symptome werden klargestellt.

Die Psychoanalyse spürt dem latenten Inhalt der krankhaften Vorstellungen nach. In dem früher zitierten Aufsatz konnte ich bereits nachweisen, daß die depressiv verstimmten Kranken ihrer verloren gegangenen Liebesfähigkeit nachtrauern. Gerade das Involutionsalter, in welchem Depressionszustände am hăufigsten ausbrechen, bringt eine Entwertung der genitalen Erotik mit sich. Bei Frauen ist das Gefühl, nicht mehr Gegenstand der männlichen Wünsche zu sein, von besonderer Bedeutung. Doch ergibt die Psychoanalyse von depressiven Geistesstörungen in früherem Lebensalter, daß hier ein ganz ähnlicher Zusammenhang besteht. Das kranke Individuum wehrt die Wahrnehmung dieser inneren Veränderung von seinem Bewußtsein ab. $\mathrm{Zu}$ gleicher Zeit aber macht die Libido eine regressive Umwandlung durch, die wir als besonders tiefgreifend ansehen müssen.

Vertiefte Einblicke in die Struktur der depressiven Psychosen haben mich zu der Annahme geführt, daß bei den Kranken die Libido auf das primitivste uns bekannte Stadium ihrer Entwicklung regrediere, auf jenes Stadium, welches wir als das orale oder kannibalistische bezeichnen lernten.

Spuren einer Rückverwandlung der Libido lassen sich auch unter normalen Verhältnissen im Involutionsalter nachweisen. Bei neurotischen Personen treten die Anzeichen dieses Prozesses mit unverkennbarer Deutlichkeit hervor. Nur handelt es sich im allgemeinen um eine weniger weitgehende Regression, welche taberdies einen ruhigen, allmählichen Verlauf nimmt. Die einschlägigen Erscheinungen sind dem Psychoanalytiker so bekannt, daß einige Hinweise genügen werden.

Im Involutionsalter wird von vielen Personen der Ernährung eine gegenüber früheren Zeiten vermehrte Aufmerksamkeit zugewandt. Mit dem Rückgang der Sexualfunktionen (im engen Sinne des Wortes) wird dem Essen, seiner Auswahl und Beschaffenheit ein gesteigertes Interesse entgegengebracht. Die regressive Tendenz dieses Vorganges zeigt sich deutlich darin, daß häufig die kindliche Vorliebe für das Süße wiederkehrt. Bemerkenswert ist auch, daß gleichzeitig die Darmfunktionen vermehrte Beachtung erfahren. Je mehr die Genitalzone als Lustquelle außer Kurs gesetzt wird, desto mehr wenden sich viele Individuen zur Mund- und Anallust zurück. Nicht selten bemerkt man bei Personen 
im Involutionsalter die wachsende Neigung, die oralen und analen Interessen zum Gegenstand der Unterhaltung zu machen.

Wie erwăhnt, finden sich derartige Erscheinungen bei Neurotikern in gesteigertem Maße. Die Vorstellungen, welche sich mit der Nahrungsaufnahme befassen, nehmen einen hypochondrischen ${ }^{1}$ Charakter an.

Bei den melancholischen Depressionszuständen scheint mir nun die Libido bis auf die früheste uns bekannte Entwicklungsstufe $z \mathfrak{u}$ regredieren. Das soll besagen: der melancholisch Verstimmte richtet in seinem UnbewuBten auf sein Sexualobjekt den Wunsch der Einverleibung. In der Tiefe seines UnbewuBten findet sich die Tendenz, das Objekt zu verschlingen, zu vernichten.

Als ich in meiner früher zitierten Schrift gewisse auffällige Übereinstimmungen in der Struktur der Melancholie und der Zwangsneurose nach wies, hob ich namentlich die Ambivalenz der Gefühlsregungen und das ursprüngliche Vorwiegen des Sadismus im Gefühlsleben der Kranken hervor. Ich sehe mich jetzt genötigt, eine - wie mir scheint - wesentliche Verschiedenheit der beiden genannten Krankheitszustände $z u$ betonen. Unverändert bleibt freilich die Auffassung, daß die Libido des Kranken dem Objekt seines Begehrens vorwiegend feindlich gegenüberstehe und es $z \mathbf{u}$ vernichten trachte. Im Gegensatz zum sadistischen Gelüste des Zwangsneurotikers aber scheint mir die unbewußte Wunschtendenz beim Melancholiker eben dahin zu gehen, diese Vernichtung durch das Auffressen des Liebesobjektes zu vollziehen.

Ein Teil der schweren Selbstanklagen der Melancholischen weist den Kundigen auf solche Triebregungen hin, obwohl dem Kranken der Zusammenhang völlig unbewußt ist.

Diese Selbstvorwürfe haben viel Typisches an sich. Mancher Kranke erklärt sich schlechtweg für den gröBten Verbrecher aller Zeiten, ja, er will das Unglück, alle Sunde erst in die Welt gebracht haben. Wer die Ausdrucksweise der Neurosen und Psychosen kennt, wird den tieferen Sinn solcher hyperbolischen Selbstbezichtigungen unschwer verstehen. Der Kranke wehrt ganz bestimmte Vorstellungen von seinem Bewußtsein ab, die ihm besonders furchtbar und unerträglich wären, und ich glaube mich zu der Annahme berechtigt, daß es sich um die kannibalischen Triebregungen handle.

In gewissen Fällen ist dies unschwer ersichtlich. So flihrt $\mathrm{Kraepelin}$ in seinem Lehrbuch der Psychiatrie unter anderen

1 Ich verweise hier auf $\mathrm{Fr}$ u d $\mathrm{s}$ Ausführungen über die Psychogenese der Hypochondrie. Sie beruht danach auf einer Regression zum NarziBmus, also ebenfalls einem der fruhen Entwicklungsstadien der Libido. (Vgl. F r e ud, „Zur Einführung des Narzißmus". Jahrb. der Psychoanalyse, Bd. VI, 1914.) 
Beispielen an: "Der Kranke hat die ganze Welt ins Unglück gestürzt, die eigenen Kinder gegessen, die Gnadenquelle fortgetrunken." Meist aber geht eine eigentlimliche Entstellung mit den Selbstbezichtigungen des Kranken vor sich.

Mit aller Deutlichkeit spricht die kannibalische Wunschphantasie auch aus einer bestimmten Form depressiver Wahnbildung. In vergangenen Zeiten war die Wahnvorstellung, die ich im Auge habe, außerordentlich verbreitet, doch auch jetzt ist sie noch nicht ganz verschwunden. Es ist die Wahnvorstellung, in ein wildes Tier verwandelt $z$ u sein, das Menschen verschlingt. Der älteren Psychiatrie war diese wahnhafte Selbstanklage so geläufig, daß man nach ihr einen bestimmten Zustand der "Besessenheit" als Lykanthropie bezeichnete. Es war der Wahn, in einen Werwolf verwandelt zu sein.

Hăufiger aber vollzieht sich an den Selbstbezichtigungen der Kranken eine eigentümliche Entstellung. Während der Kranke die Qualität der erstrebten Handlung vor seinem Bewußtsein verleugnet, bezichtigt er sich einer Quantität von Untaten, wie er sie in Wirklichkeit gar nicht begangen haben kann.

Nehmen wir an, daß die tiefsten verdrängten Wünsche des Melancholischen kannibalischer Natur seien, daß seine "Stunden" im letzten Grunde auf ein verbotenes, ja verabscheutes Essen zurluckgehen, so verstehen wir die große Häufigkeit der Nahrungsverweigerung. Der Kranke benimmt sich, als könne nur völliges Vermeiden jeder Nahrungsaufnahme ihn vor der Betătigung seiner verdrängten Regungen bewahren. Zugleich aber verhängt er uber sich diejenige Strafe, welche den unbewußten kannibalischen Antrieben allein adäquat ist: den Tod durch Verhungern.

Auch die Angst der Kranken vor dem Verhungern ist nunmehr leicht zu verstehen. Der Drang nach "Einverleibung", nach dem Auffressen des begehrten Objektes stößt auf mächtige innere Widerstände. Ganz wie andere Triebregungen, so verwandelt auch das kannibalische Verlangen sich in neurotische Angst, wenn seine Verwirklichung auf ubbergroße Widerstände stößt. Es droht ihm das Schicksal, niemals erfillt $\mathrm{zu}$ werden; nie soll die Mundzone jene vom Unbewußten ersehnte Sättigung erfahren. Die Angst vor dem Verhungern ist die Folge.

Ich kann das Thema der melàncholischen Störungen nicht verlassen, ohne noch besonders $z \mathfrak{u}$ betonen, daß ich im obigen nur den Wunschgehalt gewisser depressiver Wahnvorstellungen und die unbewußten Antriebe zu gewissen Eigentümlichkeiten im Verhalten der Melancholischen 
zu klären versucht habe, nicht dagegen die Ursachen der melancholischen Depression uberhaupt. Dieses umfassende Problem zu lösen, lag nicht im Plan der vorliegenden Untersuchung.

\section{VIII.}

Die unbewußten kannibalischen Regungen, welche mir bestimmten Symptomen der depressiven Geistesstörungen zu Grunde zu liegen scheinen, existieren auch beim normalen erwachsenen Menschen. Sie kommen gelegentlich in seinen Träumen zum Vorschein.

Ein Bekannter berichtete mir einmal folgenden Traum. Er sah vor sich eine Schüssel mit Essen, das ihm seine Frau zubereitet hatte. Die Masse in der Schüssel sah wie Gemüse aus: darauf aber lagen als wären sie in dem Gemüse gekocht - die Beine eines Kindes. Sie erinnerten den Träumer während des Traumes an die Glieder seines kleinen Sohnes. Er erwachte mit größtem Entsetzen; aus dem Schlafe aufschreckend, wurde er sich klar darüber, daß er im Begriff gewesen war, im Traume Teile seines eigenen Kindes zu verzehren.

Das Entsetzen, welches dieser Mann bei dem bloßen Gedanken an eine solche Tat empfand, ist das gleiche, das uns alle gegenuber den Gewohnheiten der kannibalischen Völker erfüllt. Noch jetzt kommt es bei gewissen Völkern vor, daß ein Häuptling etwa seinen aufsässigen Sohn tötet oder töten läßt und ihn dann verspeist.

Und in verbreiteten Sagen der Kulturvölker begegnen wir dem Gotte, der seine eigenen Kinder verschlingt. Hier ist nicht der Ort, auf mythologische und ethnologische Einzelheiten einzugehen. Ich verweise darum auf das reichhaltige Material, welches $R a n k$ in seinem Werk uber das "Inzestmotiv" verarbeitet hat, besonders auf das Kapitel, welches dem „Motiv der Zerstückelung“ gewidmet ist. Alle die mannigfaltigen Tatsachen, die ich im obigen zusammengetragen habe, nötigen uns, Freuds Annahme einer frühen kannibalischen Entwicklungsstufe der Libido anzuerkennen. Diese Phase des individuellen Trieblebens entspricht ganz der kannibalischen Kulturstufe, welche sich bei gewissen Völkern bis auf den heutigen Tag erhalten hat, die aber auch von den "Kulturvölkern" auf dem langen Wege ihrer Entwicklung einmal passiert wurde. Und wie gewisse psychische Produkte des gesunden und kranken Einzelwesens an jenes fruhe Stadium seiner Kindheit erinnern, so bewahrt auch das Volk in Sagen und Märchen die Spuren seiner entferntesten Vergangenheit. 


\section{Über Ejaculatio praecox ${ }^{1}$.}

Unter den Störungen der männlichen Potenz kommt in der nervenärztlichen Praxis keine so häufig zur Beobachtung wie die Ejaculatio praecox. Der Vorgang selbst ist nicht nur Ärzten, sondern auch Laien wohlbekannt: die Samenentleerung tritt beim Geschlechtsakt vorzeitig, d. h. alsbald nach der Immissio penis oder gar schon vorher ein, während zugleich die Erektion schwindet. Diese Beschreibung wird jedoch der Affektion nur ganz im Groben gerecht. Wohl hat die Ejaculatio praecox auch eingehendere Bearbeitungen gefunden, doch auch diese erfassen ihr eigentliches Wesen nicht; am wenigsten klären sie uns luber die Entstehung des Leidens auf.

In der psychoanalytischen Literatur hat die Ejaculatio praecox bisher keine gesonderte und gründliche Bearbeitung gefunden. Sie wurde bisher nur mit den anderen Störungen der Potenz gemeinsam behandelt. Dies gilt auch für die Schriften von Steiner und Ferenczi. Der erstere Autor gibt eine gedrängte Ubersicht der psychoanalytischen Erfahrungen auf diesem Gebiet. Eingehender befaßt sich F e re n c zi mit dem Ursprung der Störungen. In seinem Aufsatz kommen die unbewußten Ursachen der Impotenz zur vollen Geltung. Eine spezielle - Untersuchung der Ejaculatio praecox fehlt aber auch hier.

Und doch enthält die psychoanalytische Literatur bereits die Grundlagen, auf 'welchen eine genauere Untersuchung des Gegenstandes fußen kann. Neben den Werken Freuds hebe ich hier wichtige Mitteilungen von $\mathrm{Sadger}{ }^{2}$ hervor; ich werde im folgenden auf diese Quellen des öfteren zu verweisen haben.

Ich hatte Gelegenheit, die Ejaculatio praecox bei einer Reihe von Neurotikern zu behandeln. Es ist nicht meine Absicht, hier den einen oder anderen dieser analysierten Falle zur Darstellung zu bringen; vielmehr sollen die Ergebnisse meiner einschlägigen Psychoanalysen, soweit ich ihnen allgemeine Guiltigkeit zusprechen darf, in gedrăngter Kürze zusammengefaßt werden.

1 Aus „Internationale Zeitschrift für ärztliche Psychoanalyse *, IV. Jahrgang, 1916.

${ }^{2}$.Über Urethralerotik*. Jahrb.f. psychoanalyt. Forschungen. II. Bd. 1910. S. 409 u. ff. 


\section{Die Urethra als bevorzugte erogene Zone.}

Wie schon erwähnt wurde, ist die ubliche Beschreibung der Ejaculatio praecox nach verschiedenen Richtungen unvollständig. Hat man Patienten, welche sich gut beobachten, und folgt man aufmerksam ihren Schilderungen und ihren freien Assoziationen, so wird man mit einer Tatsache bekannt, die keine gentigende Beachtung gefunden hat. Man erfährt nämlich, daß bei den Kranken die Samenentleerung nicht durch rhythmische Ausstoßung erfolgt, sondern daß ein kraftloses Abfließen stattfindet. Geschieht demnach der Vorgang nicht unter energischen aktiven Körperbewegungen und maximaler Erektion noch unter rhythmischen Zusammenziehungen der Dammuskulatur, und erfolgt das Abfließen des Samens gar schon "ante portas", so erinnert nur noch das Sperma als Stoff an die normale Entleerung der Geschlechtsprodukte. Um so auffalliger wird die Ähnlichkeit der Ejaculatio praecox mit einem anderen physiologischen Vorgang: der Harnentleerung. Diese geht bei körperlicher Ruhe, nicht erigiertem Gliede und unter gleichmäBigen (nicht rhythmischen) muskulären Zusammenziehungen vor sich.

Man kann die Ejaculatio praecox somit als eine Verquickung zweier Prozesse auffassen: Hinsichtlich des entleerten Stoffes ist sie eine Ejakulation, hinsichtlich des Modus der AusstoBung dagegen eine Miktion.

Es ist überraschend, mit welcher Regelmäßigkeit die Assoziationen der Patienten früher oder später zu diesem Ergebnis führen. Ehe man zu ihm gelangt, erfährt man eine Fülle von Tatsachen, die alle auf einen besonderen Lustwert der Harnentleerung und eine stark betonte Erogeneität der Urethra bei dieser Gruppe von Neurotikern schließen lassen ${ }^{1}$.

Man wird aber einen erheblichen Unterschied zwischen Ejaculatio praecox und Harnentleerung nicht ubersehen durfen, auf welchen man ebenfalls durch die Assoziationen der Patienten geführt wird. Die Urinentleerung erfolgt jenseits der fruhen Kindheit zwar unter dem Zwange eines Reizes, der auf die Dauer nicht zu tuberwinden ist; der Zeitpunkt der Entleerung ist jedoch in ziemlich weitem Umfang von der Willkür abhängig. In gewissem Umfang gilt das gleiche auch für die normale Ejakulation.

Die vorzeitige Ejakulation hingegen ist im wesentlichen unabhängig vom Willen des Patienten. In seinem Bewußtsein wünscht er sich den normalen Ablauf des Geschlechtsaktes. Von dem vorzeitigen

:Vgl. hiezu S a d gers zitierte Abhandlung. 
Eintreten der Samenentleerung wird er jedesmal wieder uberrascht, wie von einem Ereignis, das sich übersturzt vollzieht. Viele Patienten schildern, daß sie im Augenblick der vorzeitigen Entladung ein Schamgefühl empfinden, das sich mit Angst oder Herzklopfen verbindet.

Die Ejaculatio praecox findet also wider den bewußten Willen des Individuums statt. Erinnerte uns der Vorgang zunächst an die normale Harnentleerung, so werden wir diese Anschauung jetzt etwas modifizieren müssen. Wir werden zum Vergleich die Form des Urinabganges heranziehen, wie sie der ersten Kindheit eigen ist. Das passive Fließenlassen des Samens, wie es bei der Ejaculatio praecox geschieht, lehnt sich in vollkommener Weise an die dem Willen entzogene Urinentleerung der ersten Kindheit an, die sich bekanntermaßen bei Neurotikern bis in spätere Lebensperioden in größerem oder kleinerem Umfang $z \mathfrak{u}$ erhalten vermag.

Die freien Einfälle des Patienten pflegen ein Material zu liefern, das uns in eindringlicher Weise auf diese Lösung hinfuhrt. Folgen wir ihnen ohne jedes Vorurteil, so erhalten wir anamnestische Daten, die einander von Fall zu Fall erstaunlich ähneln. Wir erfahren - abgesehen von solchen Reminiszenzen, die sich auf starke Lustbetonung der willkürlichen Harnentleerung in der Kindheit beziehen —, daß die Kranken schwer an Reinlichkeit zu gewöhnen waren, daß sie selbst bis ins erwachsene Alter öfter Urin in kleineren oder größeren Mengen unfreiwillig verloren, daB sie bis in spăte Kindheitsjahre an Bettnăssen litten, daß sie auf Erregungen aller Art sehr leicht mit einem unwiderstehlichen Harndrang reagieren. Die gleichen Menschen, welche die normale Beherrschung der Blasenfunktion erst spät oder überhaupt nur unvollkommen erwarben, neigen auch zum vorzeitigen, ubersturzten Samenabfluß. Sie geben auch an, daß die körperliche Empfindung der Ejaculatio praecox mit der des unbeherrschten Urinabflusses für sie identisch sei. Auf andere, sehr wichtige Kindheitserinnerungen wird später einzugehen sein; sie beziehen sich auf die exhibitionistische Lust an der Urinentleerung vor den Augen einer anderen Person und auf deren Hilfeleistung bei dieser Verrichtung.

Die in Rede stehenden Neurotiker sind nach dem bisher Gesagten auf einem bestimmten Punkt der Libido-Entwicklung stehen geblieben. Sie ziehen in infantiler Weise Lust aus dem Abfließenlassen körperlicher Produkte. Die Ejaculatio praecox hat jedoch für sie gleichzeitig Lustund Unlustbedeutung. Außer stande, auf dem Wege kraftvoller männlicher Aktivität die höchste Lust zu erwerben, sind sie der für sie stärksten Lust des passiven Fließenlassens hingegeben. Anderseits ist die 
Ejaculatio praecox für sie die Quelle starker Unlust. Sie leiden unter quälenden Insuffizienzgefühlen, empfinden beim Eintritt der vorzeitigen Ejakulation nervöse Angst, nicht selten auch etwas wie Selbstvorwürfe. Dieser Zustand der Ambivalenz muß besonders hervorgehoben werden, wie in der Regel der Lustcharakter der Ejaculatio praecox ganz übersehen wird. Bei dem einen Patienten ist die Lustbetonung, bei dem anderen die Unlustbetonung vorwiegend.

Schon aus dem bisher Gesagten ist ersichtlich, daB die Libido der Neurotiker, welche an vorzeitiger Ejakulation leiden, der durchgreifenden männlichen Aktivität ermangelt. Wir werden hier mit einer weiteren Eigentümlichkeit im Geschlechtsleben dieser Neurotiker bekannt; wir müssen aber zunächst von der Verfolgung dieser Spur absehen und uns der Exkretionslust der Patienten nochmals zuwenden, werden aber alsbald die verlassene Spur wieder auffinden.

Ist die Urethrallust übermäßig betont, so wird diesem "Zuviel “ ein

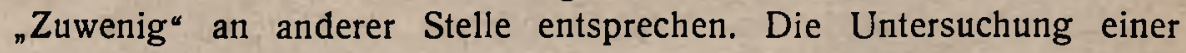
Reihe von einschlägigen Fällen ergibt - trotz vieler noch zu erwähnender individueller Abweichungen -, daß bei allen Patienten die Genitalzone (im strengen Sinne des Wortes)nichtzur Leitzone geworden ist. Es muß hier an die grundlegenden Ausfuhrungen Freuds erinnert werden, wie sie schon in der ersten Auflage der "Drei Abhandlungen zur Sexualtheorie" enthalten sind. Beim männlichen Kinde wird mit dem Eintritt der Pubertăt der Primat der Genitalzone aufgerichtet, indem die ubrigen erogenen Zonen dieser tributär werden. Sie liefern die Vorlust, während die Reizung der Genitalzone (insbesondere des Glans penis) zur Befriedigungslust führt. Beim weiblichen Geschlecht muß die höchste Erogeneität im Pubertätsalter auf die Vagina ubergehen; hier ist die Etablierung der Leitzone oft dadurch gestört, daB von der Kindheit her die vorwiegende Erregbarkeit der Clitoris bestehen bleibt, desjenigen Organes also, welches das weibliche Analogon des Penis darstellt. Durch Übergang der stärksten erogenen Bedeutung von der Clitoris auf den Scheideneingang gibt, wie Freud es ausgedrlickt hat, die weibliche Sexualität einen männlichen Zug auf. Bleibt jedoch der Vorrang der Clitoris erhalten, dann ist die Unerregbarkeit des Weibes beim Geschlechtsakt, die sogenannte Frigidität, die Folge.

Tatsächlich ergibt sich nun in sehr vielen Fällen von Ejaculatio praecox, daB bei den Patienten die Oberfläche der Glans penis $\mathrm{m}$ a n g e l h a f t e r r e g b a r ist. Sehr häufig ist bei ihnen die Intoleranz gegen die Verwendung von Kondoms; die deckende Schicht nimmt den Nervenendigungen derSchleimhaut auch noch den Rest von Erregbarkeit. 
Ein Teil der Fälle scheint dieser Erfahrung auf das schroffste zu widersprechen. Es sind diejenigen Neurotiker, bei welchen die geringste Genitalberührung mit dem weiblichen Körper - besonders aber die geringste manuelle Berührung von seiten des Weibes - genügt, um einen überstürzten Samenabfluß hervorzurufen. Diese Übererregbarkeit der Genitalzone ist aber keineswegs ein Zeichen ihres Primates, sondern im Gegenteil der Ausdruck ihrer Ohnmacht. Die eigentlichen männlichen Genitalfunktionen - Erektion, Immission, Reibung der weiblichen Teile - kommen vollständig in Wegfall. Ehe es auch nur zum Beginn der Erektion kommt, tritt ein Samenabfluß ein, der von uns bereits als einem Urinabgang gleichwertig erkannt ist. Erst später wird uns dieser Vorgang restlos verständlich werden.

Während also bei der weiblichen Frigidität die Glans clitoridis sozusagen alle Erregbarkeit an sich gerissen hat, ist bei der Ejaculatio praecox des Mannes das Umgekehrte der Fall. Die Glans penis hat ihre normale Erregbarkeit verloren; die Sexualität dieser Männer hat damit ihren eigentlich männlichen Charakter e inge b ü $B$ t.

Ejaculatio praecox und weibliche Frigidität entsprechen einander sogar in noch weiter gehendem Maße.

Neben der mangelhaften genitalen Empfindlichkeit besteht nämlich bei den Patienten häufig eine besondere Erogeneität des Dammes und der rückwärtigen Partien des Skrotums. Diese Gegend entspricht aber entwicklungsgeschichtlich dem Introitus vaginae und seiner Umgebung. Das Verhältnis zwischen Ejaculatio praecox und weiblicher Frigidität wäre nunmehr so zu formulieren: Die dem Geschlecht entsprechende Leitzone hat die ihr zukommende Bedeutung an diejenige Körperpartie abgegeben, welche das Äquivalent der Leitzone des anderen Geschlechtes darstellt.

Derjenige Teil der männlichen Harnröhre, in welchem die Lustempfindungen der Ejaculatio praecox lokalisiert sind, liegt ubrigens im $\mathrm{D}$ a m m. Besondere Beachtung verdient ferner die Muskulatur des Dammes, die der Samenausstoßung dient. Ihre Funktion vollzieht sich normalerweise in Form rhythmischer Zusammenziehungen; bei vorzeitiger Ejakulation findet dagegen ein Erschlaffen statt, ganz wie bei der Blasenentleerung. Es ist nun bemerkenswert, daß die Muskeln des Dammes sich bei einem Teil unserer Patienten gelegentlich spontan kontrahieren. Dieser Vorgang aber hat die Wertigkeit eines vom Bewußtsein unabhängigen neurotischen Symptoms. Ich meine die von den Patienten öfter geschilderten $\mathrm{Dam} \mathrm{m} \mathrm{krăm} \mathrm{p}$ fe.

Der Auffassung des Ejaculatio praecox, wie sie sich uns bisher 
auf Grund psychoanalytischer Untersuchungen gestaltet hat, scheint eine Tatsache $\mathbf{z u}$ widersprechen. In der weitaus überwiegenden Zahl der Fälle tritt nämlich die vorzeitige Ejakulation nur beim Versuch des Geschlechtsaktes, nicht aber bei masturbatorischer Reizung ein. Man darf fragen, warum in diesem Falle jenes von uns angenommene Kompromiß zwischen Ejakulation und Miktion nicht zustande kommt. Wir können diesem Einwand vorläufig mit der Vermutung begegnen, daß eben das Zusammentreffen mit dem Weibe die neurotische Störung hervorrufe; es erwächst uns dann aber die Aufgabe, die Einstellung der uns beschäftigenden Neurotiker zum weiblichen Geschlecht genauer zu untersuchen.

\section{Die Schicksale der männlich-aktiven Triebregungen.}

Die Neurotiker, welche an vorzeitiger Ejakulation leiden, kann man in zwei Gruppen teilen, die freilich nicht scharf gegeneinander abzugrenzen sind. Man findet das Symptom zunächst bei solchen Männern, deren gesamtes Wesen schlaff, energielos, passiv, kurz unmännlich erscheint. Anderseits begegnen wir ihm bei erethischen, überlebhaften, beständig hastenden Männern. Der Widerspruch, der hier vorzuliegen scheint, löst sich für den Psychoanalytiker unschwer auf. Jede Aktivität, die nur in Hast und Oberstürzung zu ihrem Ziele zu gelangen vermag, ist durch Widerstande bedroht. Der hastende Neurotiker ist auf der Flucht vor den in ihm liegenden unbewußten Widerständen; er muß seine Vorsätze in fieberhafter Eile zur Ausführung bringen, ehe seine Widerstände zum Durchbruch kommen und ihn zu völliger Resignation zwingen. Der schlaffe Neurotiker hat den Kampf gegen diese Kräfte aufgegeben; der erethische setzt sich ihnen gegentuber noch zur Wehr.

Männer mit vorzeitiger Ejakulation sind solche, welche mit starken - teils unbewußten, teils bewußten - Widerständen gegen die spezifisch männlichen, aktiven Leistungen behaftet sind.

Die Neurotiker mit vorwiegender Schlaffheit äußern in der Regel einen ganz bewußten Widerwillen gegen jede geschlechtliche Aktivität; $\mathrm{ja}$, sie haben das direkte Verlangen, die weibliche Rolle $\mathrm{zu}$ libernehmen. Ein solcher Patient, den ich beobachtete, bevorzugte die Rolle des Succubus und gab für diese Vorliebe einen rationellen Grund an: wenn er ein Mädchen bezahle, wolle er nicht obendrein noch die Anstrengung haben; vielmehr solle das Mädchen für das Geld auch "arbeiten". Es ist klar, daß Neurotiker mit diesem Höchstmaß von 
Bewegungsunlust nicht eben günstige Objekte der ärztlichen Behandlung sind, zumal dann, wenn sie für ihre Abnormität bewußt Partei nehmen. Die geschlechtliche Befriedigung ohne aktive Anstrengung zu erreichen, ist ihr Hauptinteresse.

Die erethischen, in dauernder Hast lebenden Neurotiker erblicken meist im Koitus eine lästige $\mathrm{Aufgabe}$, di e $\mathrm{schnell} \mathrm{abgemacht}$ werden $m u B$. Sie verlieren ihre nervöse Hast auch nicht im Zusammensein mit dem Weibe. Unbewußte Faktoren bewirken dann, daB für diese Neurotiker der Geschlechtsakt sein uberstürztes Ende erreicht, ehe er eigentlich begonnen hat.

Der Widerwille gegen aktive, motorische Leistungen greift auf andere Gebiete über. Ich erwähne nur das Verhalten solcher Patienten gegenüber dem Sport. Viele haben einen ausgesprochenen Widerwillen gegen jede Muskelarbeit; andere betreiben einen Sport mit übertriebenem Ehrgeiz und in tabereifriger, überhasteter Art, um bei einem Mißerfolg plötzlich ganz zu resignieren.

Die Schlaffheit und Passivität dieser Neurotiker ist aber, wie jede Psychoanalyse aufs neue lehrt, eine reaktive Erschein ung. Es läßt sich erweisen, daß sie an die Stelle allzu heftiger, sadistischgewalttätiger Antriebe getreten ist.

Die Neigung zur Ausfälligkeit in Worten, zum Jähzorn, zu gewalttätigen Handlungen, ist bei diesen Neurotikern außerordentlich groß, soweit sie nicht gelähmt wird durch einen anderen, ebenfalls höchst bezeichnenden Charakterzug: die Feigheit. Übertriebene Zornmütigkeit und Lähmung der normalen männlichen Angriffslust finden sich hier in naher Nachbarschaft beieinander. Auch das bei dieser Gruppe von Neurotikern häufige Nebeneinander von ubergroßem Ehrgeiz und schweren Arbeitswiderständen mag an dieser Stelle erwähnt sein.

Mit der soeben gegebenen Schilderung haben wir zwar eine Reihe von wichtigen Erscheinungen berüht, welche sich bei Neurotikern neben der Ejaculatio praecox vorzufinden pflegen, wir sind aber nahe an der Oberfläche der Erscheinung geblieben. Lassen wir uns von den Assoziationen der Patienten leiten, so erfahren wir, daB ihre Libido ursprünglich keineswegs einer sadistischen Komponente entbehrte. Im Gegenteil lehrt uns die Psychoanalyse in den meisten Fällen, daB neben der unmännlich-passiven oder uberhastet-aktiven Einstellung zum Weibe im Unbew uBten der Kranken eine andere, aggressiv-grausame Einstellung $z$ u $m$ Weibe besteht. Aus Träumen und anderen Phantasieprodukten der Kranken erfahren wir sehr häufig von der Vorstellung, das Weib durch den Koitus zu töten. In diesen Phantasien ist der Penis die Waffe des Sadismus. 
Die reaktive Umwandlung solcher Triebregungen führt $z u$ einem Ergebnis, welches wir bei den Patienten oft genug konstatieren können. Das männliche Genitale wird seiner Gefährlichkeit beraubt; es darf dem Weibe gegenüber nicht mehr in den Zustand geraten, in welchem es dem Sadismus dienen könnte. Vorzeitige Erschlaffung und Ejakulation beseitigen diese Gefahr. Darüber hinaus haben viele der Patienten vor Ausfuhrung des Geschlechtsaktes eine ausgesprochene Angst, dem Weibe Schmerzen zuzufügen. Ein Rest von Potenz bleibt ihnen nur, wenn sie der vollkommenen Einwilligung des Weibes sicher sind; ihre aggressiven Regungen sind dermaßen terdrückt, daß ihnen jede sexuelle Initiative im strengen Sinne des Wates abgeht. Manche vermögen uberhaupt keinerlei Beziehungen zus weiblichen Personen aus eigener Initiative anzuknüpfen; andere'sind zwar fähig, eine Beziehung einzuleiten, verlieren aber ihre Aktivität in dem Augenblick, da sie zur körperlichen Aktion übergehen sollen.

Einer meiner Patienten war im Anfang seiner Ehe im allgemeinen impotent. Er fühlte eine feindlich-aggressive Einstellung $\mathrm{zu}$ seiner Frau. Der geringste Streit mit ihr hatte bei ihm völlige Impotenz zur Folge. Er beobachtete jedoch bei sich eine verhältnismäßig gute Potenz, wenn er sich mit seiner Frau gerade a usgesöhnt hatte. War also für den Augenblick der äußere Anlaß zur Feindseligkeit und Rache geschwunden, so war ihm eine vorübergehende geschlechtliche Aktivität gegönnt.

Die Assoziationen der Kranken führen aber weiter zu dem Ergebnis, daß fü ihr Unbewußtes die Ejaculatio praecox das extreme Gegenteil des Tötens bedeutet. An die Ejaculatio praecox knlipft sich mit großer Häufigkeit die unbewußte, nicht selten sogar bewußte Vorstellung des eigenen Todes. Sie ist ein kraftloses Ersterben; manche Kranke gebrauchen den Ausdruck, daß sie sich hinschwinden, zerfließen fuhhlen. Bezeichnend ist ein nicht selten mit der vorzeitigen Ejakulation verbundenes Ohnmachtsgefühl.

Der Verlust der männlichen Aktivität zeigt sich des weiteren in dem Affekt der Angst, welcher die Ejaculatio praecox häufig begleitet. Namentlich diejenigen Patienten, deren Leben sich in dauernder Hast abspielt, produzieren solche Angst.

Ihre Hast und Angst erinnert uns von neuem an das Verhalten frigider Frauen, die nach unserer Erfahrung sich ständig in Hetze befinden. Die diesen Frauen eigentümliche Angst, "nicht fertig zu werden", die sich auf alle Aufgaben des tăglichen Lebens ausdehnt, findet sich bei unseren männlichen Neurotikern wieder. Sie erledigen ihre geschlechtlichen Funktionen in Hast, als drohte jeden Augenblick 
eine Störung. Diese Angst vor dem Gestörtwerden ist im Unbewußten der Kranken eng verknüpft mit ihrer Einstellung zum Vater. Sie ängstigen sich vor dem allsehenden Auge des Vaters und vor seiner strafenden Hand. Wir befinden uns hier auf gut bekanntem Boden; die Kastrationsangst, deren Bedeutung im Seelenleben des kleinen Knaben und im Unbewußten des erwachsenden Mannes F reud erkannt hat, entfaltet ihre Wirkung auch in der Psychogenese der Ejaculatio praecox.

Die nämlichen Patienten empfinden eine ausgesprochene Angst vor dem weiblichen Gêritale. Es trägt für sie den Charakter des Unheimlichen. Regelmäßig bestätigt uns die Psychoanalyse, daß der Mangel des Penis beim Weibe es war, der die Kastrationsangst ursprünglich hervorgerufen hat. Die körperliche Annäherung an das Weib erweckt dieses Grauen in den Patienten jedesmal von neuem.

Dieser Angst nahe verwandt ist eine zweite : durch den Geschlechtsakt selbst den Penis zu verlieren. Nicht selten bringen die Patienten dem Arzt die Mitteilung von einer Angst entgegen, die seit dem Pubertätsalter nicht von ihnen gewichen ist. Es handelt sich um die Phobie, den Penis nicht wieder aus dem Körper des Weibes zuriackziehen zu können, sondern ihn darin zurlucklassen $z \mathfrak{u}$ müssen. Die Angst lehnt sich an eine der infantilen Sexualtheorien an, welche in der Pubertät neu belebt werden. Nach dieser Theorie beraubt das Weib bei der ersten und einzigen Vereinigung den Mann seines Genitalorgans durch Abreißen oder Einklemmen desselben. Die Angst vor einem solchen Vorgang liefert einen weiteren Beitrag zur Erklärung der Tatsache, daß bei unseren Patienten vielfach zunächst Libido und Erektion vorhanden sind, daß aber gleich nach der Immissio oder schon im Augenblick der körperlichen Annäherung die Erektion schwindet. Der Patient bringt sich aus solchen unbewuBten Motiven im letzten Augenblick in Sicherheit; bewußt reagiert er auf diesen unmännlichen Rückzug mit lebhaften und peinigenden Insuffizienzgefühlen.

In einigen Fällen lieferten die Assoziationen der Patienten den Beweis, daß sie sich durch den Vorgang der Ejaculatio praecox vor den Augen des Weibes gleichsam selbst entmannten. Phantasien dieser Art werden später ihre Aufklärung finden.

Die mangelnde sexuelle Aktivität unserer Patienten findet ihren Ausdruck noch in anderer Form. Es ist uns geläufig, daß neurotische Widerstände gegen eine Verrichtung sich oftmals als Ung eschickli chkeit bei ihrer Ausfuhrung kundgeben. Neurotiker, die mit vorzeitiger Ejakulation behaftet sind, legen beim geschlechtlichen Verkehr stets eine deutliche Ungeschicklichkeit an den Tag. Typisch ist für sie 
die Unfähigkeit zur Immissio penis ohne Hilfe des weiblichen Partners. Hauptsächlich aus diesem Grunde fürchten sie den Verkehr mit einem sexuell unerfahrenen Weibe, das ihnen in solcher Weise entweder nicht beispringen kann, oder dem sie eine solche Hilfeleistung nicht zumuten dürfen. Eine weitere Erklärung dieses Verhaltens wird sich ubbrigens noch späterhin ergeben.

\section{Der Narzißmus als Quelle der Sexualwiderstände.}

Die bisherige Untersuchung hat keinen Zweifel darüber gelassen, daß bei unseren Patienten die Entwicklung der Libido eine Hemmung erfahren hat. Sie haben die normale Einstellung des Mannes zum Weibe nicht erreicht; ihre Sexualität weist vielmehr eine große Zahl infantiler Züge auf. Genauer gesagt: sie empfinden insoweit normal, daB ihre Libido sich bewußtermaßen - wenn auch nicht ausschließlich, so doch in der Hauptsache - auf die normalen Geschlechtsbeziehungen zum Weibe richtet. Wohl ist einem Teil der Patienten schon die Ankntipfung mit dem Weibe sehr erschwert; diese Eigentümlichkeit teilen sie aber mit anderen Neurotikern. In einer abnormen, für sie spezifischen Weise reagieren sie erst in dem Augenblick, da sie ihre sexuelle Aktivität im strengen Sinne des Wortes zeigen sollen. Gegen ihren bewußten Willen macht sich dann eine Störung bemerkbar, die von unbewußten libidinösen Gegenströmungen herrührt. Wir haben bereits erfahren, daß diese Strömungen infantiler Art sind. Ihre Tendenz ist, den Geschlechtsakt im eigentlichen Sinne des Wortes nicht zur Ausführung kommen zu lassen. Statt seiner findet eine kraftlose, dem unwillkürlichen Harnabfluß des Kindes ähnliche Samenentleerung statt. Das aktiv-motorische Verhalten des Mannes ist durch gänzliche Passivität ersetzt.

Es ergibt sich dann die Frage, welcher Art und Herkunft die unbewußten Widerstände seien, durch welche das Individuum gehindert wird, sich normal zum anderen Geschlecht einzustellen. Meine Psychoanalysen verweisen in dieser Hinsicht tibereinstimmend auf den Narzißmus; nicht im Sinne einer völligen Regression der Libido auf dieses infantile Stadium, so wie sie F r e u d für die paranoischen Erkrankungen nachgewiesen hat. Vielmehr handelt es sich um störende Einflüsse verdrängter narzißtischer Tendenzen, die $z \mathfrak{u}$ keiner völligen Herrschaft gelangen. Ihre Macht beweisen sie immerhin dadurch, daß sie dem Individuum gewisse Kompromisse aufzwingen, $z \mathfrak{u}$ denen auch die uns beschäftigende Potenzstörung gehört.

Bei einem Teil der an Ejaculatio praecox Leidenden legt schon die flüchtige Beobachtung diese Auffassung nahe. Unsere Patienten 
lassen schon in ihrer Kleidung und ihrem Auftreten ein ungewöhnliches $\mathrm{MaB}$ von Eitelkeit erkennen. Die geringste kritische Bemerkung eines anderen Menschen kann sie in maBlose Heftigkeit versetzen. Sie verlangen, von ihrer Umgebung bewundert zu werden, sind tiberhaupt von einem krankhaften Ehrgeize erfüllt.

Die Psychoanalyse deckt den Narzißmus der Patienten vollends auf. Sie erweist regelmäBig eine ganz mangelhafte Objektliebe; sein eigentliches Liebesobjekt ist der Kranke selbst. Und ganz entsprechend den von Fre u d mitgeteilten Erfahrungen finden wir bei jedem unserer Kranken eine besonders hohe und mit abnormen Affektäußerungen verbundene Wertschätzung des Penis. Sie äußert sich unter anderem in der libermäßigen Angst vor Verlust oder Beschädigung des Organs', von der bereits die Rede war.

Die Psychoanalyse jedes Falles von Ejaculatio praecox macht uns aber mit einer Fülle anderer Erscheinungen des Narzißmus bekannt. Um sie richtig zu würdigen, bedarf es eines kurzen Rlickblicks auf die entsprechenden Phänomene im Kindesalter.

Das Kind erlebt die ersten Befriedigungen seiner Libido bei Gelegenheit körperlicher Funktionen, wie der Nahrungsaufnahme, und der Exkretionsvorgänge. Seine erste Sympathie wendet das Kind den Personen $\mathrm{zu}$, welche ihm Nahrung, Pflege usw. angedeihen lassen. $\mathrm{Da}$ sie sich hiebei mit seinem Körper befassen müssen, rufen sie beim Kinde gleichzeitig durch Reizung erogener Zonen Lustempfindungen hervor. Das Kind nimmt diese letzteren wie Geschenke entgegen.

Dieses Stadium der Libidoentwicklung, in welchem das Kind sich selbst der Mittelpunkt seiner noch engen Welt ist und in welchem es Liebesbeweise von anderen Personen ohne Gegengabe in Empfang nimmt, bezeichnen wir als Narzißmus.

Die Beziehungen zum Liebesobjekt entwickeln sich weiter, indem das Kind anfängt, der anderen Person vom Seinigen zu geben. Die Produkte des eigenen Körpers - sie sind in der Vorstellung.des Kindes T e il e des Körpers - stellen in erster Linie die Münze dar, mit welcher das Kind bezahlt. Diese Stoffe unterliegen der narzißtischen Überwertung. Hier sei nur ein Beispiel gegeben. Es ist eine öfters zu bestätigende Erfahrung, daß ein Kind, wenn es etwa im Familienkreise von Hand zu Hand gereicht wird, mit einer den Angehörigen rätselhaften Auswahl immer eine bestimmte Person mit seinem Urin benäßt. Das ist einer der primitivsten Liebesbeweise, weit ursprünglicher als KuB oder Umarmung, die das Kind erst durch Nachahmung lernt. Wir werden an die Begrüßungsformen mancher primitiver Völker 1 F r u d, Zur Einführung des Narzißmus. Jahrb. der Psychoanalyse, VI. 1914. 
erinnert. Gibt man einem anderen Menschen von den eigenen Körperprodukten, z. B. Speichel, so will das bedeuten: ich gebe dir vom Meinigen, das mir doch kostbar sein mub, also meine ich es gut mit dir!

Wir konnten aus der Vorgeschichte unserer Patienten den besonderen Lustwert der Harnentleerung feststellen, ferner aber auch die uber das gewohnte Maß des kindlichen NarziBmus hinausgehende Wertschätzung des Penis. Der ersteren Tatsache liegt augenscheinlich eine konstitutionelle Eigentümlichkeit zu Grunde. Wird nun schon normalerweise im Stadium des kindlichen NarziBmus dem Penis eine hohe Wertschătzung zu teil, die sich sowohl auf die Beruhhrungslust als auch auf die Exkretionslust grtandet, "so sind die möglichen Folgeerscheinungen einer konstitutionell verstärkten Urethral1 u st einleuchtend. Das Individuum wird zu einer Zeit, da es sich längst der normalen Objektliebe zugewandt haben sollte, einen starken Anlaß zum Verweilen im Narzißmus in sich tragen. Ferner wird sich in den Vorstellungen des Kindes die Uberwertung des Penis als Organ der Harnfunktion in besonderem Maße fixieren. Tritt später an das Organ die Anforderung der eigentlichen Geschlech tsf unktion heran, so weigert es sich nun dieser. Die Folge ist dann jenes KompromiB, als welches wir die Ejaculatio praecox bereits erkannt haben.

Erst jetzt vermögen wir das den Patienten unbewußte Sexualziel der Ejaculatio praecox zu begreifen. Das normale Sexualziel ist eine körperliche Vereinigung mit dem Weibe; der Mann hat dabei eine motorische Leistung $\mathrm{zu}$ vollbringen, die ihm selbst, gleichzeitig aber auch dem Weibe, Befriedigung bringen soll. Die Tendenz der Ejaculatio praecox ist völlig anderer Art.

Die Libido unserer Patienten verharrt in weitem Umfang im Stadium des NarziBmus. Wie der kleine Knabe die Mutter mit seinem Urin benäBt, den er noch nicht zu halten vermag, so be nä Bt der Neurotiker durch vorzeitige Ejakulation das Weib, in welchem wir nunmehr mit voller Deutlichkeit den Mutterersatz erkennen.

Die Mutter oder Pflegerin ist genötigt, den kleinen Knaben am Genitale $z u$ beruhren, sowohl wenn sie ihm zur Urinentleerung behilflich ist, als auch beim Waschen und Trocknen des Körpers. Die Lust dieser Berthhrung offenbaren uns die aus dem UnbewuBten schöpfenden Assoziationen der Patienten. Eines ihrer unbewußten Sexualziele ist es, vom Weibe am Genitale berluhrt $\mathrm{zu}^{\mathrm{w}}$ werden ${ }^{1}$ und danach in einer der Urinentleerung ähnlichen Weise zu ejakulieren.

${ }_{1}^{1}$ Hier ist wieder auf $\mathrm{S}$ adg ers Ausfuhrungen zu verweisen. 
Auch hier wird die mutterliche Bedeutung des Weibes durchsichtig. Namentlich aber wird uns nun eine früher erwähnte Eigentlimlichkeit unserer Patienten verständlich; ihre Neigung, sich vom Weibe bei der Immissio manuelle Hilfe leisten zu lassen. Die lustvolle Berührung des Penis war einer der frühen und bedeutungsvollen Liebesbeweise von seiten der Mutter. Der an vorzeitiger Ejakulation Leidende möchte, wie wir bereits wissen, nicht lieben, sondern nur Liebe entgegennehmen. Sein Unbewußtes versucht, zu diesem Zwecke die Wege der frühen Kindheit wieder gangbar zu machen.

Unter diesen Wegen ist einer, den wir bisher nicht ins Auge gefaßt haben, auf den wir aber durch die Einfälle der Patienten mit Nachdruck hinweisen werden.

Die Abgabe von Produkten des eigenen Körpers ist nicht die einzige Liebesäußerung des Kindes im Stadium des Narzißmus. Eine andere Form des Liebesbeweises und des Liebeswerbens ist die Exhibition.

Besonders in der zweiten Hälfte des dritten und in der ersten Hälfte des vierten Lebensjahres pflegen kleine Knaben gern vor der Mutter zu exhibieren, namentlich bei Gelegenheit der Urinentleerung, zu der sie nicht mehr der mütterlichen Hilfe benötigen wie in früherer Zeit. Ein Knabe, dessen Urethralerotik keineswegs die normalen Grenzen überschritt, fragte in dem genannten Alter öfter seine Mutter, ob er ihr seinen Penis zeigen solle. Er gebrauchte für diesen Körperteil ubrigens eine selbsterfundene Bezeichnung. Hatte er Urin entleert, so fragte er öfters, ob es "viel" sei. Hier trat der-Narzißmus, das Bedürfnis, für seine Leistung bewundert zu werden, mit besonderer Deutlichkeit hervor. Als die Eltern einmal mit dem Kleinen in einem Seebad weilten, hatte er Lust daran, sein Bedürfnis in einem Augenblick zu verrichten, wenn gerade eine Flutwelle herankam. Auf eine Frage, warum er das tue, gab er zur Antwort: „Damit es recht viel Wasser ist.* Der Narzißmus des Kleinen fand offensichtlich eine besondere Befriedigung in der Vorstellung, daß das ganze Meer sein Produkt sei.

Diese narziBtische Eitelkeit auf die Menge der entleerten Stoffe, die sich bei Neurotikern in mancherlei Formen äußert, kommt auch bei der Ejaculatio praecox zur Geltung. Wie bereits erwähnt wurde, sind einzelne Patienten stolz auf die Ejakulation, die sie nicht im weiblichen Körper, sondern gewissermaßen vor den Augen des Weibes stattfinden lassen.

Der Ejaculatio praecox wohnt somit auch eine exhibitionistische Tendenz inne. In ihr setzt sich der mit dem infantilen Narzißmus 
verknüpte Glaube fort, durch die eigenen Vorzüge - besonders durch den Penis und das Urinieren - einen unwiderstehlichen Reiz auf das Weib (die Mutter) auszuuben.

Eine aus dem Narzißmus zu erklärende Selbsttäuschung wurde schon früher erwähnt. Einzelne unter den Patienten wiegen sich in den Glauben ein, die Ejaculatio praecox sei ein Zeichen ihrer besonderen Leidenschaftlichkeit. $\mathrm{Zu}$ dieser Selbsttäuschung gesellt sich gelegentlich noch eine zweite: die Ejaculatio praecox sei das Zeichen einer feineren, veredelten Mănnlichkeit, im Gegensatz zur aggressiven Roheit anderer Männer. Das aus verdrängtem Narzißmus hervorgegangene Symptom wird vom Patienten sekundär in einer narzißtischen Weise gerechtfertigt. Die Tendenz dieses Verfahrens ergibt sich leicht. Der Patient möchte den als gewalttätig und roh betrachteten Vater durch Feinheit ubertreffen und ihn dadurch bei der Mutter ausstechen. Die Vorstellung von der Gewalttätigkeit des Vaters entstammt gewissen Erlebnissen des Kindes: es hat den Verkehr der Eltern belauscht und ihn als einen Gewaltakt des Vaters aufgefaßt. Nach der eigenen Geschlechtsreife wirkt diese " sadistische" Theorie des Koitus im UnbewuBten des Sohnes nach. Der normale Geschlechtsakt erscheint dann als eine Roheit. Die Ejaculatio praecox wendet sich gewissermaßen an die weibliche Zartheit der Mutter; sie will ausdrücken: sieh, ich komme dir zarter entgegen als der Vater!

Es darf aber keineswegs tibersehen werden, daB dieses Exhibieren vor dem Weibe (der Mutter) einen ambivalenten Charakter trăgt. Es ist nicht nur ein Liebesbeweis mit der Tendenz des Bewundert- und Berührtwerdenwollens, sondern zugleich ein Zeichen der Ablehnung des W e ibes. Nach meinen lubereinstimmenden psychoanalytischen Erfahrungen handelt es sich um eine mit schweren Affekten betonte Feindseligkeit, welche sich besonders als Ver achtung des Weibes geltend macht. Die Feindseligkeit leitet sich aus infantilen Quellen her, vor allem aus kindlicher Eifersucht. Die Verachtung des Weibes erklärt sich zwanglos aus der Überwertung des Penis. Das Weib ist minderwertig, verächtlich, weil ihm dieser Körperteil mangelt. Nicht wenige der an Ejaculatio praecox Leidenden sind Verächter der Frauen im allgemeinen; sie können nicht genug liber die "Unvollkommenheit" des Weibes spotten. In manchen Fällen äußert sich diese Einstellung in einer mit heftigen Affekten betonten Gegnerschaft gegen die heutige Frauenbewegung.

Wir kommen so zu dem eigentümlichen Ergebnis, daB die Ejaculatio praecox auch ein Ausdruck der Feindschaft und Verachtung ist, welche der Patient der Gesamtheit der Frauen wie der einzelnen Frau entgegen- 
bringt. Verschiedene unter meinen Psychoanalysen klärten mich über diese von mir fruher nicht erkannte Tendenz auf. Die Ejaculatio praecox - und zwar kommt hier namentlich die ante portas geschehende in Frage - ist eine Bes ud el ung des Weibes mit einem den Urin vertretenden Stoffe. Man muB sich hier den ambivalenten Charakter der Vorgänge vergegenwärtigen, welche in der Abgabe eigener Exkrete an eine andere Person bestehen. Wir lernten sie vorher als Ausdrucksmittel kindlicher Sympathie kennen. Eine Parallele aus der Völkerpsychologie wird hier klärend wirken. Das Anspeien einer anderen Person, das bei gewissen Völkerschaften eine freundliche Begrüßungsform darstellt, wird mit fortschreitender Verdrängung, d. h. Kulturentwicklung, zum Ausdruck stärkster Verachtung. Jedes Kind durchschreitet aber ein Stadium, welches der Auffassung jener Primitiven entspricht; es ist das Stadium des Narzißmus. Ein vierjăhriges Mädchen bezeichnete einmal seinen Speichel, für den es eine von der Erziehung nicht gebilligte narziBtische Hochschätzung an den Tag legte, als "schönes, reincs Zungenwasser". Was später als unschön und unrein angesehen wird, erscheint in diesem Stadium noch in einem ganz entgegengesetzten Licht. In dem uns beschäftigenden Zusammenhang sei darauf aufmerksam gemacht, daß dem kleinen Kinde und den Primitiven auch der Ekel vor dem Urin durchaus abgeht. Man braucht nur daran zu denken, daß gewisse Negervölker ihre Kochgeschirre mit Urin reinigen. Bei ihnen herrscht noch in weitem Umfange die narziBtische Bewertung der Körperprodukte.

Mit der unbewuBten Absicht der Besudelung des Weibes ist eine andere Tendenz aufs engste verkntipft. Meine Psychoanalysen bestätigen von Fall zu Fall immer wieder, daB das Benässen des Weibes auch eine Trotzhandlung darstellt. Die Mutter hat die Aufgabe, das Kind zur Reinlichkeit, zur Beherrschung seiner SchlieBmuskeln zu erziehen. Wird die Mutter zum Objekt der Feindschaft und Verachtung, so setzt das Kind ihren Bestrebungen einen heftigen $T$ r o $t z$ entgegen, der uns oft genug im Charakter des erwachsenen Neurotikers wieder begegnet. So haben wir in der Ejaculatio praecox auch einen trotzigen Rackfall in die unbeherrschte Entleerungsform des frühen Kindesalters zu erblicken.

Es wurde oben dargelegt, daß die Verunreinigung des Liebesobjekts mit Urin oder einem anderen Körperprodukt ein infantilnarzißtischer Ausdruck der Sympathie sei. Die tiefer eindringende Analyse zeigt uns aber gerade hier ein Beispiel ausgeprägtester Ambivalenz und lehrt uns von neuem den KompromiBcharakter der vorzeitigen Ejakulation kennen. 
Der zum Weibe ambivalent eingestellte Neurotiker gibt auf dem Wege der Ejaculatio praecox dem Weibe etwas von seinem körperlichen Besitz, aber er gibt nur scheinbar. In Wirklichkeit veranlaBt ihn seine feindselige Haltung, eifersüchtig uber seinen Besitz zu wachen. Das Weib erhält $\mathbf{n}$ i c h t s : er spart seine Körperkraft,er gibt seiner Partnerin keine Lustempfindung; er vergießt sein Sperma, gibt es aber nicht ihr, gibt ihr also auch kein Kind. Im Gegenteil erregt er in ihr Erwartungen und enttä uscht sie dann.

Wie fruher ausgefuhrt wurde, befindet sich jeder unserer Kranken in einer passiven Einstellung gegenüber dem Weibe. Er ist von der Mutter dauernd abhängig und kämpft gegen diese in seinem Unbewubten begrlindete Abhängigkeit. Der Abwehrkampf tritt in die Erscheinung als ein Kampf gegen das Weib. Der Patient verfügt aber in diesem Kampf nicht über die Mittel einer kraftvollen männlichen Aktivität. Er muB sich darauf beschränken, das Weib zu enttäuschen, und tubt damit an jedem Weibe $\mathrm{Rach}$ e für Liebesenttäuschungen, denen er als Kind von seiten seiner Mutter ausgesetzt war, und die sich ihm in späterem Alter wiederholen.

Ein Hinweis sei hier noch gegeben auf häufige, neben der Ejaculatio praecox einhergehende, aus den gleichen Quellen stammende Erscheinungen, die sich im ganzen sozialen Verhalten der Patienten geltend machen. Entsprechend dem Narzißmus und der Ambivalenz ihrer Gefühlseinstellungen schwanken sie zwischen vorschneller Obertragung und allzu ängstlichem Ansichhalten. Mancher dieser Patienten reagiert auf die abweichende Meinung, auf die Kritik eines anderen Menschen usw. entweder mit einem Ausbruch von Wut und Jähzorn oder aber mit einem verbissenen Ansichhalten, durch welches er sich ganz in sich selbst zurückzieht.

Das Zusammentreffen gewisser Charakterzüge ist für unsere Neurotikergruppe so typisch, daB man aus ihnen mit einer gewissen Wahrscheinlichkeit auf das Bestehen der Ejaculatio praecox schließen kann. In einer Sitzung der Berliner psychoanalytischen Vereinigung wurden einmal in einem Vortrag abnorme Affektzustände eines Neurotikers besprochen. In der Diskussion äuberte ich auf Grund des vom Referenten geschilderten sozialen Verhaltens die Vermutung, daB der Patient an Ejaculatio praecox leide, was mir dann soforf bestätigt wurde.

Endlich mag hier auf eine seltenere, in Ärztekreisen wenig bekannte neurotische Störung hingewiesen werden, die der vorzeitigen Ejakulation als Phanomen entgegengesetzt, ihr innerlich aber nahe verwandt ist. Man kann sie als Im p ot e $\mathrm{n}$ t i a e j a $\mathrm{cu}$ l a n d i bezeichnen. 
Bei manchen Neurotikern erfolgt nämlich im Geschlechtsakt die Ejakulation überhaupt nicht. Auch hier liegt ein Zustand der Sexualablehnung vor, der aus dem NarziBmus hervorgeht. Bei diesen Patienten ist das "Ansichhalten" die überwiegende Tendenz. Der Effekt ist der gleiche wie bei der Ejaculatio praecox: der Narzißmus setzt sich durch und das Weib wird enttäuscht. Daß vom normalen Eintritt der Ejakulation zum vorzeitigen Eintritt einerseits, zum Ausbleiben der Samenentleerung anderseits fließende Übergänge bestehen, bedarf kaum der Erwăhnung. Die retardierte Ejakulation ist ein nicht seltenes Symptom mancher Ne urosen.

Es ist die Aufgabe der psychoanalytischen Behandlung, den Patienten von seiner narziBtischen Einstellung zu befreien und ihm den Weg zur normalen Gefuhlsübertragung zu zeigen. Gelingt es, seine narziBtische Ablehnung des Weibes aufzuheben, so ist die Bahn frei gemacht für den normalen Ablauf der Geschlechtsfunktionen; ganz analog gelingt es ja auch, das weibliche Analogon der Ejaculatio praecox - die Frigidität - zu beseitigen.

Selbstverständlich sind verschiedene Fälle des Leidens von sehr verschiedener Wertigkeit. Leichteste Störungen dieser Art treten bei disponierten Männern episodisch auf und können ohne jede Behandlung verschwinden; freilich ist die Gefahr des Ruckfalles stets gegeben. Die Psychoanalyse bringt auch in schweren und hartnäckigen Fällen einen Heilerfolg oder doch mindestens eine Besserung'. Prognostisch sind diejenigen Falle am wenigsten gunstig $z \mathbf{u}$ beurteilen, in denen die Ejaculatio praecox sich sogleich im Alter der Geschlechtsreife bemerkbar gemacht hat und seither durch eine Reihe von Jahren vielemal hervorgetreten ist. Es handelt sich hier um Fälle von auBergewöhnlich starkem Vorwiegen der urethralen gegentuber der genitalen Erotik; in denen die Lust der Ejaculatio praecox die Unlust zu Luterwiegen pflegt.

Die Behandlung des Leidens kann zu den technisch schwierigsten Aufgaben des Psychoanalytikers gehören, weil er den Kampf mit der bei diesen Kranken sehr beträchtlichen Macht des Narzißmus aufnehmen muß. Eine geduldige und konsequente Anwendung der Methode läBt ihn aber auch diese Schwierigkeiten aberwinden.

1 Auch in zwei Fällen von Impotentia ejaculandi ist es mir gelungen, auf psychoanalytischem Weg dauernd Heilung zu erzielen. 


\section{Einige Belege zur Gefühlseinstellung weiblicher Kinder gegenüber den Eltern ${ }^{1}$.}

Eine Mutter berichtet mir von ihrer vierjährigen Tochter: "Sie hängt mit besonderer Liebe und Zärtlichkeit an ihrem Vater. In letzter Zeit spielt sie mit Vorliebe, Vaters Frau'. Als ich sie nun fragte, warum sie Vaters Frau sein wollte, meinte sie: ,Ich möchte so gern wissen, wie das ist; und dann kann ich auch endlich mal probieren, wie Kaffee schmeckt'. Auf meine Einwendung, wo ich denn dann bleiben solle, hatte sie die Antwort bereit: ,Du bist dann eben unser Kind!' "

"Einmal" - so fährt. der Bericht der Mutter fort - "erzählte die Kleine ihrer alteren Schwester eine selbsterdachte Geschichte; die fing an: ,Es war einmal ein Zwerg, der hatte sieben kleine Zwerglein, und die Mutter davon war schon längst gestorben.' Ich fragte, warum denn die Mutter gestorben sei, und erhielt zur Antwort: ,Ach, die war ja schon uber 100 Jahre alt und sehr krank."

"Vor einigen Monaten blieb E. ... im zoologischen Garten vor dem Wildschweinkäfig stehen, in dem sich eine Sau mit vielen Jungen befand. Voll Entzücken rief E.: ,Sieh mal, da ist ein Vater Schwein mit seinen Kindern!“ Ich erklärte ihı, das sei die Mutter; darauf sie: "Nein, der Vater.' Als ich nochmals versicherte, es sei die Mutter, fragte sie: ,Aber wo ist dann der Vater? Erst als ich sagte, der sei wohl nur einmal ausgegangen, nahm ihr Gesichtchen wieder einen zufriedenen Ausdruck an."

"Eines Tages sprach E. davon, ,wenn sie erst einmal eine Braut wäre‘. Ich fragte: ,Wer soll denn dein Bräutigam sein?' Da kam prompt die Antwort: ,Nun, naturlich mein Geliebter, der Vater!' Einige Wochen danach sagte sie zum Vater, als er sich verabschiedete: ,Adieu, mein geliebter Mann!‘“

Dies ist nur eine Auswahl aus zahlreichen ähnlichen Äußerungen desselben Kindes. Sie lassen alle in tibereinstimmendem Sinne

1 Aus „Internationale Zeitschrift für ärztliche Psychoanalyse“. IV. Jahrgang 1916. 
erkennen, wie die vierjăhrige Kleine ihre Liebe vorwiegend dem Vater zuwendet, ihn sozusagen der Mutter fortnimmt und ihn als ihren Mann bezeichnet; wie sie anderseits die Mutter kurzerhand beseitigt oder aber sie zum Kinde macht (die Rolle also mit ihr tauscht). Die Beseitigung geschieht in den mitgeteilten Beispielen freilich nur in einer indirekten Form: nicht das Kind selbst, wohl aber die Zwerge oder die Schweinchen haben keine Mutter, sondern nur einen Vater!

Das Beispiel eines anderen Mädchens zeigt die gleichen Tendenzen, nur ist der Todeswunsch gegen die Mutter und das erotische Empfinden gegentiber dem Vater noch unverhüllter erkennbar.

Die vierjährige $\mathrm{H}$. . . . gab einmal, als sie in Abwesenheit der Mutter mit dem Vater zu Mittag aB, ihren Gefühlen Ausdruck wie folgt: „Es ist doch schön, daß die Mama heute nicht zu Hause ist.“ Auf die Frage des Vaters, warum sie denn darüber erfreut sei, antwortete die Kleine: "Dann kann sie uns doch nicht dazwischen reden, wenn wir uns unterhalten ". Einige Wochen spater wurden diese Beseitigungswünsche noch deutlicher. $H$. stellte jetzt ihrer Mutter die Frage: "Mama, wann stirbst du eigentlich ?" Sie beruhigte sich mit dem erhaltenen Bescheid nur scheinbar. Schon nach wenigen Tagen hieß es: „Mama, ... in zehn Jahren, lebst du da immer noch?" Während eines Zeitraumes von mehr als einem Monat wiederholten sich diese Fragen viele Male; doch galten sie stets nur der Mutter, niemals dem Vater. Als die Mutter einmal replizierte: "Wenn ich aber sterbe, dann hast du doch keine Mama mehr!", erfolgte prompt die Antwort: "Dann habe iai doch noch den Papa!"

Im gleichen Alter äußerte die Kleine eines Tages wăhrend der Mittagsmahlzeit: "Papa, ich könnte dich doch mal nackt sehen." Dergleichen kam nur dieses eine Mal in so ausgesprochener Form vor. Dem Kinde gelang es anscheinend leichter, auf die Erfüllung dieses Wunsches $\mathrm{zu}$ verzichten, als auf seine feindselige Einstellung zur Mutter.

Aus dem Verhalten älterer Kinder und Erwachsener hat $F$ re u d den Schluß gezogen, jene primitiven Regungen seien der Verdrăngung und Sublimierung verfallen; er hat auch auf die so häufige Umwandlung ursprünglicher Triebregungen in Impulse entgegengesetzter Art hingewiesen. ("Reaktionsbildung.") Es ist nun gewiB von Interesse, diesen UmwandlungsprozeB bei einem Kinde direkt zu beobachten, so wie es in dem Falle der kleinen H. . . . möglich war.

Die Todeswünsche gegen die Mutter waren eine Zeitlang ungehemmt geăubert worden. Dann vernahm man einige Wochen 
hindurch weder Äußerungen besonderer Feindschaft noch besonderer Liebe gegenüber der Mutter. Eines Tages begann H., auf Spaziergangen ihre Mutter zu bitten, mit ihr an alle möglichen Schaufensterauslagen heranzutreten. Sie fragte dann - je nach den ausgestellten Waren -: "Welcher Hut gefällt dir am besten?" "Welches Kleid möchtest du haben?" so wie sonst Erwachsene Kinder zu fragen pflegen. Zeigte die Mutter dann, welches Objekt ihr am besten gefiel, so folgte jedesmal die Versicherung der Kleinen: „Wenn ich groB bin, schenke ich dir diesen Hut " [oder sonstigen Gegenstand]. Geschenke sind in den Augen des Kindes besonders wichtige Liebesbeweise. H. hatte also bereits die Todeswänsche aberwunden und aberhäutte nun die Mutter mit Liebesbeweisen. Freilich konnte sie nur Versicherungen für künftige Zeiten geben. Aber gerade darin zeigte sich eine bemerkenswerte Kompromißbildung. $H$. verlăngte nicht mehr, daß die Mutter tot sein solle, wenn sie selbst "groß* geworden sei. Sie begnügte sich mit dem Rollentausch, den ich vorher bei der kleinen E. . . . erwăhnte. Sie druckte durch ihr Verhalten den Gedanken aus: Wenn ich gro $B$ bin, habe ich das Geld, weil ich Vaters Frau bin; dann bist $d u$ unser Kind und mußt dir von $m$ ir etwas kaufen lassen! 


\section{Das Geldausgeben im Angstzustand ${ }^{1}$.}

Das Verhältnis des Neurotikers zum Geldbesitz ist in der psychoanalytischen Literatur eingehend erörtert worden. Sowohl Freud als die Autoren, die sich nach ihm mit den " analen $^{*}$ Charakterzügen beschäftigt haben, behandeln den neurotischen Geiz, das ängstliche Zurückhalten des Geldes aus unbewuBten Motiven. Das gegenteilige Verhalten mancher Neurotiker hat, obwohl es dem Arzt in der Psychoanalyse keineswegs selten entgegentritt, nicht die gleiche Beachtung gefunden. Die Neigung zu ubertriebenen. Geldausgaben tritt bei manchen Neurotischen plötzlich, ja anfallsweise hervor und steht dann in einem auffalligen Gegensatz $z \mathfrak{u}$ ihrer sonstigen Sparsamkeit.

Es handelt sich, nach einer kleinen Reihe von Erfahrungen aus meiner psychoanalytischen Tätigkeit, um eine bestimmte Gruppe von Neurotischen: Kranke, welche sich in dauernder infantiler Abhängigkeit vom elterlichen Hause befinden und von Verstimmung oder Angst befallen werden, sobald sie sich von ihm entfernt haben.

Die Patienten selbsî behaupten, daß das Geldausgeben ihre Angst oder Verstimmung erleichtere. Sie haben auch rationelle Erklarrungen dieser Wirkung zur Hand: das Geldausgeben erhöhe ihr Selbstgefühl, oder es lenke sie von ihrem Zustand ab. Die Psychoanalyse fügt dieser rein oberflächlichen Erklärung jedoch eine tiefere, das Unbewußte berlicksichtigende hinzu.

Wie jede Psychoanalyse eines derartigen Falles aufs Neue lehrt, ist es dem Kranken infolge der Fixierung seiner Libido verwehrt, sich räumlich von den Eltern oder den sie vertretenden Personen zu entfernen. Die Entfernung vom Hause bedeutet seinem UnbewuBten eine Ablösung der Libido von ihren Objekten. Stets lassen sich zwei entgegengesetzte psychische Strömungen nachweisen : eine konservative im Sinne der dauernden Fixierung und eine andere im Sinne der Hinwendung zu den Objekten der Außenwelt.

1 Aus ,Internationale Zeitschrift für ärztliche Psychoanalyse*. IV. Jahrgang 1916. 
Jeder Versuch der Übertragung der Libido auf neue Objekte ist bei den Kranken gerade darum mit so schwerer Angst verbunden, weil das $u n b e w u B$ te Verlangen danach besonders heftig und ungestüm ist. Es braucht nur daran erinnert $z u$ werden, daß weibliche Kranke mit Straßenangst in besonderem Maße mit unbewußten, nicht selten auch mit bewaßten Prostitutionsphantasien behaftet sind. Ihr Unbewußtes will schrankenlose Hingabe an alle; die im Bewußtsein herrschende Angst aber schränkt die Übertragung der Libido aufs äußerste ein. So werden die Kranken unfähig, von ihrer Libido freien Gebrauch zu machen, und zwar keineswegs nur im engen Sinne der eigentlichen Geschlechtsbeziehungen.

Eine weitgehende Einschränkung der genitalen Geschlechtlichkeit führt zu ersatzweiser, stärkerer Betonung anderer erogener Zonen. Die anale Erotik ersetzt die genitale in mehr oder weniger weitem Umfang. In manchen Fällen läßt sich mit großer Deutlichkeit feststellen, daß die krankhafte Fixierung der Patienten an den Vater oder die Mutter durch die Analzone vermittelt wird. Ein kleiner Ausschnitt aus einer Psychoanalyse möge das belegen.

Die Patientin, welche an schwerer Straßenangst leidet, ist völlig an ihren Vater gebunden. Ihre immer wiederholten Versuche, die Fixierung zu lösen, sind miBlungen. Diese Fixierung ist vom Vater der Patientin während ihrer Jugend dadurch sehr gefördert worden, $\mathrm{daB}$ er sich im Übermaß um die Darmtätigkeit des Kindes kümmerte, sehr häufig Klysmen verabreichte usw. Diese verkehrten MaBnahmen trugen zur Erhaltung kindlicher Abhängigkeit in verhängnisvoller Weise bei; die Tochter konnte - mit einem Ausdrucke der Kinciersprache gesagt - nichts ohne den Vater "machen", konnte nur unter seiner Aufsicht "abseits" gehen. Wie die Analyse ergab, ließen auch ihre Ablösungsversuche die anale Fixierung erkennen. Den Darm ohne väterliche Aufsicht zu entleeren, bedeutete ihrem UnbewuBten Selbständigkeit. Entfernte sich die Patientin vom Hause und wurde sie unterwegs von Angst befallen, so machte sie zur Abwehr der Angst allerhand Geldausgaben, die praktisch nicht zu rechtfertigen waren. Sie verausgabte Geld statt $\mathrm{Libido}$. DaB aber das Geld diese ersetzende Bedeutung annehmen konnte, erklärt sich aus der im UnbewuBten herrschenden Gleichwertigkeit von Geld und Kot. Bemerkenswert ist, daB die Patientin sich selbst verdächtigte, sie steigere manchmal ihre Angst, um sich einen Grund zum Geldausgeben $z$ i schaffen.

Bei dieser Kranken beobachtete ich, ebenso wie auch in zwei anderen Fallen, die Neigung, wahllos vielerlei zu kaufen, meist wertlose, 
nur für den Augenblick begehrte Kleinigkeiten. Sie täuschen sich auf diese Weise eine freie Beweglichkeit ihrer Libido vor, während diese doch in Wirklichkeit aufs äuBerste fixiert und gehemmt ist. Das Kaufen von Gegenständen, die nur einen Augenblickswert haben, das schnelle Übergehen von diesem Gegenstand zu jenem, wirkt als symbolische Befriedigung eines verdrängten Begehrens: die Libido in rascher Folge auf unbegrenzt viele Objekte $z u$ ubertragen. Die Anspielung auf die Prostitution ist hier nicht zu verkennen; auch dort vermittelt das Geld flüchtige, beliebig wechselnde Beziehungen.

Die Auffassung der Patienten, sie gäben Geld aus, um ihr Selbstgefühl zu erhöhen, erfährt nun in gewissem Sinne eine Bestätigung. Das Geldausgeben täuscht sie über die Gebundenheit der Libido und damit über das peinigende Gefühl sexueller Insuffizienz für kurze Zeit hinweg. Anders ausgedrückt: die Kranken stehen unter einem abnorm strengen, von der Eltern-Imago ausgehenden Verbot, ihre Libido frei zu verausgaben. Es kommt zum Kompromiß zwischen Trieb und Verdrăngung. Die Kranken verausgaben sich dem Verbot zum Trotz, aber nicht in sexueller Libido, sondern in analen Werten.

Wir werden hier an das dauernde Verhalten gewisser Neurotiker erinnert, deren Libido gleichfalls libermäßig gebunden ist. Sie sind teilweise oder ganz - unfähig zur sexuellen Liebe im seelischen und körperlichen Sinne. Sie wenden den anderen Menschen nicht Liebe, sondern Mitleid zu, sie werden zu Wohltätern und geben an Geldeswert oft im Ubermaß. Sie sind auf diese Ersatzbefriedigung dauernd angewiesen. In der dunklen Wahrnehmung, qualitativ nicht das Richtige "zu geben, ubertreiben sie das Geben quantitativ. Ihr Geldausgeben wirkt jedoch altruistisch, während in den vorher besprochenen Fällen diese Wirkung durchaus fehlt. Das Gemeinsame beider Gruppen liegt aber darin, daB das Geldausgeben einen Ersatz für die von der Neurose verbotene Sexualübertragung bildet und zur Abwehr neurotischer Störungen dient. 


\section{Über eine besondere Form des neurotischen Widerstandes gẽgen die psychoanalytische Methodik'.}

Wenn wir. eine psychoanalytische Behandlung beginnen, so machen wir den Patienten mit der Grundregel des Verfahrens bekannt, die er unbedingt zu befolgen habe. Das Verhalten unserer Patienten gegenüber dieser Grundregel ist recht verschieden. Manche erfassen sie schnell und ordnen sich ihr ohne besondere Schwierigkeit unter, andere mússen wir häufig daran erinnern, daß sie frei zu assoziieren haben. Bei allen Kranken erleben wir zeitweise ein Versagen der freien Assoziationstätigkeit. Entweder bringen sie nun Produkte des aberlegten Denkens vor, oder sie erklären, es falle ihnen nichts ein. Es kann dann eine Behandlungsstunde ablaufen, ohne dab der Patient in ihr der Psychoanalyse irgend welches Material an freien Assoziationen ztigeführt hat. Dieses Verhalten des Patienten weist uns auf einen ${ }_{n}$ Widerstand" hin; ihn verständlich zu machen, ist unsere nächste Aufgabe. Wir erfahren regelmäßig, daß der Widerstand sich gegen Nas RewuBtwerden bestimmter psychischer Inhalte richtet. Haben wir anfangs dem Patienten erklärt, seine freien Assoziationen vermöchten uns Einblicke in sein Unbewußtes $z u$ geben, so ist die Ablehnung des freien Assoziierens die fast selbstverständliche Form, die sein Widerstand annehmen wird.

Sehen wir in den meisten Fällen einen derartigen Widerstand in öfterem Wechsel auftauchen und verschwinden, so bietet ihn eine kleinere Gruppe von Neurotischen während der ganzen Behandlungsdauer ohne Unterbrechung dar. Dieser permanente Widerstand gegen die Grundregel der Psychoanalyse kann zu einer außerordentlichen Erschwerung der Therapie fuhren, ja er stellt ihren Erfolg gänzlich in Frage. Er hat bisher in der Literatur, ebenso wie manche anderen technischen Fragen, keine Beachtung gefunden. Seitdem ich der

1 Aus "Internationale Zeitschrift für ärztliche Psychoanalyse". V. Jałırgang 1919. 
geschilderten Schwierigkeit in einer Reihe von Krankheitsfällen begegnet bin, habe ich von anderen Psychoanalytikern erfahren, daß es ihnen ähnlich ergangen ist. Neben dem theoretischen liegt daher ein praktisches Interesse vor, diese Spielart der neurotischen Reaktion auf die Psychoanalyse genauer $z u$ untersuchen.

Die Patienten, von denen hier die Rede sein soll, erklären kaum jemals spontan, daB ihnen "nichts einfalle". Sie sprechen vielmehr in zusammenhängender, selten unterbrochener Rede, ja einzelne von ihnen sträuben sich dagegen, auch nur durch eine Bemerkung des Arztes in ihrem Redefluß unterbrochen zu werden. Aber sie geben sich nicht dem freien Assoziieren hin. Sie sprechen programmatisch, bringen ihr Material nicht $z$ wanglos vor; der Grundregel widersprechend ist es unter bestimmten Gesichtspunkten orientiert und einer weitgehenden, umgestaltenden Kritik von seiten des Ichs unterworfen. Die Mahnung des Arztes zu korrekter Einhaltung der Methodik ist für sich allein ohne Einfluß auf das Verhalten der Patienten.

Dieses zu durchschauen, ist keineswegs leicht. Dem Arzt, dessen Blick für die Form des Widerstandes dieser Patienten noch nicht geschärft ist, täuschen sie eine außerordentliche und nie ermüdende Bereitwilligkeit zur Psychoanalyse vor. Ihr Widerstand verbirgt sich hinter scheinbarer Gefügigkeit. Ich gestehe, daß ich selbst längerer Erfahrung bedurfte, bevor ich dieser Täuschungsgefahr zu entgehen vermochte. Nachdem ich den systematischen Widerstand erst einmal richtig erkannt hatte, wurde mir auch seine Herkunft deutlich.

Die Neurotiker von diesem Typus, deren ich eine kleine Reihe beohachton konnte; botran nämlich in ihren Neurosen zwar eine recht verschiedenartige Symptomatik; in ihrem Verhalten zur Psychoanalyse und zum Arzt wiederholte sich dagegen eine Anzahl von Zügen init verbluffender RegelmäBigkeit. Auf diese Züge möchte ich im nachfolgenden die Aufmerksamkeit lenken.

Was sich unter der geschilderten scheinbaren Gefügigkeit bei unseren Patienten verbirgt, ist ein ungewöhnliches $M a ß$ von T rotz, der sein Vorbild im Verhalten des Kindes gegenüber dem Vate $\mathrm{r}$ findet. Lehnen andere Neurotiker das Produzieren freier Einfälle gele gent $\mathrm{lich}$ ab, so trotzen sie der Methode dauernd. Ihre Mitteilungen sind quantitativ überreichlich; wie schon erwähnt, täuscht dieser Umstand den Unerfahrenen uber qualitative Mängel hinweg. Mitgeteilt wird nur, was nichgerecht " ist. Die Patienten sind in besonders hohem Grade empfindlich für alles ihr Ichgefuhhl Verletzende. Sie neigen dazu, sich durch jede in der Psychoanalyse getroffene Feststellung 
"gedemütigt" zu fühlen und sind beständig auf der Hut vor solchen Demütigungen. Sie liefern Träume in Menge, kleben aber an deren manifestem Inhalt und verstehen es, aus der Analyse der Träume nur das $z \mathfrak{u}$ erfahren, was sie bereits wußten. Meiden sie so mit Beharrlichkeit jeden peinlichen Eindruck, so geht ihr Bestreben gleichzeitig dahin, aus der Psychoanalyse auch positiv das höchste MaB von Lust zu ziehen.

Gerade diese Tendenz, die Psychoanalyse unter die Herrschaft des Lustprinzipes $z u$ stellen, läßt sich bei unseren Patienten mit großer Deutlichkeit erkennen. Diese Erscheinung in Gemeinschaft mit einer Anzahl anderer Eigentumlichkeiten ist der klare Ausdruck ihres $\mathrm{Narzi}$ B mus. Unter meinen Patienten waren es gerade die mit dem stärksten Narzißmus behafteten, welche sich der psychoanalytischen Grundregel wie geschildert widersetzten.

Die Neigung, ein Heilmittel lediglich unter dem Gesichtspunkte des Lusterwerbs zu betrachten und darüber den eigentlichen $Z$ weck des Heilmittels zu vernachlässigen, muß als ein durchaus kindlicher Zug aufgefabt werden. Ein Beispiel möge dies erläutern. Einem achfjährigen Knaben wird das Tragen einer Brille verordnet. Er ist überglücklich, nicht weil er gewisse unangenehme Sehstörungen verlieren soll, sondern weil er eine Brille tragen darf. In der nächsten Zeit ergibt sich, daB er gar nicht darauf achtet, ob die Störungen durch die Brille behoben sind; der Besitz der Brille, mit der er sich in der Schule zeigen darf, befriedigt ihn so sehr, daB er darïber ihren therapeutischen Wert vergißt. Nicht anders ist die Einstellung unserer Patientengruppe zur Psychoanalyse. Der eine erwartet von ihr interessante Peiträge zu seiner Autobiographie, die er in Romanform schreibt. Der andére hofft, die Psychoanalyse werde ihn intellektuell und ethisch auf ein höheres Niveau bringen; dann wäre er seinen Geschwistern uberlegen, denen gegenüber er bisher peinliche Gefühle der Minderwertigkeit hatte. Das Ziel der Heilung nervöser Störungen tritt in gleichem Maße zurück, in welchem diese narzißtischen Interessen beim Patienten vorherrschen.

Ebenso narzißtisch wie der Behandlungsmethode stehen sie aber auch der Person des Arztes gegenüber. Das Verhältnis zum Arzt ist bei ihnen gekennzeichnet durch mangelhafte Übertragung; sie miBgönnen ihm die Vaterrolle. Treten Ansätze zur Ubertragung hervor, so zeigen sich die auf den Arzt gerichteten Wünsche besonders anspruchsvoll. In eben diesen Ansprïchen sind gerade die hier in Rede stehenden Patienten sehr leicht enttäuscht und reagieren rasch mit einer völligen Einziehung der Libido. Sie wollen ständig Zeichen des persönlichen 
Interesses von Seiten des Arztes sehen, sich von ihm liebevoll behandelt fühlen. Da der Arzt den Ansprüchen ihres narziBtischen Bedürfnisses nach Liebe nicht gerecht werden kann, so kommt eine eigentliche positive Ubertragung nicht zustande.

An Stelle der Ubertragung finden wir bei unseren Patienten die Neigung, sich mit dem Arzt $z u$ identifizieren. Anstatt ihm persönlich năher zu kommen, versetzen sie sich an seine Stelle. Sie nehmen seine Interessen an und lieben es, sich mit der Psychoanalyse als Wissenschaft $z u$ beschäftigen, anstatt sie als Behandlungsmethode auf sich wirken zu lassen. Sie neigen zum Tausch der Rollen, wie das Kind den Vater spielt. Sie belehren den Arzt, indem sie ihm ihre Ansichten über die eigene Neurose vortragen, halten letztere für besonders instruktiv und glauben, durch ih re Analyse müsse die Wissenschaft eine besondere Bereicherung erfahren. So treten sie aus der Rolle des Patienten heraus und verlieren dabei den Zweck der Psychoanalyse aus den Augen. Besonders aber begehren sie, den Arzt zu uabertreffen, seine psychoanalytischen Fähigkeiten und Leistungen herabzusetzen; für sich selbst nehmen sie in Anspruch, „es besser zu können". Überaus schwer sind sie von vorgefaßten Meinungen abzubringen, die im Dienst ihres NarziBmus stehen; sie neigen zum Widerspruch und wissen aus der Psychoanalyse ein Wortgefecht mit dem Arzt, ein Debattieren ums "Rechthaben" zu machen.

Hiezu einige Beispiele! Ein Neurotiker lehnt nicht nur das freie Assoziieren ab, sondern auch die geforderte Ruhelage während der Behandlung. Er springt oftmals auf, geht in die entgegengesetzte Ecke des Zimmers und beginnt, in selbstbewuBter Haltung und in belehrendem Tone seine durch Reflexion gewonnenen Anschauungen über seine Neurose vorzutragen. Ein anderer meiner Patienten bot ein ähnlich dozierendes Verhalten. Er äußerte geradezu die Meinung, die Psychoanalyse besser als ich zu verstehen, weil - er doch die Neurose habe, und nicht ich. Nach langdauernder Behandlung äußerte er einmal: "Ich fange jetzt an zu erkennen, daB Sie von der Zwangsneurose etwas verstehen." Eines Tages stellte sich eine sehr charakteristische Befürchtung des Patienten heraus: Die freien Assoziationen könnten i h m fremdartiges, dem Arzt aber vertrautes Material zu Tage fördern; der Arzt wäre dann der "Klügere", Uberlegene. Der gleiche Patient, philosophisch stark interessiert, erwartete von seiner Psychoanalyse nichts Geringeres, als daß aus ihr für die Wissenschaft die "letzte Wahrheit" hervorgehen solle.

In alldem ist ein $\mathrm{Zug}$ von $\mathrm{N}$ e id nicht zu verkennen. Solche Neurotiker mißgönnen dem Arzt jede Bemerkung, die sich auf den 
außeren Gang der Psychoanalyse oder auf die Materialien bezieht. Er soll keinen Beitrag zur Behandlung geliefert haben, sie wollen vielmehr alles selbst und allein $\mathrm{machen}$. Ich komme damit auf einen besonders auffälligen Zug, den mir diese Patienten sămtlich darboten. Das in der Behandlungsstunde unterlassene freie Assoziieren holen sie nach, wenn sie zu Hause sind. Mit der Neigung zur "Autoanalyse", wie sie dies Verfahren gern benennen, verbindet sich eine deutliche Geringschătzung des Arztes. Die Patienten sehen in ihm geradezu ein Hindernis des Fortschrittes in den Behandlungsstunden und sind taberaus stolz auf das, was sie ohne sein Zutun glauben geleistet zu haben. Die so gewonnenen freien Einfälle werden mit Ergebnissen der Reflexion vermengt und am nächsten Tage, nach bestimmten Gesichtspunkten orientiert, dem Arzt vorgetragen. Einer meiner Patienten hatte infolge übergroßer Widerstände in mehreren Behandlungsstunden nur geringe und in einer weiteren gar keine Fortschritte der Analyse gesehen. Am nächsten Tage kam er zu mir und erklärte, er habe zu Hause stundenlang allein "arbeiten" mussen. Natürlich sollte ich daraus die Unzulänglichkeit meines Könnens entnehmen.

Es handelt sich bei dieser ${ }_{n}$ Autoanalyse $^{\alpha}$ um ein narziBtisches Sichselbstgenießen, zugleich um eine Auflehnung gegen den "Vater". Die schrankenlose Beschäftigung mit dem eigenen Ich und das bereits beschriebene Gefühl der Uberlegenheit bieten dem NarziBmus reichen Lustgewinn. Das Bedürfnis, bei dem Vorgang allein zu sein, nähert diesen der Onanie und ihren Äquivalenten - den neurotischen Tagträumereien - außerordentlich an. Solchen waren meine sämtlichen in Betracht kommenden Patienten schon früher in hohem MaBe ergeben. Die "Autoanalyse* war ihnen ein durch therapeutisches Interesse gerechtfertigtes, ja sogar gebotenes Tagträumen, ein vorwurfsfreier Masturbations-Ersatz.

Ich hebe an dieser Stelle hervor, daB die einschlägigen Fälle meiner Beobachtung vorwiegend der $Z$ wangsneurose angehörten; in e in em Falle lag eine Angsthysterie mit beigemischten Zwangssymptomen vor. Bei einem Kranken handelt es sich um eine paranoide Störung. Unter Berücksichtigung der neueren psychoanalytischen Erfahrungen werden wir nicht erstaunt sein, in sämtlichen Fällen ausgeprägte sadistisch-anale Züge vorzufinden. Die feindseligablehnende Einstellung zum Arzt wurde schon erwähnt. Das übrige Verhalten der Patienten wird aus analerotischen Motiven voll verständlich. In dieser Hinsicht seien nur einige Hinweise gegeben.

Das Sprechen in der Psychoanalyse, durch welches man sich psychischer Inhalte entledigt, wird von unseren Patienten - wie auch 
sonst von Neurotikern mit starker Analerotik - der Darmentleerung gleichgesetzt. (Einige identifizieren auch die freie Assoziation mit dem Flatus.) Es handelt sich um Personen, die in ihrer Kindheit zur Beherrschung ihrer Sphinkteren und zur RegelmäBigkeit der Entleerungen schwer $\mathrm{zu}$ erziehen waren. Zur vorgeschriebenen Zeit verweigerten sie die Entleerung, um sie $z \mathfrak{u}$ ihnen beliebender Zeit nach Laune $z u$ verrichten. Ganz ebenso verhalten sie sich nun aus unbewuBten Gründen der Psychoanalyse bezw. dem Arzt gegenüber. Kürzlich hat $T$ a u $\mathrm{s}^{1}$ darauf hingewiesen, daß kleine Kinder die Erwachsenen gern hinsichtlich der Entleerung täuschen. Sie strengen sich scheinbar sehr an, den Vorschriften der Erzieher zu genligen, die Entleerung findet aber nicht statt. T a usk knüpt hieran die Bemerkung, das sei vielleicht die fruheste Gelegenheit, bei welcher das Kind bemerke, daß eine Täuschung der Erwachsenen möglich ist. Die hier in Rede stehenden Neurotiker verleugnen diese Vorgeschichte nicht. Sie kaprizieren sich gewissermaßen darauf, selbst $z u$ bestimmen, $\mathrm{ob}$, wann und wieviel sie von ihrem unbewuBten psychischen Material herausgeben. Ihre Neigung, fertig geordnetes Material zur Behandlungsstunde mitzubringen, läBt nicht nur die analerotische Lust am Ordnen und Rubrizieren, sondern noch einen weiteren $\mathrm{Zug}$ erkennen. F r e u d ${ }^{2}$ hat neuerdings auf die unbewußte Identität von $K$ ot u nd Ge schenk mit besonderem Nachdruck aufmerksam gemacht. NarziBtische Neusotiker-mit stark analer Veranlagung haben die Neigung, statt Liebe Geschenke $z u$ geben $^{3}$. Die Ubertragung auf den Arzt ist bei unseren Patienten unvollkommen. Ein zwangloses Sich-ausgeben in freien Assoziationen gelingt ihnen nicht. Sie bringen dem Arzt gleichsam als Ersatz Geschenke dar. Diese bestehen in ihren zu Hause vorbereiteten Beiträgen zur Psychoanalyse, welche der narzißtischen Bewertung gleich den Körperprodukten - unterliegen. Der narziBtische Vorteil besteht fur die Patienten darin, daB sie die genaue Kontrolle darüber behalten, was sie geben.

Einer meiner $Z$ wangsneurotiker mit Grübel- und $Z$ weifelsucht verstand es, während der Behandlung die Psychoanalyse selbst, ihre Methodik wie ihre Ergebnisse, zum Gegenstand des Grübelns und Zweifelns zu machen. Von seiner Familie in hohem Maße abhăngig, qualte er sich u. a. mit dem Zweifel, ob seine Mutter oder ob F re ud

1 ,Intern. Zeitschr, flir ärztl. Psychoanalyse*. V. Jahrg. 1919, S. 15, FuBnote 1.

2. Aus der Geschichte einer infantilen Neurose", in "K1. Schriften zur NeurosenSehre", Bd. 4, 1918.

$3 \mathrm{Vgl}$, hiezu meinen frtiheren Aufsatz über ,Das Geldausgeben im Angstzustand ${ }^{\alpha}$. Seite 279. 
${ }_{n}$ recht habe". Seine Mutter, so erklärte er, habe ihm zur Besserung seiner Stuhlverstopfung oft geraten, im Klosett nicht zu träumen, sondern bei der Defäkation immer nur an diesen Vorgang selbst zu denken. Fre ud gebe nun gerade die entgegengesetzte Regel: man solle zwanglos assoziieren, dann "komme alles von selbst heraus". Es kostete lange Zeit, bis der Patient die Psychoanalyse nicht mehr nach der Methodik seiner Mutter, sondern nach derjenigen Freuds betrieb.

Der bekannten $\mathrm{Sparsamkeit} \mathrm{der} \mathrm{Analerotiker} \mathrm{scheint} \mathrm{der}$ Umstand zu widersprechen, daß unsere Patienten für die Behandlung, die sich aus den besprochenen Grüden in die Länge zieht,. bereitwillig materielle Opfer bringen. Dieses Verhalten wird aber aus früher Gesagtem erklärlich. Die Patienten opfern ihrem NarziBmus. Die Heilung der Neurose als Ziel der Behandlung verlieren sie allzu leicht aus dem Auge. Es muB etwas anderes sein, das sie den Geldaufwand nicht achten läßt. Eine alte Anekdote variierend, möchte man sagen, für ihren Narzißmus sei ihnen nichts zu teuer.

Der Charakterzug der Sparsamkeit findet sich bei ihnen ubrigens an anderer Stelle. Sie sparen ihr unbewußtes Material auf. Sie geben sich mit Vorliebe der Erwartung hin, eines Tages ${ }_{n}$ werde alles mit einem Male herauskommen". Sie luben in der Psychoanalyse wie auf dem Gebiete der Darmtätigkeit das Verfahren der Obstipation. Die Entleerung soll nach langem Aufschub einmal unter besonderer Lust erfolgen; der Termin wird aber immer wieder hinausgeschoben.

Die Analyse solcher Patienten bietet erhebliche Schwierigkeiten. Diese beruhen u. a. in der scheinbaren Gefügigkeit der Kranken, die den Widerstand verdeckt. Die Beseitigung eines solchen Widerstancies ist eine Aufgabe, die man nicht unterschätzen darf; handelt es sich doch um ein Vorgehen gegen den NarziBmus der Patienten, gegen diejenige Triebkraft also, an welcher unser therapeutisches Bestreben am leichtesten scheitert. Jeder mit den Dingen Vertraute wird also begreifen, daB keiner der von mir behandelten Krankheitsfälle dieser Art einen raschen Erfolg gestattete. Ich füge hinzu, daß ich auch in keinem Falle einen voll kom me n e Heilerfolg erzielt habe, wohl aber eine praktisch wertvolle, bei einigen Patienten sogar recht weitgehende Besserung. Meine Erfahrungen ergeben hinsichtlich der therapeutischen Aussichten eher ein zu ungtinstiges Bild. Als ich die ersten einschlägigen Fälle behandelte, fehlte mir noch die tiefere Einsicht in die Eigenart der Widerstände. Besonders ist zu bedenken, 
daB erst Freuds grundlegende Schrift von 1914 uns das Verständnis des NarziBmus vermittelte. Ich habe durchaus den Eindruck, daB die Oberwindung solcher narzißtischer Widerstände leichter gelingt, seit ich derartige Patienten gleich am Anfang der Behandlung in das Wesen ihres Widerstandes einführe. Ich lege das größte Gewicht auf eine erschöpfende Analyse des NarziBmus der Patienten in allen seinen Äußerungen, besonders in seinen Beziehungen zum Vaterkomplex. Gelingt es, die narziBtische Verschlossenheit des Patienten zu luberwinden und - was dasselbe bedeutet - eine positive Ubertragung $\mathrm{zu}$ bewerkstelligen, so kommen eines Tages $\mathrm{zu}$ seiner Oberraschung freie Assoziationen auch in Gegenwart des Arztes zu stande. Anfangs zeigen sie sich vereinzelt; mit dem Fortschreiten des geschilderten Vorganges werden sie reichlicher. Wenn ich anfänglich die Schwierigkeiten der Behandlung hervorgehoben habe, so möchte ich daher zum Schlusse vor einer prinzipiell ungünstigen Prognosenstellung in solchen Fallen warnen. 


\section{Bemerkungen zu Ferenczis Mitteilung über "Sonntagsneurosen" 1 .}

Temporäre Verschlimmerungen nervöser Zustände im Zusammenhang mit Sonn- und Feiertagen, Ferien usw. sind auch mir nicht selten begegnet. Die folgenden Bemerkungen zur Ätiologie dieser Schwankungen sollen Ferenczis Ausführungen in keiner Weise widersprechen, sondern sie in gewisser Richtung ergänzen.

Eine erhebliche Anzahl von Menschen vermag sich vor dem Ausbruch schwererer neurotischer Erscheinungen nur durch intensives Arbeiten $z \mathfrak{u}$ schützen. Infolge $z \mathfrak{u}$ weitgehender Triebverdrängung besteht bei ihnen dauernd die Gefahr, daß Erregungsquantitäten sich in neurotische Symptome umsetzen. Durch die angestrengteste Tätigkeit im Berufe, im Studium oder in ihrem sonstigen Pflichtenkreis lenken sie sich gewaltsam von den Forderungen ihrer Libido ab. Sie gewöhnen sich an Arbeitsleistungen, die weit tiber das objektiv Notwendige hinausgehen. Die Arbeit wird ihnen ähnlich unentbehrlich und zwar in immer gesteigerten Dosen -, wie dem Morphinisten sein gewohntes Gift. Bricht bei diesen Neuropathen eines Tages eine eigentliche Neurose aus, so sind Ärzte und Laien rasch mit einer Scheinătiologie zur Hand; sie lautet: "Uberarbeitung." In einem Teile der Fälle vermag die Arbeit das Drängen der Libido nicht dauernd niederzuhalten; irgendwann bricht diese sich auf dem Wege der Konversion dennoch Bahn. In anderen Fällen - die uns hier besonders angehen - treten neurotische Symptome, mehr oder weniger schwer und akut, dann hervor, wenndie Arbeit durch ä $\mathrm{B}$ ere Umstände unterbrochen wird. Das durch die Arbeit mühsam erhaltene seelische Gleichgewicht geht so für die Dauer des Sonntags, der Feiertage usw., oder aber für längere Zeit verloren. Bei Wiederbeginn der Arbeit fühlen sich die Patienten sogleich wieder wohler.

Aber noch ein anderer Faktor verdient Beachtung. Die große Mehrzahl der Menschen benützt den Sonntag zum Lebensgenuß, sucht

${ }^{1}$ Aus "Internationale Zeitschrift für arztliche Psychoanalyse ${ }^{*}$. V. Jahrgang 1919. 
den Tanz und überhaupt die Gesellschaft des anderen Geschlechtes. So erinnert der Sonntag unsere Patienten in unerwünschter Weise an die Gebundenheit des eigenen Trieblebens, besonders an ihre Unfähigkeit zur Annäherung an das andere Geschlecht. Einer meiner Patienten mied am Sonntag die Straße, um dem Anblick der Liebespaare zu entgehen. In trüber Stimmung und quälender Unruhe hielt er sich im Hause. Die Pein dieser In $\mathrm{s} u \mathrm{f}$ i $\mathrm{z}$ i en $\mathrm{z}$ ge f ü h le schwindet mit dem Ablauf des Sonntags. Am nächsten Arbeitstag vermögen unsere Patienten sich im Gegenteil ihren Mitmenschen überlegen zu fühlen, weil diese ihnen an Arbeitsleistung nicht gleichkommen.

Während des Krieges sah ich eine Reihe von Soldaten den militärischen Dienst mit ubertriebener Gewissenhaftigkeit ausführen. Sie hialten sich auf diese Weise relativ symptomfrei. Jeder Urlaub wirkte nachteilig auf sie, indem er stärkere neurotische Erscheinungen auslöste. Ein Offizier litt während der unfreiwilligen Ruhe des Stellungskrieges unter starken neurotischen Beschwerden; er bat seine Vorgesetzten stets, ihn an einen möglichst bewegten Teil der Front zu versetzen, damit er von seinen Beschwerden frei werde.

Körperliche Erkrankungen oder Unfälle, die den Betroffenen zur Untätigkeit zwingen, ziehen nicht selten den Ausbruch oder die Verschlimmerung einer Neurose nach sich. Man bringt dann die Neurose gern in einen ätiologischen Zusammenhang mit der vorausgegangenen Infektion, dem Unfall usw. Nicht selten läßt sich alsbald feststellen, daß die unterdrückte Libido den Patienten zu der Zeit liberwältigt hat, als er zur Untätigkeit genötigt war.

Mit Hinblick auf die regelmäßige Wiederkehr der "Sonntagsneurosen" möchte ich daran erinnern, daß ein anderes, rbythmisch sich wiederholendes An- und Abschwellen der Neurose $z$ war in seiner Erscheinung wohlbekannt ist, aber noch keine Berücksichtigung in der psychoanalytischen Literatur gefunden hat. Ich meine die alltäglichen Schwankungen im Zustand der Neurotiker. Geläufig ist dem Arzte besonders der Typus des Neurotikers mit depressiver Stimmung am Morgen und Euphorie am Abend. Es wlirde sich verlohnen, auch diese Eigentümlichkeit im Ablauf vieler Neurosen einer gesonderten Bearbeitung zu unterziehen. Aus einer einzelnen Beobachtung kenne ich ferner die jährliche Exazerbation einer Neurose (Angsthysterie) im Winter um die Zeit der kürzesten Tage; sie schwand jeweils mit dem Eintritt der längeren Tage. 


\section{Zur Prognose psychoanalytischer Behandlungen in vorgeschrittenem Lebensalter ${ }^{1}$.}

Die Frage, unter welchen Bedingungen eine psychoanalytische Behandlung einen therapeutischen Erfolg verspricht, ist bisher im einzelnen fast unerörtert geblieben. In einem Aufsatz aus dem Jahre 1898, der dem ersten Bande der "Kleinen Schriften zur Neurosenlehre eingefügt ist, hat $\mathrm{Freud}$ sich in allgemeiner Form zu dieser Frage geäußert ${ }^{2}$. In den seither verlaufenen Jahren hat sich die psychoanalytische Erfahrung vervielfacht, die Technik der Behandlung weiter entwickelt. Es ist daher wohl angebracht, eine praktisch so wichtige Frage einer genaueren Betrachtung zu würdigen. Die folgenden Zeilen sollen einen ersten Beitrag zu ihrer Lösung bringen.

In dem zitierten Aufsatz hat Freud die Meinung vertreten, $\mathrm{daB}$ ein zu weit vorgeschrittenes Alter des Patienten die Wirksamkeit der Psychoanalyse begrenze. An der-allgemeinen Richtigkeif dieser Auffassung kann wohl kein Zweifel aufkommen. DaB mit dem Beginn körperlicher und psychischer Involution das Individuum weniger bereit sein werde, von einer Neurose zu lassen, die sein Leben bisher begleitet hat, war ja von vornherein wahrscheinlich. Die psychoanalytische Erfahrung jedes Tages legt uns aber nahe, an die seelischen Vorgănge nicht zu starre Normen anzulegen. Sie warnt davor, mit aprioristischen Erwartungen an die Erforschung oder an die Behandlung nervöser Zustände heranzutreten. Haben wir uns doch davon tiberzeugen müssen, daß gewisse Geisteskrankheiten, deren Unbeeinflußbarkeit ein Dogma der Psychiatrie bildete, der psychoanalytischen Methode zuganglich sind! So scheint es denn auch unrichtig, die therapeutische Beeinflußbarkeit der Neurosen im Involutionsalter grundsätzlich zu leugnen. Die Psychoanalyse als Erfahrungswissenschaft hat vielmehr zu untersuchen,

1 Zuerst veroffentlicht in .Intern. Zeitschrift f. Psychoanalyse ${ }^{\alpha}$. VI/2. 1920.

2 Seite 198. 
ob und unter welchen Bedingungen die Behandlungsmethode auch noch in späteren Lebensjahren Erfolge zeitigen kann.

In den Kreisen der Kollegen wird Freuds oben zitierte Ansicht vielfach in dem Sinne aufgefaBt, daB Behandlungen im vierten Lebensjahrzehnt bereits zweifelhafte Aussichten bieten, daB aber das fünfte Jahrzehnt und besonders das klimakterische Alter die Prognose psychoanalytischer Behandlungen höchst nachteilig beeinflussen. Jenseits des fünzigsten Lebensjahres wird unserer Therapie oft jede Wirkung abgesprochen.

In meiner psychoanalytischen Praxis habe ich eine Reihe von Neurosen mit chronischer Verlaufsart bei Personen behandelt, die das Alter von vierzig, zum Teil das von fünfzig Jahren uberschritten hatten. Besonders die ersten Falle dieser Art ubernahm ich nur zögernd. Ich wurde aber mehrfach von den Patienten, die schon anderweitig erfolglos behandelt waren, $z \mathfrak{u}$ einem Versuch gedrängt. Auch hatte ich die Zuversicht, den Patienten, falls ich ihnen keine Heilung verschaffen konnte, doch ein tiefer gehendes Verständnis ihrer Leiden entgegenbringen $z \mathfrak{u}$ können, als der psychoanalytisch nicht gebildete Arzt. $\mathrm{Zu}$ meiner Überraschung reagierte ein erheblicher Teil dieser Patienten sehr günstig auf die Psychoanalyse. Ich darf sagen, daB einige unter ihnen mir Heilerfolge gebracht haben, die $\mathbf{z u}$ den besten von mir uberhaupt erzielten gehören. Einige Belege dafür mögen hier folgen.

Der erste Patient dieser Gruppe lieb am wenigsten Gutes erhoffen : ein Fall von melancholischer Depression im Rückbildungsalter, der auf Behandlung in offener und geschlossener Anstalt durchaus refraktär geblieben war. Die Psychoanalyse hatte bei dem gehemmten Patienten, der im 50. Lebensjahre stand, schwere Arbeit zu bewältigen, aber es gelang ihr innerhalb fünf Monaten, ihn von seinen Selbstbeschuldigungen und seiner Lebensverneinung $z u$ befreien und ihn zu beruflicher Tätigkeit wieder tauglich zu machen. Das Leiden, dem ein jahrelanges nervöses Vorstadium vorausgegangen war, bestand in ausgeprägter Form bei Beginn der Behandlung 11/. Jahre. Lag in diesem Falle auch kein Erfolg bei einem langjährigen Krankheitszustand vor, so war doch die Neigung zum chronischen Verlauf nicht zu verkennen. Dazu kam die Schwere der Krankheitsform. Ich durfte daher die Behandlung eigentlicher Neurosen im Involutionsalter nicht mehr für schlechtweg aussichtslos halten.

Ich abernahm später die Psychoanalyse eines nahezu 50jăhrigen Zwangskranken. Die "Duplizităt der Fălle" führte mir bald noch 
einen zweiten Kranken der gleichen Kategorie, 53 Jahre alt, zu. Beide Patienten gelangten zu einem vortrefflichen Heilerfolg.

Der Erste, von Jugend auf mit allen. Zuggen des sogenannten $Z$ wangscharakters behaftet, hatte bis etwa $z u$ seinem 35 . Lebensjahre eigentliche Zwangssymptome nur in leichterem Grade dargeboten, jedenfalls aber unter ihnen nicht ernstlich gelitten. In seiner Ehe machte er sich vollkommen abhängig von seiner Frau, die dem Unentschlossenen alle ernsteren Entscheidungen abnahm. Eines Tages bemerkte er, daß sie einem Angehörigen eine Vertraulichkeit gestattete. Dieser Vorfall, der die Eifersucht des Patienten weckte, führte zum Ausbruch der Neurose in ihrer schweren Form. Seitdem die Frau, auf die er sein unbedingtes Vertrauen gesetzt hatte, sich als unzuverlässig erwiesen hatte, gab es für ihn nichts mehr, worauf er sich verlassen konnte. Er verfiel der denkbar schwersten $\mathrm{Z}$ weifelsucht. Unter anderem war er beständig im Zweifel darüber, ob er nicht soeben ein Verbrechen begangen habe. Verschwand vor seinen Augen auf der Straße ein Mensch in einem Hauseingang, so quälte der Patient sich mit dem Gedanken, ob er jenen etwa ermordet und die Leiche beseitigt habe. Hatte der Briefträger ihm eine Sendung gebracht und das Haus wieder verlassen, so suchte Patient in höchster Angst die Wohnung $a b$, um sich $z \mathbf{u}$ überzeugen, daB er den Briefträger nicht ermordet noch auch die Leichenteile in der Wohnung verborgen hatte. Dazu gesellten sich die quälendsten $Z$ weifel, ob er auf ein fortgeworfenes Stück Papier etwa seinen Namen geschrieben habe, so daß mit diesem ein Mißbrauch getrieben werden könnte. Ich erwähne nur diese wenigen Einzelheiten aus einer großen Menge, um einen Begriff von der Schwere des Falles zu geben. Der bei Beginn der Behandlung völlig verängstigte, hilflos unselbständige Mann erlangte eine weitgehende Wiederherstellung. Seither sind sechs Jahre verflossen, ohne daß ein Rückfall erheblicher Art eingetreten wäre. Gelegentliche Schwankungen des Befindens waren ohne größere Tragweite.

Der gleichzeitig behandelte andere Zwangskranke litt an heftigsten Angst- und Depressionszuständen. Auch er war von jeher mit den Erscheinungen des Zwangscharakters behaftet, unter welchen besonders Ubergüte und Übergewissenhaftigkeit hervortraten. Bestimmte Konflikte, die mit der Fixierung des Patienten an seine Familie zusammenhingen, riefen den Ausbruch der eigentlichen Neurose zwischen dem 30 . und 35 . Lebensjahre des Patienten hervor. Der Psychoanalyse gelang es, die schweren neurotischen Symptome, 
darunter auch die Angstanfälle, krankhaften Zweifel usw., zu beseitigen und den arbeitsunfähig gewordenen Mann wieder leistungs- und genuBfähig zu machen.

Ich erwähne sodann die Heilung einer im 41. Lebensjahre stehenden Kranken mit ausgeprägter Straßen- und Reiseangst. Von Kindheit auf mit mancherlei neurotischen Symptomen behaftet, litt sie seit mehr als sechs Jahren an den genannten ernsten Störungen. Sie wurde völlig hergestellt und ist seit nunmehr acht Jahren in ihrer Bewegungsfreiheit völlig ungehemmt.

Andere Fälle ließen sich anreihen, so auch partielle Erfolge bei schwersten, eingewurzeiten Angsthysterien, Depressionszuständen usw.

Neben diese erfreulichen Resultate stelle ich nun die M i B e r f o lg e, die ich erlebt habe. Nur kurz erwăhne ich jene extrem ungünstigen Fälle, die uns sehr bald nötigen, den Versuch der Behandlung einzustellen. Es sind Kranke, die auf jedes ihnen unerwünschte Ergebnis der Analyse, ja schon auf die Notwendigkeit, von ihrem Triebleben zu sprechen, mit instinktiver Abwehr reagieren. Wichtiger für die vorliegende Betrachtung sind diejenigen Fäle, in welchen wir uns trotz fortgesetzter Behandlung mit unvollkommenen, palliativen Erfolgen zufrieden geben müssen.

Uberblickt man eine gewisse Anzahl erfolgreicher und erfolgloser Kuren bei unserer Patientengruppe, so klärt sich das Rătsel eines so verschiedenartigen Ausganges in einfacher Weise auf. Prognostisch günstig sind auch noch in vorgeschrittenem Alter diejenigen Fälle, in welchen die Neurose mit voller Schwere erst eingesetzt hat, nachdem der Kranke sich schon längere Zeit jenseits der Pubertät befand und sich mindestens etliche Jahre hindurch einer annähernd normalen sexuellen Einstellung und sozialen Brauchbarkeit erfreut hat. Ungunstige Objekte sind dagegen diejenigen Kranken, weiche bereits in der Kindheit ausgeprägte Zwangsneurosen usw. produziert und in den erwähnten Hinsichten später niemals einen annähernd normalen Zustand erreicht haben. Patienten dieser Art sind es aber auch, bei denen in jugendlichem Alter Mißerfolge der psychoanalytischen Therapie vorkommen. Mit anderen Worten: Das Lebensalter, in welchem die Neurose ausgebrochen ist, fällt für den Ausgang der Psychoanalyse mehr ins Gewicht als das Lebensalter zur Zeit der Behandlung. Man kann auch sagen, das Alter der Neurose sei belangreicher als dasjenige des Neurotikers.

Hier drängt sich der Vergleich mit der Prognose des Ablaufes geistiger Störungen auf. Unter den als Dementia praecox 
(Schizophrenie, Paraphrenie) zusammengefaßten Psychosen bieten die in der beginnenden Pubertät oder gar im Kindesalter ausgebrochenen Fälle die ungunstigste Prognose, während die in reiferem Alter einsetzenden mehr $z \mathfrak{u}$ Remissionen neigen, die dann auch von gröBerer Dauer sind. Der Ablauf der Psychoneurosen folgt ăhnlichen Gesetzen.

Von prinzipieller Bedeutung ist die Frage, wieweit es der Psychoanalyse gelingt, bei Neurotikern in vorgeschrittenen Jahren der infantilen Sexualität nachzuforschen. Meine Erfahrungen haben mir gezeigt, daB ein Vordringen bis in die allerfrühesten Zeiten hier keineswegs ausgeschlossen ist. In einem neuerdings behandelten, noch nicht abgeschlossenen Falle von $Z$ wangsneurose gelang diese Aufgabe so vollkommen, wie man es nur bei jugendlichen Personen erwarten möchte.

Der äußere Verlauf der psychoanalytischen Behandlungen im Involutionsalter gestaltet sich in einem Teil der Fälle nicht ganz gleichartig wie im jüngeren Alter. Wăhrend wir im allgemeinen dem Patienten die Führung der Analyse insoweit überlassen, daB er selbst in jeder Behandlungsstunde den Ausgangspunkt seiner freien Assoziationen wăhlt, bedürfen bestimmte, altere Neurotiker jedesmal eines Anstoßes von Seite des Arztes. In ausgeprägter Form habe ich dieses Verhalten wiederholt bei Zwangsneurotikern älterer Jahrgänge beobachtet. Es handelte sich um Kranke mit allgemein herabgesetzter Initiative, die - von Jugend auf in bestimmten Hinsichten abhängig und unselbständig - vom Arzt gefuhrt werden wollen, der ihrem UnbewuBten in besonderem Maße den überlegenen Vater bedeutet. Mit diesen Patienten erlebte ich am Anfang der Behandlungsstunde viele Male den gleichen Vorgang. Sie fanden den Zugang zu dem bereitliegenden psychischen Material nicht selbständig. Sobald man ihnen aber eine kleine Anregung gab, etwa in Gestalt eines Hinweises auf bereits Besprochenes, so produzierten sie sogleich Einfälle. Das Verhalten ist als durchaus infantil za bewerten. Ich bin ihm auch bei der Behandlung von Kindern begegnet, so noch kürzlich bei einem intelligenten elfjährigen Knaben, der sich stark positiv auf mich als Vaterersatz eingestellt hatte. Bezeichnenderweise hört bei JugendTichen dieses Verhalten auf, wenn die Auflehnung gegen den Vater (oder Vaterersatz) in den Vordergrund tritt.

Mit den vorstehenden Ausführungen hoffe ich die Auswahl der zur Psychoanalyse noch in späterem Lebensalter Geeigneten erleichtert zu haben. Ich mache zum SchluB darauf aufmerksam, 
daß eingehende Untersuchungen darüber am Platze wären, warum gewisse Fälle des jugendlichen Alters der Psychoanalyse gegenüber refraktär bleiben. Gerade eine präzise Indikationsstellung wird uns MiBerfolge ersparen, die Wirksamkeit der psychoanalytischen Therapie aber zur vollen Entfaltung bringen. 


\section{Zur narzißtischen Bewertung der Exkretions- vorgänge in Traum und Neurose'.}

Eine in psychoanalytischer Behandlung befindliche Patientin träumt: "Ich sitze auf einem Korbstuhl an der Mauer eines Hauses. Das Haus liegt an einem großen See. Der Stuhl steht unmittelbar auf dem Wasser. Im See befinden sich viele schwimmende Menschen, außerdem Boote. In einem Boote sehe ich zwei Männer, einen älteren und einen jüngeren. Während das Boot auf mich zukommt, erhebt sich ein Windsto $B$ und erzeugt auf dem See eine ungeheure Welle, gerade hinter dem Boot. Sie verschlingt das Boot mit den Insassen. Auch die Leute, die im See schwammen, gehen unter. Nur eine Frau hält sich noch über Wasser, kommt in meine Nähe geschwommen und faßt nach meinem Stuhl. Ich denke, ich könnte ihr ein Bein entgegenstrecken, damit sie sich daran halten kann, habe aber für die Frau ebenso wenig Mitgefühl, wie für die anderen Verunglückten und unterlasse es, etwas zu ihrer Rettung zu tun."

Die Analyse des Traumes, soweit sie hier von Interesse ist, ergibt folgendes :

Der ältere und der jüngere Mann im Boot sind Vater und Bruder der Patientin; an beide ist ihre Libido übermäBig fixiert. Die schwimmende Frau ist ihre Mutter. Die psychische Konstellation, aus der heraus die Träumerin unbewußt den Tod der sämtlichen Angehörigen herbeiwünscht, kann hier übergangen werden. Dagegen soll hervorgehoben werden, a $\mathrm{f}$ welchem Wege die Beseitigung der Familie geschieht.

Bei der Patientin, deren genitale Erotik ungewöhnlich stark verdrängt ist, kommen Anal- und Urethralerotik in Träumen und neurotischen Symptomen überdeutlich zum Ausdruck. Der vorliegende Traum wird von diesen Tendenzen beherrscht. "Stuhl", "Wind " und

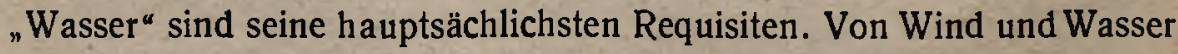
wird die Familie der Träumerin vernichtet. Sie selbst ist, aus Grïnden der Zensur, scheinbar unbeteiligte Zuschauerin. Die Gefühllosigkeit,

${ }^{1}$ Zuerst veröffentlicht in "Internat, Zeitschrift fur Psychoanalyse", VI., 1, 1920. 
mit der sie der Katastrophe zusieht, legt die Vermutung nahe, daß sie selbst das Unheil herbeiführt. Die Vermutung wird zur GewiBheit, wenn man den Schluß des Traumes berücksichtigt. Die Träumerin verursacht ja den Tod ihrer Mutter, indem sie ihr die Hilfe versagt.

Wir sind gewohnt, in den Psychoanalysen der Neurotiker die analen und urethralen Gefühle in enger Beziehung zu den infantilen Liebesregungen zu finden. Auch die Analyse unserer Träumerin bietet ein reiches, einschlägiges Tatsachenmaterial. Es entspricht nur unseren Erfahrungen uber die Ambivalenz im neurotischen Triebleben, wenn wir den Funktionen und Produkten des Darms und der Blase auch als Trägern feindseliger Regungen begegnen. Selten aber ist der Ausdruck solcher feindselıger Regungen so $\mathrm{kraß}$, wie in dem mitgeteilten Beispiel. Blasen- und Darmfunktion sind hier in den ausschließlichen Dienst des Sadismus gestellt; Urin und Flatus treten als Werkzeuge des Sadismus auf.

Besondere Beachtung verdient die ungeheure Wirkung, welche die Trăımerin ihren Exkretionen zuschreibt. Der uns geläufigen primitiven Vorstellung von der Allmacht der Gedanken darf man auf Grund unseres Traumbeispieles diejenige von der Allmacht der Blasen- und Darmfunktion an die Seite stellen. Sichtlich kommt in beiden Vorstellungen die gleiche $n$ arzi $B$ tische Selbstüberschät $z$ ung zum Ausdruck. Die hier nachgewiesene Vorstellung scheint aber die primitivere von beiden, ja geradezu die Vorstufe zur "Allmacht der Gedanken“ zu sein. Ein zweites Beispiel mag diesen Eindruck noch verstärken.

Ein Neurotiker, der sich während seiner frühen Kindheitsjahre stets als "Prinz" vorkam, "Kaiser" spielte und während der späteren Kindheitsjahre in Weltbeherrschungs-Phantasien schwelgte, machte mit elf Jahren eine eigentumliche Wandlung durch. Er war bis zu jenem Alter ganz an seine Mutter gebunden, die ihn systematisch gegen den Vater eingenommen hatte. Sie kam der Analerotik des Knaben im höchsten Maße entgegen, indem sie mit seinen Entleerungen einen förmlichen Kultus trieb. Qualität und Menge seines Stuhlganges waren ihre ständige Sorge. Fast täglich verabreichte sie ihm Klysmen. Der Sohn produzierte seinerseits einen neurotischen Magenschmerz, durch den er die Mutter zur Fortsetzung der Klysmen zwang. In dem erwăhnten Alter machte er nun eine größere Reise mit den Eltern. Im Hotel belauschte er eines Nachts den sexuellen Verkehr der Eltern. Dieses Ereignis war für ihn umso eindrucksvoller, als die Eltern daheim seit Jahren getrennte Schlafzimmer benutzten. Der Patient erinnert sich nun, wie ihm dieses Vorkommnis ganz unerträglich 
erschien, und wie er sich ganz bewußt entschloB, seine Wiederholung zu verhindern. Auf der Weiterreise wußte er es einzurichten, daB er selbst mit dem Vater das Zimmer teilte. Seit der Beobachtung des elterlichen Verkehres identifizierte er sich mit der Mutter und übertrug die Phantasie vom analen Koitus auf den Vater. Bislang hatte er der Mutter einen Penis angedichtet, der durch das Klystierrohr vertreten wurde. Jetzt dagegen stellte er sich weiblich-passiv auf den Vater ein $^{1}$. Bald darauf war er einige Zeit bettlägerig. Als er einmal ein paar Tage lang ohne Darmentleerung blieb, nahm er einen Druck im Leib wahr. In der Nacht träumte er, a us seinem Anus das Weltall herauspressen $z$ u mussen.

Auch hier findet sich die Vorstellung von der Allmacht der Defäkation in unverkennbarer Deutlichkeit. Man wird an die Schöpfungsmythen erinnert, in welchen der Mensch aus Erde oder Ton, das heißt aus kotăhnlichen Substanzen, geschaffen wird. Der biblische Schöpfungsmythus hat in dieser Hinsicht zwei verschiedene Fassungen. In der "elohistischen" Darstellung erschafft Gott das Weltall, den Menschen inbegriffen, durch sein "Es werde!" — das heißt also, durch die Allmacht seines Gedankens, Willens oder Wortes. In der "jahwistischen" Urkunde erfolgt die Erschaffung des Menschen aus einem ErdenkloB, dem Gott seinen Odem einbläst. Hier herrscht also noch die primitivere Vorstellung von der Allmacht der Darmproduktion. Auf andere mythologische Parallelen einzugehen, ist hier nicht der Ort.

Zur sadistischen Bedeutung der Defäkation zurückkehrend, will ich erwăhnen, daB die Patientin, welche ihre Familie im Traum durch ihre Exkretionen tötet, in hohem Grade mit nervösen Diarrhöen behaftet war. Die Psychoanalyse ergab neben den uns geläufigen Ursachen dieses Symptomes eine sadistische Wurzel. Die Diarrhöen stellten sich als Äquivalente unterdrückter Wutausbrüche heraus. Andere analysierte Krankheitsfälle haben mir diesen Zusammenhang bestätigt; so kenne ich eine Neurotika, die auf jedes Ärger oder Wut erregende Erlebnis ebenfalls mit Diarrhöe reagiert.

Es erscheint auffallig, $\mathrm{daB}$ ein Wutausbruch seine Vertretung gerade in die sem neurotischen Symptom findet. Zur Erklärung der Tatsache muß man das Verhalten des Kindes im frähesten Lebensabschnitt heranziehen. Das Kind zeigt im Wutaffekt den gleichen

1 Auch in späterer Zeit hielt der Patient in seinen Phantasien an der Vorstellung vom Weib mit männlichem Genitale fest; an seinem eigenen Körper versuchte er die Genitalien zwischen den Schenkeln zu verstecken, um sich selbst als Weib betrachten zu können. 
Blutandrang zum Gesicht, die gleiche Mimik, die gleichen Körperbewegungen wie beim Herauspressen des Stuhls, gibt auch bei beiden Gelegenheiten die nämlichen ächzenden Laute von sich. Diese Gemeinsamkeit der Ausdrucksmittel läßt einen nahen Zusammenhang der scheinbar heterogenen Antriebe erkennen. So wird es verständlich, daB eine explosive Darmentleerung dem Unbewußten des Neurotikers einen Ersatz für eine unterbliebene Entladung zorniger Affekte bieten kann.

Die urspringlichste und tiefste Beziehung zwischen Sadismus und Analerotik ist zweifellos darin zu erblicken, daB die mit der Analzone verknüpften passiven Sexualgefühle zusammen mit den aktivsadistischen Impulsen ein Triebpaar bilden, das die Vorstufe des späteren Gegensatzes von männlich und weiblich darstellt. Die beim Zwangsneurotiker besonders ausgeprägte Ambivalenz des Trieblebens wurzelt in dieser engen Verbindung aktiver und passiver Antriebe. Der im Obigen hervorgehobene weitere Zusammenhang des Sadistischen und Analen widerspricht dieser Anschauung nicht. Er erinnert uns vielmehr daran, daB mit der Darmtatigkeit auch libidinöse Antriebe a kt i v e r Art verbunden sind ${ }^{1}$ und lehrt uns nur eine Uberdeterminierung jener Zusammengehörigkeit kennen.

Die narzißtische Überschätzung der Exkretionen ist in der psychoanalytischen Literatur seit langem beachtet worden. Schon 1900 hat Freud in der "Traumdeutung" einschlägige Beispiele gegeben. Träume, in welchen die Urinflut gewaltige Wirkungen ausübt, finden sich namentlich bei Frauen mit stark betontem "Männlichkeitskomplex". In einem früheren Aufsatz habe ich selbst von einem dreijährigen Knaben berichtet, dessen narzißtische Größensucht noch gänzlich unverdrängt und in ihrem Zusammenhang mit den Exkretionen leicht zu erkennen war. Er suchte, als er am Strande der Nordsee urinierte, den Eindruck hervorzurufen, daB das Meer sein Produkt sei.

Dieser kindlichen Phantasie reihen sich die von mir mitgeteilten beiden Träume unmittelbar an. Wăhrend in den längst bekannten Exkretionsträumen die Körperprodukte einfach in ihrer Menge überschätzt werden, wird hier den exkretorischen Funktionen eine ungeheuere, ja allmächtige Wirkung im schaffenden oder zerstörenden Sinne zugeschrieben.

1 Die doppelte - aktive und passive - erogene Bedeutung der Analzone hat F e d e r $\mathrm{n}$ bereits 1914 in seinen ,Beiträgen zur Analyse des Sadismus und Masochismus* ausführlich erörtert. Vgl. Jahrg. II, S. 125 der "Internat. Zeitschrift für Psychoanalyse*. 



\section{Inhaltsübersicht.}

Seite

Über die Bedeutung sexueller Jugendtraumen für die Symptomatologie der Dementia praecox ..................... 1

Das Erleiden sexueller Traumen als Form infantiler Sexualbetätigung . . . . 9

Die psychosexuellen Differenzen der Hysterie und der Dementia praecox . . . 23

Die psychologischen Beziehungen zwischen Sexualität und Alkoholismus . . . . 36

Die Stellung der Verwandtenehe in der Psychologie der Neurosen . . . . . 45

Über hysterische Traumzustände ................. 53

Bemerkungen zur Psychoanalyse eines Falles von Fuß- und Korsettfetischismus . 84

Ansätze zur psychoanalytischen Erforschung und Behandlung des manisch-depressiven

Irreseins und verwandter Zustände . . . . . . . . . . 95

Über die determinierende Kraft des Namens . . . . . . . . . . . 112

Über ein kompliziertes Zeremoniell neurotischer Frauen . . . . . . . . 114

Ohrmuschel und Gehörgang als erogene Zone ..... . . . . . 120

Zur Psychogenese der Straßenangst im Kindesalter . . . . . . . . . . . 124

Sollen wir die Patienten ihre Trăume aufschreiben lassen? ......... 126

Einige Bemerkungen iiber die Rolle der GroBeltern in der Psychologie der Neurosen 129

Eine Deckerinnerung, betreffend ein Kindheitserlebnis von scheinbar ätiologischer

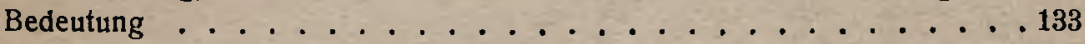

Psychische Nachwirkungen der Beobachtung des elterlichen Geschlechtsverkehres

bei einem neunjahrigen Kinde ............... 139

Kritik zu C. G. Jung: Versuch einer Darstellung der psychoanalytischen Theorie . 143 Über eine konstitutionelle Grundlage der lokomotorischen Angst . . . . . . . 159 Über Einschränkungen und Umwandlungen der Schaulust bel den Psychoneurotikern nebst Bemerkungen über analoge Erscheinungen in der Völkerpsychologie 168 Über neurotische Exogamie . . . . . . . . . . . . . . . 227 Untersuchungen taber die früheste prägenitale Entwicklungsstufe der Libido . . . 231

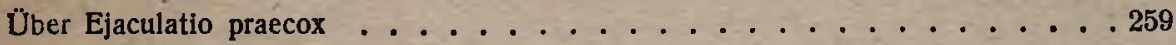

Einige Belege zur Gefühlseinstellung weiblicher Kinder gegenüber den Eltern . . 276 Das Geldausgeben im Angstzustand . . . . . . . . . . . . . . 279 Über eine besondere Form des neurotischien Widerstandes gegen die psychoanalytische

Methodik . . . . . . . . . . . . . . . 282

Bemikungen zu Ferenczis Mitteilung liber "Sonntagsneurosen" . . . . . 290 Zur Prognose psychoanalytischer Behandlungen in vorgeschrittenem Lebensalter . 292 Zur narzißtischen Bewertung der Exkretionsvorgănge in Traum und Neurose . 298 



\section{In der}

\section{Internationalen Psychoanalytischen Bibliothek}

\section{erschienen ferner:}

Nr. 1.

Zur Psychoanalyse der Kriegsneurosen

Diskussion mit Beiträgen von Prof. Froud (Wien), Dr. Abraham (Berlin),

Dr. Ferenczi (Budapest), Dr. Jones (London), Dr. Simmel (Berlin).

6 Bogen Grob-Oktav .............. Preis 5 Mlark

Nr. 2. Dr. S. Ferencxi

Hysterie und Pathoneurosen

6 Bogen Grob-Oktav ............ Preis 5 hark

Nr. 4. Dr. Otto Rank

PsychoanalytischeBeiträge zur Mythenforschung

27 Bogen Groß-Oktav . . . . . Preis 25 Mark, Halbleinen 30 Mark

Nr. 5. Dr. Theodor Relk

Probleme der Religionspsychologie

20 Bogen GroB-Oktav . . . . . Preis 20 Mark, Halbleinen 30 Minark

Nr. 6.* Dr. Gerza R6helm

S piegelzauber

16 Bogen Grob-Oktav ............. Prein 15 Mark

Nr. 7. Dr. Eduard Hitachmann

Gottfried Keller

Paychoanalyse den Dichters, seiner Gestalten und Motive,

8 Bogen Klein-Oktav ............. Prols 15 Mark

Nr. 8. Dr. Oskar Pfister

Zum Kampf um die Psychoanalyse

29 Bogen GroB-Oktay ...... Prois 60 Mark, Halbleinen 70 Mark

Nr. 9. Aurel Kolnai

Psychoanalyse und Soziologie ...... Prein 20 Mark 
